Petra Kuenkel, Elisabeth Kühn, Dominic Stucker and Douglas F. Williamson

\title{
Leading Transformative Change Collectively
}

A Practitioner Guide to Realizing the SDGs

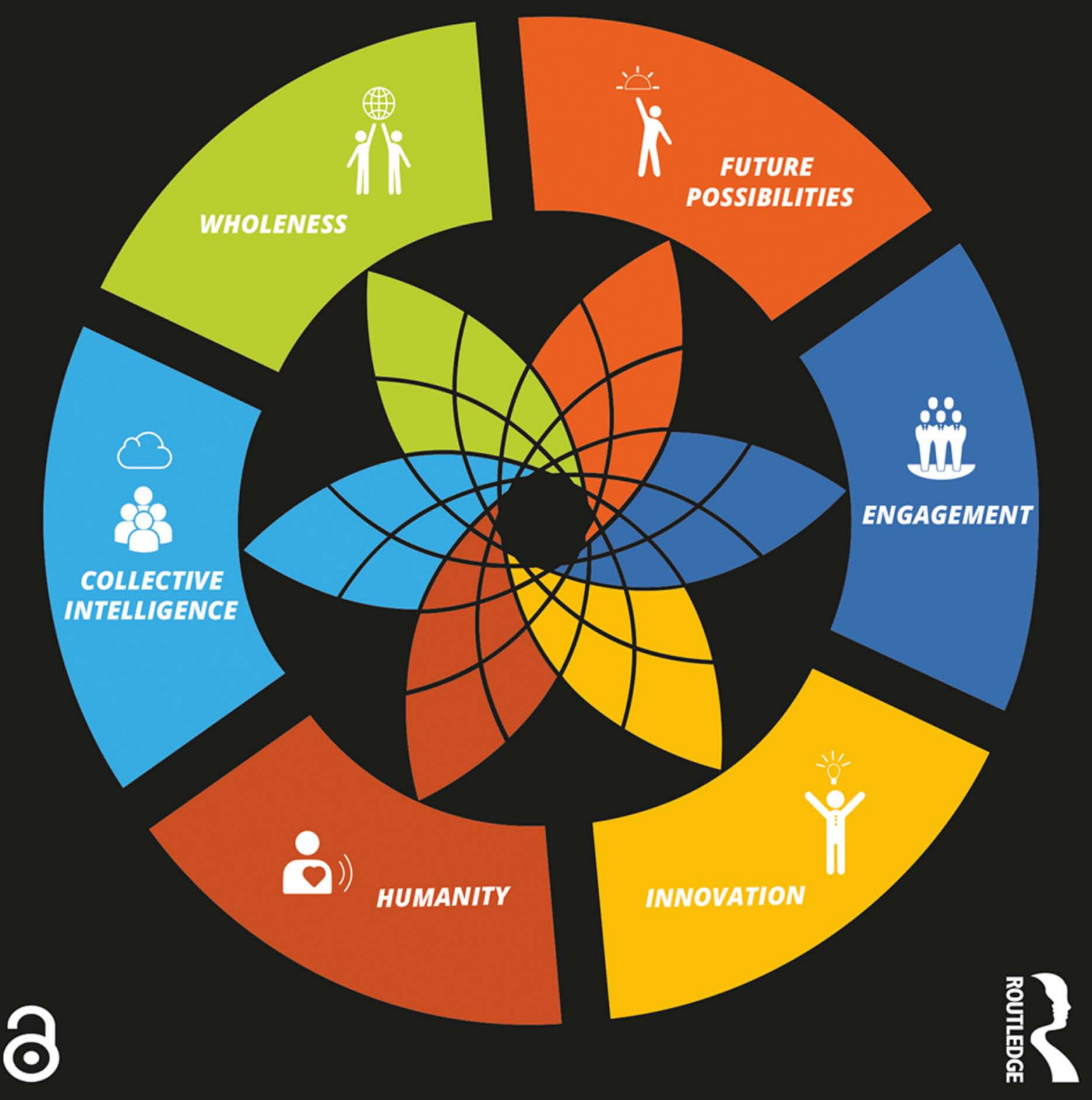




\section{Leading Transformative Change Collectively}

This book directly helps decision-makers and change agents in companies, NGOs, and government bodies become more proficient in transformative, collaborative change in realizing the SDGs.

This practitioner's handbook translates a systemic - and enlivening - approach to collaboration into day-to-day work and management. It connects the emerging practice of multi-stakeholder collaboration to easily understandable models, tools, and cases. Numerous, concrete cases not only bring this methodology to life, but also help identify the challenges and avoid common mistakes. The book can be used as a guide to apply a breakthrough approach for navigating the complexity of stakeholder systems, designing results-oriented process architectures, ensuring the success of cross-sector change initiatives, and enlivening collaboration ecosystems for SDC implementation. It is designed to enhance high quality stakeholder engagement, dialogue, and collaboration.

A must-read, the book sets a new standard for the collaborative implementation of Agenda 2030 and is a foundational guide for leading sustainability transformations collectively to achieve climate change mitigation, social integration, equitable value chains, and address broad sustainability challenges.

Petra Kuenkel, Executive Committee Member of the Club of Rome and Founder of the Collective Leadership Institute, is a systems psychologist, visionary author, and expert in complex multi-stakeholder collaborations. She drives SDG implementation by scaling-up collective stewardship skills for corporations, public sector, and civil society.

Elisabeth Kühn is an expert in transformative sustainability initiatives that empower civil society actors. As a managing partner at the Collective Leadership Institute, she has worked extensively in facilitating and building capacity for collaboration of change agents in sustainable resource management and good governance.

Dominic Stucker's passion is engaging multi-stakeholder teams to lead systems transformations for sustainability. As a Donella Meadows Fellow and managing partner at the Collective Leadership Institute, he is an expert dialogic facilitator, systems thinker, and process steward working across borders to help realize the SDGs.

Douglas F. Williamson is a managing partner at the Collective Leadership Institute, an education, facilitation, and sustainability communications expert, and an award-winning environmental filmmaker. He has substantial experience in working with international environmental NGOs, the United Nations University, and the US EPA's Climate Change Division. 
$\because$ Taylor \& Francis

http://taylorandfrancis.com 


\section{Leading \\ Transformative \\ Change Collectively}

\section{A Practitioner Guide to Realizing the SDGs}

Petra Kuenkel, Elisabeth Kühn,

Dominic Stucker and Douglas F. Williamson 
First published 2021

by Routledge

2 Park Square, Milton Park, Abingdon, Oxon OX 144 RN

and by Routledge

52 Vanderbilt Avenue, New York, NY 10017

Routledge is an imprint of the Taylor \& Francis Group, an informa business

(C) 2021 Petra Kuenkel, Elisabeth Kühn, Dominic Stucker and Douglas F. Williamson

The right of Petra Kuenkel, Elisabeth Kühn, Dominic Stucker and Douglas

F. Williamson to be identified as authors of this work has been asserted by them in accordance with sections 77 and 78 of the Copyright, Designs and Patents Act 1988.

The Open Access version of this book, available at www.taylorfrancis.com, has been made available under a Creative Commons Attribution-Non Commercial-No Derivatives 4.0 license.

Trademark notice: Product or corporate names may be trademarks or registered trademarks, and are used only for identification and explanation without intent to infringe.

British Library Cataloguing-in-Publication Data

A catalogue record for this book is available from the British Library

Library of Congress Cataloging-in-Publication Data

Names: Kuenkel, Petra, 1956- author. | Kühn, Elisabeth (Intern), author. | Stucker, Dominic, author. | Williamson, Douglas F., author.

Title: Leading transformative change collectively : a practitioner guide to realizing the SDGs / Petra Kuenkel, Elisabeth Kühn, Dominic Stucker, Douglas F. Williamson.

Description: Milton Park, Abingdon, Oxon ; New York, NY : Routledge, 2021. | Includes bibliographical references and index.

Identifiers: LCCN 2020029452 (print) | LCCN 2020029453 (ebook) | ISBN 9780367471170 (hardback) | ISBN 9780367471187 (paperback) | ISBN 9781003033561 (ebook)

Subjects: LCSH: Sustainable development. | Cooperation-Social aspects. | Leadership-Social aspects. | Organizational change.

Classification: LCC HC79.E5 K83 2021 (print) | LCC HC79.E5 (ebook) | DDC 658.4/06-dc23

LC record available at https://lccn.loc.gov/2020029452

LC ebook record available at https://lccn.loc.gov/2020029453

ISBN: 978-0-367-47117-0 (hbk)

ISBN: 978-0-367-47118-7 (pbk)

ISBN: 978-1-003-03356 (ebk)

Typeset in Scala Sans

by Apex CoVantage, LLC 


\section{Contents}

List of acronyms

vii

List of tables

List of figures

ix

List of case examples

$x i$

List of boxes

Acknowledgments

$x i i i$

$x V$

Preamble

$x v i$

Foreword

$x v i i i$

xix

Introduction

1 Getting started: understanding collaborative action for transformative change

Multi-stakeholder collaborations in SDG implementation

Leading collectively at all levels: from global to local 18

Formats of multi-stakeholder collaborations that fit purpose

23

Understanding cross-sector settings 32

Creating conditions for transformative change 43

The Collective Leadership Compass for the collaborative journey 53 
2 Getting active: making multi-stakeholder collaborations work

Stewarding collaborative change: the Dialogic Change Model 72

Examples from the field: leading transformative change 110

3 Ensuring success: the role of dialogic process facilitators in enlivening collaboration ecosystems

The purpose of dialogue in multi-stakeholder collaborations 131

Dialogic process facilitators: stewards of aliveness in collaboration ecosystems 158

4 Becoming transformative: process architectures for building impactful collaboration ecosystems 208

Planning impact in multi-stakeholder collaborations 210

The purpose of process: cultivating aliveness in collaboration ecosystems 226

The purpose of structure: governance for sustaining aliveness in collaboration ecosystems 252

5 Becoming reflective: cultivating a culture of learning

From success factors to collaboration catalysts 268

The role of process monitoring in multi-stakeholder collaboration 283

Trouble shooting guide: managing difficulties in multi-stakeholder collaboration 296

Communication: the fastest route to a learning culture 313

Methodologies for leading transformative change collectively 320

6 Epilogue

Annex 1 Collective Leadership Compass

Annex 2 The Dialogic Change Model

Annex 3 SDGs

Annex 4 Glossary

Index 


\section{Acronyms}

${ }_{4} \mathrm{C} \quad$ Common Code for the Coffee Community

ACA African Cashew Alliance

ADRA Adventist Development and Relief Agency

AUDA African Union Development Agency

BEDS Bangladesh Environment and Development Society

BMZ German Ministry for International Cooperation and Economic

Development

CTA Central Technical Amana

EC Executive Council

EDS Egyptian Dual System

EFIA Egyptian Federation of Investors Associations

EITI Extractive Industries Transparency Initiative

EU European Union

FAO Food and Agriculture Organization of the United Nations

FEI Federation of Egyptian Industries

FLEGT Forest Law Enforcement, Governance, and Trade Action Plan

FSC Forest Stewardship Council

GDP Gross domestic product

GIZ Gesellschaft für internationale Zusammenarbeit

GNF Global Nature Fund

GTA Governorate Technical Amana

IWRM Integrated Water Resource Management

KAZA Kavango-Zambezi

MAP Multi-Actor partnership 
MoETE Ministry of Education and Technical Education (Egypt)

MoFALI Ministry of Food, Agriculture, and Light Industry of Mongolia

MoU Memorandum of understanding

NAMAC National Association of Mongolian Agriculture Cooperatives

NEDLAC National Economic Development and Labour Council in South Africa

NEPAD New Partnership for Africa's Development

NEWS Nature, Environment, and Wildlife Society (India)

NGO Non-governmental organization

OECD Organisation for Economic Co-Operation and Development

PAGE Partnership for Action on Green Economy

PGS Participatory Guarantee System

POAg Multi-Stakeholder Partnership for Organic Agriculture

PPD Public Private Dialogue

RSPO Roundtable on Sustainable Palm Oil

SDGs Sustainable Development Goals

SIDS Small island developing states

SITRA Finnish Innovation Fund

SMEs small- and medium-sized enterprises

STEM Science, technology, engineering, and mathematics

TEGs Technical expert groups

TLAS Timber Legality Assurance System

TLD timber legality definition

ToC theory of change

TWG Technical Working Group

UN United Nations

UNCTAD United Nations Conference on Trade and Development

UNESCO United Nations Educational, Scientific, and Cultural Organization

US United States

VPA Voluntary Partnership Agreement

WE worldwide enhancement

WWF World Wide Fund for Nature 


\section{Tables}

0.1 Levels of skills development for multi-stakeholder collaboration

1.1 Why multi-stakeholder collaborations are a promising approach to SDG implementation

1.2 Checklist for the potential of multi-stakeholder collaboration

1.3 Understanding the difference between consultation and cooperation processes

1.4 Formats of multi-stakeholder collaborations: summary of purpose and applications

1.5 Navigating the interests of different stakeholder groups 41

1.6 From individual leadership to collective leadership 45

$\begin{array}{lll}1.7 & \text { The Collective Leadership Compass dimensions and aspects } & 61\end{array}$

$\begin{array}{lll}1.8 & \text { Levels of Compass applications } & 64\end{array}$

2.1 The four phases of multi-stakeholder collaboration 75

$\begin{array}{lll}2.2 & \text { Readiness check Phase } 1 & 103\end{array}$

2.3 Readiness check Phase 2 105

2.4 Readiness check Phase 3 106

2.5 Readiness check Phase 4 108

2.6 The 4 C initiative's high-quality collaboration in Phase 1

2.7 The 4 C initiative's high-quality collaboration in Phase 2 114

2.8 The application of the Collective Leadership Compass in Phases 1
and 2 for sustainable forestry and trade in Laos

2.9 Context understanding with the Collective Leadership Compass 123

3.1 The shared principles for stakeholder meetings 143

3.2 Design practices for co-creative conversations 154 
3.3 The workshop flow in relation to the design practices $\quad 156$

3.4 Description of systems patterns related to the Compass 175

3.5 The guiding questions for diagnosing systems patterns $\quad 177$

3.6 Initial system diagnosis for the biosphere reserve 189

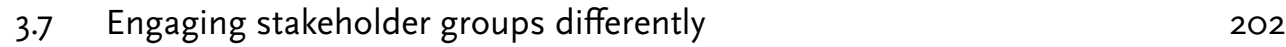

4.1 Questions for the core container to reflect on implicit theories 213

4.2 The four approaches to behavioral change 214

4.3 Levels of competences to leverage different change approaches 216

4.4 System check with the Collective Leadership Compass 219

4.5 Planning strategic components with the Collective Leadership Compass $\quad 224$

4.6 Engagement by design: implications for process architecture 231

4.7 Future possibilities by design: implications for process architectures $\quad 232$

4.8 Collective intelligence by design: implications for process $\begin{array}{ll}\text { architectures } & 234\end{array}$

4.9 Innovation by design: implications for process architectures 235

4.10 Humanity by design: implications for process architectures 236

4.11 Wholeness by design: implications for process architectures 237

4.12 Principles for process architectures $\quad 238$

4.13 Guiding questions for step 1 of developing a process architecture $\quad 241$

4.14 Planning with transformative design principles in step 4

4.15 Bodies for sustaining aliveness in collaboration ecosystems 255

4.16 Typical agreements in multi-stakeholder collaboration $\quad 261$

$\begin{array}{lll}5.1 & \text { The collaboration catalysts } & 269\end{array}$

5.2 Making the collaboration catalyst "co-designed strategy" work 272

5.3 Making the collaboration catalyst "cooperative delivery" work 274

5.4 Making the collaboration catalyst "adaptive innovation" work 276

5.5 Making the collaboration catalyst "collective value" work 278

5.6 Making the collaboration catalyst "dialogic communication" work 280

5.7 Making the collaboration catalyst "contextual impact" work 282

5.8 Different types of monitoring in multi-stakeholder collaboration $\quad 287$

5.9 Collaboration quality check for core groups 290

5.10 Quality check for collaboration ecosystems 297

5.11 Communication process and learning mechanisms for core groups $\quad 316$

5.12 Communication processes and learning mechanisms for collaboration ecosystems

$\begin{array}{llr}5.13 & \text { Communication with participating institutions } & 318 \\ 5.14 & \text { Communication with external stakeholders and the media } & 320\end{array}$

$\begin{array}{lll}5.14 & \text { Communication with external stakeholders and the media } & 320 \\ 5.15 & \text { Overview web-based Compass applications } & 324\end{array}$

5.16 Tools and applications in Phase 1: exploring and engaging 324

5.17 Tools and applications in Phase 2: building and formalizing 327

5.18 Tools and applications in Phase 3: implementing and evaluating 329

5.19 Tools and applications in Phase 4: sustaining and expanding impact 331 


\section{Figures}

0.1 The Sustainable Development Goals 2

1.1 Four typical forms of multi-stakeholder collaboration 25

1.2 Multi-stakeholder collaboration as shared interest 33

1.3 The collaboration ecosystem 52

1.4 The Collective Leadership Compass 54

1.5 Compass dimensions and systems aliveness principles 59

1.6 The Collective Leadership Compass with aspects 65

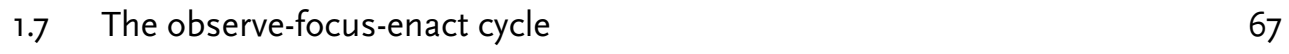

2.1 The Dialogic Change Model 74

$\begin{array}{lll}2.2 & \text { The three steps of Phase } 1 & 78\end{array}$

2.3 The three steps of Phase $2 \quad 84$

2.4 The three steps of Phase $3 \quad 92$

2.5 The three steps of Phase $4 \quad 98$

2.6 Shared vision for sustainable forestry and trade $\quad 118$

2.7 Illustrated process architecture for setting up the Nebhana

3.1 Communication patterns: from thinking alone to thinking together 137

$\begin{array}{ll}3.2 & \text { The dialogic practices } \\ 3.39\end{array}$

3.3 Shared vision for healthy Sundarbans mangrove, thriving coastal
communities, and robust aquaculture value chains

3.4 The six tasks of dialogic process facilitators 160

3.5 The three levels of competence building for dialogic process facilitators $\quad 161$

3.6 Example of a competency pattern $\quad 164$

$\begin{array}{ll}3.7 & \text { The leadership archetypes } \\ & 166\end{array}$ 
3.8 Visible action and underlying patterns $\quad 172$

3.9 The Stakeholder Landscape Analysis 180

3.10 Engaging stakeholders towards the high influence/interest quadrant 183

3.11 The four action modes $\quad 186$

3.12 Example of systems diagnosis 194

3.13 The balance between structural and dialogic interventions 196

3.14 The flow of divergence and convergence 197

3.15 Building containers for change towards collaboration ecosystems 201

3.16 Shared vision for organic agriculture in Selenge Province, Mongolia, and beyond

204

3.17 Process architecture multi-stakeholder partnership for organic $\begin{array}{ll}\text { agriculture in Mongolia } & 205\end{array}$

4.1 Implicit theories $\quad 212$

4.2 Example: theory of change - impact and outcomes 221

4.3 Example: theory of change - impact, outcomes, and assumptions 223

4.4 Example: theory of change - strategic components and outputs 225

4.5 Example: the completed theory of change 226

4.6 The connection between process quality and dialogic quality 227

4.7 Process architecture for building multi-stakeholder collaboration capacity within the Egyptian Dual System

4.8 Process architecture for strengthening the implementation of the Egyptian Dual System 251

4.9 Typical structures in multi-stakeholder collaborations 253

4.10 The EDS information fact sheet describing the collaboration structures $\quad 262$

5.1 Collective reflection enhancing Compass aspects 266

5.2 The collaboration catalysts and supporting practices 270

5.3 The collaboration catalysts matching with Compass dimensions
and aliveness principles

5.4 Example of process monitoring with the collaboration catalysts 302

$\begin{array}{ll}5.5 & \text { The different levels of communication } \\ 5.6 & 314\end{array}$

$\begin{array}{ll}5.6 & \text { Levels of Compass applications } \\ 5.7 & 321\end{array}$

5.7 Applications for collaboration ecosystems 322

5.8 Process chart methodologies for Phase $1 \quad 326$

5.9 Process chart methodologies for Phase 2 328

5.10 Process chart methodologies for Phase $3 \quad 330$

5.11 Process chart methodologies for Phase $4 \quad 332$

6.1 From isolated projects to transformation networks 337

A.1 The Collective Leadership Compass with dimensions and aspects 338

A.2 The Dialogic Change Model 339 


\section{Case examples}

\begin{tabular}{|c|c|c|}
\hline No & Title & SDG \\
\hline 1.1 & Combating malaria & SDG No. 3 \\
\hline 1.2 & Responsible supply chains & SDG No. 8 \\
\hline 1.3 & Consumer awareness for sustainability & SDG No. 12 \\
\hline 1.4 & Cooperating for empowerment & SDG No. 17 \\
\hline 1.5 & Making extractive industries transparent & SDG No. 8; 12 \\
\hline 1.6 & Ensuring forestry becomes sustainable & SDG No. 15 \\
\hline 1.7 & Honoring nature's beauty & SDG No. 15 \\
\hline 1.8 & Building economic resilience for cashew farmers & SDG No. 8; 12 \\
\hline 1.9 & Dialogue for green economic action & SDG No. $7 ; 8 ; 13$ \\
\hline 1.10 & Trusting the sustainability of textiles & SDG No. 12 \\
\hline 1.11 & $\begin{array}{l}\text { Stakeholder collaboration for empowering displaced } \\
\text { people }\end{array}$ & SDG No. 8; 16 \\
\hline 1.12 & Strengthening youth organizations & SDG No. 10, 11 \\
\hline 1.13 & Strengthening education & SDG No. 4 \\
\hline 1.14 & Dialogues for economic strength & SDG No. 8 \\
\hline 1.15 & Healing social imbalances & SDG No. 8 \\
\hline 1.16 & Ensuring sustainable palm oil & SDG No. $12 ; 15$ \\
\hline 1.17 & Managing water for life & SDG No. 6;13 \\
\hline 1.18 & Creating a community for sustainable coffee & SDG No. 2; 12 \\
\hline 1.19 & Strengthening regenerative agriculture & SDG No. 2 \\
\hline 1.20 & Empowering small and medium scale enterprises & SDG No. $1 ; 8$ \\
\hline 1.21 & Making the business environment work & SDG No. 9 \\
\hline
\end{tabular}




\begin{tabular}{|c|c|c|}
\hline No & Title & SDG \\
\hline 1.22 & Partnering for decent work & SDG No. 8 \\
\hline 1.23 & Strengthening cocoa farmers & SDG No. $2 ; 5 ; 12$ \\
\hline 1.24 & Improving health services & SDG No. 3 \\
\hline 1.25 & Empowering fishery communities & SDG No. $2 ; 12$ \\
\hline 2.1 & An international example: the global coffee platform & SDG No. $2 ; 12$ \\
\hline 2.2 & A national example: forestry management in Laos & SDG No. $1 ; 8 ; 12 ; 13$ \\
\hline 2.3 & A local example: the Nebhana Water Forum in Tunisia & SDG No. $2 ; 6 ; 13 ; 15$ \\
\hline 3.1 & $\begin{array}{l}\text { Staying in the collaborative field - towards sustainable } \\
\text { green coffee production }\end{array}$ & SDG No. $2 ; 12$ \\
\hline 3.2 & Developing a future charter for SDG implementation & SDG No. 16 \\
\hline 3.3 & $\begin{array}{l}\text { Working towards a white paper on land management in } \\
\text { Cambodia }\end{array}$ & SDG No. 15 \\
\hline 3.4 & $\begin{array}{l}\text { Example from the field: towards sustainable Sundarbans } \\
\text { Mangroves in India and Bangladesh }\end{array}$ & $\begin{array}{l}\text { SDG No. } 11 ; 12 ; 13 ; \\
14 ; 17\end{array}$ \\
\hline $3 \cdot 5$ & $\begin{array}{l}\text { Example from the field: understanding patterns for } \\
\text { managing a UNESCO biosphere reserve }\end{array}$ & SDG No. 13; 15 \\
\hline 3.6 & $\begin{array}{l}\text { Example from the field: container building for organic } \\
\text { agriculture in Mongolia }\end{array}$ & SDG No. $3 ; 8 ; 12 ; 15$ \\
\hline 4.1 & $\begin{array}{l}\text { Empowering teams of young collective leaders: } \\
\text { transforming policy dialogues for employment } \\
\text { opportunities in three Jordanian communities }\end{array}$ & SDG No. 8; 11; 17 \\
\hline 4.2 & $\begin{array}{l}\text { Example from the field: process architectures for } \\
\text { enlivening collaboration in Egyptian technical education }\end{array}$ & SDG No. 4; $; ; 8 ; 17$ \\
\hline $4 \cdot 3$ & $\begin{array}{l}\text { Example from the field: collaborative structures for } \\
\text { transformative change in the Egyptian technical education }\end{array}$ & SDG No. $4 ; 8 ; 17$ \\
\hline 5.1 & Example: co-designing integrated water resource strategies & SDG No. 6; 13 \\
\hline 5.2 & Example: pioneering a circular economy approach & SDG No. $8 ; 9 ; 12$ \\
\hline $5 \cdot 3$ & Example: building capacity for climate action & SDG No. 13 \\
\hline $5 \cdot 4$ & Example: strengthening youth organizations & SDG No. $5 ; 10 ; 12$ \\
\hline $5 \cdot 5$ & Example: networking for better health service & SDG No. 3 \\
\hline 5.6 & Example: building strong institutions & SDG No. 16 \\
\hline
\end{tabular}




\section{Boxes}

1.1 Engaging stakeholder groups differently 35

$\begin{array}{ll}1.2 & \text { Understanding aliveness in systems } \\ 1.39\end{array}$

1.3 What is unique about the Collective Leadership Compass? 53

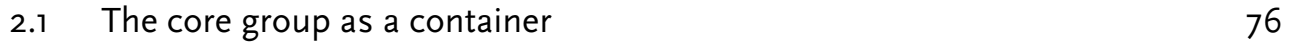

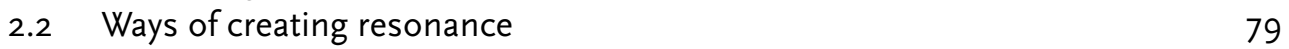

2.3 Ways of understanding the context $\quad 81$

2.4 Ways of building a container for change $\quad 82$

2.5 Ways of clarifying goals and resources 86

2.6 Ways to plan the future together 87

2.7 Ways for consolidating agreements and establishing structures 89

2.8 Ways of ensuring transparency and communication 93

2.9 Ways of creating results and celebrating success 94

2.10 Ways of establishing learning mechanisms 95

2.11 Ways of building the next-level container 99

2.12 Ways of creating management structures 101

2.13 Ways of establishing governance and learning structures $\quad 102$

3.1 Understanding check-in and check-out 149

3.2 The three levels of meeting objectives 151

4.1 Opportunities for developing a process architecture 239

5.1 Monitoring and evaluation according to the OECD 284 


\section{Acknowledgments}

This book's journey to publication has been a long, global voyage spanning more than 15 years of experimenting with multi-stakeholder collaboration and trying out methodologies and tools in the field. Step-by-step, with feedback and reflection, it became clear which methodologies served as useful guidance. This journey's significance is underlined by the advent of the Sustainable Development Goals, which directly support the idea of collaboration with their interconnected view of sustainability challenges. They even show that multi-stakeholder partnerships are a specific goal, hinting to the insight that all other goals require conscious collaboration for their implementation. This global recognition of the necessary mind shift towards collaboration in leadership and development practice inspired the authors to write this volume.

But the act of writing is only a step on a learning journey that continues. It would not have been possible without collaboration, conversations, and reflections with practitioners who offered perspectives from around the globe and ideas and knowledge from their wide variety of expertise. This diverse set of people shares, at heart, a deep care for the world and all its forms of life. Whether they come from the public sector, private sector, or civil society, they all are truly interested in improving the lives of people in their societies. This practitioner community includes more than 4,000 participants and learners from projects and transformation initiatives, from five continents, who have shared their experiences and knowledge. These inputs have led to a significant amount of the insights and practices in this practitioner guide.

Although the comprehensive approach to leading transformative change collectively as detailed in this book is in its totality very novel, we would be remiss in not mentioning the many great minds that have inspired us to venture into unchartered territory. 
This book not only captures experiences and methodologies of collective leadership practitioners, but has also been inspired by many great thinkers and practitioners in their own rights, from systems thinkers to change management experts, from dialogue practitioners to global change-makers. As practitioners know from multistakeholder collaboration, the challenges are often in the details. This also applies to this book. We would not have been able to compile this comprehensive volume between travels to so many countries and with family commitments without the tireless support of our team and the patience of our families. 


\section{Preamble}

This book is the culmination of many years of work applying transformative change and collective leadership approaches in complex collaboration environments. As the world has become ever more connected and the challenges of sustainable development more difficult, this book offers a timely analysis and a set of useful methodologies and tools for addressing the global and interconnected challenges of humankind. The pathways to leading transformative change collectively, which this book explores through conceptual explanations, practical examples, and useful tools, has been validated by its application in myriad collaboration initiatives of all shapes and sizes all around the world.

The Collective Leadership Institute and its staff of dedicated practitioners have had the privilege of carrying out the work of building functional collaboration ecosystems for more than 15 years. It is both the Institute's privilege and responsibility to share the knowledge gained through its many years of experience in successfully fostering sustainable development through fomenting strong cultures of collaboration. As a not-for-profit company, the Collective Leadership Institute (www.collectiveleadership. com) finds itself aligned with the United Nations' Agenda 2030 and specifically sees its impact in fostering excellence towards achieving the 17th Sustainable Development Goal on partnerships. This book is a direct contribution to the global sustainability movement and is aimed to accelerate the global transformation to a thriving, peaceful, and sustainable planet Earth. 


\section{Foreword}

How can we shift unsustainable systems and the behaviors they foster to lifeprotecting and thriving systems that add to the richness, diversity, and beauty of all life on Earth? This is a question I have asked myself throughout my career and is central to the sustainability challenge faced by global human societies in the 21st century.

As the world struggles to meet the noble aspirations of the United Nations' Sustainable Development Goals (SDGs) and the 2030 Agenda, it is becoming ever clearer that our common challenges must be addressed as a global community. The urgent call for worldwide solidarity to tackle our most pressing challenges such as hunger, poverty, climate change, biodiversity loss, responsible consumption and production, and many others, asks us to put aside differences and find a common vision of a sustainable and thriving future for all life on Earth. Never have our global societies had more reason to unite to secure our own future and that of our children so that they can enjoy an existence of security, opportunity, and possibility.

In spite of this urgency, which many now understand, there is still a reluctance to move towards real solutions. Climate change and the behaviors that exacerbate it are growing, resulting in extreme climate events that hurt the natural world on which we depend for our well-being. This is a time to react and to lead in a new direction.

In my former position as the Executive Director of the international LEAD (Leadership for Environment and Development) program, I observed the necessity of preparing a new generation of leaders who are more sensitized to the realities of unsustainable and destructive practices. It was clear then that the traditional understanding and practice of leadership wasn't serving the greater needs of the planet and 
its inhabitants. At LEAD, we worked with mid-career leaders from all parts of the world and from all sectors of society to reinforce their leadership skills with lessons about sustainability and the urgency to shift our societies towards a sustainable future for all. It continues to be my belief that a viable and hopeful pathway towards sustainable development is through a new leadership mindset that reflects the economic, social, and ecological realities of our global community of life.

In the spirit of preserving life I also had the privilege to be the Rector of the UNaffiliated University for Peace, where students, similar to the LEAD Fellows, focused on a sustainable future on a planet whose inhabitants will know how to live in peace and harmony with each other and with the natural world. I then had the privilege to serve as the Director General of the International Union for Conservation of Nature (IUCN). While at IUCN, I championed "nature based solutions" to help us appreciate the capacity of the natural world to provide solutions to our sustainability challenges through the conservation of ecosystems.

A key to the resilience of ecosystems is in diversity through the presence of many species with a myriad of interdependencies. This book makes the case that this principle holds for human cooperation systems as well, and that the more stakeholders are involved in finding solutions, the more responsibilities they assume in making their initiative, project, or system more successful, the more alive the system will become. This concept is the core of the collective leadership approach and it is in absolute synchronicity with the concept of thriving natural ecosystems that the nature based solutions approach at IUCN taught me.

This book describes the important role of collective leadership and provides a broad set of tools to help practitioners steer their collaborative projects or initiatives towards achieving the results we all know we need.

The authors of this book, seasoned practitioners of this collective leadership approach and well-versed in using it for stewarding systems change for sustainable development, offer a palette of tools and field-tested practices backed by many years of experience and research. They have shown their expertise in helping numerous initiatives build successful cooperation systems. The applicability of the approach across the spectrum of sustainability topics is noteworthy, as they have successfully applied the approach in initiatives dealing with global value chains, water resources, forestry, employment challenges, youth empowerment, climate change, healthcare systems, and many others. Many of their experiences are showcased in the book through examples from their fieldwork.

As my long career in the sustainability field has shown me, it is only through collaboration that human societies will be able to address the sustainability challenge the Sustainable Development Goals address. While the various topics that these Goals identify and interlink demonstrate the urgency for good collaboration, the practice of overcoming differences in approach to find and implement the best solutions has not reached the maturity needed to accomplish the feat of achieving sustainable development. This timely book is an important contribution towards helping global societies create a flourishing future for all.

Julia Marton-Lefèvre 
Member and Chair of numerous international organizations focused on the sustainability challenge (https://en.wikipedia.org/wiki/Julia_Marton-Lefèvre) and former director of the International Council for Science, of LEAD International, of the University for Peace and of the International Union for Conservation of Nature. 
$\because$ Taylor \& Francis

http://taylorandfrancis.com 


\section{Introduction}

For the first time in the history of humankind, global goals exist that guide our future. The UN's 2015 Sustainable Development Goals (SDGs) provide a detailed framework for public, private, and civil society actors globally to bring about significant and transformative change towards a world that works for 100 percent of humanity and the planet as a whole. The SDGs are meant to bring about a more prosperous, equitable, and sustainable world for all, in which people and nature can thrive. They have been created in a process of broad intergovernmental agreements resulting from extensive stakeholder consultations, and are aspirational and comprehensive. These goals are global, valid for all countries and show that the world is an interconnected place that all people need to take care of. They focus on globally and locally challenging issues such as, among many others, climate change, environmental degradation, food insecurity, inadequate health care, unequal education, gender inequality, insufficient water and sanitation, non-renewable energy, unemployment, unsustainable human settlements or destructive consumption and production patterns.

All of these challenges are examples of dysfunctional socio-ecological systems. They have emerged out of an ignorance towards the needs of our life support system that takes care of people and planet. More recently, the public attention to the climate emergency and biodiversity loss (captured in SDGs 13 on "Climate Action", SDG 14 on "Life below Water", and SDG 15 on "Life on Land"), increasingly suggests that the damages human societies have done to the world approach a crossroads, calling for significant collective action to change a dangerous trajectory. This is not the task of an enlightened few, but everybody will need to get involved, at all levels of the global society, in all cultures and regions, and across all societal sectors. The next 15 to 20 years will have a decisive impact - more than in any period before - on the conditions of life on Earth. The rising awareness about the urgency of dealing with climate change is symptomatic of an increasing concern for the future of humanity, and the planet as our life support system. 
Particularly, the climate crisis has made its way into the headlines of international news agencies. Yet, it is important to acknowledge its interlinkages with many other challenges and connect the more prominent theme with all of the other 17 SDGs, depicted in Figure 0.1. These goals do not operate in isolation; they have been formulated to address the complex and interconnected challenges of humankind and make suggestions how to overcome them collectively; they entail 169 targets with close interdependencies (Le Blanc, 2015). In that way, they are expected to function as a plan of action for world development, with voluntary achievement commitments for the public sector, the private sector, and civil society in all countries.

It is important to remember that the origins of these global goals can be traced back to the year 2012, when UN Secretary General Ban Ki-moon convened a highlevel panel of 27 eminent people from around the world. Different perspectives and diversity were key in this group of luminaries. The panel provided consultative advice for a global development framework beyond 2015 (United Nations, 2014b). Their report, published in May 2013, emphasized a new mindset fostering "the central importance of a new spirit to guide a global partnership for a people-centered and planet-sensitive agenda, based on the principle of our common humanity" (United Nations, 2014a, p. 8). The report showed a deeply transformative ambition and suggested forging a spirit of solidarity, cooperation, and mutual accountability. Up until the year 2030, and possibly beyond, these guiding and highly interconnected goals provide a framework for numerous initiatives at multiple levels. However, the profound change in the approach to work together for the systems change needed for the Agenda 2030 "Transforming Our World", or more specifically, for the implementation

\section{SUSTAINABLE DEVELOPMENT

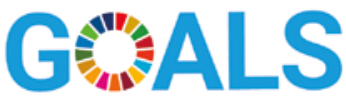

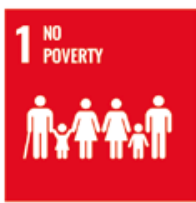
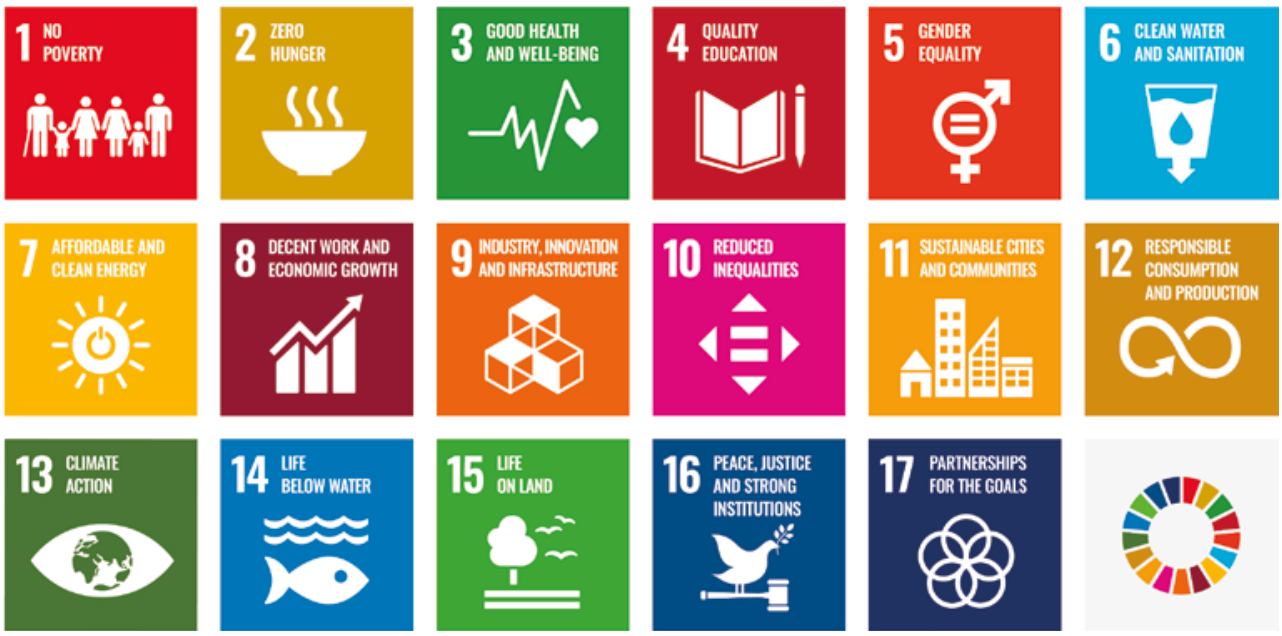

Figure 0.1 The Sustainable Development Goals 
of the 17 SDGs and our emergence from the climate emergency, is often seen merely as an administrative or technical implementation challenge.

This practitioner's guide looks beyond the current technical and administrative approaches to SDG implementation and climate action. It brings people and human competencies back into the center of transformative change. It shows that leading transformative change collectively across institutions, sectors, and nations is imperative - and that it can be achieved.

Leading never takes place in isolation; it is always a collective endeavor. Yet, the way leadership is enacted as part of the collective journey is important. When leaders and change agents not only access a deeper sense of humanity, but also connect with their intention to make a difference in the world, a decisive shift happens from self-centered consciousness to an awareness of what the world needs. Their contribution to the world - individually and collectively - is more likely to become constructively co-creative. They learn to collaborate - across silos, departments, institutions, nations, or cultures. This new way of leading transformative change collectively at scale will be necessary to implement decisive steps towards the global goals and for overcoming the climate emergency. No single actor has all the solutions, but each actor may essentially contribute a parcel of knowledge, a puzzle piece that counts. Collaboration between different stakeholders is vital. This practitioner's guide shows how to make it work in different contexts, for different challenges, and with different actors.

Unfortunately, it is clear that the capacity to collaborate in large system transformations is currently inadequate and not happening at the scale needed to progress towards the achievement of the global goals, nor to move human societies into decisive action on climate change or the prevention of biodiversity loss. This lack of capacity requires an effort of great magnitude towards increasing collaboration capacity if the challenges are to be adequately addressed in the short time necessary. Leading transformative change collectively is an emerging capacity that goes far beyond the success stories of isolated projects. It needs to become the new norm for overcoming sustainability challenges at local, regional, national, or global levels in complex multistakeholder collaborations.

Contemporary multi-stakeholder collaborations exhibit several characteristics that make them challenging specifically because the interaction among stakeholders from different societal sectors has not been seen as necessary or desirable until recently. Often, different approaches to change seem to be more competitive with each other because of differing interests and motivations, some of which may also be explicitly conflicting. Some of the challenges observed in cross-sectoral collaborations revolve around lack of trust, conflicting interests, power imbalances, and differing timelines, to name a few. In spite of these numerous differences, however, it has become clear that there must be multi-stakeholder approaches and broad inclusion to address the sometimes complicated, often complex, and occasionally chaotic characteristics exhibited in sustainable development challenges. Understanding the system of stakeholders and the patterns furthering or preventing collaboration is paramount for designing and implementing transformative change for the implementation of the SDGs. 
Most sustainability challenges, and certainly all issues around the 17 global goals, have complex stakeholder systems with actors from communities, public sector, civil society, private sector, as well as academic or educational institutions. No matter if transformations are about rehabilitating a lake district in Central Africa, introducing renewable energies in India, saving indigenous forests from deforestation in Cambodia, or introducing climate strategies in European cities, many stakeholders need to be considered who have an interest in a particular course of development, or a particular decision, either as individuals or as representatives of a group. This includes people who influence a decision, who are key players in implementation, or who are affected by the development. While multi-stakeholder collaborations may be cumbersome to navigate towards success, it is clear that the large and systemic challenges posited in the 2030 Agenda will only be successfully resolved with the active engagement of many stakeholders from different sectors and corners of societies, locally, nationally, regionally, and globally. Because these stakeholder systems are complex and are comprised of many stakeholders, initiators of transformative change need to know how to build constructive collaboration between stakeholders and who needs to be involved in a particular multistakeholder initiative. These are the actors who then become part of a Collaboration Ecosystem because they represent the stakeholder systems and work together for a certain common purpose. Building such Collaboration Ecosystems that can deliver transformative change across institutions and societal groups requires patience and persistence, but - managed well - they develop the cross-sector resilience and innovative capacities required to address local and global sustainability challenges. Above all, once operational, they bring about transformations much faster, because actors lead together rather than in isolation. This is why a new paradigm of leadership is needed - it needs to be seen as the capacity of a collective of actors - across stakeholder groups - to lead together. What is needed is Collective Leadership: the capacity to bring about transformative change together and increase the abilities of all stakeholders to collaborate effectively so that they can co-create and enact robust solutions for sustainability aspirations.

The challenges of sustainability across all 17 SDGs, and the even more pronounced climate and biodiversity crises can be re-defined as leadership challenges. The core question to ask is: how can we transform the way we lead so that it matches the future aspirations of a world that works for 100 percent of humanity and the planet as a whole? Clearly, there is a need to lead transformative change at all levels of global society. Many diverse actors need to take up leadership roles. In contrast to conventional conceptions of leadership as a purely individual and hierarchical endeavor, this practitioner's guide approaches leadership as a concept that is not confined to individuals, but looks at how cross-institutional and cross-sectoral actors can make change happen together. Collective leadership can be understood as high-quality collaboration among representative stakeholders working towards a common goal. In the context of sustainability transformations, it is the capacity of a group of leaders to deliver their contribution to a more sustainable future through assuming joint and flexible leadership in service of the common good (Kuenkel, 2016, 2019). At the core of collective leadership is the human capacity to dialogue and transform differences 
into progress. It enables the transcendence of self-centered views, a prerequisite for successfully addressing the challenges of sustainability.

The ability of a system of stakeholders or actors to effectively communicate, equitably share resources, and implement change together to achieve common goals is a vital element of collective leadership. This effective communication, in its most cocreative state, is based on the ancient human knowledge and experience of dialogue. Humankind lives in the house of language; where the capacity to dialogue is disabled, misunderstandings lead to conflict, and joint implementation degrades into disconnected actions. Collaboration rests on the capacity to dialogue, and, in multistakeholder collaborations with diverse stakeholders and interests, this requires conducive structures that ensure collective intelligence is harvested and collective actions are beneficial.

Leading transformative change collectively means aspiring to journey together towards what is increasingly understood as systems transformation - a deeply innovative approach towards thinking and acting, power structures, and relationships (Waddell, 2016; Waddell et al., 2015). Systems transformations require us to question the way we see the world and open ourselves to understanding our current and future realities in a different way. It encourages us to redefine the way humans interact with each other and the planet in an era that is called the Anthropocene, the time in the planetary history where the human impact has begun to change the course of planetary evolution (Steffen et al., 2018). Human societies need to learn fast to act as stewards of all life and work towards a livable future for all. Transformations are the processes through which this new way of operating is made real, sustainable, and at the scale and with the impact necessary for the continued thriving of life on Earth, and all through collaboration. Leading transformative change collectively unleashes the human potential to create pathways to a responsible Anthropocene.

Such an approach gets ample support from scientists across all disciplines. Future thinkers from system scientists, biologists, philosophers, environmentalists, sociologists, to economists argue that the world needs a new narrative about what it means to be human on this planet (Kuenkel, 2019). They call for humankind to become a responsible actor in an interconnected, self-regulating natural system that is our planet. Moreover, they suggest that it is time for us to learn how nature allows healthy systems to emerge - because like people, ecosystems, communities, cities, organizations, or nation states thrive under certain conditions that need to be co-created, regenerated, maintained, and sometimes safe-guarded (Waddock \& Kuenkel, 2019; Weber, 2013, 2016). Living systems and complexity theory have investigated how life emerges as interconnected patterns in continuous communication, from small to large entities and vice versa (Capra \& Luisi, 2014; Bateson, 2000; Kauffman, 2016). As leaders and change agents, humans need to become partners of the evolutionary process towards thriving systems.

Practitioners in multi-stakeholder collaborations know this; they sense when a system of collaborating stakeholders - a collaboration ecosystem - is healthy and alive. It is not in false harmony that collaboration works best. But when the quality of collaboration is high, people overcome conflicts, acknowledge differences, find common ground, and make change happen together. "What gives life to collaboration 
ecosystems?" is a fundamental question that accompanies this practitioner's guide throughout. It is the North Star that helps navigate complexity in unchartered territories and stormy waters. Good collaboration furthers a sense of aliveness, and a sense of aliveness supports collaboration. Understanding the connection between the vitality of smaller and larger systems is paramount for making multi-stakeholder collaborations in SDG implementation successful.

Finding and re-finding the North Star to help systems aliveness emerge will, in the coming chapters, be greatly supported by the Collective Leadership Compass - a metalevel framework that guides attention to mutually supportive patterns of actions so that a sense of aliveness among actors is enhanced and subsequently the effectiveness of complex multi-stakeholder collaborations. The Compass helps leaders, and groups of leaders, ascertain how a collaboration pattern can successfully emerge. It supports leaders to design collaborative process intervention strategies. The six dimensions of the Compass are not only scientifically anchored in multi-disciplinary research extracting insights from systems theory, ecology, quantum physics, architecture, psychology, sociology, resilience research, and sustainability science (Kuenkel, 2019, 2017) - but they are also tried and tested success factors in the practice of effective multi-stakeholder collaborations for SDG implementation, to which this practitioner's guide refers. The Compass has at its core the contribution to systems aliveness: the capability of small and larger systems to gain resilience, regenerate, and maintain their vitality in mutual consistency with other systems. Its dimensions mirror a pattern of aliveness and help users to translate life principles into strategic management decisions of co-creation and collaboration processes.

While navigating transformative change in troubled waters is greatly aided by the Compass, a map ensures that the journey leads in the right direction. The Dialogic Change Model functions as such a map. It is a process methodology that allows for the result-oriented planning and implementation of multi-stakeholder collaboration in four phases. Building successful collaboration ecosystems in a spirit of collective leadership requires dialogic change with structured engagement of all relevant actors and high-quality process architectures. It helps actors develop a sense of cohesion, provides orientation, and safeguards against unhelpful interventions. The two methodologies work together and support each other. Through their application, collective leaders can foster the emergence of functional collaboration ecosystems that create tangible impacts. These become more likely to succeed when key stakeholders work with the Dialogic Change Model as the process methodology and the Collective Leadership Compass as a guide navigating systems aliveness and for creating high quality collaboration.

Unleashing the potential of multi-stakeholder collaborations also requires a very conscious and, at the same time, new approach to transformative leadership. It can be a challenge to deal with the diversity of cultures, interests, and goals among stakeholders. Similarly, it may require leadership confidence to overcome an initial lack of trust between people from different stakeholder groups, particularly if some of them have stronger influence than others do. Table 0.1 shows the different levels of skills development needed for successfully implementing multi-stakeholder collaborations. 
Table 0.1 Levels of skills development for multi-stakeholder collaboration

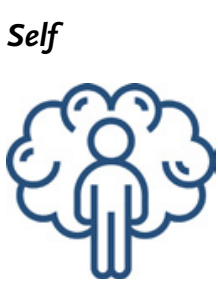

System

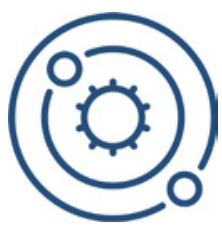

Process

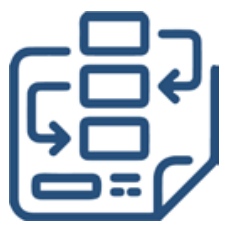

- Awareness of ourselves is an essential element for leading transformative change collectively in multi-stakeholder collaborations.

- An understanding of the system (the field we are intervening in or operating in) and its dynamic is crucial for the successful implementation of multi-stakeholder collaborations.

- Process competence is the key success factor for the design and implementation of multi-stakeholder collaborations.

The successful design of transformative change requires a high degree of process competence that enables actors to know when informal engagement processes are required, when workshops need to be held, when to attend to emotional issues, and when to create the structure for tangible outcomes. Leading transformative change collectively means changing an existing status quo. To do this successfully, it is important to understand the context in which the particular stakeholder initiative takes place: the complex, sometimes conflictive, system that is built around the particular issue at stake. Actors in collaborative change need to understand what can foster or prevent change. Hence, a sufficient level of system understanding is a prerequisite for the initiation of multi-stakeholder collaborations, and remains an important skill throughout their implementation. Most importantly, when stakeholders aspire to lead collectively, they need to also grow as individual leaders. This is about knowing their own patterns, preferences, strengths, and weaknesses. Reflecting about personal leadership styles is as important as being open to continuous learning. The success of leading transformative change collectively is built on increasing self-awareness. This practitioner's guide will touch on all of them throughout.

Chapter 1 will create an in-depth understanding of the emerging field of multistakeholder collaborations in SDG implementation and explain different forms, purposes, levels, and dynamics in cross-institutional collaboration. It will also show why the approach of leading transformative change collectively is paramount for SDG implementation, and explain the Collective Leadership Compass as a practical navigation tool for ensuring high quality collaboration in multi-stakeholder initiatives. 
Chapter 2 explains how leading transformative change collectively enhances the resilience of cross-sector dialogues, platforms, initiatives, and partnerships. It will introduce the process methodology of the Dialogic Change Model as a map for taking collaboration to success. It shows how complex multi-stakeholder collaborations emerge and become successful in four phases that each require different approaches to navigating change. It will also explore how enhancing the Compass dimensions in each of the four different phases helps collaboration ecosystems deliver results.

Chapter 3 looks in more detail into how the achievement of results is linked to the capacity of people to enhance systems aliveness in multi-stakeholder collaboration. It takes deep dives into different ways of building the capacity of actors to diagnose and improve interaction patterns in their small and large-scale change endeavors. It emphasizes the need for skills building in stewarding collaborations between multiple stakeholders. With focus on the role of dialogic process facilitators as such stewards of collaboration ecosystems, it shows how specific facilitation approaches and tools enhance the six dimensions of the Compass and make the crucial steps of the Dialogic Change Model work.

Chapter 4 explores the planning of impact in multi-stakeholder collaborations by crafting theories of change that take the Collective Leadership Compass to heart. It shows how actors can move from theories of change to actually plan step-by step change processes. Based on the experience that complex multi-stakeholder collaborations require elaborate process designs the chapter shows how these can be co-created by key stakeholders so that they become helpful guidance for the complex set of actors in an unpredictable environment. The chapter also elaborates the important role of formalizing collaboration structures, such as agreements, governance mechanisms, and learning events and how these can contain and promote transformative change.

Chapter 5 looks at the many ways a learning culture can be established in multistakeholder collaborations. It introduces success factors in multi-stakeholder collaboration and how they can be used as process monitoring to enhance and keep the quality of the collaborative process. The chapter elaborates the role of communication for learning mechanisms that can emerge in multi-stakeholder collaboration, and how reflection becomes second nature for all stakeholders involved. It concludes with a troubleshooting guide for managing difficulties in multi-stakeholder collaborations by paying attention to the dimensions and aspects of the Collective Leadership Compass and the four phases of the Dialogic Change Model.

The epilogue provides an outlook towards future ways of using multi-stakeholder collaborations for SDG implementation as a pathway to transformation literacy for sustainability. It elaborates how the skills development provided in this book will contribute to faster learning in global and local societies and thus make a contribution to a more responsible human future.

\section{References}

Bateson, G. (2000). Steps to an ecology of mind. Chicago and London: The University of Chicago Press.

Capra, F., \& Luisi, P. L. (2014). The system's view of life: A unifying vision. Cambridge: Cambridge University Press. 
Kauffman, S. (2016). Humanity in a creative universe. New York: Oxford University Press.

Kuenkel, P. (2016). The art of leading collectively: How we can co-create a sustainable, socially just future. Claremont, $\mathrm{NH}$ : Chelsea Green.

Kuenkel, P. (2017). A pattern approach to sustainability transformation: How the 17 SDG can become a starting point for systemic change. In Collective leadership studies (vol. 5). Potsdam, Germany: The Collective Leadership Institute. ISSN 2569-176

Kuenkel, P. (2019). Stewarding sustainability transformations: An emerging theory and practice of SDG implementation. Cham, Switzerland: Springer.

Le Blanc, D. (2015). Towards integration at last? The sustainable development goals as a network of targets. Sustainable Development, 23(3), 176-187. http://doi. org/10.1002/sd.1582

Steffen, W., Rockström, J., Richardson, K., Lenton, T. M., Folke, C., Liverman, D., Summerhayes, C. P., Barnosky, A. D., Cornell, S., Crucifix, M., Donges, J. F., Fetzer, I., Lade, S. J., Scheffer, M., Winkelmann, R., \& Schellnhuber, H. J. (2018, August 14). Trajectories of the earth system in thenthropocenee. Proceedings of the National Academy of Sciences of the USA, 115(33), 8252-8259. http://doi.org/10.1073/pnas.1810141115

United Nations. (2014a). A new global partnership: Eradicate poverty and transform economies through sustainable development. New York: United Nations. Retrieved June 23, 2017, from www.un.org/sg/management/pdf/HLP_P2015_Report.pdf

United Nations. (2014b). The road to dignity by 2030: Ending poverty, transforming all lives and protecting the planet. New York: United Nations. Retrieved June 23, 2017, from www.un.org/disabilities/documents/reports/SG_Synthesis_Report_Road_to_ Dignity_by_2030.pdf

Waddell, S. (2016). Societal change systems: A framework to address wicked problems. The Journal of Applied Behavioral Science, 52(4), 422-449. http://doi.org/ $10.1177 / 0021886316666374$

Waddell, S., Waddock, S., Cornell, S., Dentoni, D., McLachlan, M., \& Meszoely, G. (2015). Large systems change: An emerging field of transformation and transitions. The Journal of Corporate Citizenship, 58, 5-30.

Waddock, S., \& Kuenkel, P. (2019). What gives life to large system change? Organization Q Environment. https://doi.org/10.1177/1086026619842482

Weber, A. (2013). Enlivenment: Towards a fundamental shift in the concepts of nature, culture and politics. Berlin: Heinrich-Böll-Stiftung.

Weber, A. (2016). Biology of wonder: Aliveness, feeling and the metamorphosis of science. Gabriola Island, Canada: New Society Publishers. 


\section{chapter 1}

\section{Getting started}

\section{Understanding collaborative action for transformative change}

While collaborative initiatives in the field of sustainability are not new, their level of quality has not kept pace with the increasing urgency and complexity of the SDG challenges (Simon \& Beisheim, 2016). Since the beginning of the century, collaboration initiatives that bring together a variety of change agents - stakeholders from public sector, private sector, and civil society - have increased substantially (Beisheim, 2011; Brouwer \& Woodhill, 2015). This reflects the expanding understanding of the interconnected nature of sustainability challenges. However, such multi-stakeholder collaborations often fall short of the lasting difference they intend to make for a sustainable future. Consider the following three typical case examples of intended collaboration for SDG implementation that started with the best of intentions, but fell short on delivering transformative change.

\section{CASE EXAMPLE 1.1: COMBATING MALARIA}

3 GOOD HEALTH

$-W^{\circ}$
3 AND WELl-BEING

Several years ago, an international organization convened a multistakeholder meeting in an African country in order to combat malaria. This was a contribution to SDG 3 on Good Health and Well-being. The event organizers invited more than 100 research specialists, government representatives, and NGOs for a two-day meeting. Only about two thirds of the invitees showed up. Several representatives gave speeches and made presentations on the status quo, most of which was already known to all the other attendees. There was a question and answer session following the presentations and then the convening organization presented an action plan, 
which everyone was supposed to agree on. However, none of the other participants had been included in the drafting of the plan and in the end the participants left thinking that they would continue their work as they had been doing before the meeting. The transformative impact of a gathering with seasoned experts was minimal, as they did not feel part of driving the change together. They continued working in silo approaches. What went wrong? Although everybody would have agreed on combatting malaria, no process had been designed to pre-engage people for how to collaborate and jointly get better at combating malaria. No learning occurred that could have sparked innovative approaches or collective intelligence.

\section{CASE EXAMPLE 1.2: RESPONSIBLE SUPPLY CHAINS}

DECENT WORK AND

ECONOMIC GROWTH

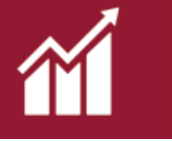

The social sustainability within many industrial value chains in Southeast Asia, particularly regarding workers' pay and living conditions is a widespread concern. A substantive improvement towards living wages for these workers contributes to SDG 8 on Decent Work and Economic Growth. In one instance, a development organization held a meeting in Europe with the intent of fostering joint action to address the issue. Only one stakeholder at the meeting was actually from Southeast Asia. Half of the companies invited declined to attend citing time constraints. The other half attended but with great reluctance. Of those that did attend, several had already conducted internal studies on the subject of how to help producers that they sourced from to increase workers' salaries while keeping their own profit margin reasonable. The subject remained difficult and they did not have a solution to present. Each company had self-interests that only would be acceptable to compromise as long as all the other companies in the sector made the same compromises, but until then, any action by a single company would have potentially reduced its market share. Tacitly, all the participating companies understood that only a substantial government-led increase in the minimum wage in the producing countries would create a level playing field for all the companies at the same time. But nor representatives from producer country governments were present. This elephant in the room was not addressed. What went wrong? The intentions of gathering the companies were good, but in the absence of representatives from the producing countries, the meeting ended with no action plan or way forward. A thorough analysis before such a gathering on understanding the context was missing.

\section{CASE EXAMPLE 1.3: CONSUMER AWARENESS FOR SUSTAINABILITY}

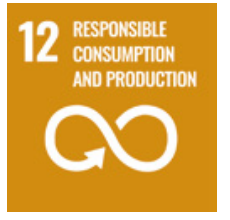

In a European country several ministries worked on the issue of consumer awareness for sustainable consumption, a contribution to the implementation of SDG 12 on Responsible Consumption and Production. They had all decided independently that there was not enough guidance for the consumer on making better product choices for sustainable consumption. One ministry financed a consumer 
awareness campaign for products with sustainability labels. Another ministry deemed this approach unhelpful, thinking that consumers would only get more confused over the various sustainability labels, so it launched an initiative that would compare and judge the quality of those labels. They financed a website that consumers could access to understand the different labels. A third ministry thought this these approaches were too limiting and not addressing the underlying transformations needed. It contended that sustainability labels on products enhanced niche markets rather than ensured that all products would become sustainably produced. It decided to drive collaboration with industry on sustainable production standards in mainstream markets. The ministries disregarded the approaches of the others and operated in competition. Companies got confused and impatient as to which approach would work for them. Consumers did not grasp the different approaches. What went wrong? Each ministry focused only on its own expertise and connections. They all wanted to profile their own actions and failed to see each other as complementary. Nobody bothered to look at the whole, and certainly not together.

The examples show that even the best of intentions to contribute to SDG implementation may fail or be ineffective unless collaboration quality is part and parcel of the strategy. Moreover, they show that even where collaboration is intended to make the difference, but the understanding of how and when and with whom to collaborate is lacking, the results may become meagre. While context and goals of the case examples vary widely, they illustrate a growing lack of effectiveness among the popular approach of multi-stakeholder collaboration (Biermann et al., 2007; Van Tulder \& Pfisterer, 2013). However, this must not be seen as a failure of the idea of multi-stakeholder collaboration for SDG implementation. Collaboration concerns all SDG implementation initiatives, and therefore the capacity to design and implement them effectively is at the heart of SDG implementation, whether it concerns overcoming the climate emergency, the fight against poverty, or the pursuit of peace and good governance. Indeed, the need for collaboration across sectors, cultures, and countries is recognized in SDG 17 - Partnerships for the Goals. As a transversal goal, it applies to all of the global sustainability challenges recognized in the SDGs, from "No Poverty" to "Peace, Justice and Strong Institutions". For realizing the SDGs, the question is therefore not whether multi-stakeholder collaboration is the approach to pursue; rather, it is a matter of making that collaboration effective so that it leaves a lasting contribution to the SDGs fundamentally. What is needed for effective collaboration is a shared capacity and understanding among all participating change agents for how a diverse array of stakeholders can work together in the face of a complex challenge and create sustainable outcomes. At the heart of building that capacity for good collaboration is an urgently needed leadership paradigm change: from targeted initiatives under the control of a particular institution or stakeholder group towards a network of complementary multistakeholder collaborations that are led collectively by its involved stakeholders.

This chapter will therefore

- explore key elements in the field of multi-stakeholder collaborations in SDG implementation, such as different forms, purposes, levels, and dynamics in cross-sector settings; 
- introduce the approach of leading transformative change collectively as the necessary capacity for successful SDG implementation, and outline its key practical concept: the collaboration ecosystem; and

- give an overview of the Collective Leadership Compass as a practical navigation tool for ensuring that actors can lead transformative change collectively in multistakeholder collaborations for SDG implementation.

\section{Multi-stakeholder collaborations in SDG implementation}

Multi-stakeholder collaborations can be conducted in a variety of forms and with varying degrees of engagement. The settings may differ, as may the motivations. Stakeholders may choose to develop consultative policy development processes, which may or may not lead to joint decision-making and implementation of co-created solutions. Or they may engage in time-bound partnerships to address a specific problem. The precise format of collaborative initiatives will be determined by the issue at hand, the objectives agreed upon, the participants, the scope of the initiative, and the timeframe. Hence, they may come in different forms depending on the issue, situation, or challenge. This means that initiators and practitioners must design initiatives tailored to their potential to achieve the goals, the overall situation, and the expected outcomes. There is not a one-size-fits-all to address all concerns.

Present-day multi-stakeholder collaborations in the field of sustainability challenges appear with many names including multi-stakeholder partnerships, multi-stakeholder platforms, multi-stakeholder consultations, multi-stakeholder dialogues, or multistakeholder governance, among others. Each of these collaborative efforts may differ and serve a particular purpose, as we will see later on, but what binds them together is that they all are based on the attempt to involve multiple stakeholders, generally from different sectors and with different perspectives. Their common purpose is to co-create solutions to common societal challenges or jointly foster change for the common good. These collaborations may address challenges as diverse as standard setting in value chains, water resource management, climate change, or delivery of social goods and services. Hence, multi-stakeholder collaborations can function in various settings, be used for many different reasons, and take place at various levels of the global society. They can be initiated by stakeholders from corporations, NGOs, governments, or research institutions, and are implemented in varying forms. However, they all exhibit some common features:

- The fundamental value: an underlying assumption that participation, engagement, accountability, constructive collaboration, mutual respect, and openness to different perspectives lead to better and more robust SDG solutions;

- The larger objective: an overarching assumption that achieving consensus for action - no matter how small or large - is always a contribution to sustainability and the future of all life on Earth;

- The dialogic approach: the conviction that change through dialogue leads to lasting solutions and ensures an issue's many facets are all integrated into the desired change; and 
- The methodology: an overarching assumption that understanding what makes multi-stakeholder collaboration effective enables practitioners to successfully employ tools, design actions, and develop collaboration process competence in a multitude of settings.

Multi-stakeholder collaborations are appropriate when dialogue is possible and when there exists the potential for listening, reconciling conflicting or competing interests, as well as integrating perspectives into the collective development of strategies. This means that initiators and practitioners must design initiatives tailored to the potential to achieve the goals, the overall situation, and the expected outcomes. In the best cases, collaboration leads to practical outcomes that would otherwise not have been possible, because all stakeholders can understand the larger goal and bigger picture. It is more easily implemented when stakeholders experience a deep level of ownership for the results of the process. Well-designed and implemented collaboration engenders high levels of trust, commitment, and the emergence of collective intelligence. Multi-stakeholder collaborations that authentically ensure the inclusion of diverse opinions, perspectives, and experiences further strong consensus-building processes instead of false compromises. They have a much higher probability for result-oriented implementation of initiatives, projects, and transformation efforts.

High quality collaboration allows for new forms of communication and understanding among a variety of stakeholders and interest groups. At the outset of such processes, this kind of exchange may cause discomfort for participating actors. However, when the processes are well designed and the commitment to larger goals has been established, participants quickly learn to effectively exchange in a true dialogic manner; in a space of respect and mutual recognition, participants learn to use their different perspectives for constructive ends. Once differences have been acknowledged with respect among stakeholders, their consensus building can reach previously unachievable levels of acceptance and authenticity. Respectful exchanges easily shift to a focus on outcomes when stakeholders have internalized the SDG's bigger picture perspective and solutions emerge naturally, if the participating stakeholders are emotionally connected to the larger goal. Furthermore, decision-making gains in credibility if it is based on the authentic listening to and understanding of the various points of view. This then easily leads to better and more effective implementation when the different actors feel a collective responsibility for the change initiative. Table 1.1 shows the advantages of multi-stakeholder collaboration for SDG implementation.

Well-designed multi-stakeholder collaborations make sure that:

- all participating stakeholders understand the full picture through active listening and being open to different points of view;

- the full spectrum of perspectives and stakeholders from all levels of influence and power are equitably represented;

- there is as much transparency around stakeholders' interests as possible;

- trust among stakeholders is established;

- all stakeholders agree to a common goal; and

- stakeholders share in the design and implementation of actions. 
Table 1.1 Why multi-stakeholder collaborations are a promising approach to SDG implementation'

Decision-making

quality is enhanced

Creativity and innovation are unleashed

Credibility of plans and decisions is enhanced

Implementation

likelihood is increased

\section{Broad information dissemination is enhanced}

\section{Cross-sector collaboration and relationships are strengthened}

- Drawing together expertise and perspectives from a number of disciplines and perspectives leads to a better understanding of the specific SDG context, the challenges ahead, and to better solutions. The quality that goes into decision-making improves exponentially.

Diversity, if brought into the structured setting of a dialogue, offers the potential for increased creativity and innovation.

- Recommendations or decisions made by including stakeholders in consultation and decision-making have a higher level of credibility, because results are based on a wider range of inputs and a balance of interests. Collaborating across diverging interests is not easy, but investing in identifying common ground, building trust, and aligning behind a shared SDG concern will pay off. This can create results that are more likely to be considered legitimate than actions or initiatives that are undertaken by one stakeholder (group) alone. The more transparently different inputs are integrated into decision-making processes, the greater the credibility of the results.

- True participation generates a deeper sense of ownership and responsibility for the SDG at hand. This in turn leads to a higher likelihood of implementation: people help to implement the future when they have the opportunity to be part of its design. Hence, engagement and inclusion of stakeholders done in the right way is often a cornerstone for success in SDG implementation. Results developed in such a way are likely to be more appropriate and based on broader commitment.

- The involvement of different stakeholders helps to convey a particular SDG issue to a broader range of people. Wider dissemination of a particular SDG initiative's concrete goal is an important feature of collaborative approaches. The different stakeholder constituencies will pass on the information to their institutions, organizations, and constituents.

- Multi-stakeholder collaborations not only improve people's capacity to see the bigger picture or broaden their position but also help people to work with stakeholders they normally would avoid, who they do not know, or with whom they would not collaborate. Structured dialogue strengthens social cohesion and thus the quality of cross-sector relationships - an important condition for tackling the challenges of SDG implementation.

- Collaboration for SDG implementation often touches upon the interest of stakeholders who do not actively participate in the process, but who nevertheless are affected by the developments of the SDG at stake (for example, the interested public, communities, or political figures involved with the issue). Well-designed collaborative initiatives include outreach activities and provide information to their constituencies during the phases of decision finding and implementation. This creates trust in those steering the initiatives, and generates wide acceptance of the process and its results. 
Table 1.1 (Continued)

\section{The capacity for complex system problem-solving increases}

Conflicts and deadlocks can be overcome

\section{Results become more} robust and sustainable
- Structured learning requires the synergy of different competences, perspectives, and expertise. Multi-stakeholder collaborations integrate experiences and knowledge, producing points of view that are often innovative. They exhibit a fast learning pace and high problem-solving capacity.

- Through active involvement in collaborative processes, stakeholders can map out and realize options for SDG implementation jointly. The collaborative effort changes and broadens participant's perspectives and opens up new possibilities for action. This often helps to overcome stalemates and conflicts.

- Multi-stakeholder collaborations produce structural results if the integration of different perspectives and interests is ensured. They bring different points of view together, leading to decisions that all stakeholders can identify with and agree to. Implementing these decisions creates a sense of ownership for collective action. This leads to more sustainable and robust results that have a much higher chance of long-term success.

Despite the many advantages multi-stakeholder collaborations have, they also present unfamiliar challenges. Including multiple stakeholders is a complex task. Sometimes stakeholders take advantage of their inclusion to increase their influence unfairly or at the expense of other stakeholders' aspirations. The inclusion of certain controversial stakeholders may also decrease the credibility of an initiative in the public. There may be reputational risks for certain stakeholders when they are seen to collaborate with certain others with whom they have historically been in oppositional or conflictive relationships. Some other typical risks that can hinder collaboration processes or jeopardize their results include a lack of attention to acknowledge that stakeholders are unable to build the minimum amount of trust. Stakeholders may not yet be able to enter into collaboration or suspend disrespectful ways of communication, such as using stereotypes to label stakeholder group members, competitive inclinations, lack of tolerance, lack of sensitivity towards the realities or constraints of other participating actors, and so forth. Sometimes oppositional goals or priorities as well as unrealistic expectations of what certain participants can achieve in allotted timeframes may slow down collaborative change. In other cases, there may be external hindrances, for example, unfavorable political situations or funding challenges that may present unsurmountable obstacles to making multi-stakeholder collaborations successful.

Some of these challenges can best be addressed by understanding the context well enough, and by designing high quality processes of engagement and joint implementation. As much as collaboration has grown in significance on the agenda of SDG implementation, it is important to know that not all SDG actions need collaborative 
approaches, although many would benefit from engaging stakeholders. Leading transformative change collectively for SDG implementation in a result-oriented and meaningful way requires looking at the quantity and quality of multi-stakeholder collaborations.

- Quantity: wherever silo solutions dominate or compete rather than cooperate, but where solutions can only be found quickly and effectively across actors, a rethinking of approaches towards collaboration should be encouraged. These are the key questions to ask: can we better solve this problem in cooperation? Do we need more collaborative initiatives?

- Quality: where work is already being done in multi-stakeholder collaboration, e.g. in alliances, networks, partnerships, joint initiatives and cooperation projects, the quality of collaboration should be the focus as it impacts on results. This is the key question to ask: how can we improve the quality of our collaboration so that the desired effects will be achieved?

Multi-stakeholder collaborations are meaningful only if they explore problems and help to work out solutions collectively with more chance of success than a unilateral approach to solutions. It makes sense to decide for a collaborative approach when

- SDGs implementation is clearly required, but the challenges can only be overcome with the support of various stakeholder groups and decision makers;

- the change of the current situation is wanted by a critical mass of stakeholders, even if relevant actors may not agree on the direction, purpose, and implementation modalities of the change;

- implementation needs the integration of different perspectives and requires the acceptance of certain stakeholder groups;

- When implementation demands innovation and collective intelligence; and

- When only the pooling of resources and expertise in joint implementation will lead to success.

If actors in international cooperation, public, private, or civil society want to initiate a multi-stakeholder collaboration for SDG implementation, it is advisable to first assess the potential. This helps the initiators to reflect on the preconditions for collaboration and encourages them to make sure to work towards a supportive environment for collaborative change. Analyzing the potential for multi-stakeholder collaboration serves to clarify whether this will be the appropriate approach to a specific issue or concern, and if there is preparatory work to be done to foster an environment for collaboration. The following checklist in Table 1.2 provides an overview of the criteria that should be considered before initiating a multi-stakeholder approach. If more than eight answers are "yes", then initiators can go ahead and start collaboration. If fewer, it is advisable to work towards the creation of conducive conditions first. 
Table 1.2 Checklist for the potential of multi-stakeholder collaboration

Is there a need for a multi-stakeholder engagement to implement change towards SDGs?

- Broad acceptance of the envisaged project or initiative for SDG imple- Yes No mentation by different stakeholders is necessary.

- Implementation of the project or initiative affects various stakeholder Yes No groups.

- The implementation of the project or initiative requires the active partici- Yes No pation of different stakeholder groups.

- The challenges present or foreseen cannot be addressed by the experi- Yes No ence, means, knowledge, or power of one stakeholder (group) alone.

Is the timing right?

- Key stakeholders are convinced that change is necessary. Yes No

- Conflicts between stakeholder stakeholders are not so strong that partici- Yes No pation in collaboration is impossible.

- Most of the key stakeholder stakeholders have confidence in the expertise Yes No of the initiators of the multi-stakeholder collaboration.

- Participation in collaborative change does not create disadvantages for Yes No the stakeholders involved.

Are the necessary resources available to conduct the multi-stakeholder collaboration?

- The team of initiators has sufficient time, personnel, and financial Yes

No resources.

- The team of initiators has sufficient knowledge about how to conduct Yes No multi-stakeholder collaboration.

- The initiator team already has established sufficient relationships with all Yes No relevant stakeholder groups.

- The collaborative approach is supported by key decision-makers in the Yes No institutions of the initiators and potential partners.

Does the team of initiators have the competence to drive the change?

- The initiators team is ready and able to co-steer a complex process, which Yes No may not be straightforward.

- All initiators are willing to respect each other's points of view or differing Yes No opinions and to allow innovative, jointly developed solutions.

- The initiators are open to change their own viewpoints or to adjust goals. Yes No

- The initiators are ready to take on leadership in a collaborative process. Yes No

\section{Leading collectively at all levels: from global to local}

The approach of multi-stakeholder collaboration can function well at many different levels of global society, depending on the participating stakeholders and outcome desired. When initiating collaborative change, it is important to clarify in advance which societal level is suitable for dealing with the respective issue around one or 
more SDGs. Collaborative change for SDG implementation takes place at the following levels:

- Global or international level

- Regional or cross-border level

- National level

- Subregional or local level

While in principle the approach to collaboration is the same at all levels, each of the levels may have specific requirements and challenges that need to be understood. In addition, many of the SDGs require approaches across different levels. The following section takes a deep dive into typical features of these levels and illustrates this with examples.

\section{Multi-stakeholder collaboration at the global or international level}

International multi-stakeholder collaborations take place when a solution to one or several issues around the SDGs cannot be found within one country, i.e. when it requires internationally active stakeholders or representatives from different countries to become involved. Such collaborative change processes usually are an attempt to find agreements and commitments to actions that can then be applied to all participating countries. They often include official government representation that take place in highly formal settings and sometimes with strict protocol. They are occasionally subject to political interventions and depend on relationships between governments. But there are also international collaboration processes initiated by NGOs or private sector actors, which do not require very formal procedures. If international multi-stakeholder collaborations are initiated and led by private organizations or NGOs, they often are more focused on implementation and less susceptible to political intervention. The following three examples illustrate the differences in settings and purpose.

\section{CASE EXAMPLE 1.4: COOPERATING FOR EMPOWERMENT}

PARTNERSHIPS

FOR THE GOALS

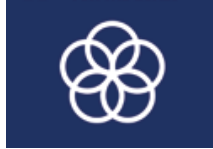

The Small Island Developing States Partnership Framework emerged out of the 2014 International Conference on Small Island Developing States (SIDS). The SAMOA Pathway helped to establish the Partnership Framework, a multi-stakeholder platform for monitoring the progress and quality of partnerships intending to address the specific challenges of SIDS. The Steering Committee is comprised of member states representatives and is open to member states and representatives of the specialized agencies (for more information, see https://sustainabledevelopment. un.org/sids/partnershipframework). 


\section{CASE EXAMPLE 1.5: MAKING EXTRACTIVE INDUSTRIES TRANSPARENT}
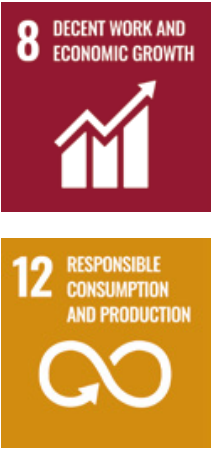

The Extractive Industries Transparency Initiative (EITI) is a global initiative that has developed a global standard for the good governance of oil, gas, and mineral resources, thus contributing to more transparency in payments for the extraction of raw materials. In 51 countries around the world, governments, as well as numerous companies and non-governmental organizations (NGOs), are working to ensure that the wealth of one country's natural resources benefits all its citizens (for more information, see https://eiti.org).

\section{CASE EXAMPLE 1.6: ENSURING FORESTRY BECOMES SUSTAINABLE}

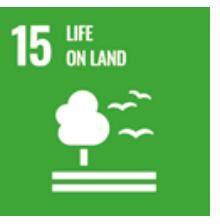

Initiated by civil society actors, the Forest Stewardship Council (FSC) is an institutionalized multi-stakeholder collaboration geared to promote sustainable forest management via an FSC sustainability standard. The members participate voluntarily, and the organization serves as a platform for the exchange and realization of their accreditation system. It has set up a governance structure with equal representation and decision-making power from different stakeholders across civil society, private and public sector (for more information, see https://fsc.org/en).

\section{Multi-stakeholder collaboration at the regional or cross-border level}

Multi-stakeholder collaborations on the regional and cross-border level take place when an issue can only be dealt with across national boundaries, or if it makes sense to advance a collaborative approach so that several countries will benefit. This can, for example, be necessary to enhance SDG implementation relevant in a particular region. It is sometimes led by government actors, but can also be initiated by NGOs by or the private sector. In those cases, such collaborative change processes focus less on political agreements and more on implementing results on the ground. The following two examples illustrate the differences in settings and purpose.

\section{CASE EXAMPLE 1.7: HONORING NATURE'S BEAUTY}

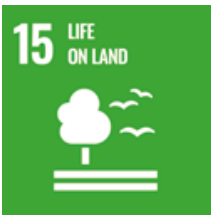

The Kavango-Zambezi (KAZA) Transfrontier Conservation Area is a cross-border protected area in Angola, Zambia, Zimbabwe, Botswana, and Namibia. The foundation was signed on 18 August 2011 by the heads of state and government of the participating countries. The main objective is the preservation of wildlife combined with the sustainable development of tourism and economic development in the participating countries, as well as the enhancement of biodiversity. One of the starting points of the 
KAZA project is the engagement of local communities and the establishment of community protection areas. Cooperation partners include NGOs, such as the WWF and the Peace Parks Foundation (for more information, see www.kavangozambezi.org/en/).

\section{CASE EXAMPLE 1.8: BUILDING ECONOMIC RESILIENCE FOR CASHEW FARMERS}

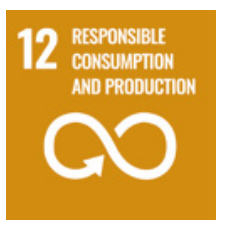

DECENT WORK AND

ECONOMIC GROWTH

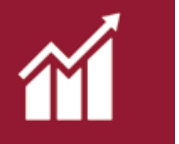

The African Cashew Alliance (ACA) is a stakeholder platform promoting the processing of raw cashews, increasing the income of African farmers, and promoting the consumption of cashew nuts globally. It supports the development of country-specific cashew policy agendas in its member countries and facilitates the exchange of information and best practices on cashew processing. It also assists its members in promoting the African cashew industry in national and international markets (for more information, see www.africancashewalliance.com/en).

\section{Multi-stakeholder collaboration at the national level}

National level multi-stakeholder collaborations can cover many different SDG initiatives. They are sometimes led by government agencies, if the objective, for example, is to develop national strategies, review, or develop national policies, or realize new regulations. If collaboration initiatives and stakeholder engagements are initiated by certain line ministries, internal governmental alignment between different ministries is indispensable. Collaborative change with countrywide relevance can also be initiated by nongovernmental, academic organizations, or industry aiming at economic improvements together, cooperatively addressing social challenges, or tackling a specific problem. The following two examples illustrate the differences in settings and purpose.

\section{CASE EXAMPLE 1.9: DIALOGUE FOR GREEN ECONOMIC ACTION}

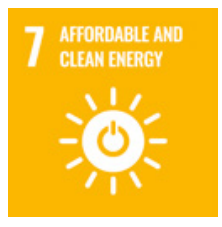
8 DECENT WORK AND

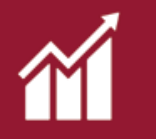

13 cumate

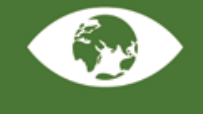

In Senegal, the Partnership for Action on Green Economy (PAGE) established a multi-stakeholder national platform. The platform functions as a forum for dialogue, information sharing, and coordinating action on topics like climate change, green jobs, and other relevant issues. It is organized by the Ministry of Environment and Sustainable Development together with the Institute of Environmental Sciences. The platform brings stakeholders together from the Senegalese government, local authorities, civil society, labor and employers unions, and academia (for more information, seewww.un-page.org/senegals-new-national-platformgreen-economy). 


\section{CASE EXAMPLE 1.10: TRUSTING THE SUSTAINABILITY OF TEXTILES}

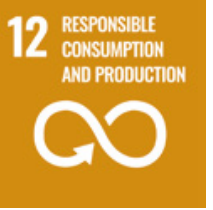

improvements alongside the entire textile supply chain. Based on jointly defined goals, members commit to sustainable production targets (for more information, see https://en.textilbuendnis.com/en/).

\section{Multi-stakeholder collaboration subregional or local level}

Multi-stakeholder collaborations within one country focusing on implementation can take place in a particular subregion, or a city, if the region is affected by the issue at stake and challenges must or can be addressed at this level. Even localized collaborative change processes can make a decisive difference towards SDG implementation, e.g. within a municipality or a district. The following two examples illustrate the differences in settings and purpose.

\section{CASE EXAMPLE 1.11: STAKEHOLDER COLLABORATION FOR EMPOWERING DISPLACED PEOPLE}

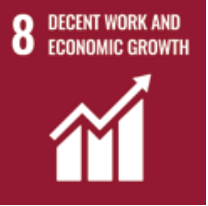

1 PEACE, JUSTICE AND STRONG INSTITUTIONS

\%

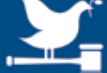

The armed conflict in eastern Ukraine caused many people to leave their homes and become internally displaced persons. A multistakeholder collaboration capacity-building component ${ }^{2}$ empowered multi-actor teams in six eastern regions of Ukraine to tackle specific economic and social challenges, related to labor market issues. These teams worked on development of regional-level projects that would improve the employability of internally displaced persons. Each team used an inclusive multi-stakeholder approach to create and implement their projects. The activities were implemented with the support of the Ministry of Temporary Occupied Territories and Internally Displaced Persons of Ukraine.

\section{CASE EXAMPLE 1.12: STRENGTHENING YOUTH ORGANIZATIONS}

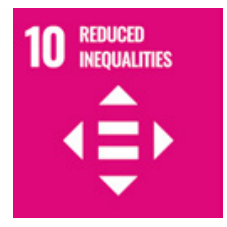

The youth-led NGO "We love Kairouan" initiated and facilitated a multi-stakeholder platform for collaborative initiatives on the sustainable development of the historic old city center of the city of Kairouan in southern Tunisia. In the aftermath of the Arab Spring, Tunisia adopted a new constitution that calls for public participation and good governance mechanisms. However, Tunisian youth remain marginalized in local development processes, and traditional power dynamics 
between citizens and public administration officials often remained. Joint projects and activities on environmental protection, restoration and community development have successfully been realized (for more information, see http://babmedina.welovekairouan.org/).

\section{Formats of multi-stakeholder collaborations that fit purpose}

The examples from the different levels of SDG implementation show that multistakeholder collaboration can be arranged in many different forms. The format chosen depends on the pertinent issues, the role of the initiators or conveners, and on the purpose of the collaborative process. However, there is an important distinction to make - between stakeholder collaborations that invite stakeholders into consultation and those that aspire to cooperate for implementation. This distinction is important because the role and intention of the initiators is different. In consultation processes, one or several stakeholders would like to improve a situation and invite other stakeholders to contribute their expertise, perspectives, and experiences. The purpose is to obtain the input from other stakeholders to improve planning and decision-making. The contributions made, such as viewpoints or recommendations are analyzed and evaluated by the initiators. It is then usually the responsibility of the initiators to make use of the inputs - for reports, policy developments, or planning documents. When consultation is the priority then singular workshops or a sequence of meetings with stakeholders can serve to integrate various perspectives into a planning or decisionmaking activity.

In cooperation processes, the initiating stakeholders are facilitators of a process with the purpose of building a collaboration ecosystem that can deliver transformative change. Stakeholders are included in the delivery of change, in the cooperative steering of the process and the implementation of results. In such collaborations, the focus is heavily weighted towards jointly achieving success, with a strong commitment of all participating stakeholders to outcomes. Stakeholders jointly decide how decisions are taken together and resources are made available to each other. The more focus is placed on implementation, the greater the willingness to work together. This increases the chances for success as stakeholders shift from being observers to being active in results achievement. Workshops and meetings assist stakeholders to come to agreements, do joint planning, and review the implementation. Table 1.3 shows the distinction in more details.

It is important to understand these distinctions between consultation and cooperation because stakeholders need to know if they are expected to contribute perspectives or to get engaged in joint delivery. A lack of clarity about the purpose of such processes leads to misunderstandings, mistrust, and ultimately disengagement of stakeholders. It is also necessary to realize that multi-stakeholder collaborations almost always cover a range from consultation to cooperation processes. Often, what starts as a consultation process, reveals that there is a need to cooperate more closely on projects. For example, a government led consultation process for the enhancement 
Table 1.3 Understanding the difference between consultation and cooperation processes

\begin{tabular}{lll}
\hline & Consultation processes & Cooperation processes \\
\hline Purpose & - The structured integration & - The cooperation of various stakeholders \\
& of perspectives and interests \\
from a variety of stakeholders & to achieve jointly agreed objectives \\
Role of & - Drivers and owners of results & - Facilitators of the collaboration process \\
initiators & - Steering of process & - Enablers of joint planning and \\
& - Decision on next steps in the & decision-making \\
Typical & process & - Promoters of joint ownership for results \\
application & Policy development (Public & - Development of voluntary sustainability \\
& sector) & $\begin{array}{l}\text { standards (public sector, NGOs, and } \\
\text { private sector) }\end{array}$ \\
& - Situational analysis (NGOs) & Compliance management \\
and stakeholder engagement & $\begin{array}{l}\text { Sustainable value chain development } \\
\text { (Private sector, NGOs) }\end{array}$ \\
& (Companies) & $\begin{array}{l}\text { Sustainable natural resource management } \\
\text { (public sector, NGOs, and private sector) }\end{array}$ \\
& & $\begin{array}{l}\text { Improving living conditions and social } \\
\text { development (public sector, NGOs, and } \\
\end{array}$ \\
& & $\begin{array}{l}\text { private sector) } \\
\end{array}$
\end{tabular}

of renewable energies in a particular region may reveal that there is interest and willingness to set up joint cross-institutional projects for decentralized renewable energy. Hence, consultation can lead to cooperation. Similarly, collaborations that want to engage certain stakeholders in joint delivery of transformative change often require consulting a broader range of stakeholders before they begin or during implementation. For example, a bottom-up initiative towards decentralized energy plants in a certain community requires consulting all stakeholders in the community (also those who will not directly be involved) before planning implementation. In consultation, the ownership of the process is with the initiators or conveners. They need to be transparent about how they use stakeholders' inputs. In cooperation, the collaborating stakeholders own the process together. This requires creating agreements for joint decision-making, joint steering and joint evaluation of progress.

Being clear about these different ways of engaging stakeholder is a vital element and key success factor for initiators of multi-stakeholder collaboration. The ability to know which form is appropriate to a situation or stage in the process is as important as initiators' ability to engage stakeholders and steward them to achieve results in a coordinated manner. Although the different forms are distinct, there are typical circumstances when one form is preferable to another, and also the forms do overlap and may develop into each other. Among the many different ways that a multi-stakeholder collaboration can use consultation and cooperation, four generic formats have crystalized. It is worth looking into them more closely to understand when and where to choose the appropriate format for a particular purpose of collaborative change. All formats require, to a certain degree, consultation processes and 


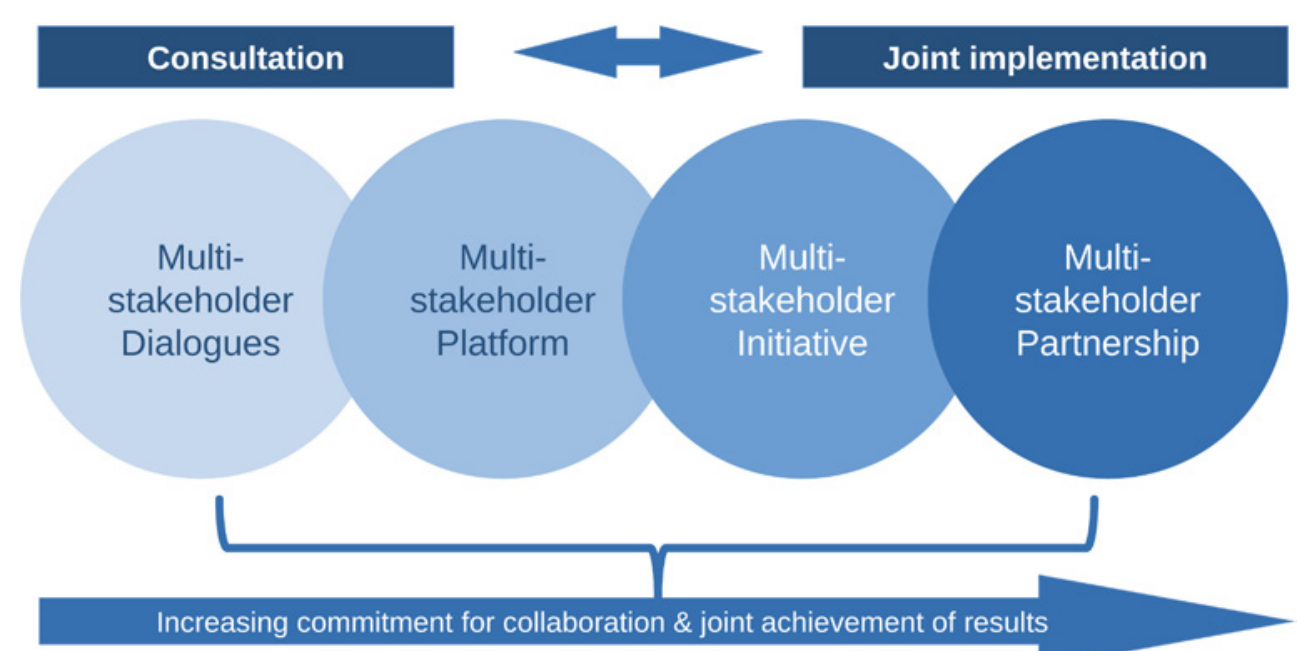

Figure 1.1 Four typical forms of multi-stakeholder collaboration

cooperation processes. The desired outcome for SDG- implementation determines which form should be chosen for a multi-stakeholder collaboration.

The first two formats for multi-stakeholder collaborations are multi-stakeholder dialogues and multi-stakeholder platforms. While dialogues can be singular events, platforms usually aim at establishing a cross-stakeholder dialogue and exchange structure that stays in existence for a longer period of time. Both tend to emphasize consultation processes. Cooperation processes are spin-offs from the exchange of stakeholders. The second two formats are multi-stakeholder initiatives and multistakeholder partnerships. Both have clear aims and objectives for implementation of collaborative change and aspire to achieve a measurable outcome. While initiatives often have broader overarching goals and involve many stakeholders, partnerships have usually fewer stakeholders involved, a clear-cut outcome expectation, and sometimes even contractual relationships between partners. Both are clearly focused on cooperation processes for joint implementation, but may use consultation processes to engage a wider group of stakeholders for impact. As multi-stakeholder collaborations for SDG implementation come in so many different constellations, all four different formats can exist distinctly or overlap. Figure 1.1 shows the range and the relationship between formats and commitment of stakeholders. The following section explains the distinct features of these four different formats of collaborative change and provides examples for each of them.

\section{Multi-stakeholder dialogues}

The purpose of multi-stakeholder dialogues is to raise stakeholders' interest in or awareness of a particular issue around SDG implementation or to get feedback from different stakeholders about a specific issue. Implementation of SDGs is complex, and when an initiative intends to undertake a planning activity, review progress, or 
monitor impact it is important to obtain the input of relevant stakeholders. Such consultation can range from singular events to a series of regular meetings. At the beginning of a multi-stakeholder collaboration, these events have the advantage of raising awareness among stakeholders about a particular issue of common interest, or may increase stakeholder interest for future collaboration. These kinds of events are consultation processes by design, as - at this stage - the stakeholders invited do not have ownership of the process. However, such gatherings, if well conducted, generate interest, foster the exchange of experiences, help stakeholders to get to know each other, and prepare them for future collaboration. Stakeholder dialogues are not meetings where only information is conveyed. For a deeper stakeholder engagement to occur and lead to constructive dialogue, stakeholders need to feel that there is true interest in their perspectives.

\section{CASE EXAMPLE 1.13: STRENGTHENING EDUCATION}

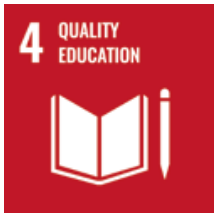

The African Union Development Agency (AUDA-NEPAD) hosted a two-day national stakeholders' consultative meeting in May 2019 on Science, Technology, Engineering, and Mathematics (STEM) Education in Addis Ababa, Ethiopia. The meeting served as an opportunity for dialogue, knowledge, and experience sharing among teachers as well as policy and decision-makers from both the public and private sector. It also strengthened knowledge and capacity of participants for evidencebased policy choices and program interventions in STEM pedagogy and teaching methodology (for more information, see www.nepad.org/news/national-stakeholdersconsultations-stem-education).

Some multi-stakeholder dialogues around SDG implementation need sustained consultation events among stakeholders. This may be, for example, a policy development initiative, the design of a strategy for participatory implementation, or simply a way of obtaining regular feedback on the implementation of an initiative. The engagement of stakeholders increases the quality of policy decisions, regulation development, and implementation of complex projects, as well as public sector planning activities. But it also contributes to good governance and credibility, which often leads to achieving broader consent among the general public. These benefits emerge, because stakeholders can have their concerns heard, can bring in their own expertise and experience, and can alert initiators of what may be missing in the planning or implementation process. Regular stakeholder consultations frequently lead towards a specific outcome, like the development of a national strategy or the implementation planning for a regulation or for a regional development plan, for example.

\section{CASE EXAMPLE 1.14: DIALOGUES FOR ECONOMIC STRENGTH} 8 DECENT WORK AND

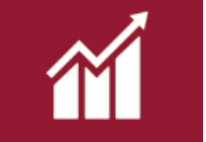

The government of Rwanda launched a Public Private Dialogue (PPD) mechanism to enable the government and the private sector to jointly discuss key business and private sector constraints and find solutions that would lead to their resolution. The dialogue mechanism was tested in a group of pilot districts and then later rolled out 
to the remaining 25 districts in Rwanda. The focus of the dialogues ranged from consultation on the setting of local taxes, local regulations that impede business activities, support for women in business, delayed payments for services rendered and goods supplied as well as land titles and security.

Governments, and intergovernmental organizations committed to good governance, can make multi-stakeholder dialogues part of their regular implementation or planning processes. Occasionally, a permanent structure is created in the form of an institutionalized multi-stakeholder dialogue and enshrined as an administrative rule. These can be long-term structures between public, private sector, and civil society stakeholders to ensure a climate that promotes economic development or legal agreements, or it may be a prerequisite for an environmental impact assessment. Often, the process of how different stakeholders are involved is anchored in an administrative procedure. Institutionalized multi-stakeholder dialogues are conducted on an ongoing basis, or when the need arises, in accordance with publicly defined rules and procedures. Well-functioning institutionalized consultations can provide insights that lead to further forms of dialogue and cooperation on specific topics, such as multistakeholder initiatives or multi-stakeholder partnerships.

\section{CASE EXAMPLE 1.15: HEALING SOCIAL IMBALANCES}

8 DECENT WORK AND

8 ECONOMIC GROWTH

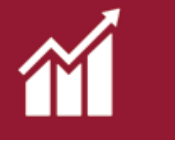

The National Economic Development and Labour Council (NEDLAC) in South Africa is an institutionalized multi-stakeholder dialogue between the state, private businesses, unions, and small communities. This institutionalized dialogue exemplifies and reviews the socioeconomic dimension of the South African societal transition and healing process. Within the context of this dialogue, participants discuss draft legislation and strategic decisions. In this way, participation and right of say have been institutionalized on a high level.

When there is a need for regular exchange and possibly coordination between different stakeholders, but no need to embed a multi-stakeholder dialogue into administrative procedures, the format of a multi-stakeholder platform is the most appropriate format for collaboration.

\section{Multi-stakeholder platforms}

The purpose of multi-stakeholder platforms can range from facilitating the coming together of different stakeholders for an exchange of experience to the coordination of various SDG implementation activities within an overall framework of action. When there is a common concern that affects multiple stakeholders or they are interested in learning, exchanging experiences, or advocating for a specific goal, stakeholders may come together to form a platform, or, as it sometimes called, a multi-stakeholder forum. The specific purpose depends on the issue of common concern, but most often, stakeholders aspire to contribute together to transformative change around a specific 
issue. Such multi-stakeholder platforms may function more as an informal network or a voluntary round-table, or they may create a legal entity with members coming from different societal sectors. Typical for platforms is that stakeholders report on activities related to a specific topic, exchange experiences, and share lessons learned and good practices. But they can also have an advocacy function, generating recommendation for actions by members or addressing action recommendations to, for example, the public sector. Multi-stakeholder platforms may be initiated by the public sector, private sector, or civil society. However, this is a form of multi-stakeholder collaboration that generally draws great interest from private sector actors as such platforms offer the chance to improve production conditions together with other companies in a precompetitive environment while accompanied by critical stakeholders such as NGOs. In multi-stakeholder platforms, corporations can show that they are interested in sustainability, but do not necessarily commit to binding targets.

\section{CASE EXAMPLE 1.16: ENSURING SUSTAINABLE PALM OIL}
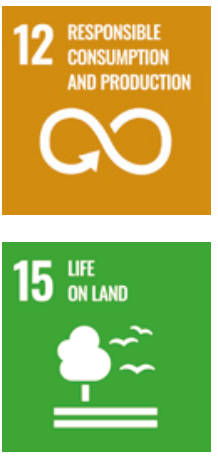

The Roundtable on Sustainable Palm Oil (RSPO) has emerged as a cross-sector collaboration and has been institutionalized as a notfor-profit that comprises stakeholders including palm oil producers, processors, and traders, consumer goods manufacturers, retailers, banks, and investors, as well as environmental and social NGOs. Its purpose is to develop and implement global standards for sustainable palm oil. With more than 4,000 members worldwide, the stakeholders aspire to minimize the negative impact of palm oil cultivation on the environment and communities in palm oil-producing regions. Their objective is to make sustainable palm oil production the norm globally (for more information, see https://rspo.org).

Multi-stakeholder platforms are recommendable if various actors and experts are to meet regularly to discuss a specific topic and bring change forward in their own institutions as well as among each other. They create a fertile ground for cooperation on the ground as well as for sector-wide transformations. In addition to exchanging views and making recommendations, they create the conditions for change to happen, for example, through the development of standards, through the setting of targets for changed behavior, or even through developing joint implementation projects of some members. Permanently established multi-stakeholder platforms require steering structures (governance) that ensure that all stakeholders are appropriately represented. Many multi-stakeholder platforms emerge from a series of consultation processes that were initiated to tackle a specific SDG challenge. A typical example for an implementation-focused multi-stakeholder platform is the water basin management committee in integrated water resource management initiatives. These platforms are comprised of a variety of actors, often including affected communities, and serve as a conduit between government actions, donor interventions, and local communities to design apt strategies to address water issues. 


\section{CASE EXAMPLE 1.17: MANAGING WATER FOR LIFE}

C CLEAM WATER

6 AND SANITATION

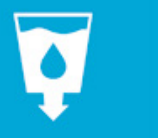
13 CUMAII

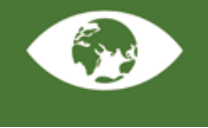

The Tunisian Ministry of Agriculture inaugurated the first Nebhana Water Forum in Sbikha, Governorate of Kairouan, in the year 2016. The Tunisian administration and local water users - mainly farmers worked together in a participatory dialogue process in order to find solutions for sustainable water management. As a first step, a joint charter was signed among the stakeholders, outlining the grounding principles of a shared approach to the management of the local water resources. Concrete measures for improved water management, developed by both parties, were planned jointly. The forum represented an unprecedented level of local governance in Tunisia, showing, against all odds, a groundbreaking re-establishment of trust between administration and citizens.

Multi-stakeholder platforms are recommended if there is a need to work together on a long-term basis, because the SDG implementation issue of concern may require the long-term engagement of all stakeholders, as well as the need to engage more and more stakeholders to achieve a result. The boundaries to multi-stakeholder initiatives may at times be fluid: platforms often emerge from consultation processes and move towards increasing cooperation processes for implementation. Multi-stakeholder initiatives start with a focus on cooperation for implementation.

\section{Multi-stakeholder initiatives}

The purpose of multi-stakeholder initiatives is to bring about transformative change for SDG implementation with measurable results within a certain time-period. Initiatives usually have a complex set-up with various stakeholders, but do not necessarily need to grow and engage more actors in order to reach their objectives. They can range from tackling a local SDG challenge to addressing global problems such as ocean acidification or air pollution. Multi-stakeholder initiatives are focused on cooperation for implementation of change in a cross-sector setting. Their objective is to jointly address complex challenges, because none of the actors can achieve results alone. Actors come together to accomplish a jointly set goal in a jointly agreed-upon timeframe. They carry out jointly planned activities and monitor the results together. The common intention to foment lasting change among participating stakeholders, accompanied by a joint responsibility for success or failure, is typical of this format of multi-stakeholder collaboration. Hence, stakeholder initiatives necessarily entail agreed-upon decision-making procedures (usually consensus), as well as jointly agreed forms of monitoring and evaluation. This means that project management tools should be used. In complex stakeholder initiatives that operate at the national, regional, or international levels and where large numbers of stakeholders are involved, equally sophisticated governance and representation mechanisms that are endorsed by all stakeholders are required. Such initiatives frequently rely on stewarding structures (e.g. steering committees) as well as a secretariat that takes responsibility for 
communication among stakeholders and the organization of stakeholder meetings and events. Stakeholder initiatives' success depends on high-quality process management, excellent communication, and transparent results of activities in order to maintain interest and alignment behind the common goal among the complex set of stakeholders.

\section{CASE EXAMPLE 1.18: CREATING A COMMUNITY FOR SUSTAINABLE COFFEE}
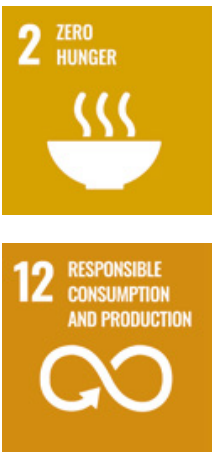

The Common Code for the Coffee Community (4C) started as a multistakeholder initiative to develop a basic mainstream sustainability standard for green coffee production with the objective to shift the entire mainstream coffee market towards sustainability practices. At the outset, a group of international stakeholders came together in a new and innovative approach that aimed at benefiting especially small-scale coffee farmers. Among them were coffee producers from all major coffee-producing countries, trade and industry as well as international NCOs. They came together as a steering committee to develop the mainstream standard, to decide on the conditions of its application and the criteria for success. With growing interest from more and more stakeholders in the coffee sector, the initiative founded an association and a membership scheme. It eventually joined forces with another global coffee initiative to create the Global Coffee Platform (www.globalcoffeeplatform.org/accelerateyour-coffee-sustainability) that has more than 140 members in 41 countries and one common agenda: sustainable coffee production.

Multi-stakeholder initiatives are recommended if the challenges around SDGs are so complex that they can only be addressed with the competence and experience of different stakeholders in planning and in implementation. This often requires resource contributions by different stakeholders, financial mechanisms for how to allocate funds, and, subsequently, transparent governance and implementation structures. Within multi-stakeholder initiatives, consultations with non-directly involved stakeholders can play an important role. Multi-stakeholder initiatives may also result in limited implementation partnerships for specific objectives.

\section{Multi-stakeholder partnerships}

The purpose of multi-stakeholder partnerships is to achieve specific project results with complementary resources and a limited number of partners in specific timeframes. The joint implementation of measures is in the foreground. Partnerships are relevant when the solution to a problem is most likely to be achieved through shared project management with other stakeholders, using different skills, resources, and expertise. This usually requires very clear rules and at times binding agreements about financial contributions, delivery targets, and measurement of progress. Such partnerships require professional project management and the creation of monitoring, 
control, and evaluation procedures. Stakeholders in partnerships are under pressure to reach agreed goals and milestones and to report regularly on the status of implementation. Each of the partners has an agreed role to fill and is responsible for implementing individual aspects of the project. More complex multi-stakeholder partnerships can be supported by a project secretariat. Often-unequal expectations of the actors in terms of speed and visibility of success need to be managed, as the operational logics and reporting cultures of stakeholders from private sector, public sector, and civil society are different. Stakeholders from very different organizational cultures must work closely together and develop mutual understanding of their internal rules, constraints, and ways of working. As implementation partnerships realize complex projects, it may be necessary to integrate further relevant stakeholders who are not directly involved in the implementation partnership into consultation processes. This helps to raise awareness for the goals of the multi-stakeholder partnership, receive new perspectives and feedback, or to adjust strategies.

\section{CASE EXAMPLE 1.19: STRENGTHENING REGENERATIVE AGRICULTURE}

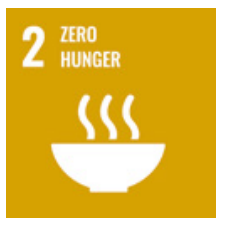

The Multi-Stakeholder Partnership for Organic Agriculture (POAg) was initiated by Adventist Development and Relief Agency (ADRA) in Mongolia and works closely in partnership with the National Association of Mongolian Agriculture Cooperatives (NAMAC), a Cooperative Union, the Ministry of Food, Agriculture, and Light Industry of Mongolia (MoFALI), different provincial and municipal administrations, and 30 primary cooperatives. The partnership improves the employment situation and economic well-being of goo households of smallholder farmers in Selenge Province ( 3.600 persons). It strives to establish a sustainable and equitable organic agriculture value chain in Mongolia supporting small farmers, processors, buyers, other government institutions, and national and regional platforms and associations.

Partnerships, once they have successfully implemented an issue-specific change in collaboration, may grow into larger projects, may create an initiative that involves more stakeholders, or may establish a platform that supports advocacy for the topic or engages more actors into awareness and collective action around SDGs.

Hence, all four formats described must be seen not as distinct categories but more as guiding features for finding the best possible home for a transformative change endeavor. The format chosen is inevitably a structure of relationships between the collaborating stakeholders. Formats that focus more on organizing consultation processes engage stakeholders into making a contribution without any binding obligations. Formats that expect results of cooperation processes need commitment by stakeholders and partners, which is usually anchored in written agreements, jointly development plans, and other forms of accountability mechanisms. Table 1.4 shows a summary of the four different formats, their purposes, and examples for application. 
Table 1.4 Formats of multi-stakeholder collaborations: summary of purpose and applications

\begin{tabular}{|c|c|c|}
\hline Format & Purpose & Applications \\
\hline $\begin{array}{l}\text { Multi-stakeholder } \\
\text { dialogues }\end{array}$ & $\begin{array}{l}\text { - To raise stakeholders' } \\
\text { interest in or awareness of a } \\
\text { particular issue } \\
\text { - To get feedback from dif- } \\
\text { ferent stakeholders about a } \\
\text { specific issue }\end{array}$ & $\begin{array}{l}\text { - Awareness raising for SDG implementation } \\
\text { - Development of national or local sus- } \\
\text { tainability strategies } \\
\text { - Policy development around SDG } \\
\text { implementation topics } \\
\text { - Policy implementation review } \\
\text { - Environmental or social impact } \\
\text { assessment }\end{array}$ \\
\hline $\begin{array}{l}\text { Multi-stakeholder } \\
\text { platforms }\end{array}$ & $\begin{array}{l}\text { - Exchange of experi- } \\
\text { ence between different } \\
\text { stakeholders } \\
\text { - Fostering cross-sector } \\
\text { working relationships } \\
\text { - Coordination of various } \\
\text { SDG implementation } \\
\text { activities within an overall } \\
\text { framework of transformative } \\
\text { change }\end{array}$ & $\begin{array}{l}\text { - Exchange of lessons learned from SDG } \\
\text { implementation } \\
\text { - Development of sustainability standards } \\
\text { - Harmonization of standards or } \\
\text { approaches to transformative change } \\
\text { - Coordination of complex tasks in e.g. } \\
\text { resource managements that require } \\
\text { multiple stakeholders } \\
\text { - Multi-stakeholder advocacy for SDG } \\
\text { implementation and sustainability issues } \\
\text { - Advocacy for political or economic } \\
\text { development agenda }\end{array}$ \\
\hline $\begin{array}{l}\text { Multi-stakeholder } \\
\text { initiatives }\end{array}$ & $\begin{array}{l}\text { Delivering transformative } \\
\text { change for SDG implemen- } \\
\text { tation complex constella- } \\
\text { tions of stakeholders with } \\
\text { measurable results within a } \\
\text { certain time-period. }\end{array}$ & $\begin{array}{l}\text { - Complex collaborative implementation } \\
\text { projects } \\
\text { - Strategic alliances for transformative } \\
\text { systems change around SDGs } \\
\text { - Sector-wide collective behavior changes } \\
\text { in value chains resource management } \\
\text { or poverty alleviation. } \\
\text { - SDG-specific coordinated implementation } \\
\text { of various activities }\end{array}$ \\
\hline $\begin{array}{l}\text { Multi-stakeholder } \\
\text { partnerships }\end{array}$ & $\begin{array}{l}\text { Achieving specific project } \\
\text { results with complementary } \\
\text { resources from selected } \\
\text { stakeholder partners in } \\
\text { specific timeframe }\end{array}$ & $\begin{array}{l}\text { - Concrete and localized improvement } \\
\text { projects for SDG implementation. } \\
\text { - Innovative approaches to solve specific } \\
\text { problems. } \\
\text { - Improving service delivery to people in } \\
\text { complementary action. }\end{array}$ \\
\hline
\end{tabular}

\section{Understanding cross-sector settings}

Both consultation and cooperation processes need high quality process architecture and serious attention to how stakeholder interact with each other in order to yield results. Chapter 2 will go into more details about the process behind quality collaboration. However, as a starting point, it is important to remember that stakeholders are different - their identity is first and foremost determined by the purpose of their particular organization 
or affiliation. Understanding the differences between stakeholders is paramount for leading transformative change collectively. Stakeholders can be broadly divided into three societal groups, the public sector, civil society, and the private sector.

Not all stakeholders fit clearly into these divisions. For example, donor organizations sometimes represent governments but can also be large civil-society organizations. Research organizations may belong to the civil-society sector or to the public sector, depending on their purpose and funding structure. However, in the context of multi-stakeholder collaboration, these divisions help to understand the motivation for, or reluctance to, engage in leading transformative change collectively. Within each of the three stakeholder groups, there are important differences that also need to be taken into account: large international corporations often have different interests than small companies; local NGOs have a different outlook on certain subjects than large international NGOs; and national and provincial government institutions are not always aligned with each other. A stakeholder analysis begins with looking at who is particularly important for bringing a change endeavor forward, who has the power and capacity to influence progress, who has specific expertise, and who will be most interested in change but may be less influential. For an effective multi-stakeholder collaboration approach, a thorough stakeholder analysis is therefore a crucial starting point. How to practically conduct a stakeholder analysis is described in Chapter 3.

Beyond this broad distinction, of course, there are many reasons why stakeholders may want to enter into a collaboration or why they may be skeptical or resistant to join. Multi-stakeholder collaboration can only become successful when the sphere of shared interest can be found and further cultivated, as shown in Figure 1.2.

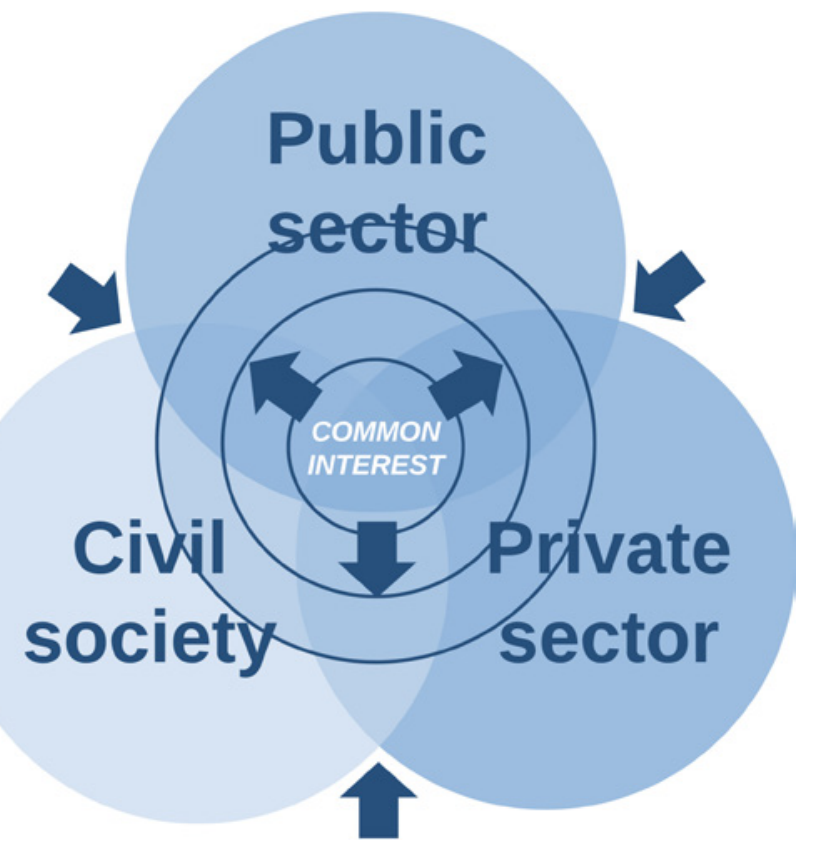

Figure 1.2 Multi-stakeholder collaboration as shared interest 
However, in preparing an approach to a complex initiative, project, or program by using a multi-stakeholder collaboration approach, it is important to understand the differences between stakeholders, to respect their particular interests, and to become aware of the dynamic that may exist between different stakeholders. The next sections give an overview over the interests, concerns, and motivations of the three different stakeholder groups.

\section{The public sector}

The public sector's rationale is guided by the rights-orientation of law and order, the regulation of access to common resources, and service delivery to citizens. Designing and enforcing rules and regulations, and complying with internal procedures are fundamental to the work of public-sector organizations. They often follow a more bureaucratic approach that is driven by adherence to tradition, processes, procedures, structures, and mechanisms. The result is a more conservative and not necessarily innovative milieu that is not always open to change. This is reflected in the decisionmaking culture of the public sector: it is sometimes slow, administrative, hierarchical, loyal to regulations and procedures, and rigid in protocol. Decision-making follows the political approach (e.g. democratic) and can include regulated internal and external consultation of stakeholders. The core principle is acting on behalf of the common good.

The public sector, with its different institutions on the national, provincial, and local levels, has, in general, a common interest and a similar motivation and approach to administration and service delivery. However, even with a similar mission there may be differences in interest between different government departments or between government institutions at national, provincial, and local levels. There can be differences in specific interests and sometimes challenges in communication between government agencies at different levels: municipalities are not always entirely aligned with their provincial administration, or the provincial administration is not fully aligned with the national government. Even among national or provincial government, ministries or departments often cautiously defend their territory. Their interests are not always the same - especially when it comes to allocating resources. Different line ministries can be in fierce competition. Some multistakeholder collaborations, therefore, may require internal government dialogues and alignment first, before the wider group of stakeholders can be engaged. Yet, public-sector-initiated multi-stakeholder collaborations, in principle, have the common good in focus. Public-sector-supported or-initiated consultation and cooperation processes can enhance consensual policy development, the development of standards, and broad compliance with regulations. The motivation of the public sector to engage in leading transformative change collectively and engage other societal stakeholder groups lies in the opportunity to create a broader base for societal well-being, steer a country towards sustainability, or create better business environments. 


\section{CASE EXAMPLE 1.20: EMPOWERING SMALL AND MEDIUM SCALE ENTERPRISES}

1 NO

POVERTY

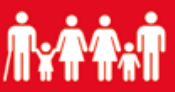

DECENT WORK AND

ECONOMIC GROWTH

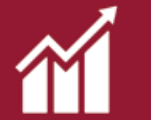

The Senegalese Ministry of Finance sees the promotion of competitiveness of Senegalese small- and medium-sized enterprises (SMEs) and the development of capacity in the microfinance sector in Senegal as key to the development of the country. An important aspect of the program is the initiation of a PPD between governmental institutions and private sector business associations on SME promotion in the West African State. This dialogue process is to provide a "creative space" for SME stakeholders to discuss options, targets as well as collaborate on implementation measures.

\section{CASE EXAMPLE 1.21: MAKING THE BUSINESS ENVIRONMENT WORK}

9. INOUSTRY, INNOVATON

AND INFRASTRUCTURE

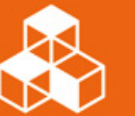

The National Committee for the Business Environment of Morocco is a high-level public-private platform that facilitates and catalyzes public-public as well as public-private collaboration needed to improve the business environment in Morocco. An important aspect of the Committee is its task to be an active listener to the needs of the private sector, in particular to identify obstacles to both national and international investment, and to provide an innovative space of dialogue between the private and public sectors to develop respective reforms to reduce such obstacles.

Another benefit of multi-stakeholder collaboration for the public sector is an increased efficiency in the implementation of public and developmental service delivery through regular feedback from stakeholders. Aside from the benefits of getting involved in collaborative change, there are also risks involved: for the public sector, it can be the perceived risk of losing power, for example by talking to more radical groups or by supporting certain private-sector companies too much.

For initiators of multi-stakeholder collaborations who do not come from the public sector, but need to raise the interest of government representatives for a certain approach to SDG implementation, it is helpful to consider the aspects and strategies described in Box 1.1 for the public sector.

\section{Box 1.1 Engaging stakeholder groups differently}

Initiators of multi-stakeholder collaborations sometimes overlook the differences of different stakeholder groups in their motivation to join and engage. It is helpful to keep in mind that each group may need to be treated in a different way to maintain interest. The following table is a reminder of what needs to be taken into 
account when engaging the three large societal stakeholder groups. Depending on the context, this may be even more complex: a stakeholder analysis helps to understand the motivations that can lead stakeholder groups to engage.

Strategies to engage the public sector:

- Understand the power dynamics and hierarchical structures.

- Recognize the importance of sociocultural factors.

- Be aware of formalities and protocol.

- Ensure your knowledge of existing rules and regulations.

- Show the reputational case for change.

- Consider supra-national and regional structures and their interests.

- Highlight sustainability aspects.

- Make reference and ensure conformity to international conventions.

Strategies to engage the private sector:

- Know that the private sector always has a busy schedule.

- Involve the private sector in the planning process.

- Link engagement to corporate sustainability commitments.

- Build a results-oriented process.

- Plan short meetings in a convivial setting.

- Show the business case for change.

- Provide private sector partners the opportunity to showcase their work and promote their image.

- Take advantage of competitiveness to stimulate involvement and commitment.

Strategies to engage civil society:

- Consider logistical and financial support (i.e. funds, transport, accommodation, per diems etc.) for participation.

- Ensure transparent and inclusive communication.

- Be aware of civil society organizations requirements to consult with their constituencies.

- Respect the different mandates of different organizations.

- Strengthen weakly represented groups (e.g. from communities).

- Respect and appeal to value-orientation.

- Show the societal case for change.

- Be prepared to address questions on impact - monitoring.

\section{The private sector}

The private sector's core motivation is growth and business opportunities, so profit orientation is at the forefront, even though companies increasingly take not of the need for sustainable development. Stakeholders from the private sector are predominantly guided by their company strategy, and are highly motivated to be loyal to the business. Corporations depend on performance indicators and stock-exchange 
analysts. Small and medium enterprises depend on their business performance. Efficiency and strategic purpose are critical to their decisions, and they always have to argue the business case for any engagement in multi-stakeholder collaborations. The private sector needs to be innovative and often creative. This leads to a fast, short-term, impatient decision-making model, which is participatory in some cases and hierarchical in others, depending on the organizational culture. At the core of decision-making is loyalty to the business purpose.

It is important to consider that there are differences between business associations and individual companies, between companies in developed and in developing countries, and between privately owned, stock-listed companies, or public companies. The interests of large companies differ from those of small and medium-sized companies. While large companies are often well organized, small and medium companies are usually less organized, particularly in developing countries or emerging markets. Therefore, they have greater difficulty in speaking with a single voice, in public - private dialogues, for example. The least organized private-sector "companies" are in the informal sector. This is often a very important stakeholder group, but has little capacity to organize itself and to voice its concerns.

The motivation to engage in multi-stakeholder collaborations often lies in being able to influence the business environment (for example, in multi-stakeholder dialogues with the public sector), to access new markets, to reduce investment risks, or to gain reputation in sustainability engagement. Multinational companies' interest in collaborating with other stakeholders is sometimes driven by the motivation to be among the leading companies in corporate responsibility. But beyond issues of reputation, more and more companies engage in multi-stakeholder dialogues, platforms, initiatives, or partnerships, because they see that they can't solve business challenges alone, or reconcile performance pressure and sustainability aspirations solely within the company's influence. Improving conditions with other actors along a value chain can be another reason for joining or initiating multi-stakeholder collaborations. This can contribute to long-term or short-term market development, as well as to risk and compliance management.

\section{CASE EXAMPLE 1.22: PARTNERING FOR DECENT WORK}

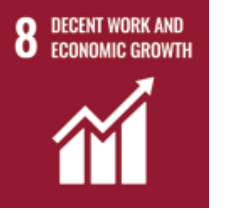

Worldwide Enhancement (WE) of Social Quality was initiated as a stakeholder partnership between the German coffee roaster and consumer-goods company Tchibo and the German development cooperation involving also NGOs in textile producing countries. The partnership aimed to improve the acceptance and implementation of social standards in supplier companies in Bangladesh, Thailand, and China. The approach combined the dialogue taking place along the entire company value chain with operational qualification measures for the implementation of labor and social standards in the workplace (for more information, see www.wesocialquality.com). 


\section{CASE EXAMPLE 1.23: STRENGTHENING COCOA FARMERS}
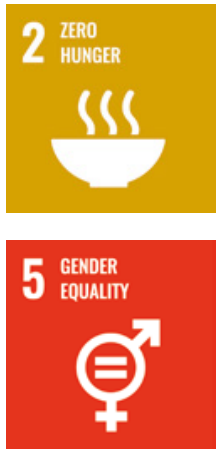

12 RESPONSIBIF AND PRODUCTION

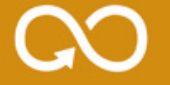

The Cocoa Life Program is a sustainable sourcing initiative by the company Mondelez with nine well-known chocolate brands, implemented in Ghana, Indonesia, Cote d'Ivoire, India, Dominican Republic, and Brazil. It aims to tackle the complex challenges of cocoa farming communities such as climate change, gender inequality, poverty, and child labor, while securing the production base for long-term sourcing of cocoa for the different brands. The program creates partnerships with communities, governments, national and international NGOs, and supply chain partners. It promotes environmentally sound agricultural practices, women's empowerment, and economic development in rural communities (for more information, see www.cocoalife.org).

Private sector companies may also initiate their own consultation processes to improve their relationships with customers and stakeholders. Most often, this takes place in the format of stakeholder dialogues. They serve to improve reputation and manage risks. This kind of engagement can provide companies with vital feedback from customers and other stakeholders about market demand for environmentally or socially responsible products and services, can help to shape company strategy and policy, and potentially lead to innovation in product development or service delivery. However, the benefit of multi-stakeholder dialogues can turn into a risk for companies, if nothing follows from the events and the company or the association is accused of only paying lip service to stakeholder engagement. For initiators of multi-stakeholder collaboration who do not come from the private sector but need to raise the interest of entrepreneurs, small-scale businesses, and corporations for a collaborative approach to SDG implementation, it is helpful to consider the aspects and strategies described in Box 1.1 for the private sector.

\section{Civil society}

There is a wide variety of civil society organizations. They may be national or international NGOs, unions, researcher institutions, women's groups, farmers, and indigenous peoples' groups, among others. These organizations represent the perspectives and interests of groups and subcultures across the societal spectrum. Civil society organizations are vital for a society as they fill many of the gaps that are not filled by the public and private sector, including protecting natural resources, advocating for justice, lobbying for economic equity and social fairness, and supporting social inclusion. Civil society organizations are an indispensable support for underrepresented segments of the population and they assist with the inclusion and participation of such groups in civic and political discourse. However, civil society groups also represent a wide array of interests. What is generally common among them is their value orientation and advocacy of weaker or underrepresented groups or the environment. For example, civil society organizations often reveal public and private 
sector behaviors that are detrimental to certain stakeholders, like abuses of the law, malpractice, corruption, or wastefulness. Civil society organizations' modus operandi can be centered on campaigning against private sector companies' business practices, or advocate for policy change targeting government institutions. Many civil society organizations work for a certain cause by raising awareness for urgent sustainability issues or building capacity to implement the SDGs. Increasingly, civil society organizations are entering into partnerships with companies, for example, to enhance sustainability practices, build capacities of small-scale farmers in responsible value chains or advice on human rights practices.

In spite of the general value orientation of civil society organizations, they do not always share goals, rationales, or interests, which occasionally may be contradictory. For example, human rights focused NGOs have very different concerns than environmental NGOs. National NGOs may have very different interests and concerns than an international NGO, although they may collaborate with each other in funded projects. Organizations that operate internationally often rely on funding sources from developed nations and require their own resources to maintain the interest, engagement, and support from their constituents. NGOs' relationship with the public sector may also be ambivalent. In developing countries, NGOs frequently work on development, empowerment, and capacity building predominantly with the public sector, but sometimes also with the private sector. On the other hand, NGOs at the national level often act in opposition to government policies and may be reluctant to enter into a structured dialogue or collaboration with the public sector. NGOs can also focus on community development at the local level and represent the interests of the people in a particular area. Larger, international NGOs often work on various projects for SDG implementation and can serve as donors for smaller development-focused NGOs or community development organizations. Multi-stakeholder collaborations that are initiated by civil society organizations often stem from the experiences that single project or silo approaches to bringing about transformative change do not work or have limited impact. Hence, they seek to set-up collaborative processes that take a wider perspective and help stakeholders to join forces for SDG implementation.

\section{CASE EXAMPLE 1.24: IMPROVING HEALTH SERVICES}

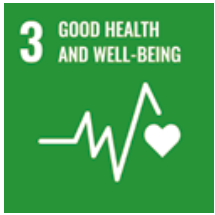

The Multi-Stakeholder Partnership for Universal Health Coverage through Access to Specialized Services in Kenya was jointly initiated by the NGO Malteser International, a relief organization, Amref Health Africa, a leading healthcare development organization in East Africa and the Kenya Healthcare Federation, a private sector representation with 160 institutional members. While engag-

ing also public sector institutions and academia, the partnership developed a joint vision for exemplary, innovative, and collaborative approaches to advance the education and recruitment of, as well as advocacy for, neglected specialized health professionals in Kenya. Special focus is on recognition, training, and representation of community health workers, health data information officers, as well as 
emergency technicians physicians. The partnership aims to strengthen public and private partnerships in health by engaging various actors and creating synergies for improved specialized care in the country (for more information, see (http://msp. co.ke/about-us/).

\section{CASE EXAMPLE 1.25: EMPOWERING FISHERY COMMUNITIES}

3 GOOD HEALTH

AND WELL-BEING
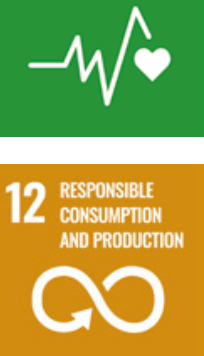

The Multi-Stakeholder Partnership for Sustainable Tuna Fisheries, Livelihoods, and Communities in Mindoro Straits and Lagonoy Gulf, Philippines was initiated by the World Wide Fund for Nature (WWF) and the Tambuyog Development Center. It promotes equitable and sustainable tuna supply chains and sustainable management of yellowfin tuna in Philippine waters, enhances the socioeconomic situation of small-scale handline tuna fishers, and secures their livelihoods in the long-term. The initiative is implemented in a partnership with several actors from the public and private sectors, NGOs, and representatives of the fisher communities along the global tuna supply chain (for more information, see https://wwf.org.ph/what-we-do/ food/stp/the-sustainable-tuna-multi-stakeholder-partnership-training/).

Due to civil-society organizations' heterogeneity, their participatory approach, and their resource shortages, they are often characterized by slow, participatory, and democratic decision-making models, or have an analytical approach when decisions are largely based on research findings. The core element of decision-making in these groups is a loyalty to the group's values and principles. Civil society organizations' motivation to engage in multi-stakeholder collaborations is the possibility of influencing public and private actors towards their value-based goals, of changing societal and global structures of inequity or disparity, or of improving their target group's situation. By their engagement in dialogues, platforms, initiatives, or partnerships, these groups also see the chance for additional opportunities for advocacy and higher efficiency and effectiveness in implementing SDGs. However, participation in multi-stakeholder collaborations can also be a risk for civil society organizations, particularly for international NGOs focusing on advocacy and campaigning: it may pose the danger of losing acceptance among their members and constituencies that give them financial support and legitimacy. People may see them engaging in dialogue or collaboration with the very organization or stakeholder group against which the NGO is advocating. Being part of multi-stakeholder collaborations may mean a loss of face, and, subsequently, a loss of financial support. This, in turn, may undermine the NGO's ability to campaign and advocate. For initiators of multi-stakeholder collaboration who do not come from civil society but need to raise the interest of NGOs, community organizations or human rights and environmental activists for a collaborative approach to SDG implementation, it is helpful to consider the aspects and strategies described in Box 1.1 for civil society.

Understanding the differences in interest, motivation, purpose, organizational culture, and operational logics of different stakeholder groups is paramount for getting them on board for collaboration. Table 1.5 summarizes the interests, motivations, 


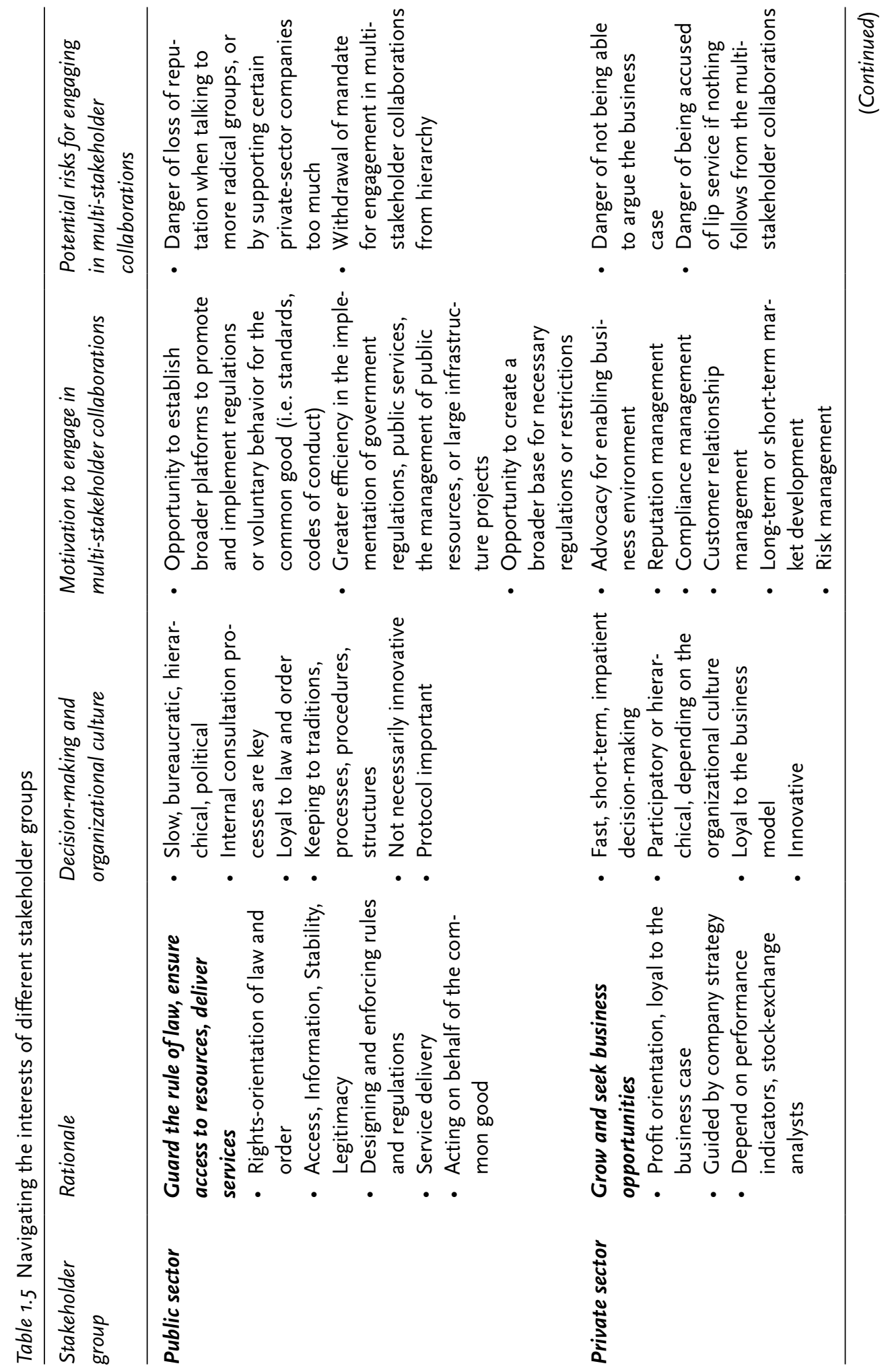




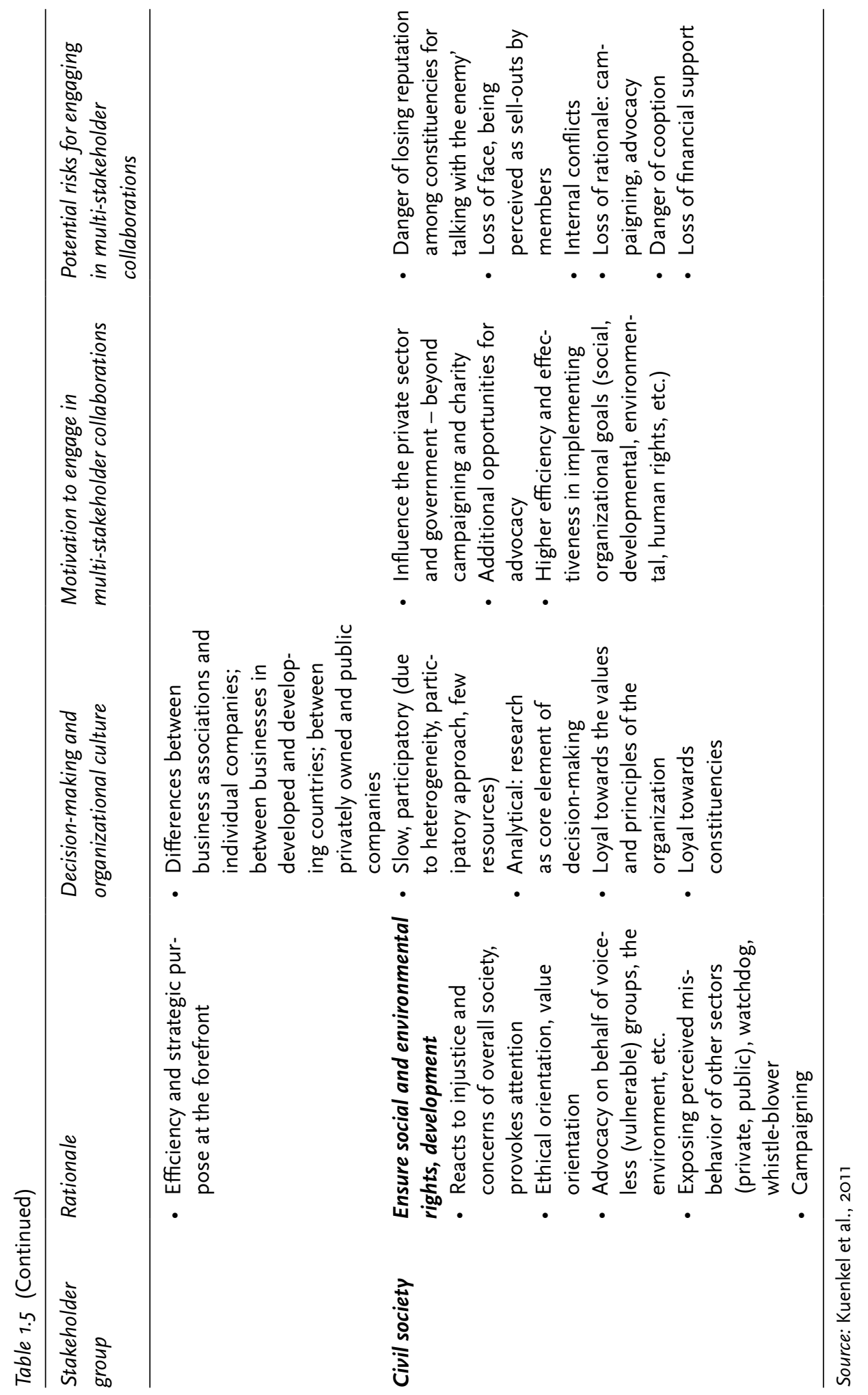


and risks of collaboration for the different societal sectors. It is important to know constraints, understand different reporting requirements, or acknowledge differences in decision-making procedures. For example, misunderstandings often occur when it comes to reporting on progress in multi-stakeholder collaborations. Private sector actors love 'dash boards' with facts and figures to show progress and report on results. NGOs, however, may need qualitative information about the real changes in the life of beneficiaries and may be skeptical in reducing information to the simplicity the private sector preferences. The public sector is accountable to its taxpayers and can't do with short reports, but requires lengthy and elaborate documents that show progress made against indicators set. Hence, navigating differences between stakeholder groups, but also within stakeholder groups, becomes the ongoing tasks of those actors who initiate, maintain, or facilitate stakeholder collaborations. What it means to collectively lead SDG implementation across all sectors of society is a learning journey that is greatly supported by navigating tools and process methodologies.

\section{Creating conditions for transformative change}

The 17 SDGs encompass our most pressing modern problems and are all connected, therefore, they cannot be interpreted or addressed in isolation. The sustainability challenges to be overcome by the global goals are all deeply interdependent and systemic in nature (Capra \& Luisi, 2014). Addressing these challenges requires collective action and jointly created impact (Kania, 2011; Patscheke, 2014), regardless of which goal they predominantly relate to. Hence, any multi-stakeholder collaboration pursuing SDG implementation needs to be driven with a mindset of leading collectively to generate solutions (Kuenkel, 2019; Hanleybrown et al., 2012).

These examples show that multi-stakeholder collaborations are increasingly happening around SDG implementation. Necessarily, they will further increase and foster societies in which tackling challenges in collaboration will become the norm. Multi-stakeholder collaborations are directed towards tangible and measurable results around SDG implementation, often with the sole focus on the issue, the solving of a problem, or the finding of new solutions. Often, little attention is placed on the process of how individuals and collectives bring about a transformed future. After all, it is people who can make a difference together and shape the future collectively. Understanding collaborative actions for SDG implementation therefore strengthens our knowledge about how human interaction processes can function well, and how - in designing consultation and cooperation processes - we can create the conditions for transformative change to happen. Hence, there is a need for methodologies and tools that support knowledge building of how cocreative processes actually happen. Not every grand ambition guarantees success in collaboration, not every carefully developed plan becomes successfully implemented. Multi-stakeholder collaborations are complex endeavors with uncertain dynamics. Leading transformative change collectively requires us to understand these dynamics and learn how we can support the emergence of constructive co-creation in multi-stakeholder settings. There are a few lessons from past multi-stakeholder 
collaborations that provide valuable insights into what aspiring change agents need to consider (Kuenkel, 2015).

- Multi-stakeholder collaborations take place in a rational issue-based environment, yet, when collaboration fails, the failure is most often attributed to people and their behavior. It can be traced back to non-rational aspects like trust, misunderstanding, pressure, disrespect, etc. Hence, methodologies need to help actors to integrate the rational (facts, figures and plans, etc.) with the nonrational aspects of transformative change (emotions, trust, anger, or a sense of ownership, etc.).

- The urgency of addressing sustainability issues and implementing the SDGs sometimes results in actors allowing too little time for extensive and joint reflection. Although it is obvious that, like all other leadership challenges, navigating transformative change in multi-stakeholder collaborations requires review and reflection, the pressure to perform and deliver impact, prevents people from sitting back to review progress deeply. Hence, methodologies in transformative change need to alert actors to when action is in focus and when it is time to reflect. The latter is fundamentally important for the cohesiveness and effectiveness of the collaboration ecosystems that emerge.

- Complex challenges around SDG implementation, as argued, require complex approaches such as multi-stakeholder collaborations. Methodologies that support transformative change need to be complex enough to help actors understand the dynamics of systems, but they still need to be useful and action oriented.

Leading transformative change collectively towards tangible results requires building functional collaboration ecosystems that can deliver change. Understanding the human mind and heart is indispensable for their success. The dynamics in a collaborative field of human interaction can help or prevent transformative change. Despite the popularity and evident success of some multi-stakeholder collaborations there is still too little attention given to the way multi-stakeholder collaborations are set up and managed. What is needed is a paradigm shift towards seeing multi-stakeholder collaborations as a new way of leading transformative change collectively. Yet, if collaboration is done well, transformative leadership emerges as the capacity of a collective of collaborating partners. This includes the human capacity to consciously act and reflect as a collective. Multi-stakeholder collaborations for SDG implementation require us to become more knowledgeable about how to best utilize these capacities. Table 1.6 shows how the conventional understanding of leadership as the capacity of individuals needs to be widened towards understanding collective leadership.

The task of leading has been the subject of research and theorizing for a long time, and the focus has most often been on the individual leader (Bennis, 2007; Drucker, 1992). Even today, most people understand the term 'leadership' as an individual who guides and directs a course of action and drives goal achievement. Following the investigation of the individual traits of leaders, the definition grew to include the context, the relationship between leaders and followers, and the organizational cultures that surround leadership actions (Bass, 1998; Boerner et al., 2007). New 
Table 1.6 From individual leadership to collective leadership

FROM: TO:

Leading change is seen as the capacity of the Leading change becomes the capacity of a individual only collective

- Silo approaches and competitive thinking dominates.

- Collaboration becomes the norm. Actors drive their interest and the greater joint purpose.

- Leadership is seen as taking place in a hierarchical context only.

- Leadership is seen as the delivery of goals through enlisting followers.

- Leadership takes place in non-hierarchical and co-operation contexts. No actor has discretionary power over other actors.

- Leadership is understood as the joint delivery of agreed-upon common goals in a climate of collective responsibility. All actors contribute according to their expertise, role, and resources.

- The focus of leadership tasks is goal attainment only, while the common good is not necessarily in focus of leadership.

- Leadership positions are clearly distinguished from followership.

- Leadership development focuses on growing individual leaders.

- Dialogue and co-operation are side issues or add-ons.

- Leadership and goal attainment is seen and enacted as a contribution to the common good. What the common good is and how to get there is negotiated among all actors. Existing structures (laws and regulations) define the boundaries.

- Depending on expertise and experience, leadership and followership are interchangeable.

- Leadership development takes into account the success factors for collective action.

- The capacity of a leadership collective to ensure outcome-oriented dialogue and future-oriented collective action becomes a decisive success factor. Such a collective can be a loose structure of actors driving change together, or can develop into a multi-stakeholder governance structure (such as steering committee, councils etc.).

Source: Kuenkel, 2019

terms have emerged that suggest that leading can be done by several individuals at the same time in shared or distributed leadership (Gronn \& Salas, 2004; Gronn, 2002). Not surprisingly, it was found that collaboration between leaders with diverse expertise as well as decentralized decision-making had a positive effect on the overall organizational performance (Boone \& Hendricks, 2009). Recently, the directing role of individual leaders has been questioned and cutting-edge theory sees leadership as a systems intervention without clear control over the outcome (Lord \& Brown, 2004; Senge et al., 2015). The question of collectivity in leadership has gradually moved onto the agenda and it is widely acknowledged that transformative change can only happen as a result of a collective of actors leading together (Wheatley, 1999; Pearce \& 
Conger, 2003; Senge et al., 2015; Kuenkel, 2019). The conceptual shift in the approach to leadership from the focus on individuals and their skills and capacity to the understanding of leadership as the capacity of a collective is logical in multi-stakeholder collaborations. In settings that are cross-institutional, where hierarchy does not exist between the collaborating actors, leading transformative change happens on equal footing between the key actors from different societal sectors. Collective leadership is at the heart of multi-stakeholder collaboration and a prerequisite for creating the conditions for transformative change for SDG implementation. It is the capacity of a group of actors to deliver their contribution to a joint purpose collaboratively while putting high priority on the common good and a balance among the needs of people, profit, and planet (Kuenkel, 2016).

\section{Understanding the dynamics of co-creation}

In practice, the reality of leading transformative change collectively has many challenges. Multiple actors, even if they aspire to lead collaborative change together, often have conflicting interests. They may see their own interests as much more important than those of others. They may overtly or covertly defend institutional and power territories. Moreover, multi-stakeholder collaborations depend on proactive commitment of stakeholders that cannot be directed in the same way as they would be in hierarchical settings. Collaboration, by definition, includes mutual dependency (such as in responsible supply chain management), power differences (such as in cross-sector water resource management that involves governments and community organizations), or conflicting interests (such as between governments, citizens, and companies in renewable energy initiatives). Success and impact rests on the actors' ability to build collaborative fields with eye-level cooperation that leverage differences into progress and achieve tangible results.

Making SDG implementation happen to the benefit of all requires initiators and stakeholders in multi-stakeholder collaborations to dive deep below the surface of stated objectives and ambitious goals. Leading transformative change collectively is a task that suggests getting familiar with our capacity to observe and design human interaction processes that are constructively co-creative. For example, fostering trust building through respect for difference and transparent processes is as important as invigorating passion for the future in inspiring conversations with stakeholders. Acknowledging conflicts and differences is essential, before attempting to find common ground among stakeholders. The step-by-step engagement of stakeholders is more successful than rushing into meetings with too many stakeholders for whom it might be unclear what is expected of them. Creating results collectively may be slower than single-minded plan delivery, but it engenders the sense of ownership that is the foundation for commitment. Ensuring a good flow of communication between stakeholders is more effective for the cohesion and accountability of stakeholders than simply informing them. Invigorating connectivity through developing personal networks goes a long way in expanding collaboratively achieved results rather than isolated projects. Above all, collaboration ecosystems composed of multiple stakeholders function best when there is a culture of mutual support. Helping each other and noticing that one can make a difference 
together creates a sense of vitality that is at the core of leading transformative change collectively. Balancing rules with creativity helps managing scarce resources and keeps humor alive. After all, stakeholders in multi-stakeholder collaborations should enjoy being part of an emotionally compelling idea for a better future that will change the world, no matter how small. For creating and maintaining constructive and effective interaction among stakeholders, it is important to remember that people are people. Their sense of achievement is fueled by humanness and results.

Every change endeavor starts with people considering future possibilities. In multistakeholder collaborations, at times, it is individuals who sense a potential for a better future, and get actively to engage others. At other times, the vision for the future is developed by a group of people together. If nurtured enough, the potential for change grows into a more structured change initiative or even a movement. The human capacity to sense future possibilities is paramount for leading transformative change collectively. It refers to people's ability to take responsibility and consciously shape reality towards a sustainable future. However, even the greatest visions for change are futile if not enough stakeholders are prepared to commit to action. In effective multistakeholder collaborations, the key task at the beginning and sometimes throughout is carefully organizing the engagement of stakeholders - the powerful and the less powerful, the influential and the affected.

Meaningful stakeholder engagement creates trust and cohesion. It invigorates network connections and fosters collective action that ultimately leads to tangible outcomes when the sense of ownership is high. The human capacity for engagement is a core element of leading transformative change collectively. It refers to people's ability to design step-by-step processes towards building effective collaboration ecosystems. However, if novelty does not also enter a collaboration ecosystem, the process might not move forward. Sometimes, actions and behaviors of stakeholders are locked in the past so that problems and challenges only get re-created. Although learning from the past is valuable it should not limit leaders in transformative change efforts to simply create new variations of existing solutions.

The human capacity for innovation is part and parcel of multi-stakeholder collaborations that can deliver change. It refers to people's ability to create novelty and find intelligent solutions. However, innovative approaches that do not take the essential humanness of people into account create distrustful environments. Becoming aware of the human story has both an individual and a collective aspect. Multi-stakeholder collaborations shift towards constructive solutions when there is mutual respect and acknowledgment of the intrinsic value of all people, regardless of their different opinions and viewpoints.

The human capacity for humanity is the ground, on which leading transformative change collectively is enacted. It refers to the ability of each person to connect to their unique human competence in order to reach out to each other's shared humanity. Increasing awareness, however, requires not only individual reflection, but also exchange with others about the actions to be taken. Life thrives on diversity, and so do human collectives. This is an important learning from successful multi-stakeholder collaborations.

Meaning-making conversations that harvest collective intelligence, be they offline or online, need to be rooted in a dialogic culture. Not just good communication, but 
creating a space for shared meaning fosters the vital energy flow between people that is so essential to making multi-stakeholder collaborations deliver results. The human capacity for collective intelligence is what helps make collaboration transformative. It enhances people's ability to harvest differences for progress.

Collaborative actions towards SDG implementation need to also be embedded in people's ability to sense wholeness - to see the larger picture, connect with a bigger story or understand the context well enough. When actors in multi-stakeholder collaboration are able to take bird's eye perspective, they shift to new insights, understand the coherence of a seemingly difficult situation, or attend to the needs of others spontaneously. Gaining perspective and seeing a collaborative change effort from within a larger context is an important step in leading transformative change collectively. The human capacity to sense wholeness enhances the transformative potential of multistakeholder collaborations. It refers to the people's ability to see a larger picture and stay connected to an emotionally compelling goal for the common good.

It is important to understand that these human capacities are interlinked, relational, and mutually supportive. Rather than simply adding to one another, they lead to results through their interconnectedness as a recurring pattern of human competences. Once this pattern emerges in the multi-stakeholder collaborations, complex change become much easier to navigate and, most of all, its potential to become transformative increases. However, leading transformative change collectively has even more ingredients that need to be understood.

\section{Systems aliveness as a guide for transformations}

All stakeholders who drive transformative change matter, whether they work within or outside institutional structures. The global call for profound sustainability transformations can be seen as an invitation to explore new forms of leading transformative change collectively on a broad scale. However, current institutional structures, top-down change interventions that ignore stakeholder engagement, and conventional linear planning methods are still prevalent. But change is on the horizon. Conscious forms of organizing collective human sense-making and co-creation in local-to-global interaction in networks is on the increase in many countries that have committed to the implementation of the SDGs (Waddell et al., 2015). Multi-stakeholder collaborations can be seen as laboratories of the future (Kuenkel, 2015, 2016), i.e. for new forms of societal transformations, the re-invention of inclusive governance systems or the repurposing of corporate goals. Yet, what transformations mean in the context of sustainability and SDG implementation is the subject of an ongoing discourse among academics and practitioners.

This practitioner guide takes a pragmatic approach. Transformations here refer to collaborative actions that rearrange stakeholder relationships in a way that there can be thriving communities, diverse and lively ecosystems, energy systems that safeguard the planetary life support system, and cities that serve both the environment and their citizens. In short, getting SDG implementation right is a good enough pathway to global transformations. But if SDG implementation is only the administrative achievement of measurable targets showing human progress, it won't work. It must be truly empowering and shift the way we see the world, act in it, and relate to each other. True 
transformations require fundamental shifts in collective behavior change, business practices, and government-citizen interaction. What is increasingly clear is that more and more people do not just hope for economic development, but are beginning to generate visions for a planet on which nature and people can thrive at the same time. No matter how they capture this sense of future possibilities, increasingly concepts like thrivability of communities, economies in service of life (source), vitality of societies, and enlivenment as a societal guide (Weber, 2013; Goepel, 2016) are making their way into the discourse on transformations. In multi-stakeholder collaborations for SDG implementation, this can refer to thriving farming communities, vital social fabrics in cities, mutually supportive networks in responsible value chains, or inspired collective climate action that reduces $\mathrm{Co} 2$ emissions. In short, SDG implementation as a collaborative effort needs to enhance the aliveness of planet and people.

In this practitioner guide, we will frequently use the concept of systems aliveness (Kuenkel, 2019) as the capability of a system - small or large - to develop a sufficient degree of vitality and resilience, as well as the ability to maintain and renew these in collaboration and interaction with other systems. Systems aliveness is always relational and interdependent. It refers to a recognizable patterned process of doing transformations as well as a recognizable patterned outcome - sustainability. Fundamentally, SDG implementation in collaboration is an attempt to shift dysfunctional patterns of activity in human and socio-ecological systems towards more functional, more flourishing - or alive - patterns that work better for all, including living beings other than humans. However, most actors in transformative change focus on the more technical content of transformations only - be they the reduction in $\mathrm{CO}_{2}$ emissions, the legislation around climate-friendly behavior change, or the metrics of ecological footprints. While all these envisaged measurable outcomes are important, the sole focus on technical and administrative procedures misses out on an incredibly important lever for change. What Weber (2013) calls 'enlivenment' and is captured here as systems aliveness (Kuenkel, 2019; Weber, 2016) is the foundation of successful transformative change.

\section{Box 1.2 Understanding aliveness in systems}

A system is here defined as a set of interrelated elements that constitute a whole with structural or agreed upon boundaries, embedded in a larger whole. Depending on the level of focus, a system can be a geographical area, an ecosystem, an organization, or a nation-state. To understand how to achieve transformative change at scale, we need to understand how healthy systems operate. Moreover, we need to understand what creates, maintains, or regenerates aliveness in systems. We can learn from natural systems such as forests or thriving ecosystems, and also from socially cohesive and well-functioning human systems. They all display certain mutually supportive characteristics that work together. It is time actors in transformative change made use of this knowledge to bring about the large systems change needed.

(Kuenkel \& Waddock, 2019) 
For leading transformative change collectively in multi-stakeholder collaborations this means that we need to look at systems aliveness at various levels - the vitality of the individuals, the collaborative quality of the way actors work together as a thriving collaboration ecosystem, and how the transformative change enlivens natural ecosystems, communities, cities, countries, and, ultimately, the planet. Why is this approach so important for leading transformative change collectively? It is the sense of aliveness that drives positive change and future orientation among people; it helps them access their humanity and encourages them to engage in productive dialogue. It makes them want to experience the difference made. Interestingly, the urge for aliveness is what we share with nature. Research has shown that all living systems are purposeful beings that aim at staying alive and furthering aliveness (Weber, 2013, 2016; Capra \& Luisi, 2014; Kuenkel, 2019). For ecosystems it is known that diversity is a prerequisite for vitality and health (Folke, 2006; Sahtouris, 2000), but it is not just the countable diversity, it is the relational interaction of different species that support each other's zest for life. This is what creates resilience. Stewarding systems aliveness is the ongoing task in leading transformative change collectively.

The systems in which multi-stakeholder collaborations take place, be they social, economic or environmental, have higher or lower degrees of aliveness. In fact, sustainability challenges are indications for compromised systems aliveness. Aliveness is a quality that may be impossible to measure, although there are many recent attempts to find metrics for the aliveness of socio-ecological systems, such as the OECD Better Life Index (Mizobuchi, 2004) or the Gross National Happiness Index. ${ }^{3}$ More practically, aliveness is relatively straightforward to understand and feel. All people have experienced moments of aliveness or spaces or groups of people that seem more alive than others. This is akin to the feeling people have when they are inspired by music, or art, or nature, or surrounded by the company of loved ones or people who stimulate them. These are feelings of aliveness. We may move this sentience into the non-rational sphere and call it subjective, but we do not need to. The architect and systems theorist Christopher Alexander (Alexander, 2004) considered the degree of life of a space as the result of designed elements he called centers and developed an entire design concept, a pattern language, to guide architects in becoming more responsible for the way the build physical and spatial structures (source). He predicted that "we shall have a view of the world in which the relative degree of life of different wholes is a commonplace and crucial way of talking about things" (Alexander, 2002, p. 22).

When socio-ecological systems are thriving and healthy, they mimic certain attributes of vital living systems (Capra \& Luisi, 2014). It is important to think about the systems multi-stakeholder collaborations try to shift in a holistic way, trying to understand the systemic and interdependent nature of the stakeholder landscape. Only by looking at and trying to understand stakeholder systems from a more holistic perspective can leading transformative change collectively have the envisaged impact. Similarly, the more 'alive' the collaboration ecosystems of stakeholders are, the more effectively they deliver change. Living systems, and subsequently social systems, are by nature not static; they are dynamic. This fact means that the complexity of a system at one point in time cannot be simply analyzed and understood. But how the system 
reacts to changes and interventions over time is observable. Hence, vigilance of the system and its degree of aliveness is necessary for multi-stakeholder collaborations to work. In spite of the fickle nature of systems, if they are working well or not is perceptible to stakeholders - they feel the results of unhealthy, fragmented, or dysfunctional systems. Hence, leading transformative change for SDG implementation needs a system's view of life that also looks at the collective of actors as a collaboration ecosystem that must thrive in order to become successful.

\section{Creating enlivening collaboration ecosystems}

Collaborative transformative change happens in complex and dynamic stakeholder systems. Stakeholders are people or institutions that have an interest in a particular course of development, or a particular decision, either as individuals or as representatives of a group. This includes people who influence a decision, who are key players in implementation, or who are affected by the development. The stakeholder system is composed of all institutional (or sometimes individual) actors that are relevant with regard to the issue that is in focus for a collaborative initiative. As mentioned before, addressing sustainability challenges requires complex stakeholder systems with actors from communities, public sector, civil society, private sector, as well as academic or educational institutions. In order to decide who is relevant to be considered part of a stakeholder system, the following questions can serve as guidance:

- Do actors or institutions have an influence on the course of development regarding the issue or sustainability challenge in focus?

- Do actors or institutions have a special expertise regarding the issue or sustainability challenge in focus?

- Do actors or institutions have an interest in changing or improving the situation regarding the issue or sustainability challenge in focus?

- Do actors or institutions have an interest in NOT changing or improving the situation regarding the issue or sustainability challenge in focus?

- Are actors or institutions important for the implementation of change regarding the issue or sustainability challenge in focus?

- Will actors or institutions be affected by any changes regarding the issue or sustainability challenge in focus?

Multi-stakeholder collaborations bring stakeholders with different perspectives and diverging interests together into a new collaboration ecosystem. Understanding systems patterns and gauging systems aliveness is paramount for identifying key stakeholders that will become part of multi-stakeholder collaborations. Figure 1.3 shows how the collaborating stakeholders form a new temporary system - the collaboration ecosystem. Bringing selected stakeholders together and into collaboration around an issue of common concern is the basis for making multi-stakeholder collaborations work. Collaboration ecosystems emerge when people work together for a certain common purpose. These issue-based, human interaction systems are comprised of multiple, usually cross-institutional actors aiming to change the status quo towards a better 


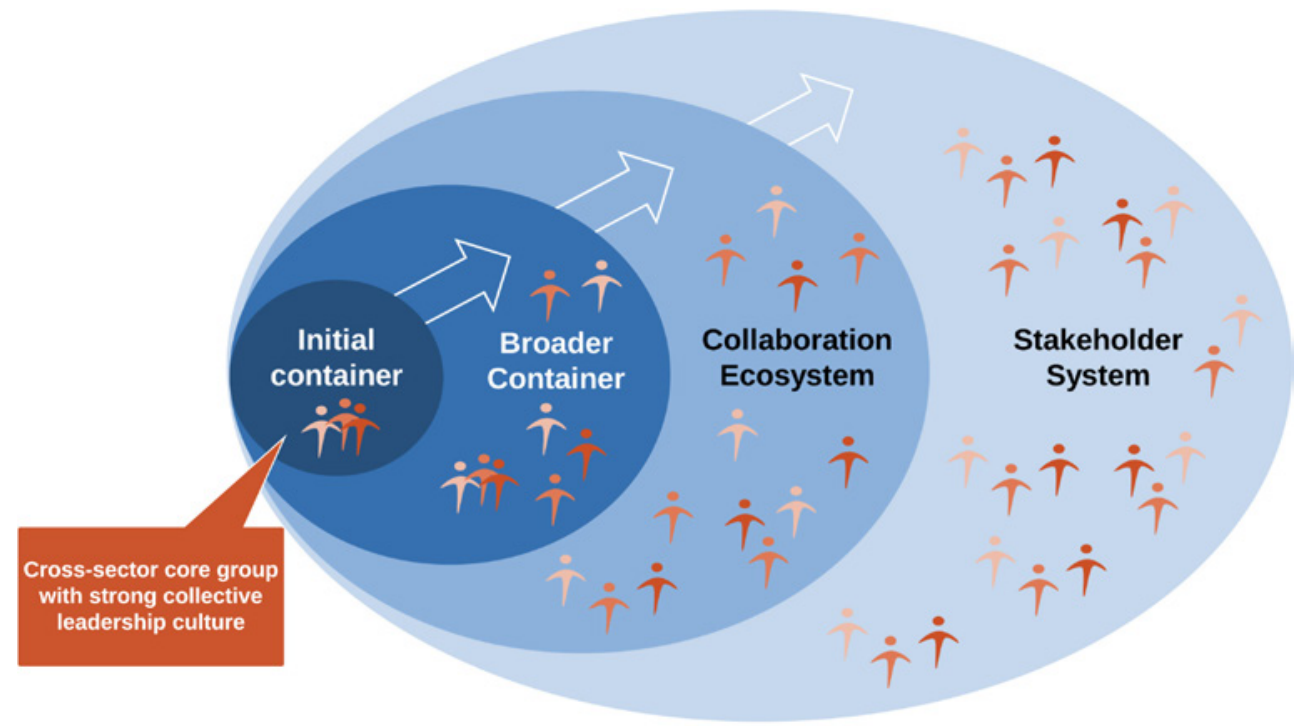

Collaboration Ecosystem

Stakeholder System

Figure 1.3 The collaboration ecosystem

future for all. They are part of the larger stakeholder system around a certain issue, region, or theme. The collaboration ecosystem aims to ensure that change will benefit all actors involved - and the community or society as a whole, and, not least, the planet Earth. They emerge from a core group of people - the initial container - who partners to initiate change. This group builds a supportive wider group - the broader container - including high-level sponsorship. The wider group helps to engage more key stakeholders until the collaboration ecosystem is eventually functional and can go about delivering change.

In well-functioning collaboration ecosystems, diverse stakeholders bring in concerns, interests, and expertise. They learn from one another about their respective thematic knowledge and geographic context. They identify key challenges and articulate goals together and, drawing on their complementary roles, they realize their shared vision. They can operate as networks, organizations, multi-stakeholder dialogues, platforms, initiatives, or partnerships. Collaboration ecosystems can exist at many levels of the global society; they can overlap, interact, and collaborate with each other. The illustrative examples mentioned before show their diversity. However, under the surface of the issues they address, the sense of co-creative collaboration that provides the relationships and capacity for pursuing ambitious aspirations needs to be present. Among the key factors for success for multi-stakeholder collaborations is the careful attention to high-quality process architectures that build enlivening collaboration ecosystems. When people have a sense of aliveness, the willingness to engage with each 
other and the commitment to drive change together, multi-stakeholder collaborations deliver impact. This means careful attention to the quality of process, the quality of relationships, and interaction among stakeholders, as well as a focus on tangible results that have value for all.

Collective leaders develop strong competencies in designing change processes that take care of systems aliveness. Process competence is the key to helping collaboration ecosystems deliver. This is why Chapter 4 is reserved entirely for building process skills. The quality of aliveness is vital to the long-term success or failure of realizing transformative SDG implementation. Stakeholders are fully aware when they dread going to meetings, when they have little interest in interacting with partners, or when they feel shut off from colleagues. These are all indicators of struggling or failing collaboration ecosystems that lack aliveness. However, inversely, people are also aware of the joy and vitality they feel when they have the chance to work with others in a lively, productive, mutually supportive, and co-creative manner. This is the sense of aliveness that is imperative to achieve and maintain in order for multi-stakeholder collaborations to succeed. Leading transformative change collectively for SDG implementation means cultivating awareness of whether the collaboration ecosystem is enlivening, to themselves, their colleagues, and partnering stakeholders. This is where the Collective Leadership Compass becomes a helpful navigation tool.

\section{The Collective Leadership Compass for the collaborative journey}

The dimensions of the Collective Leadership Compass model a pattern of six life principles. These are present in nature and evolutionary processes. When they interact, they lead to the enhancement of collaboration competencies of all involved stakeholders. Further, they foster aliveness, vitality, or thrivability in human collaboration systems. Learning to perceive and pay attention to this pattern helps shift collaboration systems out of being stuck or dysfunctional and towards better performance. Using the Compass in this manner for diagnosing and planning leads to life-enhancing qualities in collaboration systems and the improved human capacity for more successful co-creation.

\section{Box 1.3 What is unique about the Collective Leadership Compass?}

- A framework that integrates all systemic levels of collaborative change

- A patterned guiding structure that invigorates self-organized co-creation

- A tool that combines rational decision-making with intuitive sense making

- A dynamic model resembling evolutionary change patterns from nature

- An appreciative approach that invigorates existing human competences 
The Collective Leadership Compass has systems aliveness at its core. It is a meta-level guiding structure that can be used both as a diagnosis tool and a planning methodology to invigorate human competencies for future-making in six dimensions. Practically, it helps to assess, plan, and enact the transformative change required for collaborative SDG implementation or urgent climate action by creating a methodological bridge between unleashing human capacities and driving issue related actions. The Compass, as shown in Figure 1.4, supports individuals, teams, and organizations to strengthen collective leadership competencies and build vibrant and robust collaboration ecosystems of multiple stakeholders that aim at transformative change. Paying attention to the presence of the six dimensions of the Compass helps navigate complexity, crises, insurmountable challenges, and human differences. It invigorates the human capacity to harvest differences for progress, find innovative solutions to challenges, and commit to tangible results. Moreover, it guides actors to create system aliveness as core driver of transformation processes. Building competencies for collective leadership is also about remembering that we are human and that the more human we are the more we are in tune with the planet to which we belong as humankind. Using the Collective Leadership Compass as a methodology brings such a view into the mainstream planning and implementation of transformative sustainability initiatives (Kuenkel, 2016).

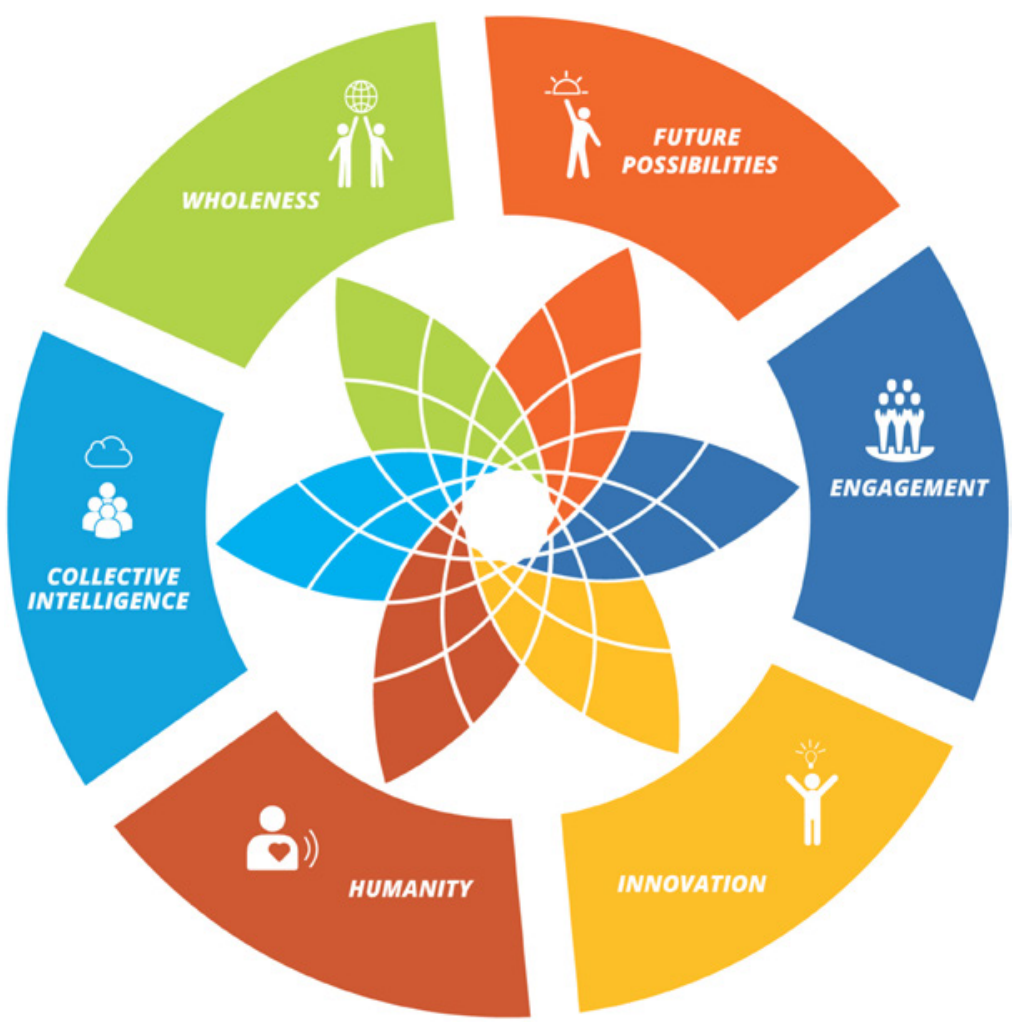

Figure 1.4 The Collective Leadership Compass

Source: Kuenkel, 2016 


\section{Translating systems aliveness into designing transformative change}

The Compass is scientifically based on thorough research exploring the question "what gives life to systems" by analyzing many different fields, including architecture, urban planning, biology, systems thinking, resilience theory, complexity theory, consciousness studies, and physics (Kuenkel, 2019; Kuenkel \& Waddock, 2019). Six systems aliveness principles that make systems thrive emerged from this research and they represent a synthesis of research findings about what characterizes healthy socioecological systems (Waddock \& Kuenkel, 2019). The understanding of these systems aliveness principles is important for leading transformative change that aspires to bring about a more sustainable future. Life in all its complexity seems to work with a principles-based approach (Capra \& Luisi, 2014), which can be thought of as fundamental propositions that underlie evolutionary processes, hence also social processes that then manifest in beliefs, behaviors, reasoning, or dynamics in collective actions in social systems. If all principles are present to a certain degree, they create a patterned dynamic that furthers life, but how this is manifest is creative, leads to incredible complexity, and is unpredictable. The six dimensions of the Collective Leadership Compass are inspired by the underlying principles and translate them into our understanding of leading transformative change in multi-stakeholder collaboration.

In addition, the reflection on 20 years of strategic support to complex multistakeholder projects has shown that navigating collaboration becomes successful if actors pay attention to the six dimensions of the Collective Leadership Compass. They serve as a meta-level guiding structure for co-creating systems aliveness through highquality collaboration in a spirit of collective leadership. In that way, the Compass mirrors a pattern of systems aliveness and thus translates the otherwise difficult to rationally comprehend notion of systems aliveness into strategic management of transformative change. Paying attention to the dimensions invigorates life-enhancing thinking and acting. The following descriptions of the six Compass dimensions trace their origin to the systems aliveness principles, also shown in Figure 1.5. They capture the central characteristics that actors in multi-stakeholder collaboration need to build into transformative change initiatives. As a pattern, the principles, and therefore also the dimensions, overlap and interact, but there is enough differentiation among them to discern them as distinct areas of attention for navigating transformative change.

\section{The first Compass dimension: future possibilities}

\section{Shaping the future together through identifying and co-developing emotionally compelling goals}

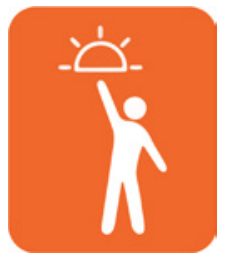

getting started
Purpose or intentionality combined with generativity is a central aspect of living systems at all levels of complexity. The underlying systems aliveness principle for the Compass dimension of future possibilities is intentional generativity - describing the urge that all living systems have to continue into the future. This includes the capacity of natural systems to renew, replenish, and restore themselves in the 
process of staying resilient. For leading transformative change collectively in multistakeholder collaborations, this principle means to tap into the human desire to shape a better future collectively in communities of different scales and for a more equitable, just, safe, peaceful, and ecologically stable existence. This human desire is invigorated by enlivening narratives that foster stories of possibilities and inspire minds and hearts. More practically, it means that the way collaborative processes are co-designed ensures that over time all relevant stakeholders drive strategy and implementation, hence co-create future possibilities. This helps people change the way they think and act, and motivates them to work towards the co-created vision. In multi-stakeholder collaborations, it requires taking care of:

- Future orientation: focusing on potential or opportunities and driving change for the better.

- Empowerment: inspiring and enabling capacities, passion, and options for change.

- Decisiveness: committing, focusing, following through, and measuring progress.

\section{The second Compass dimension: engagement}

Co-owning change by building step-by-step small-to-large collaboration ecosystems in bottom-up and top-down processes

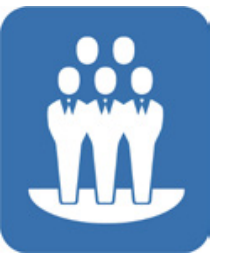

Living systems need to have 'sufficient' definitional boundaries or 'containment' to create some sort of meaningful identity, in combination with a degree of openness to new inputs and outputs that allow for energetic exchange. The underlying systems aliveness principle for the Compass dimension of engagement is permeable containment - describing the need for existing, but fluid boundaries that hold generativity in check and help maintain the identity of the system. Natural living systems, as well as collaboration ecosystems, require structures and meaning-making identities. They need to be enabling and enhance self-organization. For leading transformative change collectively in multi-stakeholder collaborations, this principle means to acknowledge the human desire for belonging, identity, meaning-making exchange, and fruitful collaboration. Defining the boundaries of a collaboration ecosystem creates invisible cross-institutional structures that become a home for a new way of leading change in dynamic networks. Step-by-step engagement of stakeholders is a way of ensuring that change processes become effective because this fosters a sense of ownership and identification with envisaged outcomes. More practically, it means that engagement requires ensuring that implementation between stakeholders is well organized and enhances identification with the joint endeavor. In multi-stakeholder collaborations, it requires taking care of:

- Process quality: building step-by-step and structured stakeholder engagement.

- Connectivity: fostering cohesion and building networks.

- Collective action: driving joint implementation and delivery of results. 
Finding new pathways through nurturing existing innovative change initiatives, fostering creative solutions, and prototyping the future

All living systems have the capacity to change and evolve as situationally appropriate by growing, becoming more complex, as well as developing new pathways and properties. The underlying systems aliveness principle for the Compass dimension of innovation is emerging noveltyrecognizing the dynamic state of all life and human systems. This includes their constant renewal, and the inherent dynamic of directing renewal towards more aliveness. For leading transformative change collectively in multistakeholder collaborations, this principle means that change processes need to be built on the human desire to venture into the unknown and create new pathways. People are always seeking to innovate and are motivated and inspired by the possibilities of stretching boundaries and venturing into discoveries. More practically, it means to allocate space and support for co-designing and prototyping technological and social innovations. This supports people in cultivating adaptive innovation and giving attention to emergent opportunities. In multi-stakeholder collaborations, it requires taking care of:

- Creativity: acknowledging innovative approaches, creating space for creativity, and encouraging the collective generation of ideas.

- Excellence: pursuing mastery and growing knowledge.

- Agility: staying flexible in planning, taking crises as opportunities, and cultivating risk taking.

\section{The fourth Compass dimension: humanity}

Accessing shared values by fostering collective reflection, building constructive relationships, and appreciating the dignity of people

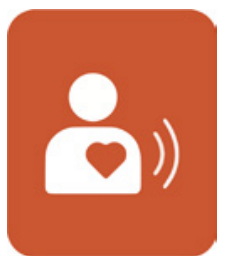

Life emerges from meaning-making cognition. Consciousness is a general property of living systems, and not only the result of human thought. However, human consciousness is the most complex manifestation of this general property, and thus significantly impacts the future of this planet. The underlying systems aliveness principle for the Compass dimension of humanity is proprioceptive consciousness describing the ability of life to become aware of its emergence, evolution, and interdependence. This includes perception (recognition), emotion (meaning or sense-making), and behavior (agency), and connects us back to larger questions of why we do what we do as a species on the planet. For leading transformative change collectively in multistakeholder collaborations, this principle means to raise the human capability for reflection in action as well as the respect for the integrity of all life. More practically, it also means to create awareness of the present sustainability challenges through facts and figures, and map pathways together towards solutions. It inevitably also means to balance the influence of stakeholder perceptions and listen to disempowered stakeholders. Attending to the presence of humanity is the most profound sense organ for 
aliveness in ourselves and in others. In multi-stakeholder collaborations, it requires taking care of:

- Mindfulness: building reflection into action, creating awareness, and acknowledging each other's potentials and shortcomings.

- Balance: bridging power differences and helping people see the person behind the viewpoint.

- Empathy: embracing the perspective of others and opening gateways for reconciliation.

\section{The fifth Compass dimension: collective intelligence}

Fostering meaning-making interaction through establishing collective learning systems at scale and ensuring structured dialogue to harvest difference for progress

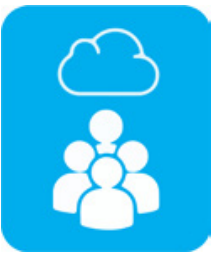

Life requires diversity in constant reciprocal communication. It works in a network of relational interaction with endless feedback-loops, which benefit from complexity in diversity. The underlying systems aliveness principle for the Compass dimension of collective intelligence is contextual interconnectedness - describing complexity in diversity as well as symbiotic, interdependent, and dynamic relationships. Similar to natural systems, which become more alive the more diverse and interconnected they are, human systems also thrive on diversity and increasing interconnectedness. For leading transformative change collectively in multi-stakeholder collaborations, this principle means fostering relationship building through meaningful conversations, leveraging collective intelligence, and subsequently invigorating networks for change. More practically, it means to conduct meetings and workshops that further collective intelligence with multiple stakeholders. It also suggests designing governance mechanisms that are not only representative, but also capable of balancing individual and common interests. In multi-stakeholder collaborations, it requires taking care of:

- Dialogic quality: creating dialogue settings that foster meaningful conversations.

- Diversity: fostering diversity in thought, viewpoints, background, and experiences.

- Iterative learning: creating space and opportunities for joint learning.

\section{The sixth Compass dimension: wholeness}

Creating networked patterns of action by staying connected to the larger goal and creating contextual impact with collaborative and complementary activities

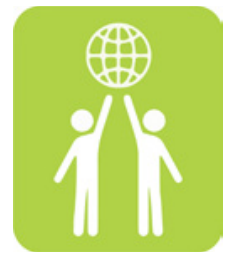

Living systems are integrated entities constituted of identifiable yet both parallel and nested 'wholes' supporting each other. The underlying systems aliveness principle for the Compass dimension of wholeness is mutually enhancing wholeness - describing the feature of life that multiple systems and subsystems provide identity, coherence, orientation, and mutual consistency. Systems aliveness emerges from a 
connection to the underlying coherence of the planet as a vast living system. This also means living systems cannot be fully understood by being fragmented into their parts. For leading transformative change collectively in multi-stakeholder collaborations, this principle means that change processes need to foster the human capability to relate to a larger system and to contribute to the world's development beyond the individual interest. The global agreement on the 17 SDGs is one indicator that leveraging this capability is possible. More practically, it means ensuring the relevance and embeddedness of multi-stakeholder collaborations in relation to their wholeness as contextual contribution and impact. This helps stakeholders to engage and commit to making a difference together. In multi-stakeholder collaborations, it requires taking care of:

- Contextuality: exploring the larger context and placing your action in it.

- Mutual support: cultivating a spirit of stakeholders supporting each other.

- Contribution: acknowledging all actors' contributions and keeping the joint contribution to a larger goal high on the agenda.

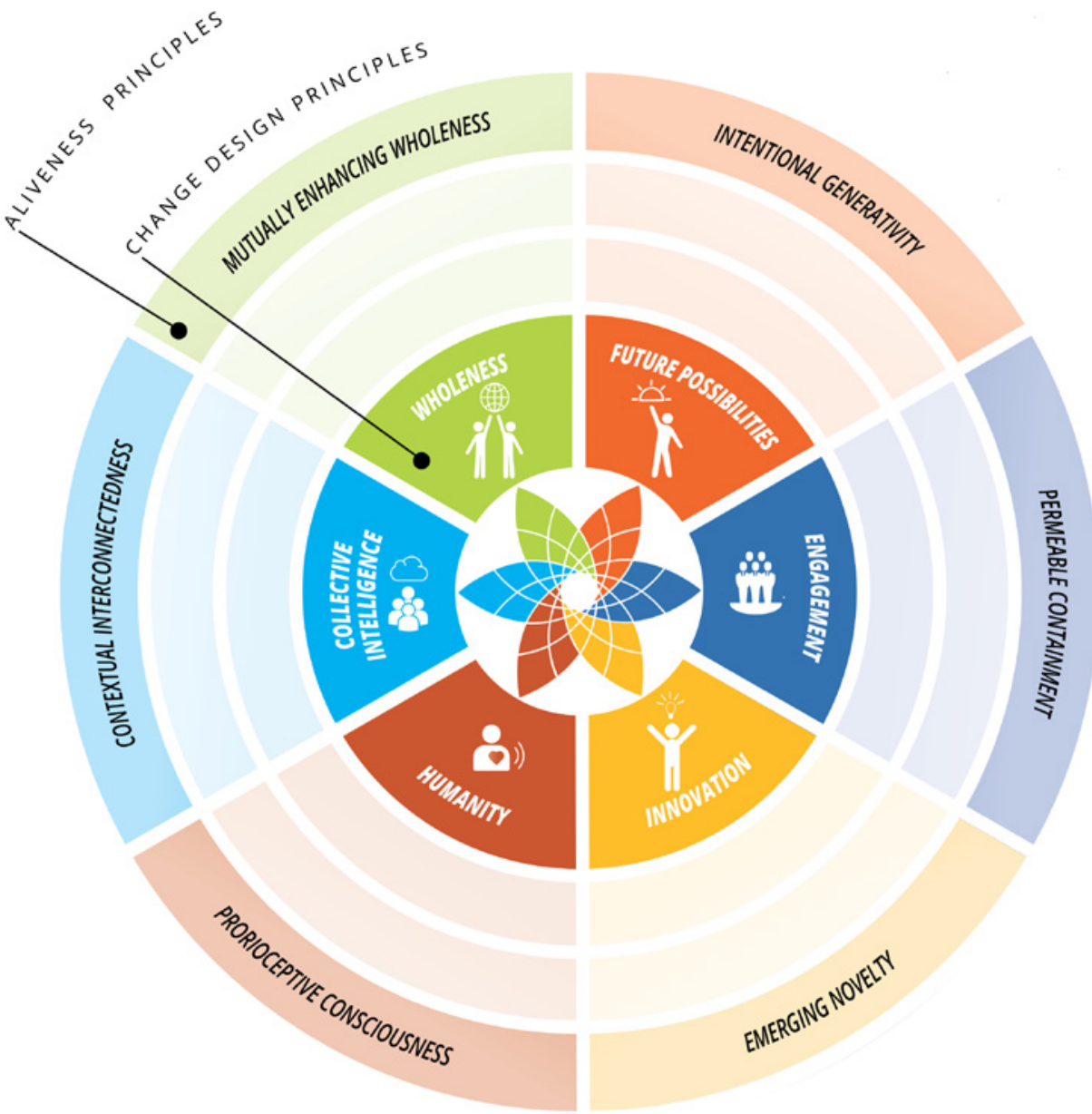

Figure 1.5 Compass dimensions and systems aliveness principles 
Using the Collective Leadership Compass for diagnosing systems and planning transformative change inevitably connects to the underlying systems aliveness principles. It enhances the skills to perceive the functional and dysfunctional patterns in the systems that need to improve and creates leverage points to shift these patterns. In that way, the Compass facilitates a new structure of attention to the joint effect of its dimensions. It also creates a conscious connection between leadership as an individual task and as a collective task, and guides thought and action towards patterns of successful human interaction. Beyond their use as a tool for diagnosis, as shown in Table 1.7, the six Compass dimensions also function as design principles for multistakeholder collaborations that can be used to plan transformative change strategies. Working with the Compass creates attention to patterns of systems aliveness - one pattern at a time. This helps collaboration ecosystems move into functionality and has a positive impact on the transformative change stakeholders aspire to deliver together.

\section{Making the Compass work for multi-stakeholder collaborations}

The purpose of the Compass is very practical: it helps improve the quality of collaboration patterns. This leads to increasing the impact for sustainability by getting things done faster, coming to better decisions, saving money, and being more content while achieving results jointly. As shown in Table 1.8, its application can strengthen individual leadership, enhance the leadership capacity of a collective, and shift systems of collaborating actors towards better co-creation.

Figure 1.7 shows the Collective Leadership Compass with all aspects. In the following chapters, this practitioner guide will illustrate the many uses of the Compass for context understanding, process planning, working group and team reviews, as well as planning for meetings and events, both in local and international multi-stakeholder processes. It is applicable in the many different forms of multi-stakeholder collaborations at all levels. In Southern Africa it has been used for the development of voluntary social and ecological standards in value chains, as well as in infrastructure projects. It has proven useful in water resource management challenges in Tunisia, sustainable forestry in Laos, land policy development in Cambodia, and economic development in Rwanda, to name just a few occasions of its use. The methodology allows actors to see the system as it is at a particular point in time as a current pattern. The Compass assists practitioners to perceive patterns in a system (the collaboration ecosystem or stakeholder system) and provides guidance in planning concrete actions that will shift patterns to enable the more balanced presence of all Compass dimensions. As a result, the quality of the collaboration will increase as will the likelihood of stakeholders leading transformative change together. This iterative practice leads to the eventual improvement of the collaboration culture within the stakeholder system and helps actors to overcome dysfunctional patterns that endanger society and ecological systems.

The collective use of the Compass and its dimensions is most effective when key stakeholders in transformative change processes work through the following three iterative learning cycle steps: observing, focusing, and enacting (Kuenkel, 2016; for more information see www.compass-tool.net). 


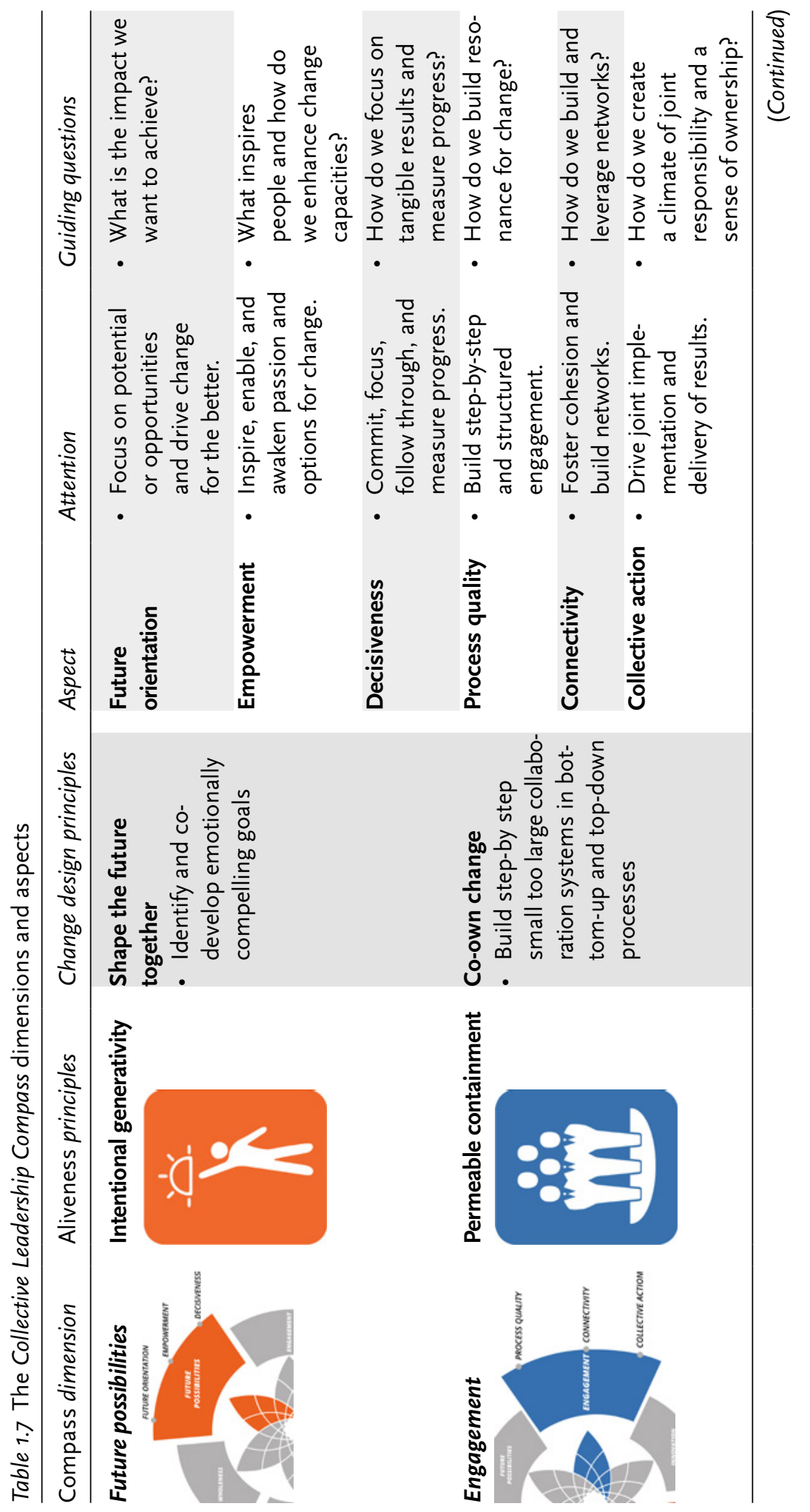




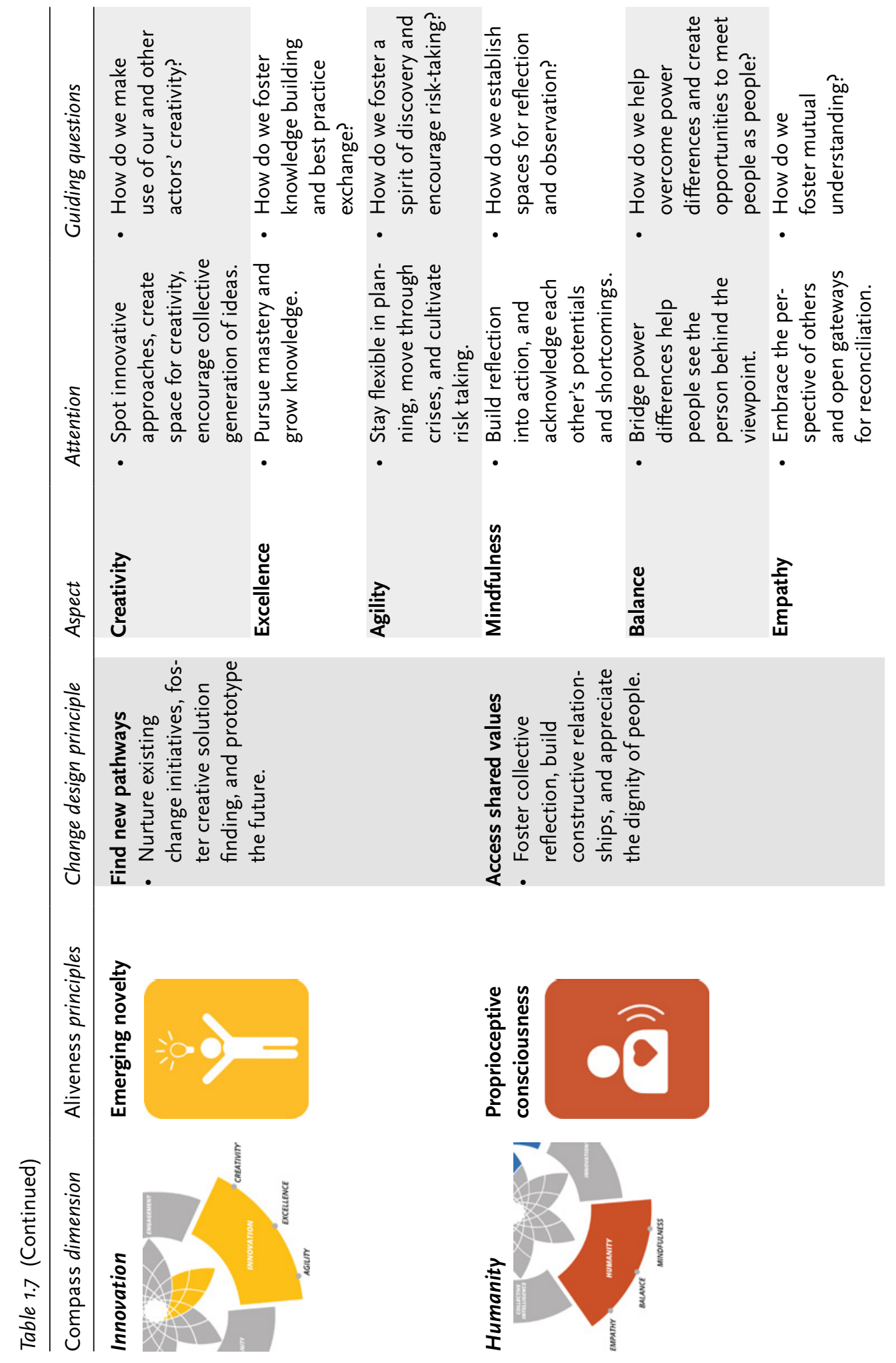




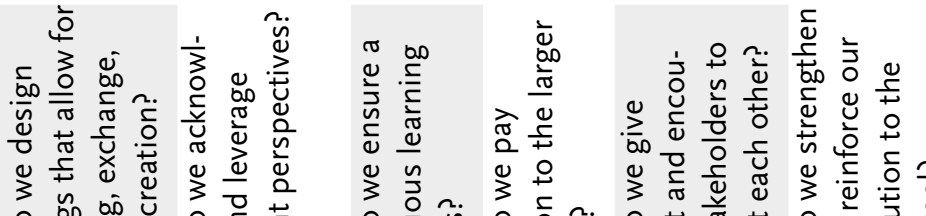

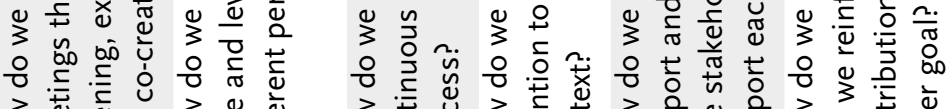

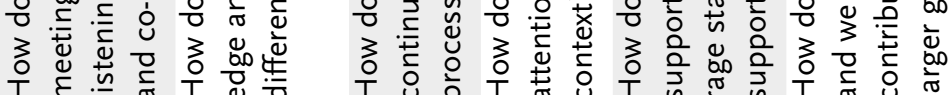

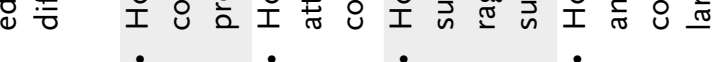

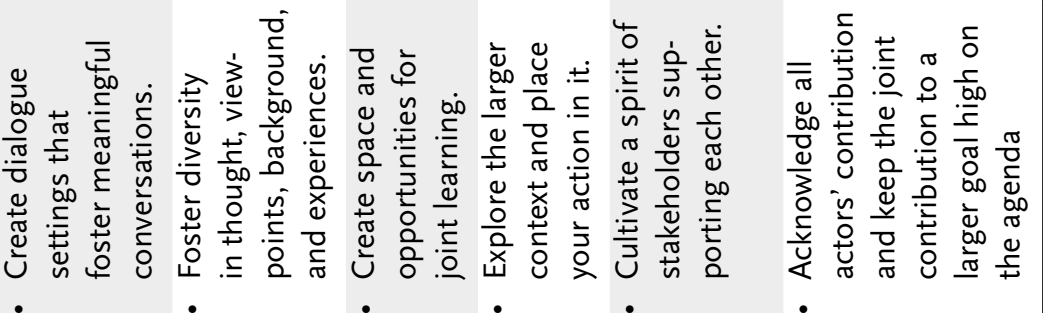

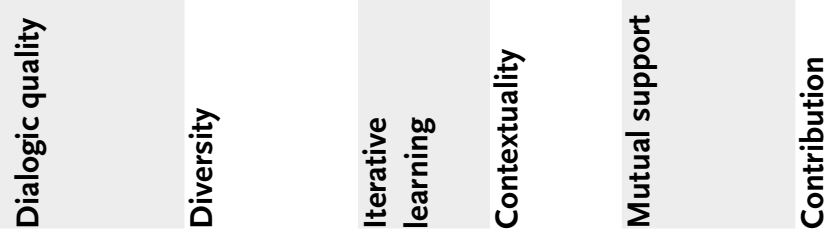

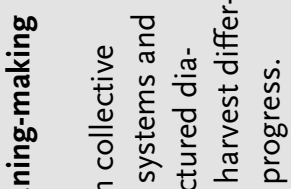
ฮँ

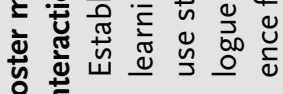

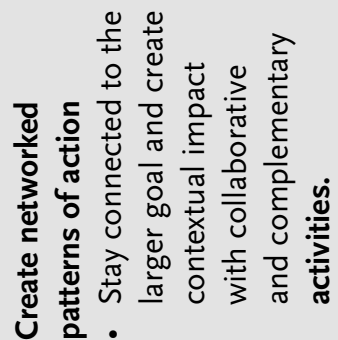

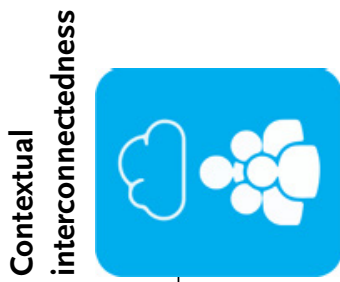
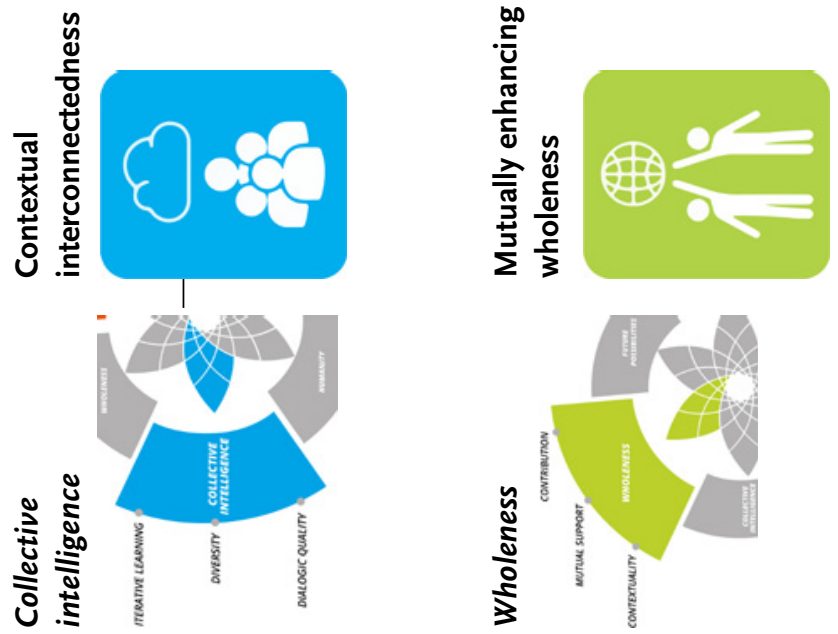


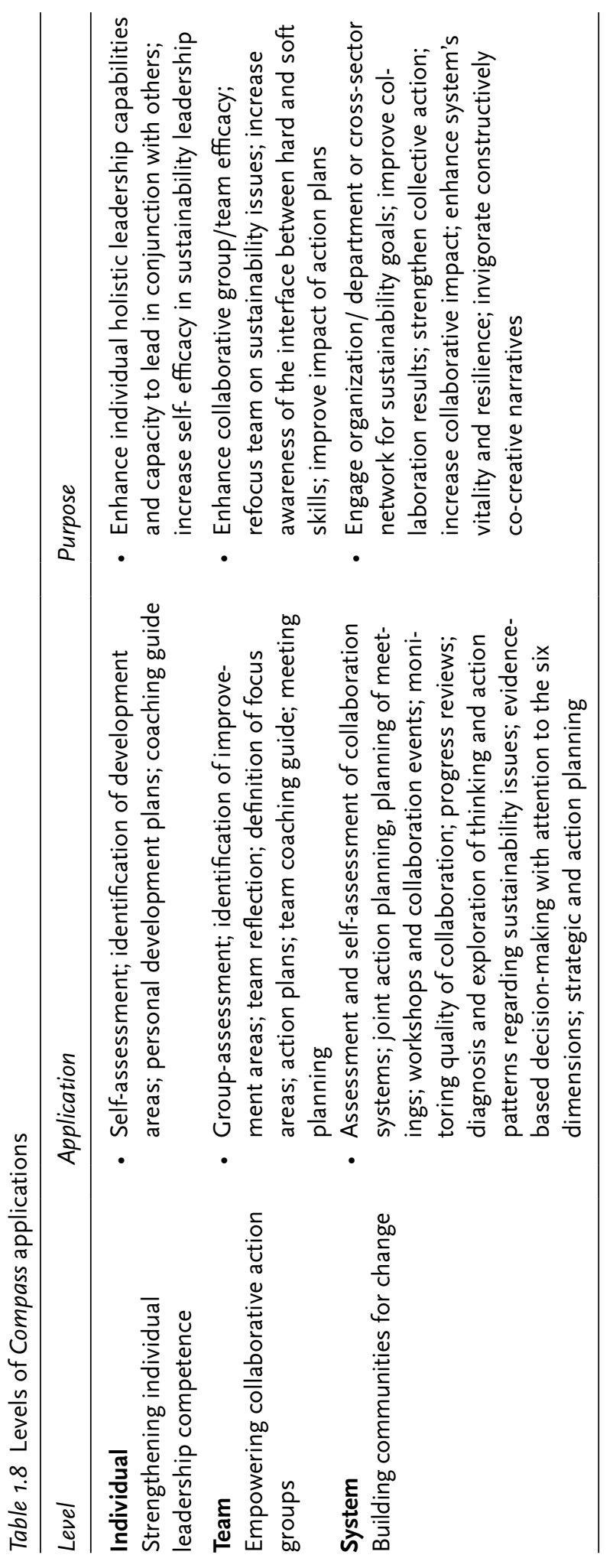




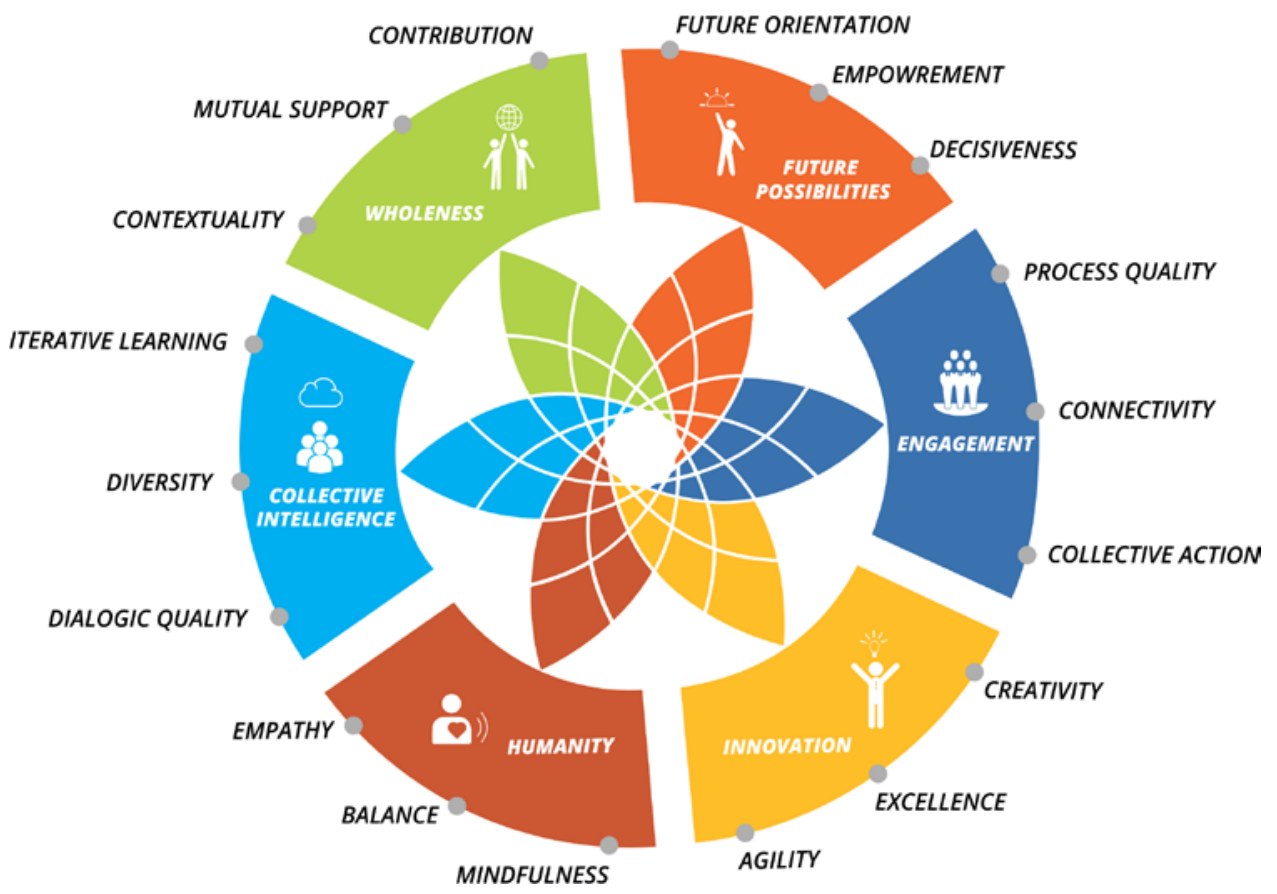

Figure. 1.6 The Collective Leadership Compass with aspects

\section{Step 1: observing patterns with the Compass}

This first step can be called diagnosing, but humans have a tendency to be critical and judgmental, and most of people are trained to spot the gaps immediately and jump at the deficits. The Compass suggests a slightly different approach: observing means identifying the patterns with the six dimensions as a lens. This could be patterns in a stakeholder system, a designated group of stakeholders working in a collaboration ecosystem, or a small group of actors carrying a collaboration process forward. It requires the following sequence: appreciating, assessing, and evaluating. Appreciating means honoring the competencies present as well as spotting development areas. But it does not judge. Appreciating the competencies available may turn into the discovery of a hidden jewel or a leverage point for success. Once actors are sure they have appreciated the pattern the next action in observing is assessing. This means looking at the relational presence of the six dimensions and how they are enacted. This can be done in response to questions that are guided by the Compass dimensions, or through a scale assessment in response to statements that are ranked according to their validity. The results are evaluated: this is about making sense of the information, interpreting the pattern in relation to the challenge or task or the larger goal that has been set. It is about consolidating insights about what the pattern observed reveals. Evaluating is not about right or wrong; 
it's about laying the basis for decision-making and knowing how to improve the planning of change and the collaboration. It's about learning to make better choices and seeing better results.

\section{Step 2: focusing on certain Compass dimensions}

Focus is the route to success in complex transformative change. It requires actors to identify entry points for change that become specific and concrete. It helps stakeholders walk in the jungle of complexity. Focusing means to select Compass dimensions that can be leveraged to improve the situation, and subsequently the collaboration and the outcomes. It requires a sequence of three actions: strengthening the strengths, nurturing development areas, and choosing the starting point for change. Strengthening the strengths means giving attention to what works well or where competencies are - and making use them. Often, these are underestimated competencies or hidden jewels of opportunities. Nurturing development areas means spotting how to bring in what is missing or undervalued or simply not known. Choosing an entry point means developing tangible next steps based on the insights gained.

\section{Step 3: enacting change based on planning with the Compass}

Multi-stakeholder collaboration needs plans. When they are based on understanding systems patterns, actors are more likely able to navigate complex realities constructively and with enthusiasm - a prerequisite for leading transformative change collectively. Planning with the Collective Leadership Compass can be combined with strategy meetings, vision workshops, implementation reviews, steering committee meetings, or impact evaluation. Enacting change means to plan actions together, test them in reality, watch the patterns, and check whether they achieve the impact envisioned. Planning with the Compass can take different forms, such as a short-term action plan, long-term strategic change, or simply the thorough preparation of the next stakeholder meeting. Reviewing progress takes actors back to observing.

With practice in collaborative change, this iterative learning cycle, summarized in Figure 1.7, becomes second nature. Stakeholders become more skillful in noticing patterns, identifying what is missing and focusing action steps not only on content issues, but also on the quality of collaboration patterns. Successful Collaboration Ecosystems require an enlivening culture of learning and collective reflection. It helps all stakeholders to develop a different attitude to situations when things go wrong: a thriving learning culture does not look to blame for mistakes, or consider objectives and results unilaterally as either won or lost. It recognizes that many challenges, and most importantly those in sustainable development, eschew thinking in these simple causal linkages. Rather, sustainable and successful solutions can only be found through a continuous cycle of collectively analyzing, strategizing, planning, enacting, and reviewing transformative change. The Compass gives actors in multi-stakeholder collaborations for SDG implementation guidance on which dimensions require attention to make collaboration effective and unearth its transformative potential. It embeds the necessary system's view of life as well as a practice of collective leadership, both key elements for 


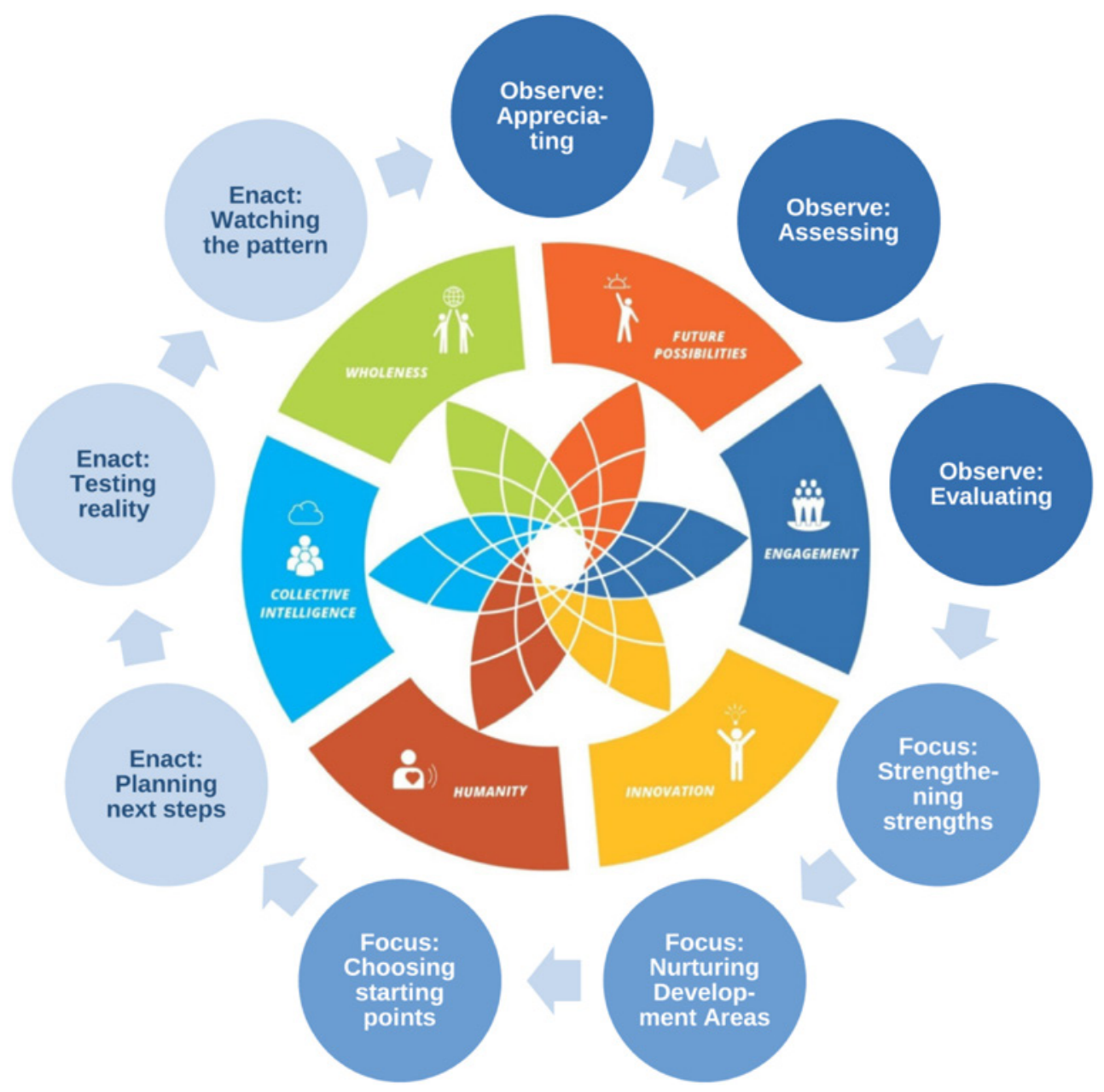

Figure 1.7 The observe-focus-enact cycle

leading not only effective, but in a transformative way. In order to strategically realize the guidance given by the Compass, well-designed and high-quality dialogue and cooperation processes are needed. Collaboration ecosystems thrive and deliver impact when they are supported by a coherent process methodology that serves as a map in the complex territories of diverse stakeholders. The next chapter will give detailed guidance on how to utilize the Compass dimensions in planning transformative change actions with the process methodology of the Dialogic Change Model.

\section{Notes}

1 Inspired by and adapted from Hemmati, 2002.

2 This was supported by the German federal enterprise Deutsche Gesellschaft für Internationale Zusammenarbeit $(\mathrm{GIZ}) \mathrm{GmbH}$ in the framework of the project 
"Vocational Integration of IDPs", funded by the German Ministry for International Cooperation and Economic Development (BMZ).

3 For more details, see www.grossnationalhappiness.com/nine-domains/ (retrieved May 3, 2017).

\section{References}

Alexander, C. (2002). The nature of order: An essay on the art of building and the nature of the universe: Book I - The Phenomenon of Life. Berkeley, CA: The Center for Environmental Structure.

Alexander, C. (2004). The nature of order: An essay on the art of building and the nature of the universe: Book IV - The Luminous Ground. Berkeley, CA: The Center for Environmental Structure.

Bass, B. M. (1998). The ethics of transformational leadership. In J. B. Ciulla (Ed.), Ethics, the heart of leadership (pp. 169-179). Westport: Praeger.

Beisheim, M. (2011). Innovative governance durch Entwicklungspartnerschaften? Chancen und Grenzen am Beispiel transnationaler Wasserpartnerschaften (S. W. Politik, hrsg., vol. 20, pp. S5-S29). Berlin: Stiftung Wissenschaft und Politik.

Bennis, W. (2007). The challenges of leadership in the modern world: Introduction to the special issue. American Psychologist, 62(1), 2-5.

Biermann, F., Man-san Chan, A., \& Pattberg, P. (2007). Multi-stakeholder partnerships for sustainable development: Does the promise hold? In P. Glasbergen, F. Biermann, \& A. Mol (Eds.), Partnerships, governance and sustainable development: Reflections on theory and practice. Northampton: Edward Elgar.

Boerner, S., Eisenbess, S. A., \& Greisser, D. (2007). Follower behaviour and organisational performance: The impact of transformational leaders. Journal of Leadership $Q$ Organisational Studies, 13(3), 16-26.

Boone, C., \& Hendricks, W. (2009). Top management team diversity and firm performance: Moderators of functional-background and locus-of-control diversity. Management Science, 55(2), 165-180.

Brouwer, H., \& Woodhill, J. (2015). The MSP guide: How to design and facilitate multistakeholder partnerships. Wageningen, The Netherlands: Centre for Development Innovation, University of Wageningen.

Capra, F., \& Luisi, P. L. (2014). The system's view of life: A unifying vision. Cambridge: Cambridge University Press.

Drucker, P. (1992). Managing for the future. New York: Truman Talley, E. P. Dutton.

Folke, C. (2006). Resilience: The emergence of a perspective for social - ecological systems analyses. Global Environmental Change, 16(3), 253-267.

Goepel, M. (2016). The great mindshift: How a new economic paradigm and sustainability transformations go hand in hand. New York: Springer.

Gronn, P. (2002). Distributed leadership as unit of analysis. Leadership Quarterly, 13(4), 423-451.

Gronn, P., \& Salas, E. (2004). Leadership capacity in teams. Leadership Quarterly, 15(6), 857-880. 
Hanleybrown, F., Kania, J., \& Kramer, M. (2012). Channeling change: Making collective impact work. Stanford Social Innovation Review, 9(1), 1-8.

Hemmati, M. (2002). Multi-stakeholder process for governance and sustainability: Beyond deadlock and conflict. London: Earthscan.

Kania, J. (2011). Collective impact. Stanford Social Innovation Review, 9(1), S36-S41.

Kuenkel, P. (2015). Navigating change in complex multi-actor settings: A practice approach to better collaboration. The Journal of Corporate Citizenship, 58, 119-137.

Kuenkel, P. (2016). The art of leading collectively: How we can co-create a sustainable, socially just future. Claremont, $\mathrm{NH}$ : Chelsea Green.

Kuenkel, P. (2019). Stewarding sustainability transformations. An emerging theory and practice of SDG implementation. Report to the Club of Rome. Cham, Switzerland: Springer.

Kuenkel, P., Frieg, V., \& Gerlach, S. (2011). Working with stakeholder dialogues: Key concepts and competencies for achieving common goals. A practical guide for change agents from public sector, private sector and civil society. Potsdam, Germany: The Collective Leadership Institute.

Kuenkel, P., \& Waddock, S. (2019, October). Stewarding aliveness in a troubled earth system. Cadmus Journal, 4(1). http://cadmusjournal.org/article/volume-4/issue-1/ stewarding-aliveness-troubled-earth-system

Lord, R. G., \& Brown, B. R. (2004). Leadership processes and follower self-identity. Hillsdale, NJ: Erlbaum.

Mizobuchi, H. (2004). Measuring world better life frontier: A composite indicator for OECD better life index. Social Indicator Research, 118, 987. https://doi.org/10.1007/ S11205-013-0457-x

Patscheke, S. B. (2014). Shaping global partnerships for a post 2015 world. In Stanford social innovation review. Stanford, CA: Stanford University Press.

Pearce, C. L., \& Conger, J. A. (2003). Shared leadership: Reframing the hows and whys of leadership. Thousand Oaks, CA: Sage.

Sahtouris, E., \& Lovelock, J. E. (2000). Earthdance: Living systems in evolution. San Jose, CA: iUniverse.

Senge, P., Hamilton, H., \& Kania, J. (2015). The dawn of system leadership. Stanford Social Innovation Review, 13, 27-33.

Simon, N., \& Beisheim, M. (2016). Multi-stakeholder partnerships for implementing the 2030 agenda: Improving accountability and transparency. Analytical paper for the 2016 ECOSOC Partnership Forum. https://www.un.org/ecosoc/sites/www.un.org. ecosoc/files/files/en/2016doc/partnership-forum-beisheim-simon.pdf

Van Tulder, R., \& Pfisterer, S. (2013). Creating partnership space: Exploring the right fit for sustainable development partnerships. In M. M. Seitanidi \& A. Crane (Eds.), Social partnerships and responsible business: A research handbook. London: Routledge.

Waddock, S., \& Kuenkel, P. (2019). What gives life to large system change? Organization Q Environment. https://doi.org/10.1177/1086026619842482

Waddell, S., Waddock, S., Cornell, S., Dentoni, D., McLachlan, M., \& Meszoely, G. (2015). Large systems change: An emerging field of transformation and transitions. The Journal of Corporate Citizenship, 58, 5-30. 
Weber, A. (2013). Enlivenment: Towards a fundamental shift in the concepts of nature, culture and politics. Berlin: Heinrich-Böll-Stiftung.

Weber, A. (2016). Biology of wonder: Aliveness, feeling and the metamorphosis of science. Gabriola Island, Canada: New Society Publishers.

Wheatley, M. (1999). Leadership and the new science, discovering order in a chaotic world. San Francisco: Berrett-Koehler Publishers. 


\section{chapter 2}

\section{Getting active \\ Making multi-stakeholder collaborations work}

The previous chapter has argued that successful implementation of the 17 SDGs requires multi-stakeholder collaborations at scale. Leading transformative change collectively enhances the resilience of cross-sector dialogues, platforms, initiatives, and partnerships. The key to success is the quality of collaboration and the quality of process architectures. While the Compass is a navigating tool for ensuring collaborative quality and connecting actors to systems aliveness when planning and strategizing transformative change, this chapter will

- introduce the process methodology of the Dialogic Change Model showing how multi-stakeholder collaboration can be led collectively through four specific phases towards success; and

- show how enhancing the Compass dimensions in each of the four different phases of multi-stakeholder collaboration helps collaboration ecosystems deliver results. This will be complemented by a readiness check for all phases.

The starting point for multi-stakeholder collaborations for SDG implementation is always an intention to change or improve an issue of common concern, solve a problem, or tackle a challenge together. People, not necessarily institutions, create ideas and intentions, which have most often undergone a process of development based on conversations with several other people. Most often, at the beginning, only a small group of people can see the future possibilities, and trust that collaborative engagement is the appropriate way to approach transformative change and gain the commitment of different stakeholders. Multi-stakeholder collaborations can most often be traced back to stories of courageous and passionate people committing to making a difference for the common good. Every official launch of 
a multi-stakeholder process has its own specific history that, ideally, is already a history of mutual learning. But it is also a history of chance encounters, paired with strategic planning.

Navigating the complexity of transformative change in collaboration is an art that requires skills in understanding how to collectively lead processes that enliven collaboration between stakeholders. The envisaged impact needs to be consciously built, designed, and iteratively adjusted. Having a sound background knowledge of the methodology for building collaboration ecosystems that can deliver transformative change will help to achieve the desired results. What many actors in transformative change tend to ignore is that, apart from the crucially important content expertise, success depends, to a large extent, on the quality of the process and the quality of the collaboration pattern. Regardless of whether the purpose of the multi-stakeholder collaboration is obtaining stakeholder feedback in a singular consultation event, achieving specific change goals together in a multi-stakeholder partnership project, or transforming complex systems through a multi-stakeholder initiative with a longterm perspective, every collaboration process requires a sequence of planning, implementation, and review steps. Because transformative change is an intervention into a complex reality, multi-stakeholder collaborations require very conscious process and communication designs. They need to become a microcosm of the larger change that they aspire to create.

\section{Stewarding collaborative change: the Dialogic Change Model}

A number of practitioners in multi-stakeholder collaboration have developed models that depict different phases of managing complex collaboration processes with multiple stakeholders (Tennyson, 2011; Kuenkel et al., 2011; Kuenkel, 2017a, 2017b; Brouwer \& Woodhill, 2015; Hanleybrown et al., 2012; Kania \& Kramer, 2011). Some of these models describe a more linear process while others depict a cyclical or spiraling process for complex multi-stakeholder collaborations. From research on evaluating success and failure in such complex processes, it is clear that complex multi-stakeholder collaboration processes can be divided roughly into four phases (Kuenkel, 2019). These phases describe a gradual shift from a stakeholder system that is loosely structured and often dysfunctional, with disconnected or even conflicting actors, towards a functioning collaboration ecosystem. In most cases, both challenges and problems are the result of dysfunctional interaction patterns between institutions, between people, as well as with the natural environment. These often have led to socially, economically, or environmentally compromised overall systems aliveness. Moreover, the dysfunctional patterns of interaction between institutions are also reflected in the way stakeholders are unable to collaborate and continue to pursue fragmented approaches to solve issues of common concern. It is therefore important to understand the four phases more in depth in order to design transformative change that can make a difference. Process architectures must invigorate the human competencies and change design principles 
of the Collective Leadership Compass described in the previous chapter for each phase. Hence, these phases need to be stewarded in quite different ways. Paying attention to the Compass dimensions helps to enact a spirit of collective leadership throughout all phases. It enhances the quality of the collaboration in each phase and leads to better and more sustained outcomes. This subchapter therefore looks at the Dialogic Change Model as a process methodology that shows how to steward collaborative change with the Compass over time. It allows for the result-oriented planning and implementation of collaborative change in four. The model, together with the Collective Leadership Compass as a navigating tool, guides the design of process architectures.

Bringing actors into multi-stakeholder collaboration together who have different backgrounds and interests requires developing an affinity for dealing with diversity, as well as a willingness to develop communication and change-management skills. The success of multi-stakeholder collaborations hinge on result-oriented process architectures that enhance systems aliveness. Each phase requires different sequences of actions. In order to apply what is appropriate at specific times, it is important to develop methodological know-how about

- transformative process and change-management designs;

- the translation of the six Compass dimension into diagnosing and planning;

- the in-depth understanding of the dialogical approach;

- a language for self-reflection as well as collective reflection;

- the patterned quality of collaboration, which leads more effectively to results; and

- the role of decision-makers, experts, and change agents and how they can become professionals in leading transformative change collectively.

This leads to an enhanced transformation literacy - the knowledge and capacity of collectives of decision-makers, change agents, and institutional actors to steward sustainability transformations effectively together in multi-stakeholder collaborations across institutions, societal sectors, and nations. The Dialogic Change Model as shown in Figure 2.1 is based on the ancient human knowledge of dialogue. It structures the design and implementation of transformative change into four distinct phases that help actors apply the Collective Leadership Compass in the most effective way. In that way, it supports and observes the emergence of the underlying principles of co-creating, maintaining, and safeguarding systems aliveness. Beneath the surface of the four phases in multi-stakeholder collaboration is a wealth of knowledge about transformative interaction and communication processes (Kuenkel et al., 2011; Kuenkel, 2015, 2019). This will be elaborated in more detail in Chapter 3. As a guiding structure for high quality change processes the Dialogic Change Model engenders a culture of collective leadership and helps collaboration ecosystems deliver results. It offers outcome-focused, well-structured planning and attention to important details that can make collaboration succeed or fail. It recommends three areas of attention in the each of the four phases and suggests key questions for reflection. 


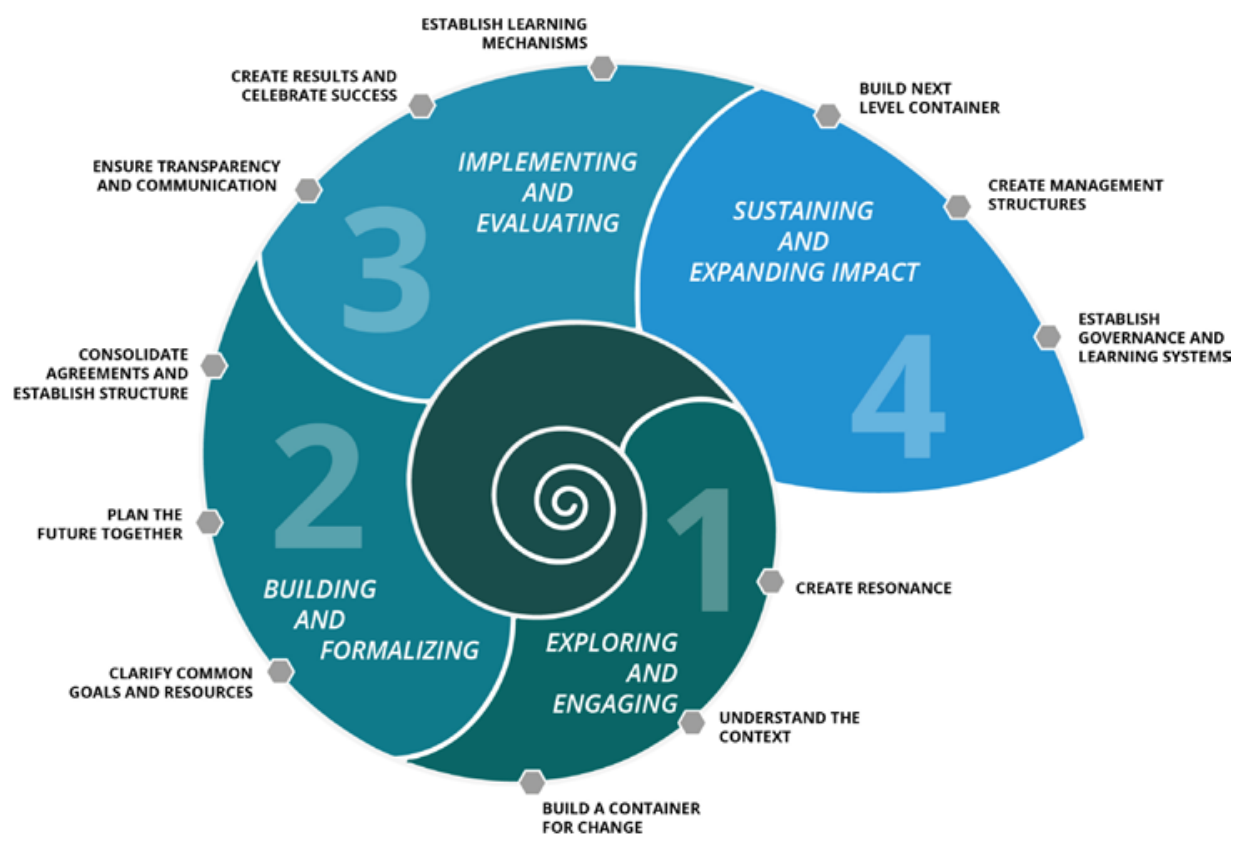

Figure 2.1 The Dialogic Change Model

\section{The Dialogic Change Model}

- helps invigorate human interaction systems as core drivers of transformative change;

- functions as a meta-level guiding structure to build complex systems of multiple stakeholders into functional collaboration ecosystems;

- provides a handrail for designing process architectures that enhance all Compass dimensions and subsequently further systems aliveness; and

- supports actors to enact the competencies and the collaboration patterns that needs to emerge for the transformative change envisaged.

With the model as a guide it is easier to design and review change processes that support stakeholders to operate as a coherent and well-functioning collaboration ecosystem. Looking at the requirements of the four development phases and their patterned quality of collaboration helps to bring about tangible results. In each of the four phases, the Collective Leadership Compass needs to come to life: this significantly increases the likelihood that the system of stakeholders works as a functional collaboration ecosystem. Looking at the quality of the collaboration pattern through the Compass as a lens helps identify which dimensions need special attention and how - over time - all dimensions can be invigorated. This improves the collaboration pattern and subsequently the effectiveness in achieving goals. It provides a pathway to invigorating the human potential for collaboration and leads to more constructive co-creation. It helps stakeholders work towards tangible results and increases the transformative effect of an initiative, a project, or a multi-stakeholder partnership. Table 2.1 gives an overview of the four phases. 
Table 2.1 The four phases of multi-stakeholder collaboration

\section{Phase 1}

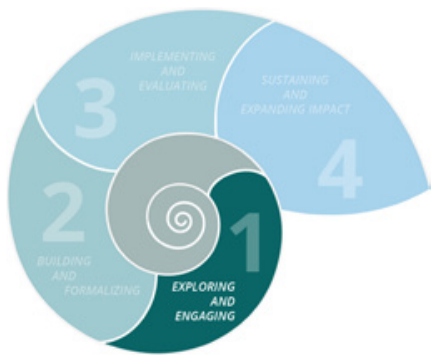

Phase 2

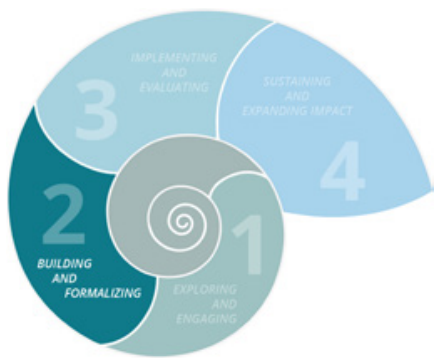

Phase 3

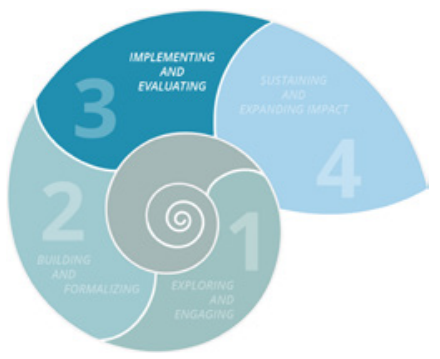

Phase 4

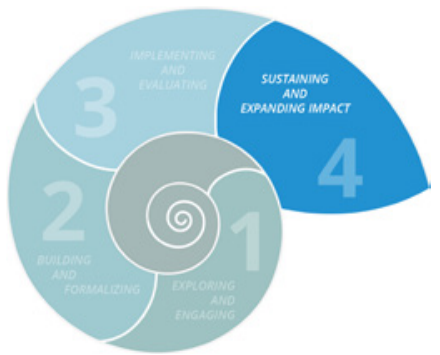

\section{Exploring and engaging}

- Raising the energy for collaborative change and preparing stakeholders for collaboration.

\section{Building and formalizing}

- Consolidating the system of stakeholders into a collaboration ecosystem that can deliver.

\section{Implementing and evaluating}

- Implementing planned activities, ensuring mutual learning and focusing on delivery of tangible results.

\section{Sustaining and expanding impact}

- Bringing the collaboration ecosystem to the next level of impact and creating long-term structures for transformative change.

The following sections describe the four development phases in more detail, followed by a readiness check that helps stakeholders determine, whether they have completed each of the phases. Guiding questions for each step in the four phases will help initiators, as well as the participating actors, to steward a result-oriented process. 


\section{Phase 1: exploring and engaging}

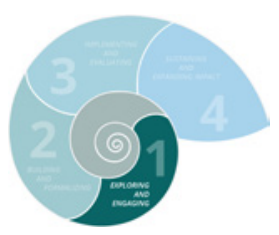

Phase 1 is the foundation for transformative change. All subsequent phases depend on the quality of the emerging collaboration pattern. It is focused on raising the energy for the envisaged change and getting stakeholders interested in collaboration. This means exploring the context of the envisaged multi-stakeholder collaboration and taking other existing initiatives and the people to potentially involve into account. Phase 1 requires understanding the factors that will influence the change process and the dynamics of the complex system in which it will take place. Building relationships and talking to selected but relevant stakeholders and opinionleaders informally in this phase can help clarify and elucidate the prospects and potential obstacles ahead. Informal dialogue is a melting pot for screening possibilities. If stakeholders are asked to shape the idea for change in conversations, they begin to commit.

It is important to anchor the potential goal in as many minds as possible, particularly in the minds of people who are relevant for the success of such an initiative and need to be actively engaged. Creating formal structures for the multi-stakeholder collaboration, such as agreements or defined procedures, are not a priority at this point. Creating structures too early can prevent the idea from taking root because structures often develop their own dynamic. This absorbs creativity and actors who have not been involved from the beginning can perceive these structures as imposed. A small multi-stakeholder team of engaged people driving the change - called the container (see Box 2.1) - can meet at various opportunities, exchange ideas, and receive inputs from interested and knowledgeable people in this phase.

\section{Box 2.1 The core group as a container}

\section{"Only dedicated circles can give birth to something new". \\ Saying by a circle of wise African women}

The term 'container' refers to the function and relational quality of an initiating team or core group of interested actors in multi-stakeholder collaboration. A good container exists if these actors develop a culture of collective leadership for the transformative change envisaged and enact high quality collaboration patterns. Ideally, this group of people already represents - to some extent, at least - the diversity of stakeholders so that it can embody the range of interests in the change initiative. It is composed of people who can make a difference, who are highly interested in change, are willing to respect each other and who are committed to the goal. They become the microcosm of the future collaboration ecosystem.

Such a container functions best when the actors

- are emotionally engaged with future possibilities and prepared to initiating and implementing the change together,

- are open to innovation and prepared to charter unknown territory,

- are prepared to support the engagement of diverse stakeholders, 
- $\quad$ respect each other as people while not negating differences in approaches and opinions (humanity),

- are willing to harvest their difference into collective intelligence, and

- are prepared to make joint contribution to solving a problem, overcoming a challenge, or transforming systems towards sustainability (wholeness).

In this way, the core group in its function as a "container" creates a holding space for the planned change. It becomes an emotional home for the joint initiative and an initial pattern of the envisaged systems aliveness.

This core group requires attention: the more this group is able to provide coherent collective leadership, the more likely the multi-stakeholder collaboration will be set on a route to success. Core groups that are "good" containers help to bring about change by engaging others and establishing ever broader containers for change. Such containers can develop and sustain the kind of legitimacy that comes not from hierarchy but from the fact that core groups as containers act in the interests of the whole, consistently.

Tangible results of a high-quality Phase 1 that has enlivened all dimensions of the Collective Leadership Compass are the following:

- Key stakeholders identified are prepared to work together constructively.

- People are looking forward to drive collaborative change around an issue of common concern together and share a connection to an emotionally compelling goal.

- There is a sufficient level of trust among collaborating key stakeholders.

- Context and external influencing factors have been explored.

- A core stakeholder group (container) jointly drives the engagement process, has credibility, and a mandate for moving forward.

As Phase 1 is about raising the energy for collaboration towards an envisaged goal and preparing a system of stakeholders for a collaborative approach, any of the dimensions of the Collective Leadership Compass can become an entry point to invigorate all other dimensions and access a sense of aliveness in the system of stakeholders.

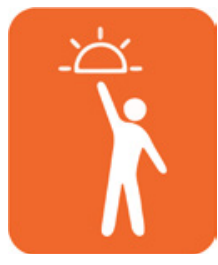

- Helping people to see future possibilities and creating resonance for co-shaping a different future raises energy and makes people feel more alive.

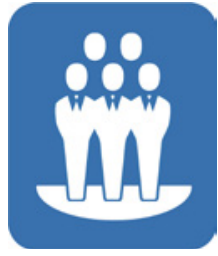

- Most often, however, in Phase 1 the dimension of engagement requires particular attention, as this is about preparing stakeholders towards collaboration and getting the quality of this engagement process right. 

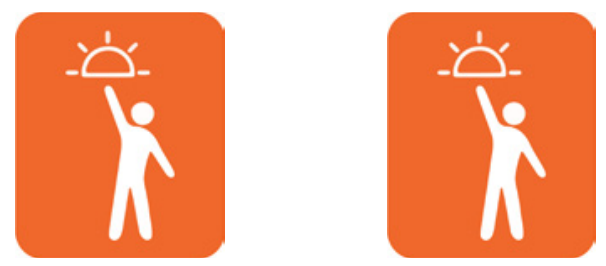

- The dimension of humanity is essential for the kind of trust building that is required - trust into future possibilities and trust in each other. Appreciation and empathy are key in this phase. It is important to respect people's expertise, experiences, and their viewpoints on the issue of common concern.
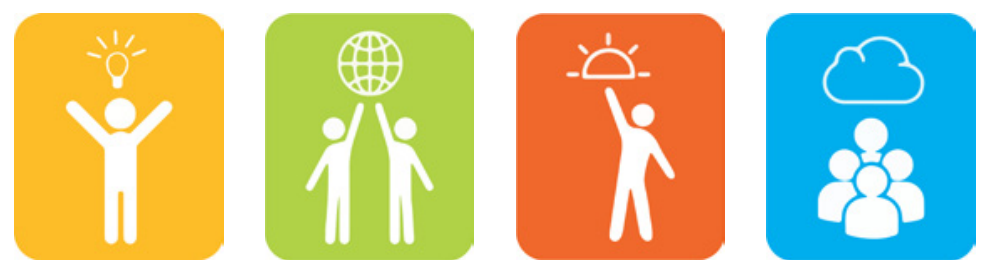

- Whether the interest of stakeholders in transformative change can be raised through the dimension of innovation (e.g. inviting people to find new pathways), or through the dimension of wholeness (e.g. taking care of a greater good or common concern), or through the dimension of future possibilities (e.g. solving a concrete problem) depends on the situation. This is why understanding the context is crucial. Situational analyses need to include inspiring bilateral or small group conversations that foster a culture of dialogic quality and collective intelligence.

Phase 1 can take a few months to about 1.5 years, depending on the complexity of issue and context. It has been completed when three steps have been sufficiently dealt with, i.e. when resonance for collaborative change has been created, the context is well understood, and a container for change has been built. These three steps are depicted in Figure 2.2 and will be explored in more detail.

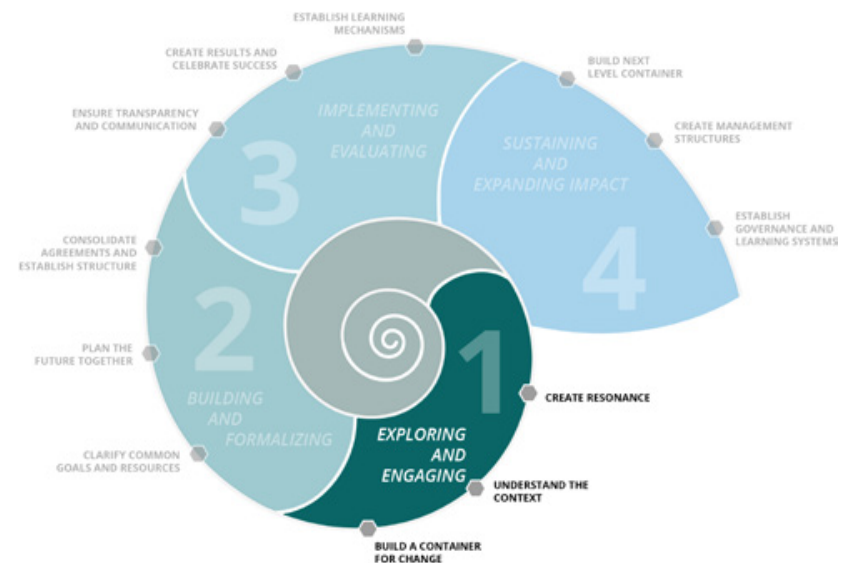

Figure 2.2 The three steps of Phase 1 


\section{Step 1: creating resonance}

Raising the energy for change in a stakeholder system requires not only information but also human-to-human connections. In both formal and informal exchanges, the initiators of a collaboration process clarify the interests, potential commitment levels, and willingness to participate of potential stakeholders. During this exchange process, the idea or the planned course of action emerges. In informal bilateral conversations, the initiators can help to clarify the different possibilities for change and test for resonance with the relevant actors. This way, the common goal becomes clearer and is further developed with the help of stakeholder feedback. It is important that the initiators have a vision for change, but do not hold this vision too tightly; they need to be open enough to let the vision take shape in conversations. These are guiding questions for creating resonance:

- Who resonates with the common goal?

- Which important stakeholders can support our cause?

- What makes our cause attractive for the different actors?

- Where is already energy and willingness for change?

- With whom do we need to speak?

- Who can help to clarify goals and possible implementation avenues?

Acknowledging how people see the current situation is the basis for engaging in empowering future-oriented conversations. Box 2.2 summarizes the most important elements of creating resonance.

\section{Box 2.2 Ways of creating resonance}

- Establish trusting relationships with potential partners.

- Acknowledge people's expertise or viewpoints of the current situation.

- Facilitate a joint thought process towards a mutual goal and create brainstorming opportunities about possible implementation.

- Clarify the idea for transformative change in bilateral or small group dialogues with stakeholders.

- Acknowledge and understand the different interests of stakeholders and their institutions.

- Engage stakeholders in inspiring and future-oriented conversations.

- Create opportunities for conversations that matter.

- Begin to knit a network of people interested in transformative change.

- Engage the support of potential high-level actors through empowering and future-oriented conversations. 


\section{Step 2: understanding the context}

Transformative change initiatives can only become successful, if the context is well understood. This includes a stakeholder analysis (see Chapter 3), a conflict mapping, and a situational analysis. Moreover, it is important to examine which attempts to tackle a challenge or solve a problem already exist or how structures and behaviors are impeding the envisaged transformative change process. Context analysis inevitably includes benchmarking; for example, evaluating similar experiences in other sectors, countries or subject areas. In some cases, technical studies or thematic situational analyses may be meaningful, the results of which can flow into the ongoing process. If the context analysis reveals that not all stakeholders are sufficiently knowledgeable about the issue, publications or information events can be planned. This serves as content capacity development and can be integrated into a multi-stakeholder collaboration at any time. If the stakeholder analysis shows that certain stakeholders are insufficiently organized or have no joint voice, these stakeholder groups need to be strengthened to contribute their knowledge, experiences, and viewpoints (e.g. farmers, consumers, community organizations, etc.). In addition, it may be necessary to reinforce stakeholders' knowledge of cooperation, dialogue, and process by holding capacity-development workshops on how to engage in multi-stakeholder collaboration.

It is also important to discover which political or high-level support the purpose of the collaborative initiative requires, and to gain this support actively. This is particularly relevant for multi-stakeholder initiatives that involve the public sector or that are initiated by this sector. It is critical to obtain the support of high-ranking people from one or more of the stakeholder groups, or, in some cases, to ensure that there is patronage for the intended change. High-level sponsors need to stand behind the purpose of the multi-stakeholder initiative, but may not need to be directly involved in them.

These are guiding questions for understanding the context:

- Which stakeholders do we need to involve?

- What do we need to know about the current situation and about future events?

- Which partners do we need to ensure the success of our cause?

- Who has influence in the outcome of our initiative, and how can we influence them?

- Are there existing best practices that we can adopt?

- Do we have to do any research on the issue?

- Who do we have to talk to in order to complete our understanding of the overall system?

- What do we know about experiences in similar situations?

- What are the potential difficulties?

- How can we support weaker stakeholders?

Box 2.3 summarizes the most important elements of understanding the context. 


\section{Box 2.3 Ways of understanding the context}

- Conduct a stakeholder analysis and identify interested and influential key stakeholders.

- Benchmark similar attempts to tackle the challenge in other sectors, countries or subject areas.

- Conduct technical studies or thematic situational analyses and make them meaningful to potential stakeholders by sharing and discussing the results.

- Find out how the collaboration initiative can be integrated into existing structures or processes, and plan the change complementarily to other existing initiatives.

- Map potential conflicts and identify power differences and patterns.

- Identify advocacy or capacity building needs for weaker stakeholders.

- Identify information gaps for powerful stakeholders.

- Clarify the need for high-level support.

- Ensure collaboration competency building for all potential stakeholders.

\section{Step 3: building a container for change}

Transformative change needs people who see collaboration and dialogue as an important resource and who are capable of implementing it. Building a good container for change consists of creating a small core group (ideally between two and six people) made up of a few dedicated key stakeholders. This initial container is a microcosm of the larger stakeholder system that needs to shift into a functional collaboration ecosystem. It acts as a source of energy for progress towards a common goal, and its role is to hold the process as well as ensure engagement, collaboration, and dialogue of all participating stakeholders in a reliable way. The task is to keep the process on track. It is beneficial if the core group is able to work together informally, and it is important for its members to build mutual trust and to create understanding of the needs and demands of the institutions they represent. Many stakeholder involvement processes fail or have little impact because there is no solid container of people who feel collectively responsible for fostering and holding the process from beginning (planning the participation) to end (taking action on the basis of the results of participation). Building a collaboration system requires actors in the core group to begin to engage a broader container: this means people, including high-level stakeholders, who may not be directly involved in driving the change, but become supporters of the change initiative. More details on how to develop a broader container will be described in Chapter 3 .

These are guiding questions for building a container for change.

- Which actors do we need at the beginning of the transformative change initiative?

- Who are the people who can drive change?

- Which actors represent the larger system?

- What setting for the first meeting will enhance stakeholders' commitment and process ownership?

- What needs to be discussed during the first meeting?

- What could compel the actors to support the transformative change? 


\section{Box 2.4 Ways of building a container for change}

- After a stakeholder analysis, create a core group of stakeholders that are both influential and interested.

- If you don't have enough influential and interested stakeholders, strengthen interested, but weaker stakeholders first, and create resonance for change with more powerful stakeholders.

- If need be, work with different containers first: for example, create a container among public sector stakeholders, one among communities or producers, and another among private sector actors - then gradually bring them together.

- Keep high level actors engaged throughout and committed to supporting a launching event at the end of Phase 2.

- Look out for where there is energy and creativity - this is what you need to build on.

- Make sure the container (core group) has opportunities to build trusting relationships and can have fun together.

- Ensure regular meetings of the container (core group) and facilitate an emerging goal clarity and implementation strategy.

Building a container for change is about creating a microcosm of the collaboration ecosystem that will eventually deliver the transformative change. Box 2.4 summarizes ways to build a container for change.

\section{Phase 2: building and formalizing}

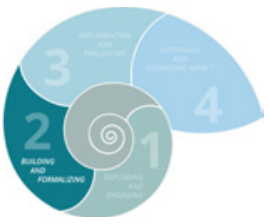

Phase 2 is about consolidating the system of stakeholders into a collaboration ecosystem that can deliver and finding the appropriate structure to work together. This means formalizing stakeholders' commitment to collaborative change. Hence, initial governance and decision-making structures are developed, project teams defined, and regular meetings planned. Phase 2 usually has a process architecture that features a series of visioning and joint planning events that includes all key stakeholders that have been consulted and engaged in Phase 1. The vision needs to be owned by all. This usually leads to agreements - the signing of a contract, a memorandum of understanding (MoU), a project plan, a jointly developed theory of change (see Chapter 4), or a public address in the interest of the change endeavor. With an official event and an agreed - upon written document, the collaborative multistakeholder collaboration process officially comes to life. Plans and roadmaps for implementing need to offer a sufficient degree of reliability of the process in an otherwise unpredictable and complex environment. Contributions, roles, and allocation of work as well as communication and process designs need to be agreed upon jointly. In complex collaboration initiatives, a project secretariat is formed, resourced, and officially mandated. It is crucial to strengthen the work of stakeholders in the initial container. 
This protects the collaboration initiative from being too vulnerable to unavoidable change of personnel. It also strengthens individuals' ability to promote the intention of the change within their respective institutions.

Tangible results of a high-quality Phase 2 that has enlivened all dimensions of the Collective Leadership Compass are:

- Participating stakeholders identify with being part of an issue-based collaboration ecosystem and aspire to implement transformative change.

- The goal of the collaborative initiative is clear to all stakeholders.

- Agreements to collaborate exist: depending on the form and purpose of the initiative, this can be anything that shows commitment and gives structure to move forward.

- A jointly agreed implementation plan has the ownership of all stakeholders.

- Resources (human and financial) for implementation have been committed.

- Stakeholders have agreed to implementation procedures and allocation of responsibilities.

- Formal governance structures to steward the change process (e.g. councils, committees, expert working groups, etc.) are established.

Most often the entry point to the Collective Leadership Compass in Phase 2 is the dimension of future possibilities as the goals become clear, the focus of the initiative is decided, and implementation plans are jointly developed. Establishing a highquality collaboration pattern in Phase 2 is the best preparation for Phase 3 of joint implementation.
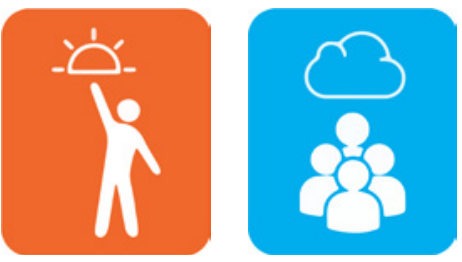

- Co-creating goals and setting the focus to pave the way towards future possibilities empowers stakeholders, if done in a way that it enhances collective intelligence. Hence, workshops and events need to become spaces for structured dialogue and acknowledgment of a diversity of interests, viewpoints, and expertise.
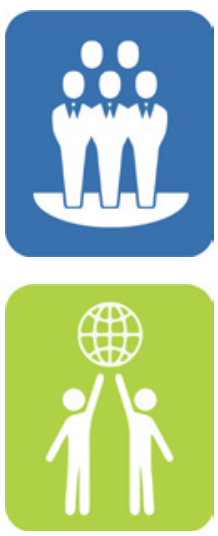

- The emotionally compelling goal and a narrative of an envisaged future emerge when stakeholders are able to relate to the dimension of wholeness - a larger goal that the initiative may contribute to. 


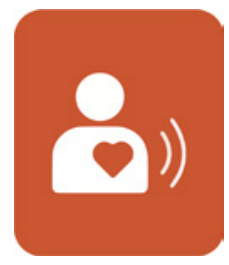

- Similar to Phase 1 the dimension of humanity that is so often neglected in the way we plan requires utmost attention. This can show up in the way workshops or meetings are carefully planned so that people can meet each other as people, or it emerges from a culture of care about stakeholders in the way they are invited to meetings or receive the meeting results. Equally important is ensuring that weaker stakeholder groups have a voice in the planning of progress.

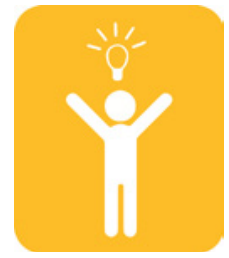

- Phase 2 needs to harvest the knowledge gained about the context in Phase 1. Bringing insights about benchmarks, innovative approaches, and existing solutions as part of the dimension of innovation into the discourse is as important as enhancing creativity in the way meetings and events take place.

Phase 2 usually takes a few weeks to a couple of months. It has been completed when three more steps have been sufficiently dealt with, i.e. goals and resources have been clarified, the future has been planned together, agreements have been consolidated, and structures for implementation have been established. These three steps are depicted in Figure 2.3 and will be explored in more detail.

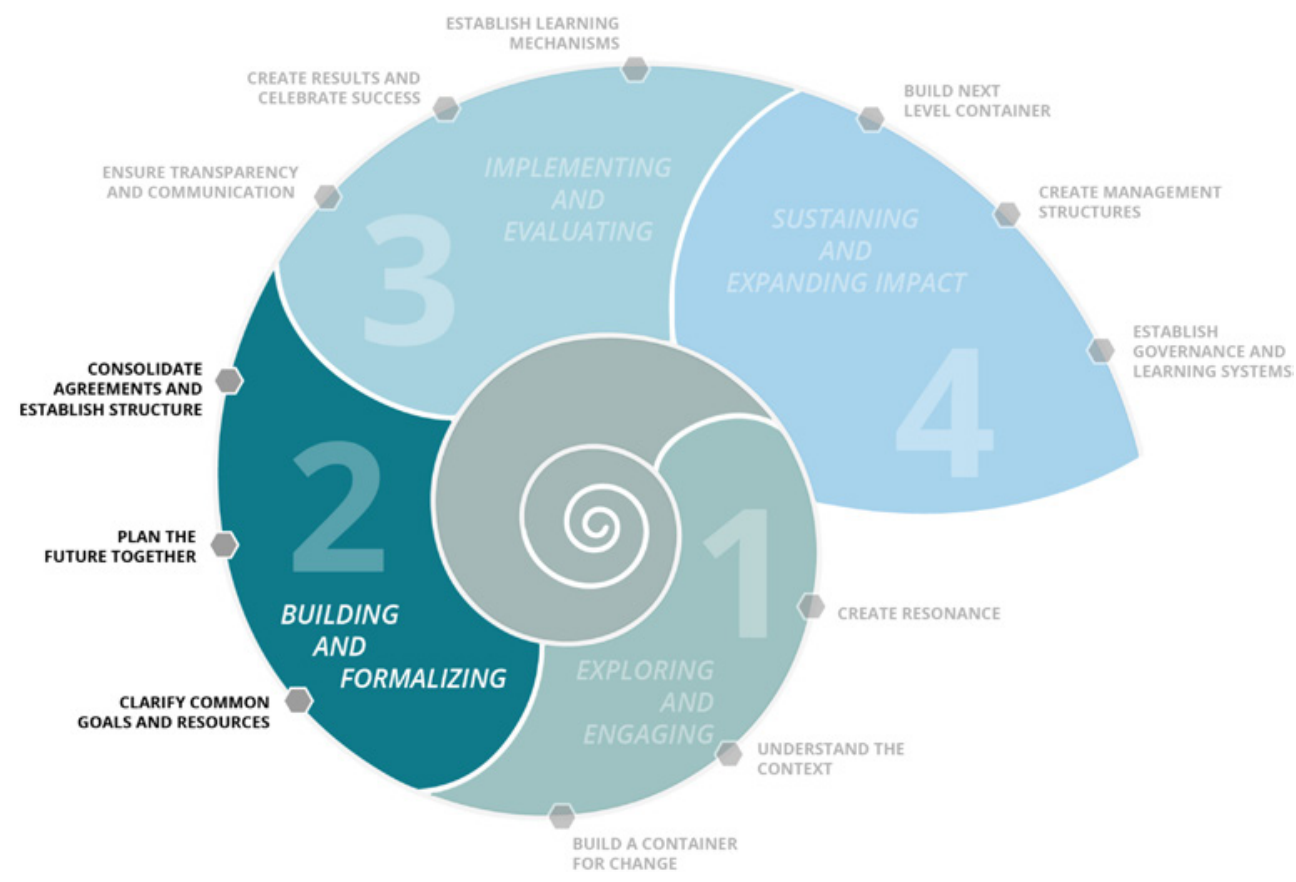

Figure 2.3 The three steps of Phase 2 


\section{Step 4: clarifying goals and resources}

The interest and commitment of stakeholders that has been built up during Phase 1 needs to be consolidated into working structures in Phase 2. This means that the purpose and goal of the multi-stakeholder collaboration process that was held mainly by a small group of stakeholders (the initial and broader container) in Phase 1 now need to be discussed, agreed upon, and, finally, owned by a larger number of stakeholders. This may require modifying or adjusting purpose and goals so that all stakeholders can identify with the way forward. Clarifying goals is much more than creating a project plan with objectives and sub-objectives. It means exploring how to co-create an emotionally compelling vision that stakeholders can relate to and identify with. It also means thinking about a narrative for the envisaged change and asking: what are the stories of possibilities we will create?

Process architectures in Phase 2 need to create a climate of collective action, evidenced by agreements on the different contributions by stakeholders. This usually requires a series of workshops with high-quality dialogue and vision development that engage important representatives from the different stakeholder groups (for a deep dive into how to design process architectures with the Collective Leadership Compass, see Chapter 4). How many meetings will be required depends on the purpose and the complexity of the initiative. In some cases, goal clarification may require conversations about the aspired future within one stakeholder group first, before all stakeholders can be brought together. Real commitment emerges with trust and the perception that it is possible to make a difference together. However, it is also important to be aware of different institutional interests. Nonetheless, doubt and occasional mistrust by different stakeholder groups cannot always be avoided: this is a normal part of complex endeavors. The core group's role is to offer reliable process architectures that keep the commonly agreed goals alive and stakeholders on board. The more stakeholders develop a sense of ownership for the multi-stakeholder collaboration, the more they will be prepared to also contribute resources. It is important to stress that not only financial contributions are valid. Resource mapping such as networks, in-kind contributions, working time, office space, expertise, access to funding, etc., is an important preparation to gauge potential contributions.

These are guiding questions for clarifying goals and resources:

- Which actors represent the larger system and need to be included in the dialogue?

- How can it be guaranteed that stakeholders feel their views are being taken seriously?

- How can stakeholders be encouraged to develop ownership of an initiative?

- What will make the actors feel they are receiving competent guidance?

- What do we want to achieve with the collaboration initiative?

- How can we create a narrative around future possibilities?

- What would be an emotionally compelling goal that inspires stakeholders?

- What resources can each actor bring in? 


\section{Box 2.5 Ways of clarifying goals and resources}

- Create kick-off and vision meetings that ensure a climate for meaningful and authentic dialogue around sharpening the goals. Fake participation will haunt you in the implementation phase.

- Aim at consensus-building, but acknowledge differences and make them transparent.

- Run a series of workshops in a step-by-step process if the challenge is complex and there are many stakeholders involved.

- Make sure agreements achieved at meetings are transparently summarized at the end of the meeting.

- Pay respect to cultural and institutional protocols.

- Find out which stakeholders can contribute in which way.

- Consider the concerns, suggestions, and expectations of different partners.

Shaping the future together requires emotionally compelling goals that people can connect with. Box 2.5 summarizes ways to clarify goals and resources.

\section{Step 5: plan the future together}

In Phase 2, the joint vision development needs to be followed by the co-development of implementation strategies and agreed-upon plans. Different stakeholder groups are familiar with different planning modalities that need to be taken into account. Private sector actors often need concise roadmaps; the public sector may require detailed objectives and indicators; and civil society may need to show an impact matrix or a theory of change (see Chapter 4). However, it is important to create a joint planning document that then each stakeholder can use for their purpose to justify their engagement in the multi-stakeholder collaboration, but which also functions as a guiding document for all. To develop ownership among all participating stakeholders, it is crucial to discuss both the analysis of the current situation and the planned changes together with all stakeholders. It can be helpful to bring in external assessments of the situation or the problem at stake. However, the most powerful driver for collective change is a joint diagnosis of the situation as a foundation for planning the future together. Only then will the case for change become rooted among all participating stakeholders. In complex collaboration initiatives, it may be important to integrate capacity development and knowledge building for stakeholders into the joint planning process. Similarly, planning can be enhanced by integrating capacity development around the methodological know-how regarding multi-stakeholder collaboration into the process architectures. Collaborative planning often requires professional facilitation. The design of meetings, events, or conferences needs to take into account that collaboration ecosystems become successful if people engage emotionally with the possible future, with the form of dialogue and collaboration, and with each other. 


\section{Box 2.6 Ways to plan the future together}

- Design the process architecture of planning together with the container (core group).

- In order to develop ownership among stakeholders, discuss both the analysis of the current situation from Phase 1 and the planned changes together with all relevant stakeholders.

- Facilitate a joint diagnosis of the situation, as this is the most powerful basis for collective change.

- Bring in external assessments of the situation, but leave the evaluation to the stakeholders.

- Develop a plan together that works for all stakeholder groups and conveys the emotionally compelling goal.

- Build content capacity development, as well as methodological know-how about collaborative change, into process architectures.

- Ensure timely and transparent documentation of workshops and meeting results.

These are the guiding questions for planning the future together:

- Are enough stakeholders prepared to shape the future together?

- Have we gathered all necessary perspectives and expertise to plan the future together?

- How can we translate the emotionally compelling goal into a plan of action?

- Which kind of roadmaps and plans would cater to different stakeholder groups and assist all actors in jointly shaping the future?

- How can we design planning events that enhance commitment and ownership?

The foundation for planning the future is always a joint diagnosis of the current situation. Box 2.6 summarizes ways to plan the future together.

\section{Step 6: consolidating agreements and establishing structure}

Phase 2 is the time when multi-stakeholder collaborations need sufficiently contained structures that make joint implementation work. While the process of engagement in Phase 1 is more informal and emergent, it is crucial that this now finds more formal expression in decision-making formats, working groups, and - in complex multistakeholder collaborations - governance structures. Stakeholders need to be able to identify with the initiative and find their role in implementation. More or less formal agreements such as a memorandum of understanding formalize the collaborative working relationship. Such agreements can be announced in an official launch or any other public event. At this point, the collaboration initiative becomes visible from the outside. The form of agreements can be different according to the form and purpose 
of the collaboration initiative. For different forms of agreements and their purpose, see Chapter 4). The signing of a memorandum of understanding is only one possible way to formalize a stakeholder collaboration. In more conflict-prone situations, the agreement may just be that another meeting will take place. But it is important that participating stakeholders show and document their commitment to the agreed upon goals and are clear about the way forward. Process architectures must be designed in a way that stakeholders perceive the process as transparent and the agreements reached as trustworthy and dependable. In complex collaboration initiatives, it is the function of a mandated project secretariat to support high-quality process architectures that serve the cohesion of the collaboration ecosystem. How to do this in a dialogic way will be explored in more depth in Chapter 3. In complex multi-stakeholder collaborations, such as standard developments in responsible value chains or land and water governance, more elaborate organizational structures are often needed. These may consist of steering committees, task forces, separate stakeholder constituency meetings, or expert working groups in order to deepen the knowledge on specific thematic issues. Chapter 4 will take a deep dive into stewarding mechanisms such as governance and decision-making structures.

It is crucial to transparently document all agreements, results, and decisions made and to distribute this documentation to all participating stakeholders in a timely fashion. The form and regularity of internal communication between the participating stakeholders and with the public can also be laid out at this point (for more details on public communication, see Chapter 3 ). Creating structures also means officially mandating supporting structures such as a project secretariat, which is often required in complex multi-stakeholder collaboration. It is important to ensure that the members of the initiating stakeholder-composed core group (container) are included in the emerging governance and steering structures.

These are the guiding questions for consolidating agreements and establishing structures:

- What form of process support do the participating stakeholders have for the road ahead?

- Which type of agreement is suitable for a specific process (Agreements, Memorandums of Understanding, project plans, pictures, joint project- or implementation plans)

- Which type of agreement will guarantee the ongoing trustworthiness and dependability of the collaboration process?

- How can a plan of action be developed so that all participants are inclined to support it?

- What are important milestones for implementation?

- Are roles and responsibilities for the implementation of the initiative clear?

- Is there an agreed-upon internal and external communication strategy?

- Is clear planning and documentation available to all stakeholders?

- Have follow-up meetings been planned, guaranteeing process dependability?

Box 2.7 summarizes ways for consolidating agreements and establishing structures. 


\section{Box 2.7 Ways for consolidating agreements and establishing structures}

- Create some kind of formal agreement that everybody commits to.

- Document the intention to work together in agreements that can be - if appropriate to the multi-stakeholder collaboration - shared with a public audience.

- Detail roadmaps and implementation plans with milestones for the time ahead.

- Clarify the roles of stakeholders in implementation.

- Create agreements on internal communication among stakeholders and external communication to the public or media.

- Mandate or re-mandate the container (core group) to jointly lead the process.

- If not already done, mandate a project secretariat to support the implementation phase.

- Create governance structures that are sufficient to ease decision-making and progress reviews and that all stakeholders feel happy with.

- Install thematic working groups for certain issues, if necessary.

- Create a process architecture that shows how often stakeholders will jointly review the process and the results.

- Ensure timely and transparent documentation of workshops and meeting results.

\section{Phase 3: implementing and evaluating}

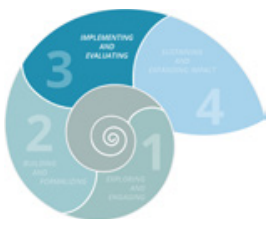

Phase 3 is about the implementation of planned activities. Progress or outcomes are evaluated. Stakeholders implement activities either jointly or in a coordinated way. Phase 3 ensures learning, monitoring of progress and process, and it is focused on results. Monitoring and evaluation practices and iterative learning mechanisms need to be firmly established so that joint readjustment of strategies can take place. This will be more deeply explored in Chapter 5. It helps particularly at the beginning - to concentrate on easily achievable results and continue to make successes and achievements visible to all. This guarantees that stakeholders will stay involved in the process and will solve conflicts and problems constructively. A well-structured Phase 3 is a showcase that change is doable. Prototyping innovative approaches might play an important role. Cooperative delivery of results is key and works best with transparency in decision-making and progress reporting.

Good communication is the glue that keeps the collaboration ecosystem together. If implementation is complex, a secretariat or support team, usually appointed in Phase 2, assists in the coordination of implementation and the monitoring of results. In Phase 3 Both structure (e.g. implementation plans, monitoring and governance structures, learning mechanisms, etc.) and process (e.g. celebrating success, sharing results, staying tuned to the joint endeavor through communication and relationship building, etc.) need to receive sufficient attention. Otherwise, actors tend to drop out, lose a sense of ownership, stop implementing, get into conflicts, or start operating 
in silos. The skill of key actors in managing the dynamic balance between dialogue, reflection, and the joint delivery of results makes complex multi-stakeholder collaborations effective in implementation. This can be called backbone support, which will be taken up in Chapter 4. In complex multi-stakeholder initiatives, it is the role of the stewarding council - as the representative structure of the stakeholder composition to guide strategy adjustment and learning. Sometimes it becomes apparent during implementation that certain contextual aspects were not adequately considered or that important stakeholders were not yet included in the process. At this point, it may therefore be helpful to take up the approach used in Phase 1 again to clarify the context fully, extend capacity building, or integrate new stakeholders into the process.

Phase 3 often reveals differences in the way stakeholders use decision-making procedures. Private sector actors tend to be fast in decision-making; public sector representative require time-consuming internal consultation processes; NGOs and communities need to get feedback from their constituencies. The role of the core group or, in complex multi-stakeholder collaboration, the project secretariat as a backbone support consists of taking care of the acknowledgement of difference, facilitating consensus building, keeping the common goal clear, and driving the agreed upon action.

Tangible results of a high-quality Phase 3 that has enlivened all dimensions of the Collective Leadership Compass are:

- Key stakeholders deliver results together in a coordinated way and milestones have been achieved.

- Decision-making is efficient and governance structures are functional.

- Successes are known to all and have been made public.

- Regular stakeholder meetings enhance innovation and learning exchange.

- Monitoring of progress and process is used for improvements.

- There is a positive feedback from beneficiaries on impact.

The complexity of a collaboration initiative often becomes evident during Phase 3, sometimes in the form of a crisis. Crisis symptoms may include criticism from external parties, stakeholders voicing new, previously unspoken interests, negative press, counter initiatives, endless non-productive discussions, or a group of actors threatening to back out of the multi-stakeholder collaboration. Political interests can often hold up an initiative's development or complicate consensus-building. The more stability and trusting relationships have been created in Phase 1 and 2, the better such phases of instability can be overcome (see also Chapter 3 on ensuring high-quality dialogue). Making sure that process architectures and meetings are planned with the Collective Leadership Compass goes a long way in reducing conflicts, maintaining trust, and getting to results.

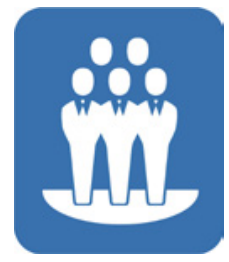

- The dimension of engagement is best enhanced by keeping the connectivity among stakeholders and ensuring good communication - progress reports, new insights from implementation, success stories, etc. But equally important are the regular meetings that help stakeholders to connect and exchange about obstacles and solutions. 


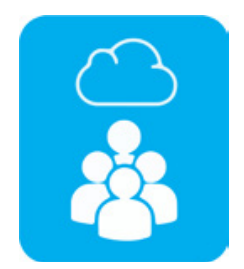

- $\quad$ Such meetings need to be deliberately designed to harvest collective intelligence by creating space not only for reflection, but also for iterative learning and mutual support to overcome difficulties.

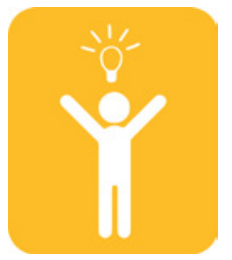

- Phase 3 thrives if the dimension of innovation receives increasing attention. In a functional collaboration ecosystem, stakeholders become creative and develop a higher degree of agility to deal with challenges. Stakeholder meetings as well as steering committee meetings should be designed in a way that they create space for innovation and learning.

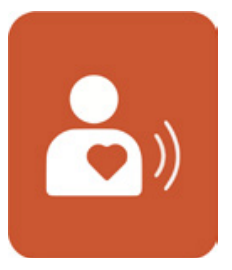

- Similar to the previous phases the dimension of humanity is a subtle guide and constant reminder that it is people who can make a difference together. Mutual respect, but also the understanding of constraints that certain stakeholders may experience, goes a long way in keeping trust alive and enables people to express as well as deal with unavoidable criticism.

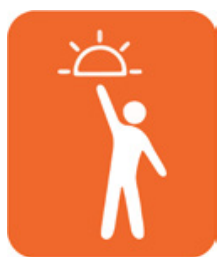

- $\quad$ Phase 3 is ultimately about making future possibilities happen and experiencing that collectively shaping the future is doable. A collaboration ecosystem with a high-quality collaboration pattern is contagious - it opens doors and creates new opportunities. But all action needs to have focus, clear plans, and an agreed upon way to track progress. This is why monitoring and evaluation becomes important in Phase 3.

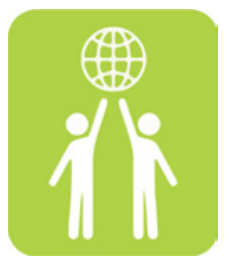

- This leads to the attention to wholeness, as Phase 3 is about asking if the collaboration ecosystem is contributing to transformative change as best as it can. Impact is always contextual and complementary. This is why the dimension of wholeness is best enhanced in Phase 3 by strengthening the goal and looking at how the collaboration initiative can collaborate with other initiatives to widen the impact.

Phase 3 can take months or years, and is concluded when the agreed-upon goals have been reached. It runs smoothly when transparency and good communication keep stakeholders on board, success can be celebrated jointly, and learning mechanisms are functioning well. A successful Phase 3 requires three further steps that are interlinked: ensuring transparency and communication, creating results, and celebrating success, as well as establishing learning mechanisms. These three steps are depicted in Figure 2.4 and will be explored in more detail. 


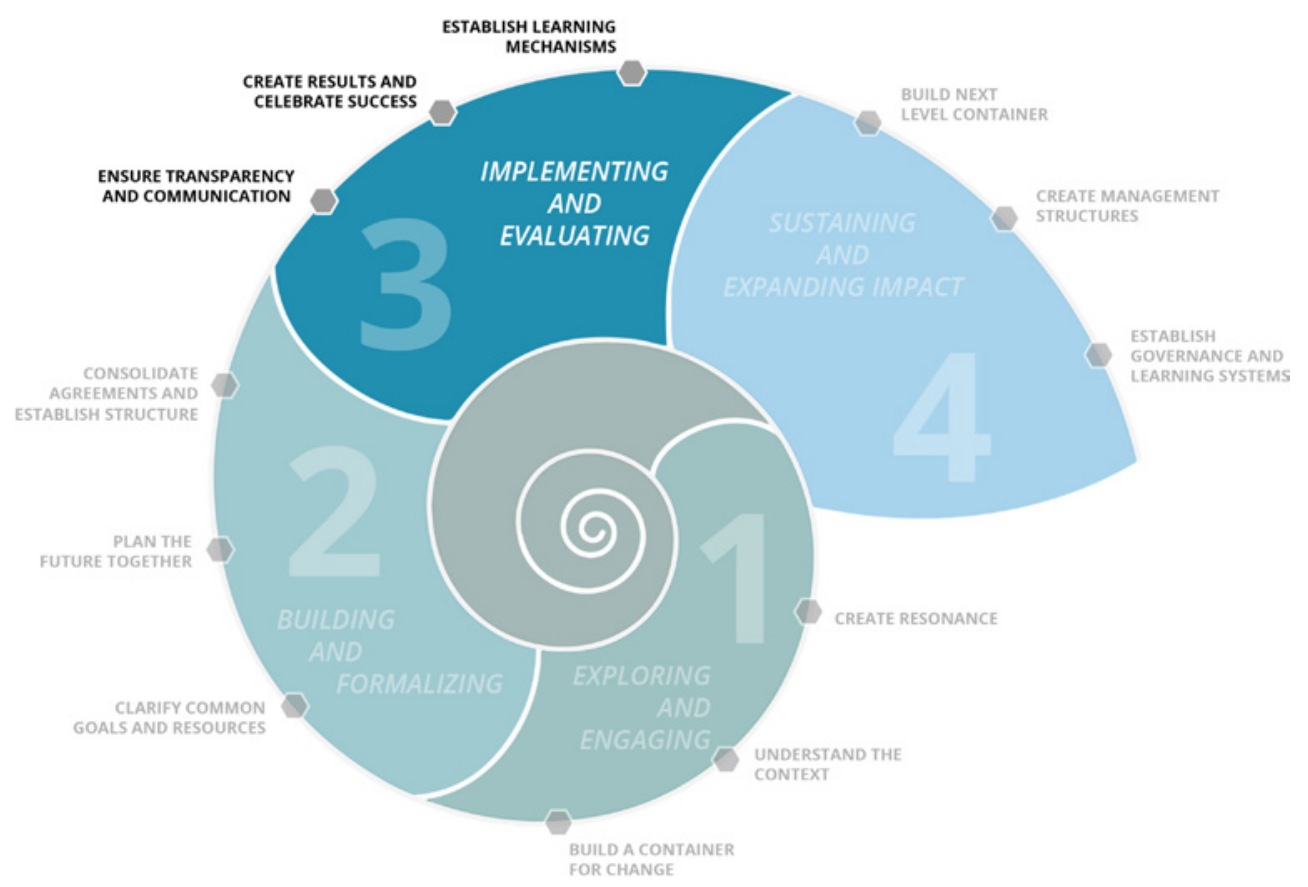

Figure 2.4 The three steps of Phase 3

\section{Step 7: ensure transparency and communication}

Once the implementation of the collaboration initiative begins in Phase 3, continuous communication of progress is of utmost importance, making the process as transparent as possible for all stakeholders. In order to maintain trust and commitment to cooperative delivery continuous relationship management and attention to goal clarity are also important. This can take the form of a newsletter, regular meeting reports, or progress updates to all stakeholders. Observing agreed upon communication policies helps to keep or rebuild trust. Collaboration ecosystems are fragile: transparency and reliability of process are essential for maintaining trust and engagement. Not only the communication to stakeholders, but also the exchange between stakeholders needs to be fostered through regular meetings and reviews. Project secretariats or core groups can make use of project management tools, operational planning, and review workshop formats familiar to most institutions. Transparent process architectures show the flow of review workshops, learning and innovation events, expert meetings, and task forces. The frequency of such meetings depends on the situation, the format of multi-stakeholder collaborations, and the geographical location of stakeholders. Stakeholders do not always need to meet in person; exchange can also be done virtually. However, virtual connections work better when face-to-face meetings have taken place beforehand and connections between people have been created.

In complex multi-stakeholder initiatives, there is often high pressure on project secretariats to make sure the collaboration ecosystem can deliver. The project secretariats 


\section{Box 2.8 Ways of ensuring transparency and communication}

- Make use of project management tools, operational planning, and workshop protocols familiar to most institutions.

- Organize regular review meetings that keep stakeholders engaged and ensure reliable process architectures.

- Plan the process architectures for maintaining engagement and delivering results carefully, including a series of workshops, events, expert meetings, task forces, etc.

- Strengthen the container (core group) and ensure they meet regularly to support the process architecture.

- Ensure sufficient resources for a supportive project secretariat responsible for communication.

coordinate activities, organize meetings, and ensure communication. Moreover, they need to prepare strategy adjustments, stay in contact with different stakeholders, and prepare the decision-making of stewarding councils. These tasks are eased if there is a core group across stakeholders (the container) that continues to represent stakeholder groups and acts as a sounding board. In Phase 3, questions of inclusion and involvement of additional stakeholders often arise. This requires agreements on mechanisms of stakeholder inclusion.

These are the guiding questions for ensuring transparency and communication:

- How do we keep stakeholders regularly informed?

- Which aspects of the implementation need to be reliably transparent?

- What are indicators of good communication?

- How can we ensure continuity of trust?

- What additional support do we need to implement an initiative successfully?

- What measures of progress can help to engender trust and strengthen working relationships?

- Are additional capacity-building measures required?

- Are guidelines for internal/external communication followed?

Stakeholders need to feel they are really part of a group of people that can make a difference together. Box 2.8 summarizes ways of ensuring transparency and communication.

\section{Step 8: create results and celebrate success}

During Phase 3, it is essential to help stakeholders experience progress and achievements of the collaboration initiative. 'Prototypes' - examples of future results - must be created early and they must be visible to stakeholders and non-participating actors alike. It often makes sense to initially focus on such easy-to-reach results. But this does not necessarily mean that one should lose sight of larger, more important goals. Stakeholders stay engaged when they can readily relate to joint successes, and can 


\section{Box 2.9 Ways of creating results and celebrating success}

- Focus on easy to reach results.

- Highlight progress and achievements.

- Create prototypes - examples of future broader results - and make them visible to stakeholders within and outside the collaboration ecosystem.

- Keep the connection to the long-term goal strong.

- Organize public events and media attention.

- Invite stakeholders beyond the collaboration ecosystem to spread the ideas.

- Get high level actors and supporters to speak at events.

- Give beneficiaries a voice in reporting progress.

- Maintain the cohesion of the container (core group).

- Link up with similar or complementary initiatives.

- Keep the agreements on external communication intact.

- Avoid confusing or misleading communication.

thus overcome difficult situations together. Success should be celebrated jointly, and, where possible or appropriate, with effective publicity. At this stage, media attention might be helpful and appropriate. The more stakeholders will spread an initiative's philosophy and achievements, the more likely it will be to receive continued support for the implementation phase, as well as for a Phase 4 for sustaining impact. It is important for stakeholders to agree formally on the form of communication to be used, for example. with media, to avoid recurring mistrust and conflict within or between stakeholder groups. No confusing or misleading results should be communicated.

These are the guiding questions for creating results and celebrating success:

- In which areas can we achieve quick results more easily?

- Which prototypes of the envisaged change can we create together?

- How can we best showcase successes to participating stakeholders and the public?

- How can we learn from positive results?

- Which wider audience do we need to keep informed about progress?

People thrive on achievements and are proud, if they know they have contributed. Box 2.9 summarizes ways to create results and celebrate success.

\section{Step 9: establish learning mechanisms}

Similar to other change projects and initiatives, multi-stakeholder collaboration requires establishing some form of learning mechanisms. While the container (core group) should have established a culture of learning right from the start in Phase 1, it is important to establish learning and innovation mechanisms in Phase 3 that include all stakeholders. This can refer to monitoring and evaluation procedures, but needs to go further. What is needed is a culture of mutual learning and creative exchange about 
innovative approaches and workable solutions. This is the time to introduce process monitoring as a learning mechanism to all key stakeholders and let as many stakeholders as possible participate in maintaining the quality of the collaboration pattern.

Nonetheless, it is equally important that all stakeholders understand and comprehend the learning mechanisms chosen. For example, different stakeholder groups often have different understandings of monitoring and evaluation. Private sector actors tend to focus on figures that can be displayed in a dashboard, public sector and civil society actors may require not only quantitative, but also qualitative monitoring results. It is therefore recommended to invest time in agreeing on how results are to be tracked, how general stakeholder satisfaction (with results and with the stakeholder process) is measured, and how stakeholders can collectively learn to improve the impact of the collaboration process. This will help to avoid stakeholders from getting the impression that the process is controlled from the outside. Process-monitoring instruments that focus on self-assessments and collective reflection are particularly appropriate for ensuring the quality of the collaboration pattern. Chapter 4 will therefore take a deep dive into how to establish process monitoring in multi-stakeholder collaborations.

These are the guiding questions for establishing learning mechanisms:

- How can we determine if we are on the right path?

- How can we integrate stakeholder feedback?

- How can we ensure that stakeholders feel their input is taken seriously?

- How can we ensure that we collectively learn from experiences?

- What is the internal monitoring and evaluation system?

- How can progress best be measured?

Mutual learning happens when stakeholders feel comfortable with each other and open up to true exchange on progress. Box 2.10 summarizes ways to establish learning mechanisms.

\section{Box 2.10 Ways of establishing learning mechanisms}

- Establish a culture of collective learning in regular learning and innovation events.

- Introduce monitoring systems: keep activity and result monitoring on track.

- Establish a self-assessment approach to process monitoring that involves relevant stakeholders.

- Find ways of obtaining views, feedback and ideas from stakeholders external to the collaboration system.

- Agree on procedures for evaluation with stakeholders. Only if agreed upon, bring in external evaluations.

- Involve high level actors occasionally in learning and innovation events.

- Create learning exchanges between beneficiaries.

- Enrich learning and innovation by inviting other initiatives and organizing exposure trips. 


\section{Phase 4: sustaining and expanding impact}

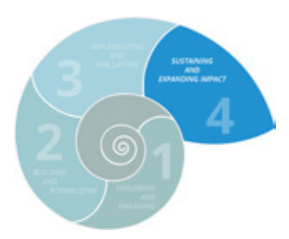

Phase 4 is about taking the collaboration initiative to the next level, expanding or replicating its activities, and creating longlasting structures for the envisaged change. Once a collaboration initiative has reached the agreed-upon results, the question remains whether it should dissolve, or if it should be further developed. If the desired goal has been achieved, success should be adequately celebrated: participation and contributions of individual stakeholder groups should be acknowledged and appreciated. However, some collaboration initiatives may want to consolidate their outcomes into sustainable structures. This can mean taking the endeavor to the next level, replicating it at another location, or integrating a new issue. Sustaining and expanding impact can take many forms, such as broadening the participation of stakeholders and forming a change-maker community or continuing the activities, but collaborating with other multi-stakeholder initiatives. It can also mean institutionalizing the collaboration, hence creating a legal structure that reflects the overall vision and ensures the representation of different stakeholder groups.

An important factor in the transition from a collaboration initiative to a more institutionalized structure is that the future setup stays faithful to the key features of the initiative and does not lose sight of the crucial role of people and process. It needs to ensure that the major aspects of the multi-stakeholder collaboration - transparency, stakeholder representation, dialogue, ownership, consensus-building, and outcome orientation - are also reflected in the institutionalization. Although the new structure will have its own dynamic and build a new identity around itself, its origins need to be recognizable, whether this is reflected in the governance structure, the openness towards continued dialogue and learning, or the willingness to integrate stakeholder perspectives. When a collaboration initiative wants to expand its impact, new stakeholders need to be integrated into the process. This is about creating the nextlevel container by inviting and integrating new participants. Previously uninvolved actors must quickly understand the urgency and importance of the initiative and be able to emotionally connect with the larger goal. Therefore, it is recommended that the original core group remains actively involved in Phase 4 of a multi-stakeholder collaboration initiative, progressively handing over their function to new actors and transferring the process step by step into its future structure.

The process from a more loosely structured initiative to an institution is not necessarily easy. This is why it helps actors to revisit some of the engagement strategies learned in Phase 1 and re-apply them appropriately. This includes evaluating context-specific factors and new trends and developments. The major challenge in Phase 4 is keeping the spirit of change alive. Replication or institutionalization often requires a professional management structure and more formal governance structures with an election process reflecting stakeholder representation. Role allocation may change and decision-making structures must become more efficient. Management and governance structures require additional legitimacy and credibility. Phase 4 can continue for a long time and may develop into a meta-collaboration with other initiatives. 
Tangible results of a high-quality Phase 4 that has enlivened all dimensions of the Collective Leadership Compass are the following:

- New stakeholders identify with purpose and goal of the initiative.

- An adjusted core group (a new container) matches the expanded ambition of the initiative.

- There is continuous high-level support.

- Management structures are functioning well.

- Credible governance systems adequately represent the stakeholder system.

- Stakeholders can learn together.

- Increased impact can be evaluated.

As Phase 4 most often means creating long-term structures for transformative change, the collaboration ecosystem will gradually merge into organizational structures that need to keep the quality of collaboration, but under new conditions. Structures always develop their own dynamics. Keeping the Collective Leadership Compass in focus while developing long-lasting structures helps to ensure that management and governance structures are effective.

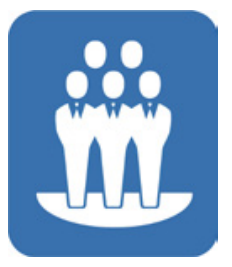

- The dimension of engagement requires a lot of attention in Phase 4, as new actors need to be integrated into the process and develop ownership for purpose and procedures of the initiative.

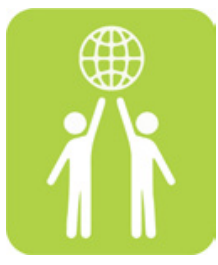

- At the same time, it is important to continuously connect with the larger goal that can be achieved by sustaining and expanding the impact. Attention to the dimension of wholeness, e.g. through continuous reminders of the potentials arising when taking the initiative to the next level, ensures that stakeholders do not lose sight of their contribution to a bigger story.

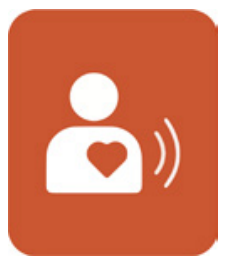

- This is important, because creating management structures or establishing a legal entity usually takes up considerable energy and time. Taking care of the dimension of humanity is therefore even more important. Relationship management needs to be constantly on the agenda in Phase 4.

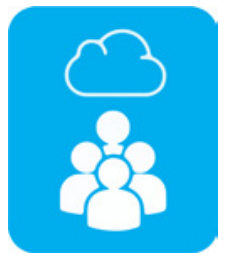

- The dimension of collective intelligence is in Phase 4 most prominently reflected in the way the culture of learning that has been cultivated in Phase 3 is carried forward into Phase 4 , e.g. in the continuation of learning and innovation meetings, in the way governance structures ensure dialogue, or in the way management structures reflect the diversity of stakeholders. 


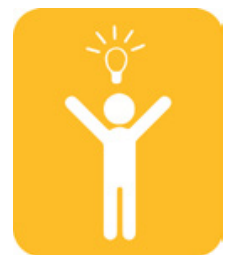

- The dimension of innovation is in Phase 4 reflected as the ability of key stakeholders to open up to new and creative approaches to expanding impact.

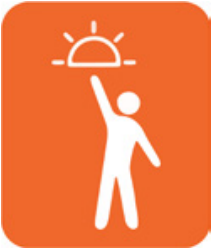

- $\quad$ Phase 4 is ultimately about bring more actors into co-shaping the future and empowering people to take part in the way this happens. The dimension of future possibilities is reflected in the way, these new stakeholders are invited to shape new goals and take a long-term outlook to the way impact will be co-created.

Phase 4 can last indefinitely. It runs smoothly when new stakeholders are integrated into a next level container, professional management structures take over running the affairs and the governance system not only formally represents the stakeholder groups, but also functions as a learning system. A successful Phase 4 requires three further steps: build the next-level container, create management structures and establish governance and learning structures. These three steps are depicted in Figure 2.5 and will be explored in more detail.

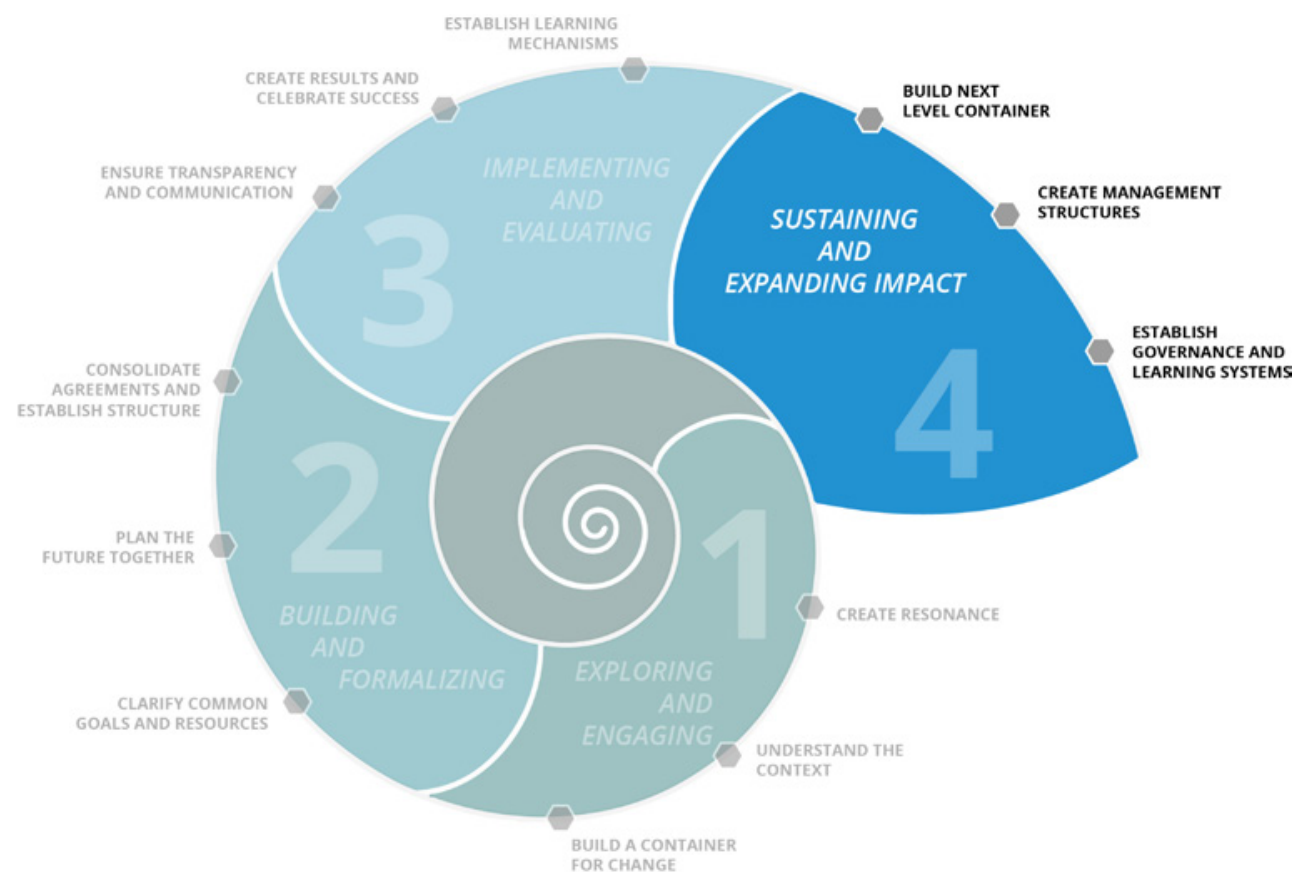

Figure 2.5 The three steps of Phase 4 


\section{Step 10: build the next-level container}

When the time comes for taking the multi-stakeholder collaboration to the next level of impact, institutionalizing or replicating its success, new challenges are bound to arise. It is not always possible for the core group or a project secretariat that successfully implemented the initiative to manage an initiative's long-term implementation as well. The container members may have done their best to take the initiative to this point; now other people need to take over and continue. New stakeholders need to get engaged. Or, in other cases where a politically consensual outcome has been achieved and publicly portrayed as thus, interest in a particular topic may fade away. This may result from, for example, a lack of know-how or a lack of resources. This is why main actors in collaboration initiative who see the need to continue the joint activities in a different form need to communicate the prospects of such new tasks in a timely manner to all participating actors. This needs to begin in Phase 3. If new stakeholders need to be engaged, it is helpful when the original core group, or the project secretariat can accompany this process. They can lobby for new supporters and participants, spread ideas, and promote change. It is important to establish a new network of interested and dedicated parties, to create a feeling of trust, and to design the new process architecture accordingly. Taking multi-stakeholder collaboration to the next level requires building a new, next-level container of dedicated people. To do this, it may be necessary to repeat some of the steps of Phases 1, 2, and 3 .

These are the guiding questions for building the next-level container:

- Can we replicate the process at another location or for another issue?

- Do we have a joint vision and the strategy in place for an expanded impact for the next level impact?

- Which cooperation partners do we need for the next level impact, or the formalization or institutionalization of the collaboration initiative?

- Which new stakeholders need to be integrated to increase the impact?

- Which alliances need to be maintained or expanded?

- What strategies worked in the past and could be used for sustaining or expanding impact?

- How can we help currently involved stakeholders to become messengers for the further development?

- How can ownership, trust, and commitment be sustained?

- How do we need to develop the governance structures further?

Engaging new people for the next level impact is of crucial importance. Box 2.11 summarizes ways to building the next-level container.

\section{Box 2.11 Ways of building the next-level container}

- Ensure that main actors in the collaboration initiative agree on strategies to take the initiative to the next level of impact. 
- Create opportunities for participating stakeholders to communicate the prospects of these strategies.

- Utilize the governance structures of the collaboration initiative to design Phase 4.

- Integrate new stakeholders into the container.

- Establish a broader network of dedicated and interested stakeholders.

- Design a process architecture for the engagement of new stakeholders following principles from Phase 1.

- Create events or meeting opportunities to engage new stakeholders.

- Design a process architecture for wider engagement in a transparent and reliable way

\section{Step 11: create management structures}

Sustaining impact requires new and more formalized management. The collaboration ecosystem now needs a larger 'home', an institutionalized management and implementation structure, and, possibly, additional funding. It may need to be converted into an organizational structure. In that case, it will assume an institutionalized identity, be it in the form of a new legal entity or through the integration into existing legal entities. Hence, management structures need to be put in place. Some aspects from Phases 1 and 2 may need to be reinitiated at this point, such as further context analysis and the adjustment of goals and agreements, as well as resource allocation. In some cases, the sustainability of results requires creating an institution with a stakeholder-governed body. Travelling this rough road can be difficult, but inevitable for long-term impact. It can be made easier if there is a sufficient degree of continuity in the composition of the main supportive stakeholders, the core group, or a project secretariat.

These are the guiding questions for creating management structures:

- What form of structure does the next level of impact require?

- Do we need to create an institution or a legal body, or can we integrate the form of dialogue and collaboration into existing institutional procedures?

- What is the management structure that can sustain outcomes?

- How can we ensure the sustainability of results?

- What is an appropriate process architecture for continuation?

- Have we sufficiently attended to people in the creation of new structures?

Entering into a more organizational approach and introducing management structures needs to be built on collaborative principles. Box 2.12 summarizes ways of creating management structures. 


\section{Box 2.12 Ways of creating management structures}

- As the purpose of the collaboration initiative is expanding, repeat elements of Phase 1, such as a renewed context analysis for expanding impact.

- Clarify the legal embeddedness and establish respective entities or integrate the initiative into existing legal entities.

- Create professional management structures that are able to lead towards the next level of impact.

- Ensure the principles of stakeholder collaboration are reflected in adapted governance structures.

- Revisit agreements between stakeholders as well as commitments and contributions.

- Secure funding for a next level impact.

- Ensure an adequate level of continuity of people in the new established management structure.

- Appreciate the core group's work, keep them engaged, and support them to accept the transition towards more formalized management structures.

- Ensure that stakeholders are consulted for strategy development by the new management structure.

\section{Step 12: establish governance and learning systems}

Taking a collaboration initiative to the next level of impact poses new challenges. With sustaining and expanding the impact, new challenges arise. Stakeholders' or supporters' expectations may rise. The public, or actors who had not been directly involved, may question whether the initiative is delivering. Political supporters might demand stronger proof of results, which could make external evaluation necessary. The visibility of the collaboration initiative continues to increase, and with it the possibility for criticism. This means that visions need to be revived and renewed. The complementary contribution and the purpose of the now much more formalized organizational structures need to be revisited. It is therefore important to stay faithful to the original intent of bringing forward transformative change in collaboration with multiple stakeholders. This will require more representative stewarding and governance structures and, above all, deliberately created mechanisms for learning together how to expand and sustain the impact. One of the biggest challenges in Phase 4 is the constant renewal of an initiative's spirit of change. It may be helpful at this point to recall the approach of Phase 1 as well as to adapt the processes for building confidence, trust, and willingness for change.

These are the guiding questions for establishing governance and learning structures:

- What are the learning structures that the continuation of the collaboration initiative requires? 
- What governance structure does a next level collaborative impact require?

- What expertise is required for expanding the collaboration initiative?

- How can we integrate further capacity-development measures?

- How can we measure the progress of success?

- Have we reevaluated/adapted our strategies for Phase 4?

- Have we evaluated the lessons learned from Phase 3 and integrated them into the next planning?

- Which other initiative should we more formally collaborate with to increase impact?

The original purpose and intent of the collaboration needs to be reflected in more formal governance structures. Box 2.13 summarizes ways to establish governance and learning structures.

\section{Box 2.13 Ways of establishing governance and learning structures}

- Keep the intent of stakeholder collaboration intact and build representative governance structures with formal election procedures.

- Ensure formalized and transparent decision-making processes. Re-establish more formalized steering committees or create an executive board.

- Institutionalize learning and innovation events that include a wide range of stakeholders and provide opportunities for collective active reflection.

- Prepare for stakeholders and supporters that expect increased results and impact.

- Prepare for public criticism or critique from not yet involved stakeholders and engage them into conversations.

- Keep the result focus and revive opportunities for creativity and collective action among stakeholders.

- Keep the long-term vision high on the agenda.

- Establish meta-collaboration with other initiatives for increased impact.

\section{Readiness check for all four phases}

Navigating the complexity of collaboration initiatives is greatly supported by understanding in which phase the change endeavor can be located and by looking at how well the phases have been completed. The following readiness checklist helps stakeholders to not only make the requirements for collaborative and transformative change transparent, but also guide actors in making sure all steps in the Dialogic Change Model are sufficiently completed. 
PHASE 1: EXPLORING AND ENGAGING

$\begin{aligned} & \text { Step 1: create resonance } \\ & \text { Have we identified relevant key stakeholders, do } \\ & \text { we know their perspectives and have we created } \\ & \text { bonds between them? }\end{aligned}$
$\begin{aligned} & \text { transformed future across to potentially } \\ & \text { relevant actors through formal and informal } \\ & \text { conversations? }\end{aligned}$
Have we been able to convince high-level or
influential actors of the urgency of the initiative
and gained their support?

Have we identified relevant key stakeholders, do we know their perspectives and have we created bonds between them? and gained their support?

\section{Step 2: understand the context}

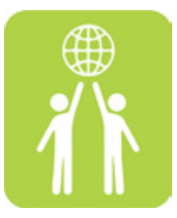

2.1 Have we explored the context of our collaboration initiative and know other activities well enough?

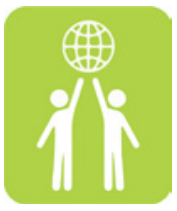

2.2 Are we aware of positive or negative factors/ structures/trends that influence the transformative change endeavor, or why change has not occurred earlier?

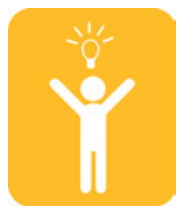

2.3 Have we researched best practices or results from similar initiatives that we can adopt or learn from?

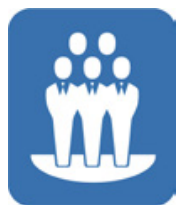

2.4 Have we conducted a Stakeholder Analysis and assessed what needs to be done for to engage both influential and interested stakeholders? 
PHASE 1: EXPLORING AND ENGAGING

Step 2: understand the context

YES

NO

2.5 Have we assessed the resources required to organize the transformative change architecture?

2.6 Have we explored potential conflict situations that might arise?

\section{Step 3: build a container for change}

3.1 Have we built a strong core group (container) composed of key stakeholders, and does it have a sufficient mandate?

3.2 Does the core group (container) meet regularly and jointly plans the roadmap and next steps?

3.3 Have we successfully completed a first small meeting of key stakeholders with jointly agreed results?

3.4 Does the core group have a good overview of the stakeholder system and the ability to engage key stakeholders into a broader container?

3.5 Have we ensured that the core group and important actors are knowledgeable about content issues as well transformative change methodologies? Dialogue? 
PHASE 2: BUILDING AND FORMALIZING

\section{Step 4: clarify goals and resources}

YES NO

4.1 Have we done the best possible engagement process for a first key stakeholder event and does the composition represent the stakeholder system?

4.2 Have we jointly analyzed the current situation together with all key stakeholders and sufficiently considered the different viewpoints?

4.3 Do all key stakeholders share the future vision and have a common understanding of the goals?
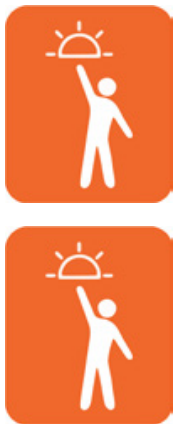

4.4 Have the resources the various actors can contribute been explored/agreed upon?

\section{Step 5: plan future together}

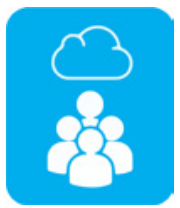

5.1 Have we created a setting for the stakeholder meeting (context, program, space) that enhances commitment and ownership?

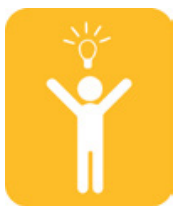

5.2 Have we provided the participating stakeholders with all necessary information and expertise required for shaping the initiative?

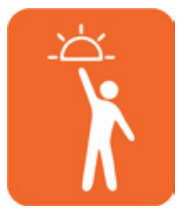

5.3 Have we maintained sufficient high-level support resulting in tangible commitments? 
PHASE 2: BUILDING AND FORMALIZING

Step 5: plan future together

YES NO

5.4 Have we developed a realistic implementation plan with milestones, and scheduled follow-up meetings?

5.5 Have we agreed how to connect with similar initiatives?

Step 6: consolidate agreements and establish structures

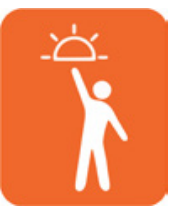

Have we consolidated the results in an appropriate form of agree-

ment for collaboration?

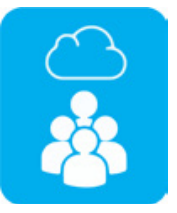

Have we set-up a structure for joint decision-making and process steering?

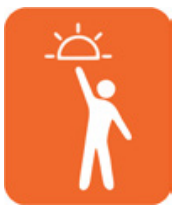

Have we agreed on roles and responsibilities for further implementation?

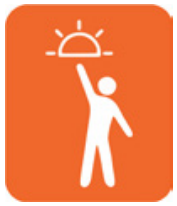

Have we transparently documented results, agreements, and planning?

Table 2.4 Readiness check Phase 3

PHASE 3: IMPLEMENTING AND EVALUATING

\section{Step 7: ensure transparency and communication}

YES NO

7.1 Are we holding regular meetings with key stakeholders that foster relationships and trust building further? 
PHASE 3: IMPLEMENTING AND EVALUATING

\section{Step 7: ensure transparency and communication}

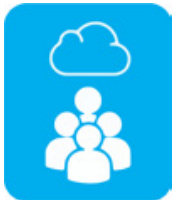

7.2 Have we established a conducive information flow between key stakeholders and agreed on internal and external rules of communication?

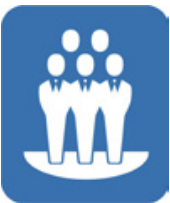

7.3 Have we included additional relevant stakeholders, if required?

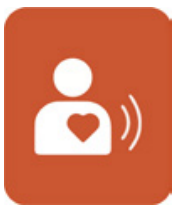

7.4 Is the core group functioning as a good container supporting the constant, active participation of the stakeholders?

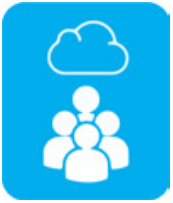

7.5 Are we leaving enough freedom for providing feedback from stakeholders and integrating it into the process constructively?

\section{Step 8: create results and celebrate success}

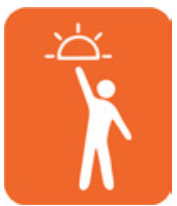

8.1 Is the implementation plan in place and are we keeping up with it?

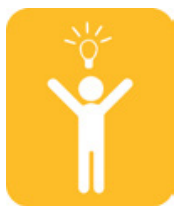

8.2 Do we prototype future ways of operating regarding the issue of our initiative?

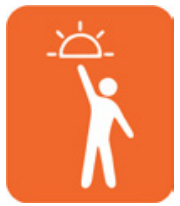

8.3 Do we regularly identify areas in which success stories are more likely and are we picking the "low-hanging fruit" sufficiently?

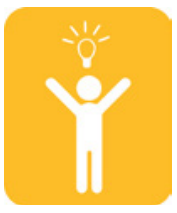

8.4 Can we show success to the public, and have we found the appropriate way of celebrating success together? 
PHASE 3: IMPLEMENTING AND EVALUATING

Step 8: create results and celebrate success

YES NO

8.5 Have we sufficiently involved high-level sponsorship into the celebration of success?

\section{Step 9: establish learning mechanisms}

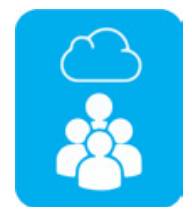

9.1 Do we have a system in place to monitor progress and the quality of the collaboration pattern?

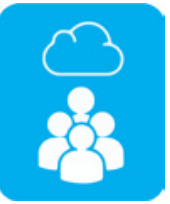

9.2 Do we hold regular implementation review meetings with all stakeholders that ensure learning, exchange, and innovation?

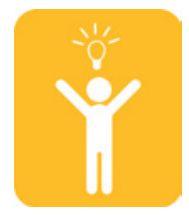

9.3 Do we implement capacity-building for the future way of operating?

9.4 Does an internal system for strategic learning exist that all key stakeholders are part of?

Table 2.5 Readiness check Phase 4

PHASE 4: DEVELOPING FURTHER, REPLICATING, OR

INSTITUTIONALIZING

Step 10: build the next-level container

YES NO

10.1 Have we created a strong and emotionally engaged new container core group?

10.2 Have we thoroughly assessed the scaling-up and replication potential with the new core group? 
PHASE 4: DEVELOPING FURTHER, REPLICATING, OR

INSTITUTIONALIZING

Step 10: build the next-level container

YES NO

10.3 Have we sufficiently integrated new stakeholders for collaboration?

10.4 Have current strategies and procedures been reviewed and, if needed, adapted for the next implementation phase?

10.5 Have we identified alliances with other initiatives required for the initiative's advancement?

\section{Step 11: create management structures}

11.1 Has the context for expanding impact been sufficiently explored to plan the next steps?

11.2 Have we evaluated the management requirements for sustaining or expanding impact?

11.3 Have we identified the appropriate management structure for scaling-up and expanding impact?

(Continued) 
PHASE 4: DEVELOPING FURTHER, REPLICATING, OR

INSTITUTIONALIZING

Step 12: establish governance and learning systems

YES NO

12.1 Do we keep up relationship management and trust building?

12.2 Have we designed stakeholder representative governance structure that ensures ownership?

12.3 Have financial support and capacity-building needs for scaling up been identified?

12.4 Have we designed a system for learning and evaluation that includes all key stakeholders?

\section{Examples from the field: leading transformative change}

The following three case examples illustrate how multi-stakeholder collaborations can be planned and successfully implemented using not only the Compass as a navigating tool for high quality collaboration, but also the Dialogic Change Model as a structured process methodology.

\section{CASE EXAMPLE 2.1: AN INTERNATIONAL EXAMPLE: THE GLOBAL COFFEE PLATFORM ${ }^{1}$}

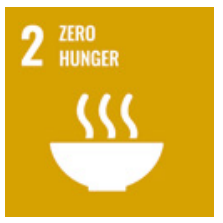

The Global Coffee Platform was inaugurated in October 2016 as an inclusive multi-stakeholder platform with the objective of creating improved coherence among the sustainability activities of many diverse stakeholders in the green coffee value chain. It aims to achieve a thriving and sustainable global coffee sector. ${ }^{2}$ The platform takes a bottom-up approach to addressing critical sustainability challenges in collaboration between farmers, civil society organizations, 
governments, and corporations. The focus is on a combination of securing a sustainable coffee supply while improving the livelihoods of coffee farming communities around the world and keeping the natural environment intact. It is an interesting example of how complex global challenges can be addressed in a mix between local action and global reach. The platform is a merger between the Sustainable Coffee Program, founded in 2011, and the Common Code for the Coffee Association (4C) Association, founded in 2007. By the end of 2007, all major coffee roasting brands had joined the association and key international NGOs, as well as coffee producers from more than 10 countries, took part. Membership grew to 300 in 2014 with members from 21 countries representing 360,000 coffee producers. What inspired stakeholders to kick-off a small multi-stakeholder partnership in 2002 between the German Development Cooperation and the German private sector coffee association were unsustainable trends in the global coffee market. The coffee sector was characterized by great asymmetries in the redistribution of returns between producing and buying countries. These limited economic returns led to unsustainable environmental and social effects for producers (Kaplinsky, 2000) and disadvantaged small-scale coffee producers. The following section illustrates the process that resulted in successful multi-stakeholder collaboration and shows how the Collective Leadership Compass inspired transformative process designs.

\section{Phase 1: exploring and engaging - preparing the global coffee community for collaboration ${ }^{3}$}

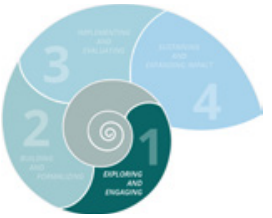

The first phase of what was in the year 2002 called the Common Code for the Coffee $(4 \mathrm{C})$ initiative served to prepare the ground for people to collaborate who had not been used to working together: critical NGOs, large coffee roasters, producer marketing cooperatives, and sustainability standard activists, among others. A small core group composed of a mixed team from development cooperation and a private sector association placed emphasis on exploring the context, testing resonance for change with key actors at international coffee conferences. A detailed context and actor analysis (including conflict mapping) led to the decision who would be engaged in the initiative. Consultations with key stakeholders helped identify major issues and established a clearer understanding of the challenges in the coffee value chain. Phase 1 comprised a sequence of consultative dialogues with private, public, and civil society actors. In addition, the initiative analyzed important insights from the challenging learning experiences of other voluntary standard setting initiatives in the commodity sector, particularly regarding ownership, inclusion of stakeholders, and mainstream applicability. This laid the ground for a later decision to explore a bottom-up approach with a focus on continuous improvement and capacity building for farmers. The main purpose of Phase 1 was to create ownership of both process and content for as many stakeholders as possible. The idea to develop a mainstream standard for sustainable coffee 
production matured, received critique, was further refined, and developed a healthy level of resilience. As a result, a network of interested people emerged even prior to the official launching of the initiative in Phase 2. The initiative extracted important insights from the challenging learning experiences of other voluntary standard setting initiatives in the commodity sector, particularly regarding ownership, inclusion of stakeholders, and mainstream applicability. This shaped the community approach and structured the process designs. Table 2.6 exemplifies how activity plans in Phase 1 received inspiration from the dimensions of the Collective Leadership Compass.

Table 2.6 The ${ }_{4}$ C initiative's high-quality collaboration in Phase 1

\begin{tabular}{ll}
\hline Compass dimension & Focus aspects \\
\hline Humanity & $\begin{array}{l}\text { Empathy: } \\
\text { - Building relationship } \\
\text { between diverse and contro- } \\
\text { versial key stakeholders. }\end{array}$ \\
\end{tabular}

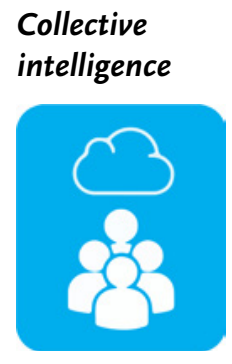

Engagement

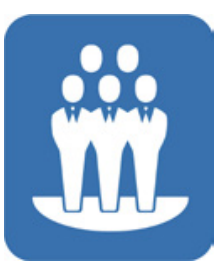

Future

possibilities

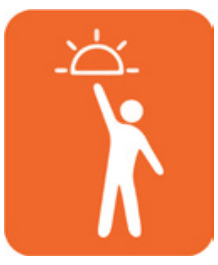

Dialogic quality:

- Building resonance for the purpose of the initiative through informal conversations

\section{Process quality:}

- Building a core group of visionary actors and designing of step-by-step engagement of more stakeholders. Establishing backbone support.

\section{Future orientation:}

- Exploring possibilities and variations of what a mainstream coffee standard could achieve and the requirements to jointly develop it.
Activities

- Explorative conversations with key stakeholders helped the initiators understand concerns, interests and constraints of key stakeholders;

- Dialogue meetings were designed in a way that stakeholders enabling them to understand each other's concerns.

- Initiators engendered bilateral and small group meetings during coffee related-conferences that stakeholders attended anyway.

- Informal, yet inspiring conversations centered on the purpose of the initiative.

- Initiators convened a small group of engaged and future-oriented key stakeholders to form the core group of the initiative.

- This group engaged more stakeholders.

- An initial small project secretariat was established.

- Development and iterations of future scenarios by core group and broader container of engaged key stakeholders. 


\begin{tabular}{|c|c|c|}
\hline Compass dimension & Focus aspects & Activities \\
\hline Innovation & \multirow{2}{*}{$\begin{array}{l}\text { Agility: } \\
\text { - Being flexible in the process } \\
\text { design and utilizing emerg- } \\
\text { ing opportunities. }\end{array}$} & \multirow{2}{*}{$\begin{array}{l}\text { - Core group and key stakeholders } \\
\text { developed a purpose-driven, short- } \\
\text { term, "not too fixed" initial project } \\
\text { strategy. } \\
\text { - The strategy was stress-tested in } \\
\text { informal conversations at coffee- } \\
\text { related conferences. }\end{array}$} \\
\hline & & \\
\hline \multirow[t]{3}{*}{ Wholeness } & \multirow{2}{*}{$\begin{array}{l}\text { Contextuality: } \\
\text { - Researching existing niche } \\
\text { market standards and } \\
\text { their feature in relation to } \\
\text { the proposed mainstream } \\
\text { standard. }\end{array}$} & \multirow{2}{*}{$\begin{array}{l}\text { The core group tasked the project } \\
\text { secretariat to analyze formats and } \\
\text { effectiveness of existing niche mar- } \\
\text { ket standards. Joint discussion of } \\
\text { insights. } \\
\text { - Detailed context and actor analysis } \\
\text { (including conflict mapping) took } \\
\text { place. }\end{array}$} \\
\hline & & \\
\hline & $\begin{array}{l}\text { Contribution: } \\
\text { - Keeping the potential } \\
\text { visionary impact of the } \\
\text { initiative of an entire value } \\
\text { chain towards sustainability } \\
\text { high on the agenda, even } \\
\text { if no roadmap towards the } \\
\text { goal could be designed at } \\
\text { this stage. }\end{array}$ & $\begin{array}{l}\text { The core group strengthened the } \\
\text { emotional engagement of key } \\
\text { stakeholders by regularly referring } \\
\text { to the potential larger impact of the } \\
\text { initiative in informal conversations. }\end{array}$ \\
\hline
\end{tabular}

Source: Kuenkel, 2019

\section{Phase 2: building and formalizing - establishing the 4C initiative as a collaboration ecosystem}

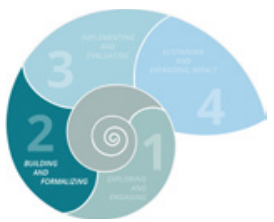

The second phase of the ${ }_{4} \mathrm{C}$ initiative was devoted to reshaping the goal, clarifying resources, creating a structure for the initiative, and agreeing on a plan of action. Because of the thoroughness done in Phase 1, most stakeholders already were an integral part of the initiative at the time of the launch. Goal development and planning meetings acknowledged tensions and stakeholder differences, but emphasized consensus-building as well. The result was an agreed-upon implementation plan, a budget plan for future financial contributions by the industry, and an allocation of roles between the stakeholders. Expert working groups started to focus on the technical aspects of the standard development. Table 2.7 exemplifies how activity plans in Phase 2 received inspiration from the dimensions of the Collective Leadership Compass. 
Table 2.7 The ${ }_{4}$ C initiative's high-quality collaboration in Phase 2

Process quality:
- Developing and jointly
agreeing on a roadmap for
implementation. $\quad \begin{aligned} & \text { Connectivity: } \\ & \text { Creating structures (agreement, } \\ & \text { organizational set-up, and work- } \\ & \text { ing groups) sufficient enough } \\ & \text { to ensure the cohesiveness of } \\ & \text { the collaborating stakeholders. } \\ & \text { Collective action: } \\ & \text { - Ensuring that all meetings } \\ & \text { are focused on jointly agreed } \\ & \text { results. }\end{aligned}$

Activities

- The project secretariat and core group convened a larger group of engaged and critical key stakeholders to diagnose current challenges and agree on the first 1-year roadmap.

- The project secretariat set up collaboration structures such as participation procedures and issue-related working groups.

- The project secretariat provided a transparent implementation plan

- Results from working groups were evaluated together with key stakeholders.

- The roadmap was agreed to as a result of a sequence of stakeholder meetings.

- All stakeholder had contributed to the roadmap

- The project secretariat ensured facilitation of structured dialogue that brought all different perspectives to bear.

- The project secretariat planned informal events around stakeholder meetings that helped actors meet as people.

- The core group helped stakeholders to understand different world-views or constraints through e.g. field visits to target groups, or companies.

\section{Future possibilities \\ Future orientation: \\ - Envisioning a different future of the coffee value chain together with all stakeholders.}

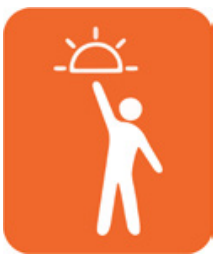

\section{Empowerment:}

- Creating a steering committee composed of all stakeholder groups that functioned as decision-making organ for the implementation process.
- A second iteration of future scenarios for the implementing of a mainstream coffee standard together with all relevant key stakeholders took place.

- The project secretariat organized a structured procedure to establish a representative steering committee for the initiative. 


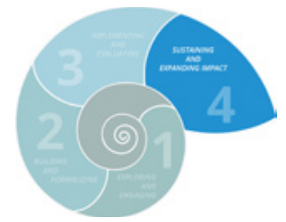

The fourth phase started when stakeholders unanimously agreed to establish a non-profit organization to provide the future formal structure for the initiative. This global membership organization - the $4 \mathrm{C}$ Association - was dedicated to implementing sustainability in the coffee sector. It invited members from the entire coffee value chain, ranging from small coffee farmers to large roasting companies, as well as to all other supporters. At the outset of the $4 \mathrm{C}$ initiative, no one would have thought about the possibility of creating such an organization. The idea developed through continuously reflective learning. The initiative began to focus more explicitly on measurable results, such as the amount of coffee traded that received the verification of the code of conduct. This attracted new members who gradually considered sustainable coffee to be more and more relevant to their business. A few years into the institutionalization, it became clear that the Association needed to look at how best to collaborate with other initiatives in the field of sustainable coffee. This eventually led in the year 2016 to the merger of the ${ }_{4} \mathrm{C}$ Association and another similar initiative, the Global Coffee Program, into what is today operating as the Clobal Coffee Platform (www.globalcoffeeplatform.org).

\section{CASE EXAMPLE 2.2: A NATIONAL EXAMPLE: FORESTRY MANAGEMENT IN LAOS ${ }^{4}$}
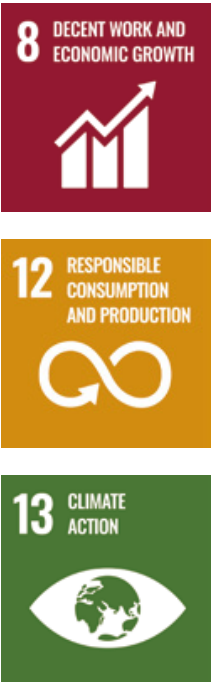

Since the turn of the century, communities, biodiversity, and the climate have been negatively impacted by the degradation and fragmentation of forests in Laos, which is second in forest density in Southeast Asia only to Myanmar. Due to weak governance, the forestry sector is opaque and corrupt, causing many communities to remain in poverty. Indeed, approximately 33 percent of Laos' GDP comes from agriculture and forestry, while providing 75 percent of the country's workforce with a livelihood (FAO, 2002). Such livelihoods, however, are not secure as the volume of exported illegal timber is at least five times that of legal timber. Unprocessed wood is sold predominantly to Thailand, Vietnam, and China, while processed wood products are then sold in places like Japan, the United States, and the European Union (EU). At the same time, global demand for wood and wood products that are sustainably grown, legally harvested, and traceable to their source is increasing.

In 2003, the EU launched its Forest Law Enforcement, Governance, and Trade (FLEGT) Action Plan, inviting major wood-producing, tropical countries, such as Laos, to enter into bilateral Voluntary Partnership Agreements (VPAs) to facilitate trade in verifiable, legally produced wood and wood products. Such bilateral agreements make the timber value chain more transparent and can help Laos to 
expand its access to international markets, while earned a higher price for its products. Transparency can help reduce illegal logging, channel revenues into state coffers and community pockets, and improve conditions for workers in wood processing factories. The VPA process requires that a timber legality definition be agreed in Laos through an inclusive and participatory multi-stakeholder dialogue process. Given the country's history, experience with participatory stakeholder processes is generally lacking, especially among government bodies, businesses, and nonprofit associations. A great deal of money flows through the forestry sector, making it politically sensitive. Power imbalances, e.g. between provincial governments and the central government or between nonprofit associations and the central government, are easy to recognize. In the business sector, there are just a handful of big forestry players that hold considerable influence, while most other businesses were SMEs. Most stakeholders recognized that building trust and cooperating to jointly deliver results in such politically sensitive and complex multi-stakeholder setting required competencies in dialogue and collaboration. While some roles were well known, e.g. those of the public sector and business associations, others were emerging or poorly defined, e.g. those of civil society, local communities, and unorganized parts of the private sector. Some actors wanted to be at the table but were not permitted to participate. Developing a shared understanding of the context, finding common ground, establishing communication channels, and agreeing to decision-making processes, was challenging in such a hierarchical context. What was needed was an overarching, multi-stakeholder engagement and capacity building process that could increase trust, commitment, and ownership for a VPA between the EU and Laos. The following shows how elements of a Phase 1 and a Phase 2 needed to be brought together in short period of time, creating the ground for a stable Phase 3 and Phase 4.

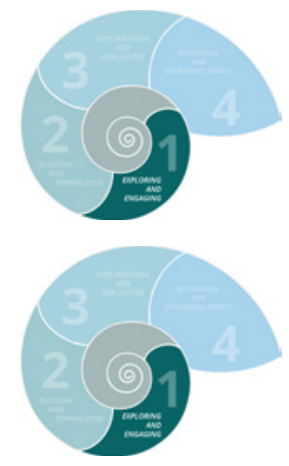

\section{Phase 1: exploring and engaging - co-creating a vision and building trust}

In 2014, the Government of Laos decided to bring a group of 24 representative Lao stakeholders together in what was initially conceived as a competence building in dialogue and collaboration $^{5}$, but included visioning as well as strategizing about next steps. The constellation of stakeholders involved, even if initially fragmented, represented an emerging Collaboration Ecosystem for sustainable forestry and trade in Laos. Participants came from the 3 leading ministries (Agriculture and Forestry, Commerce and Industry, and Natural Resources and Environment), as well as other key Ministries (Foreign Affairs, Labor, Finance, and Justice) and the National Assembly; business associations in the forestry sector; civil society organizations working on behalf of local communities and the environment; and academia. They designed engagement strategies and planned onward steps in the VPA process, while modeling the kind of collaboration that would be needed along the timber value chain for ensuring sustainable forestry and trade in their country. 


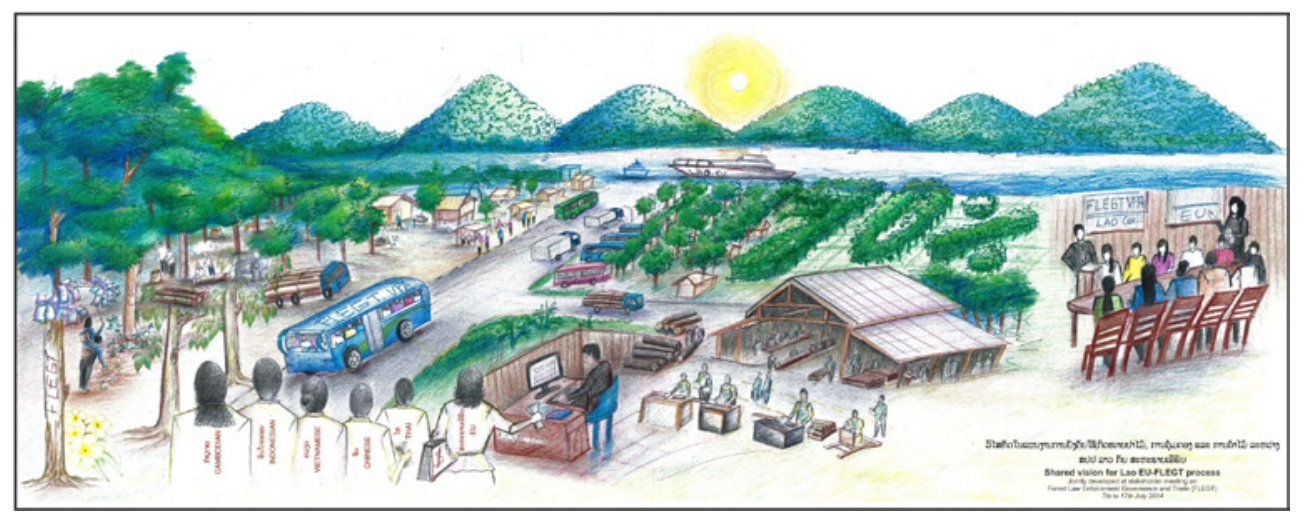

Figure 2.6 Shared vision for sustainable forestry and trade

In stakeholder systems lacking trust between actors, political will, and/or a clear case for collaboration, the first jointly created results can be decisive for getting and keeping actors on board for the collaboration journey. In this case, palpable resonance for change was generated through an inclusive, participatory, and creative visioning process that guided participants along a future, sustainable timber value chain. ${ }^{6}$ The final shared vision poster as shown in Figure 2.6 was adopted as guiding inspiration for the planning process to come.

Over the weekend, a joint excursion to visit a community-managed forest helped to build further trust among actors and stimulate new thinking on the role of local people in managing their community forests. Informal tea breaks, lunches, and this weekend excursion were very important in helping people meet as people, instead of focusing only on an individual's institution and position. All involved genuinely wanted to contribute to the shared vision and were slowly coming together as an informal container that would help move the VPA process forward.

\section{Phase 2: building and formalizing - structures for the voluntary partnership process}

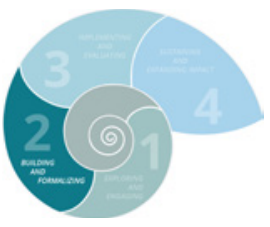

The core aim of this multi-stakeholder collaboration was conducting a formal negotiation process between Laos and the EU focused on the timber legality definition (TLD) as a key element the socalled Timber Legality Assurance System (TLAS). In order to reduce illegal logging and for the EU to pay higher prices for sustainably harvested timber and wood products, they required that this system be in place. During the second week of the workshop, it was already possible to start discussing elements of Phase 2, including the TLD itself and existing and necessary structures at the central level. Membership in these structures was a hot topic of discussion that required private discussions within each sector, especially on the involvement of civil society members in, e.g. the Technical Working Group (TWG) and Thematic Expert Groups (TEGs). The workshop provided some of the first opportunities to have discussions about the purpose and membership of these structures, with participants 
recognizing themselves (including civil society) as being appropriately positioned in the stakeholder system to constitute the TWG and to co-design and co-lead various related TEGs. With the TWG focused on the TLD, TEGs focused on specific parts of that definition; these TEGs were initiated during the workshop:

- Village Forestry as a Subsistence Wood Source

- Ensuring Safe and Healthy Workplace Conditions

- Improving Transfer Processes between Log Landings

- Verifying and Improving Export Procedures

Building on the stakeholder mapping and related engagement strategies from the first week, participant drew on their shared understanding of the context to thoroughly develop a process roadmap for the coming months, prioritizing collective action steps and highlighting key stakeholder dialogues. On the final day of the workshop, the group presented their proposed sustainable forestry vision, process roadmap, and preparedness to constitute a multi-stakeholder TWG to four high level representatives from involved Ministries, as well as the National Assembly. Furthermore, the group had come up with the metaphor of a bus for the Lao-EU FLEGT journey, representing the cohesion that had been created among involved actors, combined with clarity of direction. Participants had prepared a large drawing of the bus with diverse drivers and passengers. The high-level visitors appropriately chose to sign their names to those persons seated up front in the driver's seat. It was an inspiring moment of container building and commitment to the onward journey. Table 2.8 shows the planning of Phases 1 and 2 of this multi-stakeholder collaboration through the lens of the Collective Leadership Compass, highlighting key aspects and activities that were in focus.

Table 2.8 The application of the Collective Leadership Compass in Phases 1 and 2 for sustainable forestry and trade in Laos

\begin{tabular}{lll}
\hline Dimension & Focus aspects & Activities \\
\hline Future possibilities & $\begin{array}{l}\text { Future orientation: } \\
\text { - The way we focus on poten- } \\
\text { tial or opportunities and } \\
\text { drive change for the better. }\end{array}$ & $\begin{array}{l}\text { Co-creation of inspiring, } \\
\text { shared vision by representa- } \\
\text { tive group of core actors }\end{array}$ \\
& $\begin{array}{l}\text { Contextuality: } \\
\text { The way we explore the } \\
\text { larger context and place our } \\
\text { action in it. }\end{array}$ & $\begin{array}{l}\text { - loint stakeholder mapping } \\
\text { and analysis } \\
\text { Learning and exchange on key } \\
\text { administrative and proce- } \\
\text { dural processes related to the } \\
\text { initiative }\end{array}$ \\
& &
\end{tabular}

(Continued) 
Table 2.8 (Continued)

\begin{tabular}{|c|c|c|}
\hline Dimension & Focus aspects & Activities \\
\hline Engagement & $\begin{array}{l}\text { Process quality: } \\
\text { - The way we build step- } \\
\text { by-step and structured } \\
\text { engagement. }\end{array}$ & $\begin{array}{l}\text { - Co-development of strategies } \\
\text { to engage a range of stake- } \\
\text { holders in the initiative }\end{array}$ \\
\hline $\begin{array}{l}\text { Collective } \\
\text { intelligence }\end{array}$ & $\begin{array}{l}\text { Dialogic quality: } \\
\text { - The way we attend to the } \\
\text { structure and quality of } \\
\text { conversations. }\end{array}$ & $\begin{array}{l}\text { Increased awareness and } \\
\text { practice of the Dialogic } \\
\text { Practices to enhance quality } \\
\text { dialogue among involved } \\
\text { actors }\end{array}$ \\
\hline Humanity & $\begin{array}{l}\text { Empathy: } \\
\text { - The way we embrace the } \\
\text { perspective of others } \\
\text { and open gateways for } \\
\text { reconciliation. }\end{array}$ & $\begin{array}{l}\text { Informal moments, meals, } \\
\text { and excursions were inte- } \\
\text { grated to provide opportu- } \\
\text { nities for people to meet as } \\
\text { people and build trust }\end{array}$ \\
\hline Innova & $\begin{array}{l}\text { Excellence: } \\
\text { - The way we pursue mastery } \\
\text { and grow knowledge. }\end{array}$ & $\begin{array}{l}\text { Actors took a deliberate } \\
\text { and innovative approach to } \\
\text { designing purposeful and } \\
\text { coordinated multi-stakeholder } \\
\text { structures for their initiative }\end{array}$ \\
\hline
\end{tabular}

Phase 3: implementing and evaluating - testing the timber legality definition in pilot provinces and negotiating with the European Union

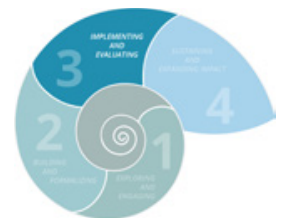

This multi-stakeholder collaboration has since moved into Phase 3 including the development of several national regulations for improving forestry governance and reduce illegal logging; multiple trainings for communities and wood processors; and testing of the TLD and TLAS in pilot Provinces. The latter occurs with coordination from the FLEGT Standing Office and through collaboration between the TWG and TEGs with related multi-stakeholder Provincial structures. Stakeholders are refining these crucial elements of a VPA to facilitate negotiations with the EU. Negotiations between Laos and the EU were officially 
opened in August 2015, with formal, annual negotiations having occurred in April 2017, June 2018, and July 2019 (Lao-EU FLEGT Website, 2019). During the most recent negotiation, Lao negotiators reported that communities can now, under the Forest Law, access nearby forests for commercial purposes, which could improve livelihood security and provide raw materials for household or SME uses.

\section{CASE EXAMPLE 2.3: A LOCAL EXAMPLE: THE NEBHANA WATER FORUM IN TUNISIA ${ }^{7}$}
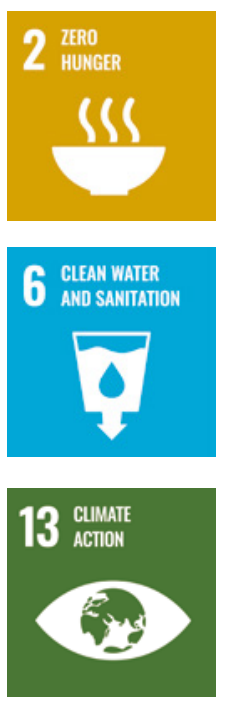

15 urf

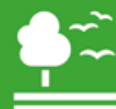

Tunisia has limited water resources, of which 82 percent is used for agriculture. Most farmers rely on groundwater or dam reservoirs for irrigation. Climate change and overexploitation of water resources have created a severely strained situation in which cities and agriculture compete for water. There are national strategies for Integrated Water Resource Management (IWRM) in place, but implementing such strategies requires not only innovation and technical knowhow, but also competencies in stakeholder engagement, as well as institutional capacity building. In the region of Kairouan, a province in the south of Tunisia, the dominant source of income is agriculture. Decreasing income opportunities from agriculture due to water scarcity increases the number of unemployed youths. Until 2015, different actors did not cohesively address the water scarcity. Local government officials tried to prosecute those who built illegal wells, but were afraid of getting attacked. Farmers illegally took water from pipelines, a crime that was partly sanctioned by a poorly resourced police force and partly ignored. Farmers' associations lodged complaints with the government about inadequate distribution and allocation of water. A support organization ${ }^{8}$ explored the possibilities to engage farmers and government officials in developing a better water management strategy and improving local living conditions. The envisaged goal was to set up a regional dialogue structure for integrated water management in a pilot region. This effort was intended to serve as a prototype for an approach that could be scaled to the national level. The intense process of engagement towards setting up the water forum included a carefully designed sequence of smaller meetings with various stakeholder groups and aimed to shift the dysfunctional patterns of interaction between farmers, government officials, citizens, and local NGOs. After a 1.5-year engagement process of various stakeholders, the first water forum took place with 300 stakeholders, including farmers, farmer associations, local government departments, municipalities and local NGOs, as well as representatives from the National Government.

The core approach was to first listen to stakeholders, and then create dialogues and collaboration experiences separately among farmers and between government departments. In a second step, the process was designed to bring the different stakeholder groups together and find pathways towards a new, more functional pattern of interaction between them. Gradually, the goal to establish a Water Forum as a lasting 
multi-stakeholder governance structure could be owned and sharpened jointly by both stakeholder groups. In a joint vision development, it became clear that water governance would indeed empower stakeholders to implement a more sustainable, integrated water management for the region. The Collective Leadership Compass was used as a diagnostic, planning, and reflection tool by the team of backbone supporters.

\section{Phase 1: exploring and engaging - acknowledging stakeholder perspectives in water-related collaboration}

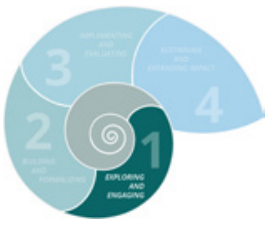

Phase 1 focused on understanding the context through deeply listening to the needs, perspectives, and concerns of the different stakeholder groups. It not only gave the facilitating support organization (called the backbone support) an insight into the complexity of the situation, but it also helped stakeholders to gain a deeper understanding of the crisis. Both the administration responsible for water resource management and the water users began to see the interconnectedness of the problems. However, engaging farmers posed a challenge. There was great variety in the size of their land holdings, the products cultivated, their access to water, and many more factors. In addition, they were geographically dispersed, not sufficiently organized, and had diverse views on the problem, potential solutions, and ways to realize them. Because of the tense political environment, the actors needed to be approached in a sensitive way. The backbone support needed to refrain from suggesting solutions, and instead, acknowledge the concerns and perspectives of the farmers without judgment. Similarly, the viewpoint of the government officials needed to be appreciated. Gradually these listening sessions shifted into parallel dialogues between different farmers, and among government officials. The latter also received capacity building for multi-stakeholder collaboration approaches to ensure the continued application of such approaches. Because of their severe mutual mistrust, farmers and government officials could not attend joint meetings at the beginning because at that stage, their positions were irreconcilable. Table 2.9 shows how the Collective Leadership Compass inspired the understanding of the context.

Six months into the preparation phase, after several dialogue sessions, the farmers as water users were prepared to enter into talks with the administration, having realized a solution to the water crisis could only be achieved through collaboration. Government officials, on the other hand, realized that simply instituting laws, regulations, and procedures would not actually reach a solution to the aggravated crisis. They began to understand the dysfunctionality of the interaction between different actors. With diligent attention to understanding context and creating resonance between both stakeholder groups, the system of actors began to look at the same situation in a new and different way. This was the starting point for building a collaboration ecosystem.

With continuous backbone support, the water users formed a network of 100 people, representing approximately 400 farmers in the pilot region. Out of this network, an additional 40 were nominated to represent the group in conversations with 
Table 2.9 Context understanding with the Collective Leadership Compass

Compass dimension Guiding question $\quad \begin{aligned} & \text { Situation summary and conclusions } \\ & \text { for design }\end{aligned}$

for design

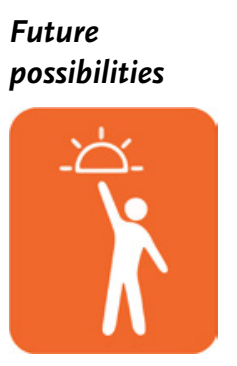

- How to create resonance within both major stakeholder groups to establish the dialogue and governance structure of the water forum?

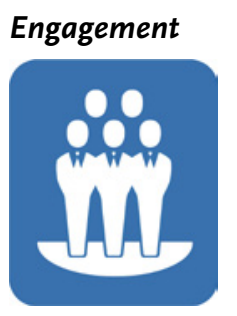

- How could the large numbers of water users be adequately included in the process of shaping the future collectively?

- How could the realization of needing to address a joint challenge emerge?
- Both water users and the administration were unfamiliar and wary of a dialogue approach and could not envisage how a Water Forum could improve the situation. Naturally, the administration in particular was apprehensive of setting up any permanent dialogue structure that might result in a power loss on their side. The farmers deeply mistrusted the administration.

- The process architecture needed to acknowledge current and dispersed opinions on causes of and solutions to challenges. It needed to keep the water forum as an option on the agenda without pressing too hard for its establishment. The relevance of the forum needed to emerge from the process.

- The geographical dispersion of farmers and their lack of identification as an entire stakeholder group, as well as lacking structures of adequate representation challenged their inclusion in a dialogue process. Problems of water scarcity were perceived as disconnected. Farmers using access to a basin in the south did not feel their problems connected to those receiving their water from a dam in the north. Dialogue between stakeholders thrives in a space of mutual trust and belonging for each group, where identities, diverse interests and common goals can emerge.

- The process architecture needed to reach out to as many farmers as possible while supporting the selforganization of a structure of mandated representatives to be included in the cross-stakeholder dialogue meetings. 


\begin{tabular}{ll}
\hline Compass dimension & Guiding question \\
\hline $\begin{array}{l}\text { Collective } \\
\text { intelligence }\end{array}$ & $\begin{array}{l}\text { How to establish } \\
\text { consultative dialogues } \\
\text { and constructive joint } \\
\text { solution finding between } \\
\text { distrustful and averse } \\
\text { stakeholder groups? }\end{array}$
\end{tabular}

Situation summary and conclusions for design

- The severe mistrust between the water users and administration was clear from the beginning. Not only were they blaming each other for the problem, neither trusted the personal integrity an important cultural factor - or the technical expertise of the other group. Each claimed to have the 'real' problem and solution figured out. A fragmented ego-system needed to be shifted to a collaboration ecosystem.

- The process architecture needed to take a step-by-step approach in first creating stakeholder group dialogue and collaboration, invigorate the confidence to be able to shape the future, and then gradually move into structured dialogue between the opposing stakeholder groups.

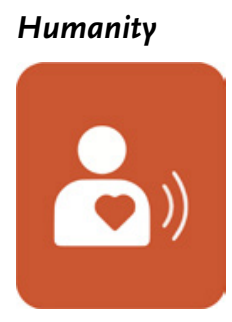

- How to ensure the necessary empathy for constructive collaboration in a class-conscious society riddled with power imbalances?

Wholeness

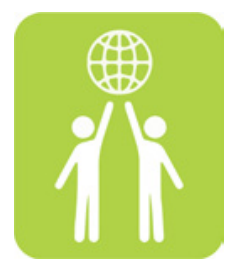

- How to shift the mindset to the common good of water, to the larger picture?
- The class-consciousness and the fear of power loss from the side of the public administration added to the divide between both stakeholder groups and the existing wall of distrust. Traditional distribution of power relationships seemed to be almost impossible to overcome.

- The process architecture needed to acknowledge the traditional role of the public administration and prepare them first for a collaborative approach between different government departments. The farmers' confidence to shape the future needed to be built without threatening the public administration and endangering reactive interventions.

- The interests of stakeholders not only differed, but were also narrow in the sense that they had lost sight of the bigger picture of water scarcity in the country as well as the impact of climate change. 


\begin{tabular}{|c|c|c|}
\hline Compass dimension & Guiding question & $\begin{array}{l}\text { Situation summary and conclusions } \\
\text { for design }\end{array}$ \\
\hline Innovation & $\begin{array}{l}\text { - How to create space for } \\
\text { innovative solutions? }\end{array}$ & $\begin{array}{l}\text { - The process architecture needed to } \\
\text { expand the particularity and narrow- } \\
\text { ness of the interests of each stake- } \\
\text { holder group and gradually build } \\
\text { resonance of seeing the connection of } \\
\text { the acute challenges to the regional or } \\
\text { national situation as well as the global } \\
\text { impact of climate change. The gradually } \\
\text { emerging goal of better water manage- } \\
\text { ment needed to be placed in context } \\
\text { by recognizing its connections to } \\
\text { climate change, sustainable agriculture, } \\
\text { equality, and participatory government } \\
\text { processes in the wake of building a new } \\
\text { democratic government. } \\
\text { - The urgency of the water challenges } \\
\text { and the deadlock between farmers } \\
\text { and public administration had pre- } \\
\text { vented any consideration of innovative } \\
\text { approaches to mastering water scarcity. } \\
\text { - The process architecture needed to } \\
\text { open spaces for different perspec- } \\
\text { tives on managing water scarcity, } \\
\text { but not push for technical solution. } \\
\text { The design needed to prepare the } \\
\text { ground for collaboration first, and } \\
\text { let the desire for better expertise and } \\
\text { innovative approaches emerge in a } \\
\text { self-driven way. }\end{array}$ \\
\hline
\end{tabular}

Source: Kuenkel, 2019

the administration. This new level of organization among the water users led to an empowerment that proved to be the decisive factor for success in the project. For the first time, they were not just dispersed actors, but could develop their position as a stakeholder group, and enter into discussion with the administration.

\section{Phase 2: establishing a water-related collaboration ecosystem}

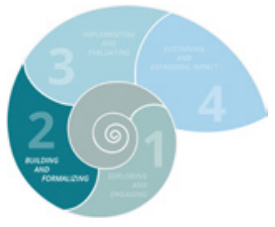

getting active
During Phase 2 small cross-stakeholder dialogue forums were established. Gradually, the level of trust increased, actors began to listen to each other's positions, and a phase of constructive collaboration began. The farmers advocated for the development of a water charter that would entail guiding principles for all 


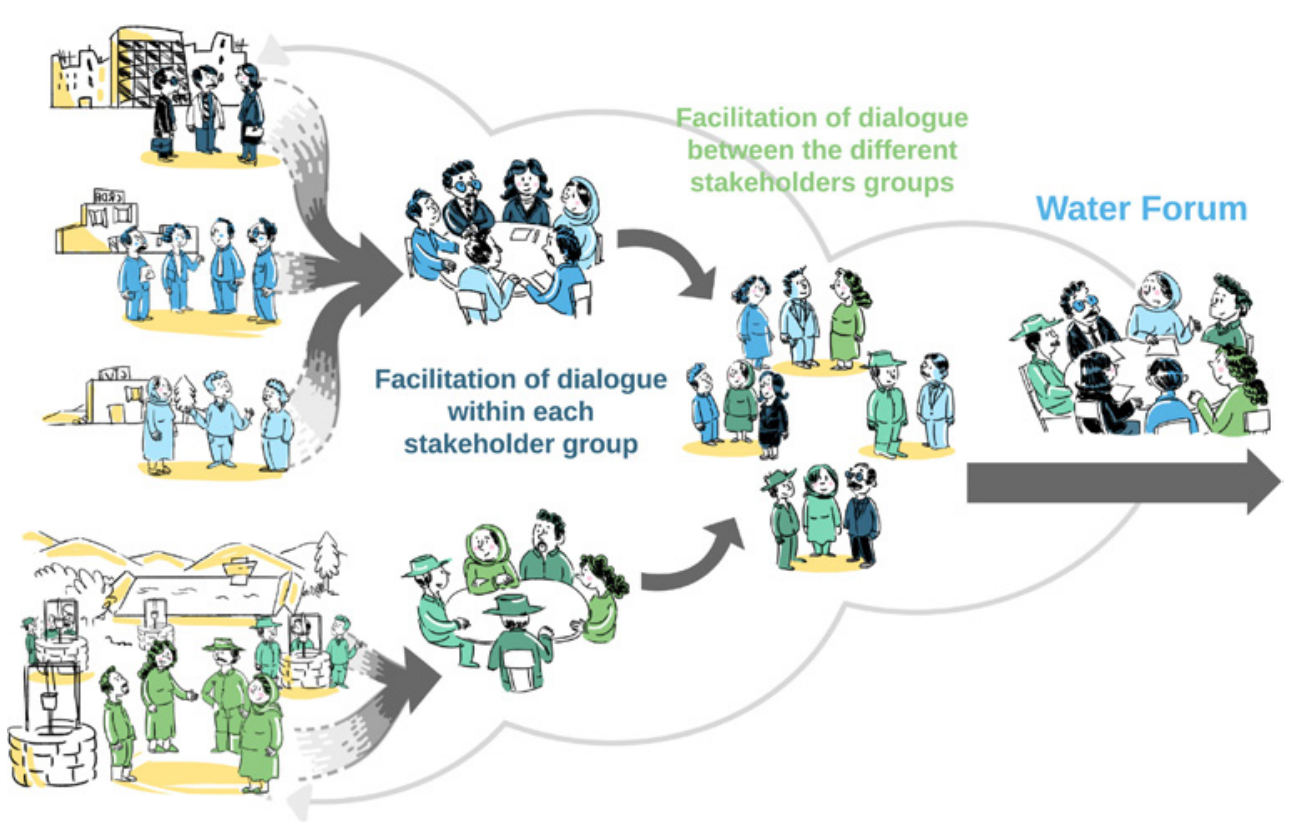

Figure 2.7 Illustrated process architecture for setting up the Nebhana Water Forum

Source: Copyright Noha Habaieb, 2016

stakeholders and would become an agreed-upon reference framework for integrated water resource management in the area. Government officials pushed for working groups on specific problematic issues, such as well drilling and water allocation. The now-official dialogue meetings grew in size and resulted in a draft water charter and recommendations from the thematic working groups. By now, the system of actors operated in a new, more collaborative pattern of interaction. Systems aliveness began to emerge, and with it, prospects for a future way of doing things differently. A joint committee organized the region's first water forum that included a variety of stakeholders. The experience showed that empowering a marginalized stakeholder group paid off in unexpected ways. The support provided to farmers to develop their authentic voice in suggesting ideas and concrete solutions to the water management problem proved to be a key leverage. The suggestions were so surprisingly constructive that the previously reluctant and fearful public administration opened up to new forms of collaboration. Figure 2.7 illustrates the process of dialogue and engagement towards the water forum done by a local artist during the process.

\section{Notes}

1 Adapted from Kuenkel, 2019; Kuenkel et al., 2011.

2 See www.globalcoffeeplatform.org/about/our-history (retrieved July 1, 2017).

3 This case example is adapted from Kuenkel, 2019.

4 Adapted from Kuenkel, 2016. 
5 With funding support from the German Federal Ministry for Cooperation and Development (BMZ), this was supported by the Gesellschaft für internationale Zusammenarbeit (GIZ) and facilitated by the Collective Leadership Institute.

6 Lao-EU FLEGT, 2014. Shared Vision for Sustainable Forestry and Trade. Available on official website at https://flegtlaos.com/.

7 Inspired by and adapted from Kuehn 2017, 2019.

8 The Government of Tunisia was supported by German Development Cooperation with GIZ (Deutsche Gesellschaft für Internationale Zusammenarbeit) as an implementing agency. The Collective Leadership Institute supported the development and establishment of the Nebhana Water Forum. For more information see www.iwrm-dialogue.com/ar/cases/25/ and www.collectiveleadership.de/apex/cli/ our-impact/our-projects/the-nebhana-water-forum-in-tunisia/.

\section{References}

Brouwer, H., \& Woodhill, J. (2015). The MSP guide: How to design and facilitate multistakeholder partnerships. Wageningen, The Netherlands: Centre for Development Innovation, University of Wageningen.

FAO. (2002). National forest products statistics, Lao PDR. www.fao.org/docrep/005/ ac778e/AC778E12.htm

Hanleybrown, F., Kania, J., \& Kramer, M. (2012). Channeling change: Making collective impact work. Stanford Social Innovation Review, 9(1), 1-8.

Kania, J., \& Kramer, M. (2011). Collective impact. Stanford Social Innovation Review, 9(1), 36-41.

Kaplinsky, R. (2000). Globalization and equalization: What can be learned from value chain analysis? Journal of Development Studies, 37(2), 117-146.

Kuehn, E. (2017). Collaboration for the SDGs: The set up of the Nebhana water forum in Tunisia. In Collective leadership studies (vol. 4). Potsdam, Germany: The Collective Leadership Institute. ISSN 2569-1171

Kuenkel, P. (2015). Navigating change in complex multi-actor settings: A practice approach to better collaboration. The Journal of Corporate Citizenship, 58 , 119-137.

Kuenkel, P. (2016). The art of leading collectively: How we can co-create a sustainable, socially just future. Claremont, $\mathrm{NH}$ : Chelsea Green.

Kuenkel, P. (2017a). Building competences for partnering: How donors can ensure multistakeholder partnerships succeed. Briefing Note 95. Maastricht: ECDPM.

Kuenkel, P. (2017b). Collaboration in action: From supporting projects to funding Partnerships. In SDG knowledge hub. International Institute on Sustainable Development (IISD). http://sdg.iisd.org/commentary/guest-articles/collaboration-in-actionfrom-supporting-projects-to-funding-partnerships/

Kuenkel, P. (2019). Stewarding sustainability transformations: An emerging theory and practice of SDG implementation. Cham, Switzerland: Springer.

Kuenkel, P., Frieg, V., \& Gerlach, S. (2011). Working with stakeholder dialogues: Key concepts and competencies for achieving common goals. A practical guide for change 
agents from public sector, private sector and civil society. Potsdam, Germany: The Collective Leadership Institute.

Tennyson, R. (2011). The partnering toolbook: An essential guide to cross-sector partnering. Oxford: The Partnering Initiative. http://thepartneringinitiative.org/wp-content/ uploads/2014/08/Partnering-Toolbook-en-20113.pdf 


\section{chapter 3}

\section{Ensuring success}

\section{The role of dialogic process facilitators in enlivening collaboration ecosystems}

The previous chapter has shown that stewarding multi-stakeholder collaborations towards success can be done. Stakeholders who act in a spirit of leading transformative change collectively can create the conditions for transformative change to happen despite the difficulties that will inevitably occur. Complex change processes cannot be controlled; they can hardly be steered. At the core of creating enabling conditions is the ability to perceive degrees of systems aliveness - or the lack thereof - and the capability to knit patterns of aliveness into the often-arduous processes of collaborating with multiple stakeholders whose interests, capacities, and power may differ greatly. Detecting dysfunctional patterns much earlier, negotiating patterns of aliveness that benefit the part and the whole, and co-creating mutual consistency among collaborating stakeholders are skills that can be learned. The skills development is greatly supported by an increasing ability to be an actor who not only tries to push an interest through or aims to achieve an important outcome in a system of stakeholders, but also at the same time looks at the system from a bird's eye perspective and thus learns to gauge its aliveness. Such a systemic perspective has a number of implications that are crucial for the way actors can learn to lead transformative change collectively.

The first implication is that it shifts people's attention from the urge to fix a problem to understanding the dysfunctional patterns that are behind the problem. This not only helps actors during, e.g. a stakeholder and context analysis in Phase 1, to understand the greater context of the problem and its relationship to other parts of the system, but it also helps them to take note of the functional aspects within the system that actually work, even if the overall system is dysfunctional. These aspects 
often get overlooked under the pressure of problem-solving, but can hold immense potential for transformative change. The already functional aspects within a system need attention in order to shift the overall pattern into more functionality.

The second implication of the systemic perspective is that it helps collective leaders in transformative change to avoid the trap of solution addiction. Naturally, stakeholders who engage in collaboration all have their own interpretation of how a difficulty or problem could be overcome. However, the theories of change of how to get there might be hugely different from one stakeholder to another. This is why emotionally compelling goals are so important. They function as a transformational guidance, while actual implementation must stay open to collective learning and goal adjustments.

The third implication is that it widens stakeholders' view. It helps them to see that their particular change endeavor is one approach among many others. This creates openness for what other actors are doing and gradually helps people to move from competitive and territorial thinking to a humbler mindset of making a contribution to a larger system of change initiatives around SDG implementation - that ultimately will only create an impact together.

Finally, the fourth implication is that being guided by the conception of systems aliveness helps actors to acknowledge that it is only enlivened people who will be able to make a difference and take ownership for change to happen. This also means moving from emphasizing the deficits of human actors to nurturing their competencies. This includes building the capacities of collectives of actors to lead transformative change.

There are many ways of enhancing systems aliveness - for individuals, core groups, collaboration ecosystems, and larger stakeholder systems that need to shift in order to achieve the 17 SDGs. The Collective Leadership Compass as a navigating tool and the Dialogic Change Model as a process methodology enhance the capacity of actors to diagnose and improve interaction patterns in small and large-scale change endeavors. They learn how to best bring systems aliveness forward. This chapter will therefore

- explore the essential role of dialogic process facilitators and how they can tune into their collective leadership competence;

- take a deep dive into specific facilitation approaches and tools that enhance the six dimensions of the Compass and make the crucial steps of the Dialogic Change Model work;

- show how dialogic process facilitators develop the competence to build and enliven containers for change towards co-creating the collaboration ecosystems necessary for realizing a shared vision; and

- provide the aspiring dialogic process facilitator guidance and an illustrative case on leading transformations collectively.

Multi-stakeholder collaborations need dialogic process facilitators who are committed to transformative change. They engage with different stakeholders in constructive and outcome-oriented communication and collaboration. They can belong to one stakeholder group or to an initiating lead agency that brings the multi-stakeholder collaboration forward. So, they do not need to be neutral about a goal: they can have 
'stakes' in an issue. But they must be willing to be open to different stakeholder perspectives, and, if need be, mediate between the different interests and ensure that different viewpoints are heard and integrated. Such dialogic process facilitators need not be in positions of formal or positional leadership - and often are not - but do need to have a mandate to take care of change processes. Versed in the collective leadership approach, they hone the capacity to cultivate systems aliveness at the levels of self, team, system, and process. An essential core element of process facilitation in multi-stakeholder collaboration is an in-depth understanding of dialogue.

\section{The purpose of dialogue in multi-stakeholder collaborations}

For multi-stakeholder collaborations to be successful, it is important for participating actors and their institutions to see the added value of engaging in them. This, what we call engagement value, can be different for each participating institution, and is inevitably multi-faceted. Reasons to engage may be transparent or opaque, outspoken or reserved. They depend on a number of factors, such as perceived gains for a stakeholder group; risk of not participating; emotional connection to the larger goal; interest in collaborating with different stakeholders; or a genuine interest in transformative change. If the engagement value drops, the continuation of the multistakeholder collaboration is endangered. Sometimes, neither the engagement value nor the common goal is clear to all stakeholders at the outset; then they observe what is happening without committing. But only stakeholders that have moved from the role of the critical observer to the role of the engaged implementer will make success happen. Commitment and ownership develop over time if relationship building, goal clarification, and, above all, high-quality dialogues receive sufficient attention. Multistakeholder collaborations are fragile and often depend on the ability of dialogic process facilitators to foster structured, yet meaningful conversations. In high-quality dialogue lies the potential for reconciling differing interests: the world suddenly becomes more whole. People realize that their previous ways of thinking were fragmented. This is the fertile ground for leading transformative change collectively.

With more understanding of the complexity, but also coherence of the whole, it is easier to suspend once inflexible positions and to pursue the common good. A pragmatic consensus is easier to reach. Hence, collaborative change requires human connections. It is only through participants and stakeholders getting to know each other more personally and understanding the context of stakeholder positions better that patience with different points of view can develop. Gradually, the participating stakeholders' world-views can shift: what seems to be rigidly entrenched at the outset starts to look different the more they are prepared to expose themselves to the complexity of multiple perspectives. When stakeholders commit to a shared goal, they are more likely to understand that they can find the most robust solutions together instead of in isolation. The diversity of actors brings key perspectives and resources for achieving the goal. The success of the whole system is also a success for each involved actor and their respective institutions or stakeholder groups. A dynamic collaborative change process creates a network of interested and committed people. High-quality 
dialogues build humanity; they are the roots of collective intelligence and become the driver of engagement. The ability to dialogue establishes the safety net that carries the process of multi-stakeholder collaboration through ups and downs, crises and resolutions, challenges and successes. It nourishes the human interaction network that is needed to lead transformative change collectively and creates the inspiration for innovation. Hence, future possibilities are more easily reached. Moreover, if the collaboration becomes a microcosm of systems aliveness it connects people with wholeness and subsequently to their inclination of care for the future, which often draws more and more people into the initiative.

High quality dialogue enlivens collaboration ecosystems, resulting in

- participating stakeholders who are willing to take collective responsibility for global or local change;

- all actors involved being willing to communicate and cooperate across the boundaries of individual and institutional world-views; and

- all stakeholders connecting with and committing to a larger goal (the contribution to SDG implementation or a common good) that includes, but lies beyond, the interests of any one particular stakeholder group.

\section{The essentials of dialogue}

Dialogue is a conversation between two or more people that serves the exploration of deeper understanding, coherence, and possibilities. Collective intelligence occurs as a result of a high-quality dialogue - the outcome of a conversation or collaboration is superior to the results the individuals would achieve in isolation. This way of communicating with each other is as old as the human race and known to all cultures in the world. It is an art of talking together that enables a flow of meaning among people. It is, then, the art of thinking together in a way that leads to progress through understanding differences and enacting respect (Isaacs, 1999). People who have experienced dialogue, often feel they have re-discovered something that seemed lost in the ordinary day-to-day conversations, something that seems to be absent in most of our conversations during meetings, conferences, and workshops. In multistakeholder collaborations, dialogue enables people to bring out differences and make sense of them. This means fostering a way of thinking and reflecting together that allows inquiry in a form in which disparate interests, tensions, power differences, and conflicts can be explored.

The ability to facilitate dialogue is an important capacity for SDG implementation efforts. It helps people in multi-stakeholder collaborations to map pathways to progress. It also allows people to maintain perspective in the face of crisis, to use conflicts productively, and to know what to ask or do when things don't move. True dialogue is not about conveying information, convincing others, or getting buy-in for a predefined strategy. Dialogue is a stance (Isaacs, 1999) - a way of being with oneself and a way of being with one another (Wheatley, 1999). At the core of it is the quality of our own presence, and our way of being in the world that helps others to bring out their best. As a practice among a group of stakeholders, it is the cornerstone for an 
approach to transformative systems change. The purpose of negotiation is to reach a compromise between parties who differ, the intention of dialogue is to reach a new level of understanding and, in doing so, to form a new basis from which to think and act collectively. Dialogue, therefore, is the ground for leading transformative change collectively towards a more sustainable world.

Since dialogue implies that no position is final, and new and un-thought of possibilities or solutions might arise out of a conversation, it requires a suspension of our habitual ways of talking with each other. Moreover, it requires the capacity to listen to the already existing wholeness, to respect the integrity and humanity of the person one is reaching out to understand. It is about the ability to observe without judgment and suspend one's own assumptions as much as it is about speaking from an authentic inner voice. High-quality dialogue engenders awareness about underlying patterns of thoughts that lead to certain interpretations of the world and how it works. These thought patterns that so often become positions, convictions, and beliefs most often are at odds with each other in the beginning of a multi-stakeholder collaboration. Then, advocating a stance is the habitual way of acting. This is important, but needs to be accompanied by the ability to inquire into the multi-faceted issue. There are many opportunities to realize a dialogic approach with balanced advocacy and inquiry in multi-stakeholder collaborations.
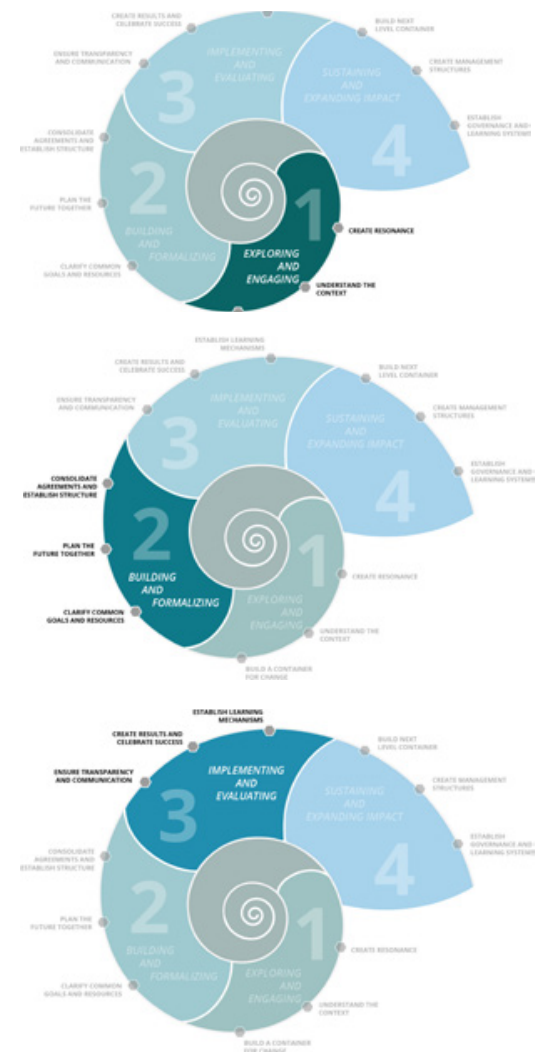

In Phase 1, it is the quality of inspiring dialogic conversations that will create resonance with stakeholders for an envisaged multi-stakeholdercollaboration. It ensures that understanding the context is a cocreative process rather than the extraction of information. It is the foundation of trusting relationships that build a container for change.

In Phase 2, it is the quality of dialogue at stakeholder meetings that helps collaborating actors to clarify goals and resources, plan the future together, and eventually find the suitable form to consolidate agreements and establish structures.

In Phase 3, high-quality dialogues are the glue that keeps the collaboration ecosystems functional for the delivery of SDG implementation. Naturally, they inform the way people ensure transparency and communication. But even celebrating success can be done in a way that does not only convey results, but engages other stakeholders in inspiring conversations. Of course, establishing learning mechanisms center around a dialogic approach to learning and innovation. 


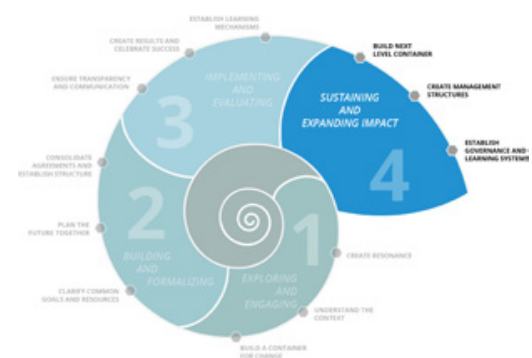

In Phase 4, building the next level container requires the inspiring conversations known from previous phases, and even establishing management structures asks for introducing the culture of dialogue. Elaborate and representative governance and learning structures function best when the capacity to dialogue is firmly anchored in the way these systems function.

Throughout all phases of applying the Dialogic Change Model to multi-stakeholder collaborations, it is the delicate mix of diversity among stakeholders that helps the group of stakeholders to shift into success and impact. This is why it is crucial to understand, how people in communicative settings become collectively intelligent and constructively co-creative. The next section will take a deep dive into this understanding.

\section{From thinking alone to thinking together}

Multi-stakeholder collaborations become successful with conversations, meetings, and events, which help people to exchange views, plan together and evaluate progress. The way such gatherings are designed and facilitated has an enormous impact on their success, and subsequently on the results of the collaborative process. However, there is often little awareness among collaborating stakeholders about what helps collective intelligence emerge. It is important to understand that meetings take place in structures some of which are visible, like room arrangements or agendas, and others are only felt subjectively, but are not necessarily visible for everybody. These could be atmosphere, moods, undiscussables, memories, injuries, mistrust or trust, or hidden agendas. Both visible and non-visible structures influence the flow of communication between people. They determine more of the course of a meeting, the content, and the results then we are likely to believe. Sometimes facilitators try to change structures by changing agendas, allowing space for personal interaction, move chairs or tables and shift between large group and small group conversations. But often it is not only the perceived structure that has an influence on the way people communicate with each other. The underlying mental models or belief systems determine much more of what is being said, what is not said, and how things are being said. Only if the effect of both perceived as well as the underlying mental structures is better understood can actors in multi-stakeholder collaborations deliberately choose to enhance communication processes that truly harvest collective intelligence.

High-quality dialogues save time: common ground is achieved more easily, decisions are made faster, agreements are reached in less time-consuming ways. People who are skilled in dialogue do not withhold their positions, or subject themselves to false compromises. They simply know that collective intelligence emerges in respect for difference and acknowledgement of people as people. Thinking together is a skill stakeholder can learn. On the path to a form of communication that enables people to enter new grounds and create an atmosphere of trust and empowerment there are different stages. In some cases, a meeting may be dominated by one or a few 
people speaking, while others stay silent and their contributions get lost. But even if more people engage in contributing their viewpoints, many meetings are characterized by a communication structure that can be described as serial monologues. In its extreme form, this means, participants utter their views one by one without really making reference to the preceding speakers. People are eager to speak and to get their viewpoint, a suggestion, or a solution across. A chairperson usually tries to bring order into the emerging chaos with a speakers list. Often, the communicative effect is that people make up what they want to say and then wait for their turn to speak. They concentrate on what they want to say, not on listening what others express. In such a conversation, the underlying and unquestioned mental model is that individual intelligence is the most important and able to convince others. Weaker stakeholders, most often, do not feature in the competition for airtime. The flow of communication is polite but usually disconnected and does not further the emergence of collective intelligence. The facilitative role of a chair is reduced to that of a traffic cop, by restricting airtime and making sure everybody on the list will be able to speak. People tend to think alone. Often, such meetings are time-consuming, leave people with the feeling they have not expressed their views sufficiently, and do not easily achieve outcomes.

If tension rise, the form of communication may develop into a debate. Although participants become more forceful, more reference is made to each other. Yet, a debate can get stuck in the opposing views of people, or may even turn into verbal brawling. Often, a win-lose situation emerges with the stronger party or those with better arguments coming out as determining the direction. Others may keep quiet. Debates do not always lead to conflict, but the inherent tendency is always there. The more the conversation gets stuck in opposites, the more time is wasted, and those participants who are not directly involved get bored. Themes get repeated and sometimes such the debate needs to be stopped by a chairperson. Debates unearth differences, but they do not necessarily further collective intelligence, because, most often, the lines of argumentation remain mutually exclusive. These are the type of conversations where people usually come to the conclusion that they need an outside facilitator.

Most stakeholder meetings, therefore, become guided conversations. The presence of a facilitator allows people to become aware of structures and patterns. Particularly in cases where very different mental models or belief systems juxtapose each other, the facilitator can create the possibility for new perspectives to be considered. A guided 'cross-model-conversation' can then take place, when a facilitator ensures that airtime is given to opposing opinions or weaker voices. Because of the facilitation, even undiscussables might come to the surface and be brought out in a safe framework. Such conversations allow people to generate a collective view of reality and go beyond their individual limited perspectives. The flow of communication arrives at a new quality that can be felt in the room, and people are usually more content with the results of such meetings. The only pitfall of guided conversations is that the responsibility for the quality of the dialogue is most often delegated to the skilled facilitator. How to do dialogue and become aware and responsible for the collectively intelligent flow of communication is 
most often not a skill that everybody has. But guided conversations are much more effective than serial monologues or debates. Multi-stakeholder collaborations can work with this form of communication when there are skilled facilitators available. But leading transformative change collectively means to even more productively access the potential for collective intelligence. It suggests that stakeholders need to become experts in dialogue.

Conversations that unearth mental structures for transformative change to happen require reflective dialogue. Facilitators in guided conversations often help to install such kinds of reflective processes, but conversational empowerment will start only if participants take the learning into unguided conversations. Reflection is a form of collective (and individual) thinking about what went well and what did not go well, what took place, which invisible structures played out, and what outcomes occurred or did not occur as a result. It leads people to start thinking about the process, about themselves in it, and it finally enables them to ask questions that lead to a deeper meaning of the conversation. Indicators for the emergence of a reflective dialogue are willingness for inquiry into difference and difficult to understand viewpoints. Such inquiry is a step to redirect the thinking process into new areas and cover new ground. The step into reflective dialogue takes place when people begin to notice that they are thinking together. Assumptions are questioned and beliefs are revisited. This is when collective intelligence emerges.

Reflective dialogues often develop further into generative dialogues. Then, new perspectives open up. Now the underlying structures of thinking, as they come to the surface, can be changed. Participants develop a new quality of openness for each other's presence and history. New insights that had not been there before are generated and new themes emerge. A deeper understanding for the coherence underneath contradicting positions develops. People begin to understand patterns of thought and how they are related to actions. Stakeholders who get used to generative dialogue experience the flow of thinking together and results achievement as a co-creative process. They notice that collective intelligence emerges as people build on each other's contributions. Such kinds of generative dialogues have practical advantages: a conversation leads to collectively owned results in a shorter period of time. Although the brilliance of individual contributions is acknowledged, it becomes less and less important to insist on one's own position. Instead, everybody is more interested in finding the optimal solution for the situation by tapping into the collective wisdom. Figure 3.1 shows the development of these communication flows towards collective intelligence.

Disagreements and conflicting viewpoints belong in multi-stakeholder collaborations because they create a fertile ground for overcoming challenges and finding new solutions. Unquestioned harmony is not desirable. But despite differences in opinions, high-quality dialogues in multi-stakeholder collaborations need to leave serial monologues and debates behind. They need to ensure guided cross-model conversations, and move into reflective and generative dialogue. This increases the likelihood that they can achieve transformative change. Therefore, an understanding of the essentials of dialogue and facilitation skills belong to the core competencies for initiators of multistakeholder collaborations. 


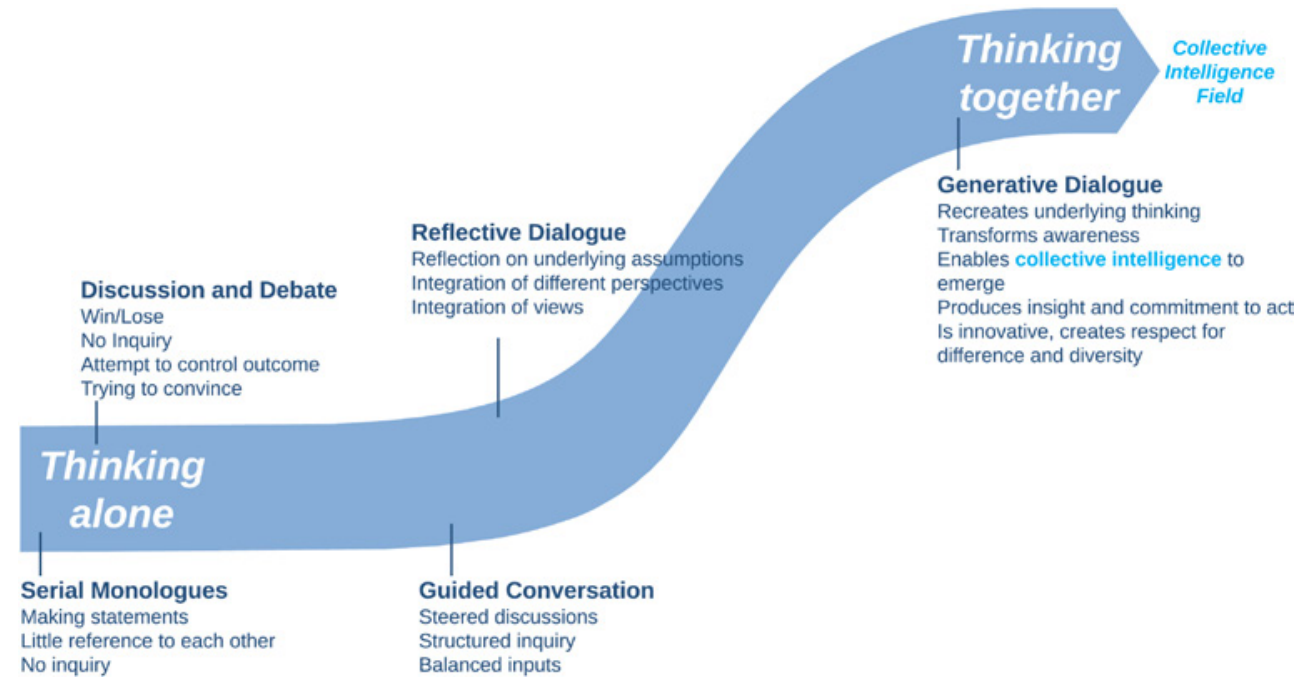

Figure 3.1 Communication patterns: from thinking alone to thinking together

Source: Inspired by and adapted from Isaacs, 1999

\section{The dialogic practices}

Every conversation or communication process is a co-creative process with participants individually and collectively holding the responsibility for the outcome. No matter how difficult or stuck a conversation seems to be, there exists an underlying coherence of the situation. The difficulties people have communicating with each other are symptoms of mental models that clash, a disconnection between people, or the dysfunctionality of a human interaction system. Dialogic practices, if understood, can reveal the underlying whole and shift difficult conversations into constructive outcomes. Every conversation unfolds in a certain logic. Visible and invisible patterns of thinking and communication create blocks in conversations that impede people to move from thinking alone to thinking together. Awareness about such underlying patterns and structures helps to change directions of conversations. People become more genuine and enter into a deeper level of communication. Ideally, they start talking about what they really need to talk about. With that, clarity unfolds. Hence, awareness about thought patterns and patterns of interaction is a gateway to having higher quality conversations and ultimately increased effectiveness.

Dialogue is a dynamic process that requires a delicate balance of inquiry (seeking new understanding) and advocacy (seeking to be understood). Inquiry needs the skills of listening and the ability to suspend judgment: only then can one gain a deeper and newer understanding of an issue, a stakeholder position, or a way forward. Advocacy requires the courage to speak one's voice or to speak on behalf of others, to convey a purpose and defend a course of action, and, at the same time, to underscore one's position or criticism of other positions while respecting difference. 
Advocacy that is conducive to dialogic conversations reveals one's thinking behind the expressed view.

- It illustrates the point of view with concrete examples that allow others to follow the line of thoughts.

- It mentions the interpretations of a situation and makes assumptions explicit.

- It makes clear what is expected to change in individual or collective behavior.

- It speaks from the heart and explains why this particular issue is so important for the person.

Inquiry that is conducive to dialogic conversations genuinely asks for other people's point of view.

- It inquires into the thinking process of people: why have they come to believe this or to advocate this or to feel this?

- It tries to suspend premature judgments as much as possible and looks for the value in the other stakeholders' arguments or feelings.

- It searches for coherence beneath conflicts and explores what is missing.

Balanced advocacy and inquiry are effective in helping participants of a multistakeholder collaboration to see the whole picture and the best possible way forward. There are four genuine dialogic practices that, if consciously kept in an overall dynamic balance, ensure high-quality dialogues. Figure 3.2 shows the four dialogic practices of voicing, listening, respecting, and suspending (Isaacs, 1999), which will be explained in more details.

The first dialogic practice is voicing, which means more than just assertive speaking.

- It is the ability to express one's concerns, ambitions, intentions, or objectives with a voice from the heart, acknowledging that not everybody sees things in the same way.

- It assumes that one's competence, intention, and view can not only bring things forward, but also stall them.

- It is built on the premise that every contribution, if authentically expressed, facilitates the emergence of collective intelligence.

- It requires the ability to listen, because listening encourages speaking.

Stakeholders are often not aware that the way we speak influences the way others listen and the way others listen influences the way we speak. If others are genuinely listening, a speaker can speak more freely, more authentically. In multi-stakeholder collaborations, it is important to ensure that all voices - those of weaker stakeholders and those of more powerful stakeholders - are heard sufficiently. Preventing stakeholders from voicing their points of view inevitably leads to mistrust, disengagement, and lack of commitment. It is important to also be aware of the dysfunctional side of voicing: at times, stakeholders dominate others, or engage in fake talk, intrigues, and non-transparent communication, etc. If that happens, it is an indicator of an 


\section{VOICE}

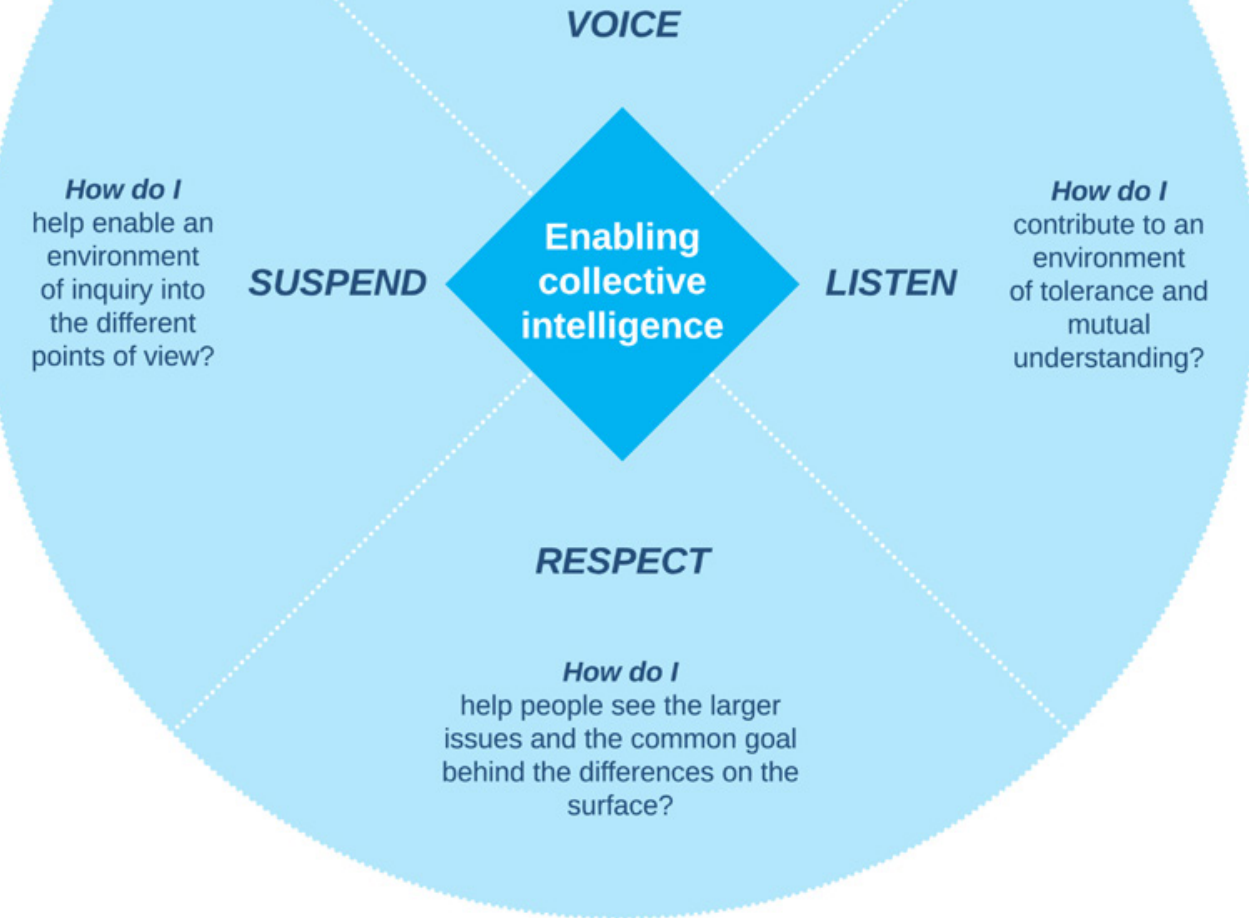

Figure 3.2 The dialogic practices

Source: Inspired by and adapted from Isaacs, 1999

emerging dysfunctionality in the collaboration ecosystem and time to reflect on how to get stakeholders back into a field of genuine dialogue.

The second dialogic practice is listening, which is much more than not speaking.

- It is the ability to create a space in which people can genuinely express themselves.

- It means being able to recognize and accept another speaker's right to an opinion - even if this opinion diverges from one's own.

- It creates trust and contributes to resilience in multi-stakeholder collaborations.

The quality of listening enhances not only the quality of talking, but also the quality of thinking. Good listening slows down thinking and enables us to suspend our judgments. Nancy Kline (1999) has developed an elaborate approach towards creating 
what she calls a better thinking environment, based on the experience that the quality of the attention a person gives to another person who is speaking positively influences the quality of thinking and the authenticity of speaking. Attention, driven by deep respect and genuine interest and without interruption is the key to a creating an enabling thinking environment. Cultivating thinking environments in multistakeholder collaboration is important throughout all phases of the Dialogic Change Model. Most often, the first step in the engagement of stakeholders is the deep and authentic listening to their concerns, viewpoints, and ideas. In the course of building enlivening collaboration ecosystems, this requires not only listening to different actors, but also creating stakeholder events in which these individuals can genuinely listen to each other. The ability to listen to each other in a structured way is the pathway into seeing beyond the interpretations of each stakeholder view into the larger picture and an underlying coherence. This becomes the ground for transformative change. Moreover, once a culture of listening has been established among a group of stakeholders, decisions are made faster, more effectively, and in a more solution-oriented manner.

The third dialogic practice is respecting, which is, at the core, appreciating people as people, no matter what they think or do, and even if one entirely disagrees with any of someone else's opinion or perspective.

- It is the ability to see others as legitimate beings.

- It thrives on the willingness to acknowledge the integrity of another person and to reach out to understand their point of view.

- It engenders acceptance of differences as part of a whole.

No multi-stakeholder collaboration can be successful without genuine mutual respect. If stakeholders are not treated with respect, they begin to treat others disrespectfully. In a mature collaboration ecosystem, stakeholders respect others' opinions, even when they do not share their point of view. But they assume that there is an underlying coherence behind the dissent that needs to be explored. Respect does not require acceptance and agreement at all stages, but the honoring of boundaries, the understanding of difference, and the embracing of diversity. Respect helps stakeholders to endure tensions that are inevitably part of transformative change processes with multiple stakeholders.

The fourth dialogic practice is suspending, which is the ability to withhold judgment.

- It means developing the ability to question our own assumptions.

- It means shutting off one's tendency to come to conclusions too quickly.

- It is the ability to notice when judgement sets in.

Suspending is the route into reflecting while acting, to observe what is happening while it is happening, because it teaches us to observe our thoughts. We all have the tendency to judge others constantly, but developing our capacity to suspend means to hold sufficiently lightly what we are convinced of or what we think is certain. It means acknowledging and observing thoughts without the need to entirely identify with our opinions. The more stakeholders in collaboration ecosystems develop this 
ability, the better their chances of reaching a consensus, establishing constructive communication patterns, and being able to concentrate on problem-solving.

The more stakeholders gain an (often intuitive) understanding of the dialogic practices of voice, listen, respect, and suspend, the higher the likelihood that a multistakeholder collaboration will move towards a communicative pattern of "thinking together" - a generative dialogue. This stimulates collective intelligence, furthers engagement, and fosters ideas and innovation; it facilitates efficient decision-making processes and encourages the taking of responsibility for future possibilities. The dialogic practices connect people with the wholeness of a larger story and bring out their humanity. Hence, they enhance all Compass dimensions and therefore make an essential contribution to systems aliveness. They reflect an inner attitude, as well as an outer ability to engender constructive, solution-oriented communication. The presence of the dialogic practices changes the flow of communication. Consensus is easier to reach, but is built on the naming and respecting of different perspectives.

At the individual level, the dialogic practices can be used as self-reflection. Knowing one's own preferred practices combined with the understanding that all practices are required in a dynamic balance to create high-quality dialogues, helps stakeholders assume a learning attitude. If we all become more versatile in all practices, the flow of communications becomes more effective. It is equally helpful to take a bird's eye view and observe communication patterns in a group of collaborating actors. Most often, identifying an imbalance between the practices and understanding which practice is missing helps people to bring the missing practice in. This will improve the quality of the conversations. It can even help to overcome conflicts. Becoming versatile in applying the dialogic practices is a capacity initiators and facilitators of multi-stakeholder collaborations need to acquire. Not every stakeholder can and will become a professional facilitator, but it helps to understand the role of facilitation in leading transformative change collectively.

\section{The role of facilitation in dialogues}

Facilitation can be described as a process in which one person or two persons guide the conversation in a group. These are usually people who have the acceptance and trust of the members of the group, are sufficiently neutral towards the different opinions, and do not have any intention to steer the group towards a predefined outcome of their particular interest. They help the group to identify or solve problems and make decisions that impact future pathways. They assist the group of stakeholders to see a wider range of possibilities, to ensure that different angles are explored, and that the conversation stays in an effective flow. The ideal result of good facilitation is always increased group effectiveness. Often, the person who is requested to facilitate is not a member of the group, he or she is an outsider, not involved into the content and only helps to guide the process with her or his professional skills. Such a facilitator will have a range of tools depending on their professional background. These tools can entail an efficient style of visualization, a good meeting design, a mixture of large group and small group discussions and procedures how to come to decisions and document them. There are many different techniques for the facilitation of 
stakeholder events available that can be applied in multi-stakeholder collaborations for SDG implementation. Examples for such techniques for meetings with smaller or larger numbers are:

- Future Search Conferences (Weisbord \& Jannoff, 2010) for joint systems diagnosis and joint planning;

- Open Space meetings (Owen, 2009) that allow many stakeholders to take the lead for themes that require in-depth conversations;

- World Café facilitation (Brown, 2005) which enable the generation of ideas and multiple perspectives on issues;

- Appreciate Inquiry and value creation approaches (Laszlo \& Cooperrider, 2010; Cooperrider \& Whitney, 2005) that build on the strength within the system;

- Design Thinking Workshop (IDEO, 2008; Stamm, 2008) which engender rapid prototyping of new ideas and approaches;

- Living Labs (Leminen et al., 2012) which support innovation in networks of stakeholders.

Not every meeting needs to adopt such methods, but understanding such techniques can be helpful especially for larger stakeholder meetings in Phase 2 of the Dialogic Change Model, when the objective is about agreeing on goals and implementation plans, or in Phase 3 when stakeholder learning events and strategic reviews are important. The purpose of such meetings is always to further the conditions for collective intelligence and engagement of stakeholders. It is, however, crucial, to choose methods that fit purpose and context. Moreover, facilitators need to understand the shared principles that underpin such techniques and mirror the conditions for systems aliveness in stakeholder meetings. Table 3.1 captures their essence.

Multi-stakeholder collaborations for SDG implementation can benefit enormously from engaging skilled facilitators. It might be recommendable in some cases to ask for the assistance of an external facilitator, particularly for large stakeholder meetings in Phase 2, in situations where trust has been eroded, or in learning events in Phase 3, when all participating stakeholders want to focus on the content. But it isn't always possible or necessary to employ external facilitators. Stewarding the process and communication flow of multi-stakeholder collaborations cannot always rely on external facilitators. Stakeholders need to take ownership of the communicative quality themselves. The skills of dialogic facilitation therefore need to be made available for every person in the group. Particularly people who aspire to lead transformative change collectively in multi-stakeholder collaborations need to acquire such skills when they engage stakeholders, call for meetings, ask for feedback, try to understand a difficult situation, or want to help other people identify their problems. The more stakeholders are versatile with the essentials of a dialogic approach, the more facilitation can happen from within the circle of stakeholders.

The dialogic facilitation skills elaborated in this chapter empower every person in the room to make facilitative moves and become an active co-creator of better group results. This leads to purposeful, result-oriented high-quality conversations in multistakeholder collaborations for SDG implementation. Dialogic facilitation moves away 
Table 3.1 The shared principles for stakeholder meetings

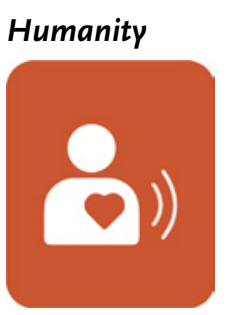

Collective intelligence

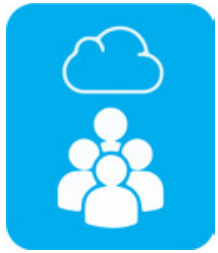

Engagement

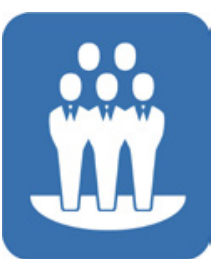

Innovation

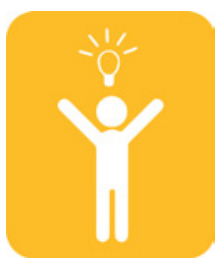

Wholeness

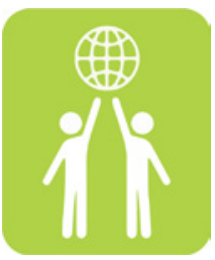

Future possibilities

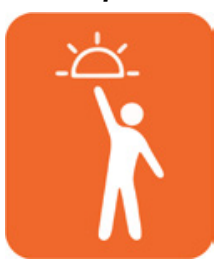

Staying aware of the influence of space and connection

- Choosing enlivening architectural or geographic locations and settings is as important as creating time and space for people to connect with each other.

Getting the system into a conversation with itself

- Bringing out and acknowledging different perspectives as respect for difference always precedes consensus building. Once differences are clear to everybody, asking stakeholders to identify underlying commonalities helps to find common ground.

Understanding the premises of collective action

- Ensuring a structured and transparent integration process towards finding common ground and getting to joint results or agreements. Planning of joint activities can only take place after consensus has been reached. This can be followed by agreements on next steps as well as roles and responsibilities.

\section{Harnessing the power of self-organization}

- Enabling stakeholders to take full ownership for the change ahead is paramount. This means to encourage them to design the envisaged change themselves (no pre-designed plans). Prototyping future ideas in content working groups is as important as always sharing results in the plenary.

Taking stakeholders in the room as a microcosm of the stakeholder system

- Ensuring a good representation of the stakeholder system in the room is crucial. Most importantly, who is in the room needs to be made visible, so that everybody can experience how the microcosm of the larger systems begins to interact.

\section{Focusing on future pathways}

- Diagnosing the current situation is a task that needs to be done together. But the next step must always be to converse about how the future could look different and pathways to get there. 
from handing over the responsibility for group effectiveness to an outside neutral person. A person who facilitates in a dialogic way is concerned with the question: what is the conversation we really need to have here in order to move forward? Such a person is continually searching for an answer to that question in collaboration with her or his colleagues. This requires a higher degree of awareness about what happens in a group and subsequently in the conversation. It also requires a certain degree of knowledge about oneself, an awareness about how one communicates with others. A dialogic facilitator will continuously cultivate a sense of inner knowing and self-observation. Coming to understand oneself and understanding others is a cornerstone of dialogic facilitation. People, who facilitate in a dialogic way, find creative ways for a group of stakeholders to learn to think together. They become guardians of the emergence of collective intelligence in multi-stakeholder collaborations. This requires the ability to notice patterns in conversations or discern different phases of a communicative flow that require different facilitative moves that make the conversation move on or deepen. Dialogic facilitators develop the ability to see and diagnose dysfunctional patterns in the way stakeholders interact, and find ways to overcome them, if they block progress. At the core of dialogic facilitation is the understanding that the positive results of multi-stakeholder collaborations that bring about transformative change are inextricably linked to the learning journeys of all stakeholders towards creating more constructive human interaction patterns. It is this inner transformation that widens choices for communicating and acting, because people begin to take responsibility for the coherence of the collaboration ecosystem. The example that follows illustrates what this can mean in a complex and conflictual multi-stakeholder collaboration.

\section{CASE EXAMPLE 3.1: STAYING IN THE COLLABORATIVE FIELD - TOWARDS SUSTAINABLE GREEN COFFEE PRODUCTION}
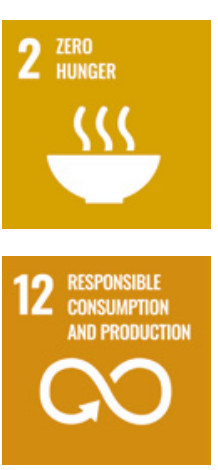

The Common Code for the Coffee Community (4C) that was introduced in Chapter 2 became a pioneering industry-wide model for improving the lives of many small-scale coffee farmers. It contributed to giving consumers environmental and social peace of mind when they enjoy a good conversation over a cup of coffee. But more so, it catalyzed the integration of sustainable sourcing of coffee into a business strategy and supply-chain management in most large coffee-roasting companies. In Phase 3, the stakeholder-composed steering committee meetings took place in different coffee producing countries. One of these meetings was held in Brazil in the year 2004 in the city of Salvador de Bahia. The stakeholders were getting close to jointly agreeing on how cash-strapped small-scale farmers could green their operational practices without going out of business. This required financial support from the large roasting companies who were hesitant to commit, while the NGOs threatened to jeopardize the entire collaboration, if they refused. Tensions were high at the meeting. But stakeholders - coffee growers, roasters, company representatives, leaders from workers' unions and coffee cooperatives, researchers and activists, presidents of coffee federations, government officials, lawyers, and sustainability 
managers - had grown into a diverse community of people who had gone beyond just negotiating their different interests. They felt they had joined a movement for sustainable green coffee production. Different versions of the proposed agreement document had been under discussion for months. The tensions around company commitments had revived mistrust between the coffee industry and international NGOs. At the meeting in Brazil, stakeholders were all aware that a mutual move into the future was at stake. This one step could move the system towards coffee sustainability towards failure or success. The joint learning journey over more than two years had equipped them with the skills to handle a difficult conversation together. Despite all the repeated political fights and contradictory positions, an atmosphere of responsibility for a joint outcome made it impossible for stakeholders to misbehave. They would not withhold their positions, but would proceed the conversation with respect for one another. Each stakeholder took responsibility for staying in the collaborative field. After a lengthy and arduous meeting, the agreement was reached.

Dialogic facilitation is the ability to make things happen through and with others in a way that ensures an ongoing dialogic conversation between people. This is not about false harmony, as disagreements are important in leading transformative change collectively. But it is the ability to help each other in a diverse group of stakeholders through difficulties, to move to a certain end point that consolidates as a joint result, or to reach a new level of thinking together. Dialogic facilitation ensures that:

- Different perspectives or viewpoints of participants are considered, which is particularly important in complex collaborative change;

- The voices of all relevant participants or stakeholders are heard and listened to;

- Meetings are held more efficiently and effectively;

- The quality of decisions is improved and problem-solving is enhanced; and

- More participation, energy, and enthusiasm are encouraged during implementation of decisions.

The ability to take responsibility for and subsequently facilitate collective intelligence processes that lead to engagement and collective action is an important foundation for leading transformative change collectively. Dialogic facilitators enhance the flow of communications towards guided conversations, as well as reflective and generative dialogues. The following deep dives into dialogic facilitation competencies will illustrate how the flow of communication in a group of stakeholders can be positively influenced. The first deep-dive sketches the levels of attention that dialogic facilitators need to take care of. The second deep-dive looks at understanding facilitative interventions and how facilitators can shift conversations towards generative dialogues. The third deep-dive suggests practical hints for designing meaningful conversations.

\section{Levels of attention in facilitation}

Without awareness of the structures and patterns in conversations, participants in or facilitators of dialogues may fail to manage unconscious dynamics that can often lead to 
ineffectiveness in group conversations and stakeholder meetings. Awareness, of course, starts with observation, and this faculty is particularly important in dialogic facilitation. As the conversation proceeds in a group of stakeholders, the dialogic facilitator, even though he or she might be part of the group, starts observing what is happening. With increasing experience, he or she begins to see the patterns in the conversation, notes the flow of energy, and gauges interest and enthusiasm or boredom. Moreover, dialogic facilitators do not just observe others, but also themselves as co-creators of conversational patterns. The ability to observe others' communicative behaviors, to observe the flow of communication among stakeholders, and to stay aware of one's own tendencies in communication requires increased attention to different levels of a conversation at the same time. Ideally, a dialogic facilitator is able to maintain attention on the following levels:

- The individual level (her/his own and that of other people in the group);

- The level of the group process;

- The system level.

All these levels are intertwined and play out simultaneously.

\section{Individual level}

At the individual level, the focus of attention of a dialogic facilitator is on noticing and understanding one's own profile and that of other people taking part in the conversation. For example, each of us may have strengths in certain dialogic practices, while having others underdeveloped. The way these strengths and development areas are often unconsciously enacted needs to be perceived by the dialogic facilitator. This means learning to notice how this has an impact on the flow of the conversation, on how people interact with each other, and on how this leads to a certain outcome of the conversation. A skilled dialogic facilitator would notice which dialogic practices are missing and then ensure they are brought in.

\section{Level of group process}

At the level of the group process the focus of attention is on observing the quality of "being together" in the group, noticing how safe people feel, noticing what can or can't be said. This also means observing the energy level of the group and noticing who is and who is not participating. A skilled facilitator helps the conversation to move into another phase through ensuring weaker voices get heard by inquiring into tensions or by helping the group reflect about the process of the conversation. This can also mean facilitating cross-model conversations that reveal different, if not opposing, interpretations of a certain reality. A skilled facilitator helps stakeholders express these conflicting models and enables others to listen to what is being expressed.

\section{System level}

At the system level, the focus of attention is on contextualizing the conversation between stakeholders in the larger system. This means acknowledging that the way 
the conversation takes place is determined by this context, by patterns of thinking in the system, or by power structures that prevail in the system. It also means connecting not only the content but also the flow of the conversation to the larger "story" that is consciously or unconsciously told about a certain reality. It may reveal underlying dominant thinking paradigms that inform the way stakeholders think about an issue or about each other. A skilled facilitator would inquire into the underlying stories and paradigms.

The different levels of attention enable dialogue facilitators to become more skilled in helping conversations towards increased effectiveness. This is supported by understanding how facilitative interventions work best.

\section{Facilitative interventions}

Dialogic facilitators are committed to helping stakeholders into meaningful conversations and outcome-oriented dialogues. This can much more likely be achieved when conversations move towards reflective and generative dialogues. The choice of facilitative moves to achieve this depends on the situation (Isaacs, 1999). Very formal settings often only permit facilitation moves that guide the conversation towards increased effectiveness. Typical forms of guiding facilitation moves include:

- Bypassing difficulties by asking participants what they suggest would be alternative ways to handle the problem.

- Making sure those who are not actively involved are asked for their opinion.

- Acting like a traffic cop in the conversation, making sure everybody is heard.

- Proactively raising questions about the content.

- In task-based settings, making sure activities remain focused.

- In a dialogic conversation, seeking to maintain balance and easing the flow of conversations.

The more familiar participants have become with the dialogue process the more they can create reflective awareness of the process that influences the communication and apply facilitation moves that belong to naming observations. Typical forms of naming facilitation moves include:

- Offering observations about patterns in communications, such as how people speak or who mostly speaks or perceived differences in viewpoints.

- Expressing observations about critical moments such as repetitions or impasses.

- Inviting reflection on the process of the conversation or certain issues that have arisen.

Skilled dialogue facilitators can take facilitation moves one step further towards engaging stakeholders with questions that take them to a deeper and more reflective or generative level of dialogue. This can immensely contribute to changing the discourse, to generating new content of conversations and it may 
open pathways to novel thinking. Typical forms of engaging facilitation moves include:

- Inquiring into the situation by asking questions that shift the perspective on an issue, such as: what would other people think, if they listened to our conversation? or What, if the way we communicate mirrors the challenge we are trying to address?

- Inviting individuals or the group to tell the story that is behind a certain concern, opinion, or perspective.

- Asking stakeholders to look at the perceptions people have of each other and how they are linked to past experiences.

Such facilitative interventions are situational and require experience with the maturity of a group of stakeholders to move towards high-quality dialogue. But it is possible to prepare the ground for such meaningful conversations.

\section{Designing meaningful conversations}

Actors in multi-stakeholder collaborations often underestimate the impact of the quality of conversations on the outcomes and the time required to get to results. As elaborated in Chapter 2, collaboration ecosystems with multiple and diverse stakeholders are created by building good containers - groups of emotionally engaged and committed people. This is the space in which good and effective conversations take place. They can be seen as a kind of vessel that can hold a lot: the individual and the group, feelings, emotions, the truth, tension, difference, sympathy, antipathy, the stories of the individuals, and the story of the group. The better the dialogic quality of the conversation is the more functional becomes the container for change - the key driver of success. The way people hold each other in respect despite difference in opinion is a key determining factor for the quality of the outcomes of multi-stakeholder collaborations. Dialogic facilitators understand how to create the conditions for such meaningful conversations. When the following sequence of practices informs the agenda design and facilitation of meetings', they ease the way to high-quality dialogues. Table 3.1 summarizes these design practices and illustrates them with examples of facilitation designs.

\section{Design practice \# 1: container}

\section{Giving attention to humanity at the beginning and the end of a conversation}

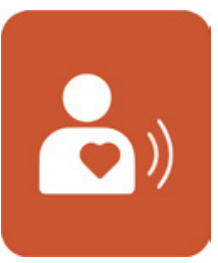

The beginning and the end of a conversation in meetings, workshops, or bilateral talks are of high importance as they determine the climate in which the conversation takes place and is contained. Particularly the beginning sets the tone in which the conversation is conducted, and even though it is often not made conscious, the tone of the beginning creates an invisible agreement in the group about how to act or not to act, what to say or not to say, if to reveal one's truth or not. Both the 
beginning and the end of a conversation can be seen as a gateway, a transition - in the beginning from individuality to collectivity, and in the end the reverse. A consciously created beginning of a conversation allows people to move into the common space in which the conversation shall take place. It helps them to shift from solitude to connectedness. The consciously created end of a conversation helps people to contain the space in which the conversation had been taking place and move back into their individual reality. This is why the beginning and the end of a conversation needs a check-in and a check-out, which is described in Box 3.1.

\section{Box 3.1 Understanding check-in and check-out}

Check-in and check-out are great tools to start and end stakeholder meetings that are meant to become meaningful and outcome-oriented. Checking-in means that every voice is in the room is heard and every person in the room is seen before the actual content conversations start. This can mean that everybody attending the meeting or workshop has the opportunity to say something about where he or she is in that exact moment, how they are feeling, or anything else that is on her or his mind. It helps participants

- to arrive at full presence,

- to take note of all people in the room as people,

- to leave behind other concerns, and

- to focus on the content of meeting.

In multi-stakeholder collaborations we often deal with people that we might not know very well, or maybe even feel resentments towards. Any kind of consciously created informal atmosphere at the beginning of a meeting or conversation is helping for building connections. Therefore, it is important to create an atmosphere of acknowledgment of people's humanity. This little ritual adds a personal note to every meeting that not only boosts the quality but also the efficiency of the conversational process. Opening up the possibility of a check-in at the beginning of the meeting or conversation may feel awkward when people are not used to it, but as people get to know them, check-ins become more and more useful. Therefore, in less formal environments, it helps before using check-in and check-out for the first time, to introduce the concept to the group and explain its effect on the effectiveness of conversations. In more formal environments the check-in may be a very brief introduction of each participant combined with a one sentence answer to a question a facilitator poses, such as: when would you call this meeting a success at the end of today?

There are many variations of check-in or check-out, so it never gets boring, once people have understood the principles of making humanity present. One can use it to tune people into a certain topic, for example by asking them to check-in with what their best experience in cross-sector collaboration was. Another variation is to cut it down to a one-word check-in to get the essence of what people are feeling at that moment. In large groups, it helps assisting people who do not know each other well by asking them to check-in in small groups, and then tune back into the plenary. At the end of each meeting, it is important to honor the collective space and also have a check-out of each person individually before the conversation ends. 
These two examples from the field illustrate the positive effect of a check-in in highly formal environments.

\section{CASE EXAMPLE 3.2: DEVELOPING A FUTURE CHARTER FOR SDG IMPLEMENTATION}

PARTNERSHIPS

FOR THE GOALS

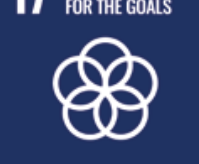

The aim of a stakeholder consultation conference with more than 300 participants convened by the German Government in 2014 aimed to identify core elements of a future strategy to implement the SDGs. The meeting was officially opened by the respective Minister, after which the professional conference facilitator took over. Much to the surprise of all participants, she did not explain the program and introduced the first keynote speaker, but asked the guests to turn to their neighbour, introduce each other, and chat for three minutes about what their dearest aspiration was to collaborate towards achieving the global goals. Only after this check-in did the official program start. It set the tone for person-to-person connections and constructive workshop sessions in the afternoon.

\section{CASE EXAMPLE 3.3: WORKING TOWARDS A WHITE PAPER ON LAND MANAGEMENT IN CAMBODIA}

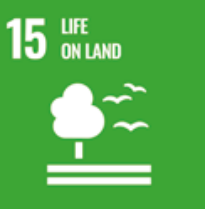

The inter-ministerial technical working group on future land management of the Government of Cambodia met to discuss the joined input for the development of a future-oriented land policy in 2008. In the highly protocol-oriented environment, the meeting began with distinguished speakers on the podium ranging from deputy directors from the collaborating ministries to the Minister of Land Management. The meeting was guided by a skilled dialogic process facilitator who was known to the speakers and had gained their trust in advance of the meeting. After each of the speakers had expressed their views on challenges and opportunities, the facilitator thanked the speakers, invited them to join participants at round tables (which all but the Minister did), and continued with a check-in related to land policy challenges at the tables. This set the tone for inter-ministerial cooperation and paved the way for understanding that land policy was affecting all stakeholders present.

\section{Design practice \# 2: intention}

\section{Connect people with wholeness and future possibilities}

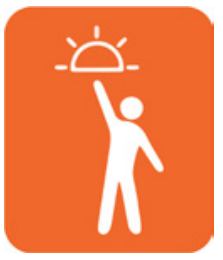

It is common good practice to create clarity of the purpose of a meeting even before the meeting starts. This is usually reflected in the invitation or at least brought to the intention of stakeholders at the beginning of the meeting. The questions that need to be answered by clarifying the intention of a stakeholder meeting are: why are we here? What is the difference we are going to make with this meeting? 


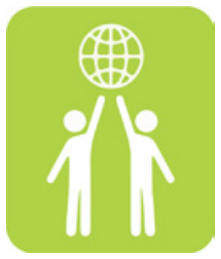

This means creating a joint understanding of what needs to be achieved on the level of content, the level of relationships, and the level of process (see Box 3.2), and captures when the time has been spent wisely. Every successful meeting needs to connect people not only with each other, but also with the joint purpose, a larger story, and an emotionally compelling goal. This is the basis for constructive communication. This connection can then become the catalysing ingredient for agreements how to lead transformative change together.

\section{Box 3.2 The three levels of meeting objectives}

If stakeholders talk about their expectations for a meeting, they naturally refer to the content objectives or tangible outcomes. Only these are usually seen as legitimate achievements. This tends to neglect that it is people with thoughts, feelings, and aspirations who bring collaboration ecosystems to life and enable the delivery of transformative change. This is why it is of utmost importance to become aware of all objectives that are relevant for achieving good meeting results. Hence, when planning meetings, envisaged objectives should be considered on these three levels:

Relationship objectives refer to a change occurring in the way stakeholders are connected or interact with each other, e.g.

- People having a better understanding of each other;

- People getting to know and appreciate each other;

- People getting exposed to each other's experiences, etc.

Process objectives refer to a change in attitude, as well as clarity and perception regarding the way forward, e.g.

- People having a sense of ownership for outcomes and process;

- People understanding how the initiative is embedded in the larger context;

- People feeling their concerns or positions have been heard;

- People being capacitated and sufficiently knowledgeable about the issue at hand.

\section{Content objectives refer to tangible and documented outcomes that create a} change in concrete joint action e.g.

- People come to a consensus on a vision or objective, which gets written up;

- People have agreed on an action plan, signed a memorandum of understanding, developed a roadmap together, or agreed on rules for coordinated implementation, etc. 


\section{Design practice \# 3: frame}

\section{Offer a process structure that ensures engagement}

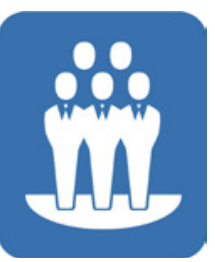

Meetings need agendas as roadmaps so that everybody will feel comfortable where the meeting will be going and when what is going to happen. Such meeting programs create the frame for the collective intention to mature and the collective action to be prepared. They show not only breaks, but also which conversations will take place in the plenary and which in small group discussions. They show something about how the group will work together, which content issues will be discussed when, and at what points results will be consolidated. Knowing and understanding the frame for the conversations creates trust and reliability. It puts stakeholders at ease.

\section{Design practice \# 4: dialogue}

\section{Create conversations that harvest collective intelligence}

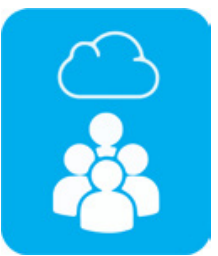

Depending on the history of how conversations have taken place in an institutional setting, people often do not freely express their points of view. Particularly in settings in which hierarchy is rendered important, people who are not in power positions are afraid to speak up. Differences in opinions are not necessarily asked for. From a dialogic standpoint, this means that opposing views that are crucially important in multi-stakeholder collaborations, will intentionally or unintentionally be silenced. This may at times be experienced as speeding up decision-making. In stakeholder meetings, it erodes trust and subsequent engagement and ownership for implementation. Ignorance towards opposers always pays back negatively. The issue here is not to necessarily agree with opposers, but hearing their voices, listening carefully to what they have to say and considering what they say might actually provide a valid contribution. But getting a diversity of viewpoints into a conversation does not only relate to opposers, it also relates to people who are not expressing themselves because they are disengaged or do not trust themselves to have anything important to say. There are various moves dialogic facilitators can use to bring in a diversity of perspectives. For example, asking people who do not speak what they think about a particular issue, inquiring into opposing views, or making transparent differences in perspectives and points of view in a respectful manner. Facilitators need to design meeting agendas so that differences in perspective, various viewpoints, and knowledge can emerge. Only then can they move into consensus building. Any meeting design that deals with content issues needs to ensure such meaningful conversations. Most often, it helps to ask stakeholders to talk about more difficult issues in smaller groups first and then integrate findings or results into the plenary. 


\section{Practice engagement and foster innovation}

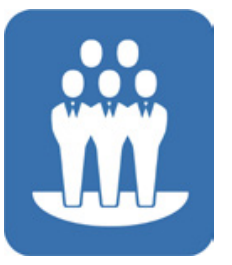

Stakeholder meetings are small and temporary laboratories of the collaboration that needs to happen once the meeting objectives have been accomplished. Engagement that connects people around concrete tasks and that leads to collective action requires practice. If people have managed to achieve jointly created results in meetings, this experience influences the way they will work together in the future. It builds trust into the group's capability to actually do change together and it enormously contributes to the satisfaction of stakeholders with the meeting they have spent time in. Hence, in the facilitative design of stakeholder meetings and the time for working together in small groups to reach a certain output are crucially important. Any intermediate result, however, needs to be brought back as a report to the plenary.

\section{Design practice \# 6: results and reflection}

\section{Ensure pathways towards future possibilities and close with humanity}
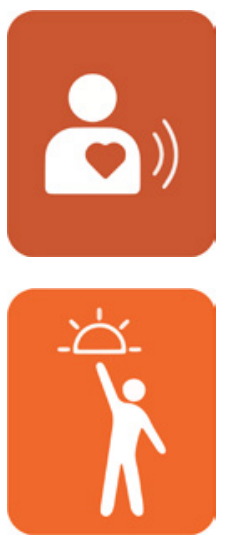

Time pressure in meetings, low quality meeting designs, and overpacked agendas often let stakeholders rush out at the end of a meeting to pursue other tasks. Dialogic facilitators do the utmost best to prevent this as it deteriorates the entire effort of convening stakeholders into meaningful conversations. Stakeholder meetings need a proper ending, of which the check-out is the last step that bridges the flow from the collective endeavor to whatever stakeholders need to move towards individually. The check-out can highlight views about the meeting, but also help each other's understanding that there is a world beyond the meeting that is demanding for each of the participants. However, bringing a meeting back to humanity without having consolidated the results haunts stakeholders sooner or later. It leaves people with the feeling of being unsure what has been achieved and if the time was spent wisely. Moreover, a lack of results consolidation may erode trust: minutes or meetings results distributed a few weeks later may look different from how each stakeholder had perceived results immediately following the meeting. Hence, the design of every stakeholder meetings needs to build into the agenda a summary of meeting results. This means going through the results achieved, the decisions made, or the agreements reached in the plenary at the end of the meeting. This should be followed by an agreement on next steps - a must in every high-quality stakeholder meeting. Only than is it time for a reflective, often short, final check-out. 
Table 3.2 Design practices for co-creative conversations

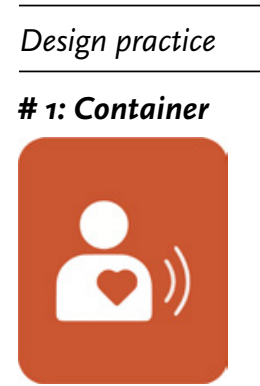

\#2: Intention

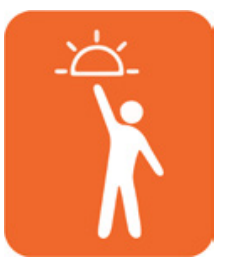

\#3: Frame

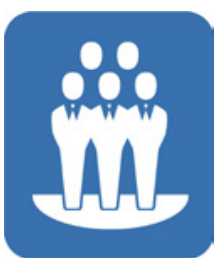

\#4 Dialogue

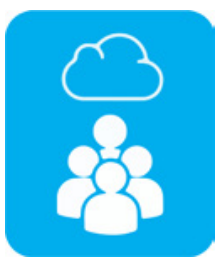

\#5 Collective action

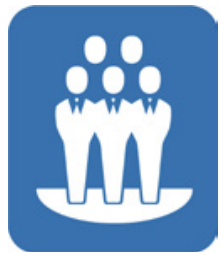

\# 6 Results and reflection

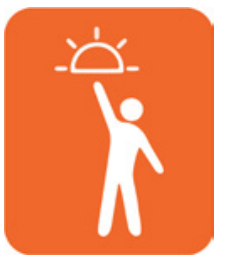

- Why are we here? What can we do to get the purpose of the meeting and the larger issue clear?

- How will we work together?

- What is the time frame?

- What are the responsibilities?

- How will we deal with differences and ensure all voices are brought into the conversation?

- How do we work together on specific tasks? How will we move towards results?

- What did we achieve together?

- How do we create room for reflection?

- What are the next steps?
Examples

- Check-in with personal questions or small round tables using guiding question

- Music and journaling before the beginning

- Coffee break before starting

- Getting together in the evening before

- Being clear about the "Why" of the meeting - Objectives

- Expected results

- Connection to the larger goal

- Agenda points and program flow

- The form of plenary and group interactions and how they are designed to ensure meaningful conversations that bring all voices in.

- The flow of task-related working groups, plenary discussions, content input, reports, or expert inputs

- The Integration of results and joint review, agreement on next steps (what, who, by when) 


\section{CASE EXAMPLE 3.4: EXAMPLE FROM THE FIELD: TOWARDS SUSTAINABLE SUNDARBANS MANGROVES IN INDIA AND BANGLADESH}
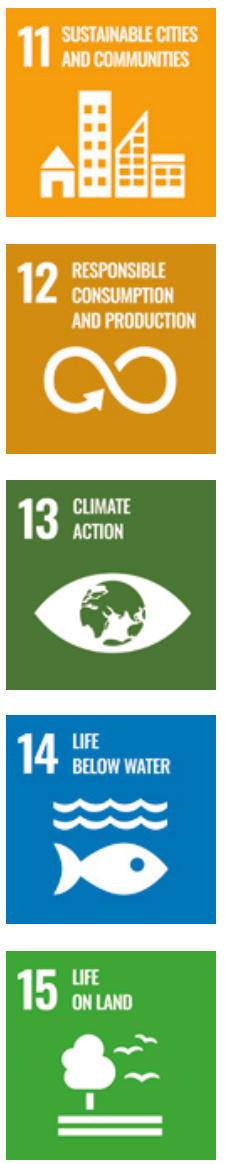

PARTNERSHIPS FOR THE GOALS

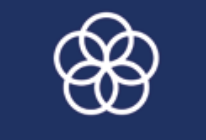

The transboundary Sundarbans mangrove forest, at $10,000 \mathrm{~km}^{2}$, is the largest in the world. It is, however, being degraded on multiple fronts including, for example, by large-scale, commercial shrimp farms. In this context, the Global Nature Fund (GNF) and the Naturland Association from Germany partnered with the Nature, Environment, and Wildlife Society (NEWS) in India and the Bangladesh Environment and Development Society (BEDS) to initiate a multi-stakeholder partnership for restored mangroves and thriving coastal communities. In preparation of a first engagement workshop that would set the tone for effective collaboration, a dialogic process facilitator convened a series of preparatory calls with key actors from the collaborating partners. Focus was on how joint vision development would strengthen the formation of the core group of partners as a container across the two countries, while remaining specific and relevant to the situation in each of the countries. It became clear that actors needed to share their understanding of the context as well as how to best create resonance for the initiative, led by the partners, among the stakeholders in the coastal communities. The aims of the meeting were finally agreed as

- Build a common understanding of the challenges in the mangrove ecosystem.

- $\quad$ Create a joint vision for the partnership.

- $\quad$ Strengthen trust and a desire among partners to work towards the vision collectively.

- Build commitment for taking next steps and identify capacitybuilding needs.

The first one-and-a-half-day workshop was held in India with the majority of participants brought in by NEWS, but joined by two representatives from Bangladesh. The second workshop was conducted in Bangladesh with the majority of participants brought in from BEDS, yet joined by two representatives from India. This strengthened the identity of the core group, helped them demonstrate their commitment to the partnership in the eyes of participants, and communicated the transboundary nature of the partnership. Round tables were selected with seating deliberately mixing people from different sectors to encourage exchange, learning, and connection. The workshop goals were arrived through a combination of contextual inputs from core group members, facilitation of a guided visioning process ${ }^{2}$ as depicted in Figure 3.3, and formation of action-oriented working groups by participants.

The working groups, both in India and Bangladesh, focused on: Mangroves, livelihoods and communities, as well as shrimps value chains. The agreed results from the workshop included: key milestones to pursue in 2020 , additional stakeholders to involve, 


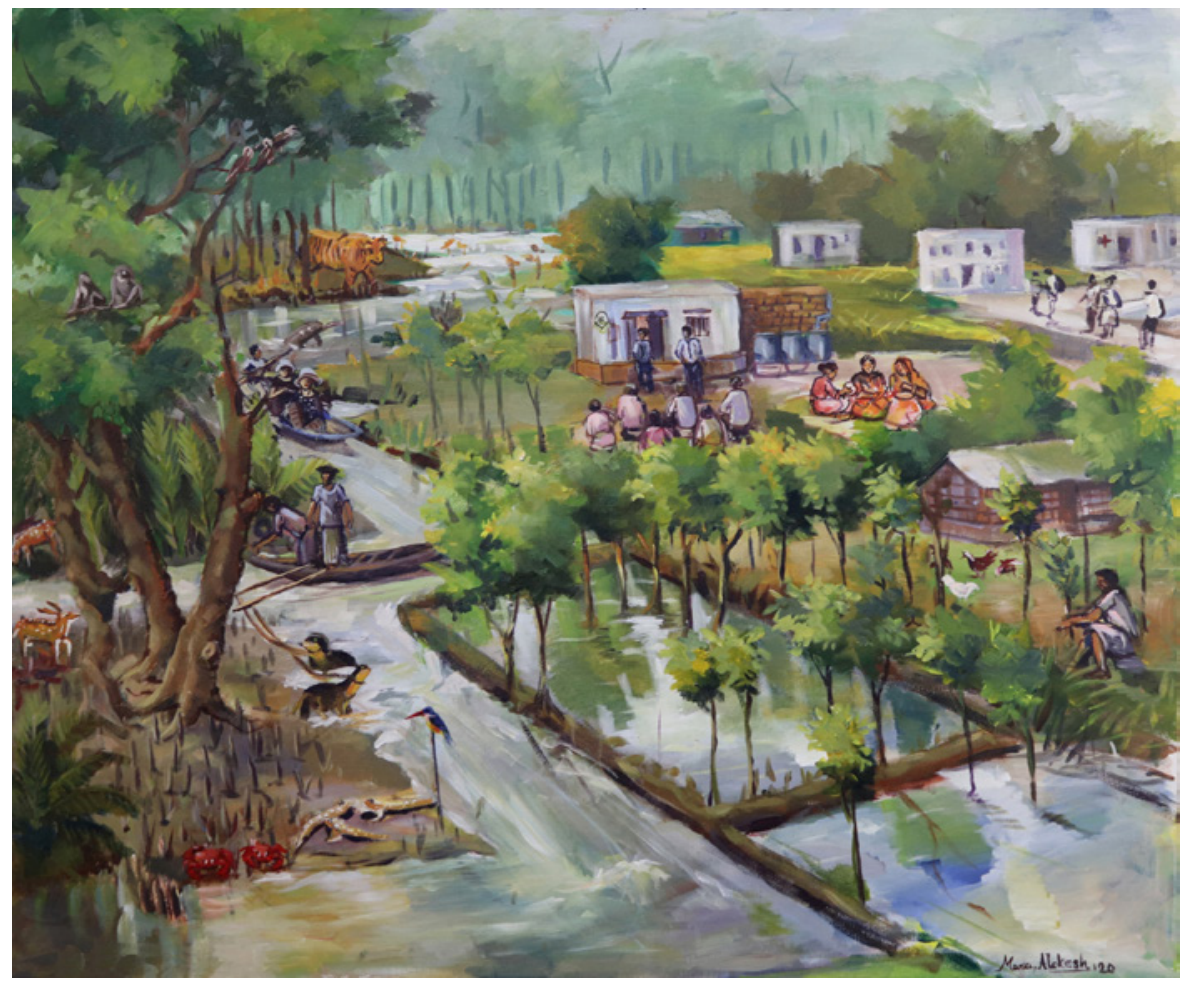

Figure 3.3 Shared vision for healthy Sundarbans mangrove, thriving coastal communities, and robust aquaculture value chains

Table 3.3 The workshop flow in relation to the design practices

\begin{tabular}{|c|c|c|}
\hline sign practice & Guiding questions & Workshop design \\
\hline \# 1: & $\begin{array}{l}\text { What can we } \\
\text { do so that } \\
\text { people can } \\
\text { encounter each } \\
\text { other as peo- } \\
\text { ple and respect } \\
\text { one another? }\end{array}$ & $\begin{array}{l}\text { - Welcome by BEDS representative and introduction of } \\
\text { core group } \\
\text { - Participant introductions with the Check-in ques- } \\
\text { tion: "What is one, key reason why you came to this } \\
\text { workshop?" }\end{array}$ \\
\hline \#2: Int & - W & - Su \\
\hline & $\begin{array}{l}\text { we do to get } \\
\text { the purpose } \\
\text { of the meeting } \\
\text { and the larger } \\
\text { issue clear? }\end{array}$ & $\begin{array}{l}\text { Build a common understanding of the challenges in } \\
\text { the mangrove ecosystem } \\
\text { o Create a joint vision for the partnership } \\
\text { o Strengthen trust and a desire among partners to } \\
\text { work towards the vision collectively } \\
\text { - Build commitment for taking next steps and identify } \\
\text { capacity building needs }\end{array}$ \\
\hline
\end{tabular}




\begin{tabular}{|c|c|c|}
\hline Design practice & Guiding questions & Workshop design \\
\hline \#3: $F$ & $\begin{array}{l}\text { - How will we } \\
\text { work together? } \\
\text { - What is the } \\
\text { time frame? } \\
\text { - What are the } \\
\text { responsibili- } \\
\text { ties? }\end{array}$ & $\begin{array}{l}\text { - Workshop program overview, goals, and workshop } \\
\text { agreements }\end{array}$ \\
\hline$\#_{4} \mathrm{Di}$ & $\begin{array}{l}\text { How will we } \\
\text { deal with } \\
\text { differences } \\
\text { and ensure } \\
\text { all voices } \\
\text { are brought } \\
\text { into the } \\
\text { conversation? }\end{array}$ & $\begin{array}{l}\text { - Creating a shared understanding of the context through } \\
\text { elaborating different perspectives on sustainability } \\
\text { challenges in the mangrove ecosystem, such as: } \\
\text { o Coastal Conservation and improving livelihoods } \\
\text { through Integrated Mangrove Aquaculture } \\
\text { o Promoting mangrove protection and sustainable } \\
\text { aquaculture } \\
\text { o Socioeconomic and socio-environmental develop- } \\
\text { ment in the Sundarbans }\end{array}$ \\
\hline \multirow[t]{2}{*}{$\begin{array}{l}\text { \#5 Collective } \\
\text { action }\end{array}$} & $\begin{array}{l}\text { How do we } \\
\text { work together } \\
\text { on specific } \\
\text { tasks? How } \\
\text { will we move } \\
\text { towards } \\
\text { results? }\end{array}$ & $\begin{array}{l}\text { Session 1: } \\
\text { - Creating a shared } 2030 \text { vision for the multi-stakeholder part- } \\
\text { nership towards a sustainable mangrove ecosystem: healthy } \\
\text { mangroves, thriving coastal communities, and a robust } \\
\text { aquaculture value chain in the transboundary Sundarbans } \\
\text { - The workshop process: creative guided visioning, individ- } \\
\text { ual, pair, and small group work; consolidation through } \\
\text { small group presentations, discussion on specifics and } \\
\text { creating an overall image, supported by a volunteer artist; } \\
\text { collecting any inputs on draft vision poster }\end{array}$ \\
\hline & & $\begin{array}{l}\text { Session 2: } \\
\text { - An invitation to engage: brainstorming next steps } \\
\text { together for working towards the vision through } \\
\text { - The workshop process: } \\
\text { o Outlines examples of multi-stakeholder dialogue forums } \\
\text { that exist and need to be supported to achieve the vision. } \\
\text { - Working groups focused on the topics: } \\
\text { o Protecting and restoring the transboundary man- } \\
\text { grove ecosystem } \\
\text { o Promoting integrated mangrove aquaculture for } \\
\text { sustainable livelihoods and thriving communities } \\
\text { o Promoting collaboration along the aquaculture value chain }\end{array}$ \\
\hline $\begin{array}{l}\text { \# } 6 \text { Results } \\
\text { and Reflection }\end{array}$ & $\begin{array}{l}\text { - What did or } \\
\text { can we achieve } \\
\text { together? } \\
\text { - How do we } \\
\text { create room } \\
\text { for reflection? } \\
\text { - What are the } \\
\text { next steps? }\end{array}$ & $\begin{array}{l}\text { - Revisiting strengths and contributions of the partner } \\
\text { organizations } \\
\text { - Identifying capacity needs } \\
\text { - Agreeing on communication procedures. } \\
\text { - Workshop feedback, closing words, check out circle }\end{array}$ \\
\hline
\end{tabular}


stakeholder dialogue events to engage new actors, and possibilities for pilot initiatives. Table 3.3 shows the flow of the workshop program in relation to the design practices.

\section{Dialogic process facilitators: stewards of aliveness in collaboration ecosystems}

Dialogic facilitation skills for high-quality stakeholder meetings are important. However, the role of collective leaders in multi-stakeholder collaborations goes further. Collective leaders need to become dialogic process facilitators. This means that their ability to shift communication patterns among diverse and often conflicting stakeholders towards life-enhancing patterns is not only enacted in stakeholder meetings, but relates to the design and implementation of the entire multi-stakeholder collaboration throughout all four phases of the Dialogic Change Model. Dialogic process facilitators support collaborative interventions into complex stakeholder systems. They act as stewards of transformative change. This contributes tremendously to a collectively held vision for change and, subsequently, to joint implementation. Actors who have gained such skills play an important role in multi-stakeholder collaborations for successful implementation of the SDGs. They embody the faculty of leading transformative change collectively. They take care of the future and venture into the unknown. They take the road less travelled if it leads to innovation and allows them to test new approaches. They are visionaries who keep a sense of wholeness alive and connect with future possibilities. They harvest collective intelligence by crafting consensual agreements among diverse perspectives with respect for difference. They inspire others towards engagement with an emotionally compelling goal. They enliven people's humanity, are masters of relationship management, and create a context of trust and continuity. They deal with conflicts and crises constructively and know that these are, in fact, often opportunities for innovation. They followthrough on agreed action. Dialogic process facilitators know that they are stewarding the collaborative field of multiple stakeholders towards increasing systems aliveness well when there is an atmosphere of commitment that makes it impossible to jeopardize outcomes despite differences in opinions and positions. When stakeholders stay in the collaborative field despite occasional mistrust, difficult to negotiate progress, and lived-through tensions, then dialogic process facilitators have done their job. If this level of commitment has been achieved, then the system of collaborating stakeholders has matured. The collaboration ecosystem will deliver transformative change. What are the six tasks that dialogic process facilitators as stewards of collaborative change actually do?

\section{\#1 Build purpose: future possibilities}

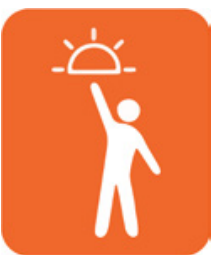

People, no matter where in the world, have a core desire to shape a better future, at whatever scale. Such an emotionally compelling purpose orients and motivates us. A collective purpose empowers diverse change agents and gets actors into the collaborative field. Dialogic process facilitators foster the sense of purpose through broadly shared vision development that is accompanied by an 
inspiring narrative encouraging everybody to take action towards a more alive future. This is greatly supported by creating an atmosphere of inspiring and forward-looking dialogic conversations. They also facilitate learning about the different stakeholders, and becoming sensitive to the needs of stakeholders.

\section{\#2 Create circles of belonging: engagement}

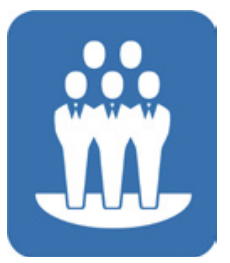

Collaboration ecosystems require meaning and identity without shutting themselves off from other stakeholders. A sense of belonging to a collaborative change endeavor is crucially important, even if the rules of who is in and who is out, once set, will not remain forever. As stewards of transformative change dialogic process facilitators build in a step-by-step approach - collaboration ecosystems that stakeholders are proud to be part of. They design encounter and connectivity between stakeholders in a way that they drive collective action, centered around the purpose, while retaining the ability to adjust to trends and developments. These collaboration ecosystems across institutions, societal sectors, nations, and cultures mature with the practice and experience of tangible results in implementation.

\section{\# 3 Prototype the future: innovation}

Thriving systems constantly seek new possibilities to evolve. Multistakeholder collaborations do the same. This is why dialogic process facilitators focus on developing prototypes of the future: this could be social or technological innovations, co-designing innovative strategies, creating new alliances, or shedding what no longer works. Such innovations need to be connected to the purpose of the multi-stakeholder collaboration, and based on state-of-the-art expertise. This also requires a continuous learning focus. Getting feedback from stakeholders, doing research on impact and redesigning strategies based on reviews, is their ongoing job.

\section{\# 4 Build reflection into action: humanity}

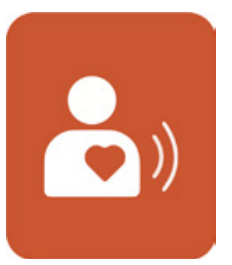

Dialogic process facilitators establish a culture of strategic reflection among stakeholders. They organize expert input, learning journeys, or exposure trips - whatever is needed to shift mindsets or open hearts to change, and helps people to see not only future possibilities, but also the potentials in each other. They bring in knowledge and information about content issues regarding the purpose of a multi-stakeholder collaboration wherever they can. This may include exposing people not only to information on sustainability threats and opportunities, but also to different worldviews and different experience. With that, collaboration ecosystems mature, become more resilient and stakeholders become able to lead transformative change collectively. 


\section{\# 5 Harvest diversity for dialogue: collective intelligence}

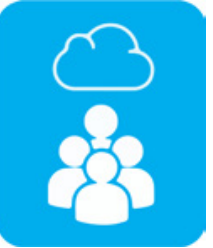

Everything in the world is connected and in constant communication. Multi-stakeholder collaborations design this interconnectedness consciously in networks of stakeholders across institutions. Dialogic process facilitators foster the capacity to connect and dialogue among stakeholders, because they know that diverse perspectives

help map the best way forward. They embody how to stay open to difference and organize constructive conversations. If need be, they contain the capacity to dialogue in multi-stakeholder governance structures, consultative events and collective action teams that drive the cooperation.

\section{\# 6 Emphasize a systems view: wholeness}

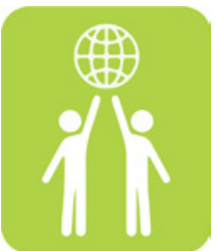

In biology, living systems can only thrive as part of or in mutual support with other systems. There is no contradiction between parts and wholes. Silo approaches and competition would not work for life to thrive. As stewards of systems aliveness for transformative change dialogic process facilitators acknowledge this simple wisdom. They encourage stakeholders to overcome silo mentalities and territorial fights. They steward collaboration with other initiatives and foster everybody's understanding of the context, the larger system or the bigger story a collaboration ecosystem is embedded in.

These six tasks are shown in Figure 3.4 in their connection with the six dimensions of the Collective Leadership Compass. Dialogic process facilitators foster communication, tap into people's creativity, and cultivate relationships. They do this with an inner attitude of service and an orientation towards performance. This is an art of leading that maintains perspective in the face of crisis, and uses conflict productively to

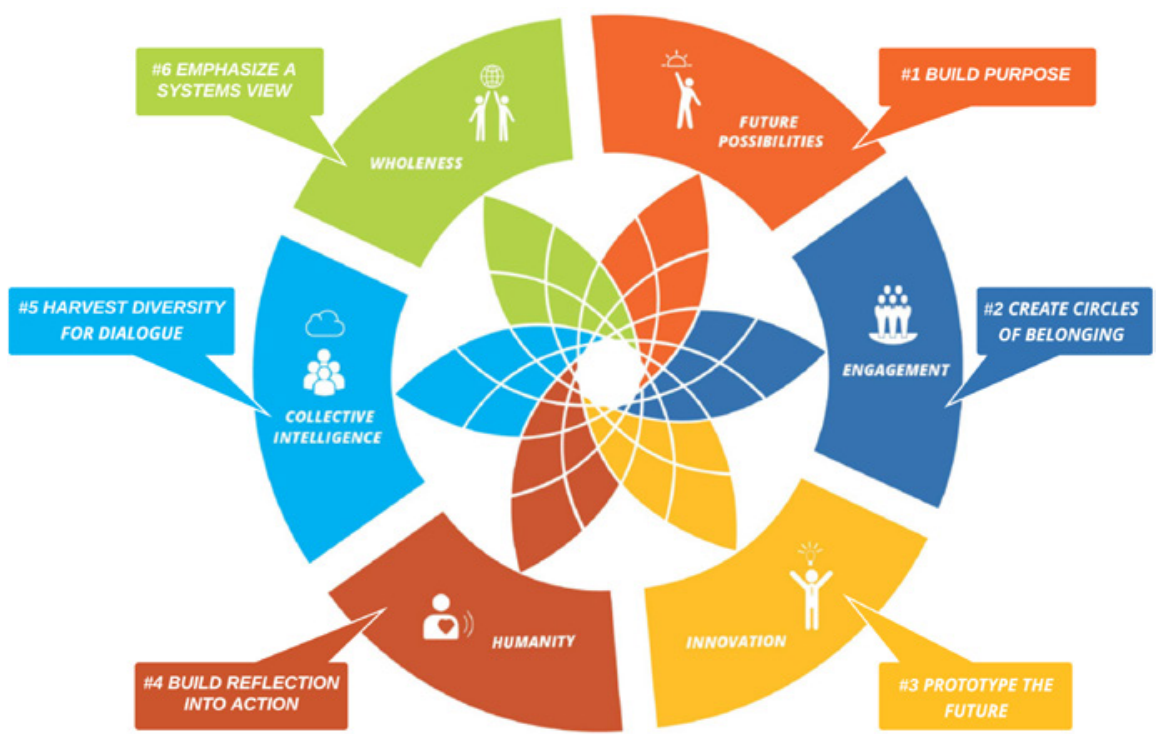

Figure 3.4 The six tasks of dialogic process facilitators 


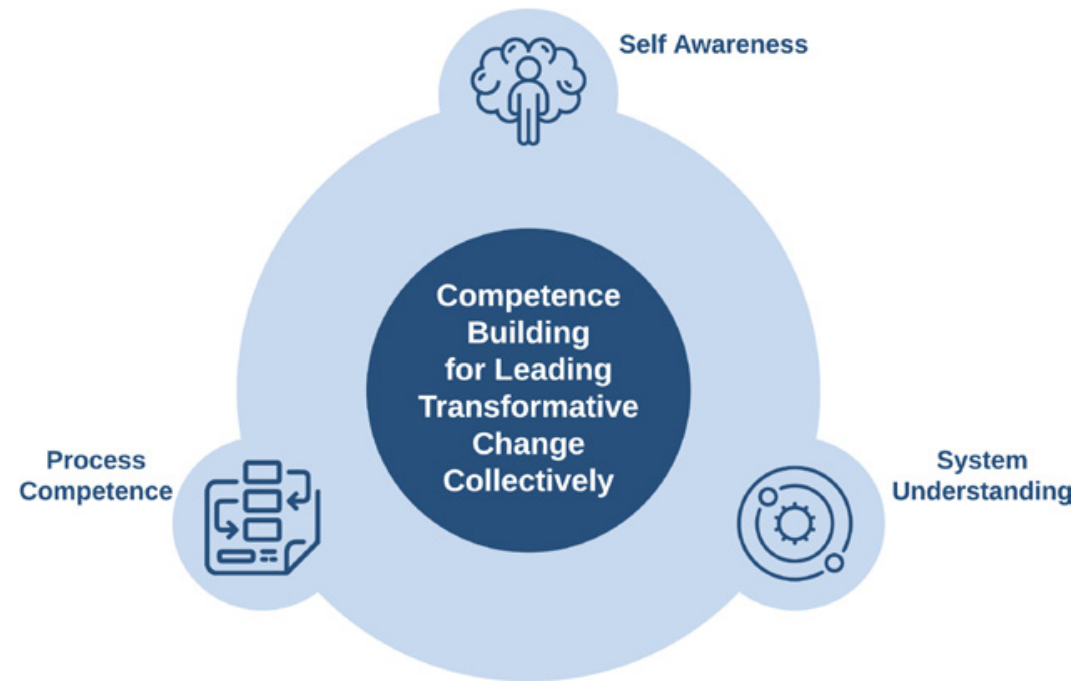

Figure 3.5 The three levels of competence building for dialogic process facilitators

Source: Collective Leadership Institute

access collective wisdom. It aims at bringing forth new possibilities. Ideally, this can unblock stuck energy among different players, create a healing atmosphere, and allow people to engage in meaningful conversations and collective endeavors. Dialogic process facilitators know that change in action is always preceded by change in thinking. They learn to tune into the complex system of actors by acknowledging differences and developing an art of communication that furthers thinking together. They know when people speak their truth, and when relationships receive enough attention that changes in thinking are more easily achieved, understanding between different stakeholders grows and so does tolerance. They know that vision, values, and direction can take on deeper meanings, if held in a collective space. One of the most important facilitation tasks is, therefore, the creation of 'space' for people to communicate well together while creating new realities, as outlined in the previous sections. This paves the way for multi-stakeholder collaborations becoming catalysts for transformative systems change. In order for dialogic process facilitators to become collective stewards of transformative change they need to continuously advance their capabilities in selfawareness, systems understanding, and process competence (see Figure 3.5). The deep dives that follow will illustrate in an exemplary way how to advance these capabilities.

\section{Cultivating self-awareness}

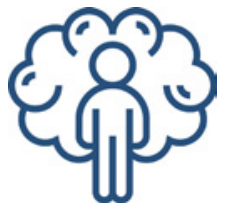

SDG implementation is focused on solving specific problems, on finding solutions to social and environmental challenges, and on taking action to change collective behavior or institutional trajectories. However, the elaborations about how to make multi-stakeholder collaborations work so far conveyed the insight from extensive 
practice experience: issue-focused multi-stakeholder collaborations become successful when they are accompanied by an increasing mindfulness towards the way people operate as part of institutions, how they communicate with each other, and how they relate to different interpretations of reality. Self-awareness, therefore, is not a nice-tohave faculty that may create more harmonious collaboration: it is the acknowledgment that we, as humankind, and the way we act together have created the challenges that we are trying to solve. Awareness begins at the individual level and is always curative (Kuenkel, 2008). The individual process of learning results from moments of introspection, either as a consequence of difficult experiences, encounters with other people, exposure to different worldviews, or the practice of contemplation. We may ask ourselves more truthfully if the dynamics we see and the dynamics we ourselves cause are fragmenting forms of co-creation or sustainable patterns of co-creation. The answer is not important - what is important is to recognize co-creative patterns that are life enhancing. We can learn from these. This is what we need more of.

Taking care of life-enhancing patterns of co-creation among stakeholders might be more time-consuming in the beginning. It calls for more complex approaches to change. But eventually, becoming aware of patterns of aliveness in the interaction between stakeholders helps actors to foster them, which in turn leads to increased effectiveness in the collaboration endeavor. This can only emerge with reflection and space for insights to emerge. If dialogic process facilitators and collective leaders of transformative change want to contribute to the wholeness of the world, they need to understand their own helpful and unhelpful contributions in bringing about or preventing change in collaboration. One aspect of this is the ability to see their own story in the midst of other stories and to gain a deeper empathy for themselves and others. When this happens, when the heart is touched by insight and human experience, the way people communicate shifts and matures. Deeper awareness is not self-indulgent introspection for its own sake. It is a gateway to leading transformative change collectively. When mindfulness grows, an appreciation of all components of experience grows and new options for action open up.

There are many different routes to introspection, self-reflection, and understanding one's own patterns in leading collectively. This practitioner's guide will focus on two deep dives that look at individual strength of a dialogic process facilitator and collective leader, and that are strongly connected with the purpose of bringing about change in collaboration with others. Both of them support not only self-awareness, but can also be used to understand interaction patterns among stakeholders. The first deep-dive looks at reviewing competence patterns with the Leadership Compass. This then becomes the basis for contributing in a more constructive way to collaborative processes, and it paves the way to observing the strengths and development areas of other stakeholders. The second deep-dive looks at typical leadership archetypes and how they play out in the way leaders bring about change. This helps to better understand the dynamics that emerge among stakeholders who may lead from very different archetypes.

\section{Competency patterns}

At the level of individual self-awareness, the Collective Leadership Compass helps to identify collaborative competency patterns. Understanding in which Compass 
dimensions we are particularly strong strengthens our leadership capacity as dialogic process facilitators for two reasons. First, it enables us to work more consciously with our strengths in leadership and facilitative actions. Second, it helps us to attend to our development areas or identify the support we need from people with complementary patterns. This can be done by deliberately bringing in other stakeholders or other leaders who are particularly strong in other dimensions. Nobody can be strong in all six dimensions at the same time. But bringing in all dimensions into transformative change processes in multi-stakeholder collaboration is important. Here, diversity in competency patterns among people who lead transformative change collectively counts. Difference in competencies becomes an asset. Acknowledging our own competency pattern can also inspire us to build it further, as leading collectively is best built on strength. It also supports us in planning action in a way that it works for better co-creation in the system of stakeholders. Using the Compass to identify competency patterns in leading change also sharpens the attention to the competency patterns of other stakeholders. This, in turn, helps understanding systems and patterns of interaction among stakeholders.

Dialogic process facilitators can use the Compass for identifying competency patterns when

- They want to understand their most natural competencies that often unconsciously inform the way they collaborate and lead change.

- They want to understand how strong areas or development areas influence their effectiveness in leading transformative change collectively.

- When they want to explore the competency pattern in relation to a specific situation or challenge in multi-stakeholder collaborations.

This is best done by taking a deep dive into the Collective Leadership Compass. For a better understanding of the dimensions and aspects, it is helpful to review the overview of the Collective Leadership Compass from Chapter 1 (page $\mathrm{xx}$ ). After going through the descriptions of all dimensions and aspects, it is easier to consider what one's most natural competencies are, in aspects and in dimensions (Alternatively use the online tool at www.compass-tool.net). The following steps are recommended:

Step 1: identify your strongest dimension

Step 2: now think about the next two dimensions that are most natural for you. Bring your three strongest dimensions into a sequence. Your strongest dimension comes first, followed by the second strongest, third strongest, etc.

Step 3: look at the remaining dimensions and decide the further sequence, until you have put all six dimensions in your particular order.

Step 4: note down any thoughts or insights that are coming up in relation to the result.

Step 5: go through the entire Compass again and look at the aspects for each dimension. Note down three aspects that you think you need to attend to and develop further. Jot down one sentence about why you need to develop them (what would be the impact?) and how you could do this. 
Step 6: look at all the results and note down your three most important insights about how this affects the way you lead change or facilitate communication.

Step 7: if several people (for example in a core group) do the exercise individually at the same time, you can then share the results and look at which competencies are available within the group and which are missing. Reflect on the impact this has on the collaborative change process and how you might be able to bring in the missing competencies.

Figure 3.6 shows an example of a competency pattern of a person who is particularly strong in future possibilities, an inspirational person committed to driving change by inspiring stakeholders to take action. Engagement comes second for this person, whose strong aspect is collective action. For her, it is about getting things done together and her strength is in making a group of people commit to change. She loves to work in a team of people who have a vision for the future. For her, this means being constantly creative, with innovation being her third strength. While wholeness only

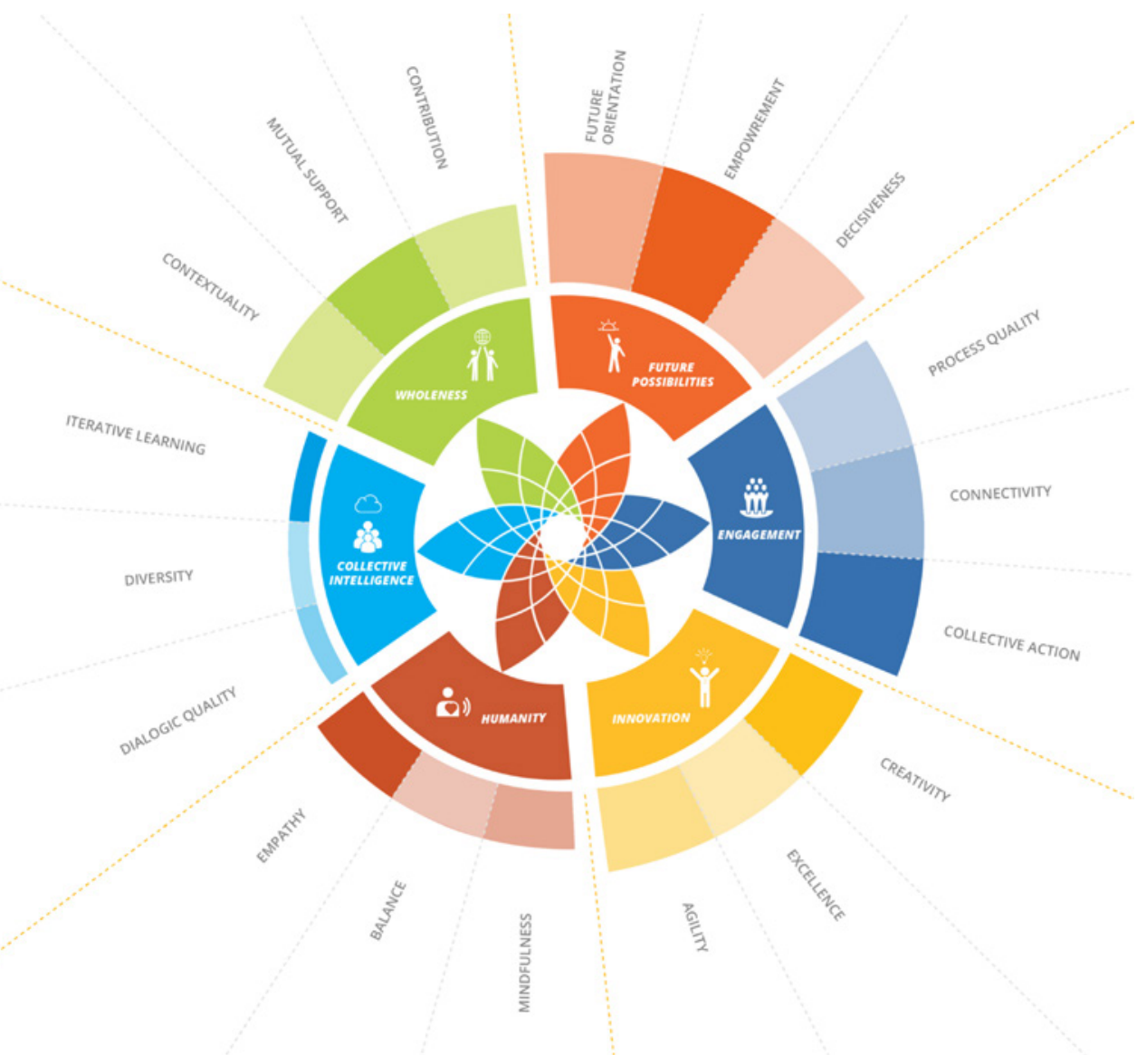

Figure 3.6 Example of a competency pattern 
in fourth position, the connection to the larger goal is important for her, although she does not feel the need to be the person who wants to deal constantly with the complexity of the context and the overall impact of the stakeholders' actions. She thrives on mutual support, which is expressed in her love for teamwork and collective action. Humanity is important for her, but her drive towards action may at times lead to her neglecting the people-aspect of delivering change. With collective intelligence coming last, she admits that dialogic facilitation is a challenge for her, as she tends to be solution and action focused, while spending time in meaningful conversations often tests her patience. But she is good at iterative learning, because this supports her action-orientation.

This example illustrates that this person, if developing her skills as a dialogic process facilitator can build inspiring action on her strength, and may have to either cultivate her skills for dialogue or collaborate with another person who is strong in the dimensions of collective intelligence and humanity.

As we contribute more and more to enacting all Compass dimensions, it makes us feel more alive. We can look at our own competency pattern with the intention of becoming more flexible in our contribution. It is important that we complement our outward leadership for sustainability with our own internal growth. Using the Compass to identify a competency pattern for leading transformative change can be done individually, with a peer coach, or in a core group of stakeholders. It enhances the awareness of capacities, the acknowledgment of development areas and complementary strength. Discovering similarities and complementarities grows trust and confidence in the ability of the group to lead transformative change collectively.

\section{Leadership archetypes}

These example showed how the awareness of competency patterns and preferences in enacting certain Compass dimensions influences the way we lead more than we would usually notice. If we remain unaware of our impact on others or on a situation, we re-create fragmentation, cause conflicts, or remain ineffective in stakeholder systems. The more we can expand our skills or consciously let them be complemented by other, the more we reconcile with our own and others' shortcomings. This is a great step into honoring our own and others' humanity as well as diversity. The observation of our preferences and the expansion of our possibilities can also be greatly supported by a leadership model that is based on archetypal leadership energies. All of them bring forth a certain aspect of contributing to the whole, yet, in their togetherness, they can shift a situation towards healing and collective intelligence. We may recognize which energy we are used to cultivating and displaying and which we have alienated ourselves from. This can be a step towards deeper integration when we gradually unleash our potential so that we can embrace all the energies and apply them when they are needed in order to provide what is missing in any given situation. Figure 3.7 shows the four archetypal leadership energies: the sovereign, the lover, the warrior, and the magician. ${ }^{3}$ 


\section{Sovereign energy \\ Taking initiative}

Being inspired by the idea that will work

Speaking on behalf of the whole

Self-confidence and trust in others

Magician

Ensuring perspective

Holding differences and the process

Stepping back to observe

Ability to create safety

Multi-level insight

Involved detachment

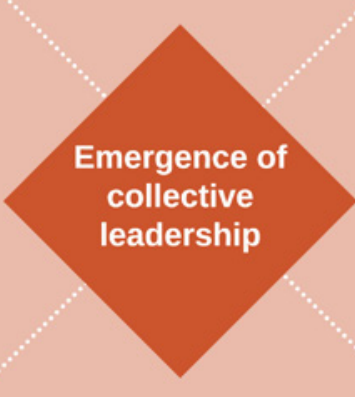

\section{Warrior}

Challenging respectfully

Following a mission towards a larger goal
Lover energy

Feeling empathy

Experiencing it from the other's point of view,

Taking care of the other

Surrender to intuition

Patience

Ability to nurture

Clarity of boundaries

Willingness to perform

Decisiveness and determination

Figure 3.7 The leadership archetypes

Source: Kuenkel, 2008; inspired by Cliff Barry

\section{\#1 The sovereign leadership energy}

We have a preference for sovereign energy when we are used to leading up-front with a strong voice and the expectation that we know the right path. In our fully developed sovereign energy we feel connected with our center. Mythologically, the sovereign speaks on behalf of 'the whole', but in fact, the whole is speaking through him/ her. Characteristic of sovereign energy is centeredness and calmness, the capacity to decide, as well as organizing and creative power, a focus on structure, and an attitude of service. Ideally, in sovereign leadership, we live what we expect from others. We are firmly behind a goal we believe in. We are prepared to inspire others to join us. From sovereign energy we see in other people their value and potential without needing perfection - we want to contribute to them making use of their potential. 
The trust we have in ourselves stems from a trust in life, and the knowing that what we follow is a purpose in service of life, a purpose that goes beyond our individuality. Our integrity and authenticity are visible, we have a clear mission, and we speak from the heart. We take initiative not from self-interest, but in the interests of all. Progress inspires us. We are convinced that the whole is best served through giving direction and inspiration.

When we lack sovereign energy, we find it difficult to believe in our path. Our voice may be weak and we withhold what we really need to say or do. We lack trust in our abilities to contribute, we doubt our initiative and find it difficult to act purposefully. We gladly delegate the upfront leading to other people. If we overemphasize our sovereign energy, we might be in danger of moving into our shadow side. This happens under stress or when we lose the connection to the whole and our deeper self. The most obvious symptom is that we ignore participation and feedback. If things get worse, we become narcissistic and suffer from vanity. As the imbalance progresses, ignorance of our own weakness grows and we become dominant, dictatorial, abusive, or simply tyrannical. We sustain our power by all means, and do not allow the slightest criticism. Cruelty is the logical consequence. As a shadow sovereign, we impose our law on others.

\section{\#2 The lover leadership energy}

When we have a preference for the lover energy, we like to create connection above everything else. We deeply know and feel that all is one, all is interconnected and interdependent. We sense that boundaries are permeable and separate identities are just different manifestations of the great life force that binds everything together. When we lead with lover energy, we take care of others and try to enhance their life force, their beauty, and their inner strength. We know empathy and often act out of intuition. We ensure inclusion and participation and do not rest before we are assured that all voices are heard. We cultivate the art of relating to others. Our prime mode is giving and we pour out compassion from a never-ending source. We are passionate about our purposeful action, and love beauty and the arts. We feel connected to the creative force of life, and foster innovation. In the lover energy our prevailing state of mind is gratitude; we can see the beauty in life's details, a smile in the street, a beautiful landscape, a child playing, a blossoming flower, an encounter with another human being. We are convinced that the whole is best served through inclusion and community building.

When we lack lover energy, we feel cut off from our center, from the creative life force and from our emotions. We hardly express what we feel. We become depressed and forget what life is all about, or we neglect all personal aspects including our own. We are constantly driven and do not consider relationship building very important. When our lover energy becomes disconnected from our center, we feel dependent on other people's approval, their attention, and thrive only where we are emotionally supported. We can become restless in the search for a feeling of an ultimate unity that cannot exist in the material, the physical world. We avoid conflicts and want to create harmony at all costs. We develop a tendency towards possessiveness, looking for nourishing life energy through encounters with other people only. As the imbalance progresses, we become addicted to people or substances. 


\section{\#3 The warrior leadership energy}

When we have a preference for warrior energy, we admire mastery and professional clarity. We believe in discipline and hard work. Our centeredness is based on skillfulness and concentration. We happily serve a purpose that requires us to use all our strength and capability. What we do, we do with courage and determination, and believe that obstacles are to be overcome. We know how to assert our boundaries and are willing to fight for a goal we can happily serve and align with. When we fight, it is for a purpose beyond our individual self and in the interest of a larger goal we believe in. We are inspired by change for the better, even at the risk of our own life. Our invulnerability stems from our inner source of clarity and alertness. What we do, we do thoroughly. When we know what to fight for, we feel the vitality of life, with respect for both fellow warriors and enemies. Our prime mode is action and quick decisions, and we avoid doubt and hesitation. We sometimes see reflection as a waste of time. Honesty, ethics, and truthfulness guide us. We usually have analytical skills and can cut to the core of the matter. We are not afraid of conflicts if they are necessary in achieving our goal. Our limits are those we set and we experience difficulties as challenges. We believe that the whole is best served by performance, mastery, and determination.

When we lack warrior energy, we find it difficult to handle confrontations and steer through crises. We have difficulty committing to anything and lack determination because we are not sure about the goal. We hesitate because there are too many aspects to consider. We easily give in and often let other people walk over our boundaries. We lose access to our vital energy and feel like a victim or a wounded warrior. When we overemphasize warrior energy, we begin to enjoy fighting for the sake of fighting. It becomes a habit. We might get attached to the feeling of victories and the thrill of warrior mode. We can lose ourselves in the pursuit of a false goal, or fighting on behalf of people who did not mandate us to do so. We dismiss people who do not display the same warrior energy and do not accept them as equals. We concentrate on performance only and are in danger of moving into burnout. When we lose our center, every move around us becomes a potential attack and we may become violent. We build armor around us and display no emotions.

\section{\#4 The magician leadership energy}

When we have a preference for magician energy, we have a good sense of the whole as well as its parts and are skillful in navigating between the two. We know how to connect the individual with the larger issue, and this is why we invite and integrate a variety of perspectives. We like to lead from behind, and often through facilitation. The magician knows that there is more to reality than what can be seen on the surface. We are like a shaman or a healer who is prepared to connect the surface level of reality with a deeper level. This understanding of the connection between the invisible and the visible world enables us to access meaning and purpose on a deeper level. We can help people make sense of their tasks and their path. We are aware of processes and the link between process and outcome. We can guide through detached involvement, through our capacity to gain perspective in the middle of a storm. We see interdependencies, rhythm, and relatedness other people don't easily notice. We can shift 
outcomes by changing the discourse in conversations, because we ask questions that resonate with people's souls and offer insights that would otherwise be lost. Ideally, we can help people be more at ease and feel safe in the world. This leads to trust in the collective endeavor. The magician is an interpreter of reality and this transforms reality in a powerful way. In our presence, people feel they can say what needs to be said. We enjoy change because we know it is a faithful companion throughout life. Our prime mode is observation and thoughtfulness. We believe we best contribute to the whole through perspective, integration of difference, and reflection.

When we lack magician energy, we have a disdain for processes and usually ignore other layers of reality. We find having to deal with difference a block to progress and experience reflection as uncomfortable. We tend to be convinced of our standpoint and we judge other opinions negatively. When we overemphasize magician energy, we feel we know much more than others and we use the power of knowing the different layers of reality to manipulate others or to enhance our own power. We lead by intrigue. Our detachment deteriorates into emotional distance. If the imbalance grows, we assume a secret superiority and exert influence through skillful manipulation. We cultivate our own omnipotence.

By reflecting on the leadership archetypes individually or collectively within, for example, the container, dialogic process facilitators can recognize their preferences in leading. If done collectively, this shows how leadership styles can become complementary, instead of competitive or conflictual. It helps to avoid negative judgment of self and others, and instead notice how different archetypal leadership energies can all be enacted in favor of the collective good. Multi-stakeholder collaboration for SDG implementation needs all four archetypal energies. Their combination helps dialogic process facilitators together to bring in direction, inspiration, inclusion, community building, performance, mastery, determination, perspective, integration of difference, and reflection. A one-sided approach will not succeed. Hence, using introspection with the leadership archetypes helps to acknowledge each other's strength and weaknesses, which contributes to the Compass dimension of Humanity and helps stakeholders move towards collective action.

\section{Understanding systems patterns}

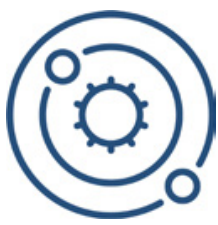

While self-awareness is crucial for understanding one own impact within a system, it is evenly important to observe how systems of stakeholders interact. A systems perspective considers the broader landscape of actors - people and institutions - in driving or preventing change. It encourages actors to shift their perspective from the parts (their own institutions and interests) to the whole (all actors relevant for an issue). When stakeholders see a system in its entirety, new options come into view. This is like zooming out so they can see the underlying patterns and relationships that create or prevent systems aliveness - a situation where all stakeholders would flourish. Dialogic process facilitators need to understand patterns in the system as a foundation for their actions for building collaboration ecosystems, convening high-quality dialogues, and following up on commitments. As stewards of 
transformative change processes that aspire to shift stakeholder systems towards better functionality and towards positive outcomes, it is important that they become familiar with the basics of what can be called systems interventions.

Systems can be more scientifically be described as entities with a clear but permeable boundary and a degree of autonomy that allows the system to define its own internal specifications (Capra \& Luisi, 2014). Chapter 1 has elaborated that the dimensions of the Collective Leadership Compass mirror certain biological principles that create conditions for systems aliveness (Kuenkel, 2019). One of them is permeable containment, which describes the boundaries of a system that can be mental or physical, visible or invisible, material or non-material. Hence, institutions in multi-stakeholder collaborations for SDG implementation can be seen as systems. When they begin to work together, they create cross-institutional collaboration ecosystems; again, these are systems, but at a different level and with much more fluid boundaries. Another of the underlying systems aliveness principles is intentional generativity, which means that systems are always purposefully seeking to stay alive. In the realm of multistakeholder collaborations this means acknowledging that all systems, institutions, organizations, communities, but also individual stakeholders act with intentions and serve a certain purpose. But in order to fulfill their purpose, particularly to overcome sustainability challenges, systems need to organize the energy-flow within and with the outer world in the more effective ways. How they do this is contextual - systems interact with certain other systems. This is where the aliveness principle of contextual interconnectedness comes in, which means, translated into multi-stakeholder collaborations, that stakeholders and their institutions start connecting with each other. Hence, they collaborate because they need to do this in order to achieve a goal or fulfill a purpose. In accordance with the purpose, this interconnectedness must be closed enough - the collaboration ecosystem, to remain functioning, and open enough to allow the outer world's influence for further development. From biology, it is known that if a system is too closed, adaptation becomes impossible, and if it is too open, its boundaries become unclear and subsequently it dissolves (Maturana \& Varela, 1991). A system can change incrementally or dramatically. In order to change or unfold, a system always needs to allow a certain degree of instability. Without instability it cannot develop a higher level of existence with a new level of stability. This reflects the systems aliveness principles of emerging novelty: in order for transformative change to happen, systems need a certain degree of instability and a constant flux between stability and instability. Looking at biology (Sahtouris, 2000), but also social systems (Luhmann, 1990), there is no stasis in systems. Systems are constantly renewing themselves by their internal and external actions and their interactions with others. Again, if stability is too high, change which is needed for adaptation is prevented. If instability is too high, because of internal or external influences on the system, a system tends to dissolve; it cannot reach the next level of existence and a new dynamic stability. Translating these more conceptual propositions into the stewarding of multi-stakeholder collaborations simply means understanding that collaboration ecosystems for SDG implementation are consciously destabilizing the arrangement of systems (existing institutions and stakeholder groups) enough so that they can adapt to handle sustainability challenges. The multi-stakeholder collaboration becomes a 
new level of a system - the collaboration ecosystem - with fluid boundaries that are more suitable to overcome the ecological and social challenges captured in the SDGs.

Systems can only exist with sufficient structures. In the stewardship of transformative change, the term structure refers to anything that creates order in a system, be it architecture, organization, hierarchy or communication patterns. Structure organizes the energy-flow within a system as well as between the system and its outer world. Structure can be visible or invisible, material or non-material, mental or physical. Systems and subsystems often have similar structures, which is called self-similarity (Kauffman, 1996). Dynamics in the context of social or ecological challenges create what is called perturbations (Maturana \& Varela, 1987), which can be seen as the kind of disturbance that leads to incremental or dramatic change within the system. This is related to the systems aliveness principles of mutually enhancing wholeness, which means that systems are embedded in complex structures that organize their role in and their impact on the whole. If the functioning of the whole, one may describe this as planetary sustainability, is endangered, systems need to rearrange their contributions to the whole, otherwise their individual survival would be at stake. Hence, transformative change will inevitably involve a change in the structures and relationships of systems. It is important to note that structure informs thinking and thinking informs action, and again, actions influence structure. Understanding structures that hold systems in place, is important for dialogic process facilitators. This is where the systems aliveness principles of proprioceptive consciousness come in. Every living being, no matter how small or highly developed has the faculty to cognize. This means observing what is happen within and in the surroundings and making sense of the stimuli for its development (Varela et al., 1992). Human beings, because of the complexity of their brains, have a highly developed consciousness, including the ability to perceive what is happening within, in the close surroundings, and also what is happening at the global scale. This is greatly supported by means and measurements that help people to make sense, from dialogic interaction to scientific insights, to metrics for progress or media coverage. Translated in the realm of multi-stakeholder collaboration it means that collaboration ecosystems, because they are composed of multiple stakeholders, are actually better equipped for the collective sense-making that is required to find solutions to sustainability challenges. However, the capacity to understand systems in order to steward them into transformative change requires more than perceiving the actions these systems display on the surface. In successful multi-stakeholder collaborations, people also begin to make sense of the underlying structures and patterns of thinking that influence actions. Donella Meadows (1999), known as a systems thinker who was concerned about the future of the world, suggested that understanding leverage points for systems interventions is crucially important for stewarding transformations. While most actors focus change interventions on technical or regulatory levels, she advised to also look at mental models and societal paradigms as the even more important leverage points. In multi-stakeholder collaborations, understanding the interconnectedness between mental models and visible actions helps dialogic process facilitators to design processes that address different layers (see also Senge, 1990; Senge et al., 2015). The diagram in Figure 3.8 shows that, most often, what is 
visible in multi-stakeholder collaborations is what actually happens, how stakeholders act, and the results they achieve. But just below the surface of the visible reality are patterns of behavior among stakeholders that can be observed over time. These patterns not only underscore and influence the visible actions, but are themselves determined by the underlying structures in the system. These can be organizational, procedural, or administrative structures, but also invisible rules-in-use that guide communication and interpersonal interaction. These structures keep the system in place, for better or for worse. Again, they are connected to an even deeper level, such as values, beliefs, or interpretations of the world.

For example, the mental models that create an interpretation of the planet Earth as an object containing resources that can be utilized indefinitely, even at the cost of widespread destruction, causes structures of resource flow and exploitation around that entire global business value chains have developed. This has influenced patterns

\section{THE ICEBERG \\ A Tool for Guiding Systematic Thinking}

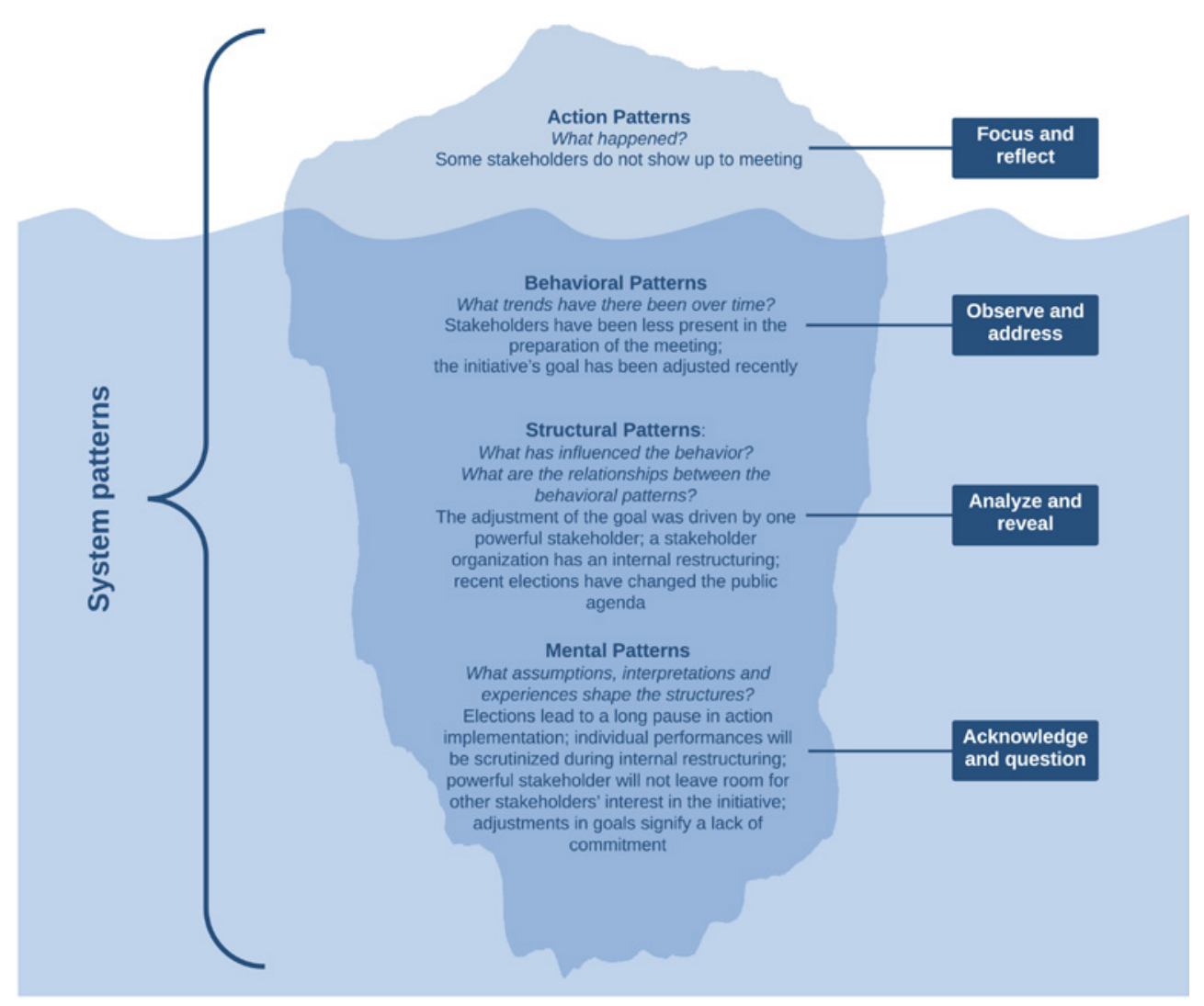

Figure 3.8 Visible action and underlying patterns

Source: Collective Leadership Institute 
of consumer behaviors that are difficult to escape, because the underlying structures are so entrenched that they engender these patterns. They lead to repeated climateunfriendly actions that are beginning to seriously endanger the planet. Capturing the need for change in SDG 13 on Climate Action is an important step, but without taking note of the mental models and structural patterns below the surface, it is difficult to become successful in leading transformative change.

This is at the core of multi-stakeholder collaboration around SDG implementation: as much as they must aim at different kinds of actions of all stakeholders and achieve tangible results, these results will only happen if the process of leading transformative change collectively reaches below the surface to the patterns, structures, and mental models. Hence, understanding systems patterns is crucially important for getting the interventions strategies right. This practitioner's guide will focus on three different tools of understanding systems for understanding the context in Phase 1 of the Dialogic Change Model. The first deep-dive looks at a systems diagnosis with the six Compass dimensions. This helps dialogic process facilitators to identify entry points for change and becomes the basis for planning process architectures, which will be the focus of Chapter 4. The second deep-dive looks at conducting a stakeholder analysis in order to identify who needs to become part of an emerging collaboration ecosystem. The third deep dive introduces the four action modes, which serve as a lens to observe typical interactions among stakeholders, and connect to the Dialogic Practices.

\section{Diagnosing system patterns with the Compass}

Diagnosing patterns in a system with the Collective Leadership Compass becomes the starting point for planning intervention strategies. Ideally, the entire container will be involved in doing the diagnosis together. The context is always diagnosed in relation to the issues that are up for change and for which many stakeholders are relevant. These issues could, for example, be: a value chain that should become more responsible; a renewable energy strategy that needs to be implemented; a youth employment initiative that requires collaboration between companies and the public sector; the improvement of the management of a biosphere reserve that can only work with engaging all stakeholders; a gender equality initiative that requires collective behavior change among many institutional actors; or any other similar multi-stakeholder collaboration related to the implementation of the SDGs. The information that goes into the diagnosis must be readily available; it can come from knowing the system well (being a stakeholder in the system) or from research obtained about the system, for example, from feasibility studies. Understanding systems patterns that impact on the initiative is paramount for identifying key strategies, designing effective process architectures, and making collaboration work. The following steps help identify the pattern. Alternatively, use the online tool www.compass-tool.net. The time required is individually between 30 minutes and two hours. If it is a core group activity, it is recommended to reserve at least a workshop session of one and a half hours to allow the group to come to answers for the different questions. Table 3.3 describes typical features of systems patterns, while table 3.4 offers guiding questions for the diagnosis. 


\section{Step 1: context and content}

Please briefly describe the stakeholder system and the change envisaged:

- What is the context in which the initiative is planned and/or implemented?

- What is the purpose or goal of the initiative for which you want understand the stakeholder system?

- What are the sources of information (e.g. feasibility studies, stakeholder analyses, research, stakeholder interviews, reports, etc.)?

- In case you have conducted a stakeholder analysis, what are the three most important conclusions?

\section{Step 2: Identifying the patterns - appreciate and assess}

Reviewing the information about the stakeholder system with the guiding questions for each Compass dimensions helps you to see the pattern in the system. This is a prerequisite for understanding the context, developing strategies to improve the system, and planning change. Table 3.3 gives an overview of the dimensions and aspects in relation to systems patterns. Table 3.4 provides the questions for the systems diagnosis. You can choose to diagnose the stakeholder system with the six dimensions only (six questions to answer as an overview) or with all dimensions and all aspects (24 questions to answer). When you have answered the questions, rate the presence of the dimensions and aspects with 3 (strongly present), 2 (somehow present), or 1 (not really present).

- Answer the questions in Table 3.4 for each aspect and dimension (or dimensions only).

- Calculate the results for each dimension.

- Highlight the strong aspects and the strong dimensions.

- Show the results on the Compass diagram.

- Answer the questions for each dimension.

\section{Step 3: reflect and focus}

Reflect on the results and note down your insights about the collaboration pattern you have been able to identify.
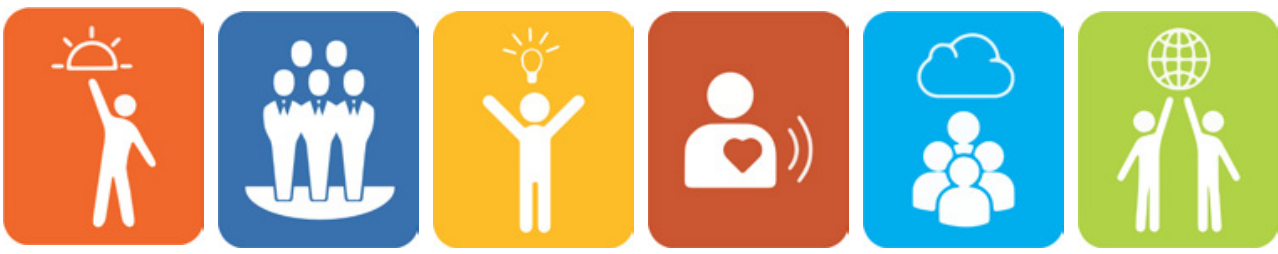

- What are your insights about the pattern that emerges?

- How can you build on the strong areas?

- How can you improve underdeveloped areas? 


\section{Step 4: creating pathways for enacting change}

Decide which dimensions will be the most promising entry points to bring about collaborative change or improve the situation in the stakeholder system or the collaboration ecosystem. Identify the three most important entry points to shift or improve the system and note down recommendations how to improve the situation in the stakeholder system from the point of view of the dimension chosen.
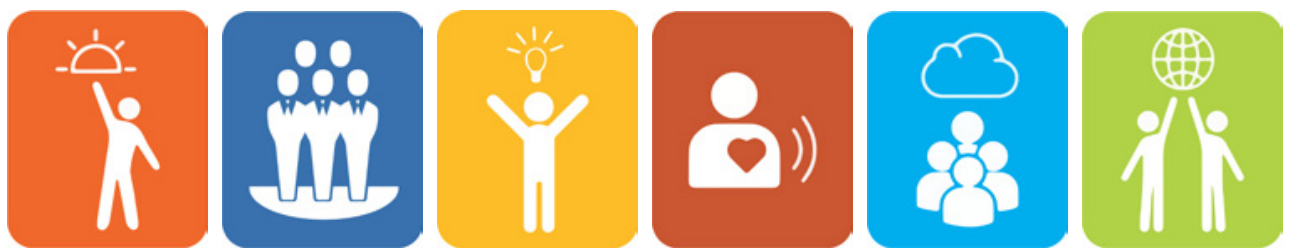

Table 3.4 Description of systems patterns related to the Compass

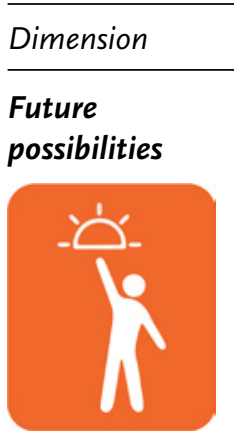

Engagement

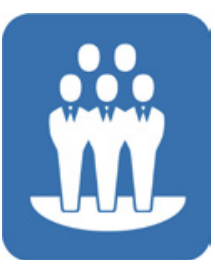

Innovation

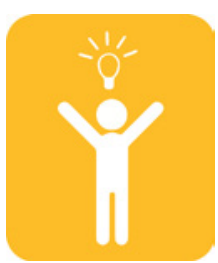

Description

- The ways in which emotionally compelling goals and roadmaps for implementation are co-developed in the stakeholder system.

- The way in which stakeholders are engaged in issue-related collaboration initiatives that drive change in both bottom-up and top-down processes.

- The way in which existing innovative change initiatives are supported or encouraged.

Aspect Description

\begin{tabular}{|c|c|}
\hline $\begin{array}{l}\text { Future } \\
\text { orientation }\end{array}$ & $\begin{array}{l}\text { - The willingness and interest of } \\
\text { stakeholders in the system to } \\
\text { drive an improved future. }\end{array}$ \\
\hline Empowerment & $\begin{array}{l}\text { The degree to which all stakehol- } \\
\text { ders are empowered to take part } \\
\text { in shaping the future. }\end{array}$ \\
\hline Decisiveness & $\begin{array}{l}\text { - The existence of agreed roadmaps, } \\
\text { plans, and accountability mecha- } \\
\text { nisms for the change ahead. }\end{array}$ \\
\hline $\begin{array}{l}\text { Process } \\
\text { quality }\end{array}$ & $\begin{array}{l}\text { - The degree to which stakeholders } \\
\text { are transparently consulted and sys- } \\
\text { tematically engaged in and reliable } \\
\text { processes that foster collaboration. }\end{array}$ \\
\hline Connectivity & $\begin{array}{l}\text { The level of networks and } \\
\text { connections between relevant } \\
\text { stakeholder institutions with the } \\
\text { purpose of driving improvement } \\
\text { of the situation. }\end{array}$ \\
\hline $\begin{array}{l}\text { Collective } \\
\text { action }\end{array}$ & $\begin{array}{l}\text { - The existence of collaborative initia- } \\
\text { tives and joint stewarding of change. }\end{array}$ \\
\hline Creativity & $\begin{array}{l}\text { The forms of support that exist } \\
\text { for creative ideas and innova- } \\
\text { tive approaches regarding an } \\
\text { improvement of the issue. }\end{array}$ \\
\hline
\end{tabular}




\begin{tabular}{|c|c|c|c|}
\hline Dimension & Description & Aspect & Description \\
\hline \multirow{5}{*}{ Humanity } & \multirow{5}{*}{$\begin{array}{l}\text { The way in } \\
\text { which the efforts } \\
\text { of different } \\
\text { stakeholders are } \\
\text { appreciated and } \\
\text { facts and figures } \\
\text { about the current } \\
\text { situation and } \\
\text { future trends are } \\
\text { transparent to all. }\end{array}$} & Excellence & $\begin{array}{l}\text { - The level of knowledge in the } \\
\text { stakeholder system about best } \\
\text { practices and state-of-the-art } \\
\text { approaches. }\end{array}$ \\
\hline & & Agility & $\begin{array}{l}\text { The level of openness of stake- } \\
\text { holder institutions to adjust their } \\
\text { approaches and plans towards } \\
\text { the improvement of the situation. }\end{array}$ \\
\hline & & Mindfulness & $\begin{array}{l}\text { - The level of access to information } \\
\text { of all stakeholders and the level } \\
\text { of awareness regarding the need } \\
\text { for change. }\end{array}$ \\
\hline & & Balance & $\begin{array}{l}\text { The degree of understanding } \\
\text { among stakeholder that they } \\
\text { need to work together to improve } \\
\text { the situation. }\end{array}$ \\
\hline & & Empathy & $\begin{array}{l}\text { - The level of knowledge and } \\
\text { mutual understanding about } \\
\text { stakeholders' interests, concerns, } \\
\text { and constraints. }\end{array}$ \\
\hline \multirow[t]{3}{*}{$\begin{array}{l}\text { Collective } \\
\text { intelligence }\end{array}$} & \multirow{3}{*}{$\begin{array}{l}\text { The way in which } \\
\text { differences in } \\
\text { interest, power, } \\
\text { and expertise are } \\
\text { acknowledged } \\
\text { and stakeholders } \\
\text { collaborate using } \\
\text { structured and } \\
\text { constructive } \\
\text { dialogues. }\end{array}$} & $\begin{array}{l}\text { Dialogic } \\
\text { quality }\end{array}$ & $\begin{array}{l}\text { The degree to which mechanisms } \\
\text { for dialogue, exchange, and gov- } \\
\text { ernance have been established } \\
\text { and are functioning. }\end{array}$ \\
\hline & & Diversity & $\begin{array}{l}\text { The way in which differences in } \\
\text { expertise are productively used } \\
\text { for collaborative approaches. }\end{array}$ \\
\hline & & $\begin{array}{l}\text { Iterative } \\
\text { learning }\end{array}$ & $\begin{array}{l}\text { The degree to which learning } \\
\text { exchanges for an improvement } \\
\text { of the issue are organized across } \\
\text { stakeholder institutions. }\end{array}$ \\
\hline \multirow[t]{4}{*}{ Wholeness } & \multirow{4}{*}{$\begin{array}{l}\text { The way in which } \\
\text { the larger context } \\
\text { of the issue is } \\
\text { known to all } \\
\text { stakeholders } \\
\text { and they see } \\
\text { their contextual } \\
\text { contribution to } \\
\text { improvement. }\end{array}$} & \multirow[t]{2}{*}{ Contextuality } & \multirow{2}{*}{$\begin{array}{l}\text { - The degree to which stakeholders } \\
\text { are aware of how the attempt to } \\
\text { improve the issue is related to } \\
\text { other broader societal or global } \\
\text { issues. }\end{array}$} \\
\hline & & & \\
\hline & & $\begin{array}{l}\text { Mutual } \\
\text { support }\end{array}$ & $\begin{array}{l}\text { - The forms of mutual support } \\
\text { between stakeholders in the } \\
\text { attempt to improve the situation. }\end{array}$ \\
\hline & & Contribution & $\begin{array}{l}\text { - The level of awareness of } \\
\text { stakeholders about their individ- } \\
\text { ual and collective contribution to } \\
\text { an improvement of the issue. }\end{array}$ \\
\hline
\end{tabular}




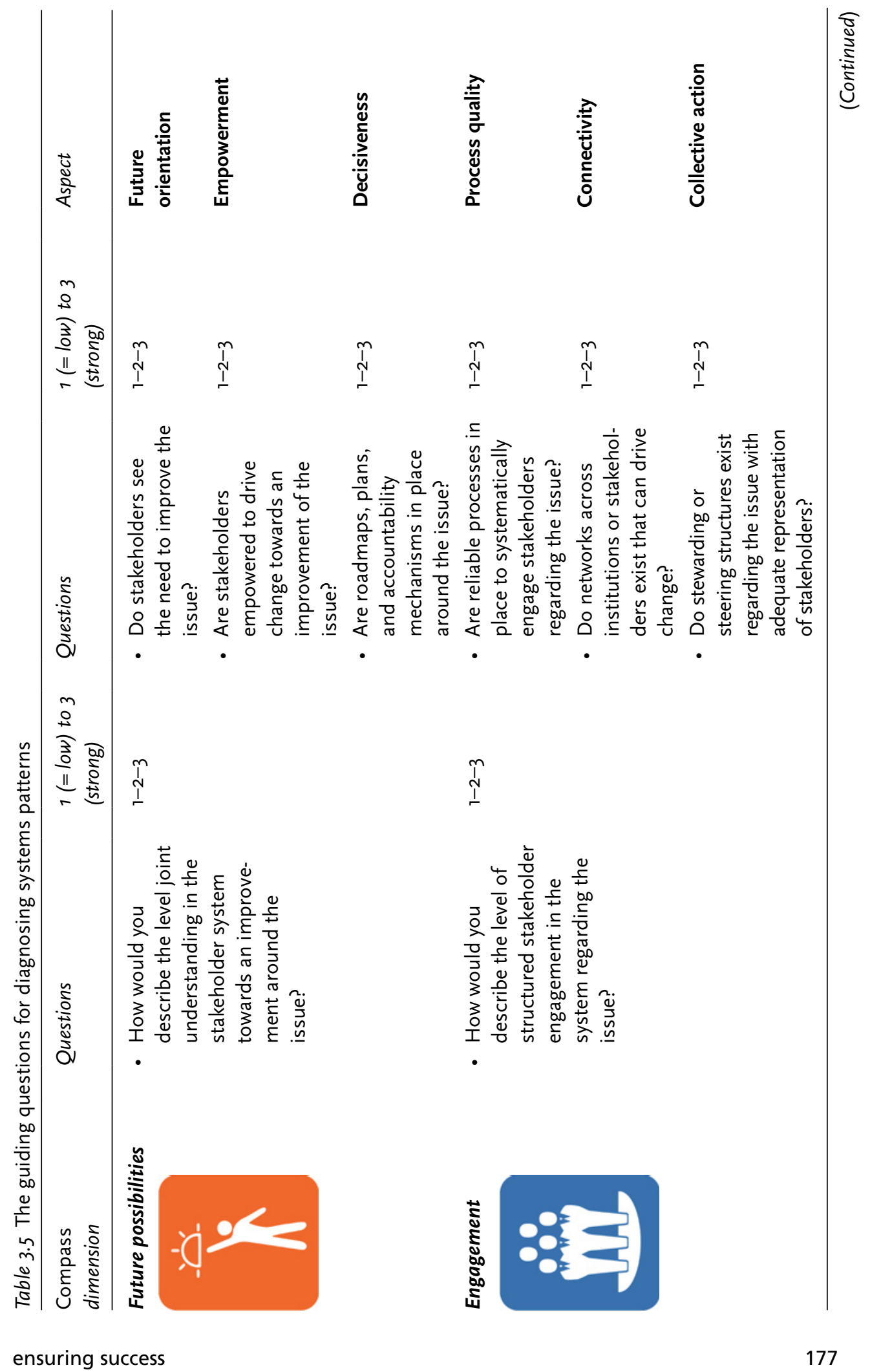




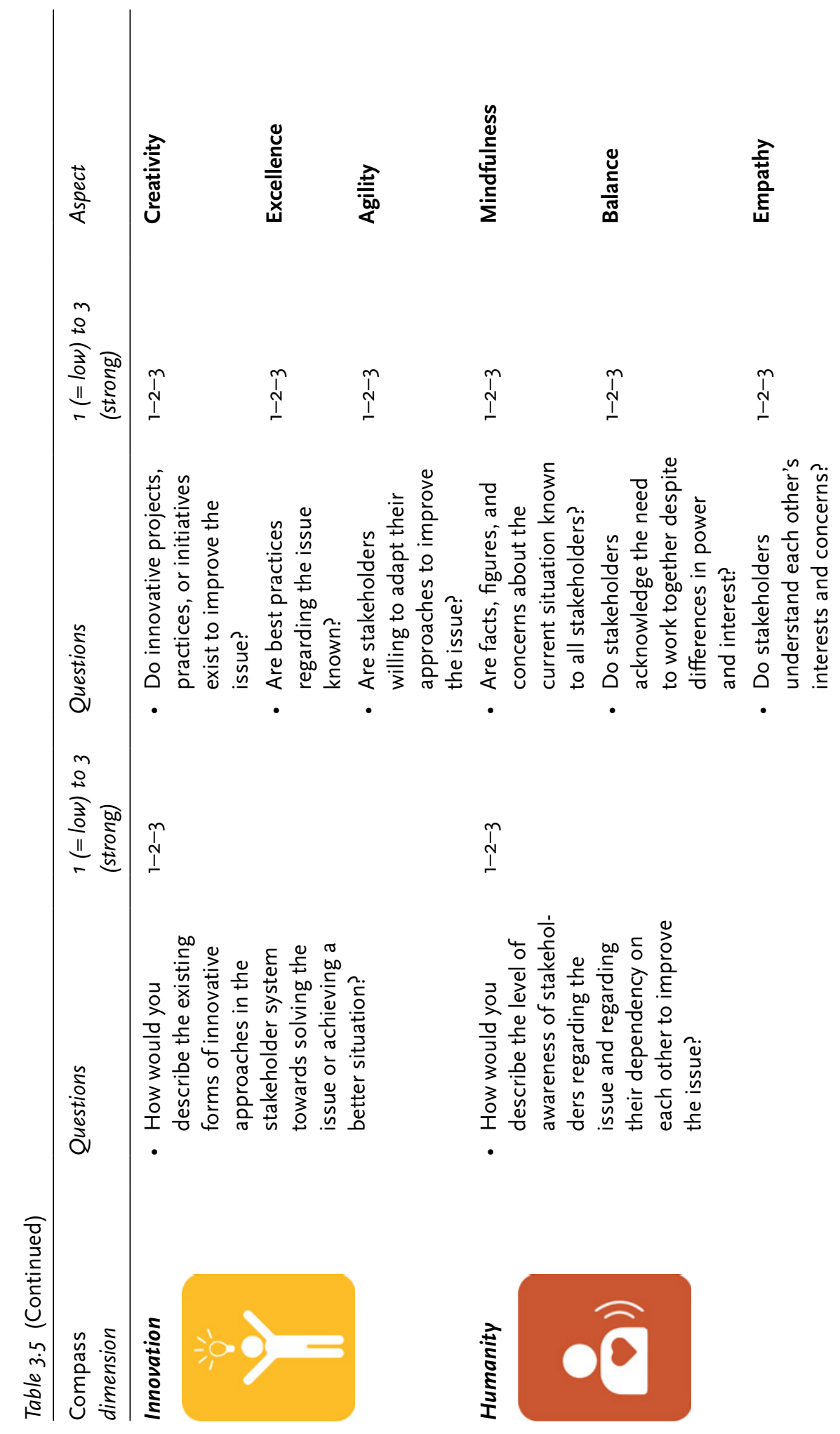




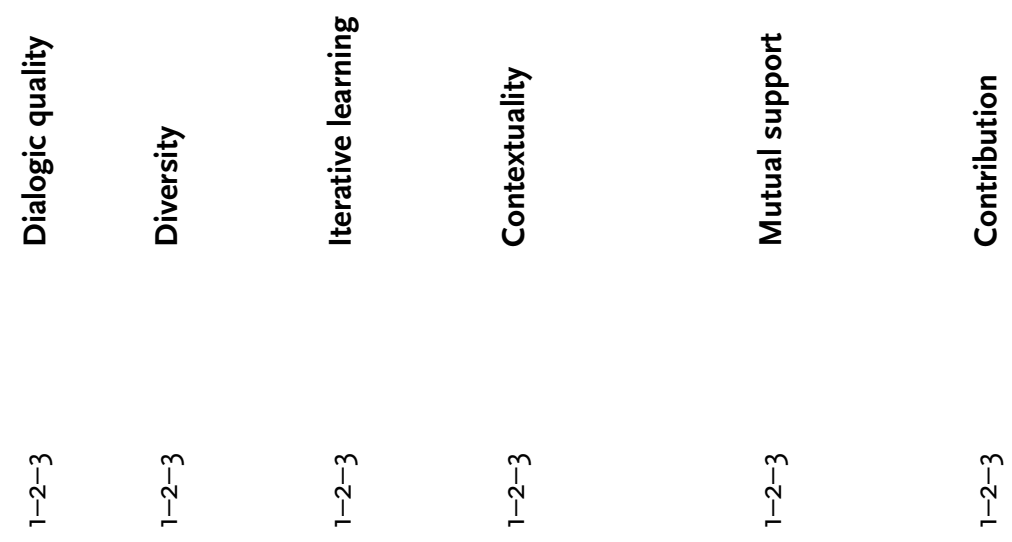

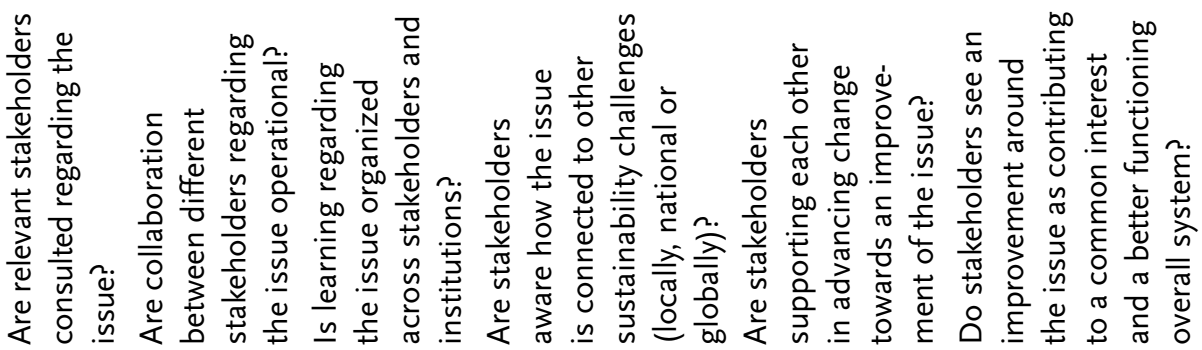

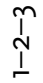

$\stackrel{?}{\stackrel{1}{1}}$

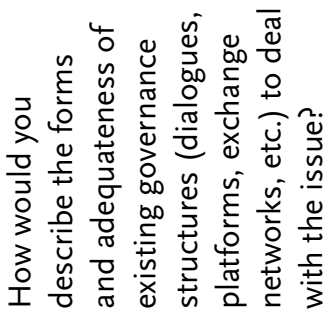
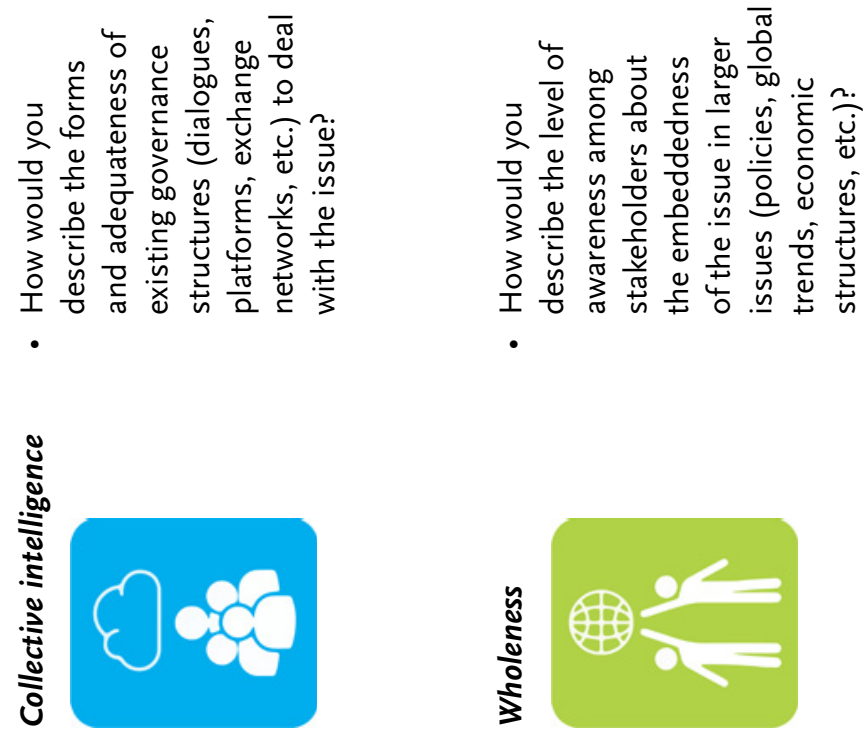
Diagnosing system patterns in Phase 1 helps dialogic process facilitators to ensure appropriate understanding of where the system stands with regard to the issue. The next step in understanding the context well enough for building enlivening collaboration ecosystems around issues of common concern is to look at the composition of stakeholders in the system. This helps to identify which stakeholders are needed, and in what way, to make multi-stakeholder collaboration work.

\section{Stakeholder landscape analysis}

Once the overall patterns are understood, the second pathway towards understanding systems patterns as part of the necessary context analysis is understanding the landscape of stakeholders in relation to their interest and their power to influence. This is best done in a stakeholder analysis. There are many tools available that dialogic process facilitators can use for this purpose. This practitioner guide will focus on a freely available tool that many stakeholders are familiar with: The Stakeholder Landscape Analysis ${ }^{4}$

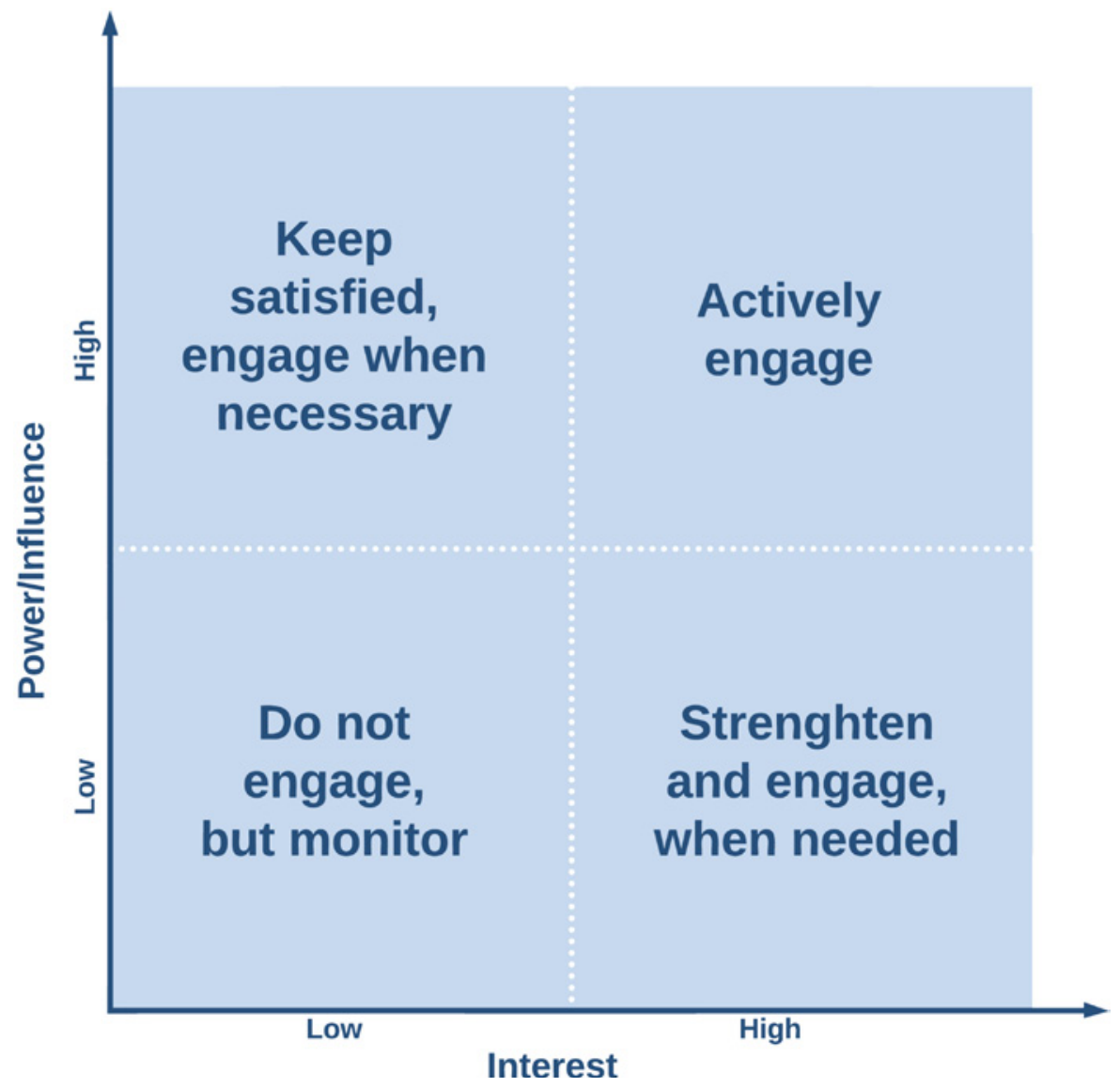

Figure 3.9 The Stakeholder Landscape Analysis

Source: Kuenkel et al., 2011 
(Kuenkel et al., 2011). Such a stakeholder analysis is best done in the core group that intends to initiate the multi-stakeholder collaboration. The purpose of applying this tool is to develop a strategic view of the human and institutional landscape and the relationships (including power differences) between stakeholders. Although the Stakeholder Landscape Analysis can be used throughout all phases of the Dialogic Change Model, it is crucial to conduct a stakeholder analysis at the outset of any envisaged collaborative change process. The use of the grid is particularly helpful in determining what type of engagement process is required to create sufficient interest in the multi-stakeholder collaboration. The results of the stakeholder analysis are the basis for a strategic conversation within the core group about who is needed for the multistakeholder collaboration and how to approach different stakeholders. A stakeholder analysis is always done in relation to an issue or even a preliminary overall goal. Stakeholders are placed on the grid in relation to their influence on or interest in this particular issue or goal. The following section describes the step-by-step approach to the stakeholder analysis and Figure 3.9 shows the influence/interest grid.

The Stakeholder Landscape Analysis has four quadrants:

- The upper right quadrant locates high-influence, high-interest stakeholders: these are the people dialogic process facilitators must make the greatest effort to engage fully. Ideally, a selected number of stakeholders located here become part of the core group (container)

- The upper left quadrant locates highly influential, but low-interest stakeholders: dialogic process facilitators need to assess how important they are including their influence on success and failure as well as the risk of not engaging them. In that case, they need to invest enough work into keeping these stakeholders informed at least. Should they be needed, it is best to gain their interest, but not overload them with information. Building good relationships is paramount, if it is necessary to involve them directly. Hence, their interest needs to be raised.

- The lower right quadrant locates low-influence, but highly interested stakeholders: if these stakeholders' interest is high, there must be a reason. For example, they may be affected groups, advocacy groups, communities, or, for example, smallscale producers that are interested in a better business environment. Often, these stakeholders have important information, perspectives, or experiences. But they may lack the capacity to make their voices heard, so they need support in doing this. They may also be badly organized and need institutional strengthening to increase their influence. Stakeholders in this quadrant can become important supporters of the multi-stakeholder collaboration. They need to become engaged, supported, and adequately informed to keep their level of interest high. Dialogic process facilitators must assess how important the point of view or experience of these actors is to the multi-stakeholder collaboration: this should be a criterion for actively involving them in the process.

- The lower left quadrant locates low-influence, low-interest stakeholders: they need to be monitored in the sense that they might get interested at a later stage. There is no need to involve them, but their role might need to be reviewed periodically, because their status can also change. 
The following describes the step-by-step approach to a stakeholder landscape analysis.

Step 1: create a list of the stakeholders relevant to the success of the Stakeholder Dialogue initiative

The first step is to create a general list of important stakeholders relevant for the issue or the achievement of the preliminary goal. In order to not arrive at a list that is too long, it is important to focus on the most relevant stakeholders: those already active in the field of work, in a collaborative process, or actors and organizations who are potentially interested in cooperation. However, it is important to not leave out stakeholders that the core group may not have access to, but could make the multistakeholder collaboration fail.

\section{Step 2: assess stakeholders' influence and interest}

The task now is to categorize stakeholders according to their potential interest in and influence on the goal, and place them on the grid accordingly. It is important to make a realistic assessment of the current situation (do not place them where you think they should be, but where they are according to your assessment). Cross-check your results if you have placed most stakeholders in the high interest/high influence quadrant: is this the reality?

When plotting stakeholders' positions on your grid, consider marking the stakeholders who you see as advocating or supporting your initiative in green, and those whom you expect to block or criticize your initiative in red.

\section{Step 3: consolidate and interpret your findings}

After discussing the results of the interest/influence grid, consolidate the conclusions. Consider the following questions related to the key stakeholders for the success of the Stakeholder Dialogue:

- Are key stakeholders sufficiently interested and influential (in upper right quadrant), or is there a need to raise their interest in the goal?

- Are key stakeholders interested, but have little influence? How can you strengthen their voice?

- Are key stakeholders influential, but show little interest? How can you raise their interest?

- Are there key stakeholders you do not know enough about to be able to assess their interest or influence? How can you learn more about them?

\section{Step 4: develop a good understanding of how best to engage the most important stakeholders}

Discuss the findings and explore strategies to change stakeholders' positions on the grid that you deem absolutely necessary for the success of the multi-stakeholder collaboration. Think about how an initial container representing the stakeholder system should be 

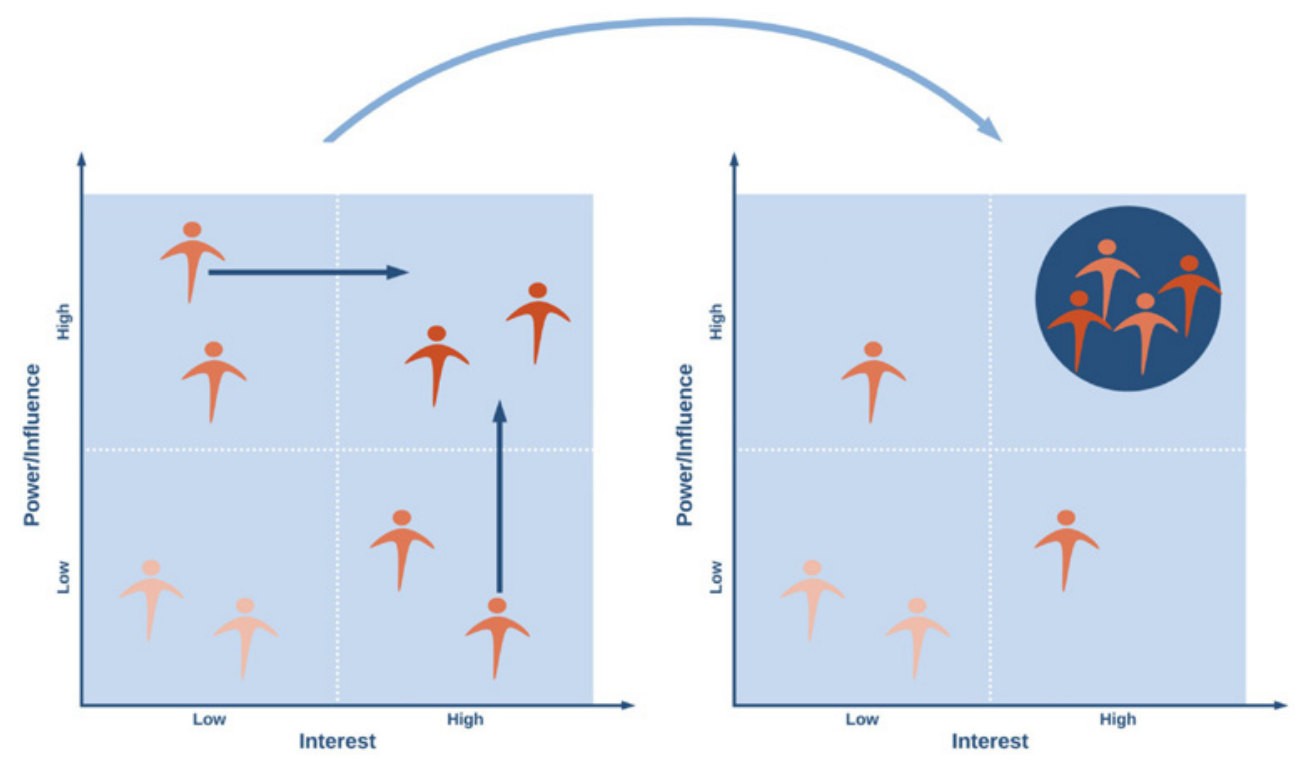

Figure 3.10 Engaging stakeholders towards the high influence/interest quadrant

Source: Collective Leadership Institute

compose. The stakeholders need to be sufficiently influential (not all need to be powerful, but they need to be able to have a voice in the process) and highly interested.

Figure 3.10 shows an example of a grid, for which a core group has recommended to engage certain stakeholder specifically by getting a powerful stakeholder more interested in the multi-stakeholder collaboration, and by supporting a weaker, but highly interested stakeholder, to gain more influence. The result of the specifically designed engagement process will then be a group of stakeholders in the upper right quadrant that can become a core group as a container for change.

If at the beginning of a multi-stakeholder collaboration not enough stakeholders can be located in the upper right quadrant, it is time to step back and think about how to change this situation first, before moving on. The third step in Phase 1-building a container for change - may be endangered. This does not necessarily mean that the intention or goal of the envisaged collaboration is wrong, but it means that there are other steps to do, before the process can move towards a Phase 2. Sometimes, information about a certain sustainability challenges is missing; hence, an information campaign might be the first step. In other cases, there might be influential actors not only not interested, but blocking change. This may require a background diplomacy strategy to change their attitude, relationship building, or a polite invitation to an exposure trip to experience the challenge or how other stakeholders see it. Again, in another case, weaker stakeholders may need to receive some sort of capacity development, before they can engage in the multi-stakeholder collaboration. The Influence/Interest Grid becomes the basis for developing engagement strategies. The diagnosis of systems patterns helps to identify the entry points for engagement conversations with different stakeholders. Although a stakeholder analysis is mostly done in the Phase 1 of the 
Dialogic Change Model, it might be necessary to redo the stakeholder analysis, once the container has been established, or at a certain point during Phase 3, when adjustments in the implementation strategy might become necessary. It is certainly important to do a renewed stakeholder analysis, if a multi-stakeholder collaboration moves into Phase 4 .

\section{Stakeholder interaction patterns}

The third pathway into understanding systems patterns is relevant when dialogic process facilitators want to look at the patterns of interaction between stakeholders - at the beginning of a multi-stakeholder collaboration or when the stakeholder collaboration ecosystem has already been established. This is particularly important when there are tensions in the system of envisaged or already engaged stakeholders, or when conflict is lingering in the background. The tool that is helpful to diagnose interaction patterns is called the four action modes, also known as "The Four Player Model" of the psychologist David Kantor ${ }^{5}$ (2012) who based it on decades of interpersonal communication research. He has shown that communication is most effective when all four action modes are present in a dynamic balance. Transferred into the realm of multistakeholder collaboration it shows the behavioral action modes that stakeholders display in the way they interact with each other. It is however, related to the underlying dialogic practices and the deeper layer of the leadership archetypes. These are the four visible actions that can be observed in multi-stakeholder collaborations:

\section{\# 1 Action mode: move}

The action mode move shows up in the form of people making proposals, initiating something, suggesting solutions, or pushing decisions. Its underlying intention is the setting of direction. If stakeholders or institutions in the stakeholder landscape are weak in this action mode, other stakeholders might dominate them. If, in a collaboration ecosystem, one stakeholder (group) is constantly in "move" mode, e.g. pressing for fast decision-making or wanting to control outcomes, the multi-stakeholder collaboration will become unbalanced, because other stakeholders feel that the direction is influenced by one actor. They will withdraw, disengage, or oppose. If, however, stakeholders lack this action mode, it is time for dialogic process facilitators to find out why: there might be fear to express opinions, or a lack of organizational capacity voice their standpoints. Questions to ask to reveal the presence or absence of the action mode 'move' are:

- Do stakeholders express their perspectives and points of view?

- Are all stakeholders as engaged as they should be?

- Are we getting things done?

\section{\# 2 Action mode: oppose}

The action mode oppose has as its underlying intention correction. It hints to the unsaid or unseen, and reminds powerful stakeholders of what they neglect or ignore. It often brings a different way of seeing things to the surface and to the attention of all stakeholders. Unheard or ignored, it can turn into fierce opposition. If continuously ignored, 
this may turn into violent opposition. In multi-stakeholder collaboration, this action mode in its mild form is reflected in any action that seeks to counteract stakeholder positions, suggests different routes to take, blocks the process, or threatens to exit the collaboration ecosystem. If there is among collaborating stakeholders a continual pattern of move/oppose prevailing, progress is blocked. If the moving stakeholders will overrun the opposer, the multi-stakeholder collaboration is doomed to fail. Hence, in dealing with opposition it is important that dialogic process facilitators learn to inquire into the underlying intention of correction. Communication can become compromised in a collaboration process, if too little understanding is shown for others' opinions. This can result in threats of leaving the collaboration ecosystem, public attacks on the people or strategies that had been agreed, or a subtle undermining of the initiative's progress. Questions to ask to reveal the presence or absence of the action mode "oppose" are:

- Are all stakeholders' points of view adequately acknowledged?

- How can be assured that even critical points of view are brought to attention?

\section{\# 2 Action mode: follow}

The action mode follow aims at consensus, integration, and is most often shown through confirming addition or agreement. Its underlying intention is completion. Without this action mode multi-stakeholder collaborations cannot succeed, as consensual agreements are the cornerstone of success. However, if a continuous pattern of move/follow develops in a collaboration ecosystem, this might be as detrimental to the overall process in the long run. It is time to ask whether all-important aspects are truly being addressed. Move/follow patterns seem to be effective and fast in the short term, but they usually lack the different perspectives and corrective views necessary for quality decision-making. In dealing with premature consensus or completion, dialogic process facilitators need to deliberately explore differences. On the other hand, if agreements cannot be reached, dialogic process facilitators must question if the interest in a common goal has been verified in the first place. Informal talks should be used to determine if criticism regarding certain issues has been withheld and if these issues need to be brought up again in the agenda. Questions to ask to reveal the presence or absence of the action mode 'follow' are:

- What gives confidence that agreements reached are sound and sincere?

- What needs to be explored, if agreements cannot be reached?

\section{\# 2 Action mode: Bystand}

The action mode bystand has as its underlying intention the bringing in of a different perspective. It is more than just observation, but an active search for perspective and collective wisdom, often as an attempt to inquire into the situation and into the interests of participating actors, or to describe observations that can take the conversation forward. When this action mode is missing, participants in multi-stakeholder collaboration lack the ability to look from a distance and assess their joint progress. 
But if well developed, regular reflection becomes part of the process. If a stakeholder group's tolerance for differences of opinion is low, or if it has little patience for dealing with different opinions or mindsets, it can be difficult to create an atmosphere of mutual respect. Dialogic process facilitators can positively influence such a situation by demonstrating respect and tolerance and by assuring that all opinions are heard and respected. If too many stakeholders passively observe as bystanders and do not partake actively, the collaboration ecosystem cannot become successful. Questions to ask to reveal the presence or absence of the action mode "follow" are:

- How can be assured that different points of view are respected?

- What needs to happen so that passive stakeholders turn into active and engaged participants?

Figure 3.11 shows an overview of the action modes and their underlying intentions. When conflicts arise in collaboration ecosystems, or if they already exist in the stakeholder system before the initiation of a multi-stakeholder collaboration, the behavior pattern is usually one of move/oppose, with protagonists openly or covertly

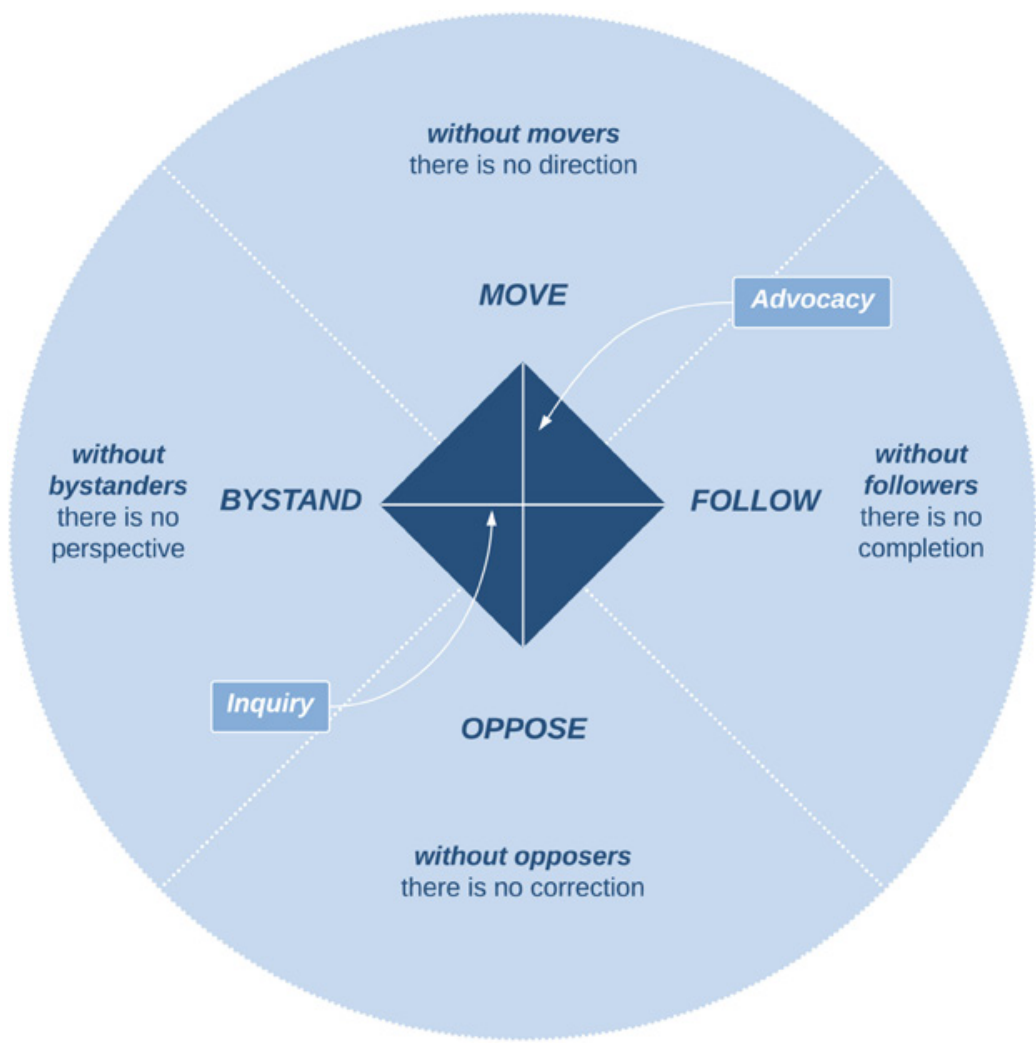

Figure 3.11 The four action modes

Source: Inspired by and adapted from David Kantor, 2012 
disrespecting each other's positions. But these tensions may also be important drivers for transformative change. For example, between the private sector and civil society organization is often a tension based on mistrust. Even though stakeholders from both stakeholder groups may work together, the tension remains. These patterns are quite common in multi-stakeholder collaborations and do not necessarily mean the collaboration will fail. But most often, some stakeholders or mandated dialogic process facilitators will turn into bystanders by moderating or mediating between conflicting stakeholders. This is a step into rebalancing the four action modes. Being transparent about disagreement and substantiating mistrust are important steps that can move a process forward - as long as it is done with respect. It is important to understand what drives major criticism, to inquire into it, and to redirect it into more solution-oriented conduct. But if any of these four action modes are entirely missing or they are constantly out of balance over time, collaboration ecosystems will become imbalanced. Dissatisfaction will arise, results will not be achieved, crises will become more common, and mistrust will spread. All four action modes - in a dynamic balance - are necessary to move the collaboration process along and get to results that all stakeholders can own. Without movers, there is no direction. Without followers, there is no completion. Without opposers, there is no critical thinking and correction, and without bystanders, there is no perspective, and no breakthrough to new solutions or a deeper understanding. Collaboration ecosystems work best with the skillful presence of the four action modes and their underlying dialogic practices. This can ensure a balance between inquiry - seeking to understand oneself, a situation and other points of view - and advocacy - arguing for a certain aspect at stake and making oneself understood. Using the action modes as one possible lens to gauge the quality and effectiveness of collaborative change processes helps dialogic process facilitators into process competence for stewarding transformative change.

\section{CASE EXAMPLE 3.5: EXAMPLE FROM THE FIELD: UNDERSTANDING PATTERNS FOR MANAGING A UNESCO BIOSPHERE RESERVE}
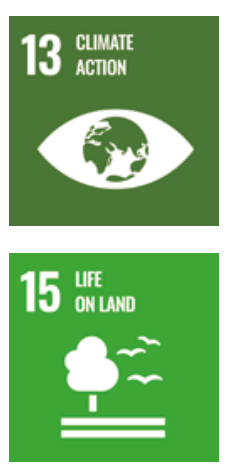

Some countries in Central America are known to be particularly vulnerable to climate change. The threat of natural disasters grows as the effects of climate-related extreme weather conditions such as drought, heavy rainfall, and flooding impact the countries' environment as well as their economic development. These trends are exacerbated by the degradation of natural resources such as soil, water and forest, e.g. through deforestation, overuse and unsuitable management methods. There is an urgent need to collaborate between local level actors in the adaptation of agricultural production, actors at community and district levels in strengthening natural resource protection, and national actors to provide enabling regulations as well as favorable policy decisions. Increasingly, the establishment and management of biosphere reserves moves into focus as a way of combining preservation of biodiversity and environmental resources with sustainable agricultural practices and climate adaptation measures. The particular case here is one of these biosphere reserves that is rich 
in biodiversity and wildlife, yet prone to illegal logging and agricultural practices that contradict the preservation and conservation of plant and animal species which would meet the criteria of a biosphere reserve. The economic pressure of the rural population is high and leads to encroachment of areas under protection. Moreover, the capacity of government actors to enforce the protection is considerably low. Due to dedicated experts from the association of local authorities in the area and the provincial forestry department, the reserve received the status of a UNESCO biosphere reserve in 2017. However, the collaborating stakeholders were aware that, in order to develop the much-needed management plan for the reserve, they would need to involve many more stakeholders and understand the system patterns that, at the time, did not yet work in favor of the ambitious environmental protection objectives. It was clear that the local population, and, most importantly, the farmers, had only limited interest in the regulation of their activities that the establishment of the biosphere reserve would require. Yet, at the same time, awareness of the need for adapting agricultural practices to climate change had already grown. There were many activities going on that already worked in the right direction, such as sustainable coffee growing, water retention projects, or pilot projects for mushroom farming and agroforestry.

The initiating stakeholders invited 150 different stakeholders in the area to a first dialogue with the intention to create a platform where issues around the management of the biosphere reserve could be discussed. But the response was limited - only 35 people actually showed up at the meeting. However, those that showed up, where highly interested in participating towards the development of a management plan, and an initial committee was established, which was also a requirement by UNESCO. It did not have representation of small farmers, and nobody from the private sector (such as industries) or the indigenous population had joined. In order to understand the system better as part of a more thorough Phase 1, the initial group of stakeholders gathered for a system diagnosis workshop. The results are captured in Table 3.6 and illustrated as a diagram in relation to the Collective Leadership Compass dimensions in Figure 3.12.

The conclusions drawn from the diagnosis were the following:

- Conduct a more thorough stakeholder landscape analysis to identify who would need to become part of a slightly bigger core group to drive the change;

- Allocate among its members conversations with identified important stakeholders to understand their perspective, but also engage them more closely into the process;

- Hold information meetings with farmers and other relevant stakeholders that would be designed as dialogue conversations to also understand farmers' concerns;

- Get the university partner to research and identify already existing good practices (by farmers or other stakeholders) and integrate the information into the meetings;

- Based on the results from stakeholder landscape analysis, the conversations and the information meetings, design a slow, but thorough Phase 1 engagement process with the committee in the lead. This would include helping the committee to identify additional representatives and prepare a kick-off meeting that would focus on a joint situational analysis as a foundation for developing a management plan. National actors would be invited to this meeting; and

- Conduct another system diagnosis after 12 months. 
Table 3.6 Initial system diagnosis for the biosphere reserve

\begin{tabular}{|c|c|c|c|}
\hline Compass dimension & Questions & Diagnosis & Detailed questions \\
\hline $\begin{array}{l}\text { Iture } \\
\text { ssibilities }\end{array}$ & \multirow{2}{*}{$\begin{array}{l}\text { - How would } \\
\text { you describe } \\
\text { the level of } \\
\text { coherence in } \\
\text { the stakeholder } \\
\text { system towards } \\
\text { future possi- } \\
\text { bilities and } \\
\text { improvements } \\
\text { around the } \\
\text { issue? } \\
\text { - (Overall: 2) } \\
\text { - Medium future } \\
\text { possibilities }\end{array}$} & $\begin{array}{l}\text { The announcement to } \\
\text { become UNESCO bio- } \\
\text { sphere reserve was a } \\
\text { big acknowledgment for } \\
\text { those who had initiated } \\
\text { the process and pushed } \\
\text { them into now driving the } \\
\text { implementation. }\end{array}$ & $\begin{array}{l}\text { Do stakeholders } \\
\text { see the need } \\
\text { to improve the } \\
\text { issue? }\end{array}$ \\
\hline & & $\begin{array}{l}\text { However, most inhabitants } \\
\text { did not really know about } \\
\text { the recognition, and if so, } \\
\text { they were not clear what this } \\
\text { would mean, so they did not } \\
\text { see any implications, neither } \\
\text { did they want to get engaged. } \\
\text { - So far, the drivers were } \\
\text { experts in the field, had a } \\
\text { clear idea about measures } \\
\text { to be taken, but not the } \\
\text { means to enact them. No } \\
\text { plan was in place yet. }\end{array}$ & $\begin{array}{l}\text { - Are stakehol- } \\
\text { ders empow- } \\
\text { ered to drive } \\
\text { change towards } \\
\text { an improve- } \\
\text { ment of the } \\
\text { issue? } \\
\text { - Are roadmaps, } \\
\text { plans, and } \\
\text { accountability } \\
\text { mechanisms in } \\
\text { place around } \\
\text { the issue? }\end{array}$ \\
\hline$t$ & $\begin{array}{l}\text { - How would you } \\
\text { describe the level } \\
\text { of structured } \\
\text { stakeholder } \\
\text { engagement } \\
\text { in the system } \\
\text { regarding the } \\
\text { issue? } \\
\text { - (Overall: 1) }\end{array}$ & $\begin{array}{l}\text { No process architecture } \\
\text { had been designed so far. } \\
\text { The group considered } \\
\text { this to be the next step } \\
\text { to discuss, who the key } \\
\text { stakeholder would be (after } \\
\text { a stakeholder analysis) and } \\
\text { how they would need to be } \\
\text { engaged. }\end{array}$ & $\begin{array}{l}\text { - Are reliable } \\
\text { processes in } \\
\text { place to system- } \\
\text { atically engage } \\
\text { stakeholders } \\
\text { regarding the } \\
\text { issue? }\end{array}$ \\
\hline & - Low engagement & $\begin{array}{l}\text { The initiators were closely } \\
\text { connected, but little did } \\
\text { they know about other } \\
\text { relevant actors in the field, } \\
\text { no thorough stakeholder } \\
\text { landscape analysis had } \\
\text { been conducted. }\end{array}$ & $\begin{array}{l}\text { Do networks } \\
\text { across insti- } \\
\text { tutions or } \\
\text { stakeholders } \\
\text { exist that can } \\
\text { drive change? }\end{array}$ \\
\hline & & $\begin{array}{l}\text { They have heard that small- } \\
\text { scale farmers associations } \\
\text { do not operate well; hence, } \\
\text { these stakeholders are } \\
\text { badly organized and not } \\
\text { well connected. }\end{array}$ & \\
\hline
\end{tabular}

(Continued) 


\begin{tabular}{|c|c|c|c|}
\hline Compass dimension & Questions & Diagnosis & Detailed questions \\
\hline \multirow{5}{*}{ Innovation } & \multirow{5}{*}{$\begin{array}{l}\text { - How would you } \\
\text { describe the } \\
\text { existing forms } \\
\text { of innovative } \\
\text { approaches in } \\
\text { the stakeholder } \\
\text { system towards } \\
\text { solving the issue } \\
\text { or achieving a } \\
\text { better situation? } \\
\text { - Overall: 2) } \\
\text { - Medium } \\
\text { innovation }\end{array}$} & $\begin{array}{l}\text { Despite the invitation to } \\
\text { the dialogue, no steer- } \\
\text { ing body existed that } \\
\text { would represent different } \\
\text { stakeholders. The commit- } \\
\text { tee emerging from the first } \\
\text { dialogue was a first step } \\
\text { in the right direction. The } \\
\text { initiators are also aware } \\
\text { that the committee is a } \\
\text { requirement from UNE- } \\
\text { SCO, but needs to develop } \\
\text { into a representative group } \\
\text { of stakeholders that really } \\
\text { drives the management of } \\
\text { the reserve. }\end{array}$ & $\begin{array}{l}\text { Do stewarding } \\
\text { or steering } \\
\text { structures } \\
\text { exist regarding } \\
\text { the issue with } \\
\text { adequate rep- } \\
\text { resentation of } \\
\text { stakeholders? }\end{array}$ \\
\hline & & \multirow[b]{2}{*}{$\begin{array}{l}\text { The group was partly } \\
\text { aware that there were } \\
\text { small islands of success } \\
\text { of sustainability projects } \\
\text { particularly for small- } \\
\text { scale farmers that had } \\
\text { the focus on sustainable } \\
\text { agricultural practices. } \\
\text { Mostly, they received } \\
\text { support from international } \\
\text { development cooperation, } \\
\text { but some were driven by } \\
\text { cooperatives. }\end{array}$} & \multirow{2}{*}{$\begin{array}{l}\text { Do innovative } \\
\text { projects, } \\
\text { practices, or } \\
\text { initiatives exist } \\
\text { to improve the } \\
\text { issue? }\end{array}$} \\
\hline & & & \\
\hline & & $\begin{array}{l}\text { The group considered } \\
\text { their own expertise high, } \\
\text { but agreed that there was } \\
\text { a serious knowledge gap } \\
\text { regarding practices in } \\
\text { agriculture as well as other } \\
\text { economic activities }\end{array}$ & $\begin{array}{l}\text { Are best prac- } \\
\text { tices regard- } \\
\text { ing the issue } \\
\text { known? }\end{array}$ \\
\hline & & $\begin{array}{l}\text { that would be suitable } \\
\text { to the management of } \\
\text { a biosphere reserve, or } \\
\text { relevant to climate change } \\
\text { mitigation. An information } \\
\text { campaign was considered } \\
\text { as well as the continuation } \\
\text { of the dialogues that could } \\
\text { engage more actors. }\end{array}$ & \\
\hline
\end{tabular}




\begin{tabular}{|c|c|c|c|}
\hline Compass dimension & Questions & Diagnosis & Detailed questions \\
\hline \multirow{3}{*}{ Humanity } & \multirow{3}{*}{$\begin{array}{l}\text { - How would you } \\
\text { describe the level } \\
\text { of awareness } \\
\text { of stakeholders } \\
\text { regarding the } \\
\text { issue and regard- } \\
\text { ing their depend- } \\
\text { ency on each } \\
\text { other to improve } \\
\text { the issue? } \\
\text { - Low level of } \\
\text { - Lowareness }\end{array}$} & $\begin{array}{l}\text { - It became clear that, } \\
\text { beyond the knowledge } \\
\text { gap, there were contradict- } \\
\text { ing interests, particularly } \\
\text { among those actors that } \\
\text { drove the illegal logging. } \\
\text { This was seen as a diffi- } \\
\text { cult to solve problem. But } \\
\text { also, the operations of } \\
\text { medium scale farmers were } \\
\text { perceived as so driven by } \\
\text { economic pressure that } \\
\text { the fact that there existed } \\
\text { criteria for behavior in a } \\
\text { biosphere reserve would } \\
\text { not make farmers change } \\
\text { their income strategies. }\end{array}$ & $\begin{array}{l}\text { Are stakehol- } \\
\text { ders willing } \\
\text { to adapt their } \\
\text { approaches to } \\
\text { improve the } \\
\text { issue? }\end{array}$ \\
\hline & & $\begin{array}{l}\text { As mentioned before, the } \\
\text { group of initiators con- } \\
\text { siders that not enough } \\
\text { knowledge about what it } \\
\text { means to live, and operate } \\
\text { economically in a bio- } \\
\text { sphere reserve, is readily } \\
\text { available to the different } \\
\text { stakeholders. }\end{array}$ & $\begin{array}{l}\text { Are facts, } \\
\text { figures, and } \\
\text { concerns about } \\
\text { the current } \\
\text { situation } \\
\text { known to all } \\
\text { stakeholders? }\end{array}$ \\
\hline & & $\begin{array}{l}\text { In the beginning, the } \\
\text { initiators, because of their } \\
\text { expertise and administra- } \\
\text { tive knowledge, expected } \\
\text { to simply develop the } \\
\text { management plan and } \\
\text { implement it. However, } \\
\text { after the first few months, } \\
\text { it became clear that the } \\
\text { actual implementation } \\
\text { would require not only } \\
\text { the consent, but also the } \\
\text { active contribution of diffe- } \\
\text { rent stakeholders, such as } \\
\text { the farmers, the private } \\
\text { sector, but also represent- } \\
\text { atives of the indigenous } \\
\text { population. }\end{array}$ & $\begin{array}{l}\text { Do stakeholders } \\
\text { acknowledge } \\
\text { the need to } \\
\text { work together } \\
\text { despite differ- } \\
\text { ences in power } \\
\text { and interest? }\end{array}$ \\
\hline
\end{tabular}

(Continued) 


\begin{tabular}{|c|c|c|c|}
\hline Compass dimension & Questions & Diagnosis & Detailed questions \\
\hline \multirow{4}{*}{$\begin{array}{l}\text { Collective } \\
\text { intelligence }\end{array}$} & \multirow{4}{*}{$\begin{array}{l}\text { How would } \\
\text { you describe } \\
\text { the forms and } \\
\text { adequateness of } \\
\text { existing govern- } \\
\text { ance structures } \\
\text { (dialogues, plat- } \\
\text { forms, exchange } \\
\text { networks, etc.) } \\
\text { to deal with the } \\
\text { issue? } \\
\text { - (Overall: 1) } \\
\text { - Low level of } \\
\text { collective } \\
\text { intelligence }\end{array}$} & $\begin{array}{l}\text { While the initiating group } \\
\text { of stakeholders is aware } \\
\text { of conflicting interests, } \\
\text { they have not yet had } \\
\text { conversations with the } \\
\text { different stakeholders to } \\
\text { gauge their concerns and } \\
\text { interest. }\end{array}$ & $\begin{array}{l}\text { Do stakeholders } \\
\text { understand } \\
\text { each other's } \\
\text { interests and } \\
\text { concerns? }\end{array}$ \\
\hline & & $\begin{array}{l}\text { The dialogue invitation } \\
\text { was a starting point for } \\
\text { a conversation, however, } \\
\text { not many stakeholders } \\
\text { attended the meeting. It } \\
\text { has now become clear } \\
\text { that engagement con- } \\
\text { versations with different } \\
\text { stakeholders had not been } \\
\text { carried out. Hence, the } \\
\text { interest remained low. } \\
\text { Apart from their assump- } \\
\text { tions, the initiators know } \\
\text { very little about the } \\
\text { perspectives of different } \\
\text { stakeholders. }\end{array}$ & $\begin{array}{l}\text { - Are relevant } \\
\text { stakeholders } \\
\text { consulted } \\
\text { regarding the } \\
\text { issue? }\end{array}$ \\
\hline & & $\begin{array}{l}\text { The collaboration between } \\
\text { the association of local } \\
\text { authorities, the forest } \\
\text { department, and a local } \\
\text { university was excellent. } \\
\text { But beyond this core } \\
\text { group, no other stakehol- } \\
\text { ders had been system- } \\
\text { atically engaged. Little } \\
\text { is known about collab- } \\
\text { orations between other } \\
\text { stakeholders regarding the } \\
\text { biosphere. }\end{array}$ & $\begin{array}{l}\text { Is collaboration } \\
\text { between diffe- } \\
\text { rent stakehol- } \\
\text { ders regarding } \\
\text { the issue opera- } \\
\text { tional? }\end{array}$ \\
\hline & & $\begin{array}{l}\text { Apart from the committee } \\
\text { that has just started, no } \\
\text { other learning mechanisms } \\
\text { have been established so } \\
\text { far. }\end{array}$ & $\begin{array}{l}\text { - Is learning } \\
\text { regarding the } \\
\text { issue organized } \\
\text { across stakehol- } \\
\text { ders and } \\
\text { institutions? }\end{array}$ \\
\hline
\end{tabular}




\begin{tabular}{|c|c|c|c|}
\hline Compass dimension & Questions & Diagnosis & Detailed questions \\
\hline \multirow[t]{4}{*}{ Wholeness } & \multirow{4}{*}{$\begin{array}{l}\text { - How would you } \\
\text { describe the } \\
\text { level of aware- } \\
\text { ness among } \\
\text { stakeholders } \\
\text { about the } \\
\text { embeddedness } \\
\text { of the issue in } \\
\text { larger issues } \\
\text { (policies, global } \\
\text { trends, eco- } \\
\text { nomic struc- } \\
\text { tures, etc.)? } \\
\text { - (Overall: 2) } \\
\text { - Medium level of } \\
\text { wholeness }\end{array}$} & \multirow[b]{2}{*}{$\begin{array}{l}\text { The initiating stakeholders } \\
\text { are well connected to a } \\
\text { national committee that } \\
\text { deals with all biosphere } \\
\text { reserves in the country. } \\
\text { This is perceived as great } \\
\text { support, ideal to receive } \\
\text { administrative support. } \\
\text { But they also see that the } \\
\text { national actors have little } \\
\text { insight into the actual chal- } \\
\text { lenges at the local level. }\end{array}$} & \multirow[b]{2}{*}{$\begin{array}{l}\text { Are stakehol- } \\
\text { ders aware how } \\
\text { the issue is } \\
\text { connected to } \\
\text { other sustaina- } \\
\text { bility challenges } \\
\text { (locally, national } \\
\text { or globally)? }\end{array}$} \\
\hline & & & \\
\hline & & $\begin{array}{l}\text { The committee started off } \\
\text { with a good meeting, but } \\
\text { as not more stakeholders } \\
\text { have been engaged and } \\
\text { the representation does } \\
\text { not really mirror the wider } \\
\text { stakeholders system, the } \\
\text { current actors operate in a } \\
\text { disconnected way. }\end{array}$ & $\begin{array}{l}\text { - Are stakehol- } \\
\text { ders supporting } \\
\text { each other } \\
\text { in advancing } \\
\text { change towards } \\
\text { an improve- } \\
\text { ment of the } \\
\text { issue? }\end{array}$ \\
\hline & & $\begin{array}{l}\text { The initiating group clearly } \\
\text { sees that there is no } \\
\text { public narrative around } \\
\text { the biosphere reserve that } \\
\text { the local population could } \\
\text { identify and engage with. } \\
\text { The connection between } \\
\text { conservation and the need } \\
\text { for climate adaptation is } \\
\text { rarely seen by ordinary } \\
\text { people, who so not have } \\
\text { climate or environmental } \\
\text { expertise. There is a clear } \\
\text { disconnect between the } \\
\text { economic operations and } \\
\text { the conservation needs. }\end{array}$ & $\begin{array}{l}\text { Do stakeholders } \\
\text { see an improve- } \\
\text { ment around } \\
\text { the issue as } \\
\text { contributing to } \\
\text { a common inte- } \\
\text { rest and a better } \\
\text { functioning } \\
\text { overall system? }\end{array}$ \\
\hline
\end{tabular}

Based on the system pattern they had identified (see Figure 3.12) they decided to build a process on the system's strength: (1) their administrative capacity (decisiveness in future possibilities), (2) their expertise, which was a foundation for an information campaign (excellence in innovation), and (3) their connection to national level support, which would help them create an engagement narrative around the biosphere's contribution to national climate change adaptation (contextuality in wholeness). 


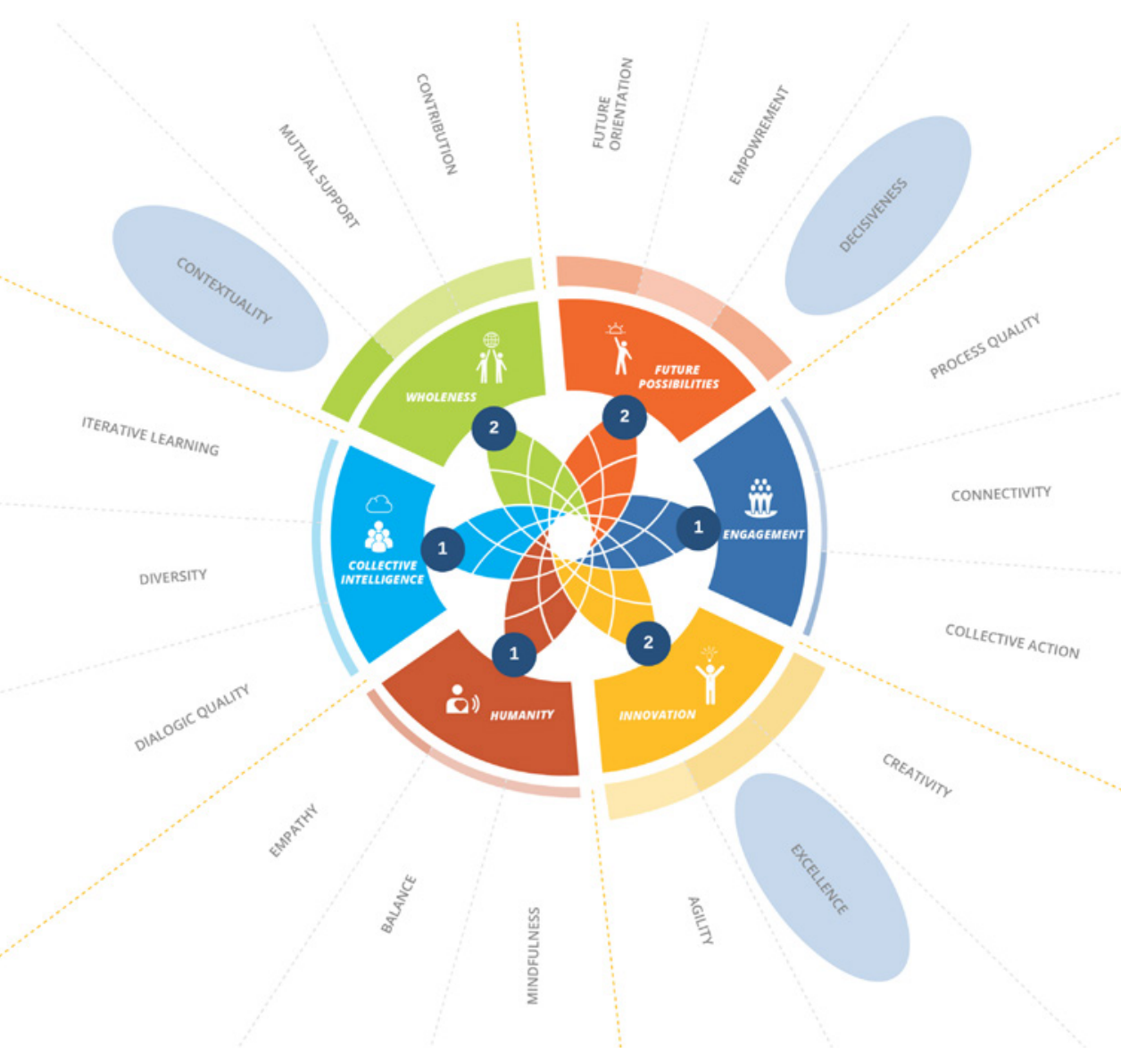

Figure 3.12 Example of systems diagnosis

Source: Collective Leadership Institute

\section{Developing process competence}

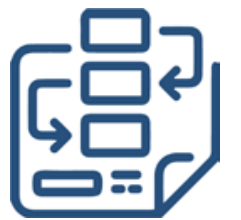

The previous section on understanding system patterns is the foundation for successfully stewarding transformative change processes because the underlying structural patterns in stakeholder systems, be they mental, organizational, or power-related, influence thinking, as well as communication and behavior of stakeholders. Understanding patterns capacitates dialogic process facilitators to organize processes that are more likely leading to envisaged outcomes. The term process refers to the sequence of steps that those who drive the change organize in order to further both a change in thinking as well as collaborative action: the way these sequences of steps are arranged to work together, is called the process architecture and will be the in-depth subject of Chapter 4. High-quality processes create the conditions for change to happen, because, as mentioned before, transformative change can only be stewarded, not controlled. 
Developing the competence to design the appropriate sequence of steps is like learning to ride a bicycle; it is difficult in the beginning to get the balance right, but once the mind has grasped the way to ride the bike, it becomes natural to do it. The rest is adhering to some rules to not endanger oneself in the traffic. Process competence enables dialogic process facilitators to steward transformative change in multi-stakeholder collaborations with in an appropriate mix of what can be described as systems interventions: conscious steps to shift a system of stakeholders into better functionality for an improved outcome in relation to SDG implementation and sustainability. These steps are always composed of a balanced combination of structural interventions and dialogic interventions.

In the four Phases of the Dialogic Change Model, structural interventions refer to all actions that consolidate a collaboration ecosystem and help it into the delivery of concrete results - such as agreements on goals, roadmaps, implementation plans, governance and stewarding structures as well as accountability and learning or monitoring mechanisms. They reorganize the relationships and the communication between stakeholders. Without these new, most often cross-institutional structures, no transformative change would manifest. Dialogic interventions refer to trust building, relationship management, facilitating the connection to emotionally compelling goals, enabling meaningful conversations and reflective and generative dialogues, and creating space for inspirations, learning, insights, and creativity. Such interventions often shift underlying mental models. For stewards of transformative change, it is important to get the balance right. A sole focus on structural interventions leads to agreements or plans - new structures - that stakeholders resist to implement, because the relationship patterns that fuel the old structures (e.g. mistrust, lack of mutual understanding, etc.) are still in place. A sole focus on dialogic interventions improves relationships, leads to new insights and excitement, but with no consolidation into structures, the impact of the interventions fade, and no tangible results are achieved. Truly transformative change processes need the emergence of new structures with new patterns of relationships. Then, new solutions emerge, higher level of trust develops, and ownership for implementation is achieved. Figure 3.13 shows how dialogic and structural interventions need to work together for transformative results.

Bringing both types of interventions more consciously into transformative change endeavors in an appropriate mix between structural and dialogic interventions is a key to success. This is the skill dialogic process facilitators need to develop. Both the Collective Leadership Compass and the Dialogic Change Model function as a meta-guidance for getting this balance right. The Compass works on the level of mental models, because attention to the six dimensions helps stakeholders to look at the same reality in a different way: they can diagnose systems patterns and plan actions that reflect the shifted mental models. Because the six dimensions integrate attention to structural and dialogic interventions into one model, attention to all six dimensions ensures that collaborative change processes are planned in the best possible way. The Dialogic Change Model serves as a roadmap for how to bring these structural and dialogic interventions into time sequence that works for the delivery of results. Process competence means that dialogic process facilitators have a deeper understanding of how interventions contribute to life-enhancing constructive interaction patterns among stakeholders. 


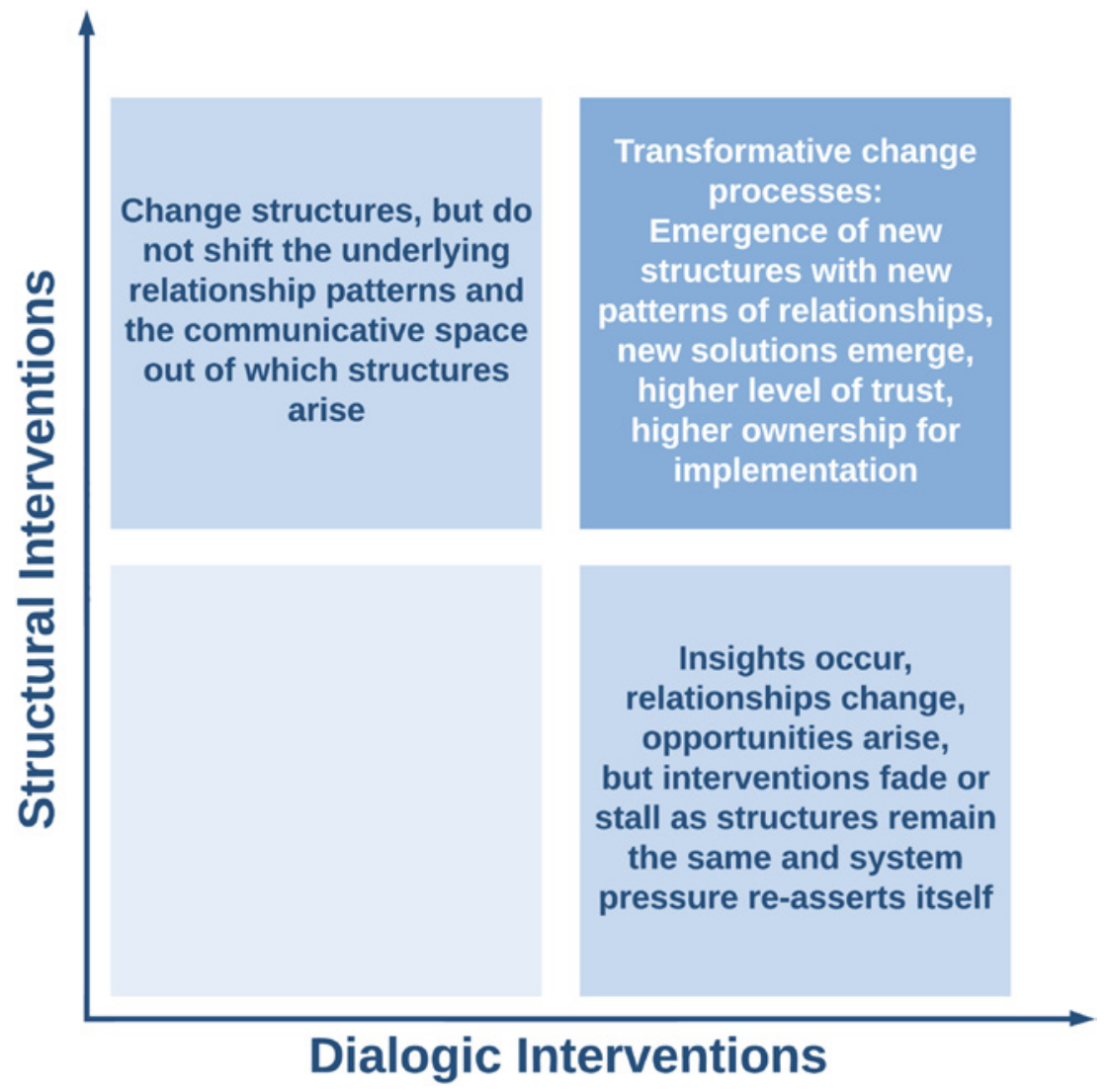

Figure 3.13 The balance between structural and dialogic interventions

Source: Copyright Collective Leadership Institute

The following section will therefore take deep-dives into how to develop process competence. The first deep-dive elaborates how a better understanding of the flow of divergence and convergence in change processes eases progress. The second deep-dive looks at the core task of dialogic process facilitators - how to build good containers for change. This is the core ingredients for successfully leading transformative change collectively, most importantly in Phase 1 of the Dialogic Change Model, but also throughout all other phases. These two deep dives create the basis understanding of the process competence that is needed to get multi-stakeholder collaboration to success. Building on this foundation, Chapter 4 will then elaborate how to apply these competencies to co-creating process architectures that become truly transformative.

\section{Understanding the flow of divergence and convergence}

There is an underlying rhythm to most successful and transformative change processes. Some of the methodologies and tools that have been portrayed in this practitioner guide have already emphasized the need to high-quality processes as key 
ingredient for transformative change. The understanding of an appropriate rhythm in such process is greatly enhance by the concept of divergence and convergence in processes (Bojer et al., 2008). Divergence relates to phases in a process that are opening up complexity - new possibilities, additional issues, or the exploration of variety of themes. They are most often created by dialogic interventions that are explorative and help stakeholder to harvest collective intelligence, ideally, when conversations move towards guided conversations, as well as reflective and generative dialogues. Such phases work best when the dialogic practices are applied and the four action modes are present. Then, it is possible to gather diverse viewpoints, generate new ideas, suspend stereotypes and judgments, and become comfortable with inquiring into disagreements. But people are different in their ability to hold the complexity that inevitably is part of phases of divergence. Some become confused, overwhelmed, or fearful of a process or a conversation that may be perceived as messy and uncontrollable. In conversations and dialogues, they tend to urge facilitators to come to conclusions; in processes, they would want to move into decisions and actions, accompanied by monitoring mechanisms. Figure 3.14 illustrates the flow of divergence and convergence.

Yet, without phases of divergence, the necessary perturbations, as Maturana and Varela (1991) called them, which are needed for systems to transform, cannot enter the minds of people. Chaos is necessary, because systems (and humankind) learn the most at the edge of chaos (Kauffman, 2016). This ability to hold complexity is also differently distributed among stakeholder groups. Research institutions as well as civil society organizations tend to be populated by actors who are more comfortable with holding complexity, while actors from the public sector and the private sector are used to keep complexity at bay. Yet, this latter faculty is also important. Successful change processes require phases of convergence, too. Convergence relates to phases in a process that are closing down possibilities and consolidating results. This could be making decisions, finding agreements, creating a roadmap, introducing accountability mechanism,

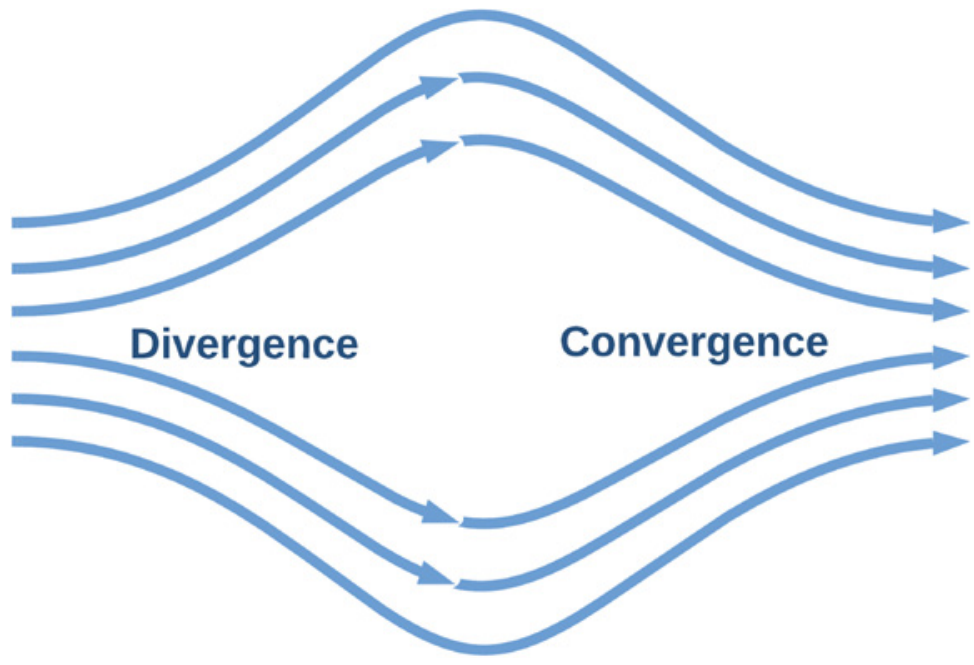

Figure 3.14 The flow of divergence and convergence 
or setting up monitoring systems. Convergence reduces complexity. It brings structure into a process that helps people act together to create future possibilities. Done too early, this undermines transformative change. Done too late, this prevents substantial change. While divergence creates the space for new insights emerge, convergence consolidates insights into structural interventions. This makes change manifest - that would not occur without opening to divergence before. For dialogic process facilitators is it important to understand that, in transformative change, divergence and convergence are married, they complement each other. The Collective Leadership Compass as a navigating tool and the Dialogic Change Model as a process model both help stakeholders to get the balance between divergence and convergence right, and find the appropriate sequence of dialogic and structural interventions. This applies to the facilitation of conversations as well as to the design of process architectures, which will be explored in Chapter 4. The following exemplifies how the different steps in Phase 1 and Phase 2 of the Dialogic Change Model ensure an appropriate flow of divergence and convergence.

\section{Phase 1: Exploring and engaging - Divergence is in the foreground}

- Creating resonance: focus is on divergence, but also convergence comes in when it is about generating interest for a particular goal.

- Understanding the context: focus is on divergence; gathering data and speaking to stakeholders makes the complexity of the situation noticeable; however, the analysis of findings speaks to convergence.

- Building a container for change: focus is on convergence, as the container is the first preliminary manifestation of the change, a group of people committed to work together. However, the dialogic quality of conversations within the container can foster diverse expertise and viewpoints, hence emphasize divergence.

\section{Phase 2: Building and formalizing - convergence is in the foreground}

- Clarifying goals and resources: focus is on convergence, as it is about defining a joint goal; but also, divergence comes in the form of stakeholder meetings, ensuring that all different voices get appropriately heard when it is about generating interest for a goal.

- Planning the future together: focus is on convergence, as it is about consolidating the findings about the context and the engagement of stakeholders into an action plan. However, meetings need to make sure that enough divergent views will be heard.

- Consolidating agreements and establishing structure: focus is on convergence, as the agreements as much as the clarification of roles and responsibilities is building a new structure intended to hold the change process. Divergence comes in, as all stakeholders need to contribute according to their difference in expertise and resources and all stakeholders need to be adequately represented.

Getting the balance between divergence and convergence right goes a long way in creating the conditions for enlivened collaboration ecosystems to emerge. This understanding helps dialogic process facilitators to build good containers for change. 


\section{Building good containers for change}

The term container as the quality indicator for a core group who jointly holds and drives the process of multi-stakeholder collaboration has been introduced in Chapter 2. It has been explained as a group of actors that develop a culture of collective leadership for the transformative change envisaged and enact high quality collaboration patterns. There is a saying from African wise women that captures the quality of a good container well. It goes like this: "Only dedicated circles can give birth to something new." It is the dedication that makes the difference. Once a group of stakeholders senses that they could make a difference together, it becomes more alive. This is the seed of transformations towards systems aliveness. But how to get from a thorough stakeholder analysis to a good container for change?

The stakeholder analysis suggests that the core group should be composed of stakeholders who are interested in the change and influential enough to make a difference. They do not need to all have the same degree of power in the system, but need to respect power differences without exploiting them. Ideally, this group of people already represents a microcosm of the diversity of stakeholders that are needed to get the envisaged change going. From a process point of view, as mentioned earlier, the core group as a good container is the first manifestation of new interaction patterns between stakeholders; in a way, it is the microcosm of the change people want to see happening. Engaging stakeholder to become part of a good container for change is an art that requires both systems understanding, relationship building and a good sense of process. It is clear that stakeholders engage when they - emotionally and rationally - resonate with the content and goal of the envisaged multi-stakeholder collaboration, regardless of whether it is a stakeholder dialogue, a stakeholder platform, a stakeholder initiative or a stakeholder partnership. However, sometimes initiators of multi-stakeholder collaborations assume that other stakeholders must be interested in the same issue, and are, by default, willing to engage. This is probably the exception. The context of most transformative change initiatives involving multiple stakeholder is much more complex: there can be contradicting agendas of stakeholders, conflicting interests, or actors who are overwhelmed by other commitments. Dialogic process facilitators need to be aware that the intention and purpose they want to promote is, at the outset, one among many others on the agenda of most of the stakeholders - even if everybody is keen to implement the SDGs. In addition to this, the importance of getting the quality and process of collaboration right, even if conceptually well framed, may not necessarily be understood by stakeholders that should become involved. Hence understanding from the stakeholder analysis who should become part of the container is important, however, getting them on board, requires very deliberate process designs. These will be different depending on the situation, the issue at hand and the context, but a few general aspects help in almost all situations:

- Once the institutional stakeholders that are (or should move) in the upper right quadrant (interested and influential) are clear, the question arises, who could best represent these institutions. In order to establish core groups, it is important to 
get representative on board who can make decisions to some degree (hence not too high level, not too low level), have a good standing in their own organization, and are emotionally engaged with the envisaged change. Members of the core group will usually be on the operational level, but with sufficient decision-making power (or access to actors in decision-making position) to be able to take charge of the change initiative.

- Personal relationship building is key. Inspiring bilateral conversations with dialogic quality, often several, as much as informal meetings between initiators and key actors anchor the ideas for change.

- For institutions that are more difficult to involve it is important to understand what their priorities are, and show sufficient empathy. Entering into conversations with representatives from these institutions requires joining them "where they are", not "where they should be". This means - in conversations - that initiators of multi-stakeholder collaborations have done their homework (understanding the institution) and acknowledge what they have done so far in the direction of the envisaged goal (even if this is little).

- Initiators who aim at becoming dialogic process facilitators foster connectivity in engagement. As part of the engagement process, they connect people with other people relevant for the issue.

The important lesson from successful multi-stakeholder collaboration is that engagement starts small. It is a step-by-step process of building enlivened collaboration ecosystems. The core group as the initial container must have time to form, create an identity, and build personal relationships. This helps to hold differences and inevitable disagreements. Content conversations are paramount, but the core group does not need to solve all issues that the multi-stakeholder collaboration process will address. The container is the guardian of the process that will be built on the collective intelligence of many more stakeholders.

With a conscious process design in Phase 1 of the Dialogic Change Model, the core group's task in its function as a good container is to gradually establish a broader container. This broader container is composed of people who are supportive of the multistakeholder collaboration purpose, may get involved in certain meetings, and take the dialogue process beyond those who form the initial container. Ideally, each member of the core group identifies who else needs to be involved as part of the broader container. Hence, the members of the core group will engage high-level sponsors, decision-makers who are crucial to the success of the transformative change endeavor. They will also get into conversations with selected key stakeholders, in Phase 1 most often in a more informal way (e.g. in bilateral meetings or small focus-group meetings). Such conversations will always center on the content and the goal, but promote the multi-stakeholder collaboration as an appropriate approach to achieve the envisaged transformative results. It is crucial for the preparation of any events in a Phase 2 of Building and Formalizing that 'structurally significant' actors - decision-makers, people who can make things move - are sufficiently engaged. They must support the goal and form of the multi-stakeholder collaboration and promote both within their respective stakeholder groups, institutions and constituencies. People engage when 


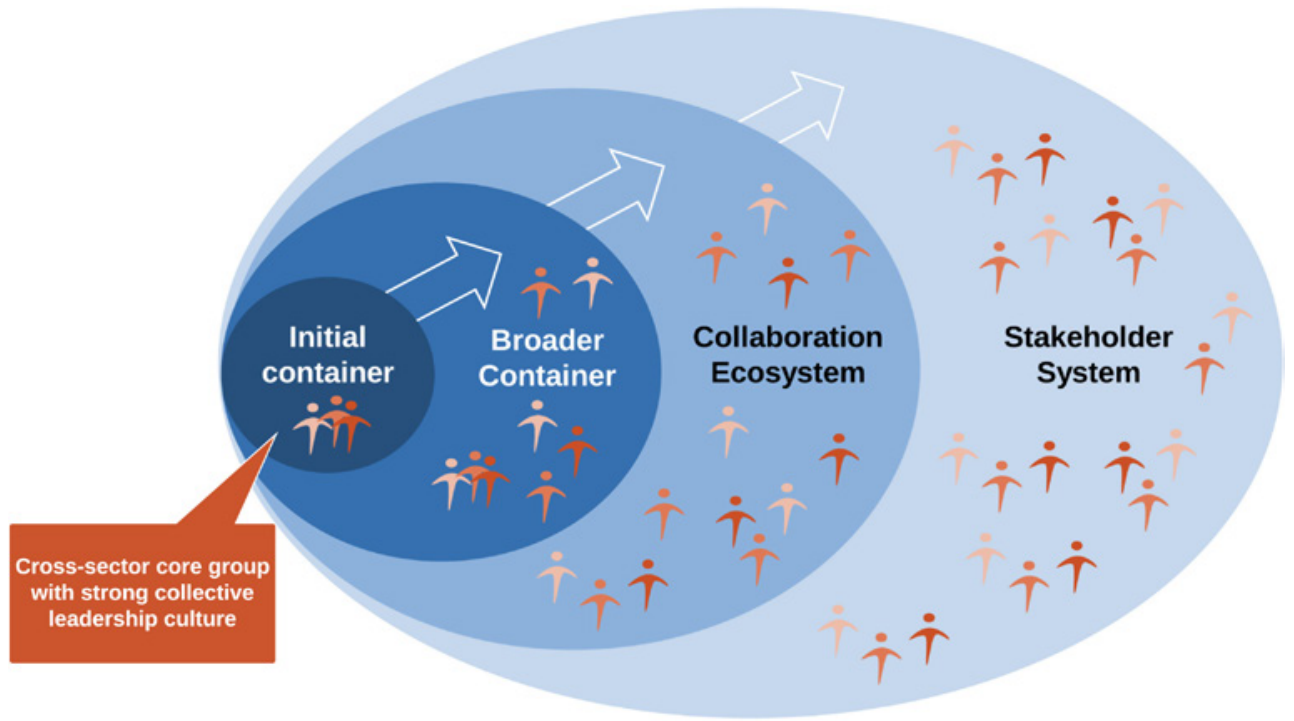

\section{Collaboration Ecosystem}

\section{Stakeholder System}

Figure 3.15 Building containers for change towards collaboration ecosystems

Source: Collective Leadership Institute

they get to experience meaningful conversations that tap into their desire to make a difference. Preparatory conversations with key stakeholders do not only serve to understand the stakeholder system better - they need to be conducted in a way that inspires potential participants to engage. Figure 3.15 reiterates the collaboration ecosystem and how it emerges from the initial container.

If the process design of Phase 1 has generated sufficient interest and resonance, it is time to prepare for the engagement of the entire collaboration ecosystem in Phase 2. These are usually those actors who participate in one or several stakeholder events, such as consultation meetings, workshops, planning meetings, etc. Good preparation of such events ensures that a sufficient number of participants have already been part of bilateral informal or formal conversations in Phase 1. The core group then knows already who is supportive, who is doubtful, who is opposed, or who is highly engaged. The structure and form of the stakeholder meetings must support further container building among the wider group of stakeholders. This is the glue that keeps the collaboration ecosystem functioning. There must be room for respectful acknowledgement of difference, authentic listening to concerns, task-orientation in the meeting itself, transparency in planning the way forward, and result-orientation to ensure tangible outcomes.

Initiators sometimes overlook the differences of different stakeholder groups in their motivation to join and engage. It is helpful to keep in mind that each group may need to be treated in a different way to maintain interest. The following is a reminder 
Table 3.7 Engaging stakeholder groups differently

\begin{tabular}{|c|c|c|}
\hline Priva & Publi & Civil \\
\hline $\begin{array}{l}\text { - Know that the private sector } \\
\text { always has a busy schedule. } \\
\text { - Involve private sector in the } \\
\text { planning process. } \\
\text { Build a result-oriented } \\
\text { process and create a flexible } \\
\text { and practical environment. } \\
\text { - Plan short meetings in a } \\
\text { convivial setting. } \\
\text { - Show the business case } \\
\text { for change (help them to } \\
\text { argue the business case for } \\
\text { engagement). } \\
\text { - Provide the opportunity to } \\
\text { showcase their work and } \\
\text { promote their image. } \\
\text { Take advantage of com- } \\
\text { petitiveness to stimu- } \\
\text { late involvement and } \\
\text { commitment. }\end{array}$ & $\begin{array}{l}\text { - Understand the power } \\
\text { dynamics and hierarchical } \\
\text { structures. } \\
\text { - Recognize the importance } \\
\text { of sociocultural factors. } \\
\text { - Be aware of formal, but also } \\
\text { traditional, structures. } \\
\text { - Ensure knowledge of exist- } \\
\text { ing rules and regulations. } \\
\text { - Always respect protocol. } \\
\text { - Show the reputational case } \\
\text { for change. } \\
\text { - Consider supra-national and } \\
\text { regional structures and their } \\
\text { interests. } \\
\text { - Highlight sustainability } \\
\text { aspects. } \\
\text { Make reference and ensure } \\
\text { conformity to international } \\
\text { conventions. }\end{array}$ & $\begin{array}{l}\text { - Consider logistical or } \\
\text { financial support for } \\
\text { participation. } \\
\text { - Ensure transparent and } \\
\text { inclusive communication. } \\
\text { - Be aware of their require- } \\
\text { ment to consult with their } \\
\text { constituencies. } \\
\text { - Respect the different } \\
\text { mandates of different } \\
\text { organizations. } \\
\text { - Strengthen weaker rep- } \\
\text { resentation (e.g. translation } \\
\text { for community groups). } \\
\text { - Respect and appeal to } \\
\text { value-orientation. } \\
\text { - Show the societal case for } \\
\text { change. } \\
\text { - Be prepared to } \\
\text { address questions on } \\
\text { impact - monitoring. }\end{array}$ \\
\hline
\end{tabular}

of what needs to be taken into account when engaging the three large societal stakeholder groups. Depending on the context, this may be even more complex: a stakeholder analysis helps to understand the motivations that can lead stakeholder groups to engage. Table 3.7 illustrates how dialogic process facilitators can attend to different stakeholders.

\section{Engaging stakeholders means gradually building larger and larger containers for change}

This is what makes the dialogic process successful. Multi-stakeholder collaborations that are geared towards cooperation for tangible impact benefit from the strong base of gradual container building for the implementation Phase 3. But even multistakeholder collaborations with focus on consultation become more effective when participants feel engaged, acknowledged and taken seriously. Engagement does not necessarily mean consensus: critical stakeholders can play an important role. But only a well-built engagement process can ensure that they stay in the process, remain constructive with criticism, and are willing to compromise if a successful outcome is at stake. Once the collaboration ecosystem is willing to engage, participating stakeholders will connect with the wider stakeholder system of indirectly involved stakeholders and will begin to create an effect. These can be people who know of the initiative, but 
do not participate directly, and people who are directly or indirectly affected by the outcomes of the multi-stakeholder collaboration. When they perceive the existence of a diverse group of actors who (and not always in agreement) move an issue forward, they become attracted to engage, too.

Good container building is the lifeblood of multi-stakeholder collaborations. Core groups as good containers often get their legitimacy not only from their official mandate but from the way they are able to engage the different stakeholders successfully. They recognize their success when they see that stakeholders beyond the actual collaboration ecosystem begin to engage, and work together collaboratively. Many initiators of multi-stakeholder collaborations do not take the engagement process in Phase 1 and 2 seriously. They sometimes skip it, or just pay lip service to it. Decision-makers may even put members of the core group under pressure to rush into stakeholder events without thorough preparation and engagement of stakeholders. It then helps to argue for the methodology and explain that the investment of thorough engagement will pay off both in consultative and cooperative multi-stakeholder collaborations.

\section{CASE EXAMPLE 3.6: EXAMPLE FROM THE FIELD: CONTAINER BUILDING FOR ORGANIC AGRICULTURE IN MONGOLIA}
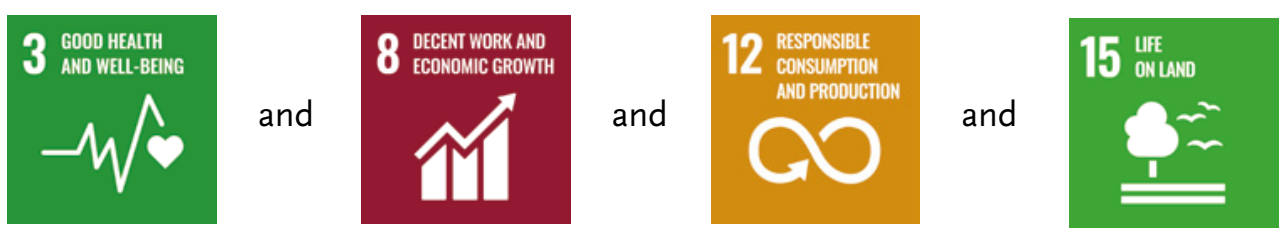

With a focus on human and environmental health, a movement for organic agriculture has been growing around the world since the mid-2oth century. The importance of organic agriculture has also been emphasized in reports from the United Nations, including a recent Trade and Environment Review with the urgent sib-title: "Wake up before it is too late: make agriculture truly sustainable now for food security in a changing climate" (UNCTAD, 2013). Further bolstered by the "Law of Mongolia Organic Food" (Government of Mongolia, 2016), the Adventist Development and Relief Agency (ADRA) responded to this call by initiating a multi-stakeholder partnership for organic agriculture involving the public sector, the chamber of commerce, and farmer cooperative members in the Selenge Province, Mongolia's breadbasket. In Phase 1, after a thorough context analysis the key challenge was to build a container for change. It turned out that, in this particular case, several containers for change where needed at different levels, such as, for example, the national and provincial level. A thorough stakeholder analysis conducted helped to identify key collaborating partners who were then engaged bilaterally considering their passion for organic agriculture, their perspectives, their institutional mandates, and personal convictions. An initial workshop with selected key stakeholders provided further opportunities to create resonance not only for organic agriculture, but also for the partnership approach. The workshop, which was combined with capacity building for collaboration, resulted in the development of a shared vision (see Figure 3.16), ${ }^{6}$ which was illustrated by a local artist. 


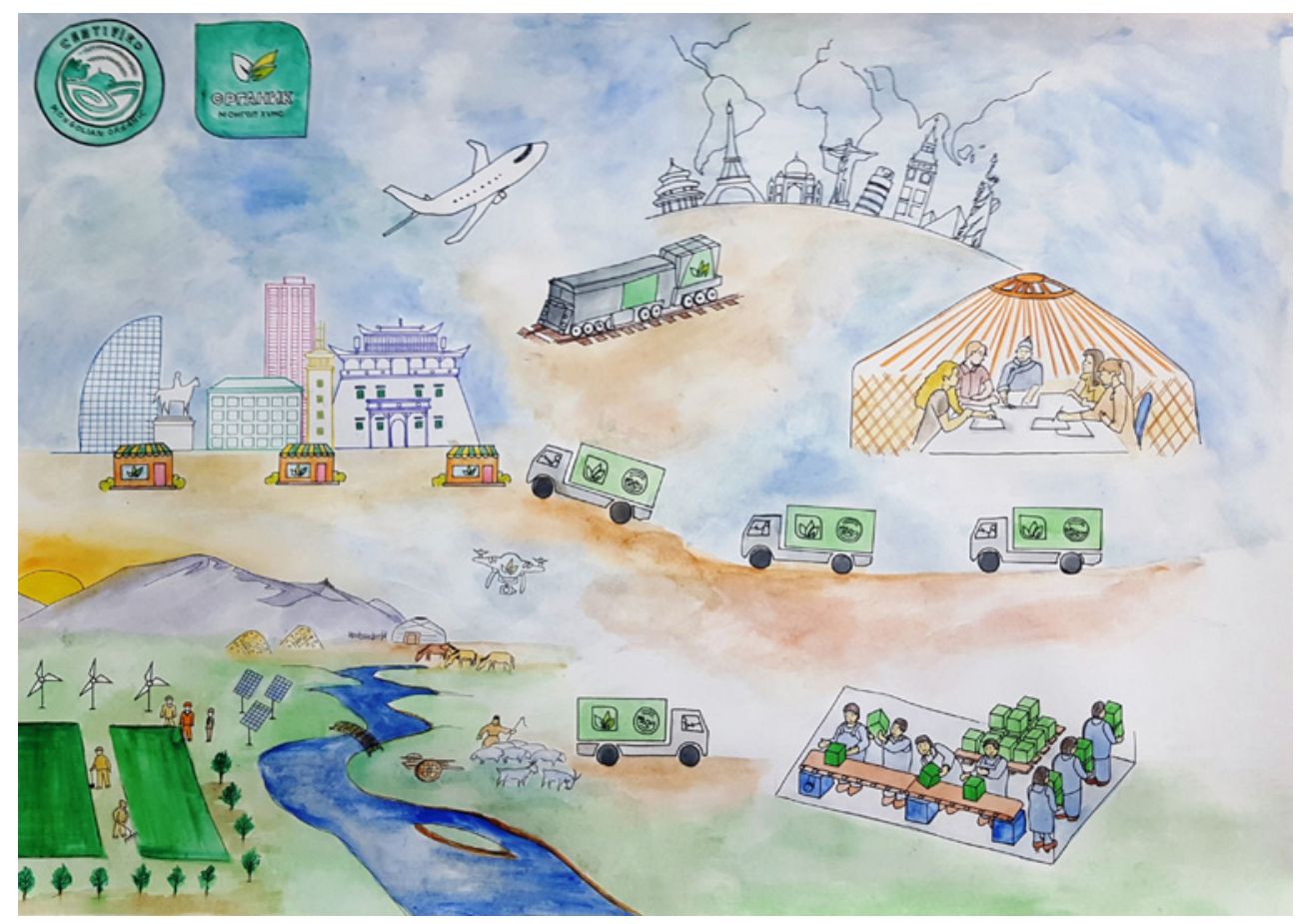

Figure 3.16 Shared vision for organic agriculture in Selenge Province, Mongolia, and beyond

In the emerging collaboration ecosystem, there was a need to engage stakeholders around different aspects and at multiple levels, which ultimately had to work together to make the initiative work. For example, stakeholders across different sectors needed to work on raising awareness about organic agriculture in Mongolia; local level actors needed to establish a participatory guarantee system $(P G S)^{7}$ for organic agriculture verification; and national level actors needed to work towards establishing a Mongolian multi-stakeholder advisory board on organic agriculture. Stakeholders translated the concept of a container as a core group driving change around certain aspects of the promotion of organic agriculture into a symbol of their traditional culture: the yurt as a symbolic meeting place for dialogue and decision-making. It conveyed the idea of safe space in which trusting relationships can be built; diverse views can be heard, respected, and integrated; and commitment for shared actions can grow. The yurt as a symbol appeared in both the shared vision (Figure 3.16) as well as in the partnership's initial process architecture (Figure 3.17) which showed the sequence of collective action and planning meetings among provincial stakeholders and national stakeholders, and how they were integrated into an overall design of successful collaboration. It also illustrates the important role of ADRA as a process facilitator. The result of the successful container building process was evidenced when it could be announced only a few months into the partnership that the first participatory guarantee system had been established, and, as a result, the local cooperatives began producing and supplying organic vegetables and honey. 


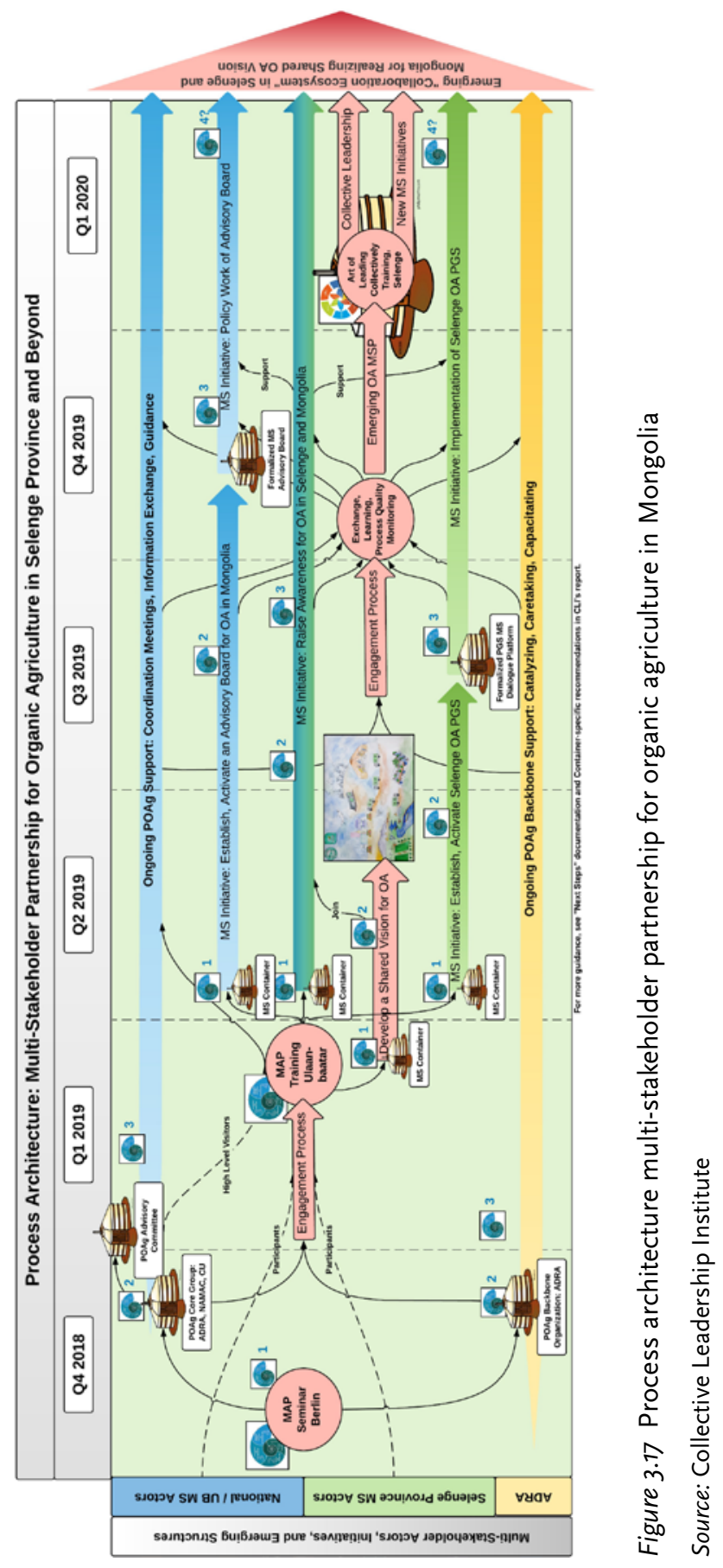


Chapter 4 will therefore look into the connections between container building and co-designing process architectures that make collaboration ecosystems successful.

\section{Notes}

1 This has been greatly inspired by the collaboration with Peter Garrett (see also Penwell \& Garrett, 2019).

2 Co-created by participants at "Visioning and Engagement Workshop," February $6-7,2020$ in Khulna, Bangladesh.

3 Adapted from Kuenkel (2008), inspired by Cliff Barry, www.shadowwork.com, The Four Quarter Model.

4 A similar version of this tool is available online at www.changingminds.org/disciplines/change_management/stakeholder_change/interest_influence.htm.

5 See the Four Player Instrument by David Kantor at www.kantorinstitute.com/ approach.

6 Co-created by participants at "Multi-Actor Partnership (MAP) Training," March 11-14, 2019 in Ulaanbaatar, Mongolia.

7 The participatory guarantee system (PGS) is defined as "locally focused quality assurance systems. They certify producers based on active participation of stakeholders and are built on a foundation of trust, social networks and knowledge exchange" (www.ifoam.bio/en/organic-policy-guarantee/participatory-guaranteesystems-pgs).

\section{References}

Bojer, M., Roehl, H., Knuth, M., \& Magner, C. (2008). Mapping dialogue: Essential tools for social change. Ohio: Taos Institute Publications.

Brown, J. (2005). The world café: Shaping our futures through conversations that matter. San Francisco: Berrett-Koehler Publishers.

Capra, F., \& Luisi, P. L. (2014). The system's view of life: A unifying vision. Cambridge: Cambridge University Press.

Cooperrider, D., \& Whitney, D. D. (2005). Appreciative inquiry: A positive revolution in change. San Francisco: Berrett-Koehler Publishers.

Government of Mongolia. (2016, April 7). Law of Mongolia organic food. Mongolia: Ulaanbaatar. http://extwprlegs1.fao.org/docs/pdf/mon159331E.pdf

IDEO. (2008). Design thinking, in Harvard business review. www.ideo.com/by-ideo/ design-thinking-in-harvard-business-review

Isaacs, W. (1999). Dialogue and the art of thinking together: A pioneering approach to communicating in business and in life. New York: Currency Doubleday.

Kantor, D. (2012). Reading the room: Group dynamics for coaches and leaders. San Francisco: Jossey-Bass.

Kauffman, S. (1996). At home in the universe: The search for the laws of self-organization and complexity. New York: Oxford University Press.

Kauffman, S. (2016). Humanity in a creative universe. New York: Oxford University Press. 
Kline, N. (1999). Time to think: Listening to ignite the human mind. London: Ward Lock. Kuenkel, P. (2008). Mind and heart: Mapping your personal journey towards leadership for sustainability. Potsdam, Germany: The Collective Leadership Institute.

Kuenkel, P. (2019). Stewarding sustainability transformations: An emerging theory and practice. Report to the Club of Rome. Cham, Switzerland: Springer.

Kuenkel, P., Frieg, V., \& Gerlach, S. (2011). Working with stakeholder dialogues: Key concepts and competencies for achieving common goals. A practical guide for change agents from public sector, private sector and civil society. Potsdam, Germany: The Collective Leadership Institute.

Laszlo, C., \& Cooperrider, D. (2010). Creating sustainable value: A strength-based whole system approach. In T. Thatchenkerry, D. Cooperrider, \& M. Avital (Eds.), Positive design and appreciative construction: From sustainable development to sustainable value. Advances in Appreciative Inquiry (vol. 3, pp. 17-33). Bingley: Emerald Group Publishing Limited. https://doi.org/10.1108/S1475-9152(2010)0000003006

Leminen, S., Westerlund, M., \& Nyström, A. G. (2012, September). Living labs as open-innovation networks. Technology Innovation Management Review, 6-11.

Luhmann, N. (1990). Essays on self-reference. New York: Columbia University Press.

Maturana, H. R., \& Varela, F. J. (1987). The tree of knowledge: Roots of human understanding. London: New Science Library.

Maturana, H. R., \& Varela, F. J. (1991). Autopoiesis and cognition: The realization of the living (vol. 42). New York: Springer.

Meadows, D. (1999). Leverage points: Places to intervene into a system. Hartland: Sustainability Institute.

Owen, H. (2009). Open space technology: A user guide. San Francisco: Berrett-Koehler Publishers.

Penwell, C., \& Garrett, P. (2019). The world needs dialogue! Volume 1: Gathering the field. Edinburgh: Dialogue Publishers Ltd.

Sahtouris, E., \& Lovelock, J. E. (2000). Earthdance: Living systems in evolution. San Jose, CA: iUniverse.

Senge, P. (1990). The fifth discipline: The art and practice of the learning organization. New York: Currency Doubleday.

Senge, P., Hamilton, H., \& Kania, J. (2015). The dawn of system leadership. Stanford Social Innovation Review, 13, 27-33.

Stamm, B. V. (2008). Managing innovation, design and creativity. West Sussex: John Wiley \& Son, Ltd.

United Nations Conference on Trade and Development. (2013). Trade and environment review 2013: Wake up before it is too late. Geneva: UNCTAD. https://unctad.org/ en/pages/PublicationWebflyer.aspx?publicationid $=666$

Varela, F. J., Thompson, E. T., \& Rosch, E. (1992). The embodied mind: Cognitive science and human experience. Cambridge, MA: MIT Press.

Weisbord, M., \& Jannoff, S. (2010). Future search: An action guide to finding common ground in organizations and communities. San Francisco: Berrett-Koehler Publishers.

Wheatley, M. (1999). Leadership and the new science: Discovering order in a chaotic world. San Francisco: Berrett-Koehler Publishers. 


\section{chapter 4}

\section{Becoming transformative Process architectures for building impactful collaboration ecosystems}

Chapter 3 highlighted the importance of organizing well thought-through processes in multi-stakeholder collaborations that help a sense of aliveness emerge among the actors that aspire to become a successful collaboration ecosystem around an issue of common concern. Such collaboration is often initiated in a context that can best be described as a "fragmented ego-system", in which institutional or even individual interests trump the common good, actions are unilateral and often conflictual, and results are, at best, only satisfactory to a few stakeholders. The possibility of shifting to a collaboration ecosystem of stakeholders aligned around and leading collectively towards a shared vision may seem far-fetched to many at this early stage, but this is precisely the kind of transformation that is needed and - through a well-designed process that integrates formalization of structures - is entirely possible.

These processes follow a flow that can be consciously designed. Multi-stakeholder collaborations often start with a focus on the Compass dimension of engagement as an entry point for enacting change. Creating resonance for future possibilities is essential for getting actors into a collaborative field in Phase 1 of the Dialogic Change Model. At this early stage, resonance is perceived by many at the individual level as a sense of aliveness - suddenly opportunities emerge that previously were considered impossible. In order for a multi-stakeholder collaboration to have a chance at success, Phase 1 needs to be designed in a way that it enlivens these opportunities and opens pathways to a new confidence in actors that change is doable despite the unavoidable obstacles. Understanding the context from various perspectives, both at a technical and an emotional level, furthers the presence of the dimension of wholeness. As described in Chapter 3, dialogic process facilitators need to learn a lot about 
the situation and about different stakeholders before they are able to approach each one in a way that people and institutions feel heard and also see the value in participating. In this regard, attention to the dimension of humanity can nourish trust and help individuals look beyond their institutional mandate to see that, together, they can contribute to the larger common good. This is essential in the formation of a container for change. Making the case for change often requires drawing on innovation, because, while humankind has engaged with invention for millennia, pathways to the future, and particularly to SDG implementation, require linking innovation with sustainability as a cutting-edge practice.

In order to get actors in aspiring multi-stakeholder collaborations into Phase 2, which consolidates the collaboration ecosystem and prepares it for collective action, dialogic process facilitators need to understand how to keep actors in the collaborative field. Some initiators think that once stakeholders are attending meetings they will stay in the process. But this is not the case. The art of taking care of people to keep them engaged is often neglected. Designing and facilitating dialogues that draw out the collective intelligence of the broader container are essential in Phase 2, especially when clarifying goals and resources and planning the future together. When people see their own aspirations in the collaboration's shared vision and see that their contributions to a changed future will make a difference, they get inspired and want to commit. People who feel alive and see possibilities are much more likely to remain engaged. If, however, there is no genuine care taking of concerns and interests, people will withdraw. In Phase 2, the appropriate structures need to create a sense of identity as well as accountability among actors in the collaboration ecosystem. This means sharing clear and complimentary roles and responsibilities, and designating decision-making and mandates to act to the lowest appropriate levels.

While collaboration ecosystems need boundaries, they should not, like institutions, develop rigid boundaries, but rather identifiable lines that make clear who is part of the collaborative field and who is not. These boundaries are constantly open to negotiation. This often comes as a surprise, as if the rules of who is in and who is out, once set, will remain forever. But this is not the case in a multi-stakeholder setting. There will be constant boundary challenges. Some stakeholders will want to draw the boundaries closer; others want them wider; others may question them altogether. Alongside the rules of the multi-stakeholder collaboration, maintaining or adjusting boundaries is a continual challenge.

In Phase 3 of a well-designed and collectively led multi-stakeholder collaboration, the system of actors is focused on implementation and evaluation, delivering on its vision. In this Phase, dialogic process facilitators need to ensure that established structures do not take on a life of their own, but help actors in the collaboration ecosystem to deliver the change. It is the relevant structures' contributions to an increasing systems aliveness that counts - the improvement around the issue of concern. Achieving such results together strengthens the collaboration. Ensuring transparency and agreed upon flows of information keeps core actors and members of the involved stakeholder system engaged in the collaborative field. Unclear or unreliable processes can make actors frustrated, suspicious, or even upset. Maintaining resonance in Phase 3 is especially important, for example through the celebration of successes. 
Since multi-stakeholder collaborations are about getting to results, dialogic process facilitators need to help stakeholders play into the same goal. This is often taken as self-evident because the collaboration is all about a joint goal. But reality is different from collective dreams. The goals can get lost or take a back seat when stakeholders begin to fight over procedures, structures, and rules. Putting the goal high on the agenda, continuously pulling it back to center stage, and creating an emotional connection with the goal is paramount, particularly in Phase 3 when everyone is busy implementing. This includes the need for regular, reflective dialogue for adapting goals and strategies for achieving them, as transformative change thrives on iterative learning. In that way, a process architecture that is co-designed and stewarded by an increasingly structured constellation of core, committed actors is the heartbeat of a thriving and impactful collaboration ecosystem.

This chapter, therefore, explores how dialogic process facilitators - as stewards of a multi-stakeholder collaboration process - can actually organize processes that create enabling conditions for enhanced patterns of aliveness among actors and help collaboration ecosystems deliver transformative change (Kuenkel, 2017, 2019).

- It takes a deep dive into planning impact in multi-stakeholder collaborations by crafting theories of change that take the Collective Leadership Compass to heart.

- It shows ways of bringing process and structure together into process architectures that are designed based on a shared theory of change and that cultivate aliveness at all levels of collaboration ecosystems.

- It describes the important role of formalizing structures in multi-stakeholder collaborations and how they can contain and promote transformative change.

\section{Planning impact in multi-stakeholder collaborations}

The term theory of change (ToC) describes how actors in collaborative change initiatives expect that impact can be achieved. This description of an "impact logic" of a project or change initiative can also be graphically represented in such a way that it shows how measures and activities lead to expected results in a certain context, and on which assumptions of the situation they are based. This helps stakeholders to jointly see how collaboratively planned activities lead to the desired goals. The term originates from project evaluation and has its origin in the Logical Framework Approach (LogFrame), which moved into development cooperation from the US Army and space travel in the 1970s. LogFrames are causal chains of inputs, activities, outputs, and results, linked to long-term project goals and are still often necessary components of project applications today. They are usually based on problem analyses. From the LogFrame approach, the Aspen Institute developed the theory of change approach at its Roundtable on Community Change in 1995. Carol Weiss, a member of the Roundtable, hypothesized in her book (Weiss, 1995) that the difficulty of evaluating complex programs is that the underlying assumptions are not clear or poorly worded. She also noted that there was insufficient attention to the early and medium-term changes needed to achieve a longer-term goal. The theory of change approach developed by her, therefore, reveals all assumptions, represents 
many small intermediate steps, and does not assume any strictly linear relationships. This approach has become very popular in planning and evaluating change initiatives among government agencies, NGOs, social enterprises, the United Nations, and many other large organizations.

For a successful multi-stakeholder collaboration initiative, it is important to develop and share a common theory of change so that it can serve as the basis for planning all activities. Even though collaborative change is more complex, and the approach to change might need to be adjusted more often, it ensures that all stakeholders have a shared understanding of what makes success likely and how to get there. It enables actors to see how success is built step by step, and how the actors, together, contribute to achievements. A theory of change can therefore be used as

- a powerful communication tool with which the complexity of a change initiative can be recorded and visualized;

- a framework for checking milestones and staying on course in multi-stakeholder collaborations;

- a basis for project applications to funders; and

- a reference for reporting to funders, decision-makers, and participating stakeholders.

While it is important to arrive at a jointly agreed theory of change, it is also important to acknowledge that the process of getting there will naturally reflect the diversity of and differences among stakeholders. Moreover, it is necessary to understand that assumptions about "how change happens" often implicitly inform the development of theories of change. It is therefore important to become aware of these assumptions. We all draw conclusions from our experiences about the world and how things work. This means, we have implicit assumptions or an "everyday theory" about a particular situation. On this basis, we develop what we call an "implicit theory of change", reflecting our own ideas about how change takes place. This results in a subsequently implicit "theory of practice", i.e. the way in which we act in concrete terms to advance change, because we believe that this is the right thing to do. Hence, different actors in multi-stakeholder collaborations may have their own implicit theories of change, which they incorporate into their actions, without ever making them explicit. However, in order for a multi-stakeholder collaboration to be successful, participants need to co-develop, apply, and regularly adapt a shared and evolving theory of change. Before we describe ways to do this using the Collective Leadership Compass, it is important to take a deep dive into how different stakeholders believe change happens. Often, this is based on implicit theories of change that unconsciously inform actions. Making such underlying theories aware, understanding how different stakeholders approach change and leveraging these differences for planning collaborative impact helps to design change processes that become effective.

\section{Understanding theories of change}

People distil life experience in different ways. This distillation leads to conclusions about how the world works, how it would be best to go about changing a situation, and which structures will best serve such a purpose. Naturally, we unconsciously 
assume that what we are most used to or what we find most comfortable must be the best way of operating for everybody. Figure 4.1 shows how, based on how we see the world and what we want to change or achieve (our 'theory of the issue'), we develop our implicit 'theory of change', and finally develop our 'theory of practice' - the way we go about changing a situation. Yet, already the theory of the issue is multi-faceted: it relates to how different stakeholders see the reality of a particular situation, hence, it is informed by observable facts, experiences, feelings, and knowledge, as well as perspectives on an issue. While stakeholders in collaborative initiatives might partly agree about what needs to change, they will inevitably have different views on reality and, subsequently, different "theories of the issue".

Chapter 3 has elaborated how dialogue furthers collective intelligence in such a way that stakeholders can combine their views of reality and arrive at a more comprehensive and more conscious 'theory of the issue' in Phase 1 and Phase 2. Yet, this does not mean that stakeholders will automatically also agree on how best to change a situation. Depending on culture, upbringing, education, and the societal sector in which people work, the strategies people assume will change a situation (the implicit 'theories of change') and will differ as much as how people are used to act (the implicit 'theory of practice'). For example, some stakeholders may be convinced that once the problem has been defined, there is a logical and undisputable line of action as a remedy. Others, however, may see the problem as a symptom, look at the situation as a complex braid of aspects, and prefer to think about how to address underlying conditions. Again, high quality dialogue not only reveals the differences and makes them more conscious, but also facilitates the emergence of collective intelligence for the design of strategies that all stakeholders can own and then they can agree on practices that leverage differences and build on complementary competences.

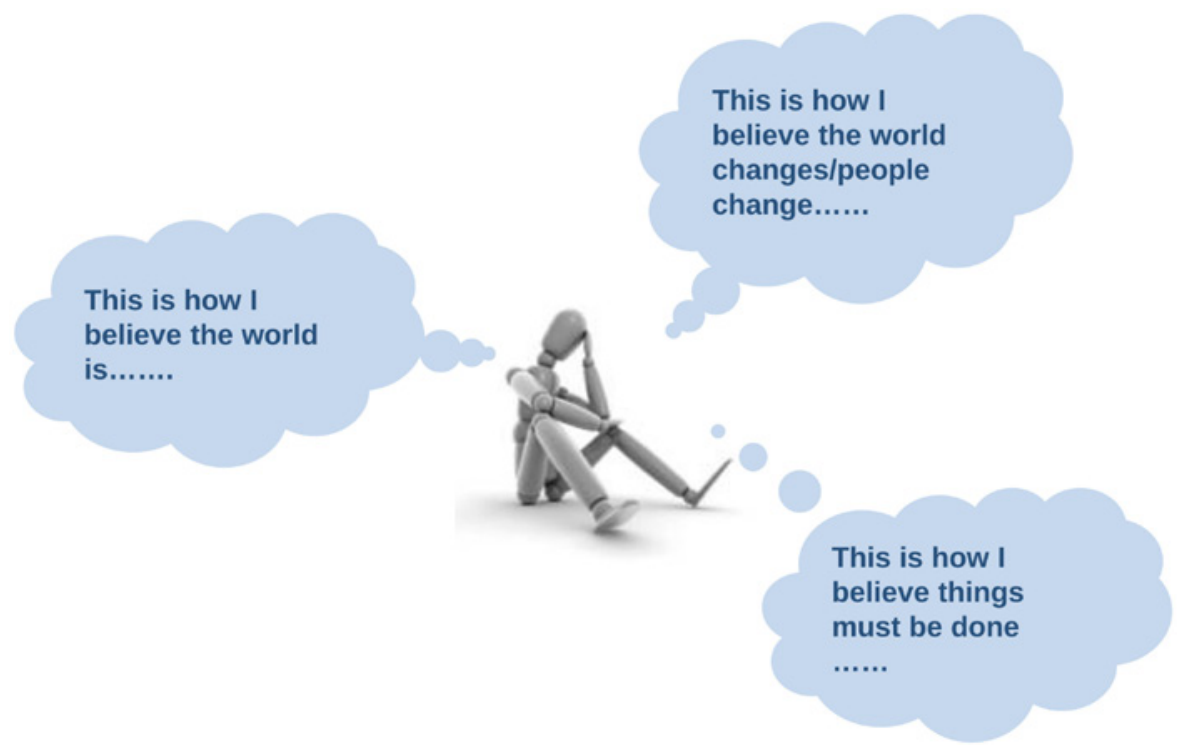

Figure 4.1 Implicit theories 
Table 4.1 Questions for the core container to reflect on implicit theories

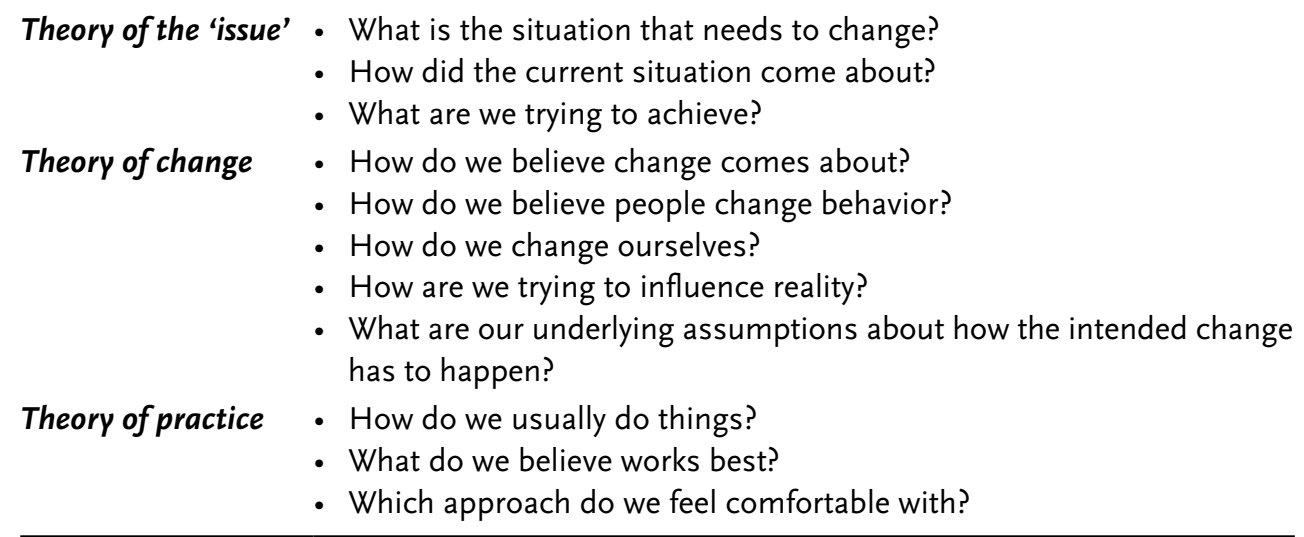

Understanding one's own implicit theories of change, therefore, helps dialogic process facilitators to notice different paradigms among stakeholders, to respect them, and to address them accordingly. Reflecting about one's own implicit theories of change helps not only to clarify one's own preferences, but also to accept that other stakeholders may have very different implicit theories. Table 4.1 suggests questions that can help a group of stakeholders, such as the core container for a collaboration initiative, to reflect on their implicit theories of change.

These questions are especially useful in Phases 1 and 2 of multi-stakeholder collaborations when initial theories of change are being explored and then agreed upon. They are also useful in Phases 3 and especially Phase 4, when there is an opportunity for reflection and adaptation of the theory of change. But especially, when it comes to designing strategies together, it is helpful to look more closely into differences that occur in how stakeholders believe change happens. Reconciling these differences or, even more importantly combining these approaches, helps dialogic process facilitators to design much more impactful process architectures.

The model in Table 4.2 helps stakeholders to become aware of the different approaches of bringing about change in human interaction systems. Based on implicit theories of change, most people tend to focus on one or two particular approaches to change: where they think change most likely begins, or how they think people can best be brought to change. They then, tend to assume that others think in the same way; if they do not, they try to convince them that their preferred approach to change is the most important or effective one. However, all of the four approaches in Table 4.2 need to be considered for multi-stakeholder collaborations as an approach to social or global change. The four quadrants offer complementary, rather than contradictory, perspectives on bringing about transformative change. The right quadrants focus more on empirical observation, while the left quadrants consider more subjective interpretation. The upper quadrants target more individual change, and the lower quadrants collective change. Each by itself offers only a partial view of reality, and all four perspectives are equally valid at different moments in a change process. 
Table 4.2 The four approaches to behavioral change

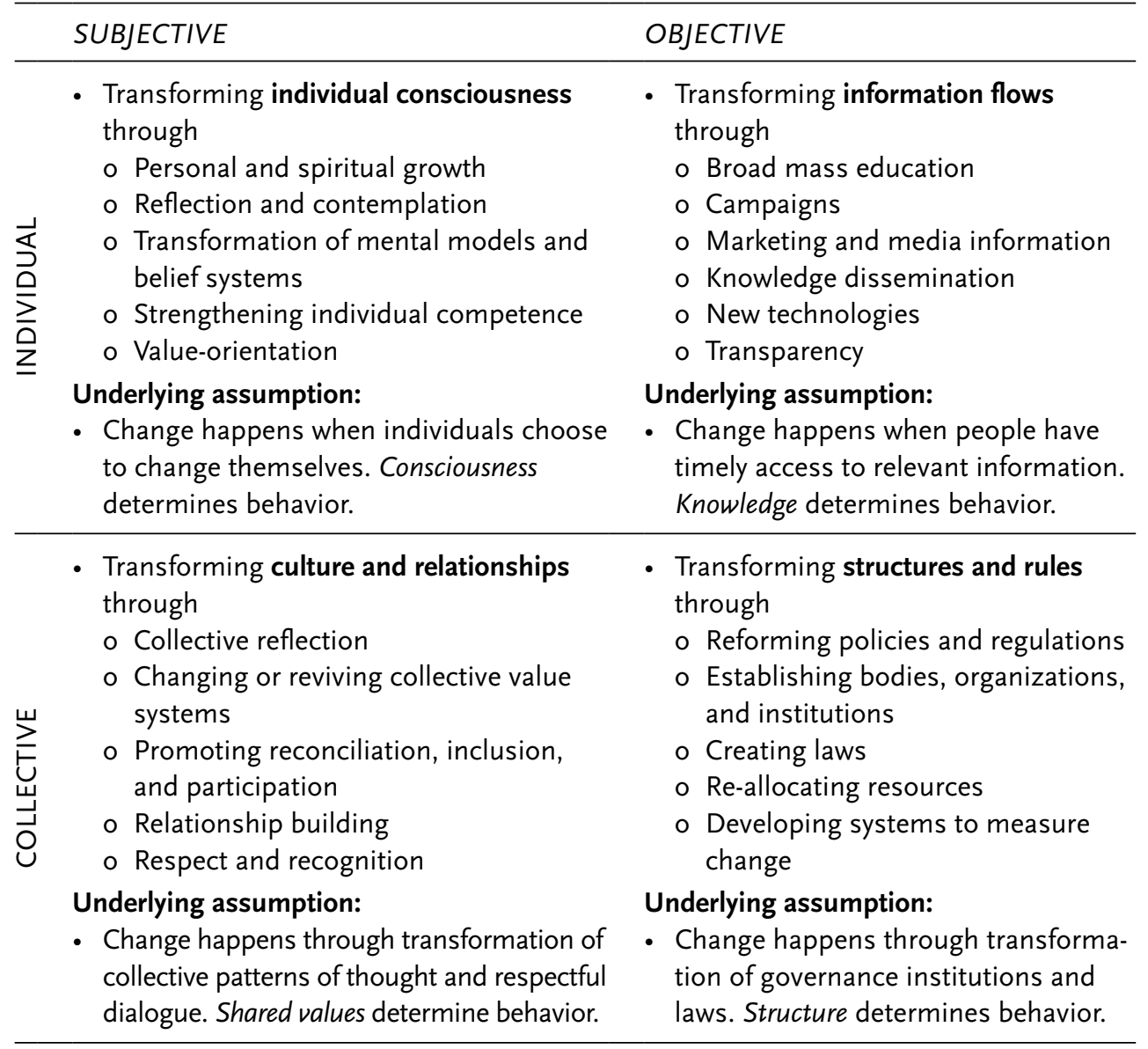

Source: Inspired by Wilber, 2002

In the upper left (individual/subjective) quadrant, the theory of change is focused on transforming individual consciousness. People who espouse this dimension hold that change happens through self-awareness, contemplation, and personal growth. Individuals must decide to change themselves by clarifying the principles they wish to embody and changing their behaviors accordingly. This can include transformation of their mental models and belief systems, as well as their own knowledge and competence for living these beliefs. Mahatma Gandhi is credited with saying "Be the change you wish to see in the world." His quote neatly summarizes this dimension. The underlying assumption of this approach to change is that consciousness determines behavior.

When attending to transforming individual consciousness, dialogic process facilitators must stay aware of the importance of humanity and personal encounter in multistakeholder collaborations as a pre-requisite for change of attitudes and the willingness to collaborate. Trying to create such opportunities in the lead-up to or during 
dialogue events is important, so that different actors who might not know one other or may have conflicting interests can discuss and come to empathize with differing perspectives. This could be through informal pre-meetings, small group discussions, informal social gatherings, or content work in task-specific working groups.

In the lower left (collective/subjective) quadrant, the theory of change is focused on transforming culture and relationships. People who espouse this dimension hold that change happens through relationships, group reflection, and respectful dialogue on changing dysfunctional collective patterns of thought and action. This can include changing or reviving collective value systems and promoting inclusion, reconciliation, and participation. The underlying assumption of this approach to change is that relationships with shared values determine behavior. Such development of values and relationships can happen within a family, a community, a culture, or even a movement for change, always with an emphasis on the importance of interdependence.

When attending to transforming culture and relationships, dialogic process facilitators must stay aware of the importance of collective intelligence and engagement to ensure that the less powerful stakeholders are listened to and that they have the opportunity to "tell their story". When designing dialogue events, it is important to include elements of exposure of participating actors to each other's diverse experiences and worldviews, priorities, and aspirations. This builds capacity for high quality dialogue and thinking together such that a new culture of collaboration and iterative learning can emerge.

In the upper right (individual/objective) quadrant, the theory of change is focused on transforming information flows. People who espouse this dimension hold that change happens when a population participates in broad education and has access to timely and relevant information. They would design campaigns and media strategies because they believe that behavioral change can only be influenced through targeted information flows, such as awareness raising, advertising, and political messaging. Information technologies, such as smart phones or social media, therefore, are especially relevant to this dimension; developing and making these available is understood as a way to influence behavior. The underlying assumption of this approach to change is that knowledge that can be imparted determines behavior.

When attending to transforming information flows, dialogic process facilitators must stay aware of the importance of wholeness in terms of understanding the context, as well as innovation in terms of sharing information. Identifying the significance of advocacy for a particular purpose, as well as awareness raising and information sharing, for the success of the multi-stakeholder collaboration is crucial. This needs to be integrated into change initiatives as capacity building on content. It also means developing communication strategies that ensure all stakeholders involved understand technical or scientific aspects of a required change and share all relevant information in a predictable and timely fashion.

In the lower right (collective/objective) quadrant, the dimension of change is focused on transforming structures and rules. People who espouse this dimension hold that change happens through the establishing or restructuring of governance bodies, institutions, or organizations, as well as legislating or reforming laws, 
regulations, or policies. This can include setting conditions and offering incentives. Reallocating resources and developing systems to monitor and evaluate change also belongs to this dimension. The underlying assumption of this approach to change is that structure determines behavior.

When attending to transforming structures and rules, dialogic process facilitators must stay aware of the importance of wholeness in terms of their contextual understanding, as well as future possibilities in terms of the purpose of the collaboration initiative. This means for stakeholder dialogue events to set an agenda with a strong future orientation, offering opportunities for empowerment, contribution, mutual support, and decisiveness when agreeing to action plans, roles and responsibilities, or structures and terms of reference. For multi-stakeholder collaborations, it is important to stick to the programs, plans, and the agreed process, as they create reliable structures that help participants in multi-stakeholder collaborations handle complexity better.

It is important to recall that people involved in multi-stakeholder collaborations may have preferences for any of the different approaches mentioned. Subsequently, they may focus their attention on one, or at least not all, of the quadrants. Dialogic process facilitators need to know their own preferences, be able to recognize the preferences of others, and respect and leverage the differences. They can act from their preferred approach, but still need to co-design multi-stakeholder collaborations in a way that integrates all four approaches to change. This can be supported by attending to the levels of competences illustrated in Table 4.3 .

Table 4.3 Levels of competences to leverage different change approaches

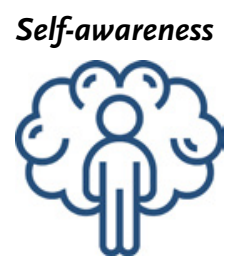

System understanding

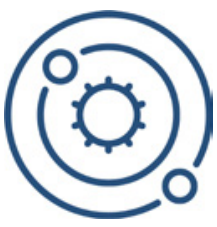

Process competence

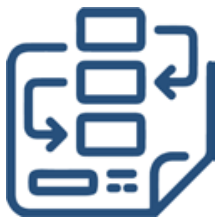

- Reflect on your preference, identify the approach to change that you are convinced is the starting point for change. Also, reflect in which area you are particularly strong and which approach to change you tend to leave to other people. Consider widening your scope of abilities so that you can work in all of the quadrants comfortably.

- Notice and observe different actors' implicit theories of change and the approaches to change that certain stakeholder groups may want to focus on. Respect and acknowledge the differences and explore, if possible, the underlying assumptions. Try to create an openness for the integration of all relevant quadrants into the multi-stakeholder collaboration as appropriate.

- Learn to become more aware of which approach to change is important during which phase of the multi-stakeholder collaboration. Become attentive to what makes a multi-stakeholder collaboration successful and try to integrate the different approaches to change. Reflect on and integrate the approaches into the design of a process architecture. 


\section{Crafting a theory of change with the Compass}

A theory of change should be developed in Phase 1, latest in Phase 2 of a multistakeholder collaboration. It should be as evidence-based as possible, hence based on a thorough context analysis in Phase 1, on concrete facts, data, studies, and stakeholder interviews. Ideally, this should be done as participatively as possible with the involvement of all initiators and the core container in Phase 1, or all relevant stakeholders in Phase 2. Throughout the four phases of the Dialogic Change Model, the assumptions and strategies in the theory of change should be tested and checked with facts, too. This may lead to co-developing a preliminary ToC in Phase 1, an agreed ToC in Phase 2, and an adjusted ToC in Phases 3 or 4. Its refinement should be based on a process of iterative learning: reflective strategic reviews among members of the core group or all relevant stakeholders, as well as results from monitoring and evaluation should be fed back into adjustments of the theory of change. The following section illustrates how a theory of change in multi-stakeholder collaborations can be developed in six steps using the Collective Leadership Compass as guidance.

In a first step, the insights gained from a thorough resonance building and context understanding in Phase 1 will be summarized as problems identified or potentials to be developed. This is about gaining clarity about exactly which challenges the collaborative change initiative can address. In a second step, the possible roles and mandates of the initiators (or the core group) of the change initiative need to be explored. In a third step, the preliminary desired long-term impact of the collaboration initiative is co-developed. Subsequently, the long- and short-term outcomes that contribute significantly to the impact will be described. In a fourth step, based on context understanding, experience, data, and facts, the assumptions about which circumstances accompany the expected change will be formulated. In a fifth step, complementary strategy components will be co-developed that need to work together to achieve the outcome. Intermediate results (or outputs) will also be defined and they should be operationalized using measurable indicators. Each strategic component should be linked to an interim result and attention should be paid to how and why these components are interrelated. In a sixth step, activities and measures will be planned that can ensure the results. The six steps will be detailed and illustrated by an example of a theory of change development for a youth empowerment project.

\section{CASE EXAMPLE 4.1: EMPOWERING TEAMS OF YOUNG COLLECTIVE LEADERS: TRANSFORMING POLICY DIALOGUES FOR EMPLOYMENT OPPORTUNITIES IN THREE JORDANIAN COMMUNITIES}

8 DECENT WORK AND

ECONOMIC GROWTH

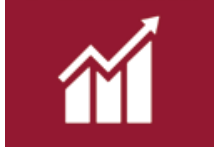

This multi-stakeholder collaboration project's purpose is to prototype the participation and contribution of Jordan's youth in public life through local public policy dialogues and action on youth economic empowerment. Its objective is to strategically empower select, young staff from youth civil society and community-based 


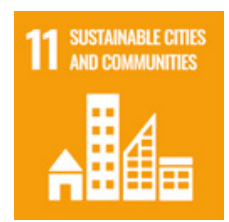

PARTNERSHIPS

FOR THE GOALS

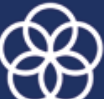

organizations as initiators and facilitators of policy dialogue between citizens, key stakeholders, and local authorities on youth employment. From these dialogues, policy action teams are expected to emerge that will develop concrete community development initiatives that sustainably address local employment needs, offer a space for active citizenship, and promote social cohesion. The project focuses on three communities in two different Governorates in Jordan.

\section{Step 1: systems check - what should change and why?}

Chapter 2 elaborated the different elements important for understanding the context in Phase 1, such as stakeholder interviews, a stakeholder analysis, learning journeys, benchmark studies, or any other relevant research. As described in Chapter 3 (Diagnosing Systems Patterns, page xx), the patterns in the stakeholder system in which problems arise and challenges occur need to be revealed, as this provides input for developing the strategic components. Understanding system patterns with the Collective Leadership Compass as a filter makes it easier to identify meaningful conclusions for interacting implementation strategies. It becomes clear which dimensions require special attention and which dimensions are already pronounced and should be used or further strengthened. This provides background information for planning transformative change interventions and flows into the design of implementation strategies (usually reflected in outcomes or outputs). The detailed results from understanding the context can be summarized in the systems check illustrated in Table 4.4 .

In the beginning of a collaboration initiative, most of the Compass dimensions will presumably rank low, as this shows the exact challenge that needs to be addressed. However, the details are important, as they inspire ideas how to overcome problems and build strategies on what is already working. In the case of the youth empowerment project, the theory of change, as is often the case for the required funding, was generated among core partners very early in the collaboration process. It was based on a context analysis that revealed not only the serious economic challenges of youth, but also the many forms of initiatives driven by young people that needed to be supported and connected. More generally, the results for the theory of change from Step 1 are:

- A shared understanding of the challenges, problems, potentials, and the patterns in the stakeholder system.

- An identification of possible starting points for changes as input for step 3.

- First ideas for impact and project outcomes as input for step 3. 
Table 4.4 System check with the Collective Leadership Compass

Presence

Scale: $1=$ low, 2 = medium,

3 strong presence

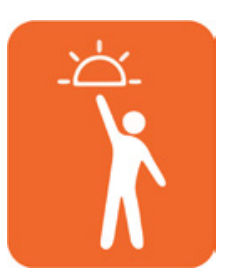

\section{Future possibilities}

$1-2-3$

- Challenges are known to all; resonance for change exists; an emotionally convincing vision is shared by all relevant stakeholders.

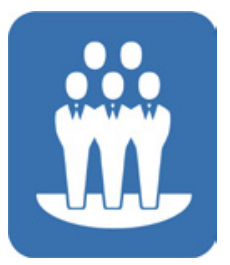

\section{Engagement}

- Organizational capacities, structures, networks, or platforms for change exist and work in favor of the envisaged future.

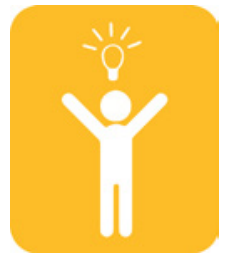

\section{Innovation}

- Change initiatives exist; new and creative approaches have been developed.

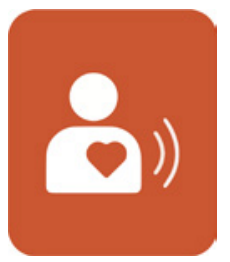

\section{Humanity}

- Mutual understanding exists; joint reflection takes place; stakeholders respect each other.

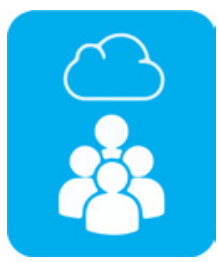

\section{Collective intelligence}

- Structured dialogues take place and enable knowledge exchange and understanding of different perspectives.

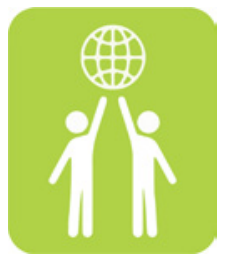

\section{Wholeness}

- The contribution of change to a larger goal is seen by all relevant stakeholders; complementary cooperation with other initiatives takes place. 


\section{Step 2: mandate - Who are we and what is our role?}

In this second step, conclusions are drawn from the system analysis in relation to the role and possible mandate of the initiators of the multi-stakeholder collaboration. This is about the initiators' role in the system, their potential or existing credibility to induce change and convene different stakeholders. It is also about deepening the Stakeholder Landscape Analysis described in Chapter 3 (page $\mathrm{xx}$ ) and looking at the best possible - and most effective - set of collaboration partners who could bring about change. This step can be done for preparatory purposes by initiators, but it should, in any case, take place together with what the core group or container has established in Phase 1. Step 2 should reveal answers to questions such as:

- How will we be perceived as initiators by relevant stakeholders?

- Who shares interest in change?

- Who do we have to work with to make a difference?

- Which important actors can support our concern?

- Where is there already "energy" or the will to bring about change?

Results for the theory of change from Step 2 are:

- Clarity about the mandate of the initiators or ways of gaining such a mandate

- Identification of strategic cooperation partners

- Ideas for building a broader container

- Ideas for strategic components for step 3

\section{Step 3: impact and outcomes - what exactly would we like to achieve?}

The purpose of step 3 is to agree on the envisaged impact of a multi-stakeholder collaboration, as well as the medium and short-term outcomes, as shown in Figure 4.2. This may be preliminary, if it takes place in Phase 1 by the core group, and can therefore be adjusted in Phase 2 when all relevant stakeholders need to agree on a joint theory of change. It is recommendable to first determine the long-term effect of the change initiative (impact) in the system. Impact refers to broader, long-term change to which the multi-stakeholder collaboration will contribute, if successfully implemented by a broad range of stakeholders. This is followed by the joint development of the longterm and medium-term outcome of the project or the change initiative, which make a decisive contribution to the impact. Outcomes refer to the medium-term effect the collaboration initiative is expected to have on structural, behavioral, and institutional changes in the stakeholder system.

The method of backcasting (Robinson, 1990) can be helpful when developing a theory of change in a small group. In backcasting, the core group or initiators of a multistakeholder collaboration mentally move into the future state that shows a desired change. They then visualize this future situation and describe it in detail, as if it was already there. 
THEORY OF CHANGE Empowering

Teams of Young Collective Leaders:

Transforming Policy Dialogues for

Employment Opportunities in Three Jordanian Communities

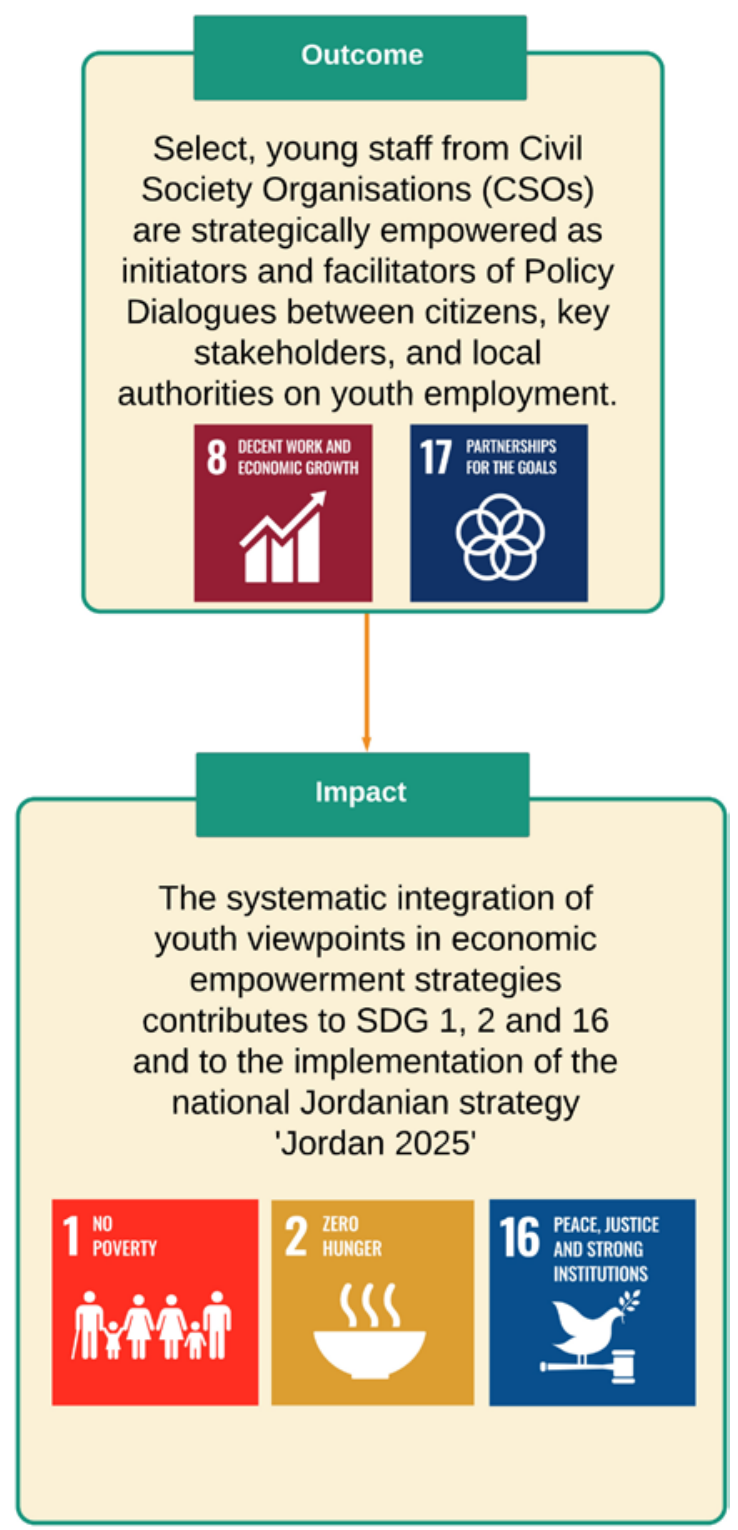

Figure 4.2 Example: theory of change - impact and outcomes

Source: Collective Leadership Institute 
The first set of key questions for backcasting is:

- What will the future look like at a certain point in time?

- How would we notice the change?

- How do the stakeholders behave differently?

From this, the impact of the change initiative (impact) can be formulated. The second set of key questions for backcasting is:

- How did we get there?

- What had to happen?

- What strategies were useful?

From the backcasting and responses to these questions, the short-term and mediumterm outcomes can be formulated accordingly, as is illustrated in Figure 4.2, using the example of strengthening youth empowerment in the country of Jordan. The second set of questions also generates first ideas for outputs and strategic components of a collaboration initiative.

Results for the theory of change from Step 3 are:

- The impact, as well as short-term and medium-term outcomes, is formulated.

- A compilation of strategic components and related outputs.

\section{Step 4: assumptions - what conditions influence change?}

In the fourth step, the major assumptions of the initiators about how the change is influenced positively or negatively will be formulated. These assumptions should, of course, be based on the thorough context understanding established in Phase 1, hence based on quantitative and qualitative insights into the situation. This can include assumptions about the way of thinking and behavior of the actors and structures to be changed, as well as assumptions about the roles of the actors involved. It is extremely important that existing assumptions are checked against available data and discussed with relevant stakeholders to ensure that they are plausible and capture the expected change process. In order for a theory of change to be logical, the underlying assumptions should be reflected in the strategy, or in the description of activities and expected results. Usually, assumptions are conditions that are influencing the situation and the envisaged change, but cannot necessarily be influenced by the initiators or the core group of a multi-stakeholder collaboration. These assumptions should be checked and adjusted continuously, particularly in Phase 3 of implementation and evaluation. This may then lead to an adjustment of the theory of change in Phase 3 or Phase 4. Figure 4.3 illustrates the assumptions for the youth empowerment project. Results for the theory of change from step 4 are:

- Assumptions shared among the core group or key stakeholders and jointly formulated. 

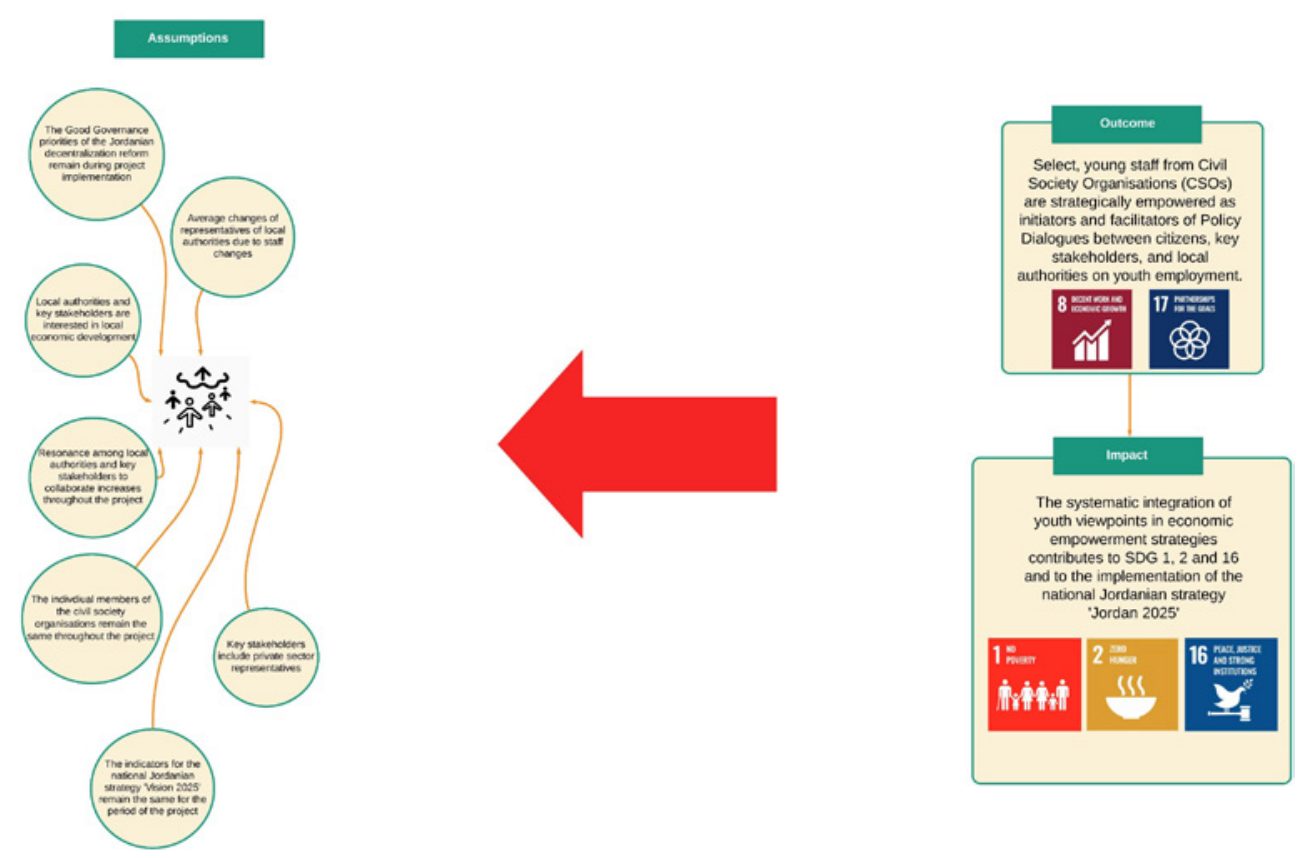

Figure 4.3 Example: theory of change - impact, outcomes, and assumptions

Step 5: strategic components and outputs - how will we bring about change?

The fifth step is to select strategic components for implementation from the ideas generated in step 3 during backcasting. This is about thinking through means, resources, as well as necessities important to engender the change the initiators or the core group want to see as a result of the multi-stakeholder collaboration. These strategic components may be implemented in a sequential way, or parallel, but they all need to be linked to expected outputs, which are the tangible results the collaboration initiative delivers or that are generated through implementing the strategic components. The theory of change needs to make clear that all outputs - together will contribute to the outcomes formulated in step 3. For selecting and planning the strategic components, it is helpful to look, again, at the systems pattern that has been diagnosed in step 2, and use the Collective Leadership Compass as a guide for planning the most effective strategic components. Table 4.5 shows how planning questions around the Compass dimensions can inform the generation and selection of strategic components.

The strategic components identified need to lead to very specific outputs that will also be formulated as part of the theory of change as depicted in the youth empowerment example in Figure 4.4. Usually, these outputs will be made operational by 
Table 4.5 Planning strategic components with the Collective Leadership Compass

\begin{tabular}{|c|c|c|c|}
\hline \multicolumn{2}{|c|}{ Dimensions as change enablers } & $\begin{array}{l}\text { Key questions to } \\
\text { generate strategic } \\
\text { components }\end{array}$ & $\begin{array}{l}\text { Examples for strategic } \\
\text { components }\end{array}$ \\
\hline & $\begin{array}{l}\text { Future possibilities } \\
\text { - Cultivating inspiring } \\
\text { narratives and show- } \\
\text { ing opportunities }\end{array}$ & $\begin{array}{l}\text { With which future } \\
\text { narratives can we } \\
\text { engage relevant } \\
\text { stakeholders? }\end{array}$ & $\begin{array}{l}\text { - Communication strategies } \\
\text { - Conversational spaces } \\
\text { - Collective learning } \\
\text { (study visits, showcasing } \\
\text { innovation) }\end{array}$ \\
\hline & $\begin{array}{l}\text { Engagement } \\
\text { - Creating collab- } \\
\text { orative, cross- } \\
\text { institutional network } \\
\text { structures and high- } \\
\text { quality processes }\end{array}$ & $\begin{array}{l}\text { Which coopera- } \\
\text { tion structures } \\
\text { promote transpar- } \\
\text { ent and effective } \\
\text { change processes? }\end{array}$ & $\begin{array}{l}\text { - Collective action teams } \\
\text { - Collaboration capacity } \\
\text { building } \\
\text { - Collective learning } \\
\text { (study trips, showcasing } \\
\text { innovation) }\end{array}$ \\
\hline & $\begin{array}{l}\text { Innovation } \\
\text { - Prototyping the } \\
\text { future }\end{array}$ & $\begin{array}{l}\text { How is space and } \\
\text { support created for } \\
\text { social, scientific, } \\
\text { and technological } \\
\text { innovations that } \\
\text { accelerate change? }\end{array}$ & $\begin{array}{l}\text { - Nurturing innovators } \\
\text { - Awards for new ideas } \\
\text { - Implementing pilots and } \\
\text { prototypes }\end{array}$ \\
\hline & $\begin{array}{l}\text { Humanity } \\
\text { - Furthering aware- } \\
\text { ness and mutual } \\
\text { understanding }\end{array}$ & $\begin{array}{l}\text { Which forms of } \\
\text { information and } \\
\text { encounter help } \\
\text { people to see } \\
\text { reality or progress } \\
\text { so that they drive } \\
\text { change? }\end{array}$ & $\begin{array}{l}\text { - Advocacy strategies } \\
\text { - Media campaigns } \\
\text { - Learning journeys } \\
\text { - Bringing diverse stake- } \\
\text { holders together } \\
\text { - Field trips }\end{array}$ \\
\hline & $\begin{array}{l}\text { Collective intelligence } \\
\text { - Enhancing own- } \\
\text { ership through } \\
\text { governance struc- } \\
\text { tures, dialogue, and } \\
\text { learning spaces }\end{array}$ & $\begin{array}{l}\text { What kind of } \\
\text { cross-stakeholder } \\
\text { exchange pro- } \\
\text { motes implemen- } \\
\text { tation and joint } \\
\text { learning? }\end{array}$ & $\begin{array}{l}\text { - Dialogue platforms } \\
\text { - Governance structures } \\
\text { - Communities of practice }\end{array}$ \\
\hline & $\begin{array}{l}\text { Wholeness } \\
\text { - Enhancing linkages } \\
\text { with other initia- } \\
\text { tives as well as with } \\
\text { high-level decision } \\
\text { makers }\end{array}$ & $\begin{array}{l}\text { How can a new } \\
\text { way of acting be } \\
\text { embedded in pow- } \\
\text { erful structures } \\
\text { and procedures? } \\
\text { Which connec- } \\
\text { tions created will } \\
\text { increase impact? }\end{array}$ & $\begin{array}{l}\text { - Policy dialogues } \\
\text { - Engagement of high-level } \\
\text { decision-makers } \\
\text { - Complementary collabora- } \\
\text { tion with other initiatives }\end{array}$ \\
\hline
\end{tabular}




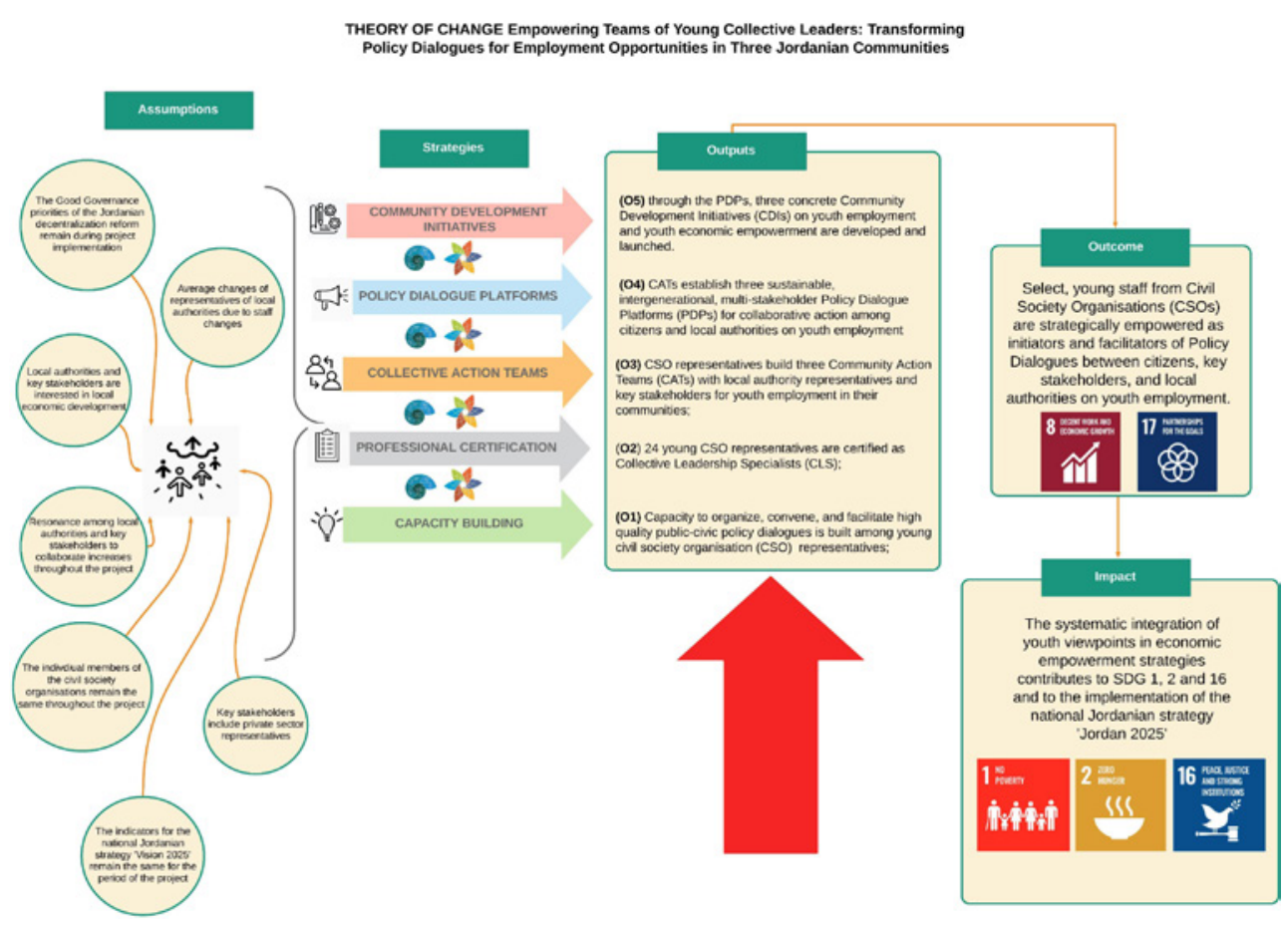

Figure 4.4 Example: theory of change - strategic components and outputs

defining indicators that show how much, for whom, and when the result should be achieved. Results for the theory of change from step 5:

- Strategic components are identified as well as their interactions with each other. The way they build on each other is comprehensible.

- Outputs are formulated.

- The flow of the theory of change is understandable, logical, and consistent.

\section{Step 6: activities - what do we actually do to bring about change?}

In the sixth and final step, measures and activities are planned that lead to the outputs. It makes sense not only to keep an eye on the results to be achieved, but also on the indicators that correspond to the respective outputs when planning the activities. Developing indicators always helps to review and cross-check the outputs formulated as the indicators must be measurable. Figure 4.5 shows an example of the completed theory of change. Results from step 6 are:

- Activities and measures are formulated and shown graphically in the flow diagram.

Throughout all four phases of collaborative change, the theory of change is crucially important as a reference point for reviewing what the collaboration initiatives 


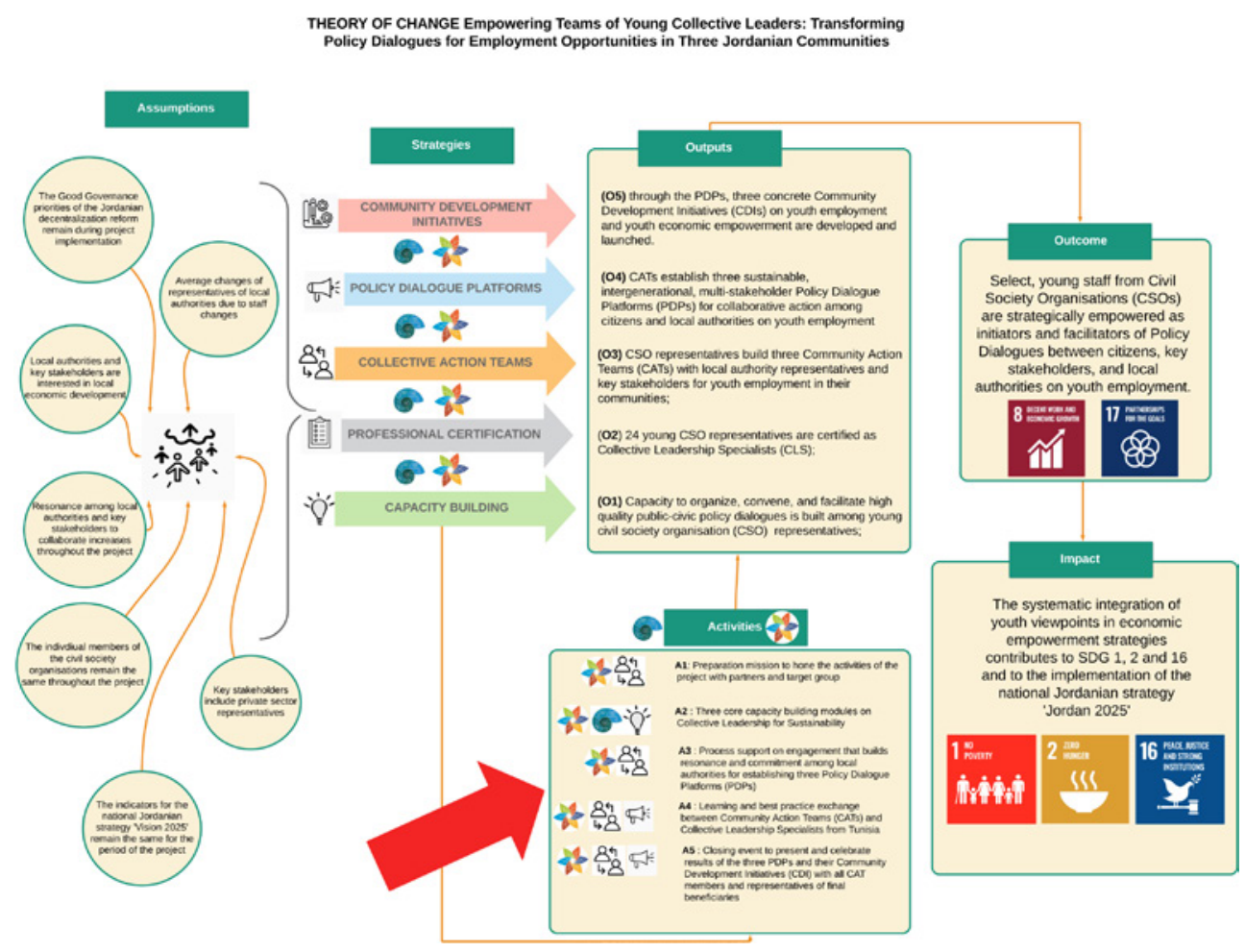

Figure 4.5 Example: the completed theory of change

intended to achieve and how progress is made. It will inform the development of detailed action plans and, above all, it will be the basis for the design of collaboration processes that bring the theory of change to life. Crafting a theory of change that is shared among stakeholders is important, but not sufficient for the success of a multistakeholder collaboration. It is the process architecture - the sequence of actions that makes the theory of change work and shows in more detail how collaboration, and finally impact, is co-constructed. A process architecture transfers the developed strategic components into a timeline, shows the process of how stakeholders interact, and differentiates between different intervention levels. The next section, therefore, focuses on how to develop such enlivening processes using the Dialogic Change Model and the Collective Leadership Compass as a guide for high-quality collaboration.

\section{The purpose of process: cultivating aliveness in collaboration ecosystems}

The previous chapters, especially Chapter 2 on the Dialogic Change Model, have shown how building success in multi-stakeholder collaboration requires attention to processes that enliven stakeholders so that they enact a more constructive future together. Taking such an approach is a choice - a choice that is sorely needed in order to achieve the SDGs by 2030 and secure a habitable and thriving planet for 
generations to come. Designing and implementing high-quality collaboration processes that model systems aliveness at all levels is an essential prerequisite for transformative change, as it enables actors to co-construct the desired sustainable future. It can enhance the capacity to adapt to and mitigate climate change, respond to biodiversity loss, address gender inequity, or decrease youth unemployment, among others. In enhancing aliveness in systems, the core effect of applying the Collective Leadership Compass, collaborating stakeholders become partners of evolution in the sense that they model a life-enhancing, future way of interacting. Good process architectures invigorate a culture of collective leadership and guide people in stewarding transformative change together. The term architecture is important because designing the sequences of stakeholder interactions creates a space not unlike the structural space of an architect-designed building: it has an effect on the level that people feel at ease, inspired, or creative, or how they feel uncomfortable, claustrophobic, or constrained. This is why, in the Collective Leadership Compass, the aspect of process quality in the dimension of engagement and dialogic quality in the dimension of collective intelligence are inextricably linked, as shown in Figure 4.6.

This connection comes to life in the way stakeholder interactions are planned and designed. The process architecture is a dynamic visualization of the sequence and interlinkages of informal and formal communicative interactions and events that enliven a collaboration ecosystem in which stakeholders lead collectively towards a desired outcome.

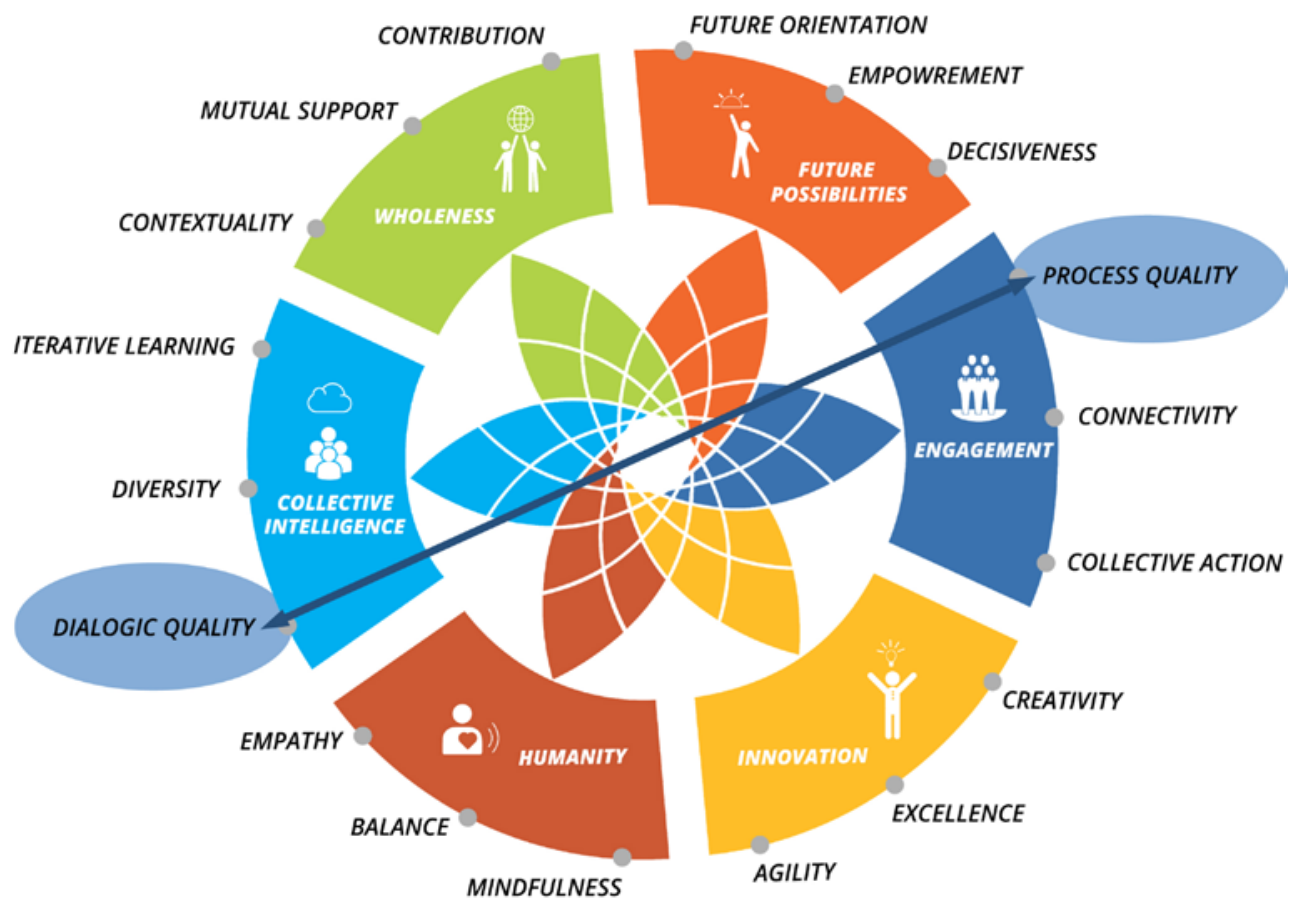

Figure 4.6 The connection between process quality and dialogic quality 
High-quality process architectures provide a space for people to think together, a space that - if created in the right way - helps collective intelligence to emerge, paves the way for collective responsibility in implementation and offers grounds for true social innovation. In leading transformative change collectively, dissent and disagreement need to be acknowledged, and consensus building happens through structured listening to concerns, expertise, viewpoints, and experience. Structured engagement of stakeholders is often the entry point for solid process architectures that create sufficient cohesion in the collaboration ecosystem. Engagement means more than having entertaining events, conferences for networking, or just a gathering of different stakeholders. It means building a new and meaningful identity around a transformative change endeavor. In that way, the dialogic approach becomes the fertile ground for collective intelligence. However, the form in which dialogic conversations take place depends on the situation, the context, the collaboration purpose, and the people involved. Chapter 3 took a deep dive into the role of dialogic process facilitators as stewards of enlivening dialogic communication. While taking process quality and dialogic quality as an entry point, process architectures need to bring in all Compass dimensions and aspects over time. They need to help people access their humanity, because - in addition to theories of change and implementation plans - it is the human-to-human encounter that helps people make a difference and invigorates a sense of wholeness when there is an opportunity to contribute to a larger goal. Well-designed process architectures invigorate the capability of collaborating stakeholders to bring about future possibilities. They create a commitment for change.

Stakeholders often have different opinions and worldviews, or, at times, standpoints that may even be oppositional. The process architecture, based on the Dialogic Change Model and inspired by the Collective Leadership Compass, can be seen as a guiding structure that keeps the complex set of actors relatively stable and within a frame of action that everybody understands. It helps to prevent chaos, but allows diverse perspectives and approaches to emerge. It creates enough freedom for the different forms of communication that collaboration ecosystems require. The more difficulties, conflicts, and differences of interest that are expected among stakeholders, the more background structure the process architecture needs to provide. This offers all actors the minimum degree of certainty that multi-stakeholder collaborations in a complex and uncertain environment require, for the initiators and conveners, as much as for the participating stakeholders. It helps the participants to develop a sense of cohesion, gives orientation, and safeguards against unhelpful interventions.

Process architectures show the flow of dialogue and cooperation within the collaboration ecosystem that intends to deliver transformative change. A process architecture visualizes all or at least some of the following:

\section{- Who interacts and communicates with whom and when?}

- The process architecture shows the sequence of dialogical and structural interventions: e.g. informal discussions, bilateral conversations, stakeholder interviews, core group meetings, stakeholder workshops, meetings of governance 
bodies, capacity building events, vision workshops, strategic reviews, innovation labs, policy labs, feasibility studies, communication flows, etc.

\section{- What takes place at which level?}

- The process architecture shows collaborative and dialogic processes taking place in parallel on several levels (e.g. local, regional, national, international) or parallel processes with specific stakeholder groups (communities, government, businesses, NGOs, research institutions), and visualizes how these different dialogic processes merge when stakeholders from different levels or groups meet to collaborate and achieve transformative change.

- How do the strategic components of the theory of change interact?

- The process architecture shows how the strategic components build on each other, are implemented in sequence or simultaneously, what they entail, and who is involved at which level.

- How is the collaboration initiative embedded in or related to other initiatives?

- The process architecture shows cooperation with other initiatives, e.g. learning and exchange meetings, conferences, and collaboration with similar or overarching initiatives.

The detailed design of process architectures - time-bound action steps and dialogic events - will be different depending on the purpose and format of the multistakeholder collaboration, as well as on the phase of the collaboration process. Preparing a system of stakeholders for collaboration in Phase 1 requires different process architectures than those needed to get to joint agreements in Phase 2, for delivering results together in Phase 3 of implementation, or even when scaling the impact in Phase 4. Leading transformative change collectively works best with process architectures that are responsive to the requirements of the different phases of complex multi-stakeholder collaboration. The following section therefore looks at how transformative design principles guide their development across all phases, while the subsequent section will illustrate the practical steps of applying these principles in co-creating a process architecture.

\section{Design principles for transformative change}

Similar to theories of change, the visualized process architecture becomes a reference point in a multi-stakeholder collaboration for the agreement on how to actually enact the envisaged change together. The key is to find a way to show how multiple actors, levels, and other pieces of the change puzzle can collaboratively work together in a desired direction. Process architectures that work in favor of enlivened collaboration ecosystems follow the design principles that are based on the Collective Leadership Compass and have been introduced in Chapter 1. Like a fractal, these principles form a pattern that is applicable at any level of a change initiative; how they are enacted, however, must be context and issue specific. 


\section{Build step-by step small-to-large collaboration ecosystems in bottom-up and top-down processes}

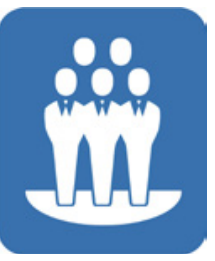

Process architectures show how engagement is done in a way that it gradually builds and eventually maintains functional collaboration ecosystems. As has been explained in Chapter 2 this is supported by taking the Dialogic Change Model as a guide to design engagement processes in all four Phases. For seemingly intractable challenges related to the implementation of the SDGs, a variety of engagement approaches and interventions are needed because of thematic, geographical, and logistic reasons, but most importantly because of the diversity of stakeholders that need to be involved. Guided by the needs of the different phases, such engagement needs to take place at multiple levels in order to become truly transformative. There is no single all-encompassing strategy to engage all stakeholders in one coherent system of collaboration, but the practice of transformative change shows that it is the engagement at different levels that makes transformations work (Kuenkel, 2019; Kuenkel \& Küehn, 2018). Hence, it is the careful integration of engagement processes at different levels and for different stakeholders. It is helpful to distinguish between top-down and bottom-up approaches that need to be assembled in process architectures.

Bottom-up engagement approaches are enlivening process designs that start at the local level. They would, after a participatory situational analysis, look at the specific needs and aspirations of local level stakeholders, and include answer to these questions: Who are they? What interest in and influence on the proposed change do they have? What contributions can they make to a multi-stakeholder collaboration? How are they organized and how can they represent their interests in an issue? What kind of capacity building might they need to make their voice heard (if not already happening) and become active stakeholders in the collaboration ecosystem? What structures and initiatives would strengthen them? Bottom-up strategies identify ways of invigorating local level stakeholders' capacity to drive change in a self-organized way. Transformative process architectures facilitate this.

Top-down engagement approaches usually start at the international or national level. They are based on a thorough context analysis of the institutional and political environment, and a thorough assessment of other actors' activities. This includes a diagnosis of systems patterns, a stakeholder landscape analysis, and a conflict mapping. Finding answers to the following questions is important: Which institutional actors are in favor of the change or impede it? What kind of institutional capacities exist for the change, or which need to be built? What are societal trends that work in favor or against the change? Top-down approaches often involve government actors, but can also convene business associations, individual companies, chambers of commerce, civil society networks, and/or NGOs, as appropriate. Their purpose is to raise the possibilities for the change through structured dialogue and cross-institutional interaction that overcome silos and help to improve framework conditions. Top-down approaches at the national level can be complemented by 
international activities, such as multi-stakeholder platforms between government, businesses, and NGOs that highlight international or transboundary issues of a given sustainability challenge.

Enlivening process architectures for both approaches may require building small, contextually relevant collaboration ecosystems first. For example, in top-down approaches, there may be the need to bring actors within or among different ministry departments or agencies into future looking conversations before inviting them into a dialogue with other stakeholders. Similarly, private sector actors or different $\mathrm{NGOs}$ may require dialogue with their constituencies before entering into collaboration with other actors. The engagement processes for each stakeholder group should be adjusted not only to each of their respective mind-sets, cultures, or decision-making structures (the most known example here is the difference between private and public sector), but should also take into account the particulars of each stakeholder's position regarding the issue of common concern. This does not just mean background research, but instead organizing a process of recurring dialogue with the respective stakeholder group. This will allow for an understanding of the context from the stakeholder's perspective, which is indispensable for designing for impact. The key to the transformative process design principle of engagement is to ultimately bring - in a stewarded step-by-step process - actors from the top-down collaboration systems together with actors from the bottom-up collaboration system into exchange, mutual learning, and collective action. Table 4.6 summarizes the implications for the design of process architectures.

Table 4.6 Engagement by design: implications for process architectures

Build step-by step small-to-large collaboration ecosystems in bottom-up and top-down processes

Overall:

- Identify relevant collaboration systems at different levels.

- Bring selected (sometimes chosen as representatives) stakeholders from international, national, and local level together.

- Build cross-level exchange and collaboration structures (e.g. learning exchanges, innovation labs, field trips, study visits, planning events, multi-level coordination committees).

Bottom-up collaboration system:

- Ensure a joint situational analysis by affected stakeholders.

- Build capacity on content issues and strengthen organizations.

- Create structured dialogue settings with relevant local stakeholders.

- Gather background research, data, benchmarks, stakeholder interviews, etc.

- Identify and strengthen existing organizational and collaboration structures before forming new structures.

Top-down collaboration system:

- Conduct thorough institutional context analysis.

- Bring cross-sector stakeholders or stakeholder caucus groups (same stakeholder group) into structured dialogue.

- Ensure benchmark experiences or best practice cases are known to all.

- Bring stakeholders across institutions into dialogue and collaboration structures. 
Foster goal coherence, ensure joint vision development, and design for empowerment

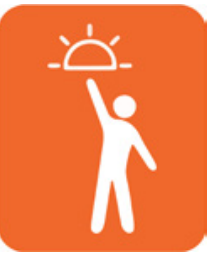

Process architectures show how an overall vision or goals are arrived at so that they can be owned by all stakeholders. Every project, program, or multi-stakeholder initiative requires a clear set of goals, expected outcomes, and a desired impact, stated in the theory of change. However, even if the goals exist in writing and relevant stakeholders have agreed, it does not mean that they are emotionally strong enough to drive collective action. It is the emotional connection to a larger goal or vision that drives changes in behavior. Hence, in transformative process designs, goal coherence is more than creating the impact and outcome statements of the theory of change, elaborating project plans, or defining numbers that have increased as a result of the collaboration. A good process architecture needs to show how to gradually build a joint vision that is attractive and coherent enough so that the complex set of stakeholders will make it happen together. It is about investing in finding the coherence among the goals of the different stakeholders and daring to bring this into an emotionally compelling format that all stakeholders can identify with. As the case example in Chapter 3 showed, the importance here is that the jointly created vision creates a picture of the desired change that is easy to remember, fosters identification, and conveys how the change contributes to the overall collective value. Such a vision can be referenced throughout the collaboration process to check the alignment of specific objectives with it; and it offers support for all involved stakeholders' motivation to contribute to the collaboration. Table 4.7 summarizes the implications for the design of process architectures.

Table 4.7 Future possibilities by design: implications for process architectures

Foster goal coherence, ensure joint vision development and design for empowerment

Overall:

- Identify the most relevant stakeholders, actors, initiatives - compare goals and targets.

- Map interests and potential conflicts.

- Facilitate future-oriented and inspiring conversations.

- Identify and appreciate existing attempts to improve the situation.

- Identify potentially useful organizational and communication structures.

- Strengthen weaker stakeholder groups to self-organize for change.

- Create settings for vision development at different levels or for different stakeholder groups.

- After a thorough understanding of the context or a participatory situational analysis, bring key stakeholders together into a joint vision development. 


\section{Transformative design principle \#3: COLLECTIVE INTELLIGENCE}

\section{Foster dialogue and establish iterative learning structures}

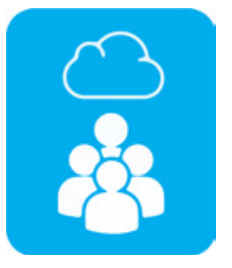

Process architectures show how and when dialogue, collective reflection, and learning take place. Joint reflection about the collaborative endeavor and its many facets are indispensable for achieving impact. This is the only way to prevent falling back into isolated action. Transformative process designs create spaces in which collective intelligence can emerge, and do this deliberately beyond the administrative procedure of steering committees or joint project management meetings. Process architectures show how this happens in Phase 1 with the core group and the broader container, or in Phase 2 for the emerging collaboration ecosystem. They design communicative spaces for the different needs of top-down and bottom-up processes, and also ways of bringing different circles or levels together into dialogue and collective reflection. This can take the form of best practice exchange, market places, field trips, structured stakeholder dialogues, innovation labs, future designs, or strategic workshops whatever is appropriate. Regular events or reunions dedicated to the dialogue and learning in a shared reflection provides a crucial balance to the necessarily more administrative, planning-focused, and outcome-oriented nature of many gatherings in the collaborative process. Acknowledging existing expertise is crucially important. Yet there might be a situation where the system of actors engaged does not have the appropriate knowledge on a particular issue. This is an opportunity to bring in additional expertise. If it is done too early, existing expertise among the stakeholders may be ignored and people will feel discouraged or withdraw their contribution. Additional expertise is welcomed if everybody can see the benefit - be it specific experience, a new point of view, a totally different perspective on the issue, or simply real-life experience. Similarly, not every content issue needs to be discussed by a wider group of stakeholders. In a collaboration process where people have gained trust, it is perfectly appropriate to delegate certain difficult content issues to expert working groups or create task forces to solve specific issues. Results should always be brought back into the wider group of stakeholders. Bringing in expertise is helpful when it encourages people to step out of their comfort zone, become inspired by something new, or learn more by receiving information they did not have before. Learning structures need to be set up in a way that participation is both enjoyable and inspiring for all actors. They also serve to continuously improve action plans. It is crucial that insights are shared collectively, commented on, amended, complemented, and, finally, owned by all stakeholders. This becomes an empowering intervention that helps relevant stakeholders see their role in and contribution to the greater initiative. Table 4.8 summarizes the implications for the design of process architectures. 
Table 4.8 Collective intelligence by design: implications for process architectures

Foster dialogue and establish iterative learning structures

Overall:

- Create regular dialogue structures that ensure all key stakeholders have a voice.

- Build interactive learning events into implementation plans.

- Ensure that steering committee, or coordination committee, or advisory or council meetings have interactive designs.

- Foster dialogue formats that that allow stakeholders to understand each other's perspectives.

- Bring in experiences from other areas and organize hands-on exposure to good practices.

\section{Transformative design principle \#4: INNOVATION}

\section{Nurture emerging development and unleash the potential for innovation}

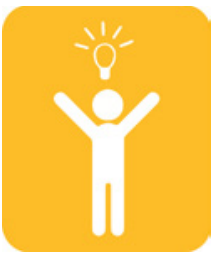

Process architectures show how innovative approaches are discovered or supported. Most logics of project planning and theories of change aim at solving a problem. They define deficits to be overcome. While this is important, it is only part of a reality in a complex system of actors. Transformative process designs spot already existing empowering change initiatives or hidden competencies that open new pathways to supporting self-organized change. They nurture existing or emerging development. This means exploring successful past approaches and existing knowledge, awareness, and competencies, or creating competency inventories, mapping good practices, and identifying pioneers and change agents. The core understanding behind the principle is to empower actors at all levels of a stakeholder system to design and enact better futures together. Moving from emphasizing deficits to deliberately supporting self-organization may not always be easy to incorporate into project planning formats. In bottom-up approaches, participatory situational analysis and thorough, continuous context analysis can help people to self-diagnose malfunctioning patterns of interaction, as well as also identify patterns that work. Transformative process designs remain open to identifying successful practices, building on them and staying faithful to empowerment through building stakeholders' capacity for self-steered development. As and when appropriate, they bring in approaches such as exchange visits, exposure to new practices, learning communities, and capacity building events. The same feature applies to top-down approaches in building collaboration ecosystems. Nurturing emerging development here means identifying the frontrunners for transformation in Phase 1, highlighting good practices, and bringing those that are motivated to change the status quo into structured dialogue in Phase 2. Only then will the building of top-down collaboration systems in a step-by step process engage those that need to be convinced that change is not only inevitable, but offers a promising future. 
Table 4.9 Innovation by design: implications for process architectures

Nurture emerging development and unleash the potential for innovation

Overall:

- Focus the context analysis not only on problems, but also on what works.

- Analyze previous initiatives and activities regarding useful results, connections, networks, and structures.

- Identify innovators and frontrunners and support them.

- Get stimulating perspectives from outside the system.

- Provide exchange opportunities around experiences and best practices.

- Experiment with innovation formats such as labs.

- Offer possibilities for exposure trips, study visits, and exchanges of experiences.

- Create innovation awards.

- Establish events that focus on learning and innovation.

Yet, the planning and implementation of projects and programs can't always spot innovative approaches. The nature of innovation is that it emerges in creative spaces that can only be steered in a limited way. What can be done, especially in Phase 3, is to create conversational and meeting spaces with a focus on innovation. This can also take the form of learning and innovation events that accompany implementation, or exchange visits that focus on innovative practices. Intentionally creating opportunities for an exchange of ideas, experiences, good practices, and innovative approaches can greatly support self-organization for transformation. Table 4.9 summarizes the implications for the design of Process Architectures.

\section{Transformative design principle \#5: HUMANITY}

\section{Foster trust building and enhance mutual understanding}

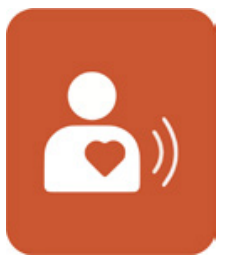

Process architectures show process designs that acknowledge the differences among stakeholders and appreciate their dignity, views, and capacities. Naturally, the design principle of humanity is difficult to visualize in a process graph. Similarly, it will not necessarily show up in official planning documents or the jointly agreed theory of change. But it is in the detail of design that this principle is revealed. Only stakeholders whose perspectives are welcomed with appreciation, who are acknowledged in their expertise, and who become engaged in inspiring conversations will eventually join the collaboration ecosystem and stay in it. As Chapter 3 has shown, designing trust building and human encounter can take many different forms, for example, the investment into relationship building in Phase 1 can show up as bilateral engagement conversations, or as stakeholder interviews in Phase 3. Smaller expert or working groups in Phase 2 or 3 may reflect this principle when they are established in a way that fosters collective action, helps stakeholders to work on something tangible together, or creates experiences of joint achievements, even if they are small. High quality transformative process designs take the 'humanness' of 
Table 4.10 Humanity by design: implications for process architectures

Foster trust building and enhance mutual understanding

Overall:

- Design attention to relationship building.

- Build in informal get-togethers.

- Ensure small short-term activities with tangible results early on in the process.

- Conduct learning events that celebrate milestones reached with all key stakeholders.

- Show how communicating progress takes place on a regular base.

stakeholders into account. They help stakeholders acknowledge each other's constraints, perspectives, and limitations, and show pathways to mutually support each other. Table 4.10 summarizes the implications for the design of process architectures.

Transformative design principle \#6: WHOLENESS

\section{Create networks and enhance impact through meta-collaboration}

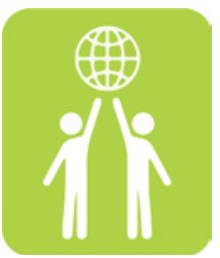

Process architectures show how functional collaboration ecosystems emerge and how they gradually embed their success in networks that foster transformation. No initiative or program can tackle the total complexity of a particular sustainability challenge; even multistakeholder collaborations can only deliver partial impact. But every collaboration ecosystem that succeeds in delivering partial change becomes a prototype of the future way of operating together and enacting new realities. Even if transformative change initiatives require starting small with a step-by-step engagement processes in Phase 1, they can eventually grow into large-scale impact networks in Phase 4. After having conducted context and situational analysis in Phase 1, or achieved results in Phase 3, process architectures need to show how to seek out what can be called complementary meta-collaboration. This describes the collaboration between different (multi-stakeholder) collaboration initiatives that may not have been planned together, but that follow similar or complementary impact strategies. This can also take the form of a coordinated approach to implementation among certain funders or implementing agencies. Metacollaboration can take place at all levels of a value chain initiative (Niestroy \& Meuleman, 2015). It means, for example, identifying projects, programs, or initiatives that operate in a similar region with different approaches. This would show up in a process architecture as stakeholder meetings for experience exchange and complementary implementation. Or it means showing how an initiative is related to similar approaches in another region. Meta-collaboration - the intentional aligned action of various initiatives - is a way of increasing impact. Although this sounds self-evident, it is not the reality in practice. There is an enormous fragmentation of efforts, if not competition. Initiatives operate in similar fields, often duplicating efforts or only addressing narrow solutions. Taking a systemic approach to strengthening the effectiveness of multi-stakeholder collaborations suggests ensuring that every project, 
Table 4.11 Wholeness by design: implications for process architectures

Create networks and enhance impact through meta-collaboration

Overall:

- Explore opportunities for meta-collaboration with other initiatives.

- Join issue-related or thematic networks in other regions, countries, or across the globe.

- Acknowledge expertise and contributions of different stakeholders.

- Connect stakeholders with other relevant initiatives that may share a similar goal or vision.

- Establish exchange structures with similar initiatives to synthesize and cooperate for the benefit of the larger shared goal.

program, or initiative is designed as a contribution to and in co-evolution with other transformative activities in a process of continuous, iterative learning. Stewarding systemic, patterned, and nested change initiatives more likely helps create coherence for the overall desired transformation (Waddell, 2016; Senge et al., 2015; Kuenkel, 2017). Table 4.11 summarizes the implications for the design of process architectures.

Table 4.12 provides an overview of the transformative design principles and how they inform the co-design of enlivening process architectures.

Multi-stakeholder collaborations are often perceived as complex and create a feeling of uncertainty among stakeholders. They enter into a complex environment in which potential conflicts arise and a feeling of loss of control occurs. Yet, simply continuing to operate in known and administrative procedures does not work for collaborative change. This is why process architectures are important. They make a bridge between the uncertainty of collaboration and the need for a degree of predictability that generates trust and confidence. The transparently developed and finally agreed upon process architecture serves as a visual script for all stakeholders. When people see what will happen when, who will meet whom and for which purpose, they can relax just enough to enable them to move forwards in a consolidated way. The next section describes the practical planning steps for process architectures.

\section{Co-designing enlivening process architectures}

Designing enlivening process architectures is important throughout all phases of dialogic change. In Phase 1, it is the resonance building and engagement of stakeholders that requires sufficient attention. In Phase 2, the focus is on creating process architectures that foster vision development and consolidate the collaboration ecosystem towards joint implementation. In Phase 3, process architectures need to emphasize transparent communication and the celebration of successes. They also need to be designed for joint learning among stakeholders. In Phase 4, it is about designing for engagement of new stakeholders and ensuring long-term impact. Box 4.1 shows typical situations that require the development of a process architecture. 
Table 4.12 Principles for process architectures

\begin{tabular}{cl}
\hline Design principle & Purpose \\
\hline Engagement & Build functional multi-level stakeholder collaboration \\
& systems. \\
000 & - Ensure integrated bottom-up and top-down approaches.
\end{tabular}

Future possibilities

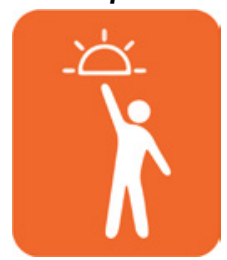

Collective intelligence

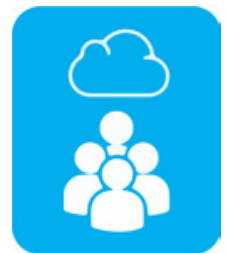

\section{Innovation}

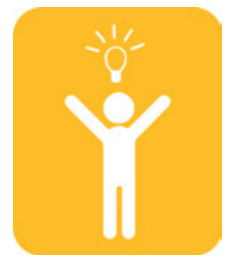

\section{Humanity}

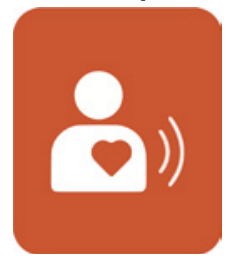

\section{Wholeness}

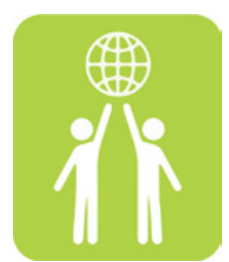

- Foster goal coherence.

- Stay faithful to empowerment.

- Establish dialogue formats.

- Create iterative learning structures.

- Nurture emerging development.

- Unleash the creative potential for innovation.

- Take an appreciative stance and acknowledge existing structures.

- Steward human encounter for increased empathy.

- Enhance impact through meta-collaboration.

- Bring the multiplicity of approaches into transformation networks. 


\section{Box 4.1 Opportunities for developing a process architecture}

- You are at the beginning of a multi-stakeholder collaboration initiative (Phase 1) and want to plan your process of resonance building, context understanding, and preparing the formation of the core container. Phase 1 process architectures show the engagement process at different levels, or for different stakeholder groups.

- You are planning a sequence of stakeholder events in Phase 2 and want to ensure the best possible conditions for planning the future together through joint vision development and implementation planning among stakeholders. Phase 2 process architectures show pathways towards the consolidation of a collaboration ecosystem manifesting in agreements and plans, or the integration of engagement processes at different levels.

- You are in Phase 2 and want to prepare together with key stakeholders the process architectures for a Phase 3 implementation roadmap that shows communication, strategic reviews, and learning mechanisms; or you are in Phase 3 and would like to readjust the implementation roadmap. Phase 3 process architectures show how implementation is coordinated and reviewed, how the system of stakeholders learns, and how the public is informed.

- You are at the beginning of Phase 4 and would like plan the process for engaging new stakeholders. Phase 4 process architectures show the impact or scaling-up strategies, how new stakeholders become involved, governance bodies meet, or learning will be organized.

As elaborated in the previous section, process architectures can show collaboration and dialogue settings at different levels or for different stakeholder groups. However, the details of a process architecture depend on the very specific purpose. It may be worthwhile during an engagement process to create a longer-term process design (e.g. two years, showing Phase 1, Phase 2, and Phase 3), for overall conversations with stakeholders and funders, so as to help them gain trust in an initiative's potential. But the more practical process architecture that, e.g. a core container develops, or that is consolidated with key stakeholders in Phase 2, will cover a period of three to twelve months. Depending on the phase or whether a theory of change has already been developed, the form and ways of designing the process will be different.

Process architectures are usually created by the initiators, core group, or dialogic process facilitators who then discuss the design with the core group. In a group, a minimum of 90 minutes time is recommended, if the results from the context analysis are already available. While a process architecture can also be drawn up as a list or as a table with a timeline, the real potential of process architectures lies in visualization; hence, it is important to have drawing boards, pinboards, flip charts, or digital equivalents readily available. Their development follows six steps, which may be adjusted according to the requirements of the phase, but the general approach is the same. In a first step, the insights gained from a context or situational analysis are reviewed and the most important entry points for change (regarding Compass dimensions) 
are identified. This is about gaining clarity on priority issues that the process design needs to address. In a second step, the levels of interventions are defined, such as national or local level, as well as the role of the core group as a container for change. In a third step, the time period for the process architecture is defined and objectives to be reached in the chosen time frame are clarified. In a fourth step, questions around the transformative design principles are worked through resulting in entry points being confirmed or complemented, as well as conclusions drawn for process strategies. In a fifth step, major communication events essential for building or maintaining the collaboration ecosystem are listed or drawn up on a chart, and activities between events and supporting measures are drawn up on a process chart. In a sixth step, the process architecture will be reviewed for consistency.

\section{Step 1: understanding entry points for change - what does} the system need?

Step 1 requires a review of the context analysis or an assessment of the current situation with respect to the state of implementation. Chapter 3 suggested methodologies such as diagnosing systems patterns, creating a stakeholder landscape analysis, or understanding stakeholder interaction patterns. A preliminary process architecture can show how initiators will arrive at a thorough context understanding through research, stakeholder interviews, focus groups, and informal conversations with stakeholders, and how this becomes part of the engagement process. However, once the context is better understood, it is important to re-design a Phase 1, and possibly, a Phase 2 process architecture that shows the step-by-step engagement towards building a functional collaboration ecosystem. Naturally, in Phase 2, the process architecture for Phase 3 will be built on jointly created goals, as well as on agreements on stewarding structures, milestones, roles, and responsibilities. In all cases, the starting points for the process architecture are the insights from a situational analysis. They could, for example, be summarized in response to the questions in table 4.13.

The result of step $\mathbf{1}$ is clarity on entry points for collaborative change such as priority issues, special dialogue or capacity needs to attend to, conflict resolution, or opportunities to leverage existing innovations, networks, or structures.

\section{Step 2: levels of intervention - what needs to happen together for transformative change?}

In this second step, the conclusions drawn from step 1 lead to defining which levels of intervention need to work together. Depending on the purpose of the multistakeholder collaboration, its ambition for impact, and the complexity of the issue, it may be necessary to build engagement and containers for change at multiple levels. Or, both need to be built within certain stakeholder groups first. This step needs to be anchored in the stakeholder landscape analysis and suggest strategies for how to engage certain key stakeholders in Phase 1, keep them on board in Phase 2 or 3, and consequently engage new stakeholders in Phase 4. Therefore, this step needs to also clarify the existing, to-be-acquired, or expected mandate of initiators or the core group 
Table 4.13 Guiding questions for step 1 of developing a process architecture

Design principle

\section{Engagement}

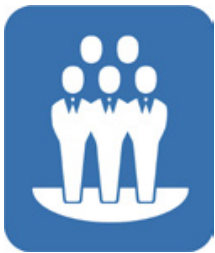

Future possibilities

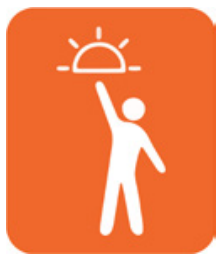

Collective intelligence

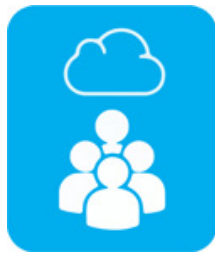

Innovation

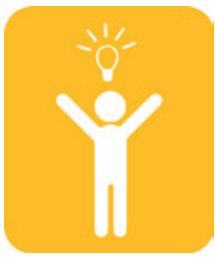

Humanity

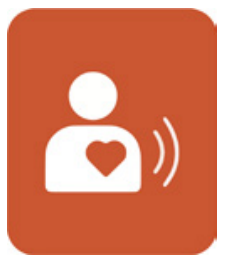

Wholeness

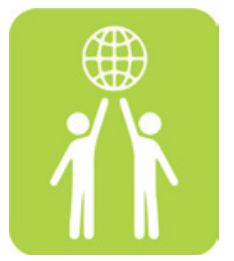

Summary of insights to exemplary questions such as:

- Which forms and structures of engagement already exist at different levels relevant for transformative change?

- How high is the level of interest in or commitment for an improvement around the issue among various stakeholders?

- How are stakeholders connected? Which forms of dialogue or networks already exist and could be leveraged?

- Which strengths, good practices, or innovative approaches are available that need to be appreciated and leveraged?

- What is the level of understanding between different stakeholders? How strong is their awareness of the need to collaborate for transformative change?

- Which other actors or initiatives around the issue exist? How are stakeholders connected to such activities? 
to access these different levels or different stakeholders groups. Step 2 should reveal answers to questions such as:

- Which levels (local, provincial, national, local, etc.) require collaboration and dialogue processes?

- Which stakeholders need to be brought on board; or which may require internal alignment processes first?

- Who has access to these different levels or different stakeholder groups, and how could such engagement take place?

The results of step 2 are clarity on chosen levels of dialogic and collaborative intervention, as well as how they relate to each other. Additionally, the results should reflect the capacity of initiators, core group, or key stakeholders to access these different levels and draw them into engagement and collaboration.

\section{Step 3: envisaged objectives - what exactly should the process architecture achieve?}

The purpose of step 3 is to agree on the time frame for the process architecture and the envisaged objective that its design should achieve. This is the time to gain clarity on the concrete objectives be achieve with a high-quality process architecture in a certain period of time. Similar to the planning of co-creative events, it is important to detail the objectives in the following way:

- Relationship objectives (everything that refers to a change between stakeholders, e.g. people have a better understanding of each other, people get to know and appreciate each other, people are exposed to each other's experiences, etc.)

- Process objectives (everything that refers to a change in attitude, clarity, and perception regarding the way forward, e.g. people have a sense of ownership for outcomes and process, people understand how the initiative is embedded in the larger context, people feel their concerns or positions have been heard, people are capacitated and sufficiently knowledgeable on the issue at hand).

- Content objectives and tangible outcomes (everything that refers to a change in concrete joint action e.g. people have agreed on an action plan, signed a memorandum of understanding, developed a roadmap together, agreed on coordinated implementation, found consensus on a vision or objective, etc.)

These objectives create guidance for the process architecture.

Step 4: transformative designs - how will the process architecture enliven the Compass dimensions?

Step 4 uses the Compass dimensions, and in particular, the transformative design principles, as a guide to detail important elements of the process architecture. It helps 
to build this on the collective intelligence of a core group, as it engenders a conversation about what is needed in order to move the collaborative change initiative towards the envisaged future state. Here, the different approaches to change (see Chapter 3) by members of the core group may pose difficulties, but, if discussed openly, they can be leveraged. The questions in Table 4.14 are related to the transformative design principles elaborated earlier, and can guide the conversations. This is about thinking together about which Compass dimensions and aspects can best support the collaborative change endeavor. The conversation and results need to build on the priorities that have re-emerged from reviewing the context analysis in step 1. Similarly, the dimensions can be ranked according to what the group of stakeholders considers priority issues. Additionally, the conversation should reveal how to utilize strong areas and which areas require specific attention. Step 4 is greatly supported by using an online version of this tool at www.compass-tool.net, or alternatively, Table 4.14. Results of step 4 for should inform the actual design of the sequence of events and activities. These can be summarized as conclusions for the process architecture.

\section{Step 5: collaborative events and activities - what forms of interaction will build or maintain the collaboration ecosystem?}

Step 5 is about creating the actual process architecture, either as a list of collaborative events and activities at different intervention levels or - which is recommended - as a graphic, showing the flow, interactions, and interdependencies. Such a chart should show the chosen levels of intervention and for each one:

- The major collaborative events that need to take place to achieve the envisaged objectives.

- Preparatory collaborative events or meetings that feed into larger events (such as small stakeholder meetings, stakeholder constituency meetings, or working group meetings).

- Capacity building that supports both content expertise as well as collaboration skills.

- Accompanying activities such as bringing in of external expertise, study trips, field trips, meetings with special actors, etc.

- The supporting and accompanying activities (from bilateral or informal conversations to core group meetings or even media campaigns).

- Collaborative and dialogue events that bring actors from different levels together.

- How stewarding structures, steering committees, or governing bodies emerge.

Not everything, of course, can be captured in one chart, but it is recommended to create an overview chart. All details may then be explained in additional charts or agreed in writing. The result of step 5 is a graphic representation of a process architecture that key stakeholders can adopt as a guiding element. 


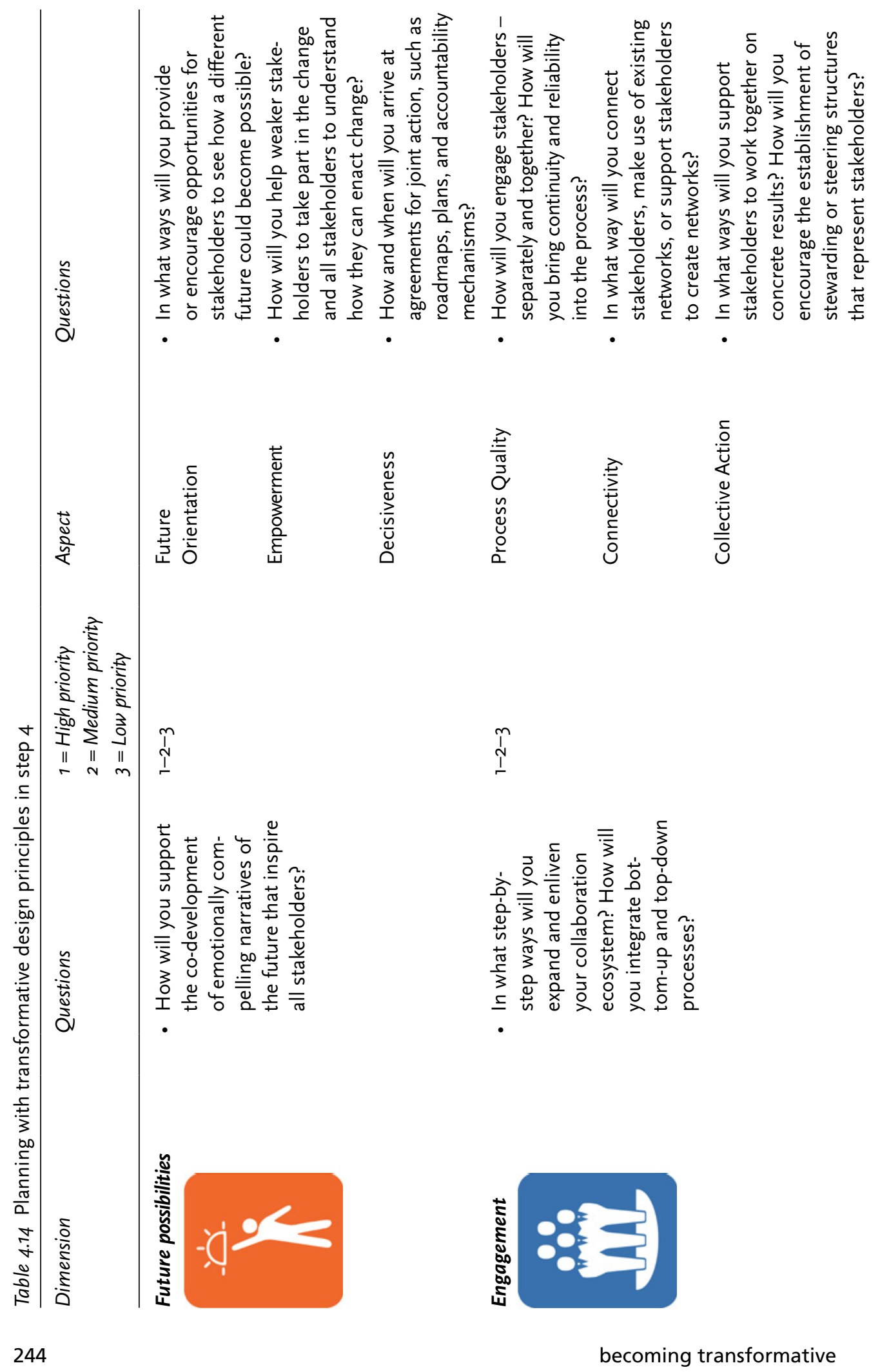




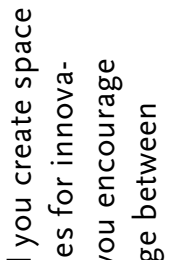

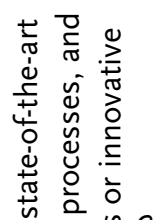

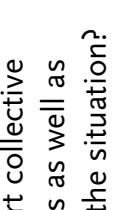

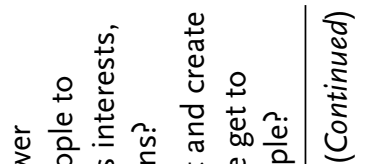

$\overline{\overline{7}}$

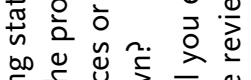

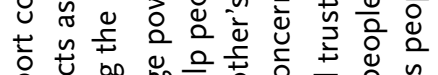
苋

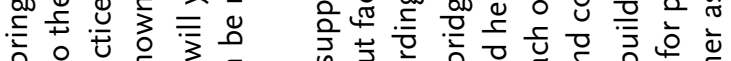

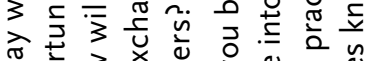

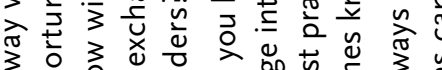

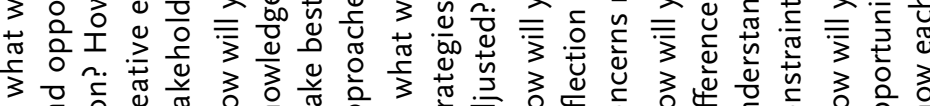

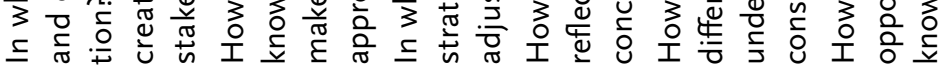

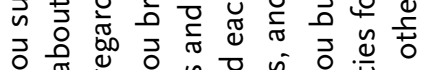

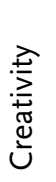

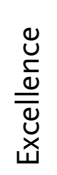

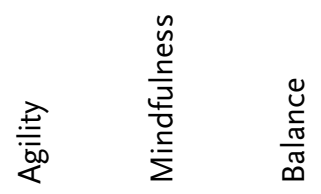

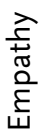

$\stackrel{n}{1}$

$\stackrel{n}{\mathfrak{n}}$

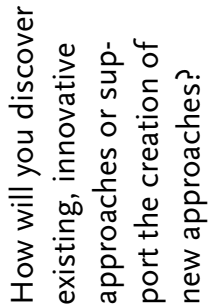

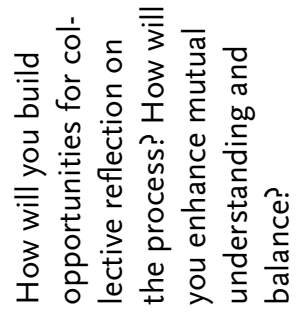

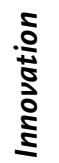

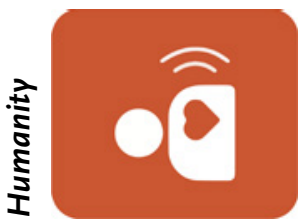




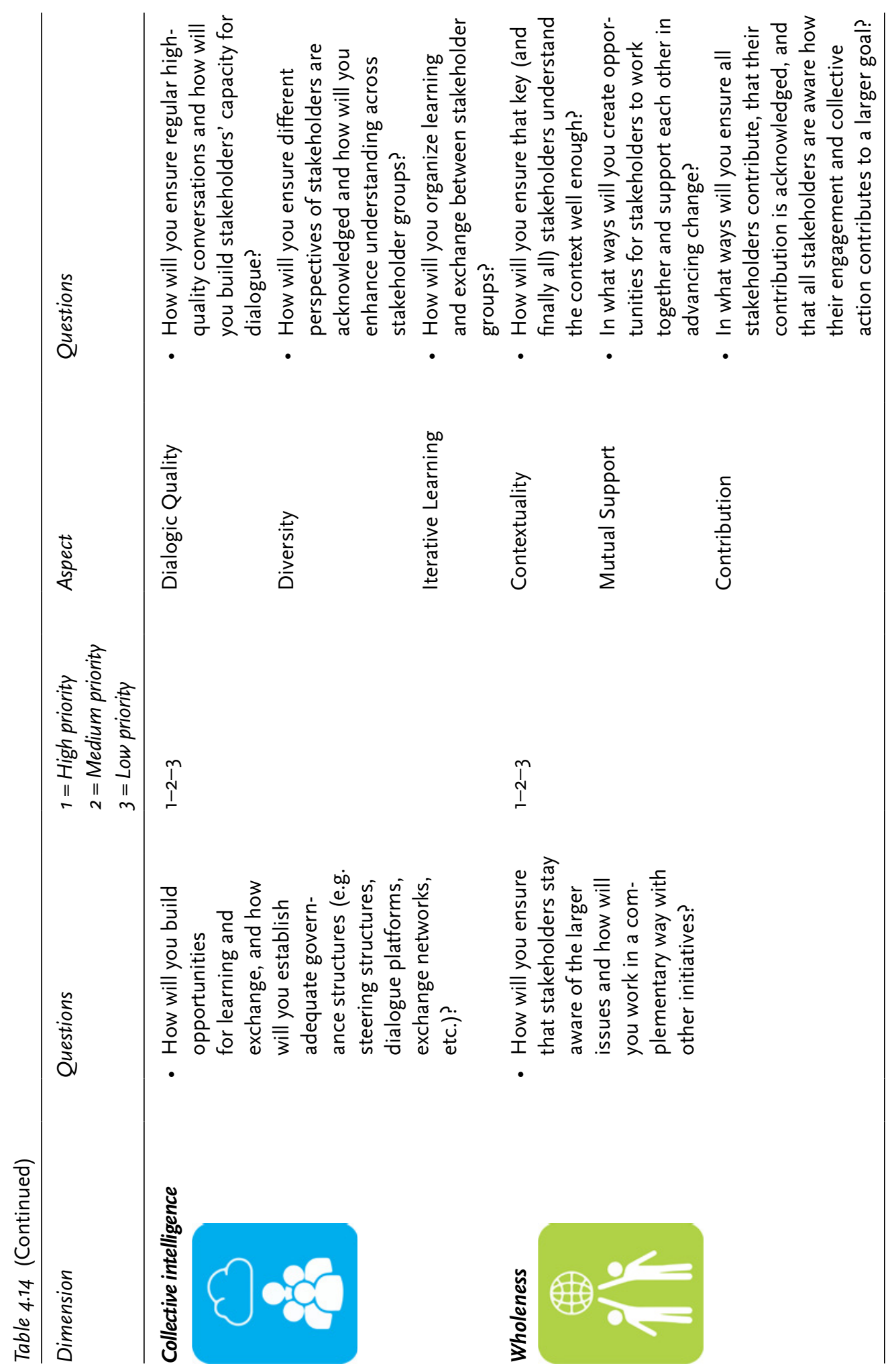


Step 6: reviewing the process architecture - will it achieve the objectives envisaged?

Step 6 requires stepping back and cross-checking the results with the three-level objectives that have been developed in step 3 , and the conclusions from the context analysis summarized in step 1. If any adjustments need to be made, this is the right moment. The complete process architecture can then be discussed with a wider group of stakeholders, used in engagement conversations or as part of collaborative events. Naturally, stakeholders will ask questions, criticize certain aspects, or make recommendations for improvement. Moreover, only time will tell, if all that has been planned will be implemented, or turns out to be contributing to the objectives. Hence, the process architecture is a living document that will be adjusted based on input and experience.

In the following section, we will illustrate the development of a process architecture with an example important for SDG implementation.

\section{CASE EXAMPLE 4.2: EXAMPLE FROM THE FIELD: PROCESS ARCHITECTURES FOR ENLIVENING COLLABORATION IN EGYPTIAN TECHNICAL EDUCATION}
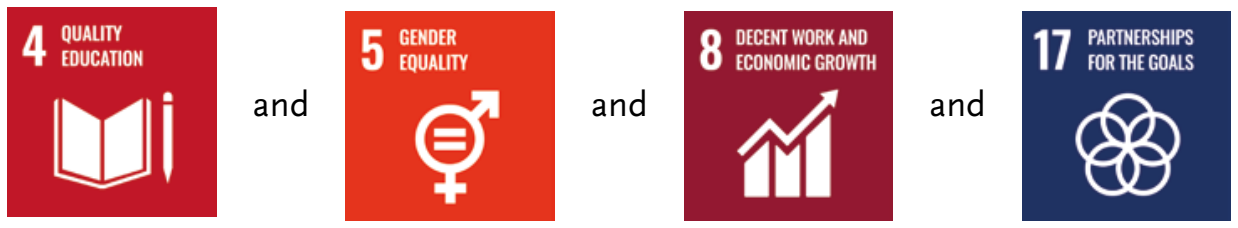

Egypt has a very young population, with over one in three people under 15 years old (Population Reference Bureau, 2019). This youth bulge is linked to a high level of unemployment of 12.8 percent, with higher rates among youth and women (World Bank, 2016). Population growth and youth unemployment make for a dangerous economic context in Egypt that calls for a better qualified workforce that meets international standards. This would strengthen the domestic economy, attract foreign companies to Egypt, and allow for the export of certain products and services. What is needed to achieve this is a relevant, high quality, and future oriented technical education system. The so-called Dual System (DS) for technical education is one important approach to meeting these needs and focuses on 15-17-year-old youths. It is a mode of delivery of vocational education that combines apprenticeships in a company or factory with school-based learning over three years. This model has proven successful in ensuring the labor market relevance of vocational education and in reducing youth unemployment.

Originally introduced in 1993', the Egyptian Dual System (EDS) of technical education made some progress but did not become self-sustaining. A concerted effort by both public and private sector stakeholders at multiple levels was needed. In 2016, the situation was reviewed resulting in clearer objectives 
agreed for increasing the number of young people enrolled in an EDS of adequate quality. ${ }^{2}$ The ambitious vision, developed with Egyptian public and private sector actors was to convene and capacitate key EDS actors as a dynamic collaboration ecosystem that would "contribute to building and expanding a high quality and dynamic Dual System through close multi-stakeholder collaboration at all levels that provides attractive, safe, and meaningful training opportunities for a new generation of students, increasing employability and benefiting the Egyptian economy and society". ${ }^{3}$

A thorough context analysis hinted at several key challenges:

- In the dimension of humanity: there was lack of trust among key central and governorate actors; a lack of mutual understanding; and the pursuit of fragmented institutional interests.

- In the dimension of collective intelligence: existing dialogues among actors were occurring in an infrequent and ad hoc manner, producing unsatisfactory results.

- In the dimension of engagement: there was a lack of alignment on a shared EDS vision; a lack of active structures to connect the different stakeholders needed to make the EDS work; and a lack of clearly established procedures that guaranteed efficiency and accountability among stakeholders.

On the other hand, the context analysis also revealed that many of the relevant stakeholders saw the future possibilities embedded in the Dual System and saw its potential for innovation. Among all stakeholders, there was a strong commitment to make a contribution to Egyptian youth and the economy, which was identified as a strength in wholeness. Based on the results from the context analysis, the key partnering actors decided to work with an integrated capacity building approach. This meant that key collaborating actors for strengthening the EDS would be equipped with knowledge and skills in multi-stakeholder collaboration for improving the delivery of technical education, and jointly building processes and structures that would ensure quality and sustainability. The initial process architecture in Figure 4.7 was built on this analysis and showed the integrated approach at different levels with a focus on Phases 1 and 2 of the Dialogic Change Model:

- The meso and macro level: this related integrated capacity building for key public and private sector actors at national with focus on the existing EDS executive council;

- The decentralized level: this related to integrated capacity building for key actors from public and private sector in the governorates.

The process architecture spanned a timeframe from September 2017 through December 2019 and illustrated the engagement of macro, meso, and decentralized level public and private sector actors in a capacity building process for resultoriented collaboration. Early on, it was important to engage high-level support, in the form of the existing multi-stakeholder Executive Council (EC) and to ensure its 


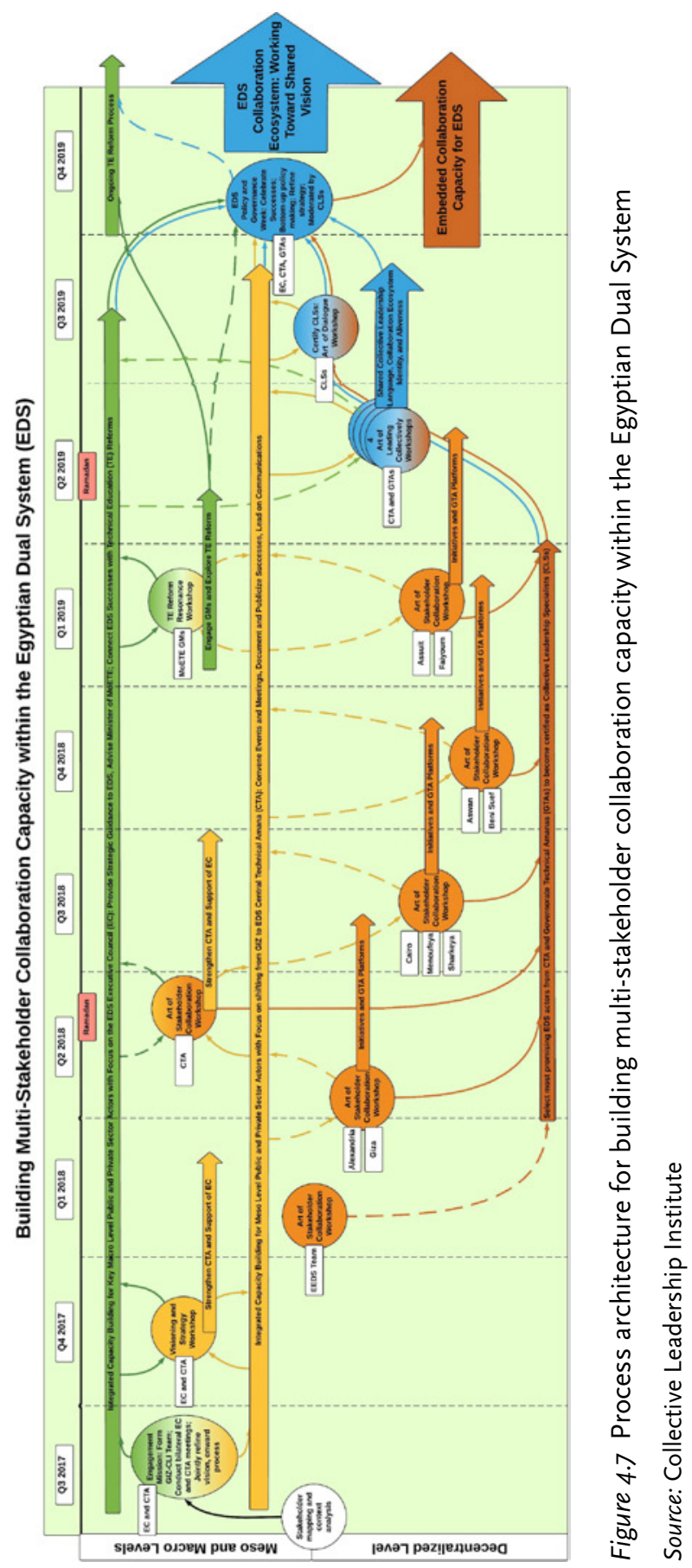


guidance (shown in Figure 4.7). Only with this EC high-level mandate, could the emerging future multi-stakeholder project secretariat and backbone support, the Central Technical Amana (CTA), be strengthened in its capacity to further articulate the EDS vision, and become the container for change that would strategize the way forward (shown in Figure 4.7 as the orange arrow in middle). What followed was a series of multi-stakeholder collaboration capacity building sessions for members of the CTA, together with key stakeholders from nine Governorates. The skills building of cross-sector key actors (122 in total, of which 35 percent came from the private sector) focused on applying the Dialogic Change Model as a process methodology; it resulted in designing concrete initiatives related to enhancing the Dual System, as well as launching multi-stakeholder Governorate Technical Amanas (GTA). This is shown in Figure 4.7 as the orange circles that gradual build up to engaging more and more actors in the blue circles.

This capacity building process finally brought the CTA and all nine GTAs into four parallel workshops focused on sharing a common approach to enhancing systems aliveness, in the sense of a strong and resilient administrative and technical delivery of a Dual System. This strengthened their iterative learning abilities, helped them identify patterns with the Collective Leadership Compass, and plan next process steps together. Members of the CTA continued to become skilled dialogic process facilitators. With their leadership support, the first ever 'Egyptian Dual System Policy and Governance Week' took place in November 2019. The preparation and implementation of the event modelled bottom-up, multi-stakeholder communications and policymaking in an otherwise hierarchical and public sector centric context. During two preparatory days and the policy summit itself, stakeholders collaboratively:

- Developed a six-month policy roadmap, including outlines of prioritized policies,

- Designed a process architecture representing annual communication and policy development flows across all levels of the Dual System (this process architecture is depicted in Figure 4.8), ${ }^{4}$ and

- Refined strategies for formalizing the CTA and GTAs, as well as replicating GTAs in further governorates.

The Summit brought together 116 members from the Executive Council, the Central Technical Amana and the Governorates' Technical Amanas of Alexandria, Aswan, Assuit, Beni Suef, Cairo, Faiyoum, Giza, Menoufeya, and Sharkeya. The Egyptian Dual System collaboration ecosystem came fully to life with active engagement, ownership, and commitment from everyone, including all levels of the Ministry of Education and Technical Education (MoETE), the Federation of Egyptian Industries (FEI), and the Egyptian Federation of Investors Associations (EFIA). Importantly and for the first time - Student Union representatives and parents actively participated. All showed a high level of commitment to taking collective action towards their shared vision. Key actors of the collaboration ecosystem co-designed and 


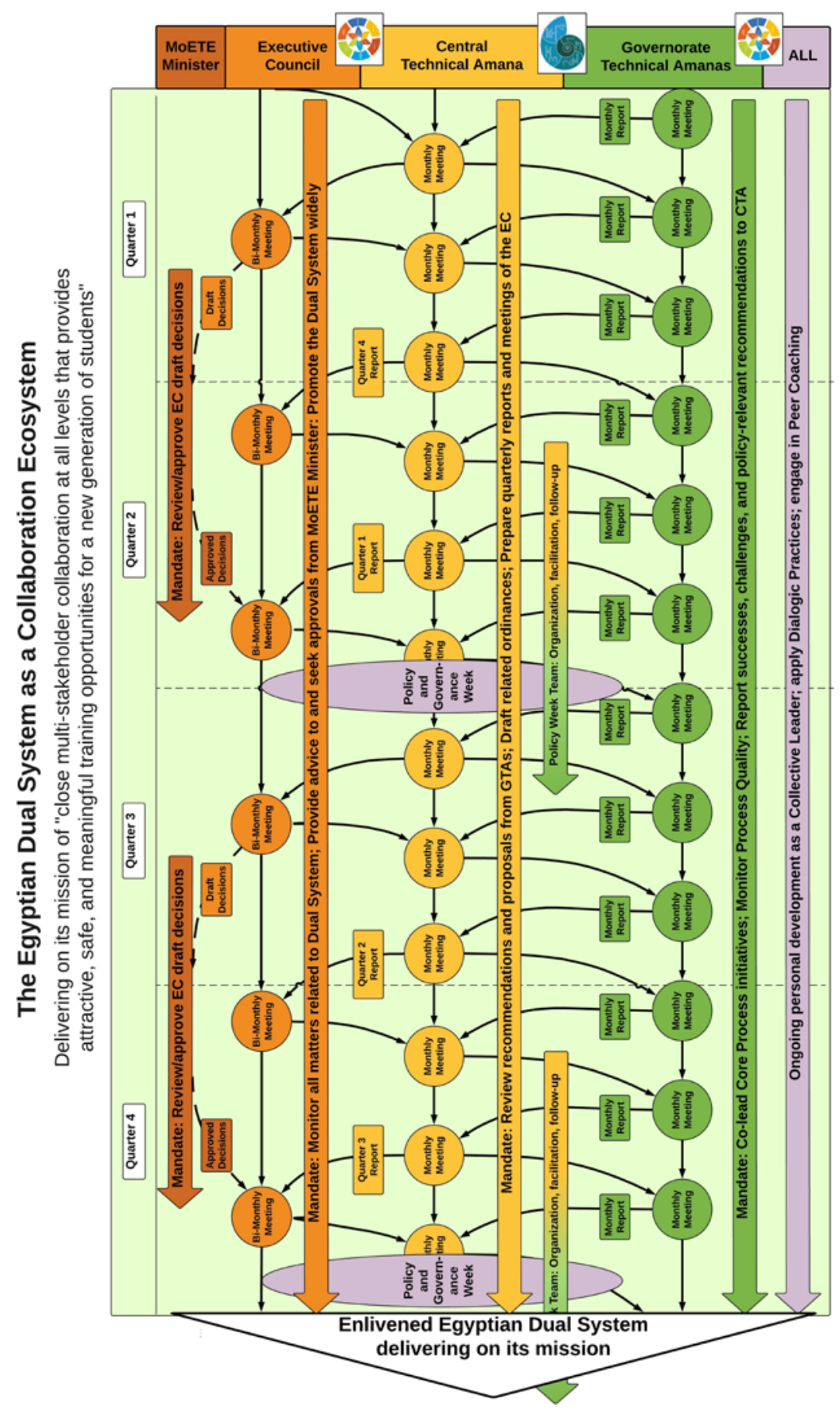

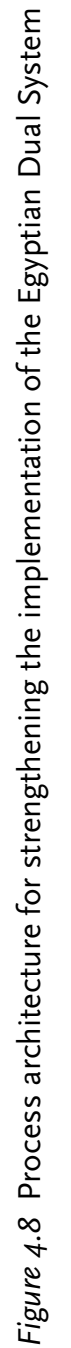


co-hosted a high-level conference on Innovative Partnerships for Formal Apprenticeships: Pioneering Approaches for the Transformation of the Egyptian Dual System: Collaboration to Achieve Egypt's Vision 2030. The event attracted over 200 diverse participants from across the technical education sector. The statistics of the Ministry showed an unprecedented increase in the number of Dual System students over the course of this process, from 38,571 in the $2017 / 2018$ school year to 61,105 in the 2018/2019 school year, an increase of well over 60 percent. The subchapter on structures will elaborate the multi-stakeholder dialogue structures built and strengthened through this process.

\section{The purpose of structure: governance for sustaining aliveness in collaboration ecosystems}

The previous sections have shown how process architectures need to gradually build diverse actors' capacity to constructively work together for a shared vision. This increasing capability to collaborate across institutional boundaries and societal sectors needs to be contained and sustained by appropriate collaboration structures. Such collaborative structures may look similar to typical project management structures, but are different because they consolidate a new way of interacting among stakeholders. Multi-stakeholder collaborations are laboratories for leading transformative change collectively, hence, the way collaboration is consolidated in implementation, decision-making, or governance structures resembles the complexity of the task and needs to model collective leadership. Moreover, such collaboration structures need to function in a way that they sustain patterns of aliveness and a spirit of driving transformative change together. They organize the relationships between stakeholders, regulate the way decisions are reached, and ensure the actual implementation of measures and activities that are expected to deliver the change. The format of such structures depends on the purpose, the level at which the activity takes place, and the complexity of the multi-stakeholder collaboration, but it is helpful to distinguish between stewarding, implementation, high-level support, and linkage structures, their different purposes and their role in the different phases of the Dialogic Change Model. Good governance in multistakeholder collaboration benefits from mandating decision-making power to the most appropriate structures within the collaboration ecosystem. This increases both the efficiency and quality of decision-making. It is important, therefore, to have clear and complimentary decision-making spheres for the different governing collaboration structures. While steering bodies are generally responsible for strategic, policy, and budgetary decisions, technical working group(s) need to be empowered to make decisions about how to best implement agreed action plans for their particular initiative. In addition, there is a need to empower backbone support - such as dialogic process facilitators - to guide and coordinate the overall process, as well as communications, and capacity building. Figure 4.9 provides an overview of typical collaboration structures important in the four phases of collaborative change. The following section explains the different structure in more detail. 
Phase 1

Exploring and

Engaging
Phase 2

Building and

Formalizing
Phase 3

Implementing

and Evaluating
Phase 4

Sustaining

Impact

\section{High Level \\ Support \\ Structures}

High level sponsorship

High level advisory group

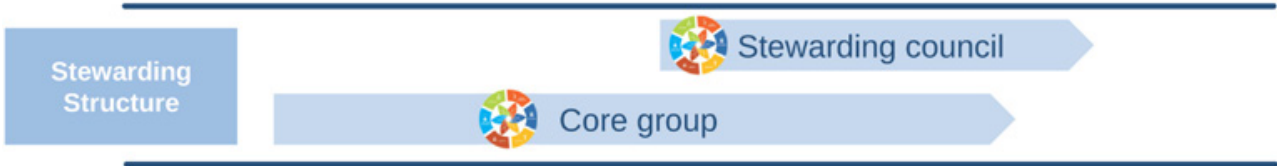

Implementation

Structures

Linkage

Structures
Backbone organization or secretariat

Technical working groups

Figure 4.9 Typical structures in multi-stakeholder collaborations

\section{Stewarding structures}

The purpose of stewarding structures (often also called steering) is to ensure high-quality collaboration patterns, to co-design and oversee process architectures, as well as guide and review implementation. In Phase 1 of Exploring and Engaging, stewarding structures remain loose and rather informal. They mainly refer to the initial container that develops into the core group as a driver of process and engagement. In Phase 2 of Building and Formalizing, the core group continues to serve as or may develop into a stewarding body that is often called the steering committee, stakeholder council, or stewarding council, and has the representation of all stakeholder groups. This is the structure in which the collaborative and cross-institutional governance becomes anchored in Phase 2, and where goals are agreed upon, process architectures adopted, and implementation structures formulated. It is important to construct a stewarding council in a way that it is mandated by all stakeholders and fully entrusted with its tasks. In complex multi-stakeholder collaborations, this is the body that - in Phase 3 of Implementing and Evaluating - makes all major decisions, reviews progress, and guides implementation. In Phase 4 of Sustaining and Expanding Impact, this stewarding body may remain or develop into fully representative governance and steering structures for long-lasting transformative change.

\section{Implementation structures}

The purpose of implementation structures is to facilitate the relationship and collaboration between stakeholders, make sure process architectures are appropriately designed, 
and ensure that the actual work is done. In Phase 1, implementation structures hardly exist and the task of facilitating stakeholder relationships and driving the process lies with the initiators or the core group. In well-funded complex multi-stakeholder collaborations, the initiators form a project secretariat or can even bring in a backbone organization as a dialogic facilitator of the collaboration process. In Phase 2, these implementing bodies become more important, especially, if many stakeholders need to be engaged, or if the multi-stakeholder collaboration takes place at different levels. Also, in Phase 3, the project secretariat or backbone organization is the organizer behind collaborative events, coordinator of thematic technical working groups, or reviewer of roadmaps. It looks at what takes place and how results are achieved and can be reviewed by stewarding structures. In Phase 4, these implementation structures will become consolidated into more professional management structures that sustain outcomes.

\section{High-level support structures}

The purpose of high-level structures is to anchor the importance of the collaboration initiative among influential actors at the policy level, the leadership of corporates or NGOs, or other actors whose influence can strengthen success. In some cases, highlevel support structures can include a patronage of the initiative; in other situations, the support needs to be anchored in the form of an advisory council. It is important to note, however, that such a council is not the decision-making body as described earlier. In Phase 1, high-level structures may not officially exist, but gaining support from high-level actors is crucially important. In Phase 2, this can be consolidated into a more official support announcement or the establishment of a patronage or an advisory council, in which influential people are positioned. In Phase 3, such highlevel support structures need to be maintained. Actors in such structures should be regularly informed about progress and invited to important events. The careful and continuous involvement of high-level support in Phase 3 can pave the way for Phase 4 . Such support structures not only need to continue, but can ease the way to further funding, support institutionalization, or help expand the impact.

\section{Linkage structures}

The purpose of linkage structures is to ensure that the collaboration initiative is connected to knowledge, trends, new developments, and other actors in the field that may not directly be involved. This can take the form of involving and keeping connections to experts in a particular field that may contribute also to the technical working groups and provides the collaboration ecosystem with important information. Experts, of course, will also be recruited from within the collaborating stakeholders, but involving external experts is equally important to ensure innovative thinking beyond the conversations that are generated from within. In Phase 1, external expertise may be utilized in the form of benchmarking or as inspiration about what other actors do in the same field. However, it is important to ensure stakeholders from within the system are empowered to show their expertise. Similarly, in Phase 2, external expertise needs to be brought in as inspiration, and not in a way that stakeholders could 
feel patronized. Particularly for joint diagnosis of the current situation, as well as in the discovery of systems patterns and goal development, the lead must be with the collaborating stakeholders. Their competency to lead transformative change must become visible. In Phase 3, external expertise may be very helpful. It needs to be integrated in technical working groups, brought in through study or exchange visits, or even invited as external evaluation. This is also the phase in which linkage structures to other initiatives can be formally established. Stewarding bodies can decide that such collaborations would increase impact, and subsequently task project secretariats or backbone organizations to follow-up on linkage structures. Often, these metacollaborations help carry a collaboration initiative into Phase 4.

Successful multi-stakeholder collaborations work with these four levels of structures that sustain aliveness in their collaboration ecosystem. They become part and parcel of high-quality process architectures that, beyond the wider stakeholder engagement, also show which body will be meeting when. Table 4.15 selects some of these bodies as core elements of governance in multi-stakeholder collaboration. A deeper understanding is needed as to how they can sustain Aliveness in collaboration ecosystems. These bodies are:

- The backbone organization as part of the implementation structures

- The stewarding council as part of the stewarding structures

- The technical working groups as part of the implementation structures

Each of these bodies is integral to the governance of multi-stakeholder collaborations and will be explored in more detail in the following sub-sections, complemented by a discussion on how to come to agreements and map resources.

Table 4.15 Bodies for sustaining aliveness in collaboration ecosystems

\begin{tabular}{|c|c|c|c|c|}
\hline & Mandate & Form & Membership & Meeting frequency \\
\hline $\begin{array}{l}\text { Backbone } \\
\text { support }\end{array}$ & $\begin{array}{l}\text { Catalyzing, } \\
\text { care-taking, } \\
\text { and capacity } \\
\text { building for the } \\
\text { process }\end{array}$ & $\begin{array}{l}\text { Funded staff } \\
\text { team trusted } \\
\text { and mandated } \\
\text { by stakeholders }\end{array}$ & $\begin{array}{l}\text { Professionals } \\
\text { with process } \\
\text { compe- } \\
\text { tence and } \\
\text { commitment }\end{array}$ & $\begin{array}{l}\text { - Ongoing work } \\
\text { and weekly to } \\
\text { monthly team } \\
\text { meetings }\end{array}$ \\
\hline $\begin{array}{l}\text { Stewarding } \\
\text { council }\end{array}$ & $\begin{array}{l}\text { - Strategic } \\
\text { decision- } \\
\text { making, includ- } \\
\text { ing on budgets }\end{array}$ & $\begin{array}{l}\text { Body duly } \\
\text { appointed and } \\
\text { formalized by } \\
\text { stakeholders }\end{array}$ & $\begin{array}{l}\text { Strategic- } \\
\text { level multi- } \\
\text { stakeholder } \\
\text { representatives }\end{array}$ & $\begin{array}{l}\text { - Bi-annual } \\
\text { to monthly } \\
\text { meetings, plus } \\
\text { extraordinary } \\
\text { meetings }\end{array}$ \\
\hline $\begin{array}{l}\text { Technical } \\
\text { working } \\
\text { group(s) }\end{array}$ & $\begin{array}{l}\text { - Technical } \\
\text { inputs, action } \\
\text { planning, } \\
\text { budgeting, } \\
\text { implementation }\end{array}$ & $\begin{array}{l}\text { Action-oriented } \\
\text { teams that carry } \\
\text { out initiatives, } \\
\text { dissolve when } \\
\text { completed }\end{array}$ & $\begin{array}{l}\text { - Technical- } \\
\text { level multi- } \\
\text { stakeholder } \\
\text { representatives }\end{array}$ & $\begin{array}{l}\text { - Monthly to } \\
\text { bi-monthly meet- } \\
\text { ings, as required } \\
\text { for specific } \\
\text { initiatives }\end{array}$ \\
\hline
\end{tabular}




\section{The role of backbone support for thriving collaboration ecosystems}

Stewarding multi-stakeholder change process requires stakeholders to play different and complimentary leadership roles. The collective leadership approach generates a sense of aliveness, making for a more dynamic and resilient culture of collaboration that spans and leverages the differences between individuals, institutions, and stakeholder perspectives. In this regard, one form of leadership is providing backbone support for collaboration processes (Hanleybrown et al., 2012; Kania \& Kramer, 2011; Kuenkel, 2019). Indeed, a key structure in a thriving and impactful collaboration ecosystem is that of the backbone support or project secretariat. We will use the former term here, as backbone support can be done by individuals, core groups, or funded project secretariats, or even an organization that is mandated to facilitate the process of collaboration. What is crucially important: people who provide backbone support are highly engaged for the goals, yet impartial towards the different stakeholders, and they are skilled dialogic process facilitators.

Backbone support is part of the implementation structures, because its focus is on process management for the multi-stakeholder collaboration, which includes navigating the connections between the different structures, and ensuring the process architectures are implemented. Members of the initial container often function as backbone support in the beginning of an initiative, connecting stakeholders, clarifying the context and bringing people together for change. But in the course of the initiative, the process management work that needs to be done might overburden members of the core container. Moreover, as the collaboration ecosystem emerges and more and more stakeholders join, it is important to acknowledge and mandate backbone support more formally. Starting in Phase 1, a central role for the backbone support is facilitating the co-design of the collaboration's process architecture with a focus on inclusiveness, building ownership of the process, and increasing commitment to delivering results. Moving into Phase 2, this work includes supporting the co-development of emotionally compelling goals and attendant strategies and action plans. Backbone support seeks to build and maintain cohesion and aliveness in the emerging collaboration ecosystem by paying attention to the way stakeholder meetings take place and achieve results. As part of Phase 3, backbone support focuses on the coordination of activities as well as creating spaces for reflection and mechanisms for learning (Hanleybrown et al., 2012; Turner et al., 2012). This role is crucially important for adapting the collaboration's goals, theory of change, strategy, action plan, and/or structures, as well as ensuring that people stay focused on achieving results.

Often, it is the backbone support that holds a complex multi-stakeholder collaboration together. The people tasked with it should have a very good overview of the collaboration ecosystem, the constraints and realities of each of the stakeholder groups, and understand how process and results are inextricably linked. This positions them well to provide for communications and relationship management among involved actors and, when agreed, with the public. Given this overview, they are also responsible for addressing capacity-building needs, especially for increasing the ability of all stakeholders involved to lead the transformative change collectively. When backbone support is not assigned by participating institutions, but needs to receive funding, either from stakeholders involved or external funders, these funding sources need to be made transparent. Backbone support needs to be tailored to each multi-stakeholder collaboration, generally focused on a 
combination of the following roles: as a catalyst for change, as a caretaker of the process, and as a capacity builder for collaboration capacity. These are described in the following.

\section{The catalyst role}

Multi-stakeholder collaborations emerge when there are initiators who not only see future possibilities, but are convinced that only the engagement of many actors will achieve results. This catalyzing role, in some instances, originates from people who are already experienced in multi-stakeholder collaborations or have been practicing backbone support in such initiatives. They can come from civil society, development cooperation, the government, or the private sector, or, sometimes they emerge from existing coalitions of actors. Regardless of their sector, it is often the catalyzing role of backbone supporters that creates new connections in the system of stakeholders and helps people to tune into future possibilities for change. They recognize the complexity of the change process, e.g. for realizing a particular SDG, as well as the necessity for multi-stakeholder collaboration for achieving the desired results. In order to play the catalyst role well, people who do backbone support need to exercise a high level of humanity to earn and maintain the trust of all stakeholders and create resonance for a compelling change. While they need to be seen as a neutral broker and bridge builder when it comes to the stakeholder system, they are not neutral - and can even be quite passionate - about the proposed aspirations of the collaboration.

\section{The caretaker role}

The typical role of backbone support is nurturing connectivity in the stakeholder system, and facilitating dialogue and collaboration. With a focus on engagement and collective intelligence, this role focuses not only on relationships, communication, and high-quality dialogue, but also on ensuring the collective development, ownership, and implementation of an agreed-upon process architecture. As the caretaker role is crucially important to shift the system of actors towards functioning as a thriving collaboration ecosystem, this role needs to be acknowledged and officially mandated. Beyond the facilitation of separate dialogic events, people assuming the caretaker role have a good sense of which sequence of interconnected meetings, events, and workshops would move the collaboration forward. In this way, they become strategists for the collaboration process, and cultivate the quality of dialogue and cooperation. Even when multi-stakeholder collaborations are not overly complex, the active engagement of a team of professionals - in the form of backbone support or secretariat - with expertise in dialogic facilitation, cross-sector collaboration, and process management has been shown to increase efficacy (Hanleybrown et al., 2012).

\section{The capacity-building role}

Multi-stakeholder collaboration efforts work better when stakeholders develop a common understanding of the conditions for high-quality collaboration and ways of transformative change processes (Buuren, 2009). For backbone supporters, who most 
often are already skilled dialogic process facilitators, this means that they find ways of not only supporting other actors in collaborative change, but also of conveying their knowledge about how to construct collaborative success. This requires them to have a sufficient Wholeness view of the system to recognize gaps in capacity, while tapping into Innovation for addressing those gaps. The success of multi-stakeholder collaborations depends on participating actors having a shared understanding of the context and technical issues on the one hand, while also acquiring having dialogue skills and process competence on the other. Additionally, integrated capacity building of all involved actors in how best to collectively steward transformation - particularly in Phases 1 and 2 of the Dialogic Change Model - decreases dependence on the backbone support, strengthens self-organization, and empowers actors to effectively deliver results together (Kuenkel \& Aitken, 2015; Kuenkel et al., 2011).

People who provide backbone support in multi-stakeholder collaboration are the guardians of aliveness in the collaboration ecosystem. Their skills to understand the 'patterns that work' and navigate differences towards constructive collaboration paves the way for delivering results. Given the importance of backbone organizations for multistakeholder collaborations, it is pertinent to note that most funders who contribute resources to such initiatives underestimate their role (Kuenkel, 2017; Pattberg \& Widerberg, 2014; Turner et al., 2012). Putting backbone support in place requires funding, effort, and time, but is well worth the investment in terms of the quality of process design and implementation, integration of capacity building, collective reflection, and adaptation, and for delivering results. Backbone support should not be under-resourced, or else the success of the multi-stakeholder collaboration could be at risk.

\section{The role of a stewarding council}

More complex multi-stakeholder collaborations do well with establishing strategic steering and decision-making structures in the form of a stewarding council. This is usually established at the end of Phase 2 with representation from all key stakeholder groups. In organizations this would be equivalent to a board, however, one needs to consider that collaboration structures are voluntary commitments and connections. As much as stewarding structures' purpose is strategic guidance, there is no fixed hierarchy or line of reporting between stakeholders. This only occurs once, for example, a multi-stakeholder collaboration has been institutionalized as a legal entity in Phase 4. Then, the stewarding council can transform into an executive board with all its normal functions, even though it might be composed of representatives from different stakeholder groups. During Phase 3 the key responsibilities of such a stewarding council is to focus on outlining the collaboration's core strategy, making decisions related to policy, and approving budgets. Such councils work closely with the backbone support. The latter prepares regular meetings, offers updates on the overall process, and makes recommendations for capacity building and next process steps. The stewarding council also works closely with one or more technical working groups, which contribute topical research inputs, offer updates on implementation, and make recommendations for any necessary changes in the collaboration's action plan. The capacity of the stewarding council to lead transformative change collectively is crucially 
important, because it has a decisive influence on the quality of collaboration. This is the body that needs to model the new way of interacting constructively among stakeholders. The more members of this body can move towards generative dialogue, deal with conflicts constructively, and understand the delicate needs of functional collaboration ecosystems, the more likely will they be able to steward the multi-stakeholder collaboration towards success.

It is important to pay special attention to how stewarding councils are established, how their mandate is defined, and how members are appointed or selected. Different from a high-level advisory group that may be composed of influential actors that are not directly involved in the process, the stewarding council needs to emerge from engaged actors within the collaboration ecosystem. Such a council reflects the system of stakeholders; it becomes a microcosm of the stakeholder system that needs to operate differently together. In more complex multi-stakeholder collaborations, it is important to ensure the credibility of a council by empowering stakeholder groups to nominate members for the stewarding structure from their constituencies according to agreedupon criteria. As stewardship councils often emerge from the initial core group in Phase 2 , it is important that the core stakeholders together discuss the stewarding council's format, the terms of reference, and, based on these responsibilities, the composition of the membership. This can be prepared by facilitators who are tasked with the backbone support. Depending on the complexity of the multi-stakeholder collaboration, stewarding councils can range from three to twelve persons. The general rule of thumb is to only make the body large enough to constitute a satisfactory representation of the involved stakeholder system. Making it too big will complicate decision-making and create inefficiencies. It is also wise for such bodies to agree on who, if anyone, may act as a proxy for an absent member. Some steering bodies choose to rotate chairpersonship among represented sectors. A further good practice is rotating, e.g. on an annual basis, the sector that provides hosts meetings in their institution, business association, or organization. Such rotations can help share responsibilities while maintaining credibility of the collaboration vis-à-vis the wider stakeholder system. Depending on the need for strategic guidance and budgetary cycles, stewarding councils can meet anywhere from bi-annually to monthly, in addition to holding extraordinary meetings, as needed.

\section{The role of technical working groups or task forces}

In parallel with - or sometimes informally preceding - the establishment of stewarding councils, many multi-stakeholder collaborations also establish technical or expert working groups (sometimes also called task forces). Complex collaborations require content work on specific issues, be it research, preparation of decisions, or recommendations to the stewarding council. Depending on the complexity of the collaboration, there may be several technical working groups. These action-oriented teams of technical experts focus on specific topics or change initiatives that are part and parcel of the purpose of the collaboration. Technical working groups can be composed of different stakeholders to ensure that the expertise and interests of different stakeholder groups are represented. They need to be endorsed by the stewarding council. This appointment or approval is important to working group members, as it gives them a mandate to 
dedicate some of their formal work time to their initiative. If appropriate and agreed by stakeholders, technical working groups can also include external experts.

In either scenario, technical working groups are generally responsible for making technical inputs to the stewarding council; hence, they work on an issue, deliver results, and report back to the council. These could also be certain deliverables for the collaboration ecosystem's strategy, such as drafting an action plan for review by the steering body, accompanying this action plan with a draft budget, and, ultimately, implementing the respective initiatives. Depending on the nature of their expertise and terms of references, technical working groups may meet bimonthly or monthly. Leading up to key events in their initiative, these meetings may well become more frequent. When an initiative has been completed, evaluated, and celebrated, a technical working group can dissolve. Some or all members may join other technical working groups or, as the need arises, form new working groups. Most often, technical workings groups are the place where the actual content work of multi-stakeholder collaboration happens. Hence, the way they are composed, the way they interact and collaborate, or are acknowledged by the stewarding council, as well as empowered by the backbone support needs to mirror the constructive inspiration that emerges from high-quality collaboration patterns.

All these governing bodies need to move the collaborative process forward by coming to agreements that then be implemented. The next sub-section on agreements applies to technical working groups, as well as to the stewarding councils and the backbone support. Coming to agreement is important, as is defining a regular process for revisiting and potentially revising these arrangements.

\section{Agreements in multi-stakeholder collaboration}

Agreements are the common thread that carries collaborations through the process architecture and into tangible results. These agreements occur in various formats. The unique value of multi-stakeholder collaboration lies in the contribution that all stakeholders can make to the process. While Phase 1 is characterized by informal working structures, it is important in Phase 2 that the commitment to transformative change is consolidated into more formal agreements. This can be a signed document that shows the scope of the commitment, such as a strategy paper, a documented joint statement of the current situation and the way forward, or a declaration of a joint interest in the goal. Agreements formalize and consolidate the results of the more informal building up of engagement in Phase 1. They strengthen further cooperation and dialogue, offer guidance and support in the case of unavoidable conflicts, and serve as an orientation in the complex environment of the collaboration ecosystem. They create identity and foster accountability. So, they are important for creating cohesion among collaborating stakeholders.

Agreements in multi-stakeholder collaborations

- require those who are involved in the drafting and signing to have a clear mandate;

- need to be developed jointly and consensually among key stakeholders;

- should be based on mutual respect and the principles of equality between different stakeholders; 
- do not need to be legally binding, but show and convey commitment;

- can (but do not need to) develop from less to more formal agreements, such as from a declaration of interest to a memorandum of understanding or a formal contract; and

- $\quad$ are based on voluntary commitments.

The types of agreements suitable for collaboration initiatives depend on the form, purpose, composition of stakeholders, and complexity. The more the collaboration moves towards joint implementation, the more detailed and comprehensive the agreements will need to be. This means formalizing stewarding and implementation structures, thereby creating the governance structures elaborated earlier. Agreements refer to these structures, but also to internal and external communication, roles and mandates, finances, or other contributions. They define timelines for implementation. It is important to note that more binding agreements can often not be decided by participating stakeholders, but may need to be approved by the senior management of the respective institutions involved. Table 4.16 shows examples of agreement types, in ascending order of formality.

Table 4.16 Typical agreements in multi-stakeholder collaboration

\begin{tabular}{|c|c|}
\hline $\begin{array}{l}\text { eclaration of } \\
\text { terest }\end{array}$ & $\begin{array}{l}\text { - Often used by private-sector stakeholders to show their interest in } \\
\text { dialogue and collaboration pragmatically. }\end{array}$ \\
\hline $\begin{array}{l}\text { Agreement on next } \\
\text { teps }\end{array}$ & $\begin{array}{l}\text { - In complex or fragile collaboration ecosystems, the only form of agreement } \\
\text { possible, but good enough to make a next meeting and build a process. }\end{array}$ \\
\hline $\begin{array}{l}\text { inutes of } \\
\text { eetings }\end{array}$ & $\begin{array}{l}\text { - In smaller collaboration initiatives, a pragmatic for } \\
\text { results-documentation that creates commitment a }\end{array}$ \\
\hline $\begin{array}{l}\text { eclaration of } \\
\text { articipation }\end{array}$ & $\begin{array}{l}\text { - Particularly for multi-stakeholder platforms or initi } \\
\text { ing commitment to both the group of stakeholder }\end{array}$ \\
\hline loint declaration of & $\begin{array}{l}\text { - Important for multi-stakeholder initiatives and partnerships as a way } \\
\text { of showing, internally and externally, the commitment to collaborate } \\
\text { and achieve results. }\end{array}$ \\
\hline $\begin{array}{l}\text { ct plan, } \\
\text { hitectures } \\
\text { bs }\end{array}$ & $\begin{array}{l}\text { - Important at the end of Phase } 2 \text { as a document for accountability. } \\
\text { This can include roles and responsibilities, activity planning, and } \\
\text { forms of monitoring. }\end{array}$ \\
\hline $\begin{array}{l}\text { Agreements on } \\
\text { governance } \\
\text { structures }\end{array}$ & $\begin{array}{l}\text { - Agreements here define the terms of reference for stewarding councils, } \\
\text { backbone support, and technical working groups. This includes selection } \\
\text { procedures, sequence of meetings, and decision-making responsibilities. }\end{array}$ \\
\hline $\begin{array}{l}\text { Memorandum of } \\
\text { Understanding } \\
\text { (MoU) }\end{array}$ & $\begin{array}{l}\text { - A form of consolidating cooperation commitment between two or } \\
\text { more stakeholders. It can include detailed paragraphs on the form of } \\
\text { cooperation. }\end{array}$ \\
\hline $\begin{array}{l}\text { Joint press } \\
\text { statement }\end{array}$ & $\begin{array}{l}\text { - This makes the collaboration known to the public, can show mutual } \\
\text { commitment, or showcase first results. }\end{array}$ \\
\hline $\begin{array}{l}\text { Cooperation } \\
\text { contract }\end{array}$ & $\begin{array}{l}\text { - A legally binding contract specifying roles and responsibilities, } \\
\text { resource contribution, and allocations, duties, and obligations. Most } \\
\text { often used for multi-stakeholder partnerships. }\end{array}$ \\
\hline
\end{tabular}




\section{CASE EXAMPLE 4.3: EXAMPLE FROM THE FIELD: COLLABORATIVE STRUCTURES FOR TRANSFORMATIVE CHANGE IN THE EGYPTIAN TECHNICAL EDUCATION}

The emerging collaboration ecosystem for the widespread implementation of the Egyptian Dual System became successful when key actors were capacitated to manage, or more specifically, steward successful multi-stakeholder collaborations. They integrated different views, ideas, and expertise from stakeholders such as the public sector, the private sector, schools, parents and students. The goals were ambitious: to make a decisive contribution to Egypt's 2030 Sustainable Development Plan by ensuring skilled and qualified technical workers had received trainings in diverse and new skills, and in a way that would be responsive to the needs of labor market. The Dual System was meant to provide new opportunities for students that would decisively

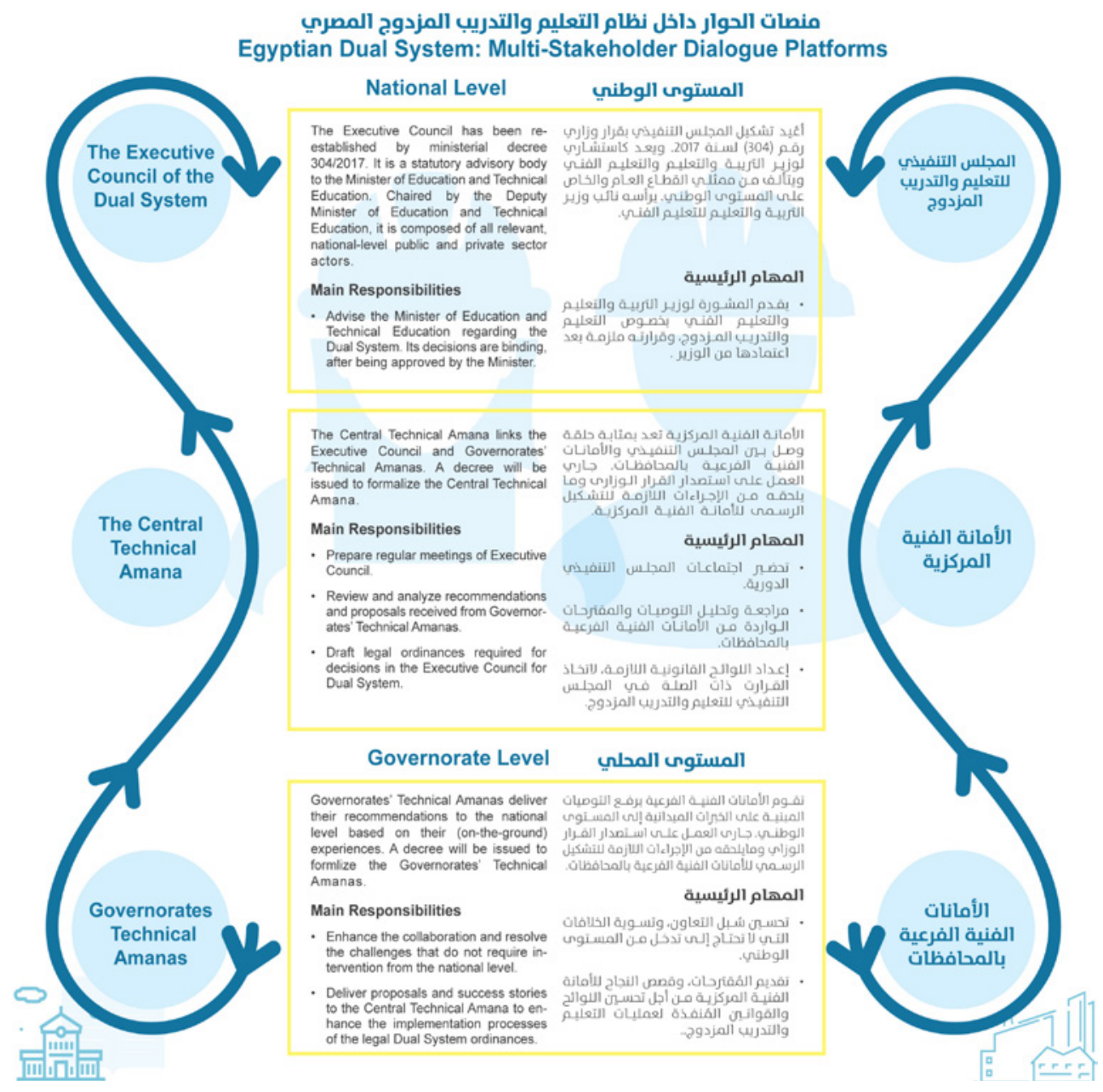

Figure 4.10 The EDS information fact sheet describing the collaboration structures

Source: GIZ 
increase their employability. But progress would not have been achieved without sufficiently collaborative structures. The government-led multi-stakeholder collaboration needed to acknowledge and enliven existing stewarding structures, such as the Executive Council, and capacitate and empower existing and newly developed implementation structures, such as the Central Technical Amana and the Governorate Technical Amanas. As the process architecture for the implementation (Phase 3) showed (see Figure 4.8), these different bodies would come together on a regular base for a 'Policy and Governance Week' as an opportunity to track progress, share learnings, and inspire innovation. For all of them, roles and responsibilities were agreed transparently, so that they knew their tasks as well as their decision-making powers. It was done in a way that all actors felt comfortable with and could take ownership of their roles and tasks for the implementation. This collaborative spirit and clarity created the conditions for their emerging capacity to lead the transformative change towards the functional Egyptian Dual System collectively. Figure 4.10 shows how the different collaborative structures were agreed on, documented, and communicated to all key stakeholders.

This case example already hints to an important element of Phase 3 - the establishment of learning mechanisms such as the week, for which all actors would come together on a regular base. Chapter 5 will take up the challenges and opportunities around learning in multi-stakeholder collaborations.

\section{Notes}

1 In 1993, the Egyptian and the German Governments initiated a cooperation to establish the Dual System in Egypt, the so-called "Mubarak-Kohl Initiative".

2 Funded by the German Federal Ministry for Economic Cooperation and Development, a partnership was agreed in consultation with the Ministry of Education and Technical Education (MoETE), the Federation of Egyptian Industries (FEI), and the Egyptian Federation of Investors Associations (EFIA) between the Gesellschaft für internationale Zusammenarbeit (GIZ) and the Collective Leadership Institute (CLI).

3 Co-created by EDS central level actors, visioning and strategy workshop, Cairo, Egypt, November 27-28, 2017.

4 The Arabic version of the original process architecture has been designed from right to left, following the written language style.

\section{References}

Buuren, A. V. (2009). Knowledge for governance, governance of knowledge: Inclusive knowledge management in collaborative governance processes. International Public Management Journal, 12(2), 208-235.

Hanleybrown, F., Kania, J., \& Kramer, M. (2012). Channeling change: Making collective impact work. Stanford Social Innovation Review, 9(1), 1-8.

Kania, J., \& Kramer, M. (2011). Collective impact. Stanford Social Innovation Review, $9(1), 36-41$. 
Kuenkel, P. (2017). Building competences for partnering: How donors can ensure multistakeholder partnerships succeed. Briefing Note 95. Maastricht: ECDPM. http:// ecdpm.org/publications/building-competences-partnering/

Kuenkel, P. (2019). Stewarding sustainability transformations: An emerging theory and practice of SDG implementation. Cham, Switzerland: Springer.

Kuenkel, P., \& Aitken, A. (2015). Key factors for the successful implementation of stakeholder partnerships: The case of the African cashew initiative. In V. Bitzer, R. Haman, M. Hall, \& E. W. Griffin (Eds.), The business of social and environmental innovation: New frontiers in Africa. Berlin: Springer.

Kuenkel, P., Frieg, V., \& Gerlach, S. (2011). Working with stakeholder dialogues: Key concepts and competencies for achieving common goals. A practical guide for change agents from public sector, private sector and civil society. Potsdam, Germany: The Collective Leadership Institute.

Kuenkel, P., \& Kühn, E. (2018). Leveraging multi-stakeholder collaboration for systemic change in responsible value chains: Six principles for transformative process designs. In Collective leadership studies (vol. 6). Potsdam, Germany: The Collective Leadership Institute. ISSN 2569-1171

Niestroy, I., \& Meuleman, L. (2015). Common but differentiated governance: Making the SDGs work. Sustainability, 7(9), 12295-12321.

Pattberg, P., \& Widerberg, O. (2014). Transnational multi-stakeholder partnerships for sustainable development. building blocks for success. IVM Report, R-14/31. Amsterdam: Institute for Environmental Studies.

Population Reference Bureau. (2019). Egypt data. Washington, DC. Retrieved February 23, 2020, from www.prb.org/international/geography/egypt

Robinson, J. B. (1990). Futures under glass. A recipe for people who hate to predict. Futures, 22, 820-843.

Senge, P., Hamilton, H., \& Kania, J. (2015). The dawn of system leadership. Stanford Social Innovation Review, 13, 27-33.

Turner, S., Merchant, K., Kania, J., \& Martin, E. (2012, July 18). Understanding the value of backbone organizations in collective impact: Part two. Stanford Social Innovation Review. Blog post. www.ssireview.org/blog/entry/understanding_the_ value_of_backbone_organizations_in_collective_impact_2

Waddell, S. (2016). Societal change systems: A framework to address wicked problems. The Journal of Applied Behavioral Science, 52(4), 422-449. http://doi. org/10.1177/0021886316666374

Weiss, C. H. (1995). Nothing as practical as good theory: Exploring theory-based evaluation for comprehensive community initiatives for children and families. In J. Connell, A. Kubisch, L. Schorr, \& C. Weiss (Eds.), New approaches to evaluating community initiatives: Concepts, methods and contexts (pp. 65-92). New York: Aspen Institute.

Wilber, K. (2002). A theory of everything: An integral vision for business, politics, science, and Spirituality. Boston: Shambhala.

World Bank. (2016, Spring). Egypt's economic outlook. Washington, DC. Retrieved February 23,2020 , from www.worldbank.org/en/country/egypt/publication/economicoutlook-spring-2016 


\section{chapter 5}

\section{Becoming reflective Cultivating a culture of learning}

The previous chapters showed that successful multi-stakeholder collaboration requires attention to way different actors communicate with each other. Moreover, they become effective with elaborate process architectures that, if based on enlivening methodologies, are the pathways towards co-shaping futures that benefit individuals as well as larger systems. It is, however, important to stay mindful of the fact that any attempt to initiate, implement, or facilitate multi-stakeholder collaborations is an intervention into sometimes fragile, often controversial systems of actors. So, careful attention to the quality of process, the quality of relationships and interaction among stakeholders, as well as to the functionality of collaboration structures is not "nice-to-have", but paramount. It is essential for increasing effectiveness and outcomes, utilizing time and resources in a responsible way, and ensuring better impacts of change initiatives. Enlivened collaboration ecosystems are more capable to deal with complex local to global sustainability challenges, because anchoring dialogue and collaboration in cross-institutional structures opens new and faster avenues to collective learning. The Dialogic Change Model and the Collective Leadership Compass guide stakeholders towards co-creating increased systems aliveness, but they are no blueprints. Understanding and applying methodologies and tools can offer just the degree of orientation and common language that diverse key actors need in order to stay in the collaborative field. After all, people's passion and ability to learn together counts in all collaborative processes. Moreover, learning over time and adjusting process designs are important faculties to develop. A key to learning is structured reflection: certainly, by key actors, and by the core group, but ideally by a wider group of people involved in the collaboration ecosystem. Reflection can be a challenge, because most highly engaged actors will be overworked and not used to spending time for reflection. Yet, as Figure 5.1 shows, collective reflection among key 


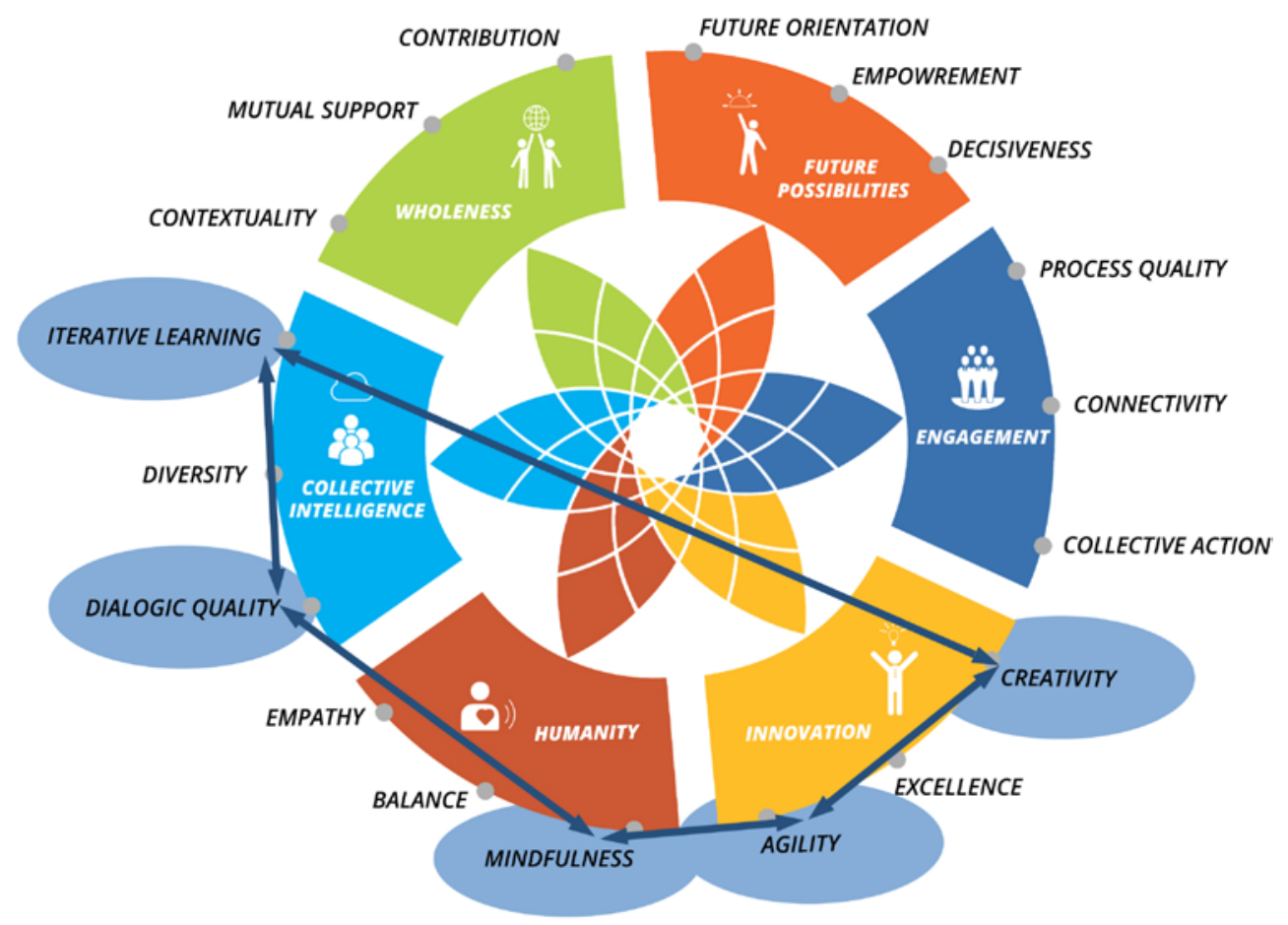

Figure 5.1 Collective reflection enhancing Compass aspects

actors invigorates Compass aspects that are crucial for taking the multi-stakeholder collaboration to impact. It is mindfulness combined dialogic quality enhance iterative learning, which unleashes creativity and agility.

Hence, developing a culture of learning requires attention right from the start in Phase 1. If a core group as a good container has established a pattern of regular reflection on process and progress, and sees the task in front of them as a learning space, this culture will more easily be reflected also in the collaboration with a wider group of stakeholders. Once established as a core approach, it pays off in Phase 2 in the way meetings are held so that they enhance mindfulness, iterative learning, and the agility of stakeholders. The quality of results to be achieved in Phase 3 is essentially dependent on the quality of the learning culture. Such learning mechanisms should not just be part of the process, but officially established as part of review meetings, as an essential element of governance structures, and as a way of keeping the system of actors in a continuous reflective conversation. The focus in Phase 3 on getting to results and showing the benefits of the collaboration to the institutions involved, as well as to the public, naturally creates the sort of pressure that at times causes stakeholders to resort back into ways of thinking and acting "alone". Without an enhanced capability to reflect, to acknowledge human shortcomings, and to build in opportunities to learn together, this subsequently will create conflicts, misunderstandings, or even fragmentations in the collaboration ecosystem. 
This Chapter therefore looks at the many ways a learning culture can be established in the four phases of the Dialogic Change Model using the Collective Leadership Compass as a helpful guide towards quality collaboration. It

- looks at how success factors in multi-stakeholder collaborations show up as Collaboration Catalysts related to the six dimensions of the Collective Leadership Compass and how they can be used as a process monitoring tool to enhance and keep the quality of the collaborative process;

- takes a look at the role of communication for the many forms of learning mechanisms that can emerge in multi-stakeholder collaboration, and how they can be integrated in all four phases of collaborative change, so that reflection becomes second nature for all stakeholders involved;

- provides a troubleshooting guide for managing difficulties in multi-stakeholder collaborations by paying attention to the dimensions and aspects of the Collective Leadership Compass and the four phases of the Dialogic Change Model; and

- helps actors to steward pathways by summarizing the methodologies for leading transformative change collectively for all four phases.

Multi-stakeholder collaborations are laboratories for a future way of negotiating and cocreating sustainable futures in global and local societies. Cultivating a culture of learning is an important step ahead as it helps to make the management requirements for collaborative cross-institutional processes more visible. Most often, dialogic process facilitators, coordinators, or initiators of collaboration manage processes intuitively while other actors have a limited understanding of the significance of good process management for collaboration ecosystems. This needs to change - the more stakeholders become aware of patterns that further collaboration and systems aliveness, as well as high quality process architectures, the more likely will the laboratories of multi-stakeholder collaborations find their way into the mainstream of SDG implementation. It will then become the common practice in co-constructing societies that take sustainability issues to heart.

Like any other designed change processes, collaboration between multiple actors rests on trust, a sense of ownership, the clarity of goals and the visibility of outcomes that offer rewards for the time invested. Because of its cross-institutional and crosssector nature, however, change in multi-stakeholder collaboration processes is more complex and less contained than organizational change processes. The structures that arise like those mentioned in the previous chapter, such as governance models, rules of participation and inclusivity, agreements, plans, or communication strategies need to be arrived at in consensual agreements that are inevitably more time consuming. Cross-institutional collaboration is not only complex, it is essentially democratic in the sense that all partners have - in principle - an equal say in the process, because the outcome depends on the engagement of all. Results of collaborations are dependent on the self-organized and collectively monitored action of the partners without any of them having any discretionary power over the other. Any approaches to monitoring and evaluation must therefore be built on a jointly agreed approach of accountability rather than control. Collaboration ecosystems essentially embark on a collective learning journey where iterations become the norm, as plans need to be adjusted many 
times. The more stakeholders are capable of understanding and, ultimately, managing success factors as tangible and intangible conditions for progress, the higher the likelihood of achieving the envisaged impacts - or even going beyond them.

\section{From success factors to collaboration catalysts}

Implementing the SDGs in multi-stakeholder collaborations across the boundaries of the private sector, the public sector, and civil society holds the potential to shift existing societal settings and rearrange them towards better functionality for solving sustainability challenges. They become successful when they enhance the aliveness of systems and subsystems of actors who then begin to shape their future collectively. Yet, the achievement of tangible results always depends on people and their ability to individually and collectively learn. Moreover, they need negotiate pathways into the future between the interest and ambitions of their particular institutions and the joint purpose of a collaboration. Multi-stakeholder collaborations may be influenced by external factors that the initiators have little power to change, such as political instability or economic crises. As the previous chapters have shown, most factors crucial for success can actually be influenced to a certain degree. Paying attention to them helps to maintain a positive dynamic of process, to keep stakeholders sufficiently within the collaborative field, and, finally, to achieve tangible outcomes or successful implementation. Not surprisingly, there is an ongoing debate among experts in multistakeholder collaboration that aims to identify such success factors. These deliberations are an important contribution to the role of cross-sector and cross-institutional change processes in the context of sustainability transformations (Brouwer \& Woodhill, 2015; Byers et al., 2015; Pattberg \& Widerberg, 2014; Beisheim, 2011; Kuenkel et al., 2011). However, as the previous chapters have shown, whatever is identified as success factors needs to be anchored in a deeper understanding of the multiple dynamic layers of change in complex socio-ecological systems. Decontextualized prescriptions of static building blocks for success will not necessarily lead to successful results. In order to inform the process of multi-stakeholder collaboration, success factors need to reflect a pattern of aliveness in the sense that they acknowledge the complex and dynamic balance between the emergent collaboration and a sufficiently contained process architecture. In this practitioner guide, we have shown that applying the Dialogic Change Model together with the Collective Leadership Compass guides stakeholders towards managing the conditions for success. Hence, the success factors suggested here are indicators for the degree of collaboration quality that has been achieved. Indeed, these success factors can be used for collective reflection and empower stakeholders to maintain or improve the quality of collaboration patterns.

The following section therefore shows how the success factors for multi-stakeholder collaboration can be captured as collaboration catalysts based on the Compass dimensions. The term catalyst here means that these factors engender and speed-up collaborative change. The presence or absence of a catalyst in a collaborative process can therefore indicate how well the Compass dimensions have been enacted. Table 5.1 and Figure 5.2 show an overview of the collaboration catalysts and their supporting practices subsequent section explains the Catalysts in more detail. 
Table 5.1 The collaboration catalysts

The compass dimensions

The corresponding collaboration catalyst

and their supporting practices

Future possibilities

- Shape the future together - identify and co-develop emotionally compelling goals

\section{Engagement}

- Co-own change - build step-by-step small to large collaboration systems in bottom-up and top-down processes

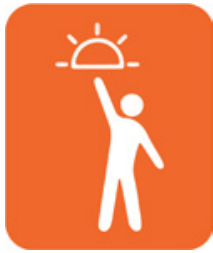

\section{Co-designed strategy}

- Ensure that over time all relevant stakeholders drive strategy and implementation. It is enhanced by goal clarity, inclusivity, and accountability.

\section{Innovation}

- Find new pathways nurture existing change initiatives, foster creative solution, and find and prototype the future

\section{Humanity}

- Access shared values foster collective reflection, build constructive relationships, and appreciate the dignity of people

Collective intelligence

- Foster meaning-making interaction - establish collective learning systems and use structured dialogue to harvest difference for progress

\section{Wholeness}

- Create networked patterns of action - stay connected to the larger goal and create contextual impact with collaborative and complementary activities.
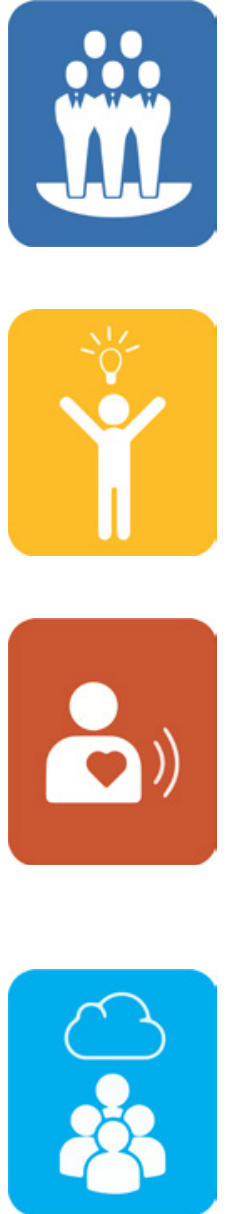

\section{Co-operative delivery}

- Ensure ownership and result-orientation of the collaboration ecosystem through well-organized engagement of stakeholders. It is enhanced by quality engagement management, network building, and result-orientation.

\section{Adaptive innovation}

- Ensure novel pathways for the collaboration ecosystem through co-creation of transformation prototypes and attention to emergent opportunities as well as dealing with concerns. It is enhanced by creative prototyping, knowledge management, and planning flexibility.

\section{Collective value}

- Ensure balanced influence and integration of weaker stakeholders. It means ensuring that the transformative change process creates value for all stakeholders in the collaboration ecosystem. It is enhanced by appreciative approaches, balancing power, and mutual understanding.

\section{Dialogic communication}

- Ensure communication architectures that acknowledge diversity as well as create cohesion and networks in the collaboration ecosystem. It is enhanced by structured dialogue, governance, and collective learning.

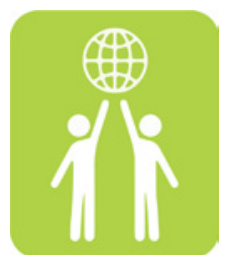

\section{Contextual impact}

- Ensure the relevance for the stakeholder system and the embeddedness of the collaboration ecosystem in larger transformations. It is enhanced by context relevance, capacity building, and impact focus. 


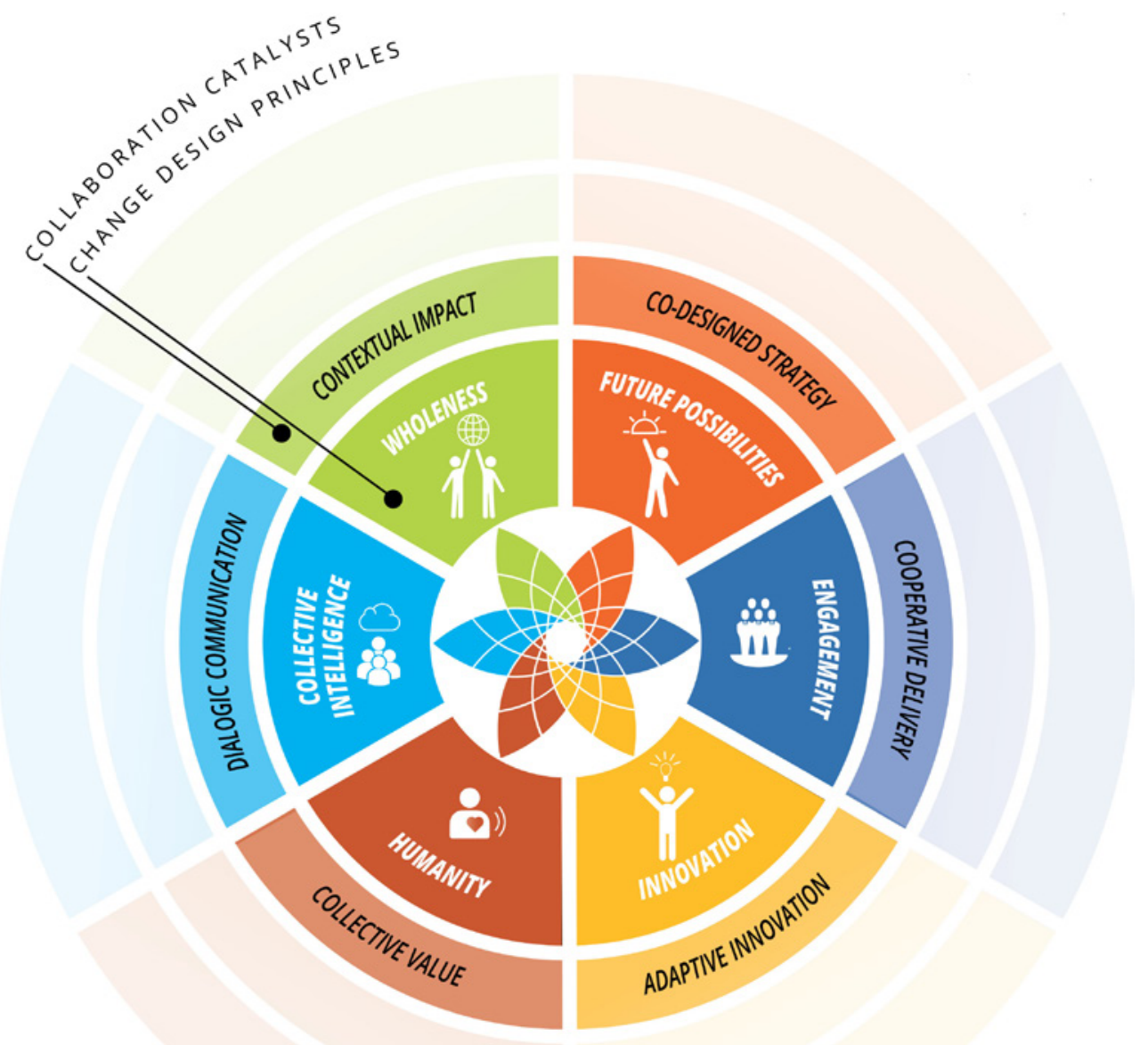

Figure 5.2 The collaboration catalysts and supporting practices

\section{Collaboration catalyst \#1: co-designed strategy}

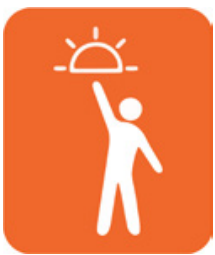

An important factor for success in multi-stakeholder collaborations is the degree of ownership stakeholders feel for the process and envisaged outcomes. Such a sense of ownership emerges when the goal of the multi-stakeholder collaboration is relevant to all stakeholders, when the strategy for implementation is transparent and reliable, and when stakeholders perceive that their contribution counts. Keeping people engaged is an important road to success. Authentic participation in the way contributions are handled, workshops are run, and communication takes place ensures ownership. People implement what they have helped to create. This is why dialogic process facilitators give sufficient attention to the first collaboration 
catalyst - co-designed strategy - that ensures that, over time, all relevant stakeholders drive strategy and implementation. This reflects the Compass dimension of future possibilities and is, at a deeper level, related to the aliveness principle of intentional generativity. Co-designing the vision and strategies is a multi-layered process important throughout all four phases of collaborative change and requires continual high-quality communication. The purpose is to generate agreed-upon action plans that get implemented in a self-organized way. While the core group plays an important role in preparing strategy development, all relevant stakeholders need to be able to own it as their strategy. This is when accountability becomes an intrinsic motivation. Because highlevel support is so essential for complex multi-stakeholder collaborations, strategies need to include ways of creating a sense of ownership with supporters as well, even though they might not be directly involved in the operational aspects of the collaboration ecosystem. The collaboration catalyst co-designed strategy is enhanced by the three supporting practices of goal clarity, inclusivity, and accountability.

- Goal clarity leverages the Compass aspect of future orientation and is the outcome of high-quality process architectures for resonance building and vision development. This starts from a joint diagnosis of the current situation by all relevant stakeholders to the co-development of a future vision all stakeholders can identify with. As elaborated in Chapter 4, this often includes the joint clarification of a theory of change as well as action plans and milestones. Yet, goal clarity is an emerging process subject to collective iterative learning. It is not only relevant in Phase 1 or 2, but also needs to receive attention throughout Phase 3 or be expanded in Phase 4. High-level emotional sponsorship, from heads of the collaborating institutions or politicians, can strengthen goal formation and implementation.

- Inclusivity leverages the Compass aspect of empowerment and is a consequence of acknowledging that only a diversity of stakeholders representing the system which needs to change collectively - will be able to bring about the necessary transformations. It is important to engage both weaker and more powerful stakeholders in strategy development. At times, it might even be necessary to consult critical actors from the outset. On the basis of a thorough stakeholder landscape analysis as described in Chapter 3, some powerful stakeholders' interests need to be raised or interested weaker stakeholders' voices need to be strengthened. Inclusivity in Phases 2 and 3 also refers to inclusive decision-making procedures as well as inclusive and representative steering or governance structures.

- Accountability leverages the Compass aspect of decisiveness and is a result of role clarity, implementation competence, and ownership. For a collaboration ecosystem that moves towards Phase 3 of implementation, the agreement on clear roles and responsibilities is paramount and a prerequisite for collective action. Shifting from visioning to planning requires agreements on milestones and results monitoring. This may also include agreements on resource allocations and transparency of financial flows.

Table 5.2 shows how the collaboration catalyst co-designed strategy can be enhanced through paying attention to the supporting practices. 
Table 5.2 Making the collaboration catalyst "co-designed strategy" work

\begin{tabular}{|c|c|c|}
\hline larity & Enhancing inclusivity & Enho \\
\hline \multicolumn{3}{|c|}{$\begin{array}{l}\text { Co-designed strategy means ensuring that over time all relevant stakeholders drive strategy } \\
\text { and implementation as a functional collaboration ecosystem. }\end{array}$} \\
\hline $\begin{array}{l}\text { - Co-develop and regularly } \\
\text { revive emotionally compel- } \\
\text { ling goals. } \\
\text { - Agree on objectives, but anchor } \\
\text { them in their contribution to a } \\
\text { larger goal that all stakeholders } \\
\text { can identify with. } \\
\text { - Ensure a joint diagnosis of } \\
\text { the current situation together } \\
\text { with relevant stakeholders. } \\
\text { - Co-develop the future vision } \\
\text { and theory of change. } \\
\text { - Jointly develop agreements } \\
\text { on the impact chain and } \\
\text { milestones. } \\
\text { - Obtain high-level sponsor- } \\
\text { ship for the emotionally } \\
\text { compelling goal. }\end{array}$ & $\begin{array}{l}\text { - Conduct a thorough } \\
\text { stakeholder analysis. } \\
\text { - Start small with a good } \\
\text { container (core group), } \\
\text { but gradually involve } \\
\text { more stakeholders. } \\
\text { - Strengthen weaker part- } \\
\text { ners with advocacy and } \\
\text { capacity building. } \\
\text { - Ensure inclusive } \\
\text { decision-making. } \\
\text { - Establish inclusive and } \\
\text { representative steering or } \\
\text { governance structures. } \\
\text { - Introduce appropriate } \\
\text { support structures, such } \\
\text { as a project secretariat } \\
\text { and working groups. }\end{array}$ & $\begin{array}{l}\text { - Define clear roles and } \\
\text { responsibilities. } \\
\text { - Jointly agree on imple- } \\
\text { mentation plans with } \\
\text { milestones. } \\
\text { - Agree on reporting } \\
\text { procedures. } \\
\text { - Jointly agree on results } \\
\text { and process monitoring. } \\
\text { - Establish regular joint } \\
\text { progress reviews. } \\
\text { - Be as transparent as } \\
\text { possible about resource } \\
\text { allocations and financial } \\
\text { flows. } \\
\text { - Create adequate legal } \\
\text { structures where } \\
\text { necessary. }\end{array}$ \\
\hline
\end{tabular}

\section{CASE EXAMPLE 5.1: CO-DESIGNING INTEGRATED WATER RESOURCE STRATEGIES}
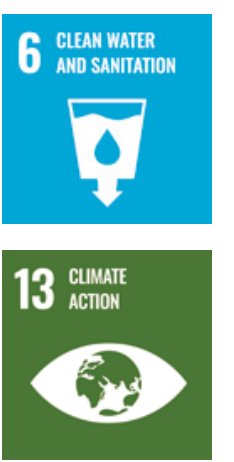

In Tunisia, the agricultural region of Kairouan experienced a severe reduction in their water resources brought about by climate change, mismanagement, and overexploitation. Integrated water resource management was urgently needed, but difficult to achieve because of severe challenges in aligning stakeholders' interests. While strategy development for water resource management was seen as the sole responsibility of government agencies, averting a severe economic crisis and social conflict required building a vital collaboration ecosystem between the local administration and farmers. However, before any strategy could be co-designed, core collaborative groups first needed to be built among administration and farmers separately. A highly inclusive facilitated process support for the 400 farmers resulted in them building a representative structure. High quality dialogues led them to propose a clear vision of the change needed. This bottom-up vision development provided the turning point for engaging the administration in a co-creative definition of goal clarity, which led to joint planning of activities and role distribution among farmers and administration alike. The result was an increased sense of ownership and accountability for a jointly agreed water charter and strategies on reducing water consumption. A joint committee made up of farmers and administration began to monitor and support the implementation process. 


\section{Collaboration catalyst \#2: cooperative delivery}

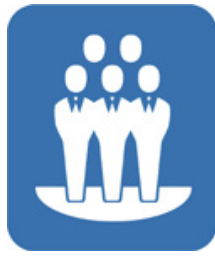

Important factors for success in multi-stakeholder collaborations are the result-orientation of all stakeholders combined with sufficient cohesion of the collaboration ecosystem. Focus on outcomes is a prerequisite for commitment. In multi-stakeholder collaborations, it is important that dialogic process facilitators make achievements visible. This can range from a basic agreement like stakeholders agreeing to meet again to documented recommendations, or from agreed-upon action plans to progress reporting on implementation. The second collaboration catalyst - cooperative delivery - means enacting ownership and ensuring collective action for a complementary contribution with mutual support. An often-neglected element of such initiatives is creating a sense of belonging to the collaborative effort; hence, at the latest in Phase 2, stakeholders must truly be able to identify with being part of a collaboration ecosystem. This reflects the Compass dimension of engagement and relates at a deeper level to the aliveness principle of permeable containment. Engaging people for a larger goal or a meaningful change creates cohesion, but collaboration ecosystems also need to create structures that bring the purpose into the reality of delivering impact. The collaboration catalyst cooperative delivery is enhanced by the three supporting practices of engagement management, network building, and result orientation.

- Engagement management creates cohesion and leverages the Compass aspect of process quality. It is the skilled way of building the collaboration ecosystem in a step-by-step fashion from core partners to all relevant stakeholders. Reliability of planning and implementation processes contributes to trust building, which is the prerequisite for effective implementation in complementary roles. In more complex collaboration initiatives, such processes are supported by project secretariats or backbone support.

- Network building leverages the Compass aspect of connectivity and is a conscious re-arrangement of institutional silos that are unable to tackle sustainability challenges. This means that much attention is required to building the adequate cohesion between people and organizations. High-level political and institutional support eases collective impact, but equally important are action networks between key stakeholders.

- Result orientation leverages the Compass aspect of collective action and entails the continuous focus on making progress regarding the issue of common concern. While this is most measurable in Phase 3 of implementation, it is equally important in Phases 1 and 2 in the way meeting results are captured and agreed upon. A continuous orientation towards tangible results and early wins keeps actors engaged and the initiative on track. This requires sufficient resource allocation for those key cross-institutional stakeholders that drive the collaboration initiative, including financial resources for the project secretariat or backbone support.

Table 5.3 shows how the collaboration catalyst cooperative delivery can be enhanced through paying attention to the supporting practices. 
Table 5.3 Making the collaboration catalyst "cooperative delivery" work

Enhancing engagement Enhancing network building Enhancing result orientation
management

Co-operative delivery means enacting ownership and collective action of the collaboration ecosystem through well-organized engagement of stakeholders. It is enhanced by quality engagement, network building, and result-orientation.

- Build step-by-step engage- - Foster and regularly revive ment of core partners and relevant stakeholders.

- Ensure reliability of planning and implementation processes.

- Foster relationships.

- Build high quality process architectures.

- Cultivate space for meaningful conversations.

- Ensure transparent decision-making

- Obtain backbone support (project secretariats) for coordination of process and events. stakeholders' identification with the collaboration ecosystem.

- Create topic-related and action-oriented networks between key stakeholders.

- Foster the network of actors with transparent communication on progress.

- Foster and maintain highlevel political and institutional support.

- Support actors to communicate the purpose of the collaboration initiative to their institutions.
- Ensure achievable milestones in joint implementation plans.

- Orient process architectures towards tangible results and early wins.

- Attend to joint or complementary implementation.

- Ensure sufficient resource allocation.

- Establish and maintain a well-functioning, mandated, and stable cross-partner core group (container).

- Combine progress reporting with mutual learning.

\section{CASE EXAMPLE 5.2: PIONEERING A CIRCULAR ECONOMY APPROACH}

DECENT WORK AND

ECONOMIC GROWTH

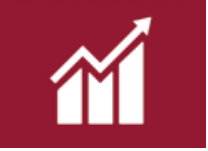

9 INDUSTRY, INNOVATON

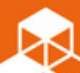

$\infty$

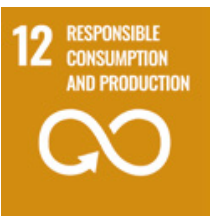

Finland's Roadmap to a Circular Economy is an ambitious plan for the transition of an entire country towards sustainably economic activities that use materials and resources efficiently so that production and consumption creates as little loss and waste as possible. The Finnish Innovation Fund (SITRA) facilitated the development of a roadmap and functioned as the backbone organization stewarding the engagement of relevant cross-sector stakeholders. It eased the conditions for implementation by creating a steering group that connected all relevant stakeholders and their institutions. The map as an agreed upon document showed complementary collective action by detailing policy actions, key private sector projects, and pilots for issues such as sustainable food systems, transport, and logistics. It also ensured that the pilot projects were connected for mutual learning and suggested steps to create networks and synergies between government departments (www.sitra.fi/en/projects/ critical-move-finnish-road-map-circular-economy-2-o/). 


\section{Collaboration catalyst \#3: adaptive innovation}

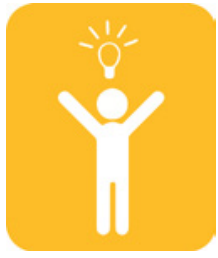

Multi-stakeholder collaborations need to make a tangible contribution to innovative problem-solving. This might not be achieved in Phases 1 or 2, but at the latest in Phase 3 participating stakeholders (and others) expect to see tangible changes happening and new ways of tackling challenges emerge. The third collaboration catalyst adaptive innovation - means enlivening creativity, leveraging diversity, and ensuring iterative learning, all Compass aspects that build stakeholders' capacity to deliver change and find solutions to problems. This refers to the Compass dimension of innovation and relates, at a deeper level, to the aliveness principle of emerging novelty. Problem-solving for sustainability challenges requires bringing together different expertise and complementary resources. Moreover, helping stakeholders see the contextuality of a problem through information and exchange between stakeholders is paramount. Capacity building, throughout all phases, helps to strengthen the understanding of the content issues and the contribution of weaker stakeholder groups. Participatory iterative learning mechanisms ensure cooperative delivery of all partners and allow evaluation of results to be rapidly integrated into the next process steps. The collaboration catalyst adaptive innovation is enhanced by the three supporting practices of creative prototyping, knowledge management, and planning flexibility.

- Creative prototyping leverages the Compass aspect of creativity and shows up as courageous and concrete steps to try out new ways of doing things. Collaborative change needs to go beyond negotiations and instead, open up opportunities for creative co-designs of new solutions, pathways, methodologies, or any other approaches. This is greatly enhanced by process architectures that foster exposure to different knowledge, world-views, and experiences.

- Knowledge management leverages the Compass aspect of excellence and is an important prerequisite for adaptive innovation. Multi-stakeholder collaborations need to make use of the existing knowledge of stakeholders and, additionally, bring in state-of-the-art new knowledge around the issue of common concern. Exposure to innovative ideas engenders new thinking and encourages pathways to action.

- Planning flexibility leverages the Compass aspect of agility and is the capacity of key stakeholders to adjust strategies and process architectures based on reflection about progress, effects, or obstacles. This requires structured learning mechanisms as well as a consensual openness to emergent opportunities. Once a learning culture has been adopted by stakeholders, dealing with conflicts and crises constructively is the most acceptable way of ensuring progress.

Table 5.4 shows how the collaboration catalyst adaptive innovation can be enhanced through paying attention to the supporting practices. 
Table 5.4 Making the collaboration catalyst "adaptive innovation" work

\begin{tabular}{lll}
$\begin{array}{l}\text { Enhancing creative } \\
\text { prototyping }\end{array}$ & $\begin{array}{l}\text { Enhancing knowledge } \\
\text { management }\end{array}$ & Enhancing planning flexibility \\
\hline
\end{tabular}

Adaptive innovation means ensuring novel pathways of the collaboration ecosystem through co-creation of transformation prototypes and attention to emergent opportunities and concerns. It is enhanced by creative prototyping, knowledge management, and planning flexibility.

- Look for existing innova- - Benchmark experiences tive approaches.

- Create space for exchange about and the co-design of new approaches.

- If challenges arise, let stakeholders participate in finding solutions.

- Organize exposure to different world-views and experiences (site-visits, study trips, exchanges, expert inputs).

- Design learning and innovation into process architectures.
- Build regular collective and expertise.

- Integrate high quality technical and content expertise.

- Ensure a continuous update of state-of the art content knowledge.

- Integrate capacity building for collaboration literacy into process architectures.

- Keep all stakeholders informed of new developments, learnings, and innovations. reflection and joint progress reviews into process architectures.

- Keep plans flexible and agree on ways to jointly adapt project strategy.

- Attend to emergent opportunities.

- View crises and conflicts as opportunities to strengthen the approach and the collaboration ecosystem.

- Establishment complaint mechanisms.

\section{CASE EXAMPLE 5.3: BUILDING CAPACITY FOR CLIMATE ACTION}

\section{CUMAIE}

ACTION

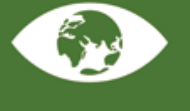
The Moroccan Center for Climate Change Competency (www.4C.ma/ en) is an institution uniting representative from ministries, business associations, civil society organizations, and research institutions who are tasked with facilitating synergies and collaboration across all sectors on climate change mitigation. Beyond networking, experience exchange, and collaboration, knowledge management and capacity building are crucial in establishing the innovative competence of the Center. The latest technical expertise and innovative approaches in climate change mitigation and adaptation are combined with building competence in facilitating collaboration across sectors in Morocco.

\section{Collaboration catalyst \#4: collective value}

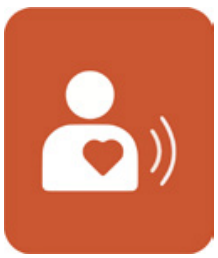

Probably most underestimated in multi-stakeholder collaboration is the experience of people sharing human values. This is not only the connective spirit that helps build collaboration ecosystems in Phases 1 and 2, but also the common thread that enlivens the cooperative delivery in Phase 3. Most collaborative efforts around SDG 
implementation emerge at least partly from an ethical imperative, such as fairer distribution of resources, access to resources, overcoming economic imbalances, or safeguarding the natural environment. But the fourth collaboration catalyst collective value - means more than creating rationally acceptable win-win situations. It requires accessing emotional and deeply shared human values. This reflects the Compass dimension of humanity, and, at a deeper level, the awareness of human connections. If stakeholders experience how the collaborative approach not only benefits the individuals and the whole, but also helps them see situations differently or explore new potentials, they have touched the aliveness principle of proprioceptive consciousness. Dialogic process facilitators need to cater for opportunities to discover the values shared. This contributes to a greater awareness of the interconnections and interdependencies. The collaboration catalyst collective value is enhanced by the three supporting practices of appreciative approaches, balancing power, and mutual understanding.

- An appreciative approach leverages the Compass aspect of mindfulness and is the cornerstone for stakeholders feeling acknowledged as they are and as they see the situation. This is crucial for building trust in collaboration ecosystems. The respect for the integrity and dignity of all actors is the foundation for a new way of working together. With mutual respect established, conflicts that arise can be dealt with in a constructive way. This also includes an understanding for the organizational constraints of participating stakeholders' institutions.

- Balancing power is crucial for the necessary rearrangement of dysfunctional interaction patterns among stakeholders. Balance is leveraged in multi-stakeholder collaborations when power differences are made transparent and weaker stakeholders are deliberately strengthened. Ignoring differences in power and capacity deteriorates the relationship between the stakeholders. Ensuring that weaker stakeholders have a voice and are adequately represented may at times mean that initiatives need to deliberately engage in advocacy support for those weaker stakeholders.

- Mutual understanding leverages the Compass aspect of empathy and is a practice that can be anchored in multi-stakeholder collaborations through process architectures that emphasize dialogue. Going the extra mile to understand how different stakeholders look at the same issue may not always be easy, but is indispensable for success. Openness to listening to other stakeholders' viewpoints is a necessary learning journey for all involved. Exposure to the conditions, worldviews, and operational conditions of other stakeholders helps to foster mutual support.

Table 5.5 shows how the collaboration catalyst collective value can be enhanced through paying attention to the supporting practices. 
Table 5.5 Making the collaboration catalyst "collective value" work

\begin{tabular}{|c|c|c|}
\hline $\begin{array}{l}\text { Enhancing appreciative } \\
\text { approaches }\end{array}$ & Enhancing balancing power & $\begin{array}{l}\text { Enhancing mutual } \\
\text { understanding }\end{array}$ \\
\hline
\end{tabular}

Collective value means ensuring that the transformative change process creates value for all stakeholders in the collaboration ecosystem. It is enhanced by appreciative approaches, balancing power, and mutual understanding.

- Acknowledge the different interests of individuals and institutions.

- See all stakeholders as people who can make a difference for a transformed future.

- Respect individual or organizational constraints.

- Acknowledge the contribution of weaker partners.
- Stay aware of power differences.

- Ensure in process architectures that voices of weaker stakeholders get heard.

- If need be, organize or support advocacy for weaker stakeholders.

- Build capacity for weaker stakeholders to join the collaboration.

- Ensure value creation for all stakeholders.
- Make the effort to understand the operational logic of participating stakeholder institutions.

- Build into process architectures space for mutual learning about participating stakeholders' institutional cultures.

- Help stakeholders to acknowledge cultural differences.

- Build into process architectures the exposure to world-views, living conditions, and constraints of different stakeholder groups.

\section{CASE EXAMPLE 5.4: STRENGTHENING YOUTH ORGANIZATIONS}
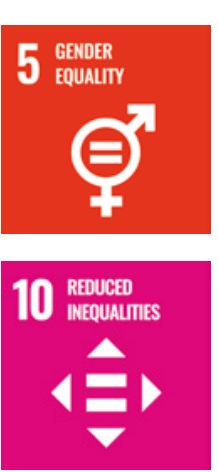

$12 \begin{aligned} & \text { RESPONSIBLE } \\ & \text { CONSUMPIION }\end{aligned}$ AND PRODUCTION Q0

In the aftermath of the Arab Spring, a public-civic collaboration platform on sustainable urban development in Tunisia adopted a new constitution that called for public participation and good governance mechanisms. However, Tunisian youth remained marginalized in local development processes and traditional power dynamics between citizens and public administration officials mostly continued unchanged. The urban youth NGO We Love Kairouan (http:// welovekairouan.org/en/) initiated and facilitated a youth-led platform for public-civic dialogue on the sustainable development of the historic city center in Kairouan that featured the contribution of local youth for the creation of collective value for the city. Their strong focus on appreciating the fears of administration officials of losing power, as well as including exercises on mutual appreciation in all meetings ensured trust-building, mutual understanding, and respect for the enormous potential the youth could add. 


\section{Collaboration catalyst \#5: dialogic communication}

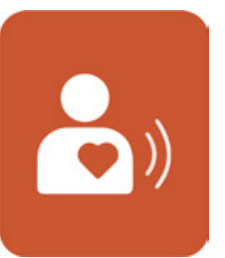

The importance of high-quality dialogue and skilled communication as success factors for multi-stakeholder collaboration has already been heavily stressed. The fifth collaboration catalyst - dialogic communication - is best enhanced by diving deep into Chapter 3 and ensuring as many stakeholders as possible gain skills in dialogic process facilitation. Any change initiative requires dialogue, but as collaboration ecosystems are

built across the boundaries of institutions and societal sectors, the capacities for constructive dialogue are even more important. This area of activity refers to the Compass Dimension of collective intelligence and, at a deeper level, relates to the aliveness principle of contextual interconnectedness. The lesson from many multi-stakeholder collaborations is that progress cannot be built on convincing others to follow a predefined goal, strategy, or action plan, but rather must be built on the broad willingness to cocreate new pathways into the future (Kuenkel et al., 2011; Kuenkel, 2016, 2019). Reliably taking into account the recommendations, expertise, knowledge, perspectives, or learnings from different stakeholders not only strengthens the collaboration ecosystem, but also invigorates the Compass aspects of agility, iterative learning, contextuality, and mutual support. The collaboration catalyst dialogic communication is enhanced by the three supporting practices of structured dialogue, governance mechanisms, and collective learning.

- Structured dialogue leverages dialogic quality and is the core element of good process architectures. The process management for understanding differences as well as consensus building, vision development, and planning action is the lifeblood of multi-stakeholder collaborations. Skilled dialogic process facilitation, by stakeholders or external professional facilitators most often eases the road to success. Moreover, collaboration ecosystems require agreed and transparent rules of communication within and beyond the participating stakeholders.

- Governance mechanisms leverage diversity of stakeholders in a structured way and contribute significantly to the credibility of any multi-stakeholder collaboration. This is reflected in decision-making, process reviews, and mechanisms of conflict resolution. In complex multi-stakeholder collaboration, this requires formal structures such as steering committees and advisory councils, as described in Chapter 4. This ensures different perspectives and expertise are acknowledged and integrated.

- Collective learning leverages the many forms of reflection on process and progress that need to be cultivated to gauge systems aliveness and adjust process architectures accordingly. Success hinges on regular joint reviews of roles, purpose, and procedures. These become the bases for empowering monitoring systems that are fully owned by the collaboration ecosystems, but can also include on external evaluations that are agreed to by and then discussed by all stakeholders.

Table 5.6 shows how the collaboration catalyst dialogic communication can be enhanced through paying attention to the supporting practices. 
Table 5.6 Making the collaboration catalyst "dialogic communication" work

\begin{tabular}{lll}
\hline $\begin{array}{l}\text { Enhancing structured } \\
\text { dialogue }\end{array}$ & $\begin{array}{l}\text { Enhancing governance } \\
\text { mechanisms }\end{array}$ & Enhancing collective \\
\hline
\end{tabular}

Dialogic communication means ensuring communication architectures that acknowledge diversity and create cohesion in the collaboration ecosystem. It is enhanced by structured dialogue, governance, and collective learning.

- Ensure that the events in process architectures are designed for consensusbuilding and joint purpose formation.

- Cultivate listening and integrating different perspectives.

- Establish transparent and regular communication mechanisms.

- Make sure dialogue is the core approach to agreements, implementation reviews, and conflict resolution.

- Agree on rules for external communication among all relevant stakeholders.
- Establish transparent decision-making structures.

- Create collaborative and representative governance structures (Phase 3).

- Ensure the utilization of complementary knowledge, competencies, and resources.

- For complex collaboration initiatives, establish multi-level governance mechanisms.

Transparently inform stakeholders about plans, decisions, and progress.
- Create process architectures that include joint review of progress, roles, purpose, and procedures.

- Regularly review strategies and theories of change with key stakeholders.

- Regularly conduct process monitoring together with key stakeholders.

- Ensure that process architectures include events for mutual learning and exchange.

\section{CASE EXAMPLE 5.5: NETWORKING FOR BETTER HEALTH SERVICE}

GOOD HEALTH

AND WELl-BENG

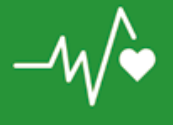

Supported by the EU, the Government of the Ukraine embarked on a decentralization reform program that included the improvement of service delivery in the health sector. In order to support the strengthening of institutional capacity as well as cross-institutional cooperation, a network of change agents was formed consisting of health care professionals, civil society activists, representatives of provinces, and local administrations. The group of diverse actors in support of the health care reform was conceived as a voluntary informal network that would ease dialogue and communication between sectors and institutions. Moreover, they built competence for collaboration and the collective stewarding of the complex change processes for implementing the reform.

\section{Collaboration catalyst \#6: contextual impact}

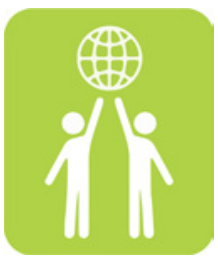

Multi-stakeholder collaborations need to show their relevance and complementary contribution to a larger transformation context. Not that vision and goals might not be ambitious and connected to the respective SDGs, but often, engaged stakeholders lose sight of other actors who may be trying to do something 
similar. Particularly with the advent of more collaboration initiatives that aim to implement the SDGs, there is a danger that collaboration initiatives around one particular issue of common concern narrow the focus and lose sight of the larger SDG context. Funding mechanisms that focus on a certain issue or target group can exacerbate this danger. Hence, the collaboration between multistakeholder collaborations is an important factor that, ultimately, will increase impact. The sixth collaboration catalyst - contextual impact - means continuously taking note of what other actors are doing, connecting with them for learning, and developing wider impact strategies together. This refers to the Compass dimension of wholeness, and, at a deeper level, relates to the aliveness principle of mutually enhancing wholeness. Success in SDG implementation is much more likely when various activities see themselves as part of a wider transformation ecosystem. The collaboration catalyst contextual impact is enhanced by the three supporting practices of context relevance, capacity development, and impact focus.

- Context relevance leverages the Compass aspect of contextuality and requires constant attention to changes in the system throughout all four Phases. Collaboration ecosystems need to have clear issue-related identities, but also ensure all stakeholders have state-of-the art knowledge about how others are approaching the issues or challenges and who else is active in the field of activities. This includes updates through research, stakeholder interviews, or exchange with other initiatives. In more complex collaborations this means well-planned integration of global and local activities.

- Capacity development leverages the Compass aspect of mutual support and is crucial for collaboration initiatives to succeed. This is about expertise in the issue, but evenly important is competence building for dialogic process facilitators. Anchoring the understanding of process quality among many stakeholders is paramount and invigorates their willingness to support each other on the route to impact. This includes bringing the collaborative approach into the respective institutions of the different stakeholders.

- Impact focus leverages the Compass aspect of contribution and is the true underlying intention of multi-stakeholder collaborations that needs to be continuously renewed and revived. In the day-to-day management of implementation, particularly in Phase 3, with delivery pressure and time-consuming consensus building, the actual aspiration of joint impact might at times move into the background. This is why iterative learning mechanisms such as strategic reviews or learning and innovation events are important. They help actors stay in touch with the specific context and the larger picture.

Table 5.7 shows how the collaboration catalyst contextual impact can be enhanced through paying attention to the supporting practices. 
Table 5.7 Making the collaboration catalyst "contextual impact" work

Enhancing context relevance Enhancing capacity building Enhancing impact focus

Contextual impact belongs to the Compass dimension of wholeness. It means ensuring the relevance for and the embeddedness of the Collaboration Ecosystem in larger transformations. It is enhanced by context relevance, capacity building, and impact focus.

- Regularly update the understanding of the context.

- Look out for similar and other relevant initiatives.

- Bring change initiatives at multiple levels into one coherent approach (top-down and bottom-up or local/national/ international)

- Build learning and communication between levels of interventions into process architectures.

- Create meta-collaboration with other initiatives.
- Understand the different capacities of stakeholders and their institutions.

- Build content-specific, as well as collaboration capacity building, into process architectures.

- Support stakeholders to anchor the collaboration initiative into their respective institutions.

- Utilize the strength and expertise of stakeholder institutions for complementary implementation.
- Regularly adjust and adapt the theory of change.

- Focus on mutual benefits and take a long-term perspective.

- Integrate the updated understanding of the context into regular joint strategy reviews.

- Ensure results and impact monitoring (end of Phase 3).

- Keep the contribution to a larger emotionally compelling goal high on the agenda.

- Jointly agree on scaling-up strategies (Phase 4).

\section{CASE EXAMPLE 5.6: BUILDING STRONG INSTITUTIONS}

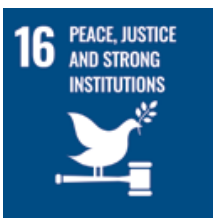

Countering Organized Crime in the Western Balkans remains a challenge, as the region is a key thoroughfare for organized crime organizations, in particular regarding human trafficking, illegal drugs, and weapons. Any approach to counteract the challenges requires looking beyond the individual countries. Serbia, Bosnia and Herzegovina, Albania, Montenegro, Kosovo, and the Republic of North Macedonia agreed to coordinate their efforts in reducing organized crime across the region. In addition to national as well as regional security, and despite their different interests, they were also pursuing individual country-related goals as prerequisites for joining the European Union, for which the reduction of organized crime rates plays an important role.

Figure 5.3 shows how the different layers of Compass dimensions, systems aliveness principles, and the more practical collaboration catalysts belong together in the way they create an effect for collaboration ecosystems to thrive and achieve results. These catalysts are an ideal basis for establishing a sense of quality collaboration among stakeholders busy trying to achieve results and concerned with creating collaboration ecosystems that can deliver change. As part of reflection and learning mechanisms, the quality of this kind of collaboration can be monitored. This is why the next section looks at the role of monitoring in multi-stakeholder collaborations. 


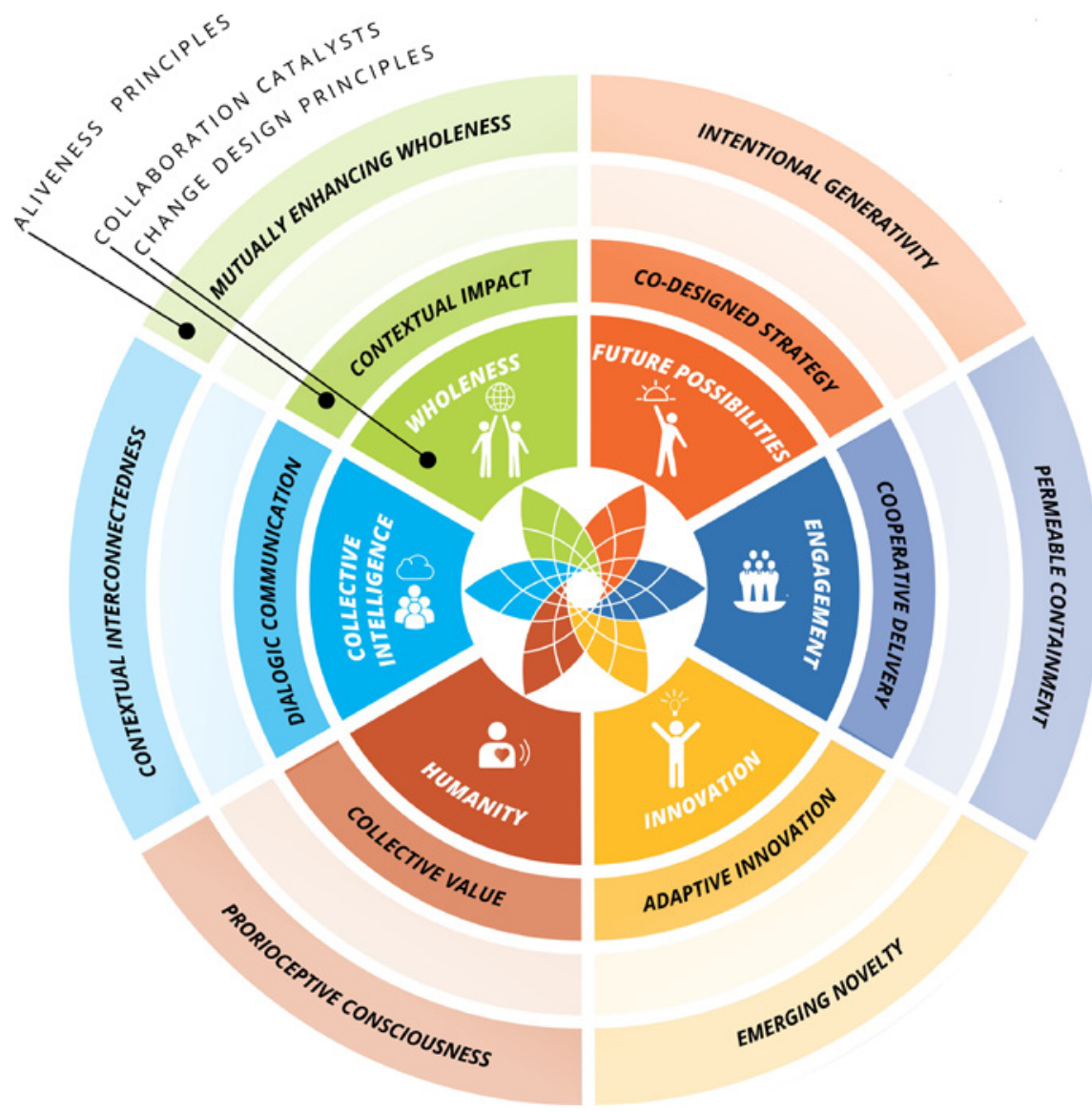

Figure 5.3 The collaboration catalysts matching with Compass dimensions and aliveness principles

\section{The role of process monitoring in multi-stakeholder collaboration}

Monitoring and evaluation procedures are familiar to most stakeholders in collaborative SDG implementation initiatives. The procedures as such might differ in their form and focus, but the main characteristics remain the same: monitoring serves the need to find shared instruments for measuring progress, tracking implementation, adjusting strategies, and ensuring learning. When introducing monitoring systems in multi-stakeholder collaboration, funders and stakeholders need to be mindful in their contribution to create a collective learning culture for collaboration ecosystems. Most often, monitoring and evaluation are seen to belong together, however, it is not only important to understand the difference despite fluid boundaries, as described in Box 5.1, and also be clear of the different purposes of monitoring as such. In addition, actors in multi-stakeholder collaboration need to be aware that different stakeholder constituencies, such as governments, development agencies, NGOs, community organizations, and private sector actors may have different approaches to monitoring. The general underlying idea of monitoring is to check if a project, program, or 


\section{Box 5.1 Monitoring and evaluation according to the OECD}

The OECD (2002) defines monitoring and evaluation as follows:

"Monitoring is a continuous function that uses the systematic collection of data on specified indicators to provide management and the main stakeholders of an ongoing development intervention with indications of the extent of progress and achievement of objectives and progress in the use of allocated funds."

"Evaluation is the systematic and objective assessment of an ongoing or completed project, program, or policy, including its design, implementation, and results. The aim is to determine the relevance and fulfillment of objectives, development efficiency, effectiveness, impact, and sustainability. An evaluation should provide information that is credible and useful, enabling the incorporation of lessons learned into the decision-making process of both recipients and donors."

(p. 21)

initiative delivers on the stated objectives. But the details are much more complicated. Multi-stakeholder collaboration initiatives, in many instances, require funding by governments, NGOs, international organizations, or even companies (Kuenkel, 2017). Hence, the funder's requirements need to be met, for example, by clearly stating theories of change and elaborating log-frames with indicators (see Chapter 4) that show the often-quantitative difference between the current state and the future to-be-achieved state. As the previous chapters have elaborated, this may, at times, be challenging, because multi-stakeholder collaborations are more complex and more difficult to plan than simpler projects. Process quality, iterative learning, planning flexibility, and the continuous engagement of new stakeholders are difficult to break down into measurable indicators. Similarly, the essential dialogic quality, the empowerment of weaker stakeholders, and the crucial ways of cultivating a sense of future possibilities that help actors to shape the change ahead collectively might escape the rigidity of monitoring requirements. However, multi-stakeholder collaborations also aspire to tangible results, hence it is important to find monitoring systems that satisfy funders and help the collaboration ecosystem learn at the same time.

Experiences from multi-stakeholder collaborations suggest that the adoption of monitoring systems should take the particularity and complexity of each individual multi-stakeholder collaboration into account on its own. A few ground-rules help monitoring systems really serve their purpose and enhance effectiveness.

- Firstly, it is important to not introduce monitoring too early in the process of collaborative change. As long as stakeholders or dialogic process facilitators are busy building trust and relationships in Phase 1 of Exploring and Engaging, the introduction of a monitoring tool can endanger the process unless it is done in a small 
and very committed container. At a later stage, in Phase 2, and certainly in Phase 3, once the collaboration ecosystem has been established and is implementing action plans, monitoring can actually enhance trust and stabilize the collaboration ecosystem as making progress monitoring transparent supports the reliability of the approach.

- Secondly, an important condition for success is ensuring that the form of monitoring is agreed upon by all relevant stakeholders and is not determined by one party alone, even if this is part of their funding requirements. Particularly, in complex or even conflictual multi-stakeholder collaborations, the introduction of monitoring tools requires the commitment of at least the key stakeholders. This also reduces the fear of outside control.

- Thirdly, it is important to use monitoring instruments that all stakeholders can understand. This may, at times, not be easy, as different stakeholder constituencies may have different opinions about what is easily understandable. Most NGOs are used to measuring progress according to indicators established in project proposals, while for private sector actors it is more common to talk about milestones and assess their achievements. Community organizations may have value systems that do not appreciate any focus on facts and figures, but expect change to be measured qualitatively. International companies, however, often require reporting back to their management with dash-boards full of figures.

- Hence, fourthly, it is important to respect that all participating institutions will have their own style of monitoring and the approach to a joint monitoring system needs to cater for these differences.

Introducing monitoring procedures systems into multi-stakeholder collaborations can be a challenge. It is far more complicated than doing this for one particular organization, as different stakeholders will have different assumptions about how change can happen (see Chapter 4) and, subsequently, how it can be tracked. Emerging collaboration ecosystems are, particularly in the beginning, fragile and loose systems that depend on consensual agreements. If trust is low or if stakeholders are ambivalent towards the collaborative approach, a proposal to introduce monitoring systems can further endanger the process, as some stakeholders might perceive this as pressure to perform, an attempt to manipulate, or an exertion of undue power or influence. However, as with all change processes, multi-stakeholder collaborations need to track progress. The benefits of introducing monitoring tools are as follows:

- Stakeholders can see progress: this, in turn, increases commitment to contribute more.

- Stakeholders become more aware of critical success factors for thriving collaboration ecosystems: as their understanding of the potential of collaboration increases, they become more capable of participating and contributing to functional patterns.

- Funders or external supporters feel more trust: the building of confidence in the delivery capacity of collaboration ecosystems is an important issue in sourcing and maintaining the finances and resources required for implementation. It also keeps high-level sponsors and supporters on board. 
One can broadly distinguish between three different, but mutually supportive approaches to monitoring in multi-stakeholder collaboration.

- Activity and Result Monitoring: the purpose is to keep track of the activities agreed upon and to assess the results achieved.

Here, most of the known instruments of monitoring and evaluation can be used. It is important to track agreements signed, road maps, as well as operational and implementation plans. Jointly looking at activities and results should be part of the regular meetings of stakeholders in Phase 2 and Phase 3. Often, a designated process- or projectmanagement team or secretariat or a steering committee is tasked with monitoring progress. At the beginning of each larger stakeholder meeting or steering committee meeting, the container or a process secretariat usually provides an overview of the progress made. Activity monitoring can already start in Phase 1 for the container and needs to be agreed upon among stakeholders as an essential element in Phase 2 and Phase 3.

- Impact Monitoring: the purpose is to look beyond activities and results, and to assess if multi-stakeholder collaborations have had the effect they were expected to have. It is often used synonymously to evaluation.

Impact monitoring enables stakeholders to observe desired or undesired changes. It creates a foundation for discussions around such changes, and, subsequently, a basis for adjusting, planning, and implementation, for reviewing approaches, or for creating the basis for continuous learning in Phase 3. It becomes the basis for designing particularly in Phase 4 of Sustaining and Expanding Impact. As multi-stakeholder collaborations are fragile and complex systems, impact monitoring can only start when the collaboration system is stable enough, stakeholders trust each other sufficiently, and implementation in Phase 3 has already led to visible results. Impact monitoring can be done from within the circle of key stakeholders, or, if jointly agreed upon, by external actors in the form of an evaluation. Impact-monitoring can build on participatory instruments available (Khandker et al., 2010) and is best started during or at the end of Phase 3.

- Process Monitoring: the purpose of monitoring the process is to keep track of the quality of process architectures towards increasing systems aliveness, and the quality of collaboration patterns. It helps key stakeholders to understand the role of process better and to check which interventions help to ensure that the collaboration is leading towards the expected outcome.

Process monitoring is therefore done as a collective assessment and fosters awareness of and commitment to high quality collaboration patterns. It enables the container to stay in tune with success factors for collaboration and to keep track of the best possible process. If done well, it contributes to building and maintaining an enlivening learning culture among the stakeholders. It also supports the agility to adjust strategies according to insights gained. Process monitoring improves outcomes and helps to manage the collective stewarding of the process. 
Table 5.8 Different types of monitoring in multi-stakeholder collaboration

\begin{tabular}{|c|c|c|c|}
\hline Type of monitoring & Purpose & Tools & Guiding questions \\
\hline $\begin{array}{l}\text { Activity- and } \\
\text { result monitoring }\end{array}$ & $\begin{array}{l}\text { Keeps track of } \\
\text { activities agreed } \\
\text { upon and } \\
\text { evaluates results } \\
\text { achieved }\end{array}$ & $\begin{array}{l}\text { Any known monitor- } \\
\text { ing system applica- } \\
\text { ble in the respective } \\
\text { context can be used } \\
\text { and should refer to } \\
\text { the agreed-upon } \\
\text { plans. }\end{array}$ & $\begin{array}{l}\text { - Did we do what we } \\
\text { agreed to do in the } \\
\text { implementation/ action } \\
\text { plan of the collaboration } \\
\text { initiative? } \\
\text { - Are our plans leading } \\
\text { to the agreed-upon } \\
\text { outcomes? }\end{array}$ \\
\hline $\begin{array}{l}\text { Impact } \\
\text { monitoring }\end{array}$ & $\begin{array}{l}\text { Looks beyond } \\
\text { activities and } \\
\text { results and } \\
\text { assesses if a } \\
\text { collaborative } \\
\text { change led to } \\
\text { the envisioned } \\
\text { impact }\end{array}$ & $\begin{array}{l}\text { - Can be done in a } \\
\text { participatory way } \\
\text { by stakeholders } \\
\text { involved, or, if jointly } \\
\text { agreed upon, by } \\
\text { external experts. } \\
\text { - Uses methods } \\
\text { known and under- } \\
\text { standable to the all } \\
\text { stakeholders }\end{array}$ & $\begin{array}{l}\text { - What effect did the } \\
\text { collaboration have on the } \\
\text { participating institutions, } \\
\text { the beneficiaries, and the } \\
\text { wider community? } \\
\text { - In what way has the } \\
\text { collaboration contributed } \\
\text { to the sustainability goal } \\
\text { that the stakeholders set } \\
\text { out to achieve? } \\
\text { - Has the collaboration } \\
\text { ecosystem delivered its } \\
\text { purpose? }\end{array}$ \\
\hline $\begin{array}{l}\text { Process } \\
\text { monitoring }\end{array}$ & $\begin{array}{l}\text { Keeps track of } \\
\text { the quality of } \\
\text { the process } \\
\text { architecture and } \\
\text { key factors for } \\
\text { success. }\end{array}$ & $\begin{array}{l}\text { - The collaboration } \\
\text { catalysts form the } \\
\text { basis for process } \\
\text { monitoring. } \\
\text { - Can be done in the } \\
\text { form of a collective } \\
\text { assessment among } \\
\text { the container or } \\
\text { key stakeholders in } \\
\text { Phase } 3 \text {. }\end{array}$ & $\begin{array}{l}\text { What is the quality } \\
\text { of the process and } \\
\text { management of the } \\
\text { collaboration? } \\
\text { - Does the process lead to } \\
\text { the expected results and } \\
\text { effect? }\end{array}$ \\
\hline
\end{tabular}

Process monitoring, as with all other forms of monitoring, is based on the continuous observation of qualitative data that can be based on the Compass dimensions or the collaboration catalysts as indicators for high-quality collaboration. The initiators, the core group (container), and the key stakeholders enhance their collaboration literacy when they - together - ensure that the Compass dimensions, indicated in the collaboration catalysts, are sufficiently enacted, and that the steps in the four phases of the Dialogic Change Model are followed. Hence, process monitoring is a key to cultivating a reflective learning culture among stakeholders that helps improve the interaction among stakeholders and, subsequently, the results of the collaboration. It also functions as an early warning system to avoid conflicts and difficulties. 
Process monitoring can start towards the end of Phase 1, if the core group decides to review its collaboration quality with a group assessment based on Compass dimensions, or the quality of the entire collaboration with the collaboration catalysts. Throughout the four phases of the Dialogic Change Model both can be applied and re-applied at different stages. Most importantly, the collaboration catalysts provide a reflective tool for key stakeholders in Phase 3. Applied in a complementary way with activity and result monitoring, it will then become an innovative basis for learning together, which increases the commitment to participation and implementation.

The following deep dives illustrate the practical application of such process monitoring. The first deep dive elaborates a self-assessment (done individually and collectively) that can be used to gauge the quality of collaboration in a core group based on the Compass dimensions. The second deep dive looks at process monitoring for the entire multi-stakeholder collaboration initiative. This is based on individual and collective assessments with the collaboration catalysts as indicators. Both help stakeholders to better manage conditions for success.

\section{Collaboration quality check 1: self-assessment for core groups}

Core groups or containers are the nucleus for the collaboration pattern that emerges among stakeholders. Because they are a microcosm of the stakeholder system, collaboration challenges in core groups often mirror the challenges in the interaction between stakeholders in a collaboration ecosystem. Yet, leading transformative change collectively requires core groups to function well. High quality collaboration patterns enhance the effectiveness of core groups (containers) to contribute to collaborative sustainability transformations. Successful human agency is built on a lived culture of collective leadership. Checking the collaboration patterns regularly helps improve the quality of collaboration, and invites to reflective conversations. This may be particularly useful to do in Phase 1 (and all other phases) with the core group (container), in Phases 2 and 3 for expert working groups, and in Phase 4 with the new management structure. Any assessment can only be an inspiration for reflection that fosters a learning culture. The steps to conducting the collaboration quality check for core groups are described in the following sections. Table 5.9 contains the actual assessment that members of the core group can use.

Monitoring the quality of collaboration in a core group can be done individually by each member as a basis for a joint conversation of how different actors see the situation. Or it can be done together as an entire group. In both cases, the individual and collective assessment engenders a dialogue on how the situation is perceived and how it could be improved. This is best done by going through the following steps (alternatively see also www.compass-tool.net). 


\section{Step 1: observe and contextualize}

Answer the information about the core group's collaboration purpose, composition, and aspirations.

- What is the context of the collaborative effort your team or core group is operating in?

- What is the purpose of the collaboration ecosystem (your team or core group of key stakeholders)?

- What is the composition of the collaborative multi-stakeholder system?

- If the collaboration improved or became successful, what would be the best possible outcome to achieve?

\section{Step 2: assess and discover}

The 36 descriptions of attention points in Table 5.9 are typical features of collectives that are doing well together while achieving results. They are indicators of a microcosm in which each individual feels valued and the group can take pride in making a difference together that is greater than any of them could do alone. The statements describe features of well-functioning core groups.

- Go through the statements and give a ranking on a scale between 1 (low presence) and 10 (strong presence).

- Calculate the results for each aspect, and for each dimension.

- Highlight the strong aspects and the strong dimensions.

- Show the results on the Compass diagram in Annex 3.

\section{Step 3: reflect and focus}

Reflect on the results and note down or discuss insights about the collaboration pattern you have assessed. Where could be the focus for improvements?

\section{Step 4: generate and enact}

Generate concrete ideas for improvement:

- How could you improve the collaboration pattern?

- How can you appreciate and further strengthen the strong areas in the core group?

- How can you improve the development areas?

Note down or discuss any thoughts or insights that arise in relation to the result.

Write down or agree in the core group which three actions you will take to improve the collaboration pattern (if needed) and note down the time frame for the actions. 


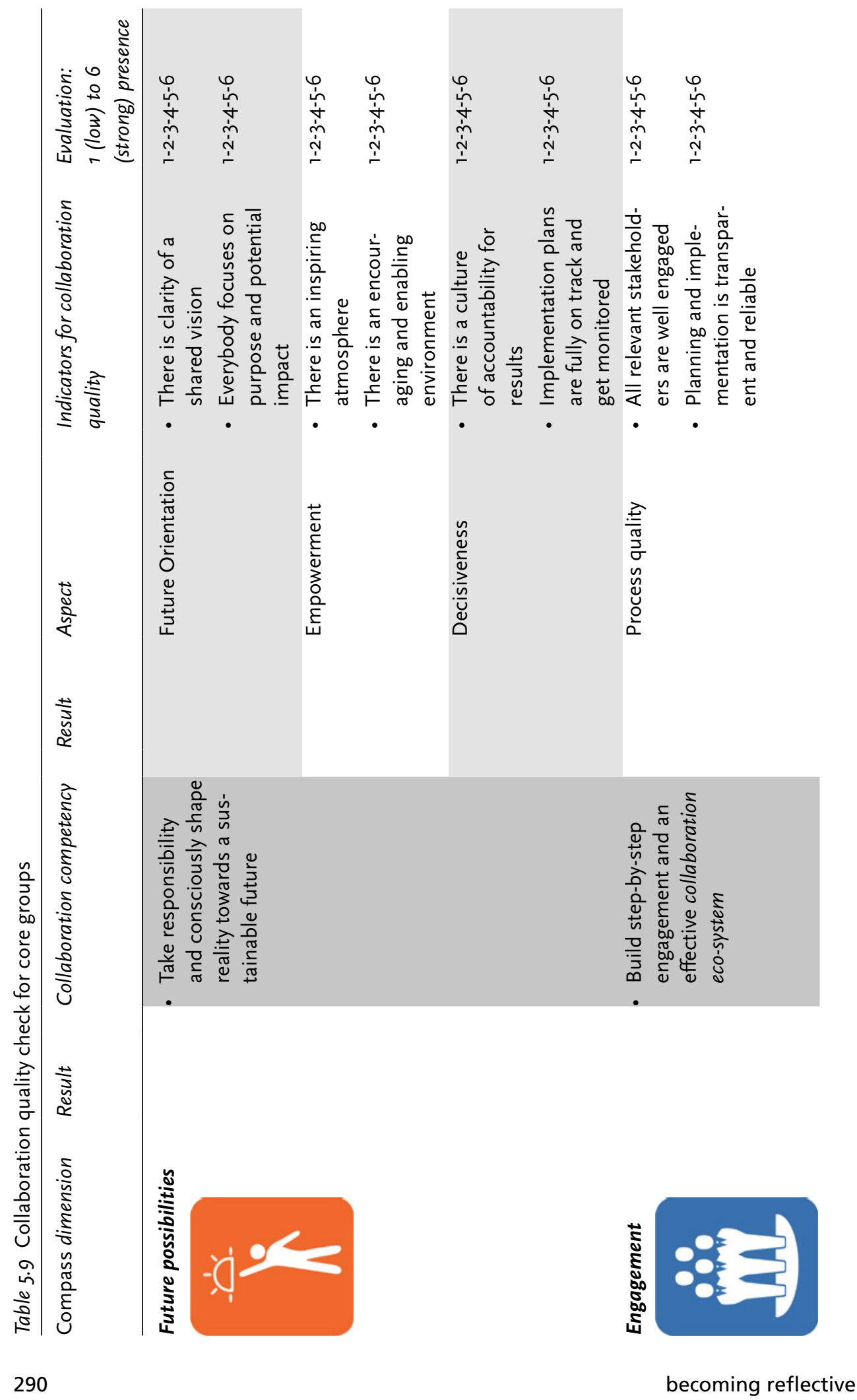




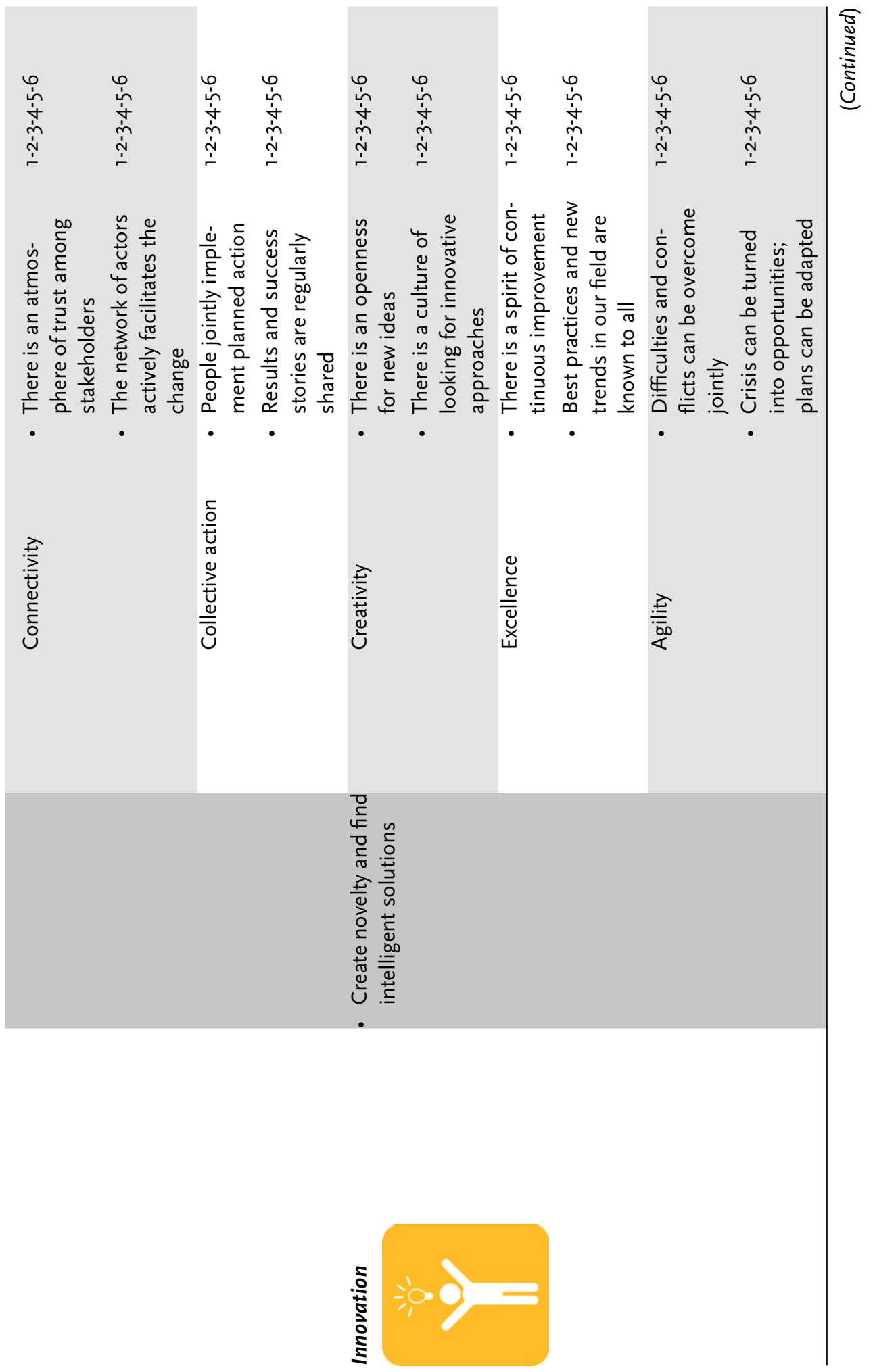




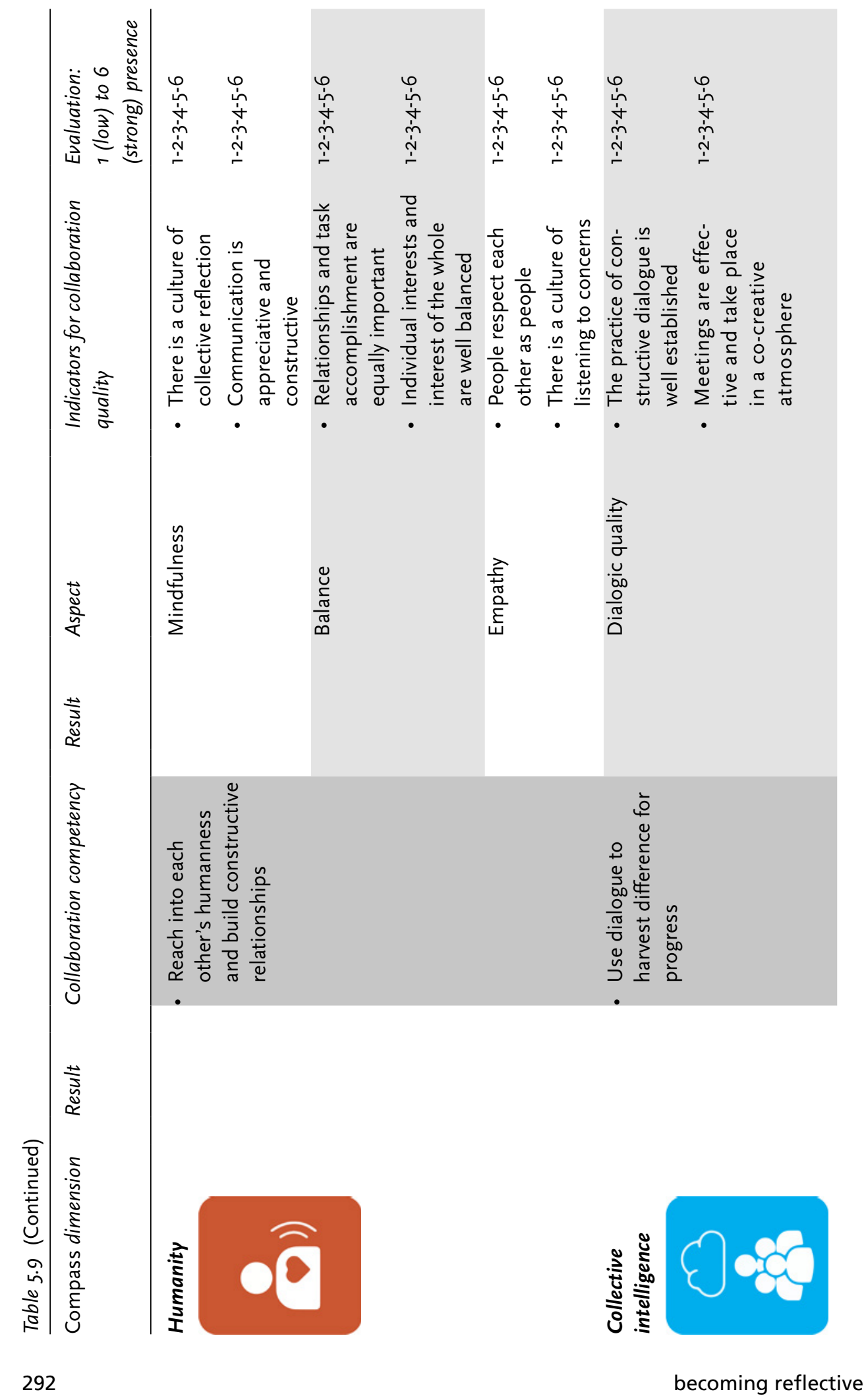



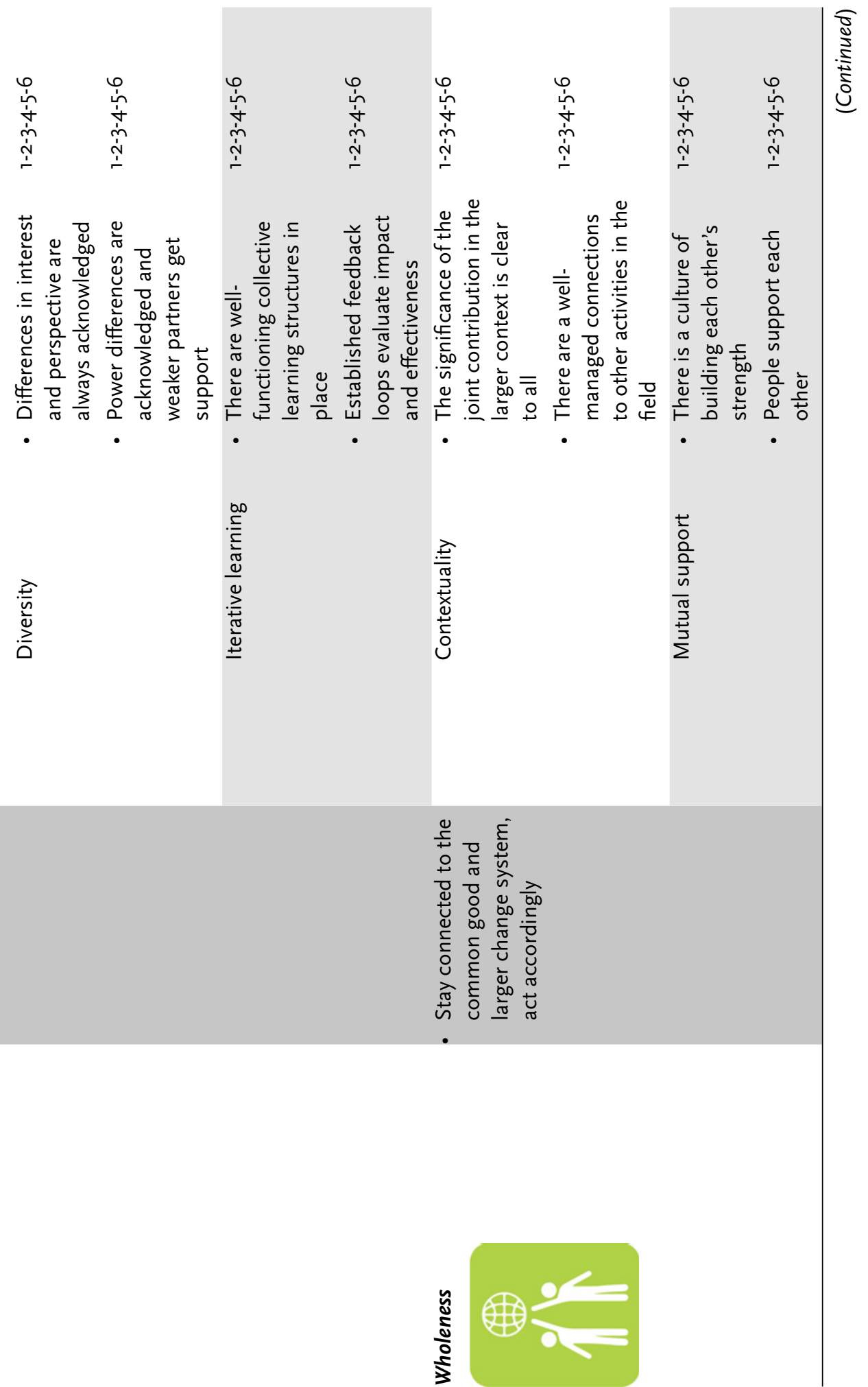


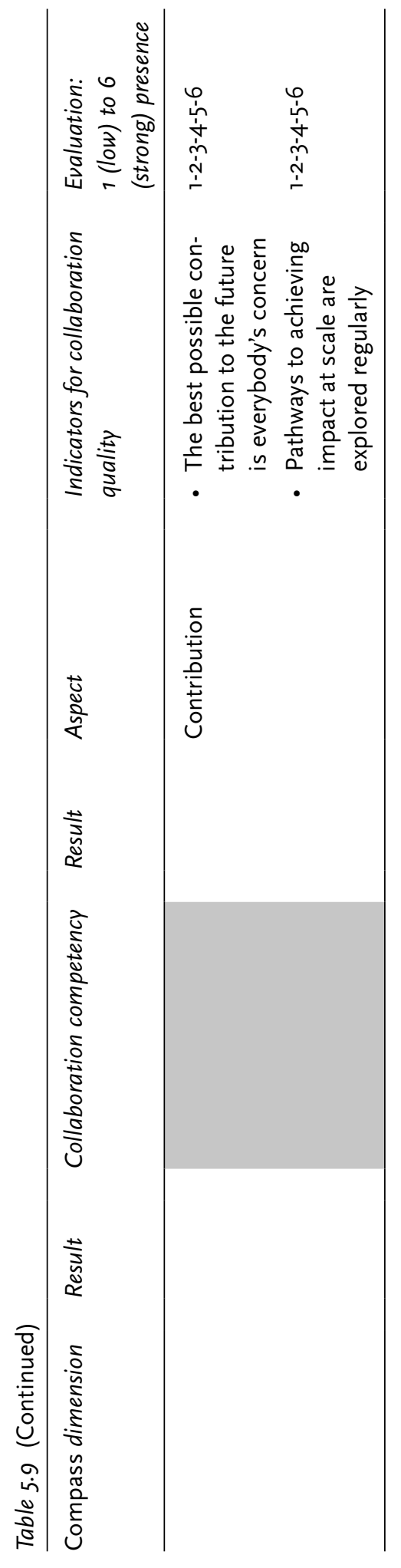




\section{Collaboration quality check 2: assessment for collaboration ecosystems}

The crucial question in process monitoring is not whether interaction and collaboration exists, but whether it is functional and contributes to the system's aliveness. As described in Chapter 3, the diagnosis of systems patterns can be done by answering system-related guiding questions in accordance with the Compass dimensions. The result shows the interaction patterns of a stakeholder system, which then becomes the basis for designing high-quality process architectures as they have been explained in Chapter 4 . Using the collaboration catalysts as a process monitoring does not look at the entire stakeholder system, but focuses on the quality of collaboration within the collaboration ecosystem, hence assesses its functionality. The collaboration catalysts indicate success factors for impactful multi-stakeholder collaborations. They connect the quality of the collaborative process with the quality of the outcomes, and are therefore ideal to use as a process-monitoring tool for collaboration ecosystems. Regular monitoring of the collaborative quality will ensure that key actors take care of outcome-oriented process architectures that help stakeholders to constructively shape the future and create the desired impact. It supports them to look at patterns in systems and interactions between people and guides them to shift these patterns towards systems aliveness. Process monitoring with the collaboration catalysts is best done on a regular basis in Phase 3 when implantation is in full swing. However, as an inspiration of how to improve process architectures, it might already be applied in Phase 2 by the core group or key actors. The results naturally will not yet show a well-functioning collaboration ecosystem, but they may hint towards actions that help build collaboration quality in the best possible way. In any case, process monitoring with the catalysts engenders reflective dialogue, cultivates a learning culture, and helps stakeholders to see the crucial connection between high quality processes and tangible outcomes.

Learning over time and adjusting process architectures is an important faculty to develop. The collaboration catalysts indicate how well the Compass dimensions have been enacted in a collaboration ecosystem. The quality check helps to improve process architectures so that they lead to ownership and commitment. It encourages the observation of both rational and intuitive aspects that influence progress and outcomes of collaboration. The assessment can be done individually, while sharing results in a conversation, or together with key stakeholders. This is best done by going through the following steps (alternative use the application on www.compass-tool.net).

\section{Step 1: observe and contextualize}

Answer the information about the collaboration purpose, composition, and aspirations.

- What is the context of the collaborative effort?

- What is the purpose of the collaboration ecosystem? What are the goals? 
- What is the composition of the collaborative multi-stakeholder system?

- If the collaboration improved or became successful, what would be the best possible outcome to achieve?

\section{Step 2: assess and discover}

High quality collaboration patterns enhance the effectiveness of collaboration ecosystems to contribute to sustainability transformations. The 36 statements in Table 5.10 describe indicators for all six collaboration catalysts.

- Go through the list and give a ranking on a scale between 1 (low presence) and 6 (strong presence)

- Calculate the results for each aspect, and for each dimension and capture them graphically (see also Annex 3 and for an example see Figure 5.4)

- Highlight the strong aspects and the strong dimensions.

- Show the results on the Compass diagram.

\section{Step 3: reflect and focus}

Reflect on the results and note down insights about the collaboration pattern you have assessed individually or together. Create ideas about how some or all of the collaboration catalysts could be improved.

\section{Step 4: generate and enact}

Individually recommend or jointly agree on what will be three priority action steps to improve the collaboration ecosystem and design process architectures accordingly. Decide on the time frame for the action steps.

\section{Trouble shooting guide: managing difficulties in multi-stakeholder collaboration}

Difficulties and conflicts in multi-stakeholder collaborations are normal side effects of contrasting points of view and different, or even opposing, interests. They can cause disagreements and misunderstandings and can complicate implementation. If collaborative change is not given enough attention in preparation and process design stakeholders run the risk of creating stagnant or failing collaboration patterns. Many difficulties can be prevented by applying careful planning with the Dialogic Change Model (see also the readiness checks for each phase in Chapter 2) and the Collective Leadership Compass and by equipping dialogic process facilitators with the skills to facilitate dialogue and lead transformative change collectively. However, multi-stakeholder collaborations remain complex processes and will always need to overcome difficulties 


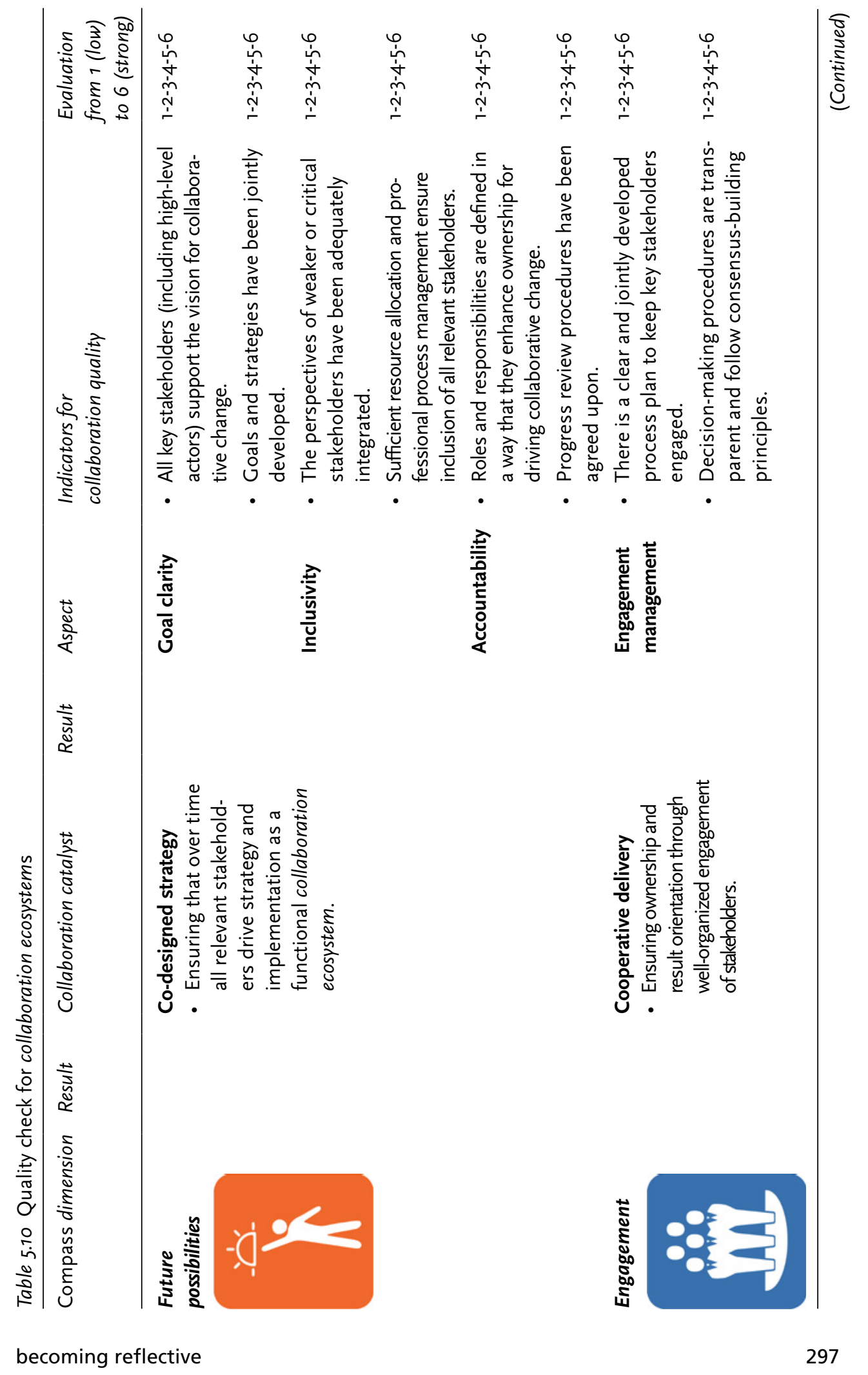




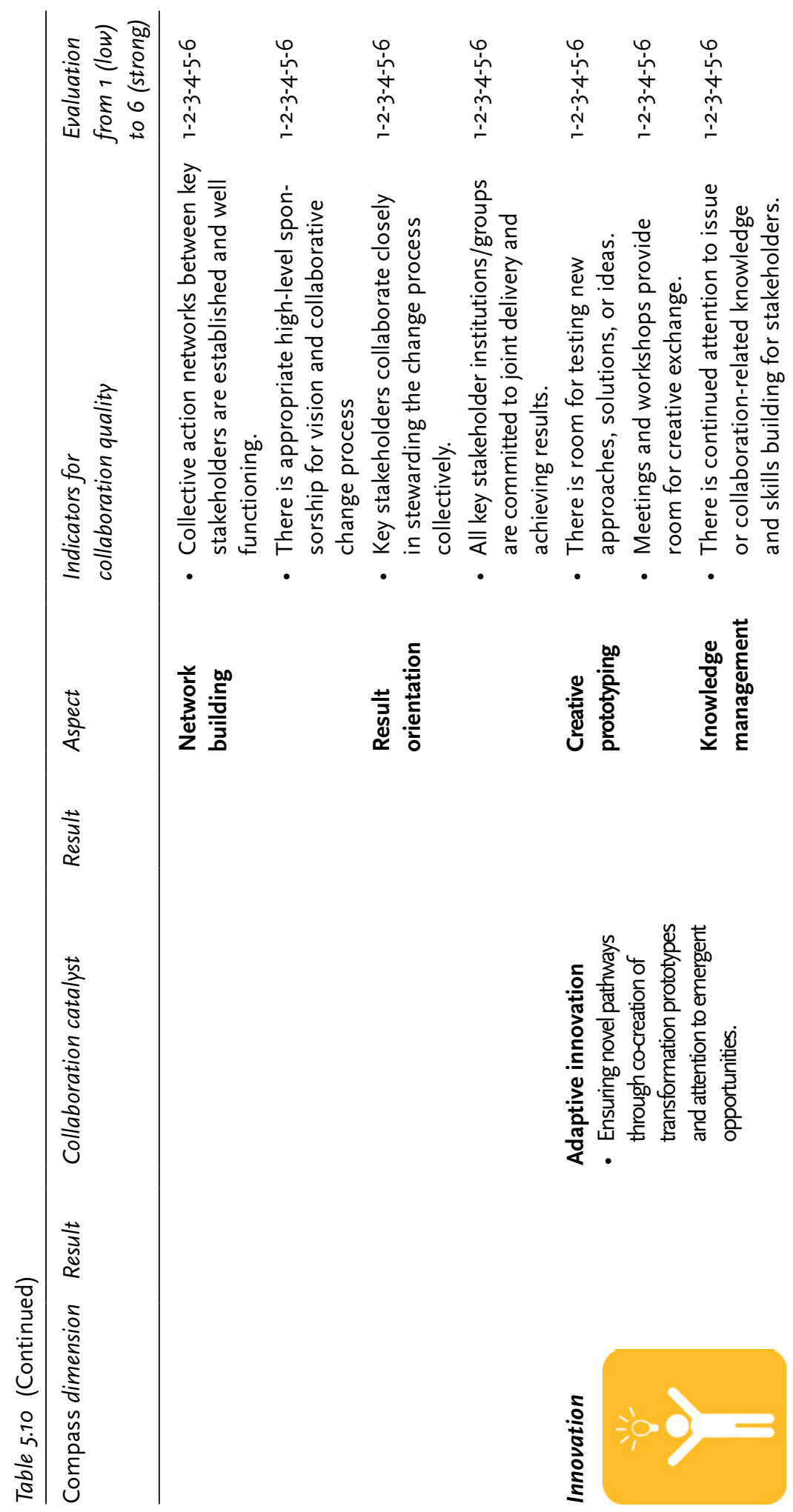



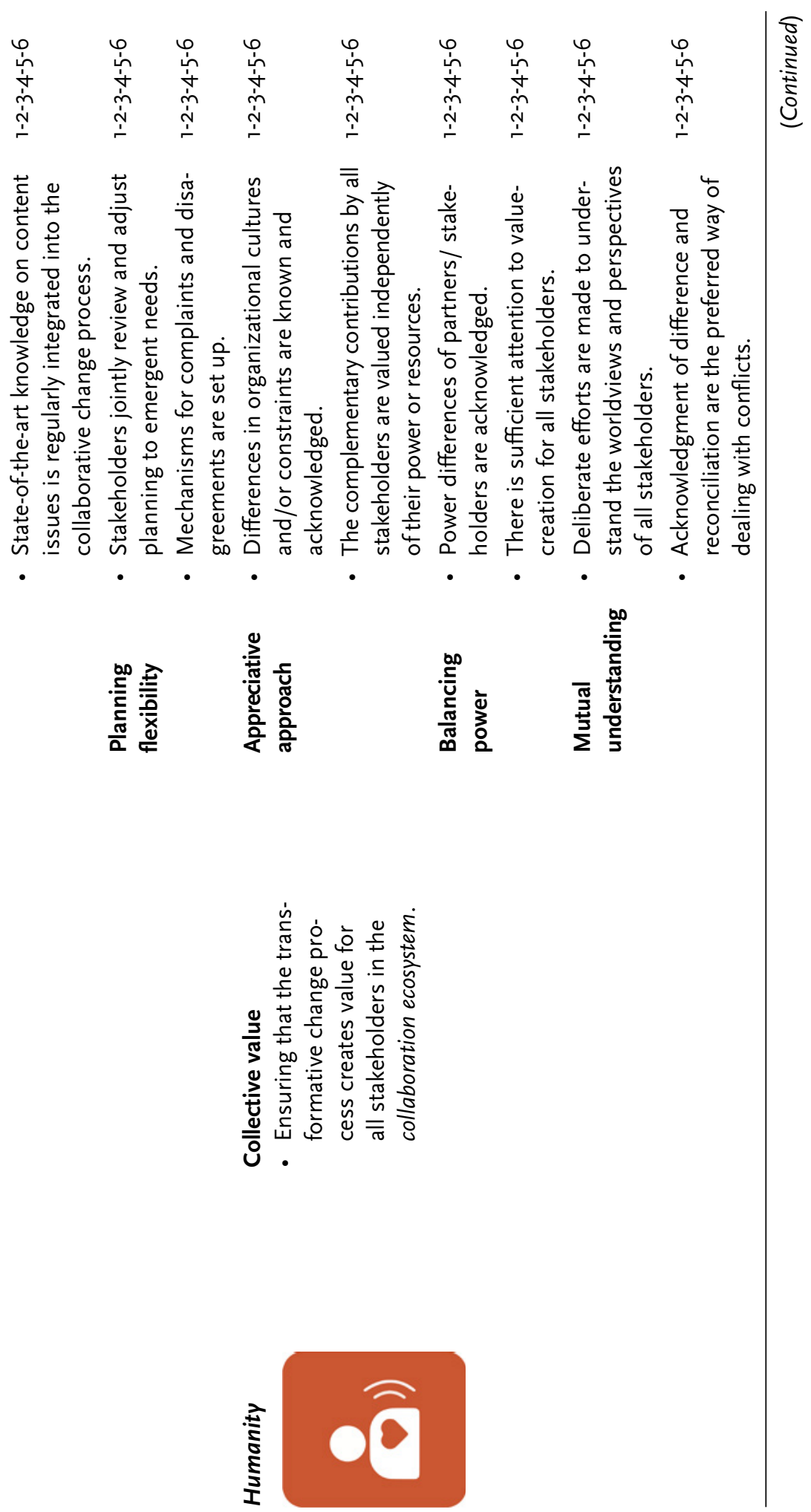


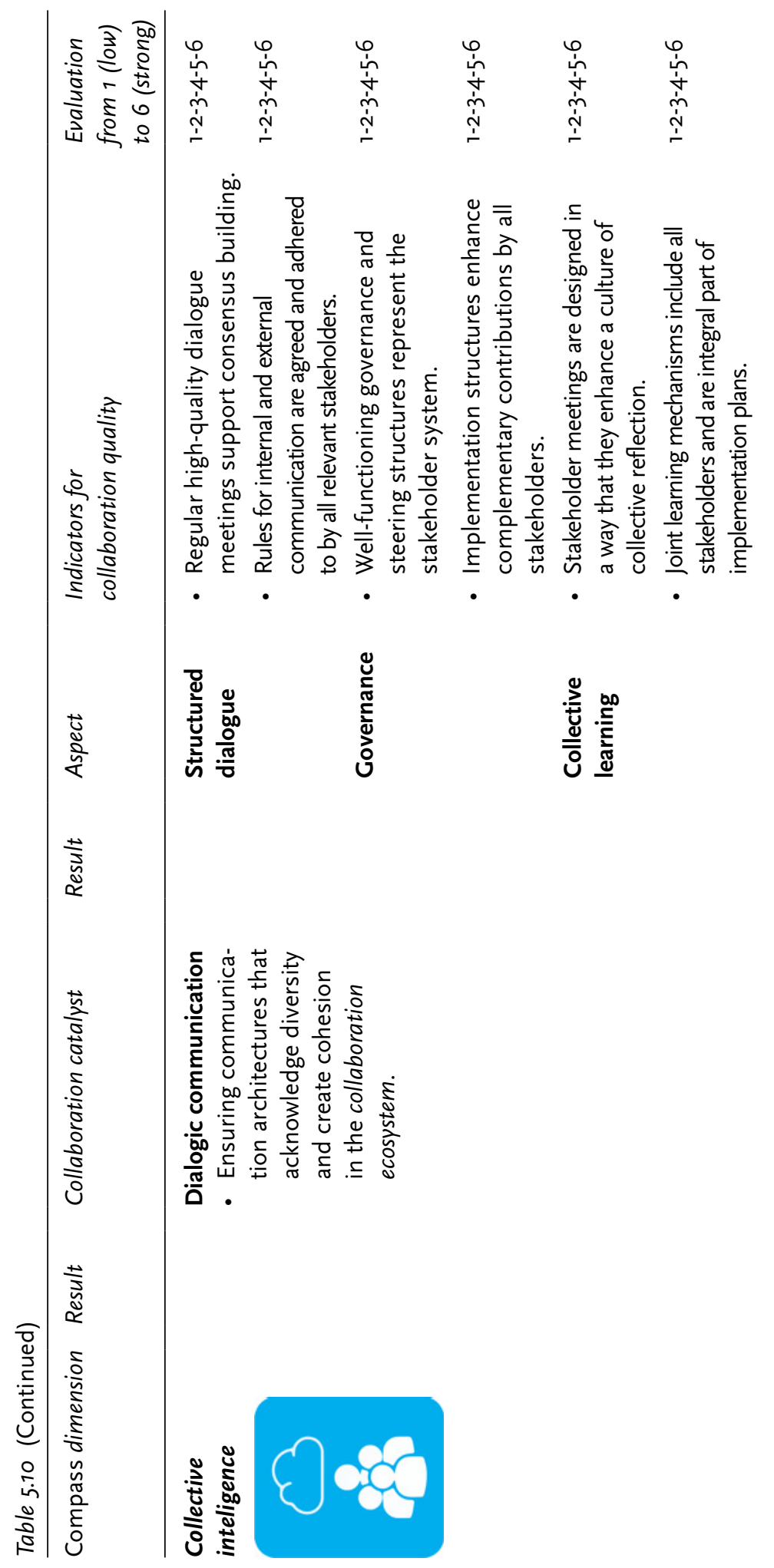




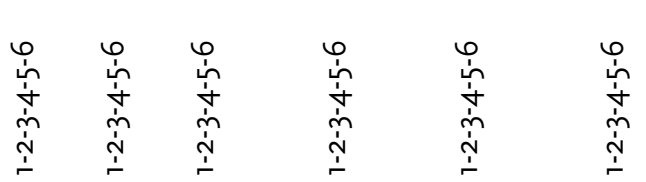

世

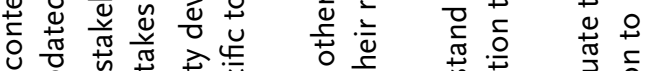

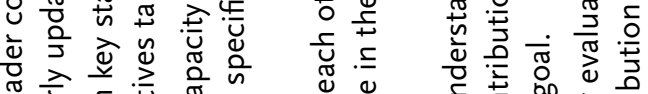

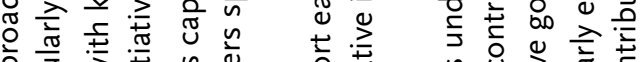

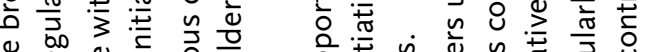

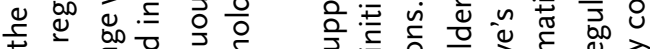

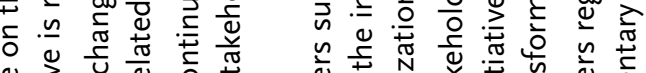

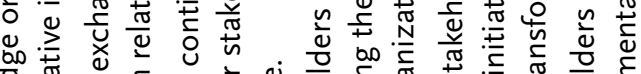

O

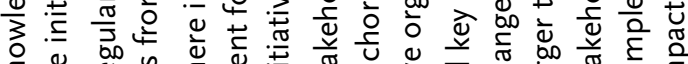

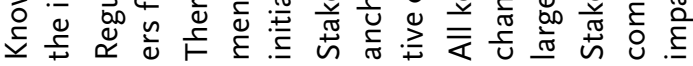

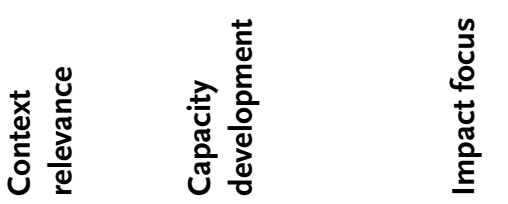

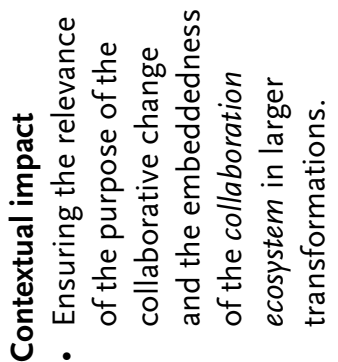

$\frac{\tilde{y}}{\frac{\tilde{u}}{2}}$

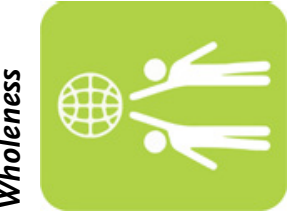




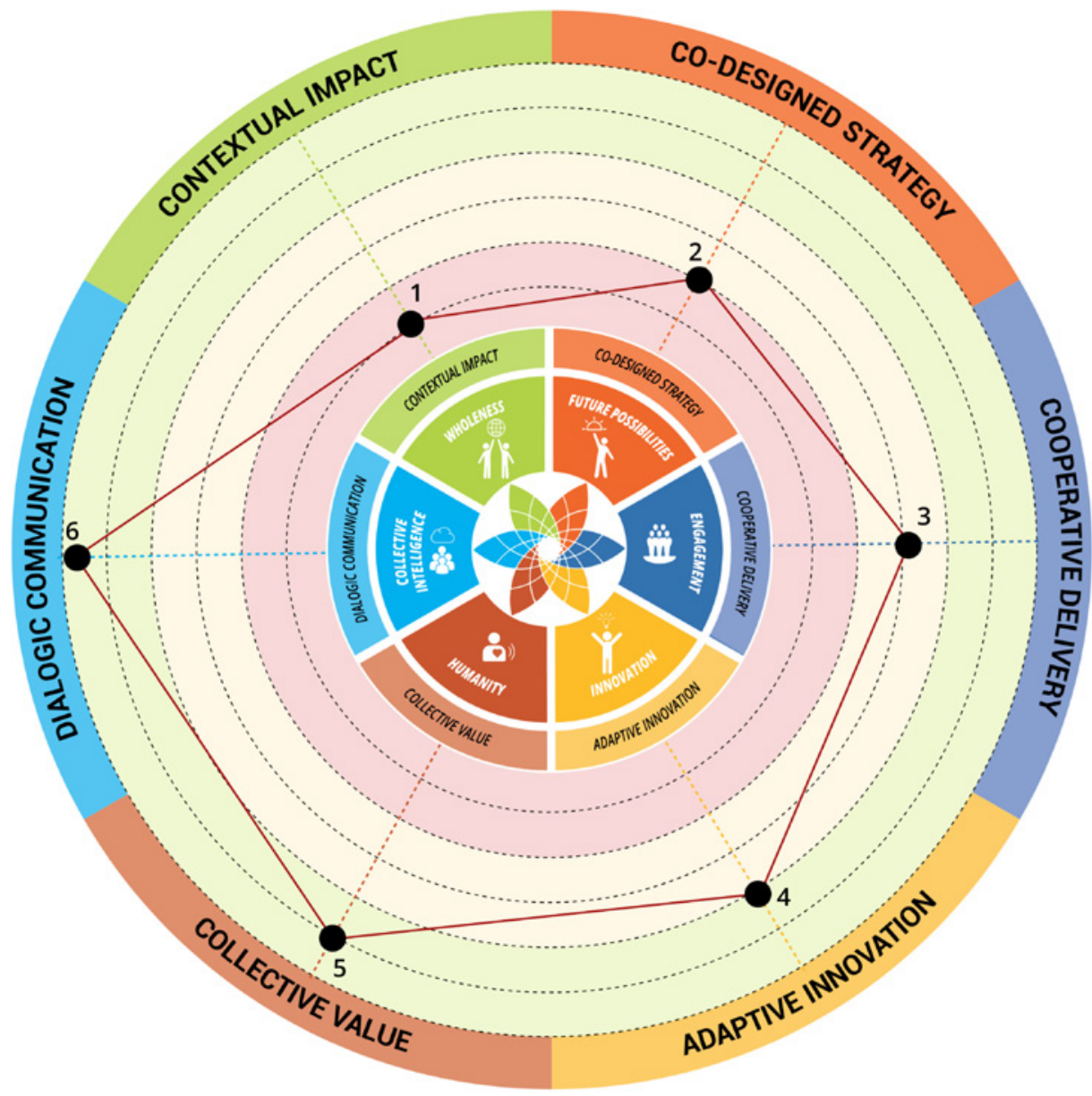

Figure 5.4 Example of process monitoring with the collaboration catalysts

at some stage. This makes it important to be aware of difficulties and conflicts when they arise and how to deal with them properly. It is not possible to avoid them completely; however, it is possible to avoid the escalation of such difficulties through good communication and relationship-management. The following section offers a "troubleshooting guide" based on navigating difficulties with the Collective Leadership Compass in mind. It lists the most common challenge patterns that occur in complex collaborations.' A timely, thought-through adjustment of focus, communication, or engagement strategies can ensure the constructive continuation of the collaboration and strengthen the collaboration ecosystem. 


\section{Challenge Pattern \# 1:}

Some stakeholders do not have the willingness to communicate or talk with each other.

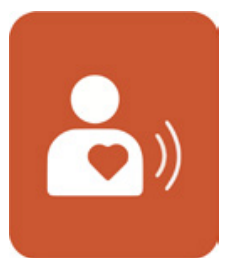

In order to overcome this difficulty, it helps to focus on the Compass

dimensions of collective intelligence and humanity. This means:

- Engage actors individually and informally in conversations;

- Understand and solve the conflict outside the formal structures of the collaboration process;

- Hold bilateral conversations to clarify objectives and topics;

- Explain the premises and methodology of multi-stakeholder collaborations;

- Clarify the participants' different needs;

- Get a bilateral commitment for staying in the process; and

- Allow time for informal conversations creating opportunities where stakeholders can meet as people.

\section{Challenge Pattern \# 2:}

Hierarchy or authorities feel they have not been sufficiently involved and question the collaboration initiative.

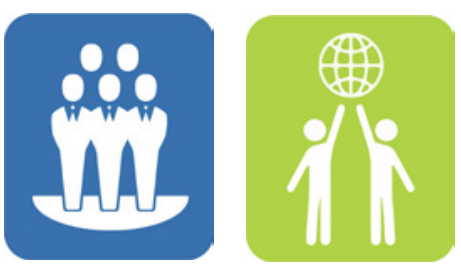

In order to overcome this difficulty, it helps to focus on the Compass dimensions of engagement and wholeness. This means:

- Go back to the essentials of Phase 1 and reclarify the context or conduct a stakeholder analysis;

- Redo a systems diagnosis with the Collective Leadership Compass;

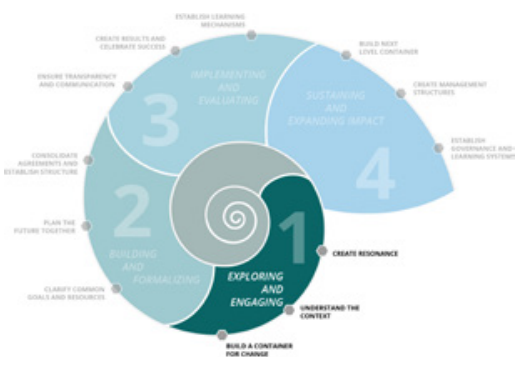

- Engage hierarchically or important powerful actors bilaterally or informally and on an individual basis; build resonance by understanding their interests, perspectives, and concerns, then engage them officially and integrate them into the process;

- Inform the hierarchy using a report and, through this, gain interest for the process; and

- Agree on regular communication with high-level actors. 


\section{Challenge Pattern \# 3:}

"Territorial" conflicts occur: the multi-stakeholder collaboration is perceived as covering topics that are considered to be the territory of certain (involved or not involved) stakeholder institutions.
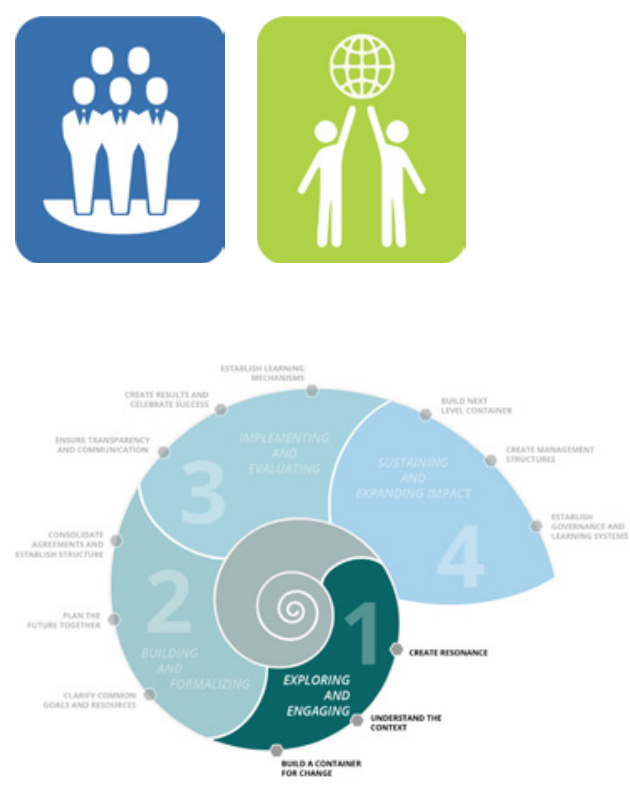

In order to overcome this difficulty, it helps to focus on the Compass dimensions of wholeness and engagement. This means:

- Go back to the essentials of Phase 1 and re-clarify the context;

- Make yourself aware of territories that exist and how a change initiative would be perceived by different stakeholders;

- Clarify conflicting boundaries before starting engagement processes;

- Engage in bilateral conversations, build or re-build resonance, and start genuine dialogue with stakeholders that may feel threatened or are annoyed; and

- Look for synergies between conflicting parties.

\section{Challenge Pattern \# 4:}

The collaboration initiators are not supported because they have no official mandate.

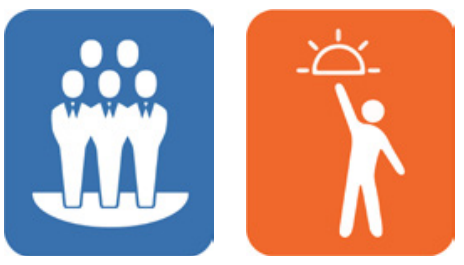

In order to overcome this difficulty, it helps to focus on the Compass dimensions of future possibilities and engagement. This means:

Reiterate steps of Phase 1:

- Get high-level sponsorship for the topic of the collaboration initiative;

- Promote the benefits of multi-stakeholder collaboration;

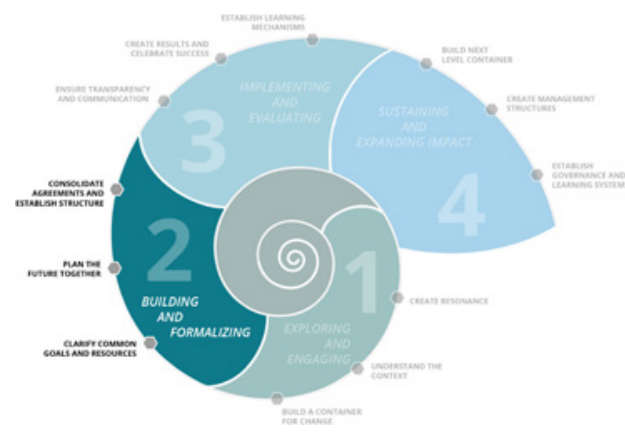

- Improve ways of communicating the potential benefits of the collaboration initiative;

- Listen to stakeholders, refrain from teaching them about the future;

- Carefully compose a core group with the consent of high-level sponsors; and

- Strengthen or rebuild the core group as a good container and include important stakeholders.

Deep dive into the essentials of Phase 2:

- Explore which stakeholders can give a clear mandate; 
- Explain the initiator's role to important stakeholders;

- Underline the initiator's goal of bringing about positive change and demonstrate that there is no hidden agenda; and

- Interact neutrally with stakeholders but with a clear engagement towards the collaboration goal.

\section{Challenge Pattern \# 5:}

Clashes of interest, ideological differences, or hidden agendas arise.
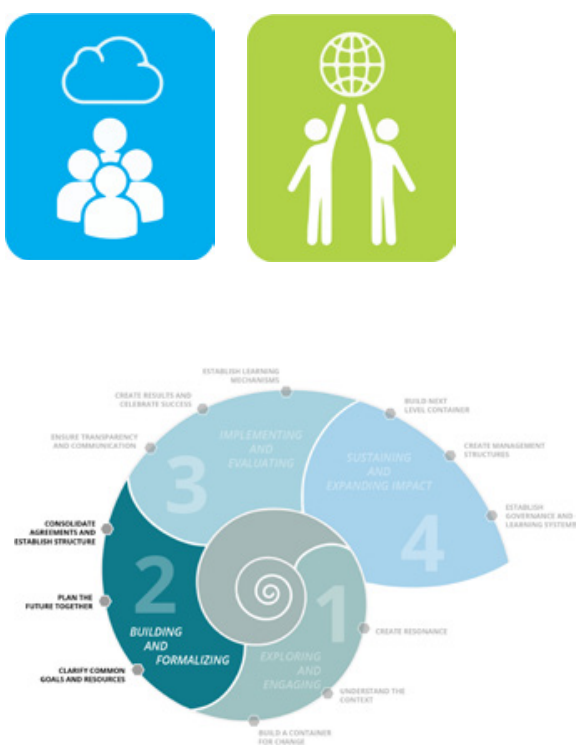

This is a difficulty that usually emerges in Phase 2 and is best dealt with by focusing on the Compass dimensions of wholeness and collective intelligence. This means:

Reiterate steps of Phase 1:

- Understand the system: redo conflictmapping, redo the situational diagnosis with the Collective Leadership Compass, and improve the stakeholder analysis;

- Clarify what is in it for all parties; and

- Clarify the underlying interests in bilateral conversations.

Deep dive into the essentials of Phase 2:

- Review the process architecture using the Collective Leadership Compass (see Chapter 4);

- Carefully construct dialogic settings and co-creative meetings using the Compass (see Chapter 3)

- In stakeholder meetings, ensure structured dialogue and make differences transparent (see Chapter 3); let parties state their differences and discuss with them what is at stake if no solution is found; and

- Seek support from other important actors, if necessary.

\section{Challenge Pattern \# 6:}

\section{Stakeholders complain about a lack of transparency.}

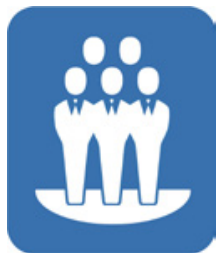

This is a difficulty that often emerges in Phase 3 and is best dealt with by focusing on the Compass dimension of engagement with a special focus on process quality. This means: 


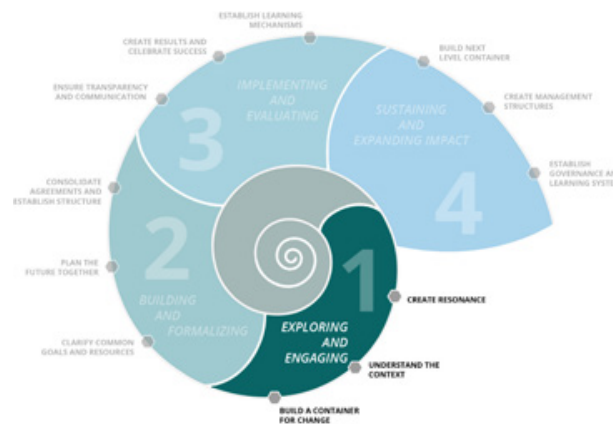

Deep dive into the essentials of Phase 3:

- Ensure comprehensive information about the process and progress to all involved;

- Make sure that issues of communication and information are agreed upon by the stakeholders involved;

- Conduct individual conversations with critical stakeholders and obtain their feedback on the process; and

- Review the process architecture and check for elements that ensure transparency, using the Collective Leadership Compass (see Chapter 4);

\section{Challenge Pattern \# 7:}

\section{Power differences become obvious and create mistrust in the process and purpose of the multi-stakeholder collaboration.}
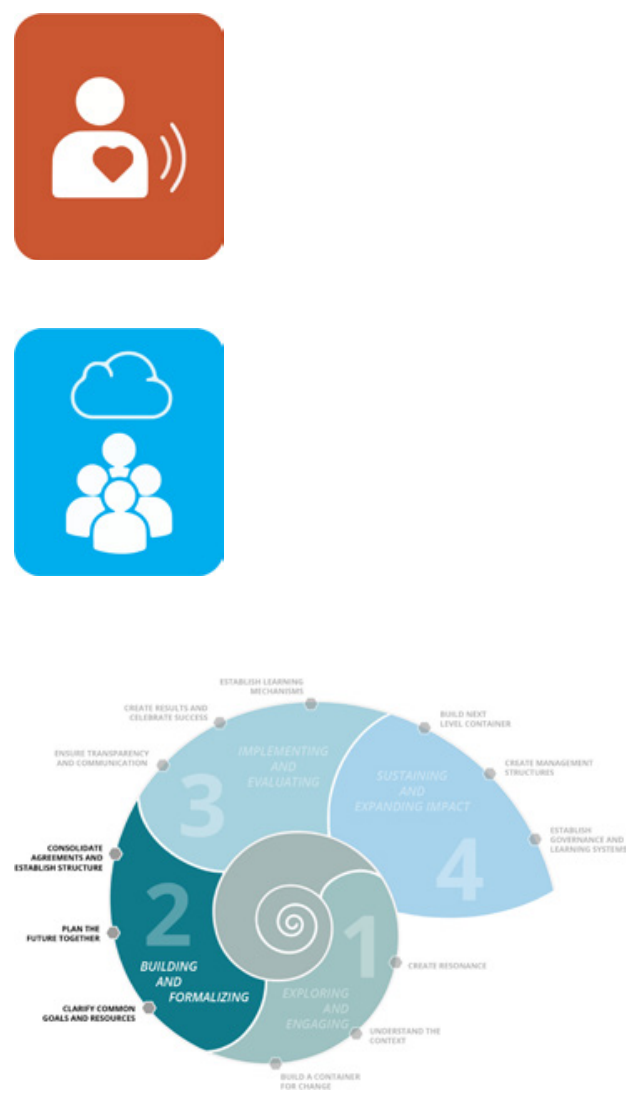

This is a difficulty that can emerge in all phases, but mostly shows up in Phase 2 when the collaboration ecosystem is still fragile. It can also occur in Phase 3 if not enough attention has been given to the quality of Phase 2. It is best dealt with by focusing on the Compass dimensions of humanity and collective intelligence. This means:

Reiterate steps of Phase 1:

- Understand the system: improve the stakeholder analysis; and

- Design strategies to engage weaker stakeholders and strengthen their capacity and voice.

Deep dive into the essentials of Phase 2:

- Ensure that all voices are heard;

- Ensure that less powerful stakeholder groups remain in the process or enter into the process; get support for this from key stakeholders;

- If necessary, address power issues with stakeholders separately and talk about their effects; remind more powerful stakeholders of their impact on the success of the multistakeholder collaboration;

- Review process architectures with the Compass (see Chapter 4); and

- Support weaker groups with capacity building and advocacy. 


\section{Challenge Pattern \# 8:}

\section{There is a lack of willingness to come to an agreement.}
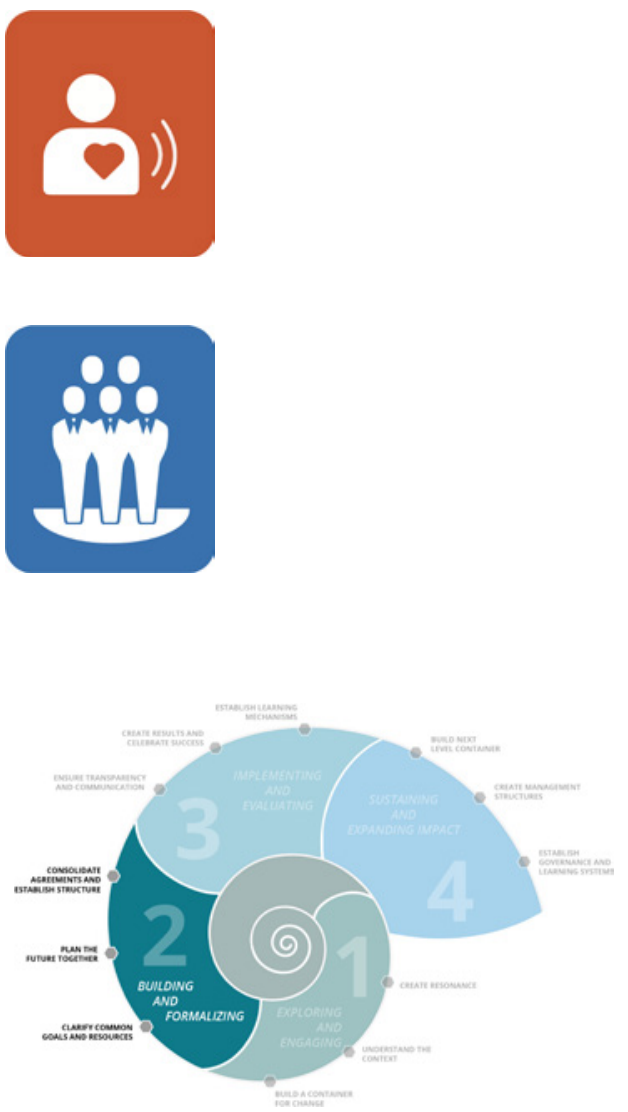

This is a difficulty that is typical for Phase 2 when the system of actors needs to move from dialogue to action. It is best dealt with by focusing on the Compass dimensions of humanity and engagement. This means:

Reiterate steps of Phase 1:

- Reanalyze the situation (diagnose systems patterns) with the Collective Leadership Compass, and redo the stakeholder landscape analysis;

- Try to understand fears and constraints individually by applying the dialogic practices;

- Consider the possibility that some stakeholders may benefit from the continuation of the status quo; and redo essentials of engagement and resonance building from Phase 1.

Deep dive into the essentials of Phase 2:

- Find out about stakeholders' willingness to commit individually and facilitate their coming to a solution separately and informally;

- If no willingness exists, postpone the stakeholder meetings and work backstage on Phase 1 essentials; and

- Assess the influence and importance of the stakeholders blocking agreements and explore the possibility of moving on without the stakeholders in question.

\section{Challenge Pattern \# 9:}

There is a lack of resources to carry out the process steps for the multi-stakeholder collaboration.

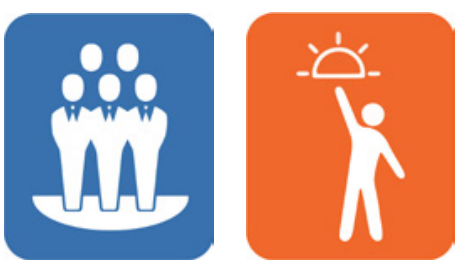

This is a difficulty that is very common when initiators are passionate about collaborative change, but have not secured sufficient resources. Not all collaborations need to be well funded, but lack of financial or professional resources may impact on quality and results. Such a situation is best dealt with by focusing on the Compass dimensions of future possibilities and engagement. This means: 


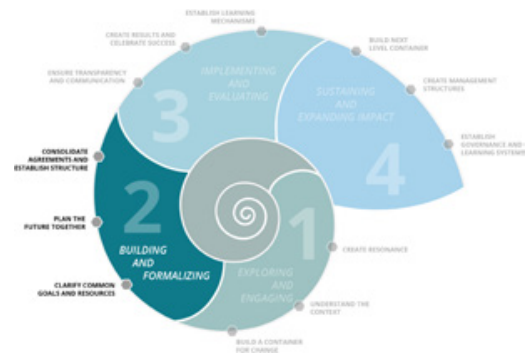

Reiterate essential steps of Phase 1:

- Create resonance with key stakeholders and highlevel sponsors;

- Get the help of high-level actors to connect to funders;

- Promote the potential result-orientation of the multi-stakeholder collaboration;

- Redo the diagnosis of the system with the Collective Leadership Compass and assess the maturity of key actors for change; and

- Redo the stakeholder analysis and devise strategies to engage powerful and financially well-set stakeholders.

\section{Challenge Pattern \# 10:}

Stakeholders do not understand or agree with the purpose or objective of the multistakeholder collaboration. They do not see the urgency to act together.
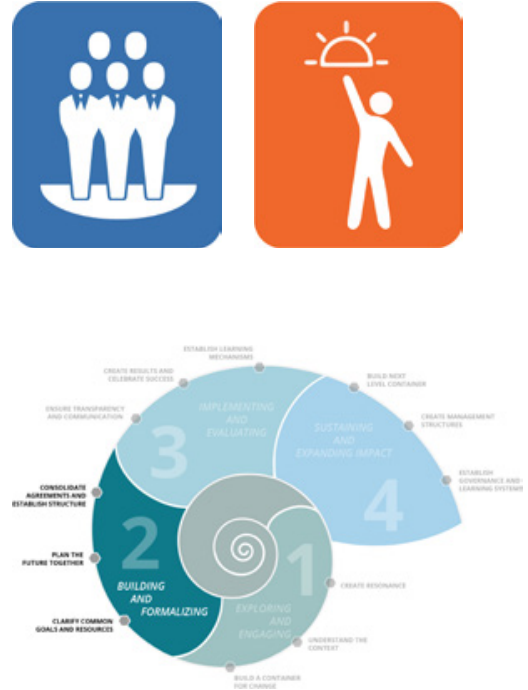

This is a difficulty that hints to an insufficient quality of Phase 1 that has not built resonance for change. It may happen in situations for which some actors see an extreme urgency, while other stakeholders are complacent towards the situation. Such a situation is best dealt with by focusing on the Compass dimensions of future possibilities and engagement. This means:

Reiterate essential steps of Phase 1:

- Consider advocacy strategies and information campaigns around the issue;

- Create awareness about the issue by engaging potential stakeholders into the process;

- Integrate content-related capacity building into the process design; and

- Re-address goal alignment as part of the engagement process.

\section{Challenge Pattern \# 11:}

Stakeholders do not understand the requirements of multi-stakeholder collaboration; they lack skills in leading collectively.
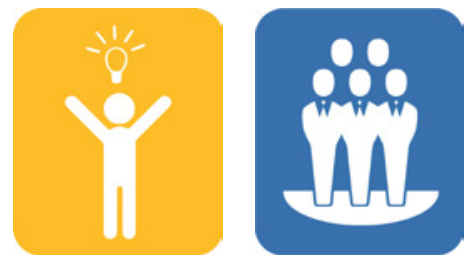

This is a difficulty that often occurs in multi-stakeholder collaboration, as many actors assume collaborative change is no different from the way they are used to work in other areas. This difficulty can occur in all phases but is best addressed in Phases 1 and 2. It is best dealt with by focusing on the Compass dimensions of innovation and engagement. This means: 


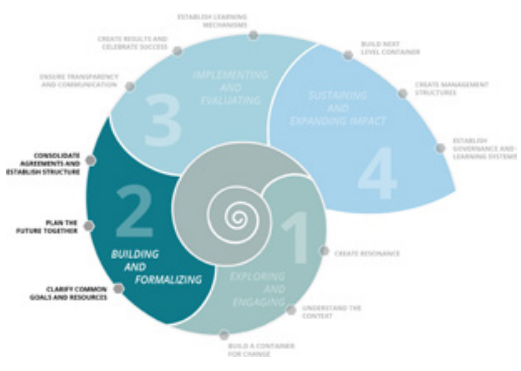

Integrate capacity building steps into Phase 1 and Phase 2:

- Expose stakeholders to examples of successful multi-stakeholder collaboration or make them familiar with the collaboration catalysts as easy understandable success factors;

- Integrate capacity building for collaboration as a methodology into the process design of Phases 1 and 2; and

- Specifically build the capacity of the core group to become experts in dialogic process facilitation.

\section{Challenge Pattern \# 12:}

There is a lack of leadership or initiative by participating stakeholders; there is no sense of collective responsibility and ownership.

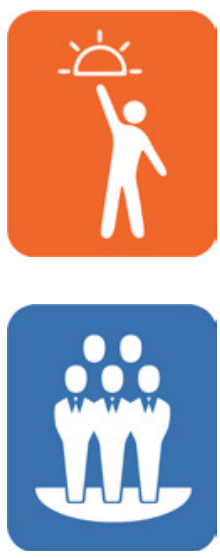

This is a difficulty that can occur in all phases, most often as a result of an insufficiently completed Phase 1 and Phase 2. It is best dealt with by focusing on the Compass dimensions of engagement, collective intelligence, and future possibilities. This means:

Reiterate the essentials of Phase 1:

- Adhere to the principles of an engagement process, strengthen the initial container, then gradually build the broader container towards a functional collaboration ecosystem (see Chapter 3); only gradually involve more stakeholders;

- Reflect adjustments in process architectures with the core group;

- Build collaboration capacity building into Phase 1 and combine it with visioning exercises;

- Emphasize the importance of each stakeholder's contribution;

- Improve full understanding of the problem; redo a systems diagnosis with the Collective Leadership Compass; and

- Conduct stakeholder interviews to explore the reasons for lack of ownership.

Deep dive into the essentials of Phase 2:

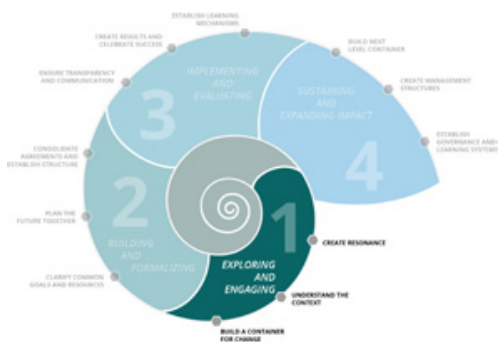

- Ensure strategies are co-designed by all key stakeholders; 


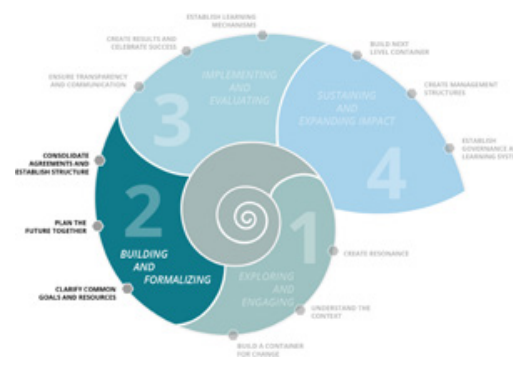

- Redo a resource mapping to understand the constraints of stakeholders;

- Focus on the benefits of result-orientation;

- Review process-architectures and improve them using the Compass dimensions;

- Conduct a process monitoring with the collaboration catalysts to identify entry points for improvements;

- Address in informal conversations what would create the feeling of ownership;

- Ensure honest participation;

- Apply dialogic practices in stakeholder meetings (see Chapter 3); and

- Create a clear vision with all participants (see Chapter 3 and 4 ).

\section{Challenge Pattern \# 13:}

Conflicts arise about decision-making logics, speed of implementation, or reporting requirements between the public sector, private sector, and NGOs (e.g. clash of organizational cultures).
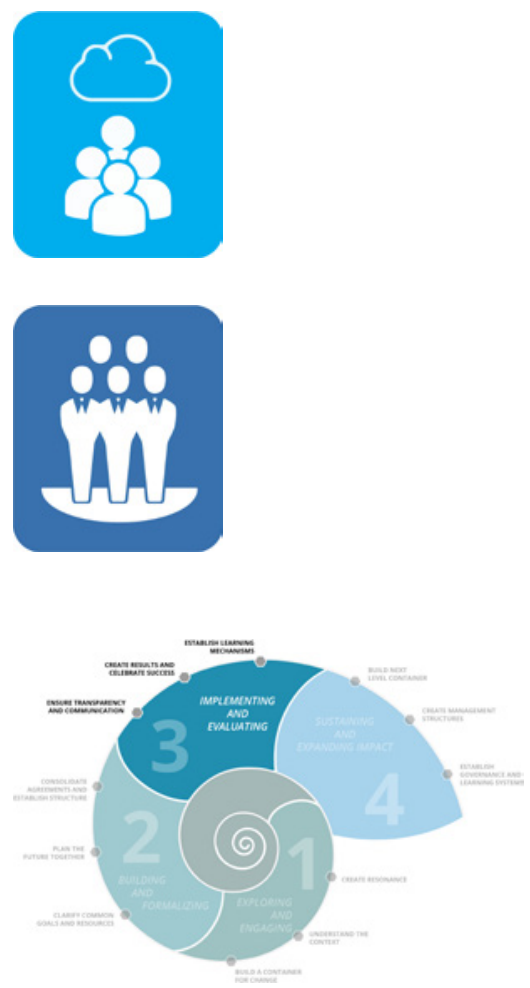

This is a difficulty that often occurs in Phase 3, when stakeholders tend to be under pressure to deliver and naturally resort back to their own way of doing things. It is best dealt with by focusing on the Compass dimensions of engagement and collective intelligence. This means:

- Make differences in decision-making structures, reporting requirements, and cultures/rationales of different stakeholder groups transparent;

- Integrate capacity building for multi-stakeholder collaboration and the understanding of inherent sectoral differences into the process architectures;

- Create mutual understanding through structured dialogues about the constraints, expectations, and rationales of the different institutions; and

- Explore the needs for reporting with different stakeholder groups. 


\section{Challenge Pattern \# 14:}

\section{Roles and responsibilities are unclear among participating stakeholders.}
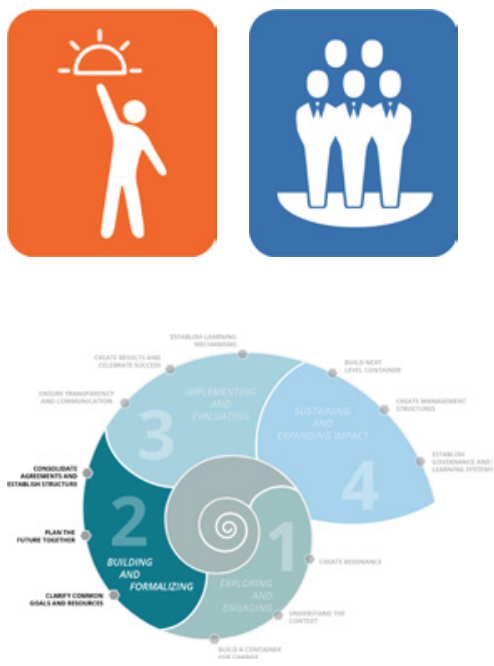

This is a difficulty that occurs after an insufficiently completed Phase 2. It is best dealt with by focusing on the Compass dimensions of future possibilities and engagement. This means:

- Take a deep dive into the essentials of Phase 2 (see Chapter 2) and invest in co-designing strategies and developing joint action plans;

- Re-clarify roles, structures and responsibilities;

- Agree on accountability mechanisms;

- Re-clarify the mandate and make it transparent;

- Address issues of engagement that lead to a sense of ownership; and

- Conduct a process monitoring exercise with the collaboration catalysts and identify improvement areas.

\section{Challenge Pattern \# 15:}

\section{There is the perception of deteriorating or absent trust.}
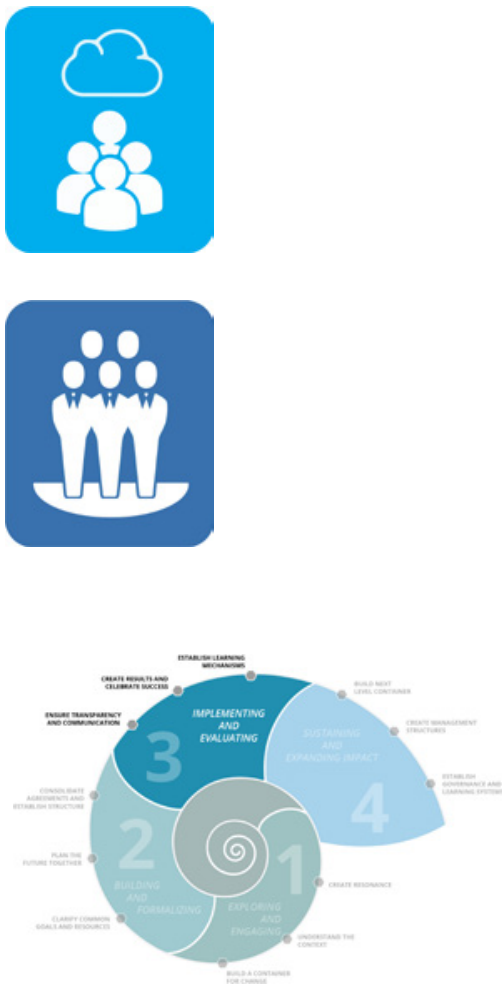

becoming reflective
This is a difficulty that occurs in Phase 3 either after a not fully transparent or insufficiently completed Phase 2; or in Phase 2, if the process architecture is not transparent and reliable. It is best dealt with by focusing on the Compass dimensions of engagement and collective intelligence. This means:

- Conduct a process monitoring exercise within the core group using the collaboration catalysts and review the process architectures with the Collective Leadership Compass;

- Ensure that dialogic practices are implemented in all stakeholder meetings (see Chapter 3); conduct events in a way that allows for good conversations and frequent interaction among participants (round tables, coffee break, etc., see Chapter 3);

- Engage in one-on-one conversations to explore the reasons for a lack of trust;

- Ensure that the initiator/facilitator is a living example of trustworthiness;

- Ensure transparency and reliability of process and time planning;

- Keep agreements and keep to the agreed process-designs;

- Genuinely engage and involve stakeholders; do not make false promises; 
- Work both informally and in a structured way on relationship - building;

- Create face-to-face situations in communications; and

- Create and celebrate common successes (success must be tangible).

\section{Challenge Pattern \# 16:}

Key actors do not want to get engaged and refuse to join the initial container or the broader container; or stakeholders change positions, drop out, or send substitutes.

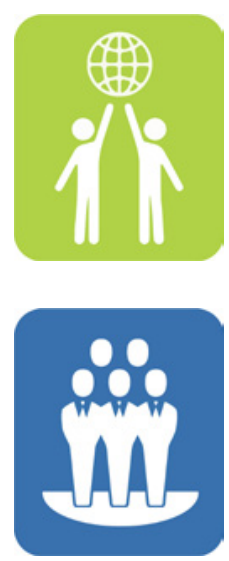

This is a difficulty that occurs in a neglected Phase 1 that does not invest sufficiently into the three key steps of resonance building, understanding the context, and building a container for change. It can also occur in Phase 2 after a not fully completed Phase 1. It is best dealt with by focusing on the Compass dimensions of wholeness and engagement. This means:

- Conduct a systems diagnosis with the Collective Leadership Compass and re-evaluate the stakeholder landscape analysis;

- Develop specific engagement strategies for highly influential stakeholders that are needed to make the initiative a success;

- Design specific strategies to engage difficult

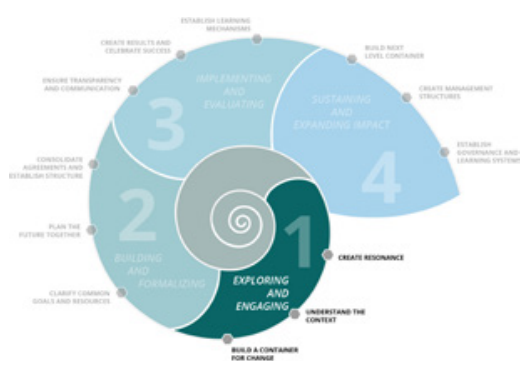
actors, and be sure that you understand what makes them engaged or disengaged;

- Check if the timing for the initiative is right;

- Invest in additional resonance building by exploring the interests of important stakeholders in inspiring conversations;

- Meet the important stakeholders where they feel comfortable, for example at issue-related conferences;

- Convey the goal but link it to the interest of the difficult stakeholders;

- Accept that you may need to slow the process down and ensure that you get the right people on board;

- If the people attending meetings continuously change try to engage superiors more consciously and explain how important it is that the same people attend consistently; and

- Invest in relationship building and invest time in getting people on board. 
Not all key actors will engage in the same way. Some stakeholders are more difficult to engage. In many organizations, people continually change positions, send new people to meetings without briefing them, or drop out of processes from pressure to attend to other commitments. 'Staff turnover' may lead the core group to include people who were not included before, or to deal with the loss of a key supporter who is suddenly called to a different task. The composition of collaboration ecosystems may shift over the course of the four phases. Hence, relationship management and good communication remains the key task for dialogic process facilitators that aspire to achieve results. Setbacks and difficulties are normal. What counts is their in-depth understanding of high-quality processes and high-quality dialogue. The next section, therefore, summarizes the essential knowledge about the role of internal and external communication strategies for building thriving learning cultures in multi-stakeholder collaborations.

\section{Communication: the fastest route to a learning culture}

For all the careful planning invested in the design of good process architectures, we only see its effects once they are put into action. Successful action to shift dysfunctional patterns in a stakeholder system towards SDG implementation with enlivened collaboration ecosystem requires a culture of learning and collective reflection. The complexity of the SDG challenges demands that all stakeholders become versatile in taking a systems view in understanding contexts, planning action, and evaluating outcomes. Such a view brings the awareness of patterns of aliveness into a system of actors to the fore (Kuenkel, 2019), and helps actors to pass through the reflective circle of observe-focus-enact that has been described in Chapter 1 . If reflection in action becomes second nature to many of the participating stakeholders, the jointly driven change process becomes much more resilient, and faster in delivering results. An enlivened culture of learning creates intrinsic motivation to continue and improve the collaboration, promotes engagement and collective responsibility by all stakeholders. It incites curiosity to try things differently. Most importantly, it helps all stakeholders to develop a different attitude to situations when things go wrong: in a thriving learning culture, people do not look to blame others for mistakes or consider objectives and results unilaterally as either won or lost. They recognize that many challenges, and most importantly those in sustainable development, eschew thinking in these simple causal linkages. Rather, successful solutions to sustainability challenges can only be found through a continuous cycle of analysis, strategizing, planning, enacting, reviewing and observing, adjusting the planning, and going into action again. The systems aliveness principles translated into the Collective Leadership Compass embody a learning culture at the heart of successful collaboration ecosystems. For this to happen, it is important to understand the role of communication in multi-stakeholder collaboration and how it can enhance a learning culture. 


\section{Levels of communication in multi-stakeholder collaboration}

Chapter 3 has emphasized that attending to the quality of dialogic communication is a crucial factor for success in multi-stakeholder collaborations throughout all phases. This chapter has elaborated the importance of the collaboration catalyst dialogic communication for progress and tangible outcomes in collaborative change. Yet, communication processes in collaborative change may differ, depending on the phase of the process and on whether they are for internal or external purposes. While the essentials of dialogue need to be applied in all forms of communication, it is helpful to understand the different avenues for communication in the four phases, both within the collaboration ecosystems and with external actors. Figure 5.5 illustrates the levels of communication that are relevant to consider.

- Internal communication refers to communicative processes within the collaboration ecosystem, hence between those actors or institutions that are directly involved in bringing about change in a particular multi-stakeholder collaboration.

- External communication refers to communicative processes with the general public, with other stakeholders who are relevant but not directly involved in the process, and among the involved actors and their respective constituencies or institutions.

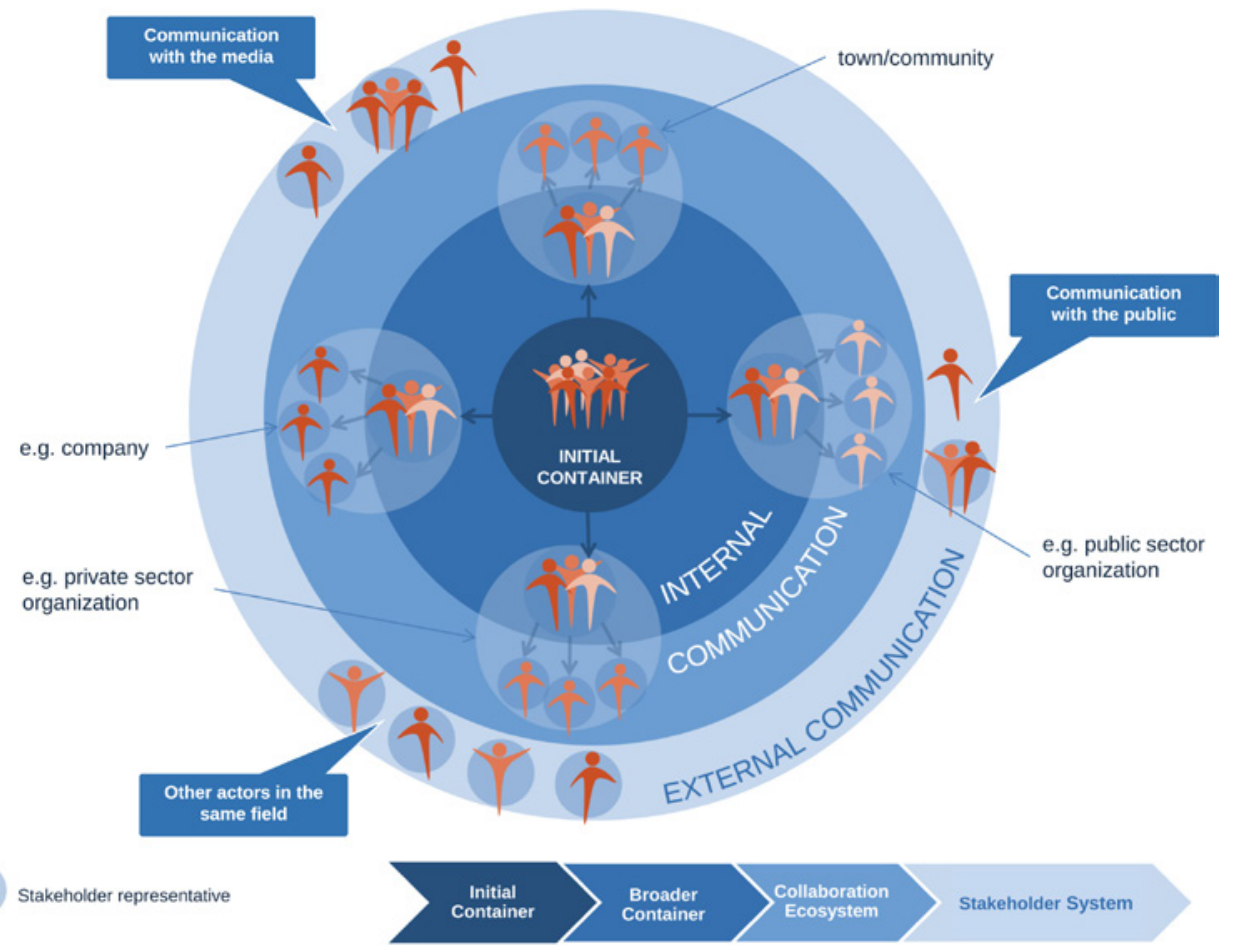

Figure 5.5 The different levels of communication 
Each of these two levels of communication has a direct influence on the course of a collaborative change process and, therefore, also on its results: lack of attention to high-quality internal communication can lead to the difficulties described in the section on managing difficulties. Premature or insufficiently aligned communication with external stakeholders can severely deteriorate trust within the collaboration ecosystem. Each level may have different requirements and challenges. Particular within the group of collaborating actors, regular and authentic communication is indispensable for building trust. Mistrust leads to delays, and, in some cases, can undermine the stakeholder consultation or cooperation all together. Quality communication is the "oil" for creating cohesion among the otherwise diverse, and at times conflicting or mutually distrustful, stakeholders of a collaboration ecosystem. It can overcome difficult situations and contribute to a sense of belonging in an otherwise complex endeavor. The following paragraphs therefore highlight important aspects of internal and external communication in multistakeholder collaborations and how they relate to forms of learning mechanisms that can be established.

\section{Internal communication: core group and collaboration ecosystem}

For the core group in its function as a good container, dialogic competence is crucial for finding an appropriate and efficient form of leading transformative change collectively and for developing a straightforward, informal style of collaboration. It is an enormous asset for the success of a collaborative change process if the core group of initiators and drivers becomes more than an official committee or a formal task force. The more informal the style of communication between members of the core group is, the more it emerges as a good container for change. With increasing degrees of cohesion, members can reflect together, quickly discuss and address challenges, or adjust strategies. An atmosphere of mutual trust and support emerges. This is greatly enhanced by acknowledging diversity in the core group as a crosssector team that brings the collaborative change process further. An investment in team building can pay off because relationship building is key. Table 5.11 shows typical communication processes in the core group and how they can contribute to learning mechanisms.

Similarly, as Chapter 3 emphasized, the role of dialogic process facilitators is to guard the dialogic quality in the communication between stakeholders in the collaboration ecosystem and establish a culture of iterative learning that enhances the agility of stakeholders to deal with difficulties and to always keep future possibilities open. This enlivens the relationships and helps to achieve tangible results faster. It is important that all participating stakeholders feel well informed and well looked after. The more open and transparent the form of communication, the more constructively feedback and criticism can be handled, which leads to learning. But a certain degree of formality and structure is equally important, such as joint agreements on the form 
Table 5.11 Communication process and learning mechanisms for core groups

\begin{tabular}{|c|c|c|}
\hline Communication processes & Learning mechanisms & Purpose \\
\hline $\begin{array}{l}\text { - Conduct regular } \\
\text { meetings or conference } \\
\text { calls. }\end{array}$ & $\begin{array}{l}\text { - Integrate process } \\
\text { reviews into check- } \\
\text { ins and check-outs or } \\
\text { reserve a time slot for } \\
\text { process review on the } \\
\text { agenda. } \\
\text { - Keep minutes of meet- } \\
\text { ings for tracking process } \\
\text { and progress. }\end{array}$ & $\begin{array}{l}\text { - Create confidence in do- } \\
\text { ability through process. }\end{array}$ \\
\hline $\begin{array}{l}\text { - Plan process architec- } \\
\text { tures jointly }\end{array}$ & $\begin{array}{l}\text { Regularly review the } \\
\text { process architecture } \\
\text { together. }\end{array}$ & - Build trust and ownership. \\
\hline $\begin{array}{l}\text { Ensure that members } \\
\text { of the core group are } \\
\text { fully informed about all } \\
\text { relevant issues }\end{array}$ & $\begin{array}{l}\text { - Update on process steps } \\
\text { regularly. }\end{array}$ & $\begin{array}{l}\text { Keep core group engaged } \\
\text { and anchor attention to } \\
\text { process. }\end{array}$ \\
\hline $\begin{array}{l}\text { Create informal } \\
\text { settings between core } \\
\text { group members (joint } \\
\text { dinners, field trips, etc.) }\end{array}$ & & $\begin{array}{l}\text { - Enhance person-to-person } \\
\text { understanding. } \\
\text { - Enhance understanding of } \\
\text { issue. }\end{array}$ \\
\hline
\end{tabular}

and sequence of internal communication, as well as structured exchanges between stakeholders that enhance iterative learning. Table 5.12 shows typical communication processes in collaboration ecosystems and how they can be used for learning mechanisms.

\section{Internal communication: participating stakeholders and their institutions}

Stakeholders directly involved in multi-stakeholder collaborations represent participating institutions. Examples are company employees, public servants, association members, or representatives of civil society organizations. This implies that they are representing not necessarily their own personal beliefs, but rather, and primarily, the interests and perspectives of their employers. However, people engage in collaborative change as people: they develop a sense of understanding for the complexity of the situation and for other points of view. But these individuals do not always have the required decision-making power in their organizations to be able to agree on a course of action on behalf of their organizations. Some concessions may first need to be approved by their superiors. This process can 
Table 5.12 Communication processes and learning mechanisms for collaboration ecosystems

\begin{tabular}{|c|c|c|}
\hline Communication processes & Learning mechanisms & Purpose \\
\hline $\begin{array}{l}\text { In Phase 1: } \\
\text { - Engage stakeholders with } \\
\text { inspiring and enlivening } \\
\text { conversations. }\end{array}$ & $\begin{array}{l}\text { Bring insights from engage- } \\
\text { ment conversations back to } \\
\text { the core group. } \\
\text { - Do a system diagnosis with } \\
\text { the Collective Leadership Com- } \\
\text { pass together with the core } \\
\text { group. }\end{array}$ & $\begin{array}{l}\text { - Building resonance for } \\
\text { change. }\end{array}$ \\
\hline $\begin{array}{l}\text { In Phase 2: } \\
\text { - Jointly agree on process } \\
\text { architectures (roadmaps, } \\
\text { plans) with all relevant } \\
\text { stakeholders. }\end{array}$ & $\begin{array}{l}\text { Regularly review the process } \\
\text { architecture together. } \\
\text { - Use the readiness check } \\
\text { around the Dialogic Change } \\
\text { Model for process reviews. }\end{array}$ & $\begin{array}{l}\text { Create confidence in } \\
\text { do-ability by making } \\
\text { progress visible. }\end{array}$ \\
\hline $\begin{array}{l}\text { In Phases } 2 \text { and 3: } \\
\text { - Conduct reliable sequences } \\
\text { of stakeholder meet- } \\
\text { ings with all involved } \\
\text { stakeholders. }\end{array}$ & $\begin{array}{l}\text { Prepare strategic review } \\
\text { insights with the core group. } \\
\text { - Integrate dialogue about } \\
\text { reviews into the agenda. } \\
\text { - Use the Collaboration Cata- } \\
\text { lysts for monitoring process } \\
\text { quality with key stakeholders. } \\
\text { - Keep minutes of meetings } \\
\text { for tracking process and } \\
\text { progress. }\end{array}$ & $\begin{array}{l}\text { - Build trust and } \\
\text { ownership. }\end{array}$ \\
\hline $\begin{array}{l}\text { In Phases } 2 \text { and 3: } \\
\text { - Attend to relationship } \\
\text { building in meetings; cre- } \\
\text { ate informal settings (joint } \\
\text { dinners, field trips, study } \\
\text { visits, etc.) }\end{array}$ & $\begin{array}{l}\text { - Foster opportunities for } \\
\text { stakeholders to reflect } \\
\text { informally about process and } \\
\text { progress. }\end{array}$ & $\begin{array}{l}\text { - Enhance person-to- } \\
\text { person understanding. } \\
\text { - Enhance understanding } \\
\text { of issue. }\end{array}$ \\
\hline $\begin{array}{l}\text { In Phases } 2 \text { and } 3 \text { : } \\
\text { - Agree on the form of exter- } \\
\text { nal communication with } \\
\text { the public and non- partici- } \\
\text { pating stakeholders }\end{array}$ & & $\begin{array}{l}\text { Create a reliable and safe } \\
\text { space for actors in the } \\
\text { collaboration ecosystem. }\end{array}$ \\
\hline $\begin{array}{l}\text { In Phase 3: } \\
\text { - Conduct learning and inno- } \\
\text { vation meetings. }\end{array}$ & $\begin{array}{l}\text { Foster exchange of knowl- } \\
\text { edge, ideas, progress, and } \\
\text { successes. } \\
\text { - Introduce creative ways of } \\
\text { reflecting on progress. }\end{array}$ & $\begin{array}{l}\text { Keep stakeholders } \\
\text { engaged as drivers of } \\
\text { shaping the future. }\end{array}$ \\
\hline $\begin{array}{l}\text { In Phase 3: } \\
\text { - Introduce process moni- } \\
\text { toring as a tool for focused } \\
\text { learning exchanges. }\end{array}$ & $\begin{array}{l}\text { Use the Collaboration Cata- } \\
\text { lysts for monitoring process } \\
\text { quality with all stakeholders } \\
\text { in the collaboration ecosystem. }\end{array}$ & \\
\hline
\end{tabular}


prove difficult. Particularly in Phase 2, the emerging common vision for the future needs to be embedded in the participating stakeholder groups. At times, the collaboration process may lead to changes in the strategic outlook of the participating institutions, or already-planned procedures may need to be re-modeled. The core group needs to support this process and communicate with key stakeholders about how the initiative can be embedded in their respective institutions and how to raise interest, trust, and confidence in the collaborative initiative. This can be done by disseminating information consisting of recent results and achievements or simply with an update on the state of affairs. While most obvious in Phase 2, this reliability in communication should be carefully considered during each of the four phases to keep silent supporters on board and to prevent active critics from becoming obstructers.

In order to ensure the continued backing of high-level supporters of multistakeholder collaborations - politicians, for example - it is essential to keep these actors informed on a regular basis. This can take different forms and depends on the relationship between members of the core group to the supporting hierarchy or patronage. Key to success is ensuring that any progress or success in the collaborative change process also becomes the success of the high-level supporters. It is equally important to plan and maintain steady, rather informal communication with potential critics of the initiative, as well as with important individuals within the specific field. Table 5.13 shows how communication processes with

Table 5.13 Communication with participating institutions

\begin{tabular}{|c|c|c|}
\hline Communication processes & Learning mechanisms & Purpose \\
\hline $\begin{array}{l}\text { In Phase 2: } \\
\text { - Consider the different } \\
\text { trust-building informa- } \\
\text { tion needs of different } \\
\text { stakeholder groups. }\end{array}$ & $\begin{array}{l}\text { Bring the under- } \\
\text { standing of different } \\
\text { stakeholder needs for } \\
\text { communication back } \\
\text { into strategic reviews } \\
\text { with the core group. }\end{array}$ & $\begin{array}{l}\text { - Create confidence in do- } \\
\text { ability by arguing bene- } \\
\text { fits, purpose, potential } \\
\text { to achieve goals. } \\
\text { - Build the support-base } \\
\text { in the management of } \\
\text { participating stakeholder } \\
\text { institutions. }\end{array}$ \\
\hline $\begin{array}{l}\text { In Phases } 2 \text { and 3: } \\
\text { - Provide information } \\
\text { in different forms (e.g. } \\
\text { short and crisp for } \\
\text { private sector, reports } \\
\text { for public sector, back- } \\
\text { ground information for } \\
\text { civil society). }\end{array}$ & $\begin{array}{l}\text { - Bring the understand- } \\
\text { ing of different stake- } \\
\text { holder reporting needs } \\
\text { back into strategic } \\
\text { reviews with the core } \\
\text { group. } \\
\text { - Integrate these } \\
\text { requirements into } \\
\text { reporting procedures } \\
\text { in implementation. }\end{array}$ & $\begin{array}{l}\text { - Enhance credibility of } \\
\text { the multi-stakeholder } \\
\text { collaboration. } \\
\text { - Build confidence that } \\
\text { participants' time is } \\
\text { time well spent } \\
\text { - Build trust and } \\
\text { ownership. }\end{array}$ \\
\hline
\end{tabular}


participating institutions and how they contribute to learning mechanisms in the collaboration ecosystem.

\section{External communication: non-participating stakeholders and the media}

External communication consists of all communication between the collaboration ecosystem and its environment regarding goals, courses of action, and results. This may include communication with non-participating but observing actors, the general public, and the media. External communication is often one-dimensional, meaning that information mostly flows in one direction, e.g. information about the course of the multi-stakeholder collaboration. The form and content of information that should go to non-participating stakeholders always needs to be agreed upon among the participating stakeholders.

Non-participating actors often observe multi-stakeholder collaborations closely. These observers may be actors who have not yet decided to participate in the collaborative change, individuals who are only indirectly interested in the topic, people who doubt the chances of success or the initiative's validity, or people who have been consciously or unconsciously excluded. The degree of observation depends on the topic and on the political importance of the multi-stakeholder collaboration. In initiatives that have a political dimension, and where progress can, or should, have an effect beyond participating stakeholders, attention to the need for appropriate external communication is key. Criticism from non-participating actors can have a negative effect on the process, bring the fragile collaboration ecosystem into discredit, and endanger the results. Such communication with external actors needs to be strategically planned. This may involve withholding certain information, on one hand, if communicating it to the outside world would mean a loss of trust within the group of stakeholders directly involved. On the other hand, it may be in the interest of the multi-stakeholder collaboration to make certain information public, if it will have a positive effect on the process and advance it further. At the end of Phase 2, or in Phase 3, stakeholders need to agree on the form of communication that should take place with the public or nonparticipating stakeholders.

In more complex multi-stakeholder collaborations, especially in national or international political processes, observation by the press plays an important role. In other cases, collaborative initiatives may receive little media attention but an upbeat portrayal of achievements by the press could facilitate the implementation of goals. In general, the media should not be informed of a process too early unless this is unavoidable for political reasons. They should be engaged after initial successes result from the multi-stakeholder collaboration, which is most often only the case in Phase 3. Table 5.14 shows communication with external stakeholders and how this can contribute to learning mechanisms in the collaboration ecosystem. 
Table 5.14 Communication with external stakeholders and the media

\begin{tabular}{|c|c|c|}
\hline Communication processes & Learning mechanisms & Purpose \\
\hline $\begin{array}{l}\text { In Phase 2: } \\
\text { - Decide among participat- } \\
\text { ing stakeholders how to } \\
\text { communicate with non- } \\
\text { participating actors. }\end{array}$ & & $\begin{array}{l}\text { Keep trust and the cohe- } \\
\text { sion of the collaboration } \\
\text { ecosystem. }\end{array}$ \\
\hline $\begin{array}{l}\text { In Phases } 2 \text { and } 3 \text { : } \\
\text { - Keep interested but } \\
\text { non-participating actors } \\
\text { regularly informed. }\end{array}$ & & $\begin{array}{l}\text { - Build trust in the course } \\
\text { of action. } \\
\text { - Keep external actors } \\
\text { sufficiently informed. } \\
\text { - Show progress. } \\
\text { - Create confidence. }\end{array}$ \\
\hline $\begin{array}{l}\text { In Phase 3: } \\
\text { - Develop mechanisms of } \\
\text { bringing external feedback } \\
\text { into the multi-stakeholder } \\
\text { collaboration. }\end{array}$ & $\begin{array}{l}\text { - Use the Collective Leadership } \\
\text { Compass to guide interviews } \\
\text { with external stakeholders. } \\
\text { - Bring results into strategic } \\
\text { reviews, or learning and } \\
\text { innovation meetings. } \\
\text { - Bring external expertise into } \\
\text { the process. }\end{array}$ & $\begin{array}{l}\text { Ensure the relevance } \\
\text { and responsiveness of } \\
\text { the collaborative initia- } \\
\text { tive to the situation. }\end{array}$ \\
\hline $\begin{array}{l}\text { In Phase 2: } \\
\text { - Avoid involving the media } \\
\text { at an early stage, before } \\
\text { results have been pro- } \\
\text { duced, and agree on the } \\
\text { form of media involvement } \\
\text { among all stakeholders. }\end{array}$ & & $\begin{array}{l}\text { Strengthen trust and } \\
\text { cohesion within the } \\
\text { collaboration ecosystem. }\end{array}$ \\
\hline $\begin{array}{l}\text { In Phase 3: } \\
\text { - Focus on success stories } \\
\text { when involving media. }\end{array}$ & & $\begin{array}{l}\text { - Enhance credibility by } \\
\text { making results known. } \\
\text { - Broaden support. } \\
\text { - Pave the way for the } \\
\text { engagement of addi- } \\
\text { tional stakeholders }\end{array}$ \\
\hline
\end{tabular}

\section{Methodologies for leading transformative change collectively}

This chapter has emphasized the role of a learning culture in multi-stakeholder collaborations that is supported by understanding the different levels of communication, applying process monitoring in the different phases, and the increasing ability to know when and how to navigate difficulties. It shows that collaborative change is possible; it is doable, and many more stakeholders can learn how to lead transformative change collectively. Because this is at the core of collaborative change-acknowledging 
that no societal actor can tackle sustainability challenges alone and realizing that the future of leadership is collective. It is the task of many at the same time, in their sphere of influence and based on their specific expertise. Hence, multi-stakeholder collaborations pave the way into a future, in which collaborative learning societies will become the norm.

This last section therefore provides practitioners with a user guide that shows how to use the Dialogic Change model, the Collective Leadership Compass, and several other tools as supportive methodologies for building successful multi-stakeholder collaborations. It summarizes the different approaches and tools that have been introduced in the practitioner guide and specifically refers to the freely accessible online tool: www. compass-tool.net. The web application provides background information on most of the methodologies introduced in this practitioner guide. No tool can be a substitute for the human-to-human interaction and appreciation of human competences and expertise. It can, however, serve as a meta-level guide that invites collaborating stakeholders to understand the complex dynamics of multi-stakeholder collaborations much better and use the methodologies to understand the systems they are trying to change for the better. It also provides structure for collectively diagnosing a situation and planning joint action. Hence, it strengthens all actors to design and implement multi-stakeholder collaborations that can deliver transformative change. The purpose follows the intent of this book - to enhance as many actors' capacity as possible to lead transformative change collectively in SDG implementation.

The web application takes the Collective Leadership Compass as an entry point to the ensuring quality in multi-stakeholder collaborations. As Figure 5.6 shows, it provides applications for collaborative change-makers, for actors who need to build and maintain collaboration ecosystems, and those for actors who drive change in transformation networks.

The guidance captured in the following figures and tables shows how best to make use of methodologies and the web-application in the four phases of the Dialogic Change Model. It takes up an application from the collaborative change-maker route (focusing on the competence level of Self), but focuses mainly on the application route of collaboration ecosystems as the main content of this practitioner guide (addressing the competence levels of Self, System and Process). As Figure 5.7 shows,

\section{Levels of Compass Application}
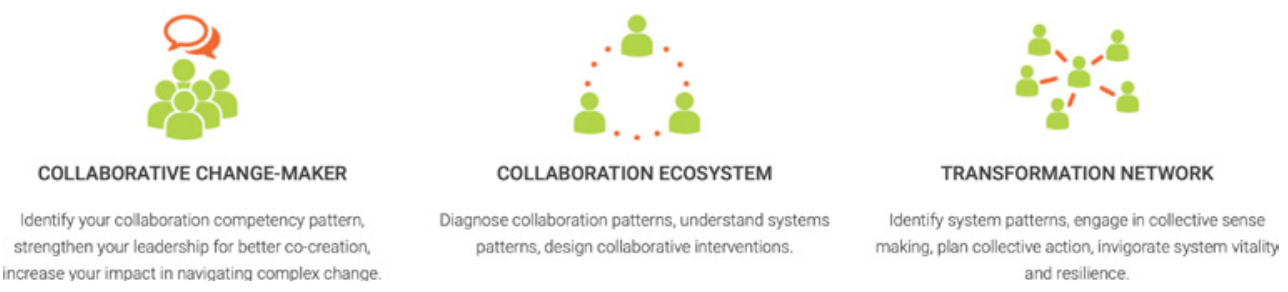

Figure 5.6 Levels of Compass applications 


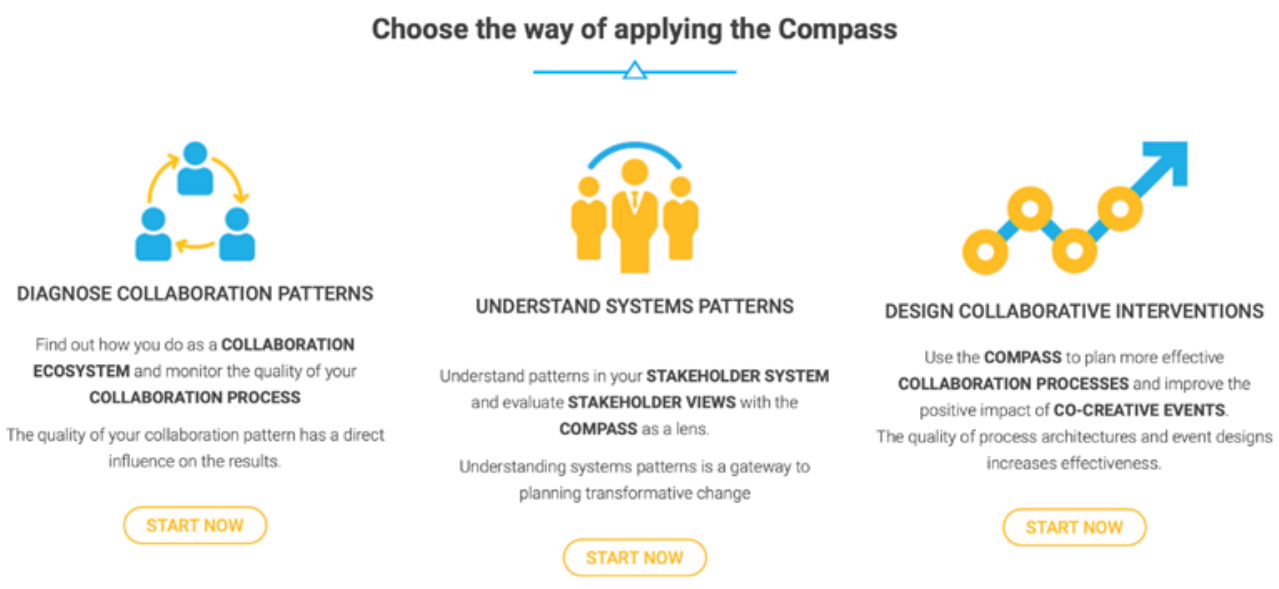

Figure 5.7 Applications for collaboration ecosystems

it supports actors in diagnosing collaboration patterns, understanding systems patterns, and designing collaborative interventions.

When stakeholders intend to diagnose collaboration patterns, because the quality of the collaboration pattern has a direct influence on the results, they will be able to choose between the following applications:

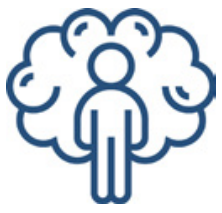

- Assess the potential of collaborative action groups: this application refers to the competence level of Self and helps to diagnose the collaborative quality of a team or core group as a container. How to use the tool has been described extensively in Chapter 5 pages 288, called Quality check 1: self-assessment for core groups. As mentioned in the Chapter this web application is helpful at the end of Phase 1 and throughout all other phases.

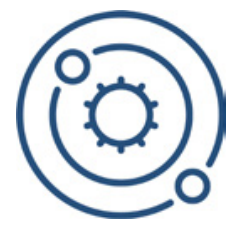

- Process monitoring of collaborative stakeholder initiatives: this application refers to the competence level of System and helps to monitor the quality of a collaborative process with multiple stakeholders. How to use the tool has been described extensively in Chapter 5 pages 295, called Quality check 2: assessment for collaboration ecosystems. As mentioned in the chapter, this web application is helpful earliest at the end of Phase 2, most useful during Phase 3.

When stakeholders intend to understand systems patterns as a gateway to planning transformative change, they will be able to choose between the following applications:

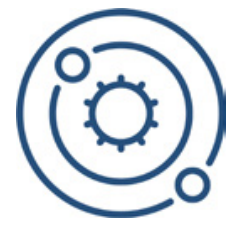

- Diagnose a stakeholder system: this application refers to the competence level of System and helps actors to understand systems patterns that impact on the multi-stakeholder collaboration initiative. How to use the tool has been described extensively in Chapter 3 pages xx, called Diagnosing systems patterns with the compass. 


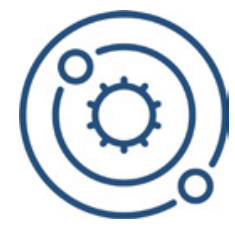

As mentioned in the chapter, this web application is helpful in Phase 1, and can be repeated at any time in all other phases.

- Evaluate stakeholder interviews: this application refers to the competence level of System and helps to understand the patterns emerging from the perspective of different stakeholder. It helps backbone supporters and key stakeholders to use the Compass as a lens to evaluate stakeholder views. They can then draw conclusions from the patterns that are emerging and develop strategies that can ensure all Compass dimensions are adequately addressed. This tool has not explicitly been explained in the practitioner guide, but actors can follow the instruction $\sin$ the web application. It is a helpful support for understanding the context in Phase 1 or Phase 3.

When stakeholders intend to design collaborative interventions, because the quality of process architectures and event designs increases effectiveness, they will be able to choose between the following applications:

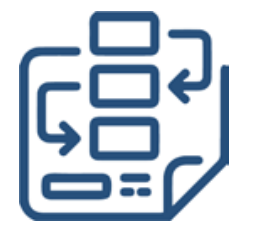

- Plan collaboration processes: this application refers to the competence level of Process and helps actors to Use the Compass to co-create transformative process architectures. How to use the tool has been described extensively in Chapter 4 pages $\mathrm{xx}$, called Co-designing enlivening process architectures. As mentioned in the chapter, this web application is helpful towards the end of Phase 1, the end of Phase 2, and of course for process adjustments in Phase 3 and Phase 4.

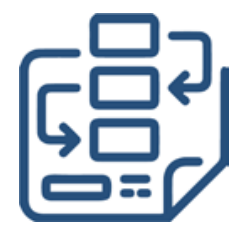

- Design co-creative events: this application refers to the competence level of Process and helps to use the Compass to ensure constructive co-creation among stakeholder in meetings and events. It helps backbone supporters and members of the container to ensure that all Compass dimensions will be addressed during meetings. This application is greatly supported by using the tool described in Chapter 3, pages xx, as Designing meaningful conversations. Following the design practices elaborated in the chapter, the web applications helps design the program flow around the Compass dimensions and allows for a detailed session planning. This web- application is useful throughout all phases of the multi-stakeholder collaboration.

Table 5.15 shows an overview of the web-based applications.

The following tables $(5.16,5.17,5.18$, and 5.19) summarize opportunities to use the tools described in the preceding chapters and the web applications for diagnosing and planning transformative change collectively in the four phases of the Dialogic change model. Figures 5.8, 5.9, 5.10, and 5.11 illustrate the process architectures that show when these tools and applications best support the process of building and maintaining successful collaboration ecosystems in each of the Phases. 
Table 5.15 Overview web-based Compass applications

\begin{tabular}{lll}
\hline Diagnose Collaboration & $\begin{array}{l}\text { Understand Systems } \\
\text { Patterns }\end{array}$ & $\begin{array}{l}\text { Design Collaborative } \\
\text { Interventions }\end{array}$
\end{tabular}

- Find out how you do as a COLLABORATION ECOSYSTEM and monitor the quality of your COLLABORATION PROCESS

- The quality of your collaboration pattern has a direct influence on the results.
- Understand patterns in your - Use the COMPASS to plan STAKEHOLDER SYSTEM more effective COLLABOand evaluate STAKEHOLDER VIEWS with the COMPASS as a lens.

- Understanding systems patterns is a gateway to planning transformative change RATION PROCESSES and improve the positive impact of CO-CREATIVE EVENTS.

- The quality of process architectures and event designs increases effectiveness.
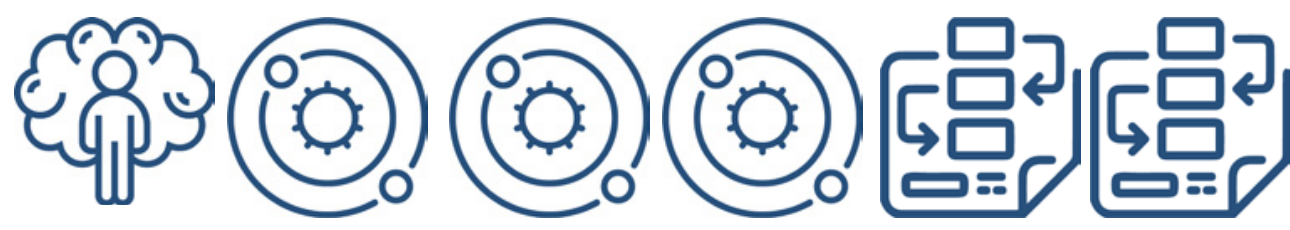

\begin{tabular}{|c|c|c|c|c|c|}
\hline $\begin{array}{l}\text { Assess the } \\
\text { Potential of } \\
\text { Collabora- } \\
\text { tive Action } \\
\text { Groups }\end{array}$ & $\begin{array}{l}\text { Process } \\
\text { Monitoring of } \\
\text { Collaborative } \\
\text { Stakeholder } \\
\text { Initiatives }\end{array}$ & $\begin{array}{l}\text { - Diagnose a } \\
\text { stakeholder } \\
\text { system }\end{array}$ & $\begin{array}{l}\text { Evaluate } \\
\text { stakeholder } \\
\text { interviews }\end{array}$ & $\begin{array}{l}\text { - Plan Col- } \\
\text { laboration } \\
\text { Processes }\end{array}$ & $\begin{array}{l}\text { - Design } \\
\text { Co-creative } \\
\text { Events }\end{array}$ \\
\hline $\begin{array}{l}\text { Diagnose } \\
\text { the collabo- } \\
\text { rative quality } \\
\text { of a team or } \\
\text { core group. }\end{array}$ & $\begin{array}{l}\text { Monitor the } \\
\text { quality of a } \\
\text { collaborative } \\
\text { process with } \\
\text { multiple } \\
\text { stakeholders. }\end{array}$ & $\begin{array}{l}\text { - Understand } \\
\text { systems } \\
\text { patterns } \\
\text { that impact } \\
\text { on your } \\
\text { initiative }\end{array}$ & $\begin{array}{l}\text { Look at pat- } \\
\text { terns emerg- } \\
\text { ing from } \\
\text { the view of } \\
\text { stakeholders }\end{array}$ & $\begin{array}{l}\text { - Use the } \\
\text { Compass } \\
\text { to create } \\
\text { transforma- } \\
\text { tive process } \\
\text { architectures }\end{array}$ & $\begin{array}{l}\text { - Use the } \\
\text { Compass } \\
\text { to ensure } \\
\text { constructive } \\
\text { co-creation }\end{array}$ \\
\hline
\end{tabular}

Table 5.16 Tools and applications in Phase 1: exploring and engaging

Step 1: create resonance

- Check your individual leadership styles and become aware of

o how you as initiator tend to approach change.

o the leadership archetypes available in the initial container.

o the competency patterns within the initial container.

- Conduct a potential analysis for a multistakeholder collaboration approach.
- Web application: Collaborative changemaker/competency patterns

- Practitioner guide:

- Implicit theories and approaches to change (Chapter 3, Table 4.2, page 214)

o Leadership archetypes (Chapter 3 , pages $\mathrm{xx}$ )

- Co-designing enlivening process architectures (Chapter 4, Figure 3.7, page 166)

- Practitioner guide: checklist for the potential of multi-stakeholder collaboration (Chapter 1, Table 1.2, pages 18) 
- Prepare for inspiring conversations to engage stakeholders.

- Prepare the initial process design for your engagement strategy with the Compass.

- Map the stakeholder landscape and understand who needs to be engaged in what ways.

- Analyze potential conflicts and understand the interactions between stakeholders.

- Look at how the perspective of stakeholders shows the presence or absence of certain Compass dimensions.

- Plan impact together with the initial container.

Step 3: build a container for change

- Prepare the event design for a first meeting of key stakeholders with the Compass.

- Assess the quality of the collaboration pattern of your initial container or core group.

- Co-create with core group a process architecture for Phase 2.

- Check if Phase 1 has been sufficiently completed.
- Web application: Get inspired by the questions in the application

- Evaluate Stakeholder Interviews

- Practitioner Guide: The Dialogic Practices (Chapter 3, Figure 3.2, page 139)

- Web application: Plan Collaboration Processes

- Practitioner Guide: Co-Designing Enlivening Process Architectures (Chapter 4, page 237)

- Web application: Diagnose a Stakeholder System

- Practitioner Guide: Diagnosing Systems Patterns with the Compass (Chapter 3, page 173)

- Practitioner Guide: Stakeholder Landscape Analysis (Chapter 3, pages xx)

- Stakeholder Interaction Patterns (Chapter 3, page 184)

- Web application: Evaluate Stakeholder Interviews

- Practitioner Guide:

- Craft a theory of change with the Compass (Chapter 4, page 210)

- Web application: Design Co-creative Events

- Practitioner Guide: Designing Meaningful Conversations (Chapter 3, page 237)

- Web application: Assess the Potential of Collaborative Action Groups

- Practitioner Guide: Quality Check 1: Core Group Assessment (Chapter 4, page 288)

- Web application: Plan Collaboration Processes

- Practitioner Guide: Co-Designing Enlivening Process Architectures (Chapter 4, page 237)

- Practitioner Guide: Readiness Check Phase 1 (Chapter 2, Table 2.2, page 103) 


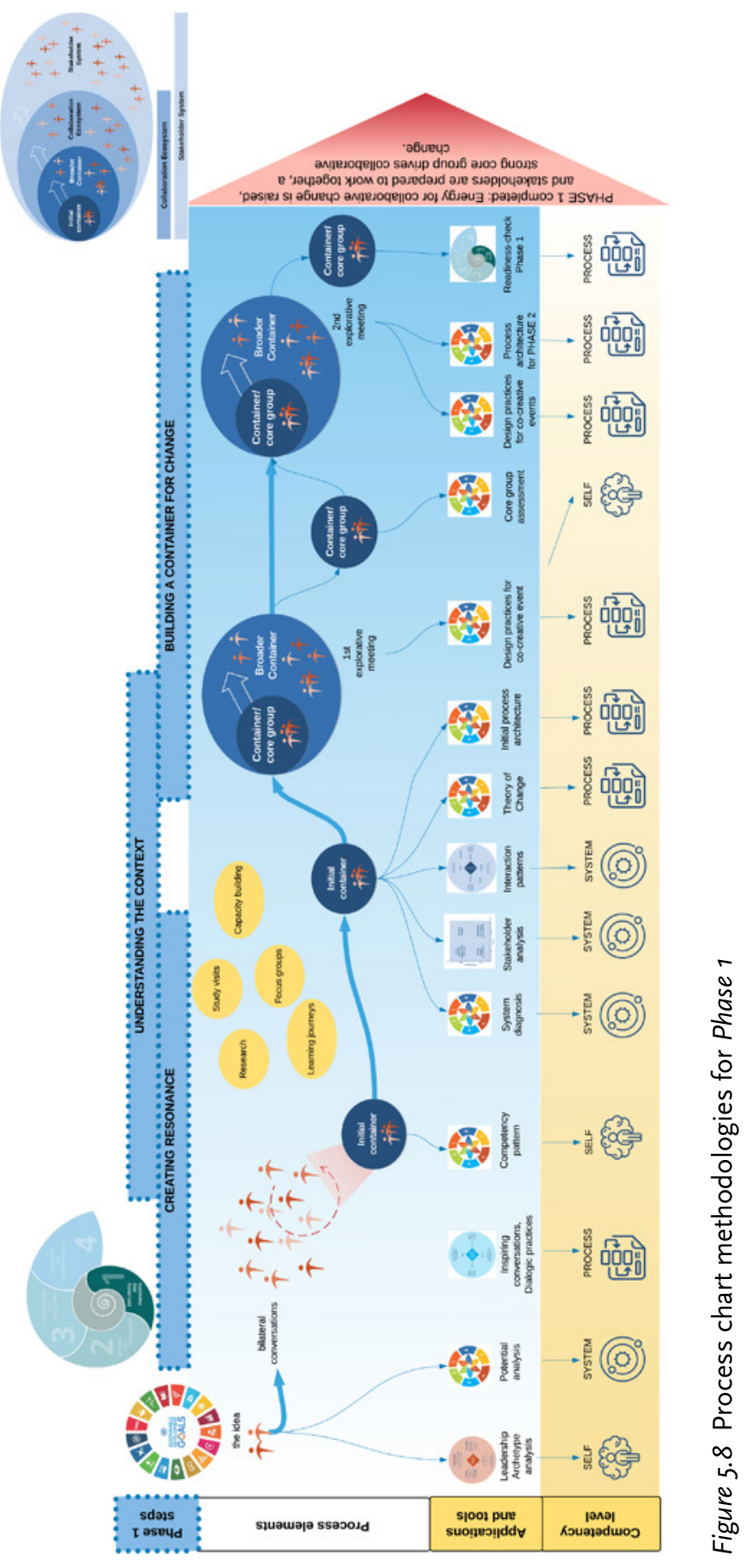


Table 5.17 Tools and applications in Phase 2: building and formalizing

How to use the tools and applications in Phase 1: Exploring and Engaging

Step 4: clarify goals and resources

- Prepare events that help stakeholders to generate a jointly owned vision

- Web application: Design Co-creative Events

- Practitioner Guide: Designing Meaningful Conversations (Chapter 3, page 148); Example from The Field: Sundarbans (Chapter 3, page 155)

Step 5: plan the future together

- Prepare effective planning meetings as stakeholder events.

- Web application: Design Co-creative Events

- Practitioner Guide: Designing Meaningful Conversations (Chapter 3, page 148); Example from The Field: Sundarbans (Chapter 3, page 155); Dialogic Practices (Chapter 3 , Table 3.2, page 139).

- Assess the quality of the collaboration pattern of container or core group.

- Web application: Assess the Potential of Collaborative Action Groups

- Practitioner Guide: Quality Check 1: Core Group Assessment (Chapter 4, page 288)

- Adjust and consolidate the Theory of

- Practitioner Guide: change together with key stakeholders.

- Craft a theory of change with the Compass (Chapter 4, page 210)

Step 6: consolidate agreements and establish structures

- Identify the most suitable collaboration

- Practitioner Guide: structures.

- Typical Structures in Multi-Stakeholder Collaborations (Chapter 4, Figure 4.9, page 235);

- Case from the field: Egyptian Technical Education (Chapter 4, page 262).

- Make a preliminary assessment of the quality of the collaboration ecosystem as input for process architectures.

- Prepare the process architecture for Phase 3 with key stakeholders.

-Web application: Process Monitoring of Collaborative Stakeholder Initiatives

- Practitioner Guide: Quality Check 1: Assessment for Collaboration Ecosystems (Chapter 4, page 295)

- Web application: Plan Collaboration Processes

- Practitioner Guide: Co-Designing Enlivening Process Architectures (Chapter 4, page 237)

- Check if Phase 2 has been sufficiently

- Practitioner Guide: Readiness Check Phase 2 completed. (Chapter 2, Table 2,3, page 105) 


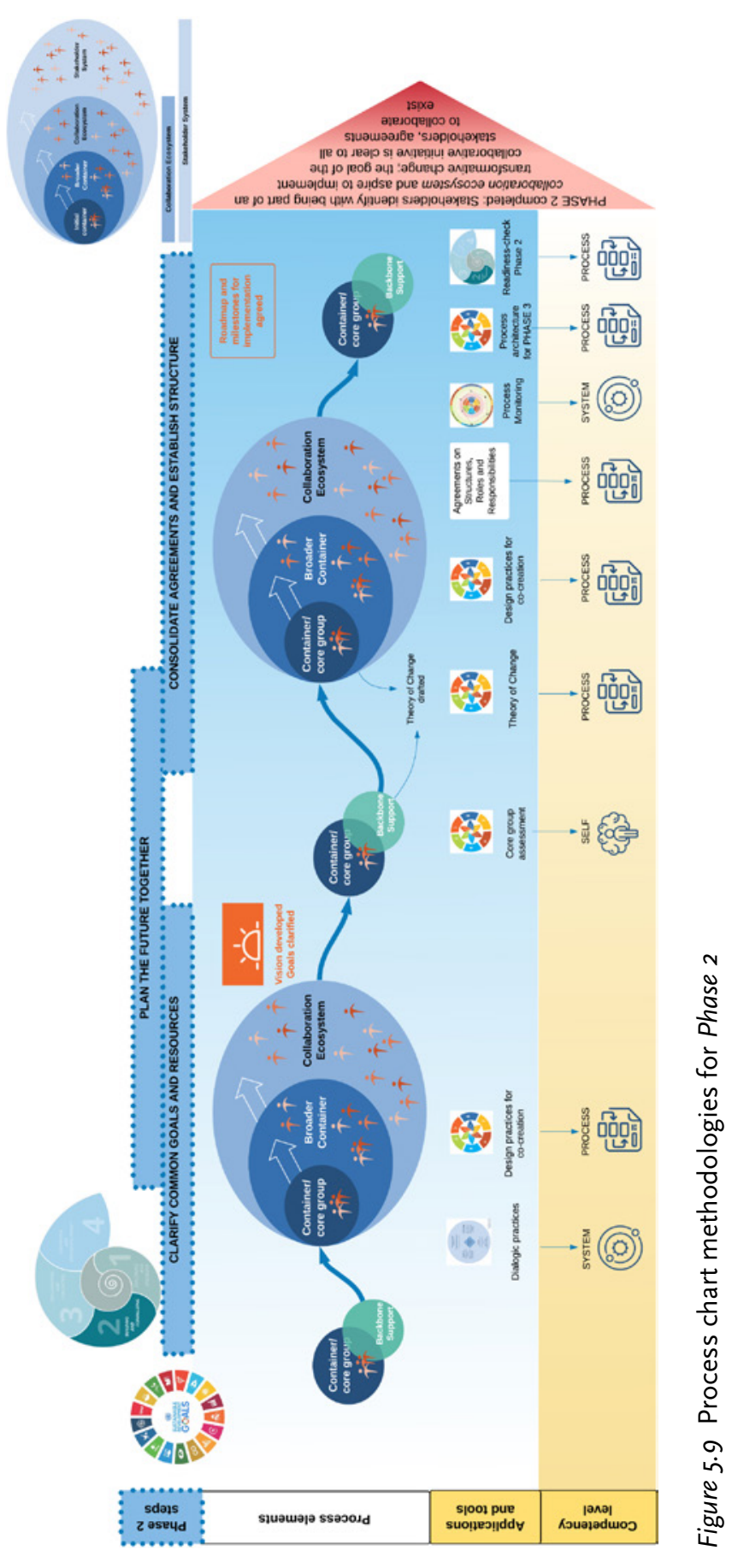


Table 5.18 Tools and applications in Phase 3: implementing and evaluating

Step 7: ensure transparency and communication

- Prepare the communication strategy with inspirations from the Compass.

- Review the stakeholder landscape to ensure all relevant actors are on board with communication.

Step 8: create results and celebrate success

- Redo a diagnosis of systems patterns to gauge required adjustments of the process architecture.

- Review the implementation roadmap with the Compass.
- Web application: Plan Collaboration Processes

- Practitioner Guide: Levels of Communication in Multi-Stakeholder Collaborations (Chapter 5, Figure 5.5. page 314)

- Practitioner Guide: Stakeholder Landscape Analysis (Chapter 3, Figure 3.9, page 180 )

- Web application: Diagnose a Stakeholder System

- Practitioner Guide: Diagnosing Systems Patterns with the Compass (Chapter 3 , page 173)

- Web application: Plan Collaboration Processes

- Practitioner Guide: Co-Designing Enlivening Process Architectures (Chapter 4 , page 237)

Step 9: establish learning mechanisms

- Look at how the perspective of stakeholders shows the presence or absence of certain Compass dimensions.

- Assess the quality of the collaboration pattern of container or core group.

- Make an assessment of the quality of the collaboration ecosystem as input for process architectures.

- Prepare strategic review and stakeholder innovation and learning events with the Compass.

- Prepare the process architecture for Phase 4 with key stakeholders.

- Check if Phase 3 has been sufficiently completed.
- Web application: Evaluate Stakeholder Interviews

- Web application: Assess the Potential of Collaborative Action Groups

- Practitioner Guide: Quality Check 1: Core Group Assessment (Chapter 4, page 288)

- Web application: Process Monitoring of Collaborative Stakeholder Initiatives

- Practitioner Guide: Quality Check 1: Assessment for Collaboration Ecosystems (Chapter 4, page 295)

- Web application: Design Co-creative Events

- Practitioner Guide: Designing Meaningful Conversations (Chapter 3, page 148)

- Web application: Plan Collaboration Processes

- Practitioner Guide: Co-Designing Enlivening Process Architectures (Chapter 4, page 237)

- Practitioner Guide: Readiness Check Phase 3 (Chapter 2, Table 2.4, page 106) 


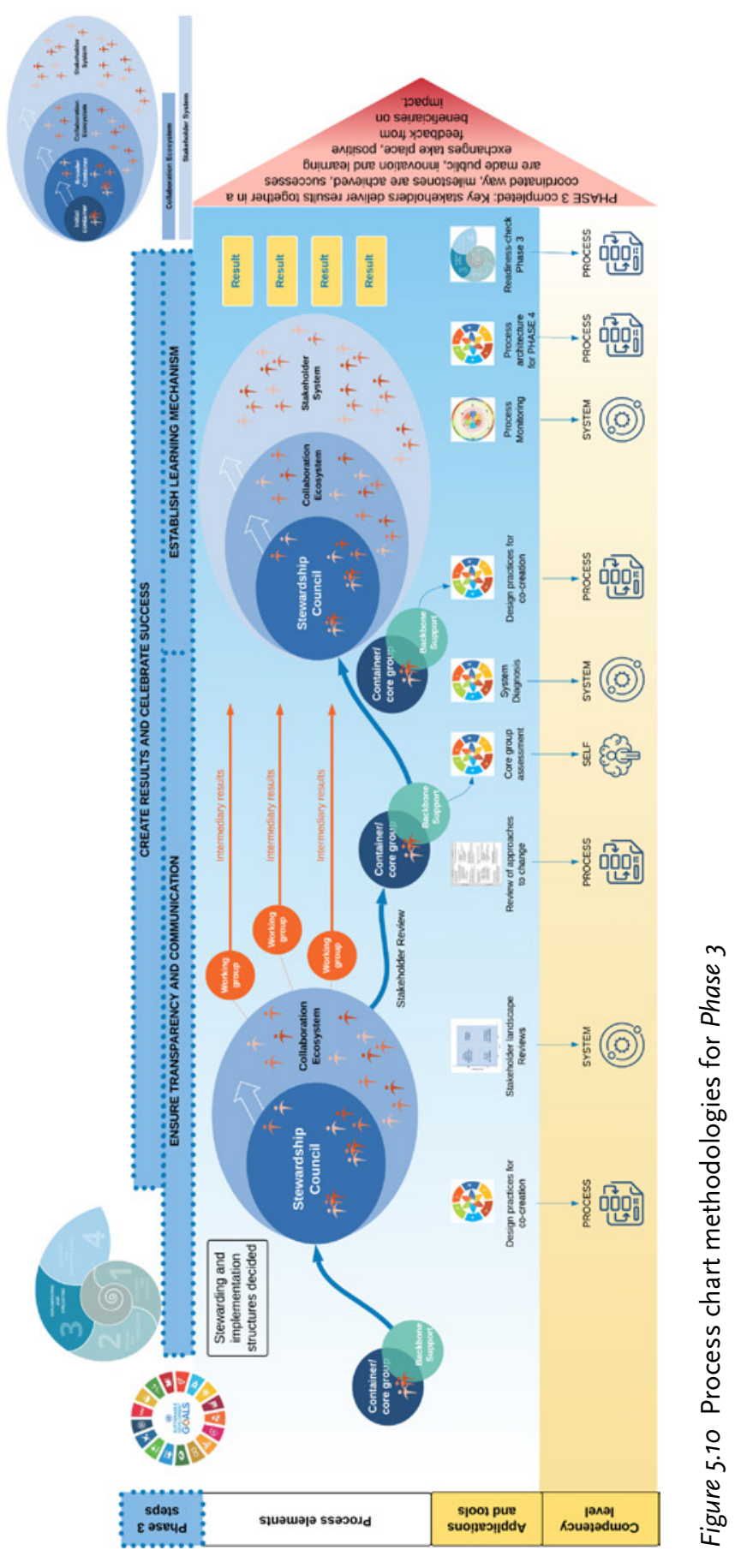


Table 5.19 Tools and applications in Phase 4: sustaining and expanding impact

Step 10: build next level container

- Review the stakeholder landscape to ensure relevant new actors are identified.

- Practitioner Guide: Stakeholder Landscape

Redo a diagnosis of systems patterns to understand conditions for sustaining and expanding impact.

- Prepare for inspiring conversations to engage stakeholders.

- Prepare planning meetings with the next level container with the Compass. Analysis (Chapter 3, Figure 3.9, page 180)

- Web application: Diagnose a Stakeholder System

- Practitioner Guide: Diagnosing Systems Patterns with the Compass (Chapter 3, page 137)

- Web application: Get inspired by the questions in the application

- Evaluate Stakeholder Interviews

- Practitioner Guide: The Dialogic Practices (Chapter 3, Figure 3.2, page 139)

- Web application: Design Co-creative Events

- Practitioner Guide: Designing Meaningful Conversations (Chapter 3, page 148)

Step 11: create management structures

- Attend to the quality of the collaboration pattern in the newly established management structures.

- Adjust the process architecture for Phase 4 with key stakeholders.

- Web application: Assess the Potential of Collaborative Action Groups

- Practitioner Guide: Quality Check 1: Core Group Assessment (Chapter 4, page 288)

- Web application: Plan Collaboration Processes

- Practitioner Guide: Co-Designing Enlivening Process Architectures (Chapter 4, page 237)

Step 12: establish governance and learning structures

- Create governance structures that represent the stakeholder system.

- Prepare stakeholder meetings and learning events with the Compass.

- Use the perspective of stakeholders to learn about how people perceive the changes or the overall situation.

- Make an assessment of the quality of the expanded collaboration ecosystem as input for ongoing process architectures.

- Check if Phase 4 has been sufficiently completed.
- Practitioner Guide: The Role of a Stewarding Council (Chapter 4, page 258); a Implementation Structures (Chapter 4, page 253)

- Web application: Design Co-creative Events

- Practitioner Guide: Designing Meaningful Conversations (Chapter 3, page 148)

- Web application: Evaluate Stakeholder Interviews

- Web application: Process Monitoring of Collaborative Stakeholder Initiatives

- Practitioner Guide: Quality Check 2: Assessment for Collaboration Ecosystems (Chapter 4, page 295)

- Practitioner Guide: Readiness Check Phase 4 (Chapter 2, Table 2.5, page 108) 


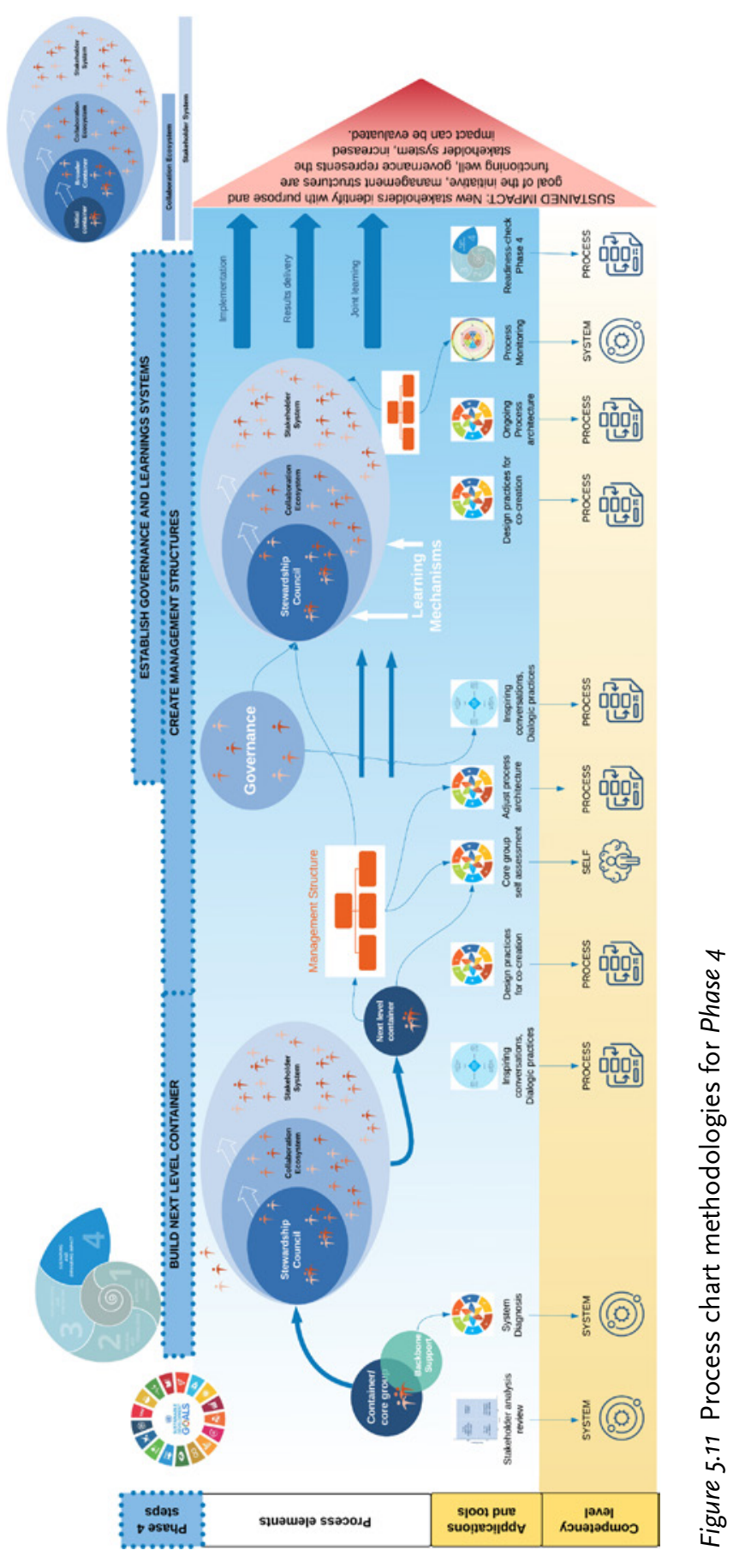




\section{Note}

1 These challenges are derived from actual experiences of stakeholders in collaborative change and compiled across more than 40 projects supported by the authors (see also Kuenkel et al., 2011).

\section{References}

Beisheim, M. (2011). Innovative governance durch Entwicklungspartnerschaften? Chancen und Grenzen am Beispiel transnationaler Wasserpartnerschaften (vol. 20, pp. 5-29). Berlin: Stiftung Wissenschaft und Politik.

Brouwer, H., \& Woodhill, J. (2015). The MSP guide: How to design and facilitate multistakeholder partnerships. Wageningen, The Netherlands: Centre for Development Innovation, University of Wageningen.

Byers, B., Guadagno, F., \& Karaki, K. (2015). From looking good to doing good: Mapping CSO-business partnerships. ECDPM Discussion Paper 182. Maastricht: ECDPM.

Khandker, S. R., Koolwal, G. B., \& Samad, H. A. (2010). Handbook on impact evaluation quantitative methods and practices. Washington, DC: The World Bank. https:// openknowledge.worldbank.org/bitstream/handle/10986/2693/520990PUBo EPI1101OfficialoUseoOnlyı.pdf

Kuenkel, P. (2016). The art of leading collectively: How we can co-create a sustainable, socially just future. Claremont, $\mathrm{NH}$ : Chelsea Green.

Kuenkel, P. (2017). Collaboration in action: From supporting projects to funding partnerships. In SDG knowledge hub. International Institute on Sustainable Development (IISD). http://sdg.iisd.org/commentary/guest-articles/ collaboration-in-action-from-supporting-projects-to-funding-partnerships/.

Kuenkel, P. (2019). Stewarding sustainability transformations: An emerging theory and practice of SDG implementation. Cham, Switzerland: Springer.

Kuenkel, P., Frieg, V., \& Gerlach, S. (2011). Working with stakeholder dialogues: Key concepts and competencies for achieving common goals. A practical guide for change agents from public sector, private sector and civil society. Potsdam, Germany: The Collective Leadership Institute.

OECD. (2002). Glossary of key terms in results-based management. Paris: OECD, DAC Publications.

Pattberg, P., \& Widerberg, O. (2014). Transnational multi-stakeholder partnerships for sustainable development: Building blocks for success. IVM Report, R-14/31. Amsterdam: Institute for Environmental Studies. 


\section{chapter 6}

\section{Epilogue}

This practitioner's guide has elaborated that multi-stakeholder collaborations are not simply a new trend for how to design projects for the implementation of the SDGs. Instead, they are laboratories for a future way of operating more effectively in a global society that ensures that no one is left behind and that the planet returns to health. It has also shown that awareness of self, systems, and processes is a crucial capacity that enables actors in transformative change endeavors to become collective leaders.

People who lead collectively take care of the future and venture into the unknown. They take the road less travelled if it leads to innovation and allows them to test new approaches. They are visionaries who keep a sense of wholeness alive and connect with future possibilities. They harvest collective intelligence by crafting consensual agreements among diverse perspectives with respect for difference. They inspire others to engage with an emotionally compelling goal. They enliven people's humanity, are masters of relationship management, and create a context of trust and continuity. They deal with conflicts and crises constructively and know that these are, in fact, often opportunities for innovation. They follow-through on agreed actions.

In this way, collective leadership for sustainability transformations is the capacity of a group of actors to make their collaborative contribution to a more sustainable future through assuming joint, flexible, and complementary leadership that is always in service of the common good, the jointly agreed goal, or the larger sustainability vision. At the core of collective leadership is the human capacity to dialogue and transform the differences between stakeholders into progress. It enables the transcendence of self-centered views, a prerequisite for not only successfully addressing the challenges of sustainability, but also shaping a thriving future for all.

Sustainability challenges need strategic action, behavioral change, and futureoriented planning. They require collaborative structures and collaboration ecosystems 
that can hold and maintain such collective action and model new behavior on a global and local level. Inspired by tangible results, multi-stakeholder collaborations can show that a sustainable future is possible, with responsible businesses, people-oriented public services, and strong civil society actors. Working towards transformative change for shared wellbeing and a healthy planet needs to become the mainstream activity of all societal actors. It is no longer solely the privilege of an enlightened few, but rather the core concern of everyone who lives in a local and global society. Above all, it needs to become the core focus of those who are in leadership positions, whether they work in the private sector, public sector, or civil society organizations.

The preceding chapters highlighted a new and unfamiliar focus for pathways to SDG implementation: they reminded readers that bringing about transformative change in multi-stakeholder collaborations means taking care of the aliveness of systems, from individual to global, from human to natural systems. The book introduced the concept of stewardship and suggested that the manner in which global to local behavior needs to take place to realize the SDGs is not a matter of control or simply administrative management, but a movement that necessitates every person's participation. This movement needs to enliven people's aspiration, their willingness to care, and their commitment to follow-through on agreed action.

Stewardship is an ethical stance based on reverence for the world as an interconnected system. It means assuming responsibility for safeguarding planetary and human wellbeing in all societies by fostering strategies and activities that are likely to enhance systems aliveness. At the same time, it is important to remember that systems aliveness is not an ideal state to be reached; rather, it is the capacity of a system (natural or human) to constantly create, maintain, re-create, or rehabilitate patterns that enhance aliveness, and open up towards new possibilities of regeneration and further development. This is the basis for resilience in human beings, for the resilience of ecosystems, organizations, societies, and the world as a whole.

The current world is full of news about negative pathways that exhibit conflict, exploitation, societal disparity, and the degradation of natural resources. Multi-stakeholder collaborations, if they increase in quality and quantity, will certainly contribute to the improvement of societal and global forms of governance that negotiate the balance between the interest of the individual and the interest of the whole. Translating this idea into pathways to address the world's complex challenges means acknowledging that achieving Agenda 2030 requires much more than technical, administrative, or social solutions. This effort must entail reaching into people's imagination about sustainable future possibilities as well as enhancing their concrete experience, showing them that it is possible to bring about such a future together with other actors, even if steps may be small.

Transformations to sustainability must be the work of multiple actors at multiple levels of the global society. These transformation practitioners will inevitably use a multiplicity of approaches in the way they lead transformative change collectively across different societal sectors. The ability to collaboratively implement the SDGs can also be called transformation literacy, which can be understood as the ability of decision-makers, change agents and institutional actors to steward the dynamics of societal patterns (Kuenkel, 2019) into the direction of sustainability. It means building multi-stakeholder collaborations in an appreciative way on extant human competencies and on what already works in the right direction. 
Turning human-induced sustainability challenges into opportunities for collective learning and collective action is probably the most important shift that multistakeholder collaborations can contribute to achieving. The new geological age is called the Anthropocene, which means that the global to local changes humankind has caused in the composition of the biosphere and stratosphere will have a decisive impact on the further evolution of the Earth (Steffen et al., 2007, 2018). This calls for a decisive shift in consciousness: only if we recognize the role of human agency in changing the dangerous trajectories of our planet will we be able to restore and maintain the delicate balance of the human-Earth system. Invigorating human competencies is central to leading transformative change collectively.

There is an important concept from systems theory that helps clarify how invigorating people, building enlivening collaboration ecosystems, and creating social systems that leave no one behind and foster a healthy planetary life support system connect: the concept of self-similarity between smaller and larger systems that so often goes unnoticed in the realm of the difficult daily tasks of leading change. Yet, it is important to understand for leading transformative change in multi-stakeholder collaborations that collaboration ecosystems, in which actors build their capacities to deliver change together, are like fractals of a future way of operating in society. While they may be arduous and require a lot of learning by stakeholders involved, they knit the new way of collective action, balanced governance, involvement of weaker stakeholder groups, and negotiating powers of influence into the way societies - including the global society - operates.

These new islands will gradually collate and become the building blocks of large systems change (Waddell et al., 2015). The large systems change envisaged in the SDGs will eventually be an 'organic' process that involves multiple pathways and practices. Although there is no 'one right way' to bring about transformations to sustainability, it helps to acknowledge the complexity of the systems, the multiple efforts at multiple levels, and create learning across multiple different approaches. Transformative change in large systems can only be stewarded by integrating different approaches and staying open to collective learning. Hence, the follow-on learning journey that takes the insights from multi-stakeholder collaborations further is the meta-collaboration between different collaborative initiatives in order to gauge how diverse approaches can complement each other.

There is an exciting pathway in global development that takes us from the era of isolated projects to the emerging era of high-quality multi-stakeholder collaborations to what can be called transformation networks, as is depicted in Figure 6.1. These transformation networks are composed of many different collaboration ecosystems around similar or different issues of common concern, or collaboration ecosystem in a certain geographical area. The difference to today's way of operating is that, in the future, multiple actors, levels, and initiatives will identify with being part of a larger transformation network that aspires to shift a large system towards a positive sustainability tipping point (see also Waddell, 2016). When this happens collaboratively, people take up the work collaboratively and move the system together in a desired direction.

For the implementation of the 17 SDGs in the period between now and the year 2030 this is an important outlook. The more actors who see that they become more effective when they relate to and identify with other collaborative efforts within a larger transformation network, the more they will begin to create synergistic connections across different 


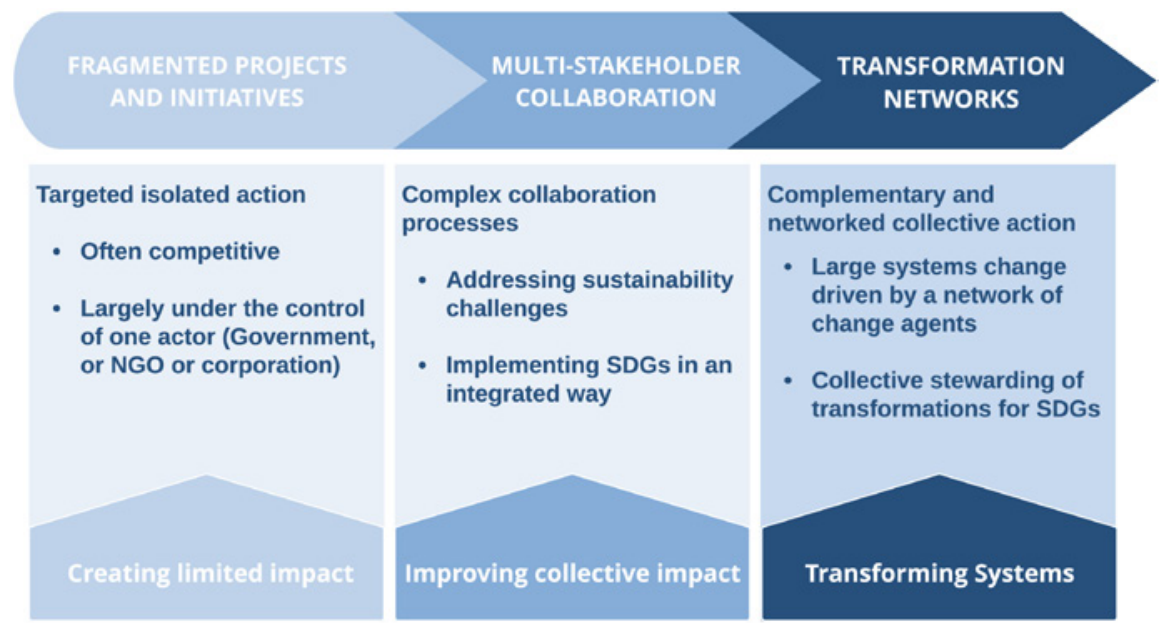

Figure 6.1 From isolated projects to transformation networks

transformative change initiatives and stay aware of the bigger picture and common goal. While specific issue-focused multi-stakeholder collaborations are extremely important, their effectiveness in the overall large-scale system change is dependent on the complementary efforts of many other actors. Hence, planning impactful interventions for SDG implementation needs to overcome fragmented institutional actions, cultivate the quality of multi-stakeholder collaborations, and look out for complementary approaches and initiatives to grow cross-institutional, cross-sectoral, and cross-border transformation networks that lead transformative change collectively at the scale needed to steer our societies and all inhabitants on planet Earth towards a thriving and sustainable future.

\section{References}

Kuenkel, P. (2019). Stewarding sustainability transformations: An emerging theory and practice of SDG implementation. Report to the Club of Rome. Cham, Switzerland: Springer. Steffen, W., Crutzen, P. J., \& McNeill, J. R. (2007). The anthropocene: Are humans now overwhelming the great forces of nature? Ambio, 36(8), 614-621. http://doi. org/10.1016/j.gloenvcha.2015.09.017

Steffen, W., Rockström, J., Richardson, K., Lenton, T. M., Folke, C., Liverman, D., Summerhayes, C. P., Barnosky, A. D., Cornell, S., Crucifix, M., Donges, J. F., Fetzer, I., Lade, S. J., Scheffer, M., Winkelmann, R., \& Schellnhuber, H. J. (2018, August 14). Trajectories of the earth system in the anthropocene. Proceedings of the National Academy of Science of the USA, 115(33), 8252-8259. http://doi.org/10.1073/pnas.1810141115

Waddell, S. (2016). Societal change systems: A framework to address wicked problems. The Journal of Applied Behavioral Science, 52(4), 422-449. http://doi. org/10.1177/0021886316666374

Waddell, S., Waddock, S., Cornell, S., Dentoni, D., McLachlan, M., \& Meszoely, G. (2015). Large systems change: An emerging field of transformation and transitions. The Journal of Corporate Citizenship, 58, 5-30. 


\section{Annex 1 \\ Collective Leadership Compass}

The Collective Leadership Compass has systems aliveness at its core. It is a meta-level guiding structure that can be used as both a diagnosis tool and a planning methodology to invigorate human competencies for future making in six dimensions. Practically, it helps to assess, plan, and enact the transformative change required for collaborative SDG implementation or urgent climate action by creating a methodological bridge between unleashing human capacities and driving issue related actions. The Compass supports individuals, teams, and organizations to strengthen collective leadership competencies and build vibrant and robust collaboration ecosystems of multiple stakeholders that aim at transformative change. The Compass mirrors a pattern of systems aliveness and thus translates the otherwise difficult to rationally comprehend notion of systems aliveness into strategic management of transformative change. Paying attention to the dimensions invigorates life-enhancing thinking and acting

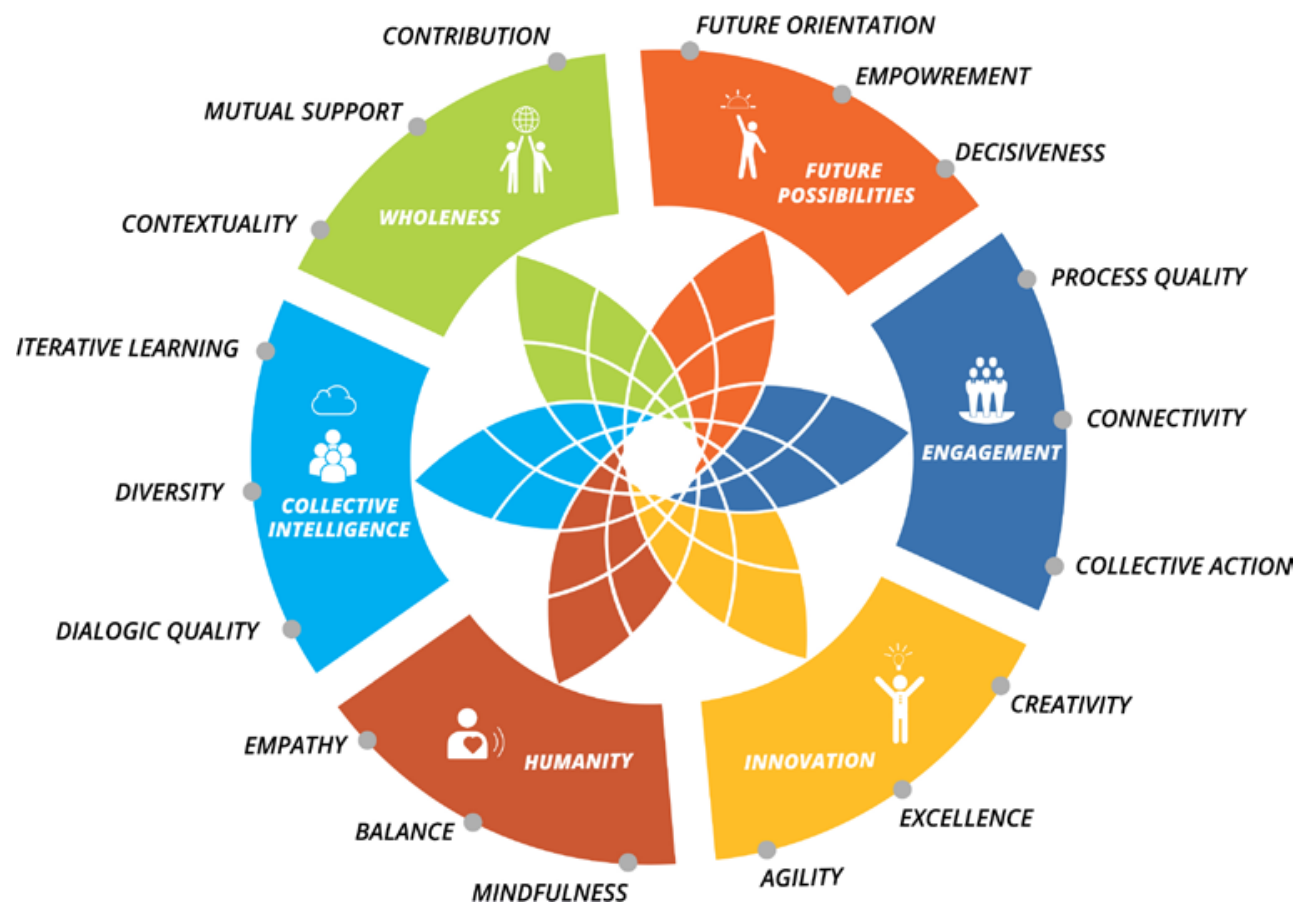

Figure A.1 The Collective Leadership Compass with dimensions and aspects 


\section{Annex 2}

\section{The Dialogic Change Model}

The Dialogic Change Model is a process methodology that allows for the result-oriented planning and implementation of multi-stakeholder collaboration in four phases. It provides a handrail for designing process architectures that enhance all dimensions of the Collective Leadership Compass in the most effective way. It supports the emergence of the underlying principles of co-creating, maintaining, and safeguarding systems aliveness. Beneath the surface of the four phases in multi-stakeholder collaboration is a wealth of knowledge about transformative interaction and communication processes.

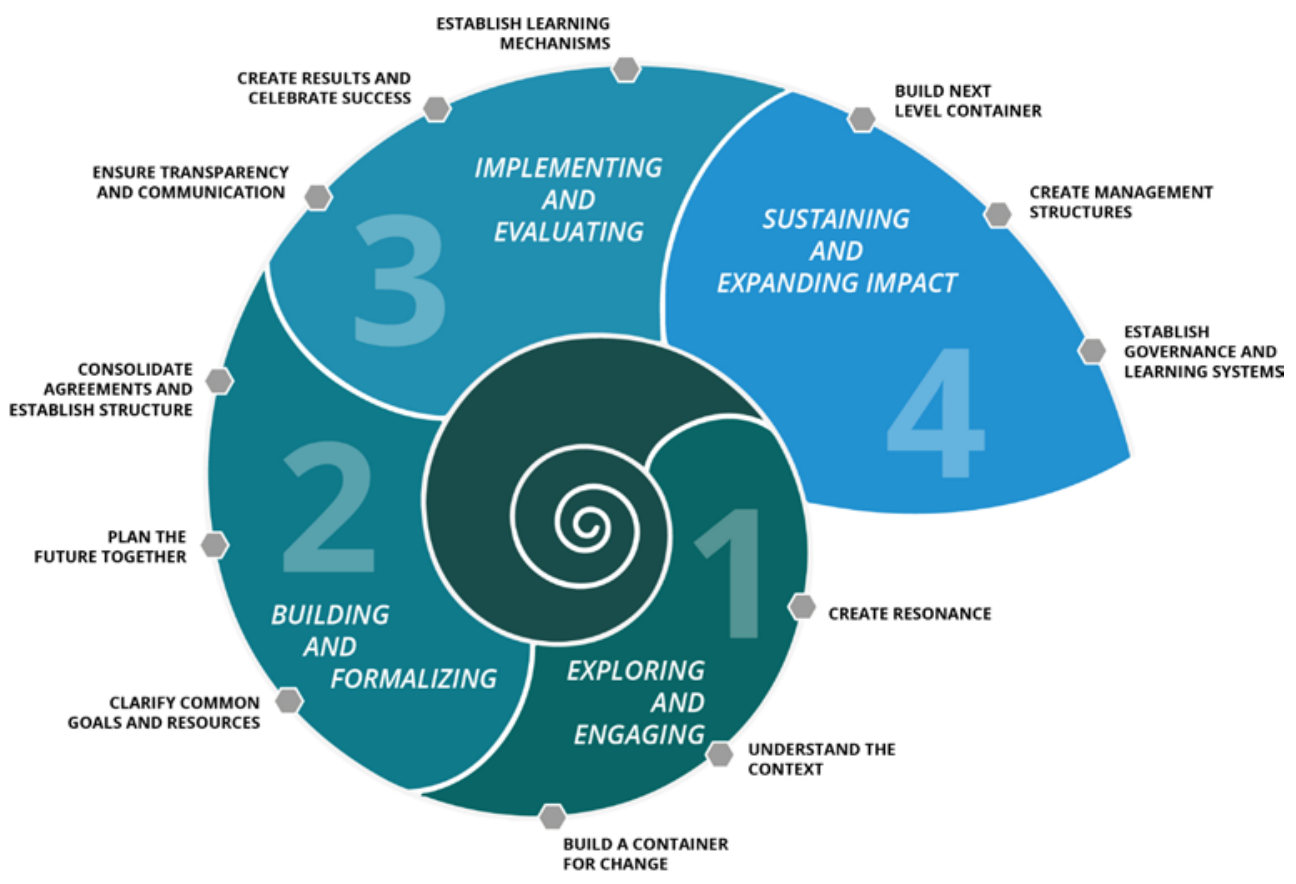

Figure A.2 The Dialogic Change Model 


\section{Annex 3 \\ SDGs}

\begin{tabular}{ll}
\hline SDG 1 & No Poverty \\
SDG 2 & Zero Hunger \\
SDG 3 & Good Health and Well-being \\
SDG 4 & Quality Education \\
SDG 5 & Gender Equality \\
SDG 6 & Clean Water and Sanitation \\
SDG 7 & Affordable and Clean Energy \\
SDG 8 & Decent Work and Economic Growth \\
SDG 9 & Industry, Innovation, and Infrastructure \\
SDG 10 & Reducing Inequality \\
SDG 11 & Sustainable Cities and Communities \\
SDG 12 & Responsible Consumption and Production \\
SDG 13 & Climate Action \\
SDG 14 & Life with Water \\
SDG 15 & Life On Land \\
SDG 16 & Peace, Justice, and Strong Institutions \\
SDG 17 & Partnerships for the Goals \\
\hline
\end{tabular}




\section{Annex 4 \\ Glossary}

\section{Aliveness principles}

The six aliveness principles are mutually dependent conditions that engender patterns of aliveness in smaller and larger systems at multiple scales, in natural and social systems, in socio-ecological systems, and at the global level. If attended to at scale the principles engender systems aliveness. The six principles are: (1) intentional generativity, (2) permeable containment, (3) emerging novelty, (4) contextual interconnectedness (5) mutually enhancing wholeness and (6) proprioceptive consciousness. They are derived from the multi- and transdisciplinary deep dive into Living Systems Theory.

\section{Anthropocene}

The era of the Anthropocene is the most recent period of planetary evolution where the human footprint has become so profound that it begins to change the course of evolution so much that it calls for humankind to learn how to act as stewards of a livable future for all.

\section{Backbone support}

Backbone support is the support for the process of dialogue and cooperation in multistakeholder collaboration by process mandated process facilitators. The backbone support usually has a funded staff team that is trusted and mandated by stakeholders and comprises professionals with process competence and commitment.

\section{Collaboration}

Collaboration includes mutual dependency (such as in responsible supply chain management), power differences (such as in cross-sector water resource management that involves governments and community organizations), or conflicting interests (such as between governments, citizens, and companies in renewable energy initiatives).

\section{Collaboration catalysts}

Based on researched success factors in multi-stakeholder collaboration the collaboration catalysts are a set of six dimensions that enhance the effectiveness of collaboration ecosystems, if attended to in a patterned composition and relational interaction. The 
six collaboration catalysts are co-designed strategy, cooperative delivery, adaptive innovation, dialogic communication, contextual impact, and collective value. In relational interaction with the dimensions of the Collective Leadership Compass, they guide the codesign of successful process architectures in complex multi-stakeholder initiatives.

\section{Collaboration ecosystem}

Collaboration ecosystems are issue-based human interaction systems, comprised of (cross-institutional) actors aiming to change the status quo (usually a common good) for the better. Collaboration ecosystems emerge when people work together for a certain common purpose. These issue-based, human interaction systems are comprised of multiple, usually cross-institutional actors aiming to change the status quo towards a better future for all. They are part of the larger stakeholder system around a certain issue, region, or theme. The collaboration ecosystem aims to ensure that change will benefit all actors involved - and the community or society as a whole, and, not least, the planet Earth. A sense of co-creative collaboration that provides the relationships and capacity for pursuing ambitious aspirations needs to be present.

\section{Collective leadership}

Collective leadership is at the heart of multi-stakeholder collaborations and a prerequisite for creating the conditions for transformative change for SDC implementation. It is the capacity of a group of actors to deliver their contribution to a joint purpose collaboratively while putting high priority on the common good and a balance among the needs of people, profit, and planet. At the core of collective leadership is the human capacity to dialogue and transform differences into progress. It enables the transcendence of self-centered views, a prerequisite for successfully addressing the challenges of sustainability.

\section{Collective Leadership Compass}

The Collective Leadership Compass has systems aliveness at its core. It is a meta-level guiding structure that can be used as both a diagnosis tool and a planning methodology to invigorate human competencies for future making in six dimensions. Practically, it helps to assess, plan, and enact the transformative change required for collaborative SDG implementation or urgent climate action by creating a methodological bridge between unleashing human capacities and driving issue related actions. The Compass supports individuals, teams, and organizations to strengthen collective leadership competencies and build vibrant and robust collaboration ecosystems of multiple stakeholders that aim at transformative change. The Compass mirrors a pattern of systems aliveness and thus translates the otherwise difficult to rationally comprehend notion of systems aliveness into strategic management of transformative change. Paying attention to the dimensions invigorates life-enhancing thinking and acting 


\section{Container}

The term container refers to the function and relational quality of an initiating team or core group of interested actors in multi-stakeholder collaboration. Ideally, this group of people already represents - to some extent, at least - the diversity of stakeholders so that it can embody the range of interests in the change initiative. It is composed of people who can make a difference, who are highly interested in change, are willing to respect each other and who are committed to the goal. They become the microcosm of the future collaboration ecosystem.

\section{Dialogic Change Model}

The Dialogic Change Model is a process methodology that allows for the result-oriented planning and implementation of multi-stakeholder collaboration in four phases. It provides a handrail for designing process architectures that enhance all dimensions of the Collective Leadership Compass in the most effective way. It supports the emergence of the underlying principles of co-creating, maintaining, and safeguarding systems aliveness. Beneath the surface of the four phases in multi-stakeholder collaboration is a wealth of knowledge about transformative interaction and communication processes.

\section{Dialogic Facilitation}

Dialogic facilitation is a facilitation mode that moves away from handing over the responsibility for group effectiveness to an outside neutral person. A person who facilitates in a dialogic way is concerned with the question: what is the conversation we really need to have here in order to move forward? Such a person is continually searching for an answer to that question in collaboration with her or his colleagues. A dialogic facilitator is also required to continuously cultivate a sense of inner knowing and self-observation. Coming to understand oneself and understanding others is a cornerstone of dialogic facilitation. At the core of dialogic facilitation is the understanding that the positive results of multi-stakeholder collaborations that bring about transformative change are inextricably linked to the learning journeys of all stakeholders towards creating more constructive human interaction patterns.

\section{Dialogic intervention}

In the four phases of the Dialogic Change Model, dialogic interventions refer to trust building, relationship management, facilitating the connection to emotionally compelling goals, enabling meaningful conversations and reflective and generative dialogues, and creating space for inspirations, learning, insights, and creativity.

\section{Dialogic process facilitation}

Dialogic facilitation aims to shift communication patterns among diverse and often conflicting stakeholders towards life-enhancing patterns that are not only enacted in stakeholder meetings, but relate to the design and implementation of the entire 
multi-stakeholder collaboration throughout all four phases of the Dialogic Change Model. Dialogic process facilitators support collaborative interventions into complex stakeholder systems and act as stewards of transformative change.

\section{Facilitation}

Facilitation can be described as a process in which one person or two persons guide the conversation in a group. These are usually people who have the acceptance and trust of the members of the group, are sufficiently neutral towards the different opinions, and do not have any intention to steer the group towards a predefined outcome of their particular interest. They help the group to identify or solve problems and make decisions that impact future pathways. They assist the group of stakeholders to see a wider range of possibilities, to ensure that different angles are explored, and that the conversation stays in an effective flow.

\section{Patterns of Aliveness}

Patterns of Aliveness are the relational compositions or constellations of transformative and life-enhancing co-creation in natural, human, or socio-ecological interaction systems that aggregate to systems aliveness at multiple scales.

\section{Process architecture}

A process architecture is a dynamic visualization of the sequence and interlinkages of informal and formal communicative interactions and events that enliven a collaboration ecosystem in which stakeholders lead collectively towards a desired outcome. The process architecture, ideally the result of collective reflection and agreement, can be seen as a guiding structure, almost like a balustrade that creates reliability and transparency. The more difficulties, conflicts, and differences of interest can be expected among stakeholders the more structure needs to be provided by the process architecture. It also helps the collaboration ecosystem develop its own identity and safeguard it from unhelpful interventions.

\section{Stakeholders}

Stakeholders are people or institutions that have an interest in a particular course of development, or a particular decision, either as individuals or as representatives of a group. This includes people who influence a decision, who are key players in implementation, or who are affected by the development.

\section{Stakeholder system}

The stakeholder system is composed of all institutional (or sometimes individual) actors that are relevant with regard to the issue that is in focus for a collaborative initiative. Most sustainability challenges have complex stakeholder systems with actors from communities, public sector, civil society, private sector, as well as academic or educational institutions. 


\section{Stewardship}

Stewardship is the proactive and collaborative engagement for sustainability transformations by many complementary actors. Together, they foster transformation networks, mutually supportive strategies and multiple pathways to enhance patterns of socio-ecological systems aliveness. It is anchored in a sense of responsibility for safeguarding planetary and human wellbeing at all levels of the global society.

\section{Structural intervention}

In the four phases of the Dialogic Change Model, structural interventions refer to all actions that consolidate a collaboration ecosystem and help it into the delivery of concrete results - such as agreements on goals, roadmaps, implementation plans, governance and stewarding structures as well as accountability and learning or monitoring mechanisms. They reorganize the relationships and the communication between stakeholders.

\section{Sustainability}

Sustainability is here defined as the ability of humankind to live well with each other, with nature and within the planetary boundaries and their systemic logic.

\section{Sustainable Development Goals}

The Sustainable Development Goals (SDGs), as part of the Agenda 2030 "Transforming Our World", alternatively also named global goals, are a collection of 17 interdependent goals that convey call to action in order to end poverty, protect the life support systems of the planet, and ensure that all of humanity enjoys peace and prosperity. The SDGs inspire and guide Government planning, policy development and implementation, but also encourage non-state actors, such as the private sector and NGOs to align their activities with the targets formulated. Their aspiration is to work in a spirit of partnership for a sustainable way of living that shows responsibility for current and future generations. The 17 Goals and their 169 targets have been developed in a broad consultation process with stakeholders from public, private, and civil society sectors.

\section{System}

In this context, a system is defined as entity with a clear but permeable boundary and a degree of autonomy that allows it to define its own internal specifications.

\section{Systems aliveness}

Systems aliveness is the capability of small and larger systems to gain resilience, regenerate, and maintain their vitality in mutual consistency with other systems. Systems aliveness is always relational and interdependent. It refers to a recognizable patterned process of doing transformations as well as a recognizable patterned outcome - sustainability. 


\section{Theory of change}

The term theory of change describes how actors in collaborative change initiatives expect that impact can be achieved. This description of an "impact logic" of a project or change initiative can also be graphically represented in such a way that it shows how measures and activities lead to expected results in a certain context, and on which assumptions of the situation they are based. This helps stakeholders to jointly see how collaboratively planned activities lead to the desired goals.

\section{Transformations}

Transformations here refer to collaborative actions that rearrange stakeholder relationships in a way that there can be thriving communities, diverse and lively ecosystems, energy systems that safeguard the planetary life support system, and cities that serve both the environment and their citizens. In short, getting SDG implementation right is a good enough pathway to global transformations. It must be truly empowering and shift the way we see the world, act in it, and relate to each other. True transformations require fundamental shifts in collective behavior change, business practices, and government-citizen interaction.

\section{Transformation literacy}

Transformation literacy is the knowledge and capacity of a collective of decisionmakers, change agents, and institutional actors to steward sustainability transformations effectively together across institutions, societal sectors, and nations.

\section{Transformation networks}

Transformation networks are composed of many different complementary collaboration ecosystems around similar or different issues of common concern, or collaboration ecosystem in a certain geographical area. Actors in transformation networks aspire to shift a large system towards a positive sustainability tipping point. They consciously operate in a distributed networked action mode, create synergistic connections across different change initiatives, and stay aware of the impact on the overall large-scale system. 


\section{Index}

Page numbers in italic indicate a figure and page numbers in bold indicate a table on the corresponding page.

action modes 184-187, 186, 197

activity and result monitoring $286, \mathbf{2 8 7}$

Adventist Development and Relief Agency

(ADRA) 31, 203, 204

African Cashew Alliance (ACA) 21

African Union Development Agency (AUDA-

NEPAD) 26

agreements: consolidation of $87-89,133,198$;

in multi-stakeholder collaboration 260-261,

261; Voluntary Partnership Agreements

$116-117,120$

Alexander, Christopher 50

aliveness 6, 49, 50, 52-53, 129, 208; in collaboration ecosystem, sustaining 252-263, 255; cultivation in collaboration ecosystems 226-252; patterns of 55,129 , $162,210,252,268,313$; see also systems aliveness

Amref Health Africa 39

backbone support 90, 122, 252, 255, 255,

256-257; capacity-building role $257-258$;

caretaker role 257 ; catalyst role 257 backcasting 220, 222

Bangladesh Environment and Development Society (BEDS) 155

Ban Ki-moon 2

Cambodia, land management in 150

check-in 149-150

check-out 149, 153

civil society $36,38-40,42,197$

climate crisis 2

Cocoa Life Program 38

co-creation, dynamics of 46-48

collaboration catalysts 268, 269, 270, 283, 288, 295; adaptive innovation 275-276, 276; co-designed strategy 270-271, 272; collective value $276-278,278$; contextual impact 280-282, 282; cooperative delivery 273-274,

274; process monitoring with 302

collaboration ecosystem $4,5-6,52,72$, 170-171, 208, 267-268; $4 \mathrm{C}$ initiative as 113 , 114-115; and action modes 184, 185, 186, 187; applications for 322; and backbone support 256-258; bodies for sustaining 
aliveness in 255; boundaries 209; building, in bottom-up and top-down processes 230-231, 231; and communication 89; communication processes and learning mechanisms for 317 ; and cooperation processes 23; creation of 51-53; cultivation of aliveness in 226-252; and Dialogic Change Model 73, 74; and dialogue 132, 133; and engagement 47, 56; forestry management in Laos 117; internal communication 315-316; and learning culture 66; and mutual support 46; Nebhana Water Forum 122, 125-126; sense of belonging 159; and transparency 92 collaborative structures 252, 253; agreements 260-261, 261; backbone support 256-258; Egyptian Dual System of technical education 262-263; high-level support structures 254; implementation structures 253-254; linkage structures 254-255; stewarding council 258-259; stewarding structures 253; technical working groups 259-260; see also process architecture collective intelligence $47-48,58,63,143$, 197, 209, 334; and backbone support 257; collaboration quality check 293, 299-300; and competency patterns 165 ; conversations that harvest 152; and culture and relationship transformation 215; Dialogic Change Model 78, 83, 91, 97, 112, 114, 120, 124; dialogic communication 279-280, 280; and dialogic process facilitators 158, 160; and dialogue 132, 134-136, 141, 142, 144, 145, 212, 228; and process architecture 228, 233, 234, 243, 246, 248; and systems patterns 176, 179, 192; and trouble shooting 303, 305, 306, 309, 310, 311 collective leadership $4-5,45-46,45,162$, 252, 256, 334; competencies for 54; and containers 199; and core group 76, 77; and Dialogic Change Model 73; and process architecture 277

Collective Leadership Compass 6, 53-54, 54, 73, 74, 130, 195, 268; applications 64; applications, levels of 321 ; aspects $6 \mathbf{1}-\mathbf{6}_{\mathbf{3}}$, 65; collective intelligence $58,63,78,83$, 91, 97, 112, 114, 120, 124, 176, 179, 192, 209, 233, 234; and collective reflection
266; competency patterns 162-165, 164; connection between process quality and dialogic quality 227; crafting theory of change with 217-226; diagnosing systems patterns with 173-180, 189-193, 194; dimensions 59, 61-63, 66; enacting change based on planning with 66-67; engagement $56,61,77,83,90,97,112,114$, 120, 123, 175, 177, 189-190, 230-231, 231; future possibilities $55-56,61,77,78,83$, 91, 98, 112, 114, 119, 123, 175, 177, 189, 208, 232, 232; humanity $57-58,62,78,83,91,97$, $112,114,120,124,176,178,191-192,209$, 235-236, 236; innovation 57, 62, 78, 83, 91, $98,113,115,120,125,175-176,178,190-191$, 208, 234-235, 235; observing patterns with 65-66; purpose of 6o; systems aliveness $54,55-60$; and tasks of dialogic process facilitators 158-160, 160; and trouble shooting 302-313; uniqueness of 53; web-based applications 324; wholeness $58-59,63,78,83,97,113,115,119,124-125$, 176, 179, 193, 208, 236-237, 237; see also collaboration catalysts

Common Code for the Coffee Community (4C) 30, 111; dialogic facilitation 144-145; Global Coffee Platform 113, 114-115, 116; goals, implementation and evaluation of 115 communication 5, 89, 91-93, 133, 303, 313; and action modes 184; and collective intelligence 134-136; constructive 151; dialogic 279-280, 280; and dialogic practices 141; external 319, 320; internal 315-319; levels of 314; with participating institutions 318; patterns 137; processes, for core groups 316; between stakeholders 46; see also dialogue competency patterns 162-165, 164 consultation processes $23-24,24,25,26$, 28,34

consumer awareness for sustainability 11-12 container(s) 76-77, 78, 148, 209; broader 77 , 81, 200, 209, 312; building 81-82, 133, 198, 199-202, 201; collaboration quality check for 288-290; and engagement of stakeholders 202-203; initial 81, 83, 200, 201, 256, 312; internal communication 315-316; 
and meaningful conversations 148-149;

Mongolia, organic agriculture in 203-204,

204, 205; next-level 96, 99-100, 134

content objectives 151, 242

context analysis $80-81,111,218,230,234$,

240,248

convergence 196-198, 197

cooperation processes 23-24, 24, 25, 34

cross-border multi-stakeholder collaborations

20-21

cross-model conversation 135

cross-sector collaboration 3, 28

cross-sector dialogue/conversation 26-27, 35

cross-sector settings $32-34$; civil society $38-40$,

42; private sector 36-38, 41-42; public

sector 34-36, 41

debates 135

Dialogic Change Model 6, 71, 72-75, 74, 130,

134, 195, 268, 321; building and formalizing

(phase 2) 82-89, 105-106, 198, 209, 327;

consolidating agreements and establishing structures $87-89,133,198$; containers

$76-77,78,81-82,133,198,200,208$;

context, understanding $80-81,133,198,208$,

218; creation of results and celebration of

success 93-94, 133; exploring and engaging

(phase 1) 76-82, 103-104, 198, 208-209,

324-325; Global Coffee Platform 110-116; goals and resources, clarification of $85-86$, 133, 198, 209; governance and learning structures 101-102, 134; implementing and evaluating (phase 3) 89-95, 106-108, 209, 329; Laos, forestry management in 116-121; learning mechanisms 94-95,

133; management structures 100-101, 134; Nebhana Water Forum, Sbikha 121-126; next-level containers 99-100, 134; planning the future $86-87,133,198,209$; readiness check 102, 103-110; resonance, creation of 78, 79, 133, 198, 208, 209; sustaining and expanding impact (phase

4) 96-102, 108-110, 331; transparency and communication 91-93, 133

dialogic communication 279-280, 280

dialogic facilitators see dialogic process

facilitators dialogic interventions 195, 196, 197, 198 dialogic practices 137-141, 139, 197; listening 139-140; respecting 140; suspending 140-141; voicing 138-139

dialogic process facilitators 130-131, 142, 144, 158, 208-210; building purpose 158-159; circles of belonging 159; culture of strategic reflection 159; designing meaningful conversations 148; diversity for dialogue, harvesting 160; facilitative interventions 147-148; in guided conversations 135, 136; individual level, attention at 146 ; level of group process, attention at 146 ; levels of competence building for 161 ; process competence 194-204; prototypes of future 159; self-awareness 161-169; system level, attention at 146-147; systems patterns, understanding 169-193; systems view, emphasizing 160; tasks of 160 ; see also facilitation

dialogic quality 227, 227, 228, 315

dialogue 5, 58, 212; advocacy and 137-138, 187; diversity for 160 ; essentials of 132-134; fostering 233, 233; generative 136, 141, $145,147,197$; inquiry and 137, 138, 187; multi-stakeholder 25-27, 32, 38; and multistakeholder collaborations 13, 14; policy dialogues 217-218; purpose in multistakeholder collaborations 131-158; reflective $136,145,147,197,210$; role of facilitation in 141-144; from thinking alone to thinking together 134-136, 137

dialogue platform 21, 25, 29, 35

divergence 196-198, 197

Egyptian Dual System (EDS) of technical education 247-252, 249, 251, 262-263, 262

engagement $47,56,61,143,200,334$; and backbone support 257; bottom-up approaches 230, 231; collaboration quality check 290-291, 297; and competency patterns 164; cooperative delivery 273-274, 274; and culture and relationship transformation 215; Dialogic Change Model 77, 83, 90, 97, 112, 114, 120, 123; and dialogic process facilitators 158, 159; and dialogue 132, 140, 141, 142, 145, 153, 155; and listening 
140; and process architecture 228, 230-231, 231, 240, 244, 248; and process structure 152; and systems patterns 175, 177, 189-190; top-down approaches 230-231; and trouble shooting 303, 304, 305, 307, 308, 309, 310, 311,312

engagement value 131

expert working groups see technical working groups

external communication 314, 319, 320

external facilitators 142

Extractive Industries Transparency Initiative (EITI) 20

facilitation 135, 141, 161; Common Code for the Coffee Community (4C) 144-145; connecting people with wholeness and future possibilities 150-151; creating conversations that harvest collective intelligence 152; design practices for co-creative conversations 154; humanity in beginning/ end of conversations 148-149; interventions 147-148; level of attention in 145-147; meaningful conversations, designing 148 ; pathways towards future possibilities and close with humanity 153; practicing engagement and fostering innovation 153; process structure that ensures engagement 152; role in dialogues 141-144; Sundarbans mangrove forest (India/Bangladesh) 155, 156, 158; techniques 142; three levels of meeting objectives 151; see also dialogic process facilitators

Finland's Roadmap to a Circular Economy 274 Finnish Innovation Fund, The (SITRA) 274

Forest Law Enforcement, Governance, and Trade (FLEGT) Action Plan 116, 120

Forest Stewardship Council (FSC) 20 fragmented ego-system 208 future possibilities $47,55-56,61,143,208,334$; and backbone support 257; co-designed strategy 270-271, 272; collaboration quality check 290, 296; and competency patterns 164; and convergence 198; Dialogic Change Model 77, 78, 83, 91, 98, 112, 114, 119, 123; and dialogic process facilitators 158-159; and dialogue 132, 141, 150-151; pathways towards 153; and process architecture 228, 232, 232,
244, 248; and systems patterns 175, 177, 189; and transformation of structures/rules 216 ; and trouble shooting 304, 307, 308, 309, 311

generative dialogues 136, 141, 145, 147, 197

German Partnership for Sustainable Textiles 22

Global Coffee Platform 30, 110-111; 4 C initiative as collaboration ecosystem 113, 114-115; $4 \mathrm{C}$ initiative's goals, implementing/evaluating 115; institutionalization of collaboration ecosystem 116; preparation for collaboration 111-112, 112-113

Global Nature Fund (GNF) 155

goals and resources, clarification of 85-86, 133, 198, 209

governance: and learning systems 101-102; structures $87,96,101-102,134,252$

guided conversations 135-136, 145

high-level support structures 254

humanity 47, 57-58, 62, 143, 209, 334; and backbone support 257; in beginning/end of conversations 148-149; collaboration quality check 292, 298-299; collective value 276-278, 278; and competency patterns 165; Dialogic Change Model 78, 83, 91, 97, 112, 114, 120, 124; and dialogic process facilitators 158, 159; and dialogue 132, 133, 141, 148-149; and individual consciousness transformation 214; pathways close with 153; and process architecture 228, 235-236, 236, 245, 248; and systems patterns 176, 178, 191-192; and trouble shooting 303, 306, 307

Iceberg tool 172 impact monitoring 286, 287 implementation structures 253-254, 256 innovation 47, 57, 62, 143, 208, 334; adaptive 275-276, 276; and backbone support 258; collaboration quality check 291-292, 297-298; and competency patterns 164; Dialogic Change Model 78, 83, 91, 98, 113, 115 , 120, 125; and dialogic process facilitators 158 , 159; and dialogue 132, 141, 153; and process architecture 228, 234-235, 235, 245, 248; and systems patterns 175-176, 178, 190-191; and transformation of information flows 215; and trouble shooting 308 
integrated water resource management (IWRM) 28, 272

internal communication 314; core group and collaboration ecosystem 315-316; participating stakeholders and their institutions 316, 318-319

International Conference on Small Island Developing States (SIDS) 19

international multi-stakeholder collaborations 19-20

joint planning document 86

Jordan, youth economic empowerment project in $217-218$

Kantor, David 184

Kavango-Zambezi (KAZA) Transfrontier

Conservation Area 20-21

Kenya Healthcare Federation 39

Kline, Nancy 139-140

Laos, forestry management in 116-117; application of Collective Leadership Compass 119-120; co-creation of vision and building trust 117-118, 118; negotiation with European Union 120-121; timber legality definition, testing 120; voluntary partnership process, structures for 118-119

leadership 3, 44-45; archetypes 162, 165-169, 166; collective $3,4-5,45-46,45,54,73,76$, 77, 162, 199, 252, 277, 334; energy 166-169; individual 45; lack of 309-310; shared/ distributed 45

learning mechanisms 94-95, 133, 266, 275, 281; for collaboration ecosystem 317; for core groups 316

learning structures 101-102, 134, 233

linkage structures 254-255

local multi-stakeholder collaborations 22-23 Logical Framework Approach (LogFrame) 210 lover leadership energy 167

magician leadership energy 168-169

malaria, combating 10-11

Malteser International 39

management structures 100-101, 134

Maturana, H. R. 197

Meadows, Donella 171 media 319,320

memorandum of understanding 88

Ministry of Food, Agriculture, and Light Industry of Mongolia (MoFALI) 31

Mongolia, organic agriculture in 203-204; process architecture multi-stakeholder partnership for 205; shared vision for 204 monitoring: activity and result monitoring 286,287 ; benefits of 285 ; ground rules 284-285; impact monitoring 286, 287; OECD definition of monitoring and evaluation 284; types of 287; see also process monitoring

Moroccan Center for Climate Change Competency 276

multi-stakeholder collaborations 3, 4, 5-6, 10-13, 71-72, 208; agreements in 260-261, 261; building and formalizing 82-89; challenges 16; collective leadership 44, 45-46, 45; Collective Leadership Compass 53-67; cross-sector settings 32-43; exploring and engaging 76-82; factors for choosing 17; features of 13-14; formats of 23-31, 25, 32; at global and international level 19-20; implementing and evaluating 89-95; interventions, designing 323; levels of communication in 314-319; levels of skills development for 7; managing difficulties/ conflicts in 302-313; meta-collaboration 236; at national level 21-22; phases of 72, 75; planning impact in 210-226; potential, checklist for 18; as a promising approach 15-16; purpose of dialogue in 131-158; quantity and quality of 17; at regional and cross-border level 20-21; role of process monitoring in 283-301; in SDG implementation 13-17; as shared interest 33; at subregional and local level 22-23; sustaining and expanding impact 96-102; see also collaborative structures; Dialogic Change Model

multi-stakeholder dialogues 25-27, 32, 38 multi-stakeholder forum 27

multi-stakeholder initiatives 25, 27, 29-30, 32, 80, 90,92

Multi-Stakeholder Partnership for Organic Agriculture (POAg) 31

Multi-Stakeholder Partnership for Sustainable Tuna Fisheries, Livelihoods, and 
Communities in Mindoro Straits and

Lagonoy Gulf, Philippines 40

Multi-Stakeholder Partnership for Universal

Health Coverage through Access to

Specialized Services in Kenya 39-40

multi-stakeholder partnerships 25, 27, 30-31,

32, 37, 39-40

multi-stakeholder platforms 25, 27-29, 32

National Association of Mongolian Agriculture Cooperatives (NAMAC) 31

National Committee for the Business

Environment of Morocco 35

National Economic Development and Labour

Council (NEDLAC) 27

national level multi-stakeholder collaborations

21-22

Nature, Environment, and Wildlife Society

(NEWS) 155

Naturland Association 155

Nebhana Water Forum, Sbikha (Tunisia) 29,

121-122; Collective Leadership Compass

123-125; process architecture for setting

up 126; stakeholder perspectives,

acknowledging 122, 125; water-related

collaboration ecosystem 125-126

non-governmental organizations (NGOs) 39,

$40,43,310$

observe-focus-enact cycle 65-67, 67

organic agriculture 204-205

partnership: multi-stakeholder 25, 27, 30-31,

$32,37,39-40$; voluntary partnership 116-117, 118-119, 120

Partnership for Action on Green Economy

(PAGE) 21

pattern language 50

pattern of aliveness $55,129,162,210,252,268,313$ pattern(s): action patterns 171, 172, 172, 184-186,

186; behavior patterns 172-173, 186-187;

collaboration patterns 322; competency

patterns 162-165, 164; conversation 145-146;

dysfunctional 129, 144; mental patterns 171,

172-173; observing 65-66; structural patterns

$171,172,173,194$; systems patterns 51 ,

169-193, 216, 218, 322-323

perturbations 171 platforms, multi-stakeholder 25, 27-29

private sector $36-38, \mathbf{4 1 - 4 2}, 43,197,310$

process architecture 52, 72-73, 85, 88, 194,

210, 227-229; co-designing 237, 239-247;

collaborative events and activities 243 ;

development, guiding questions for

241; Egyptian Dual System of technical

education 247-248, 249, 250, 251, 252; entry

points for change 240 ; envisaged objectives

242; levels of intervention 240, 242;

opportunities for developing 239; organic

agriculture in Mongolia 204, 205; principles

for 238 ; process quality and dialogic quality

227, 227, 228; reviewing 247; for setting

up Nebhana Water Forum 126; and theory

of change 226; transformative design

principles 229-237, 242-243, 244-246; see

also collaborative structures

process competence 7, 53, 194-196, 216;

containers for change, building 199-202,

201; flow of divergence and convergence

196-198, 197

process monitoring 94, 95, 283, 286-288,

287; with collaboration catalysts 302 ;

collaboration ecosystem, collaboration

quality check for 295-296, 296-301, 301;

core groups, collaboration quality check for

288-290, 290-294

process objectives 151,242

project secretariats $31,82,88,92,254,256$

prototypes 93, 159

Public Private Dialogue (PPD) 26-27

public sector $34-36,41,43,197,310$

readiness check 102, 103-110

reflective dialogues 136, 145, 147, 197, 210

regional multi-stakeholder collaborations 20-21

relationship objectives 151,242

resonance 78, 79, 133, 198, 208, 209

Roundtable on Sustainable Palm Oil (RSPO) 28

Rwanda, Public Private Dialogue mechanism in $26-27$

\section{SAMOA Pathway 19}

self-awareness 7, 161-162, 216; competency

patterns 162-165, 164; leadership archetypes $165-169,166$

self-similarity 171,336 
Senegal: Ministry of Finance 35; Partnership for

Action on Green Economy (PAGE) 21

serial monologues 135

small-and medium-sized enterprises (SMEs)

35,37

Small Island Developing States Partnership

Framework 19

sovereign leadership energy 166-167

stakeholder analysis 33, 36, 199, 203

stakeholder dialogue $25-27,32,38,182$

stakeholder interaction patterns 184-187

stakeholder landscape analysis 180-184, 180, 240

stakeholder(s): civil society 38-40, 42; in

consultation processes 23 ; in cooperation

processes 23; divisions 33; engaging

$182-183,183,202-203,204,313$; groups,

engaging 35-36, 202; groups, interests of

41-42; influence/interest, assessment of 182; internal communication 316, 318-319;

list, creation of 182; meetings, shared

principles for 143; non-participating, external

communication 319, 320; private sector

36-38, 41-42, 43; public sector 34-36, 41,

43; systems 4,51 ; view of 130,131 ; virtual

connections between 92; see also multi-

stakeholder collaborations

stewarding: council 90, 253, 255, 255, 258-259,

260; structures 29, 195, 253; see also dialogic process facilitators

structural interventions 195, 196, 198

subregional multi-stakeholder collaborations

22-23

Sundarbans mangrove forest (India/

Bangladesh) 155, 158; shared vision for 156;

workshop flow in relation to design practices

156-157

sustainability 3, 4-5, 43, 335-336; consumer

awareness for 11-12; green coffee production

30, 110-116; and system aliveness 49, 50;

textiles 22

Sustainable Coffee Program 111

sustainable development 1, 3, 66, 313

Sustainable Development Goals (SDGs) $1-3$,

2, 12-17, 15-16, 43; see also multi-stakeholder collaborations

system, definition of 49

systems aliveness $6,73,129,130,209,227$,

335; and Collective Leadership Compass 54,
55; contextual interconnectedness 58, 170, 279; emerging novelty 57, 170-171, 275; and facilitation 142; as guide for transformations 48-51; intentional generativity 55-56, 170, 271; mutually enhancing wholeness 58-59, 17; permeable containment 56, 170, 273; principles 55-60, 59, 283; proprioceptive consciousness 58, 171; and systems patterns 169

systems change $3,133,161,336,337$

systems interventions 170, 171, 195

systems patterns 51, 169-173, 216, 218, 322-323;

biosphere reserve 187-188, 189-193; context and content 174; description of 175-176; diagnosing with Compass 173-180, 189-193,

194; guiding questions for diagnosing

177-179; identification of 174; pathways for enacting change 175; reflection and focus 174 ; stakeholder interaction patterns 184-187; stakeholder landscape analysis 180-184, 180; visible action and underlying patterns 172

systems transformation 5

system understanding 7, 216

Tambuyog Development Center 40

task forces see technical working groups

technical working groups 254, 255, 255, 259-260 territorial conflicts 304

theory of change (ToC) 130, 210-211; activities

225; approaches to behavioral change 214;

assumptions 222, 223; completed 226;

crafting with Compass 217-226; impact and outcomes 220, 221, 222; implicit theories 212, 213, 213; mandate 220; outputs 223, 225 , 225; strategic components 223, 224, 225,

225; systems check 218, 219; understanding 211-216; youth economic empowerment project $217-218$

theory of practice 212

thinking environment 139-140

Timber Legality Assurance System (TLAS) 118

transformation literacy 73, 335

transformation networks 336-337, 337

transformative change $3,4,5,7,17$,

72; creating conditions for 43-53;

methodologies 44, 320-323; process chart methodologies 326, 328, 330, 332; rational and non-rational aspects of 44; review and reflection 44; systems aliveness principles 
55-6o; tools and applications 324-325, 327, 329, 331

transformative design principles 229, 238 , 242-243, 244-246; collective intelligence

233, 234; engagement 230-231, 231; future possibilities 232, 232; humanity $235-236$, 236; innovation 234-235, 235; wholeness 236-237, 237

transparency 91-93, 133, 305-306

Tunisia: Nebhana Water Forum, Sbikha 29,

121-126; water resource management in 272;

We love Kairouan 22-23, 278

Ukraine: empowerment of displaced people in 22 ; health care reform in 280

Varela, F. J. 197

Voluntary Partnership Agreements (VPAs) 116-117, 120

wages of workers 11

warrior leadership energy 168
Weber, A. 49

Weiss, Carol 210

We love Kairouan 22-23, 278

Western Balkans, countering organized crime in 282

wholeness 48, 58-59, 63, 143, 208, 334; and backbone support 258; collaboration quality check 293, 300-301; and competency patterns 164-165; contextual impact 280-282, 282; Dialogic Change Model $78,83,97,113,115,119,124-125$; and dialogic process facilitators 158,160 ; and dialogue 132, 133, 141, 150-151; and process architecture 228, 236-237, 237, 246, 248; and self-awareness 162; and systems patterns 176, 179, 193; and transformation of information flows 215; and transformation of structures/rules 216 ; and trouble shooting 303, 304, 305, 312 Worldwide Enhancement (WE) of Social Quality 37

World Wide Fund for Nature (WWF) 40 